TESIS DOCTORAL

\title{
FABRICACIÓN DE MEMBRANAS DE ACETATO DE CELULOSA APTAS PARA ÓSMOSIS INVERSA Y NANOFILTRACIÓN MEDIANTE EL MÉTODO DE INVERSIÓN DE FASE
}


La presente Tesis para optar al grado de Doctor en Ingeniería Industrial se enmarca dentro de la línea principal de investigación sobre membranas de la sección de Ingeniería Química del Departamento de Ingeniería Química y Nuclear de la Universidad Politécnica de Valencia.

José M. GOZÁLVEZ ZAFRILLA

\section{ABSTRACT (English):}

Membrane processes are widely used in several industrial fields. $R \& D$ in membrane production aims to obtain membranes with efficient separation and resistance characteristics and adapted to specific processes. This thesis is a contribution in this field and it faces:

- The determination of the most influent variables in the preparation by the phaseinversion method by immersion-precipitation of composite membranes of Cellulose Acetate over non-woven support in the reverse osmosis and nanofiltration ranges.

- To establish the basis of composite membrane production in an industrial machine by comparing the results obtained using a manual method with those obtained in a prototype to produce flat membranes placed in the Chemical and Nuclear Eng. Department of the Universidad Politécnica de Valencia.

The results obtained were useful to study the effect of the production conditions over the performance and characteristics of the membrane made. The results of the manual method showed high variability and low reproducibility; however these results are useful orientate the machine production. 


\section{RESUMEN (Español):}

Los procesos de membrana han alcanzado una amplia aceptación dentro de diversos campos. La investigación y desarrollo en la producción de membranas busca obtener membranas con características de separación y resistencia eficaces y cada vez más adaptadas a procesos específicos. La presente tesis entra dentro de esta línea afrontando:

- La determinación de las variables influyentes en la preparación mediante el método de inversión de fase por inmersión-precipitación de membranas compuestas de Acetato de Celulosa sobre soporte no-tejido dentro de los rangos de ósmosis inversa y nanofiltración.

- El establecimiento de las bases para la fabricación en máquina de membranas compuestas mediante la comparación de los resultados experimentales del método manual de fabricación con los obtenidos en un prototipo de máquina de fabricación industrial de membranas planas existente en el Departamento de Ingeniería Química y Nuclear de la Universidad Politécnica de Valencia.

Los resultados obtenidos permitieron evaluar los efectos de la variación de las condiciones de fabricación sobre el comportamiento y las características de la membrana fabricada. Los resultados del método manual presentaron elevada dispersión y baja reproducibilidad, si bien, los resultados que se obtienen son útiles para orientar la fabricación en máquina. 


\section{RESUMEN (Valenciano):}

Els processos de membrana tenen una ampla acceptació dins de diversos camps. L'investigació i desenroll en la producció de membranes busca obtenir membranes en característiques de separació i resistència eficaces cada vegada més adaptades a usos específics. La present tesi, dins d'esta línea, afronta:

- La determinació de les variables influents en la preparació mitjançant el mètodo d'inversió de fase per immersió-precipitació de membranes compostes d'Acetat de Celulosa sobre suport no-teixit dins dels rangs d'osmosi inversa i nanofiltració.

- L'establiment de les bases per a la fabricació en màquina de membranes compostes mitjançant la comparació dels resultats experimentals del mètode manual de fabricació en els obtinguts ab un prototip de màquina de fabricació industrial de membranes planes existent al Departament d'Enginyeria Química i Nuclear de l’Universitat Politècnica de Valéncia.

Els resultats obtinguts varen permetre l'avaluació dels efectes de la variació de les condicions de fabricació sobre el comportament i les característiques de la membrana fabricada. Els resultats del mètodo manual varen presentar elevada dispersió i baixa reproductibilitat; no obstant, son útils per a orientar la fabricació à màquina. 

A mis padres

\section{AGRADECIMIENTOS:}

Quiero expresar mi agradecimiento a mi director de tesis Jaime Lora por sus consejos y a mi familia por su apoyo. También a los amigos que me animaron y a los compañeros del Departamento que me apoyaron para realizar la tesis, en especial a J. Miguel Arnal por su ayuda con la máquina de fabricación.

Finalmente, a todos los profesores que desde la escuela alimentaron mi interés por aprender e investigar. 




\section{INDICE}

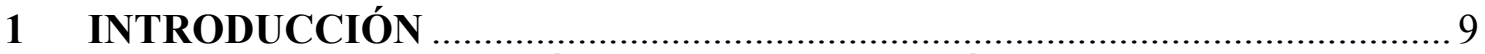

1.1 MEMBRANAS SINTÉTICAS Y TECNOLOGÍA DE MEMBRANAS ........ 9

1.1.1 Definición de membrana y procesos de membrana .................................... 10

1.1.2 Aspectos generales de los procesos de membrana..................................... 11

1.1.3 Clasificación de los diferentes procesos. Aplicaciones ................................ 17

1.2 ESTADO ACTUAL DE LA TECNOLOGÍA DE MEMBRANAS ................ 27

1.3 FUNDAMENTOS DE LOS PROCESOS DE ÓSMOSIS INVERSA Y

NANOFILTRACIÓN. MODELOS DE TRANSPORTE ............................................ 31

1.3.1 Fenómeno osmótico y ósmosis inversa ........................................................ 31

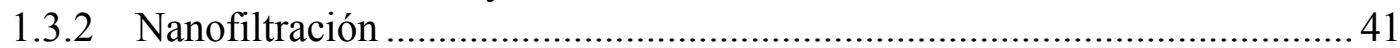

1.3.3 Modelos de transporte para membranas de ósmosis inversa y nanofiltración 44

1.4 TÉCNICAS DE FABRICACIÓN DE MEMBRANAS ……........................... 79

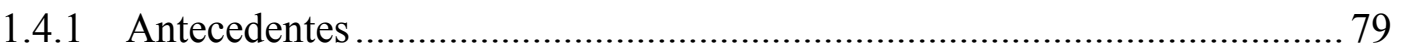

1.4.2 Descripción de las técnicas de fabricación de membranas ......................... 80

1.5 PROCESOS DE PREPARACIÓN DE MEMBRANAS POR INVERSIÓN

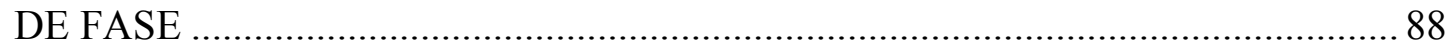

1.5.1 Aspectos generales de las técnicas de inversión de fase ........................... 88

1.5.2 Clasificación de los procesos de fabricación por inversión de fase ............. 98

1.5.3 Técnica de inversión de fase por inmersión- precipitación ....................... 102

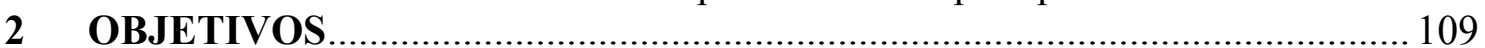

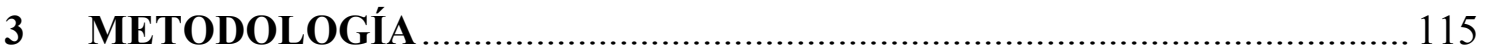

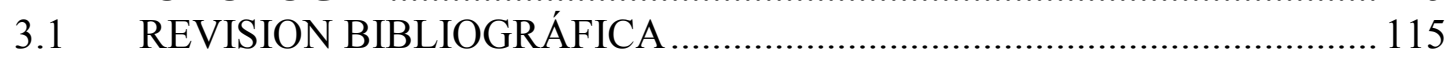

3.2 SELECCIÓN DE MATERIALES. CARACTERÍSTICAS Y NORMAS DE

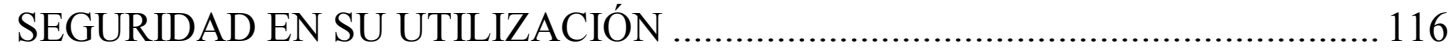

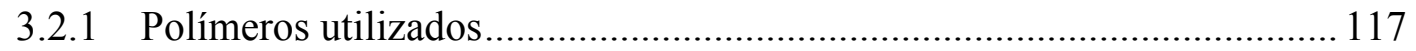

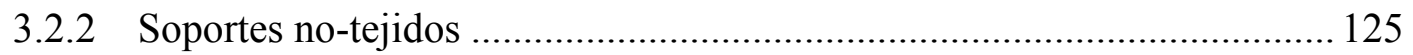

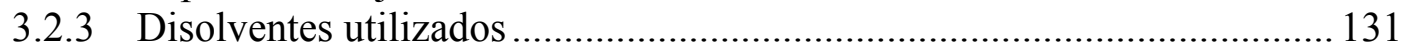

3.2.4 Componentes del baño de coagulación.................................................. 140

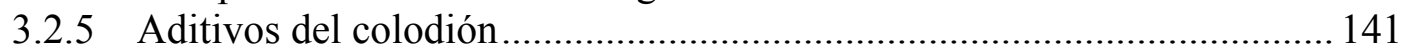

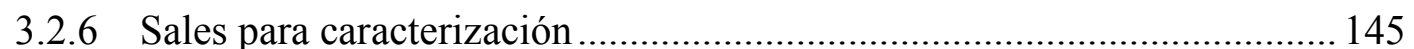

3.3 METODOLOGÍA DE DESCRIPCIÓN DEL PROCESO TEÓRICO DE

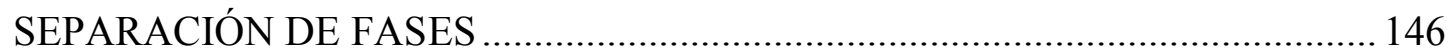

3.3.1 Determinación experimental de las curvas binodales para el sistema

Acetato de celulosa/dimetilacetamida/agua .................................................... 147

3.3.2 Obtención de parámetros de interacción binarios y ajuste del modelo..... 150

3.4 METODOLOGÍA DE PREPARACIÓN Y CARACTERIZACIÓN DE

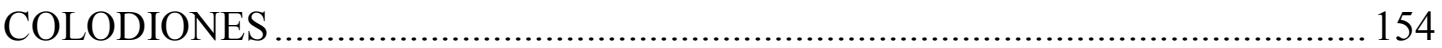

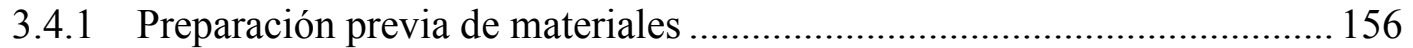

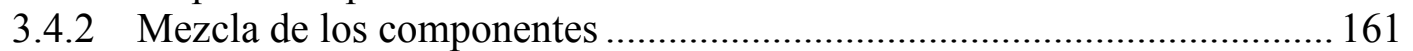

3.4.3 Estandarización de los colodiones ........................................................ 165

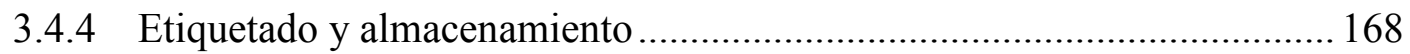

3.4.5 Métodos de caracterización de los colodiones........................................ 169

3.5 METODOLOGÍA DE PREPARACIÓN MANUAL DE MEMBRANAS .. 171

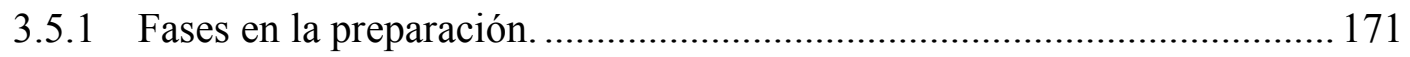




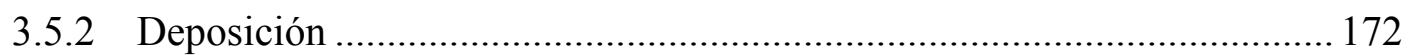

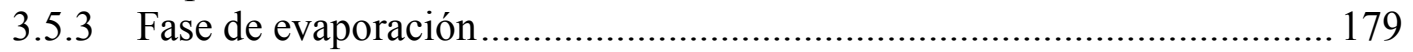

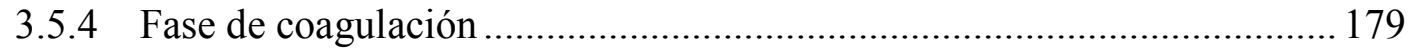

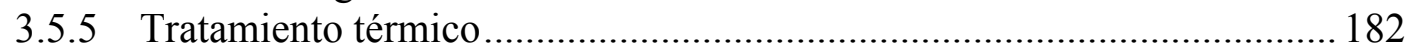

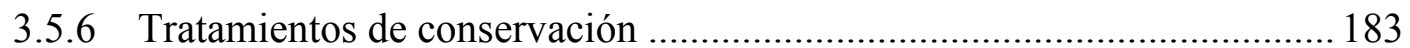

3.6 METODOLOGÍA DE FABRICACIÓN DE MEMBRANAS EN MÁQUINA. 184

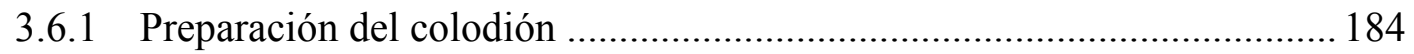

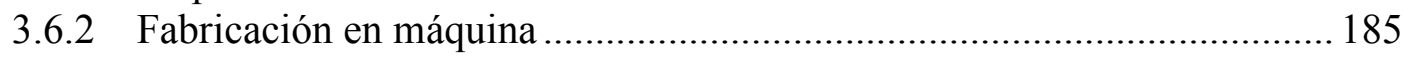

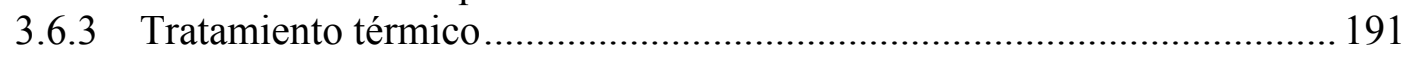

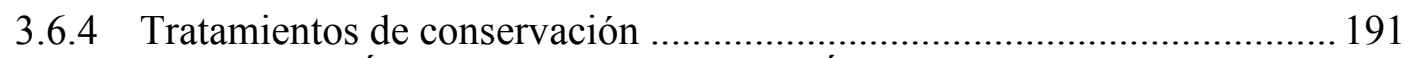

3.7 METODOLOGÍA DE CARACTERIZACIÓN DE MEMBRANAS............ 192

3.7.1 Caracterización de propiedades estructurales ............................................. 192

3.7.2 Caracterización en planta de propiedades permeoselectivas ..................... 198

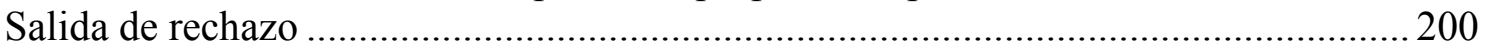

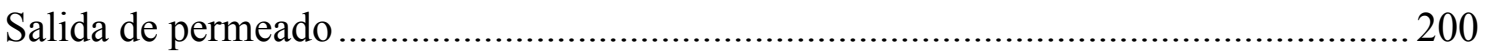

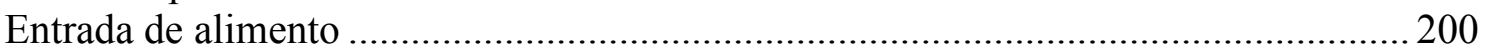

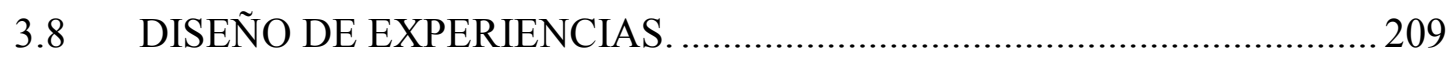

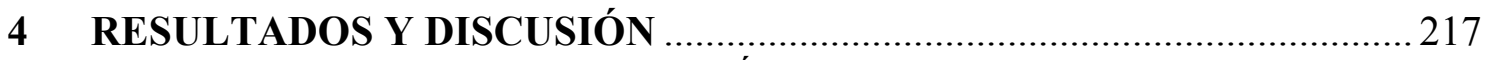

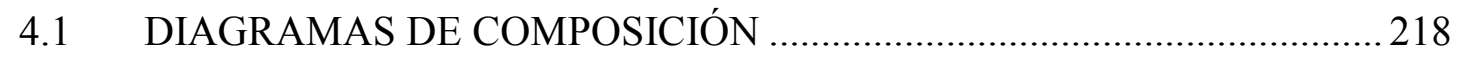

4.1.1 Datos experimentales de la curva binodal ............................................. 218

4.1.2 Datos experimentales y bibliográficos de coeficientes binarios ............... 223

4.1.3 Datos obtenidos del ajuste del diagrama............................................ 225

4.1.4 Efectos calculados de la modificación de parámetros sobre la binodal.... 226

4.2 CARACTERIZACIÓN DE COLODIONES …............................................ 230

4.3 RESULTADOS OBTENIDOS EN LAS MEMBRANAS FABRICADAS EN

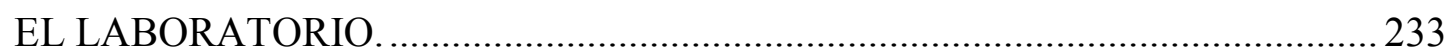

4.3.1 Evaluación del método de caracterización...............................................2235

4.3.2 Evaluación de la reproducibilidad del método de fabricación...................239

4.3.3 Experimentos preliminares para la selección de composiciones ............... 241

4.3.4 Experimentos de fabricación manual para la determinación de la influencia

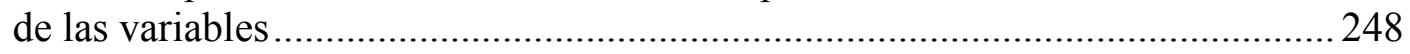

4.3.5 Serie de experimentos para el estudio de la interacción entre los factores de

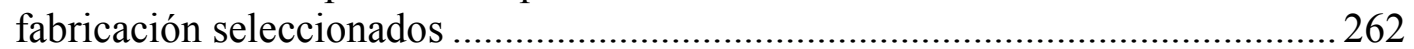

4.3.6 Análisis de la estructura mediante microscopía...................................... 282

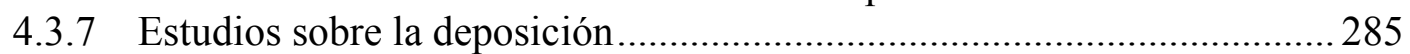

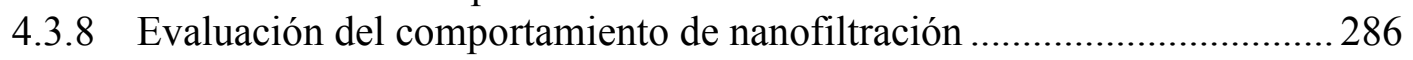

4.4 ESTUDIO DE LA VIABIALIDAD DE UTILIZAR LOS RESULTADOS

DEL MÉTODO MANUAL EN LA FABRICACIÓN EN MÁQUINA..................... 290

5 CONCLUSIONES .................................................................................. 297

6 ANEXO I: Tablas de datos de fabricación de membranas y caracterización en

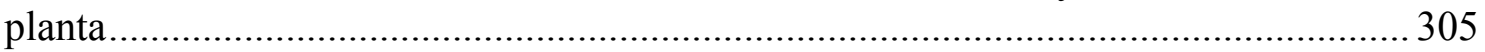

7 ANEXO II: Fotografías realizadas en el microscopio electrónico ........................327

8 ANEXO III: Determinación teórica del diagrama ternario ...................................339

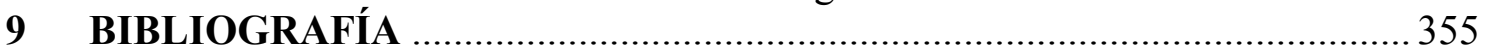

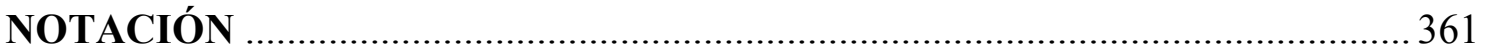




\section{INTRODUCCIÓN}





\section{INTRODUCCIÓN}

\subsection{MEMBRANAS SINTÉTICAS Y TECNOLOGÍA DE MEMBRANAS}

En la sociedad industrial actual cobra gran importancia la reducción de los problemas medioambientales y la mejora de la eficiencia de los procesos. El desarrollo y mejora de los procesos separadores permite un doble beneficio. Por una parte un mejor aprovechamiento de la energía y los recursos con la consiguiente disminución de los costes (tecnología limpia) y por otra la minimización de los residuos (tecnología limpiadora). Las tecnologías de membranas aún pueden decir mucho en este campo. De hecho son consideradas por la mayor parte de los expertos en medio ambiente como las técnicas más prometedoras en aplicaciones medioambientales desde los dos puntos de vista expuestos.

Además de ser tecnologías "limpias", su integración dentro de los procesos productivos va a ser capaz de crear nuevos procesos que aprovechen los recursos con más eficiencia al permitir la reutilización de compuestos de las corrientes de proceso. Estas nuevas tecnologías se están demostrando además más eficaces y rentables económicamente que otras tecnologías obsoletas y contaminantes.

Las aplicaciones de los procesos de membrana son amplias y variadas. Por ejemplo, los procesos que tienen como fuerza impulsora la presión, microfiltración (MF), ultrafiltración (UF), nanofiltración (NF) y ósmosis inversa (OI), están ampliamente extendidos y pueden ser usados para concentrar un agente contaminante hasta un determinado punto económico o para producir agua purificada. También tienen aplicaciones importantes en la industria alimentaria. Otros procesos como pervaporación (PV), permeación por vapor, separación de gases y membranas líquidas pueden ser usados para extraer selectivamente un componente o clase de componentes. Estos componentes pueden ser a su vez contaminantes que deseamos eliminar de una corriente o productos valiosos desde el punto de vista industrial que pretendemos reciclar o concentrar.

Las membranas, en las aplicaciones mencionadas, tienen que competir con otros procesos separadores. El que se muestren como la tecnología más oportuna depende de 
lo adecuada que sea la membrana para el proceso global concreto donde intervienen, ya que la eficacia de los procesos basados en membranas depende mucho del comportamiento de la membrana frente a los fluidos del proceso. Es pues, de suma importancia el conocer cómo afectan las condiciones de fabricación a las características de funcionamiento de la membrana. Con este conocimiento, se estará en disposición de optimizar los procesos tanto desde el punto de vista económico como medioambiental.

\subsubsection{Definición de membrana y procesos de membrana}

Una membrana es una barrera permeoselectiva entre dos medios, es decir, es una barrera que permite la transferencia, desde un medio a otro y a través de ella, de ciertos componentes, mientras que impide, o al menos restringe, el paso de otros componentes. Es decir, los procesos basados en membranas son operaciones de separación con una interfase física distinta a los medios que separa (es decir, la propia la membrana) en los que la separación se produce porque un componente o componentes pasan en mayor proporción que otros a través de la membrana.

Existen sistemas en la naturaleza que cumplen esta definición de membrana, son las llamadas "membranas biológicas". Las membranas biológicas desempeñan el importante papel de regular los intercambios entre la célula y el medio exterior (raíces, seres unicelulares, etc.) o los intercambios dentro del mismo medio interno de los seres por lo que son de gran interés dentro de los campos de la Biología y la Medicina.

Las membranas biológicas son de poca aplicación industrial actualmente. Sin embargo, el hombre ha sido capaz de crear "membranas sintéticas" (fabricadas a partir de polímeros o compuestos inorgánicos) y empezar a emplearlas con éxito en separaciones selectivas a partir de mediados de este siglo XX. Los procesos industriales basados en estas membranas sintéticas tienen una importancia considerable habiendo desplazado o sustituido otros procesos separadores empleados por el hombre. (A partir de ahora cuando nos refiramos a "membrana" en la presente Tesis se entenderá el término según la acepción de membrana sintética). 
Para que la separación se pueda llevar a cabo, el transporte a través de la membrana debe ser sensible a una o varias propiedades moleculares o físico-químicas de los componentes. Para que esta interacción se dé, la membrana deberá tener unas determinadas propiedades químicas o de estructura.

También, para que el transporte de componentes se produzca es necesaria la acción de una fuerza impulsora, es decir, una diferencia de una magnitud físico-química entre las fases que se manifieste como un gradiente a través de la membrana capaz de originar un flujo de componentes. Ejemplos de fuerzas impulsoras pueden ser un gradiente de presión, concentración, temperatura o potencial eléctrico. Estas magnitudes mencionadas pueden darse a su vez combinadas en un mismo proceso de membrana y pueden recogerse desde un punto general dentro del concepto de potencial químico o electroquímico.

La fuerza impulsora establece, pues, un flux de componentes aportando la energía necesaria para la separación de la mezcla en un proceso que no es espontáneo. La energía disminuye la entropía global del sistema y vence ciertas resistencias que se producen, tal como la fricción de los componentes a través del medio que constituye la membrana. Además, debe ser capaz de superar las fuerzas impulsoras adicionales contrarias a la separación que se puedan establecer, por ejemplo, la presión osmótica explicada en 1.3.1. Para que el proceso se lleve a una velocidad adecuada, la fuerza impulsora tendrá que ser varias veces mayor a la mínima necesaria para que se establezca el flux.

\subsubsection{Aspectos generales de los procesos de membrana}

\section{Variables que definen el comportamiento}

En la Ilustración 1 se muestra esquemáticamente como actúa una membrana.

Las corrientes involucradas son las siguientes: 
- Alimento: Es la disolución a tratar.

- Permeado: constituido por las cantidades que han pasado a través de la membrana y por tanto es más rico en las sustancias con mayor tendencia a pasar.

- Rechazo o retención: Es el resultado de la pérdida por parte de la disolución alimento de las cantidades que constituyen el permeado, y por tanto estará enriquecido en las sustancias que permean en menor grado.

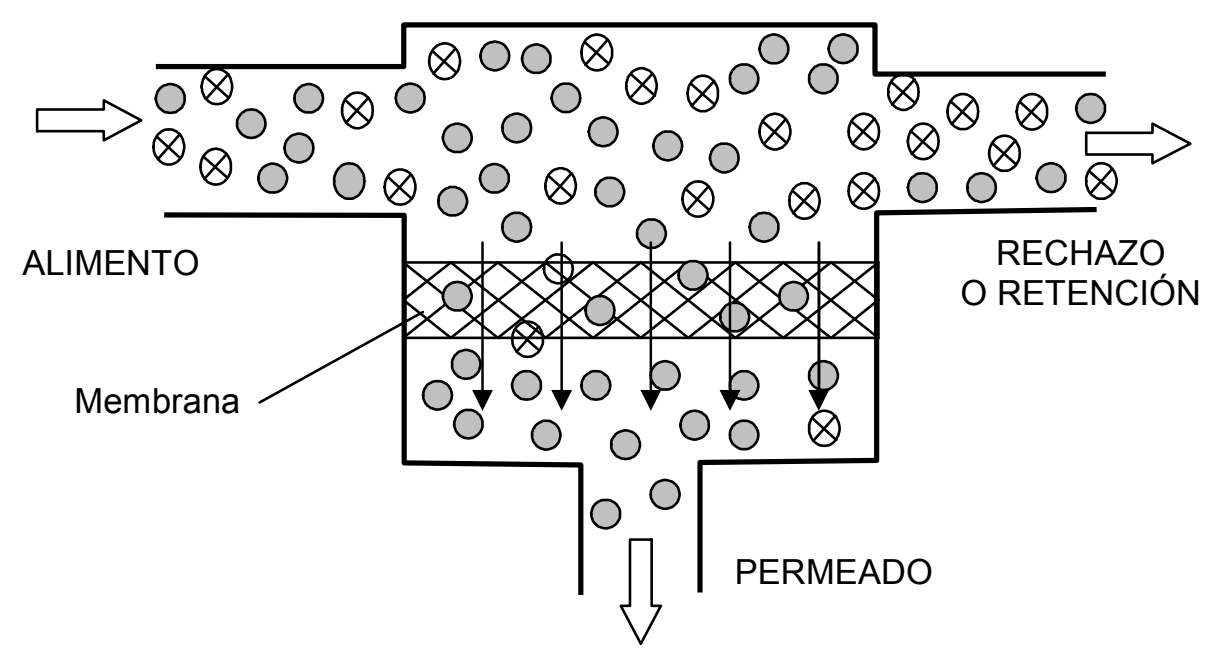

Ilustración 1. Funcionamiento esquemático de una membrana

Hay que tener en cuenta, sin embargo, que lo que diferencia un proceso de membranas de un proceso de filtración simple es que no se busca una formación de torta de material sólido en el medio separador, el proceso es continuo en sí mismo por lo que se extrae continuamente una corriente de rechazo resultante de la circulación del alimento introducido en el módulo que varía con ello su concentración progresivamente, pero sin producirse cambio de estado.

Las características definitorias del comportamiento de una membrana son, pues:

- Flux o densidad de flujo:

Normalmente entendido como densidad de flujo volumétrico, es decir como caudal que atraviesa la membrana por unidad de área. Las unidades que se emplearán son $\mathrm{m}^{3} \cdot \mathrm{m}^{-2} \cdot \mathrm{s}^{-1}$, litros $\cdot \mathrm{m}^{-2} \cdot$ día ${ }^{-1}$, litros $\cdot \mathrm{m}^{-2} \cdot \mathrm{h}^{-1}$. Cuando se refiere a "densidad de flujo másico" 
viene expresado normalmente en $\mathrm{kg} \cdot \mathrm{m}^{-2} \cdot \mathrm{seg}^{-1} \mathrm{y}$ para "densidad de flujo molar" en $\mathrm{mol} \cdot \mathrm{m}^{-2} \cdot \mathrm{seg}^{-1}$.

- Selectividad:

Este factor cuantifica la capacidad separadora de la membrana, normalmente se emplean los siguientes factores:

- Índice de retención o factor de rechazo de un componente: Este factor se calcula a partir de las concentraciones de componente en el alimento $\left(C_{a}\right)$ y en el permeado $\left(C_{p}\right)$ como:

Ec. 1: $\quad R=\frac{C_{a}-C_{p}}{C_{a}}$

- Factor de selectividad entre dos componentes $A$ y B. Se calcula a partir de sus concentraciones o fracciones (molares o másicas) en el permeado $\left(y_{A}, y_{B}\right)$ y en el alimento $\left(x_{A}, x_{B}\right)$.

Ec. 2:

$$
\alpha_{A / B}=\frac{y_{A} / y_{B}}{x_{A} / x_{B}}
$$

- Umbral de corte molecular. Este parámetro es normalmente utilizado en membranas de ultrafiltración y se define como la masa molecular a la que se obtiene una retención prácticamente total (normalmente un $90 \%$ de una macromolécula determinada). Una información completa la proporciona la curva de retención para una serie de compuestos moleculares del mismo tipo pero con diferentes tamaños moleculares. 


\section{Estructuras posibles de las membranas}

El tipo de estructura de la membrana tiene una influencia determinante en el problema de la separación.

A grandes rasgos podemos distinguir los siguientes tipos generales:

- Membranas porosas

- Membranas no porosas o densas

- Membranas de transporte (membranas líquidas y de transportador fijo)

- Membranas intercambiadoras de iones

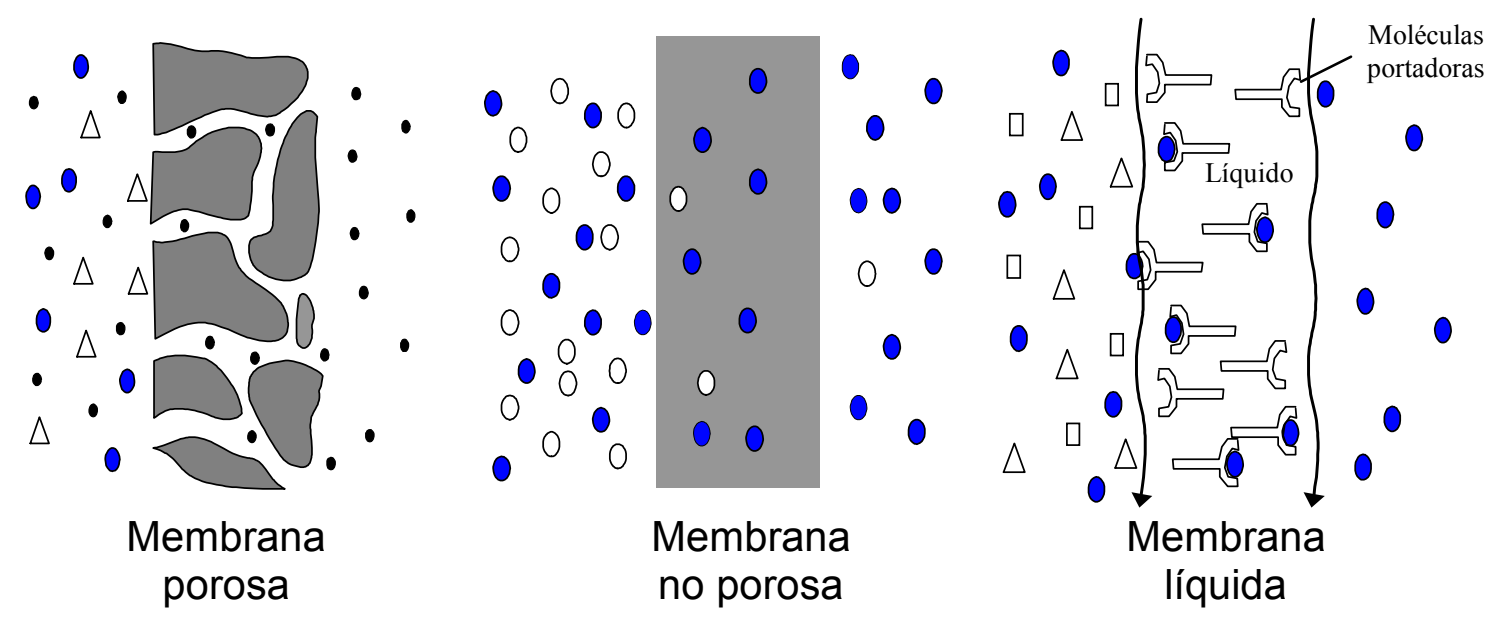

Ilustración 2. Tipos de estructura de las membranas

Membranas porosas:

Las membranas porosas presentan poros físicos, el tamaño de los cuales, en la zona en contacto con la mezcla de fluido a separar (capa activa), determina las características de la separación. El mecanismo de separación, a grandes rasgos, es el tamizado que se ejerce al permitir el paso de las partículas o moléculas de tamaño inferior al del poro y rechazar a las de tamaño superior. Cuanta mayor diferencia exista entre el tamaño de las partículas a separar y el resto de componentes de la disolución mayor selectividad puede alcanzarse. Este tipo de membranas es característico de la microfiltración y la ultrafiltración. 


\section{Membranas no porosas:}

Son capaces de separar moléculas del mismo tamaño, en corrientes líquidas o gaseosas. Este tipo de membranas no contiene poros macroscópicos. El mecanismo de transferencia predominante es el de disolución-difusión. Según este mecanismo, determinados componentes se disuelven con preferencia en la membrana (por tener una determinada afinidad química hacia el material de la membrana) y luego difunden, merced a la fuerza impulsora, con mayor o menor rapidez a través de ésta (dependiendo la rapidez de la difusión de la interacción de los componentes con el material de la membrana). Tanto las diferencias en solubilidad como en difusividad marcan la capacidad de separación. Este tipo de membranas es usado en separación de gases y pervaporación.

\section{Membranas transportadoras:}

La separación está determinada en estas membranas por una molécula transportadora específica y no por el material o la estructura. La molécula transportadora presenta una afinidad específica hacia un componente o clase de componentes, lo cual implica una alta selectividad. Además al depender la separación de la interacción entre transportador y soluto, cualquier tipo de componentes puede ser extraído, ya sean gaseosos o líquidos, iónicos o no. El transportador puede fijarse en una estructura polimérica o inorgánica (transportador fijo), o bien mantenerse móvil en una fase líquida inmovilizada en una membrana porosa (membranas líquidas ML).

Hay que tener en cuenta que los dos primeros tipos expuestos pueden no darse de forma pura, debido a la dificultad de definir a escala muy pequeña el tamaño físico de un poro y a que los mecanismos de disolución-difusión y de selección por tamaño de poro pueden combinarse, como ocurre especialmente en el caso de la nanofiltración.

Las estructuras simétricas representadas en la Ilustración 3 presentan la misma resistencia al flujo a lo largo de toda la membrana. Sin embargo la separación en la membrana se suele producir en las primeras micras de la capa enfrentada a la mezcla (capa activa). Por ello interesa utilizar estructuras asimétricas en las que la capa activa tenga el tamaño de poro adecuado o sea no porosa y el resto sea bastante poroso ejerciendo únicamente funciones de soporte. 


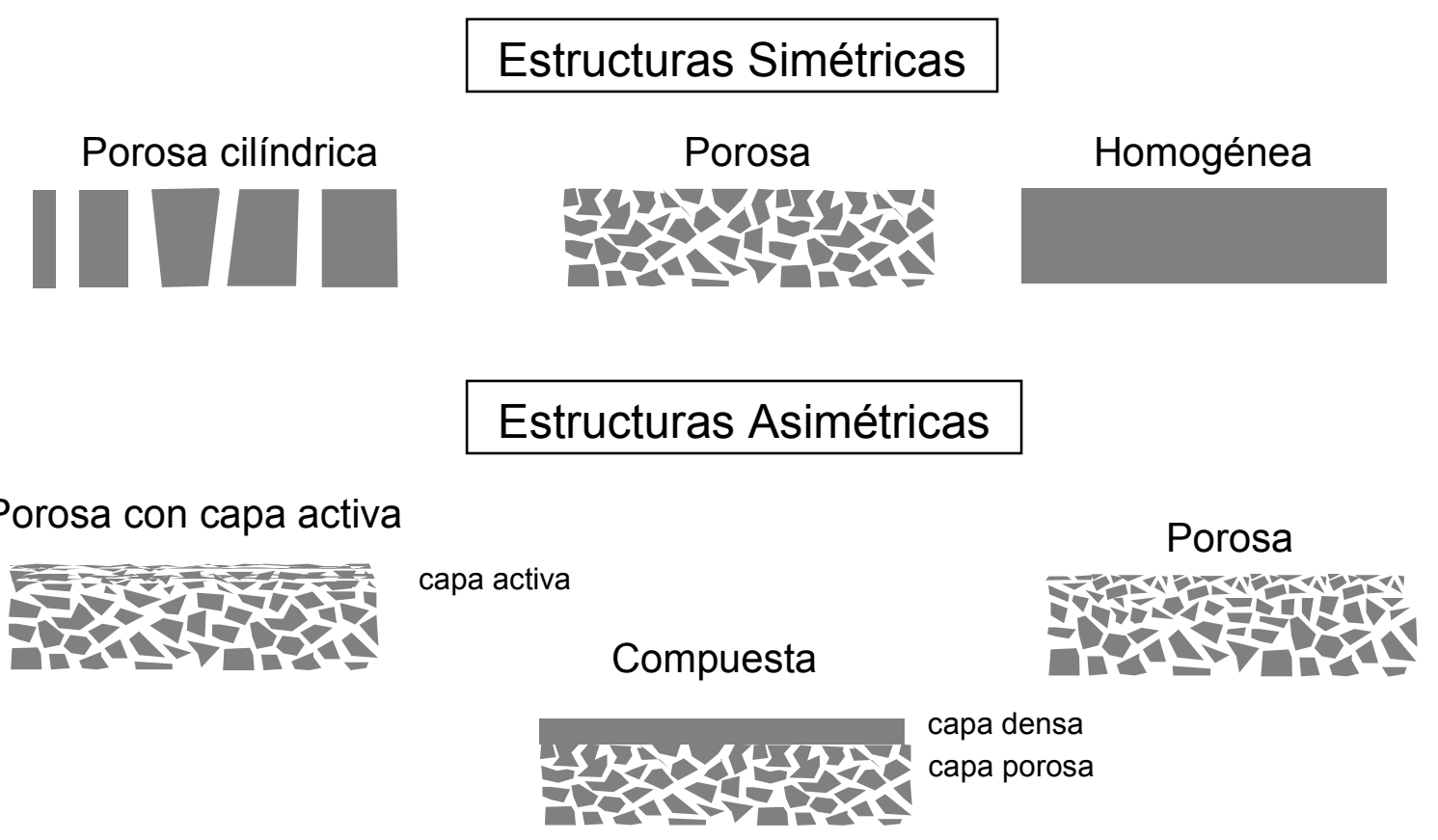

Ilustración 3. Tipos de estructura global de las membranas.

\section{Clasificación según la naturaleza de los materiales}

Desde el punto de vista de los materiales empleados podemos clasificar las membranas sintéticas en:

- Membranas orgánicas

- Membranas inorgánicas

- Membranas líquidas.

Las membranas orgánicas están basadas en materiales poliméricos y pueden presentar estructuras muy variadas, tanto porosas como no porosas. Las membranas inorgánicas están basadas en materiales metálicos y cerámicos y sólo presentan estructuras porosas. 


\subsubsection{Clasificación de los diferentes procesos. Aplicaciones}

Podemos clasificar los procesos de membrana desde dos puntos de vista:

- La propiedad molecular importante en la separación.

- La fuerza impulsora utilizada.

En la Tabla 1 se muestran distintas propiedades moleculares que pueden presentar las sustancias y los procesos donde esta propiedad representa el más importante factor de separación. En algún caso, como la nanofiltración, pueden ser importantes los efectos de más de una propiedad molecular. También hay que resaltar que el hecho de que una de estas propiedades sea favorable a la separación de un determinado compuesto no es condición suficiente para que éste se separe en forma importante. Por ejemplo, la afinidad por el material de la membrana se deberá combinar con la capacidad del componente de difundir de forma apreciable para que exista una separación adecuada.

\section{Tabla 1. Procesos de membrana clasificados según las propiedades moleculares importantes en la separación.}

\begin{tabular}{|l|l|}
\hline Propiedad molecular & Procesos de separación por membrana \\
\hline Tamaño & $\begin{array}{l}\text { Nanofiltración, Microfiltración, Ultrafiltración, Diálisis, Separación } \\
\text { de gases. }\end{array}$ \\
\hline Presión de vapor & Destilación por membranas \\
\hline Afinidad & Ósmosis inversa, Separación de gases, Pervaporación \\
\hline Carga eléctrica & Electrodiálisis \\
\hline Naturaleza química & Membranas líquidas \\
\hline
\end{tabular}

La clasificación de los procesos según la fuerza impulsora se presenta en la Tabla 2. Esta clasificación se ha combinado con información sobre los estados de las fases (líquido o gas) involucradas en el proceso. En este caso, la fuerza impulsora se crea 
aumentando una magnitud o propiedad en una de las dos fases. Sin embargo, otras fuerzas impulsoras no aplicadas que no interesan desde el punto de vista de la separación podrían tomar inevitablemente parte en el proceso, tal es el caso de la presión osmótica.

\begin{tabular}{|c|c|c|c|}
\hline Fuerza impulsora & $\begin{array}{c}\text { Fase } \\
\text { alimento }\end{array}$ & $\begin{array}{c}\text { Fase } \\
\text { permeado }\end{array}$ & Proceso \\
\hline Presión & $\mathrm{L}$ & $\mathrm{L}$ & $\begin{array}{l}\text { Nanofiltración } \\
\text { Ósmosis inversa } \\
\text { Microfiltración } \\
\text { Ultrafiltración } \\
\text { Piezodiálisis }\end{array}$ \\
\hline $\begin{array}{l}\text { Diferencia de actividad } \\
\text { (presión parcial) }\end{array}$ & G & G & Separación de gases \\
\hline $\begin{array}{l}\text { Diferencia de actividad } \\
\text { (presión ) }\end{array}$ & $\mathrm{L}$ & G & Pervaporación \\
\hline $\begin{array}{l}\text { Diferencia de actividad } \\
\text { (concentración) }\end{array}$ & $\mathrm{L}$ & $\mathrm{L}$ & $\begin{array}{l}\text { Diálisis } \\
\text { Membranas líquidas }\end{array}$ \\
\hline Potencial eléctrico & $\mathrm{L}$ & $\mathrm{L}$ & $\begin{array}{l}\text { Electrodiálisis } \\
\text { Electro-ósmosis }\end{array}$ \\
\hline Diferencia térmica & $\mathrm{L}$ & $\mathrm{L}$ & $\begin{array}{l}\text { Termo-ósmosis } \\
\text { Destilación por membranas }\end{array}$ \\
\hline
\end{tabular}

\section{A) Microfiltración (MF), Ultrafiltración (UF), Nanofiltración (NF) y Ósmosis inversa (OI)}

Estos procesos tienen en común el tener como fuerza impulsora la presión. Para establecerla se eleva la presión de la corriente alimento mediante una bomba, con lo cual, aunque la corriente alimento sufra algo de pérdida de carga al atravesar el módulo, se 
encuentra a mayor presión que la corriente de permeado, existiendo un gradiente de presión a través de la membrana.

Otra característica común de estos procesos es que tanto la fase del permeado como la del alimento son líquidas. Estos cuatro procesos se usan normalmente para concentrar o purificar disoluciones acuosas diluidas.

Sin embargo existen diferencias claras entre los procesos, especialmente en cuanto al tamaño de partícula, mecanismo de separación y estructura de membrana (véanse Tabla 3, Tabla 4 e Ilustración 4).

Tabla 3. Comparación de procesos de membrana gobernados por la presión

\begin{tabular}{|c|c|c|c|c|}
\hline & $\begin{array}{l}\text { Hiperfiltración } \\
\text { (ósmosis inversa) }\end{array}$ & Nanofiltración & Ultrafiltración & Microfiltración \\
\hline $\begin{array}{l}\text { Nivel de } \\
\text { separación }\end{array}$ & $\begin{array}{l}\text { Sales } \\
\text { monovalentes } \\
\text { Solutos de bajo } \\
\text { PM (glucosa, } \\
\text { lactosa) }\end{array}$ & $\begin{array}{l}\text { Solutos de bajo } \\
\text { PM, Sales } \\
\text { multivalentes }\end{array}$ & $\begin{array}{l}\text { Macromoléculas } \\
\text { (proteínas), } \\
\text { Coloides }\end{array}$ & $\begin{array}{l}\text { Partículas } \\
\text { (bacterias, } \\
\text { levaduras) }\end{array}$ \\
\hline $\begin{array}{l}\text { Principio en el } \\
\text { que está basada } \\
\text { la separación }\end{array}$ & $\begin{array}{l}\text { Diferencias de } \\
\text { solubilidad y } \\
\text { difusividad }\end{array}$ & $\begin{array}{l}\text { Diferencias de } \\
\text { solubilidad y } \\
\text { difusividad, } \\
\text { Tamaño de } \\
\text { partícula, Carga }\end{array}$ & $\begin{array}{l}\text { Tamaño de } \\
\text { partícula } \\
\text { (tamizado) }\end{array}$ & $\begin{array}{l}\text { Tamaño de } \\
\text { partícula } \\
\text { (tamizado) }\end{array}$ \\
\hline $\begin{array}{l}\text { Mecanismo de } \\
\text { transferencia }\end{array}$ & $\begin{array}{l}\text { Disolución - } \\
\text { difusión }\end{array}$ & $\begin{array}{l}\text { Disolución - } \\
\quad \text { difusión } \\
+ \text { Capilar }\end{array}$ & Capilar & Capilar \\
\hline $\begin{array}{l}\text { Influencia de la } \\
\text { presión } \\
\text { osmótica }\end{array}$ & $\begin{array}{c}\text { Alta } \\
(5-25 \text { bar })\end{array}$ & Moderada & Despreciable & Despreciable \\
\hline $\begin{array}{l}\text { Presión } \\
\text { aplicada } \\
\text { (bar) }\end{array}$ & $\begin{array}{c}15-25 \text { (agua } \\
\text { salobre) } \\
40-80 \text { (agua de } \\
\text { mar) }\end{array}$ & $10-40$ & $2-10$ & $0.2-2$ \\
\hline $\begin{array}{l}\text { Fluxes } \\
\text { obtenidos } \\
\quad\left(\text { litro } \cdot m^{-2} \cdot h^{-1}\right)\end{array}$ & $5-40$ & $20-80$ & $5-200$ & $>200$ \\
\hline
\end{tabular}




\begin{tabular}{|l|l|c|c|l|}
\hline \multicolumn{4}{|c|}{$\begin{array}{l}\text { Tabla 4. Características de las membranas utilizadas en los procesos de } \\
\text { membrana gobernados por la presión. }\end{array}$} \\
\hline & $\begin{array}{l}\text { Hiperfiltración } \\
\text { (ósmosis inversa) }\end{array}$ & Nanofiltración & Ultrafiltración & Microfiltración \\
\hline $\begin{array}{l}\text { Estructura de la } \\
\text { membrana }\end{array}$ & asimétrica & asimétrica & Asimétrica & $\begin{array}{c}\text { simétrica } \\
\text { asimétrica porosa }\end{array}$ \\
\hline Tamaño de poro & $<0.5 \mathrm{~nm}$ & $\approx 1$ & $1-100 \mathrm{~nm}$ & $100-10000 \mathrm{~nm}$ \\
\hline Espesor & $150 \mu \mathrm{m}$ & $150 \mu \mathrm{m}$ & $150 \mu \mathrm{m}$ & $10-150 \mu \mathrm{m}$ \\
\hline $\begin{array}{l}\text { Espesor de la } \\
\text { capa activa }\end{array}$ & $0.1-1.0 \mu \mathrm{m}$ & $0.1-1.0 \mu \mathrm{m}$ & $0.1-1.0 \mu \mathrm{m}$ & $10-150 \mu \mathrm{m}$ \\
\hline $\begin{array}{l}\text { Material de la } \\
\text { membrana }\end{array}$ & $\begin{array}{l}\text { - acetatos de } \\
\text { celulosa } \\
\text { - poliamidas } \\
\text { aromáticas }\end{array}$ & $\begin{array}{l}\text { - acetatos de } \\
\text { celulosa } \\
\text { - poliamidas } \\
\text { aromáticas } \\
\text { - polivinil alcohol }\end{array}$ & $\begin{array}{l}\text { Polímeros: } \\
\text { - polisulfona } \\
\text { - poliacrilonitrilo } \\
\text { Cerámicos: } \\
\text { - óxidos de Al }\end{array}$ & $\begin{array}{l}\text { Materiales } \\
\text { poliméricos o } \\
\text { cerámicos }\end{array}$ \\
\hline
\end{tabular}

En los procesos de microfiltración y ultrafiltración el mecanismo de separación es por diferencia de tamaño, influyendo mucho el tamaño y distribución de poros de la membrana. En estos procesos la membrana ejerce un tamizado de las partículas dejando pasar en mayor grado a las más pequeñas que el tamaño de poro. En ambos procesos tiene mucha importancia la velocidad tangencial ya que tiene un efecto importante sobre el flux de permeado obtenido (aumenta con la velocidad tangencial), especialmente en microfiltración. La microfiltración es capaz de separar pequeñas partículas y la ultrafiltración macromoléculas.

En ósmosis inversa, también conocida como hiperfiltración, el mecanismo de separación es el de disolución-difusión. Los componentes que constituyen el permeado deben tener cierta afinidad con el material de la membrana para "disolverse" en su estructura. De ahí que en ósmosis inversa cobre mucha más importancia el material de la membrana que en los dos procesos anteriores. La nanofiltración es un proceso intermedio entre la ósmosis inversa y la nanofiltración en el que tanto la separación por tamaño como los mecanismos de disolución-difusión adquieren importancia. Ambos procesos son capaces de separar sales y solutos de bajo peso molecular. En ambos procesos no resulta tan decisivo como en los anteriores el efecto de la velocidad 
tangencial, sin embargo cobra importancia la presión osmótica y las membranas son menos permeables, debiéndose trabajar a valores superiores de presión para lograr que exista flux razonable de fluido desde la fase concentrada al permeado.
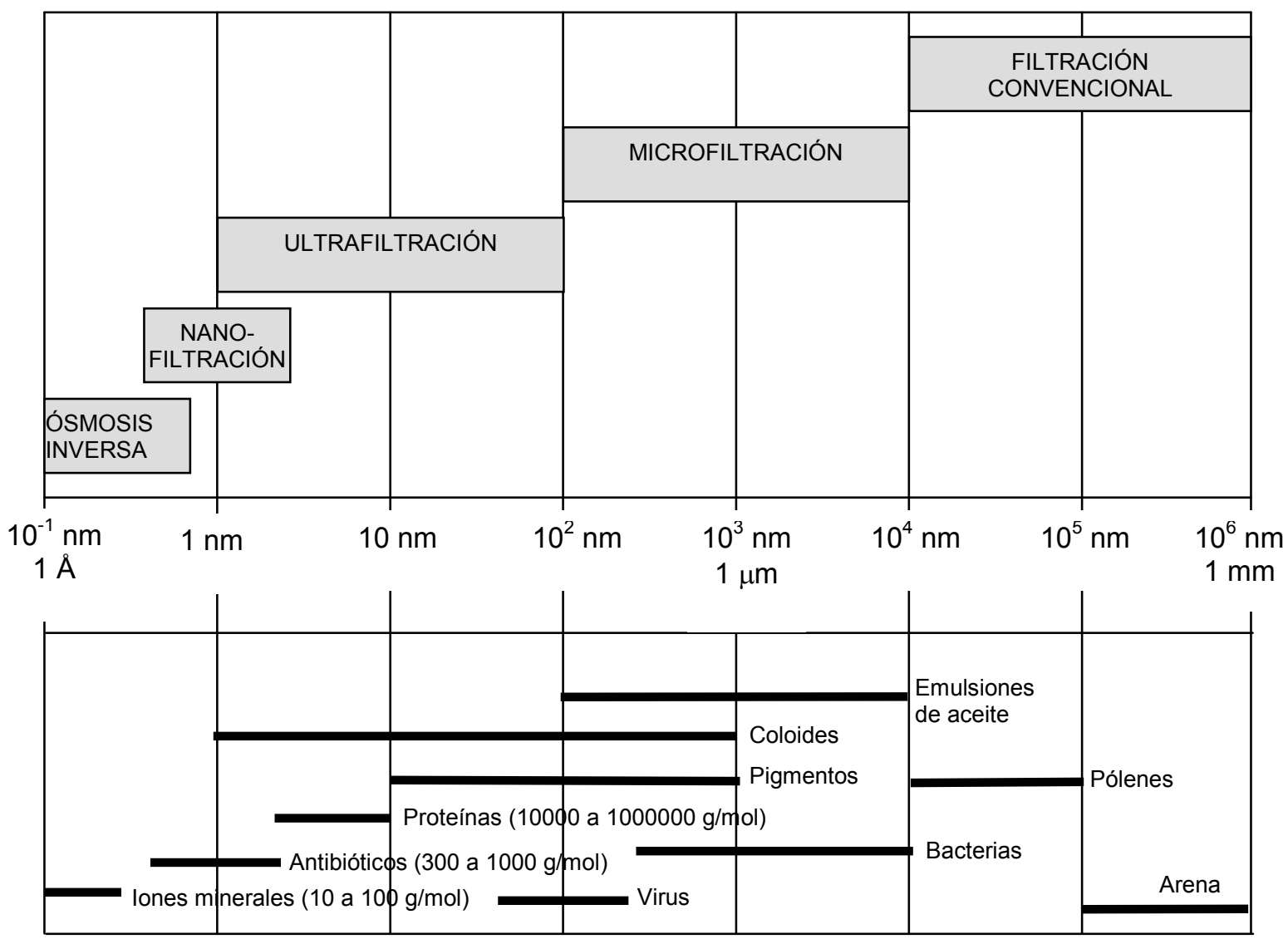

Ilustración 4. Niveles de separación en los procesos gobernados por la presión

Las aplicaciones de estos procesos son muy amplias, algunas de ellas son ya utilizadas desde hace tiempo y están ya ampliamente extendidas. En la Tabla 5 se resumen algunas de las más importantes, siendo de destacar las aplicaciones de la ósmosis inversa en desalación y de la ultrafiltración en la concentración de líquidos alimenticios. 
Tabla 5. Aplicaciones de los procesos de membrana gobernados por la presión.

\begin{tabular}{|c|c|c|c|c|}
\hline & $\begin{array}{l}\text { Hiperfiltración } \\
\text { (ósmosis inversa) }\end{array}$ & Nanofiltración & Ultrafiltración & Microfiltración \\
\hline $\begin{array}{l}\text { Agua potable y } \\
\text { medio ambiente }\end{array}$ & $\begin{array}{l}\text { Desalación de } \\
\text { aguas salobres y } \\
\text { marinas } \\
\text { Concentración de } \\
\text { lixiviados y de } \\
\text { efluentes } \\
\text { químicos }\end{array}$ & $\begin{array}{l}\text { Potabilización } \\
\text { Desmineraliza- } \\
\text { ción }\end{array}$ & $\begin{array}{l}\text { Efluentes de la } \\
\text { industria papelera } \\
\text { Separación de } \\
\text { emulsiones } \\
\text { aceite-agua en } \\
\text { metalurgia }\end{array}$ & $\begin{array}{l}\text { Eliminación de } \\
\text { bacterias }\end{array}$ \\
\hline Alimentación & $\begin{array}{l}\text { Concentración de } \\
\text { zumos de frutas, } \\
\text { azúcares y leche } \\
\text { Eliminación de } \\
\text { alcohol } \\
\text { Concentrado de } \\
\text { suero }\end{array}$ & $\begin{array}{l}\text { Concentrado y } \\
\text { desmineralización } \\
\text { de suero } \\
\text { Reducción de } \\
\text { sales }\end{array}$ & $\begin{array}{l}\text { Industria láctea } \\
\text { (leche, suero, } \\
\text { queso) } \\
\text { Concentración de } \\
\text { proteínas } \\
\text { Eliminación de } \\
\text { azúcar }\end{array}$ & $\begin{array}{l}\text { Esterilización de } \\
\text { alimentos } \\
\text { Clarificación de } \\
\text { bebidas }\end{array}$ \\
\hline Industria & $\begin{array}{l}\text { Concentración } \\
\text { Agua ultrapura } \\
\text { (Ind. Electrónica) }\end{array}$ & $\begin{array}{l}\text { Concentración y } \\
\text { desalación de } \\
\text { productos } \\
\text { químicos }\end{array}$ & $\begin{array}{l}\text { Electropintado } \\
\text { Textil (índigo) } \\
\text { Farmacéuticas } \\
\text { (enzimas, antibió- } \\
\text { ticos, pirógenos) }\end{array}$ & $\begin{array}{l}\text { Agua ultrapura } \\
\text { (semiconductores) } \\
\text { Esterilización de } \\
\text { productos } \\
\text { farmacéuticos } \\
\text { Análisis } \\
\text { Cultivo de células, } \\
\text { biorreactores } \\
\text { Plasmaféresis, } \\
\text { medicina } \\
\text { Separaciones de } \\
\text { látex }\end{array}$ \\
\hline
\end{tabular}

\section{B) Diálisis}

El proceso de diálisis también se efectúa entre dos corrientes acuosas, pero en este caso la fuerza impulsora que origina el transporte del componente es la diferente concentración de éste entre las dos fases. La separación se establece gracias a las diferentes velocidades de difusión de los componentes a través de la membrana.

Tiene su mayor aplicación en el tratamiento de la sangre de los enfermos cuando falla esa membrana natural que es el riñón. Tiene alguna aplicación medioambiental 
marginal como la recuperación de sosa cáustica en el proceso de fabricación de viscosa o industrial (recuperación de iones uranilo)

\section{C) Pervaporación (PV)}

En este caso la fuerza impulsora es el gradiente de actividad química que se establece para el componente por el hecho de tener una presión parcial muy baja en el permeado (en fase gaseosa). En este proceso el alimento es un líquido introducido a la presión atmosférica que en algunas variantes es precalentado. En la cara del permeado la presión parcial debe ser lo suficientemente baja para los compuestos que deben permear. Ello se logra de dos maneras:

- Mediante la utilización de un gas portador inerte con presión cercana a la atmosférica que arrastre al componente que permea.

- Mediante la creación de una presión total de vacío.

Merced a la fuerza impulsora creada los componentes atraviesan la membrana en una secuencia de tres pasos:

1) Disolución selectiva en la cara del alimento de la membrana.

2) Difusión selectiva a través de la membrana.

3) Desorción a la fase vapor en la cara del permeado.

Dependiendo del material de la membrana y de las mismas sustancias, éstas presentarán distinta capacidad de realizar estos tres pasos y en consecuencia unas sustancias pasarán selectivamente en mayor cantidad a la corriente de permeado.

Los componentes que han permeado deben retirarse continuamente para que no aumente su presión parcial en el permeado. Para ello se condensan a temperaturas bajas, lo cual en los sistemas basados en la disminución de la presión total contribuye al acercamiento al vacío.

Una aplicación típica de la pervaporación es la desalcoholización de bebidas, proceso en el que la membrana es tal que el alcohol tiene tendencia a disolverse y pasar a través de la membrana.

La aplicación medioambiental más importante es la extracción de compuestos orgánicos del agua, tales como alcoholes, aromáticos, clorados, etc.). 
Otras aplicaciones recuperativas son:

- Separación de mezclas azeotrópicas

- Deshidratación de disolventes orgánicos

- Separación entre compuestos polares y no polares (p.e. alcoholes de aromáticos)

- Separación entre saturados e insaturados (p.e. ciclohexano de benceno)

- Separación de isómeros (p.e. isómeros $\mathrm{C}_{8}$, xilenos)

\section{D) Permeación de gases (PG)}

En la separación o permeación de gases, la fuerza impulsora es una diferencia de presión creada entre las dos fases gaseosas situadas a ambos lados de la membrana, bien incrementando la presión en el lado del alimento o disminuyéndola por debajo de la atmosférica en el lado del permeado.

Se logra separar unos componentes del gas de otros gracias a las diferencias en el mecanismo de disolución-difusión que los gases presentan en las membranas no porosas o al distinto comportamiento en flujo de Knudsen que presentan en las membranas porosas.

Sus aplicaciones ambientales son importantes al permitir la recuperación de gases útiles para la industria que de otra forma serían arrojados a la atmósfera. Entre las separaciones más típicas se encuentran:

- Recuperación de $\mathrm{H}_{2}$ o He de gases residuales

- Separación de $\mathrm{CH}_{4}, \mathrm{CO}_{2}, \mathrm{H}_{2} \mathrm{~S}$ de corrientes gaseosas

- $\quad$ Aire enriquecido

- Secado de gases

- Extracción de compuestos orgánicos del aire

\section{E) Membranas líquidas}

Utilizan como fuerza impulsora la diferencia de concentración. Es el único proceso donde la membrana no es una fase sólida, sino un líquido. 
Podemos distinguir, atendiendo a la estructura, los dos tipos siguientes:

- Membranas donde el líquido está inmovilizado en una membrana porosa (MLI)

- Membranas de líquido emulsionado (MLE)

Casi siempre se añade una sustancia que forma complejo de manera selectiva con el componente que se quiere separar (sustancia transportadora). De esta manera no se tiene un flux difusivo hacia la otra fase del componente, sino de su complejo, el cual libera a la sustancia en la otra fase regenerando la sustancia transportadora.

Entre las aplicaciones de esta tecnología en desarrollo se tiene:

- Extracción de iones específicos (p.e.: recuperación de metales)

- Biotecnología

- Extracción de gases

- Separación de líquidos orgánicos

- Extracción de fenol

\section{F) Procesos con electricidad como fuerza impulsora. Electrodiálisis.}

Estos procesos se basan en la capacidad de las membranas de quedar cargadas impidiendo el paso en un sentido dado de iones que posean el mismo signo que la carga de la cara de la membrana. Así las membranas pueden clasificarse en aniónicas, catiónicas y bipolares. La presencia de un campo eléctrico entre dos electrodos origina la formación de iones que son separados selectivamente en función de su carga por las membranas.

Entre las aplicaciones de estas membranas se encuentran:

- Desalinización de aguas muy cargadas en sales

- Desalinización de alimentos y fármacos

- Separación de aminoácidos

- Producción de ácido sulfúrico e hidróxido sódico

La producción de hidróxido sódico e hipoclorito sódico por el proceso cloroalcalino es uno de los ejemplos más impresionantes del beneficio medioambiental de un proceso que utilice membranas. Este proceso ha sustituido casi completamente al muy contaminante método tradicional de producción por amalgama de sodio. 


\section{H) Procesos con la temperatura como fuerza impulsora}

La destilación por membranas es un proceso en el que la separación se produce por diferencias en la presión de vapor, actuando como fuerza impulsora la diferencia de temperaturas entre las fases. La membrana es porosa pero hidrófoba, ya que a través de sus poros debe pasar el vapor generado en la disolución alimento caliente. El vapor condensa posteriormente en el permeado que circula en contracorriente. La membrana actúa meramente como una simple barrera no influyendo en la selectividad.

Entre sus aplicaciones se encuentran las típicas del proceso convencional de rectificación, más concretamente:

- Retención de sales de todo tipo, agua destilada

- Eliminación de trazas de disolventes orgánicos en el agua.

El proceso de termoósmosis utiliza la diferencia de temperaturas entre dos fases. En este proceso se establece un flux volumétrico desde la fase caliente a la más fría. No parece de momento tener aplicaciones importantes frente a otros procesos.

\section{I) Otros procesos}

La per-extracción es una extracción especial realizada con membranas que ponen en contacto la fase a tratar con una fase disolvente extractora (contactor de membrana). Podría llegar a extraer compuestos orgánicos volátiles del aire y del agua así como $\mathrm{SO}_{2}$, $\mathrm{NO}_{x}, \mathrm{NH}_{3}$ y PAC's.

La piezodiálisis utiliza la presión como fuerza impulsora y se realiza entre dos fases líquidas. A diferencia de la ósmosis inversa, los solutos iónicos permean en mayor grado a través de la membrana merced a una interacción de cargas. Permitiría concentrar disoluciones iónicas, pero de momento solo tiene interés teórico. 


\subsection{ESTADO ACTUAL DE LA TECNOLOGÍA DE MEMBRANAS}

En la Tabla 6 se presentan los distintos procesos de membrana mencionados de manera que quedan clasificados como:

- Tecnologías maduras: Aquellas que han alcanzado tal nivel que no se espera que sufran un desarrollo espectacular en cuanto a membranas o módulos. Son procesos bastante fiables desde el punto de vista industrial. Sin embargo, es de esperar mejoras y optimización de los sistemas existentes, así como nuevas aplicaciones especiales.

- Tecnologías en desarrollo: Son aquellas en las que pueden aparecer nuevas aplicaciones y experimentarse avances importantes.

- Poco aplicables: Por sus características no parecen tener muchas aplicaciones actuales, y no parecen experimentar desarrollo a corto plazo, limitándose su interés al campo teórico, sin embargo su desarrollo futuro no se puede descartar.

Tabla 6. Procesos industriales de membrana según su estado de desarrollo

\begin{tabular}{|l|l|l|}
\hline Tecnologías maduras & Tecnologías en desarrollo & \multicolumn{1}{|c|}{$\begin{array}{c}\text { Poca aplicabilidad } \\
\text { industrial actual }\end{array}$} \\
\hline $\begin{array}{l}\text { Diálisis (D) } \\
\text { Microfiltración (MF) }\end{array}$ & $\begin{array}{l}\text { Pervaporación (PV) } \\
\text { Separación de gases (SG) }\end{array}$ & Piezodiálisis \\
Ósmosis inversa o & Destilación por & \\
hiperfiltración (OI) & membranas (DM) \\
Electrodiálisis (ED) & Membranas líquidas (ML) & \\
Nanofiltración (NF) & Electrodiálisis con & \\
& membranas bipolares & \\
& (EMB) & \\
& Biorreactores de & \\
& membrana (BM) & \\
& &
\end{tabular}

Además de las tecnologías industriales reseñadas en la Tabla 6, existen aplicaciones punteras de las membranas en los campos de la ciencia y la Medicina como pueden ser la Administración controlada y las Membranas de transporte activo. 
Como se puede ver en Tabla 6 los procesos de membrana que han alcanzado mayor grado de desarrollo en la actualidad son los procesos que utilizan la presión como fuerza impulsora (MF, OI, UF). Una de las aplicaciones con más éxito ha sido la de la obtención de agua potable por medio de osmosis inversa a partir de agua de mar o salobre, lo que permite abastecer a poblaciones y regadíos de zonas áridas con un agua de calidad. Estos procesos son muy aplicados también en la ingeniería medioambiental, la ósmosis inversa en la eliminación de compuestos inorgánicos, la ultrafiltración en la eliminación de compuestos orgánicos de peso molecular medio y la microfiltración en la eliminación de partículas y microorganismos. A ellos habría que añadir la nanofiltración, la cual está adquiriendo el carácter de tecnología madura.

Los otros procesos, de los cuales ya se han mencionado algunas aplicaciones, también están produciendo un continuo desarrollo en distintos campos de la industria y la vida ordinarias, pudiendo producir una revolución en determinados sectores económicos. Como ejemplo, podemos incluir la línea de investigación del Departamento de Ingeniería Química de la U.P.V. que busca aprovechar los excedentes de producción de vino mediante desalcoholización por pervaporación. Ello contribuiría a dar salida a estos excedentes como un nuevo producto desalcoholizado.

Como se ve, los procesos de membrana han alcanzado una amplia aceptación dentro de diversos campos de la ingeniería química y en áreas relacionadas como la ingeniería medioambiental y la tecnología de alimentos y ello a pesar de que muchas de las funciones que desempeñan éstos podrían ser realizables por otras operaciones de separación. Esto es debido a que presentan una serie de características muy importantes desde el punto de vista económico:

1) Consumen muy poca energía en comparación con otros procesos separadores.

2) Al no requerir temperaturas extremas no degradan térmicamente las sustancias que tratan, este hecho es de suma importancia en tecnología de alimentos.

3) Permiten concentrar disoluciones muy diluidas a muy bajo coste.

4) En muchos casos realizan separaciones que serían muy dificultosas bajo otros procesos.

5) Se combinan muy fácilmente con otros procesos.

6) El paso de escala es sencillo.

El punto tercero limita el rango económico de aplicación, ya que las tecnologías basadas en membranas son apropiadas cuando es necesario pasar de disoluciones muy 
diluidas a una concentración media, siendo necesario acudir a otro tipo de procesos para lograr concentraciones más elevadas. Es común por otra parte desechar corrientes residuales porque el contaminante que contienen está en una concentración poco aprovechable o mezclado con otras sustancias. Las membranas pueden llegar a separar y concentrar los contaminantes permitiendo su aprovechamiento económico por otros procesos o su destrucción.

Se comprende, pues, que debido al gran atractivo económico de estos procesos y a que las nuevas legislaciones medioambientales las hacen indispensables, la demanda de las membranas va en aumento. En la Ilustración 5 aparecen los datos previstos para el mercado teniendo en cuenta que la tendencia de aumento va a seguir siendo probablemente exponencial.

\section{MILLARDOS DE DOLARES}

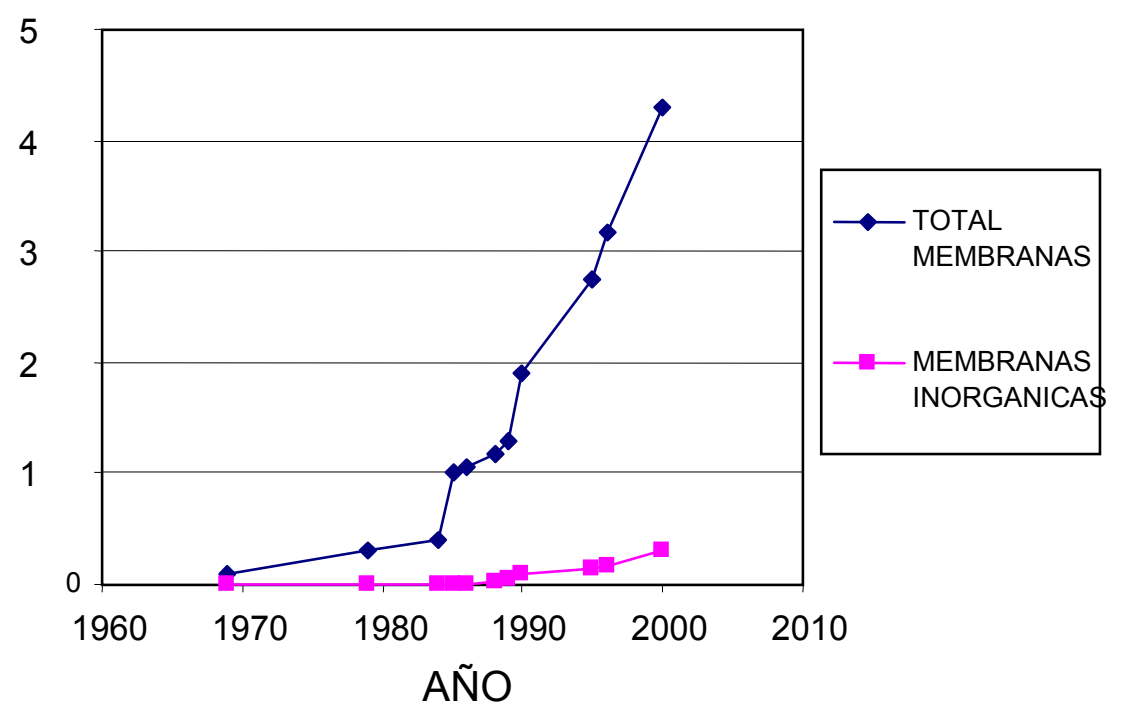

Ilustración 5. Mercado mundial de membranas y previsión

Dentro del mercado mundial Estados Unidos es el máximo productor copando alrededor del 60\% de las ventas, sin embargo representa el 35\% del mercado. Europa, con una producción del 10\%, representa el 30\% del mercado, por lo que es un claro importador. Al poseer Europa la capacidad tecnológica suficiente le interesa estimular la producción de membranas para corregir el desequilibrio. 
La investigación y desarrollo en la producción de membranas busca obtener membranas para realizar una determinada separación de componentes de forma eficaz, es decir, con altos fluxes de producto y una separación selectiva de componentes razonable. También interesa orientar la fabricación hacia la obtención de membranas con propiedades como la resistencia al ensuciamiento, elevada vida, resistencia térmica o biocompatibilidad, según el caso, para tener competitividad en el mercado.

Otra línea de desarrollo que enlaza con la anterior es el diseño de procesos de membranas para un fin concreto, donde es necesario diseñar instalaciones que contengan módulos de membranas eficaces junto con las bombas, distribuciones hidráulicas, utillaje de control, etc., necesarios. También es importante el posterior mantenimiento adecuado del proceso, controlando los parámetros de funcionamiento con el fin de obtener una buena calidad de producto y evitar un deterioro prematuro de las membranas. Se debe tener en cuenta, además, el momento oportuno para un tratamiento regenerativo o el remplazo. No solo los procesos estrictamente de membranas experimentan un gran impulso, sino que se intuye que en un futuro próximo los procesos mixtos lo van a experimentar también. Entre ellos estarán:

- Reactores bioquímicos con membranas.

- Membranas catalíticas o que incluyan catalizadores y biocatalizadores en su seno.

- Celdas electroquímicas de combustible.

- Electrónica, sensores, etc. 


\subsection{FUNDAMENTOS DE LOS PROCESOS DE ÓSMOSIS INVERSA Y NANOFILTRACIÓN. MODELOS DE TRANSPORTE}

Tanto la nanofiltración como la ósmosis inversa son procesos en los que el transporte es producido por un gradiente de presión. También ambos procesos se llevan a cabo sin que exista cambio de fase, lo cual los hace ventajosos desde el punto de vista de ahorro energético en muchos casos, además del hecho de que por realizarse a baja temperatura son procesos aptos para la industria alimentaria.

Ambos procesos se utilizan en la separación de pequeñas moléculas, por lo que el fenómeno osmótico, descrito más adelante, tendrá importancia, siendo necesario en ambos casos que la fuerza impulsora constituida por el gradiente de presión supere la presión osmótica.

Las siguientes variables son importantes tanto en ósmosis inversa como en nanofiltración:

- Diferencia de presión

- Temperatura

- $\mathrm{pH}$

- Velocidad tangencial y estado de turbulencia en la cara del alimento

- Concentración de solutos

- Concentración de sólidos suspendidos

\subsubsection{Fenómeno osmótico y ósmosis inversa}

La ósmosis inversa, también conocida como hiperfiltración, es un proceso de membrana que es utilizado en la separación de sales inorgánicas o pequeñas moléculas inorgánicas de un disolvente. Tales solutos, de bajo peso molecular, no pueden ser separados apreciablemente por otros procesos de membrana, como por ejemplo la ultrafiltración, en los que la selectividad de la membrana se produce por un mecanismo de tamizado entre las moléculas de soluto y disolvente que deberán tener, por tanto, 
diferencias de tamaño apreciables. En el caso de solutos de bajo peso molecular, debido a su tamaño comparable con el disolvente ambos pasarían libremente a través de la membrana. De hecho, las membranas para ósmosis inversa son intermedias entre las membranas porosas de ultrafiltración y las membranas densas y no porosas del tipo de las utilizadas para pervaporación y separación de gases. Sin embargo, los mecanismos que permiten la diferente velocidad de paso de los distintos componentes a través de la membrana de ósmosis inversa son los debidos a la diferente solubilidad y difusividad de los componentes en ésta.

La fuerza impulsora que permite el paso de los distintos componentes a través de la membrana es la diferencia de presión existente entre ambas caras de ésta. Entre dos componentes con la misma difusividad en la membrana, el componente más soluble dentro del material que la constituye tenderá a pasar en mayor cantidad que el menos soluble. Y a la inversa, para una misma solubilidad de los componentes en la membrana los fluxes de cada componente a través de ella aumentarán con la mayor difusividad. La relación de fluxes de permeación entre dos componentes dependerá de la solubilidad y difusividad relativa entre ellos, así como de la presión de trabajo.

Cuando se trabaja con disoluciones acuosas, que contienen solutos de bajo peso molecular, el fenómeno osmótico tiene importancia, siendo necesario superar un determinado valor de presión (presión osmótica) para que se pueda establecer el paso del disolvente (normalmente agua) a través de la membrana.

\section{Fenómeno osmótico}

El fenómeno osmótico se puede observar en dos recipientes que contengan disoluciones acuosas con diferente concentración de un soluto de bajo peso molecular (por ejemplo: una sal). Ambas disoluciones son al efecto dos fases diferentes que denominaremos:

Fase 1: Fase de mayor concentración

Fase 2: Fase de menor concentración

Cuando ambos recipientes están conectados a través de una membrana semipermeable, es decir, permeable al disolvente pero no al soluto se observa un flujo de líquido a través de la membrana desde la disolución menos concentrada hacia la más 
concentrada como tendiendo a diluirla. El fenómeno, conocido como ósmosis directa, se produce mientras la diferencia de presión existente entre la disolución más concentrada y la menos concentrada sea menor que un cierto valor (Ilustración 6 ).

Al alcanzarse dicho valor relacionado con la diferencia de concentraciones entre ambas fases se llegará al equilibrio y el flujo de líquido que atraviesa la membrana se detendrá. Esta diferencia de presión de equilibrio es la diferencia de presiones osmótica entre ambas fases.

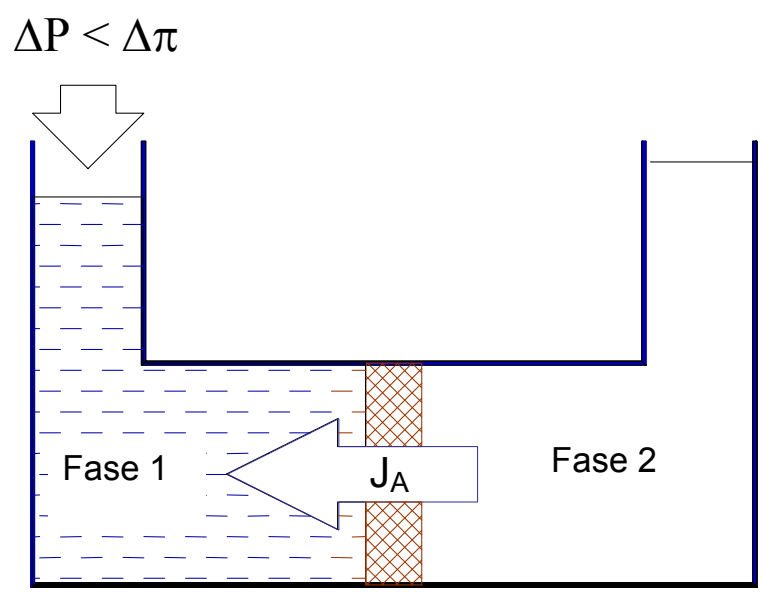

$$
\mu_{\mathrm{A}, 1}<\mu_{\mathrm{A}, 2}
$$

Ilustración 6. Fenómeno de ósmosis directa

\section{Equilibrio osmótico y presión osmótica}

La condición de equilibrio se puede expresar desde el punto de vista termodinámico. Según la condición general de equilibrio entre fases se tendrá para las dos fases 1 y 2 :

Ec. 3:

$$
\sum_{F=1,2} \sum_{i=A, S, \ldots} \mu_{i, F} \cdot d n_{i, F}=0
$$

El disolvente $(A)$ es el único que sufre transporte apreciable entre las dos fases y en este caso se tendrá: 
Ec. 4:

$$
d n_{A, 1}=-d n_{A, 2}
$$

Se saca como conclusión que la condición de equilibrio físico-químico implica una igualdad de potenciales químicos del disolvente en cada fase:

Ec. 5:

$$
\mu_{A, 1}=\mu_{A, 2}
$$

El potencial químico de un componente i en una fase F se expresa como:

Ec. 6:

$$
\mu_{i, F}=\mu_{i, F}^{\mathrm{o}}\left(T, P^{\mathrm{o}}\right)+R \cdot T \cdot \ln a_{i, F}+v_{i, F} \cdot\left(P_{F}-P^{\mathrm{o}}\right)
$$

$v_{i}$ : $\quad$ Volumen específico molar del disolvente $\left(\mathrm{m}^{3} \cdot \mathrm{mol}^{-1}\right)$

$R: \quad$ Constante universal de los gases perfectos $\left(8.314 \mathrm{~J} \cdot \mathrm{mol}^{-1} \cdot \mathrm{K}^{-1}\right)$

$T: \quad$ Temperatura absoluta $(\mathrm{K})$

$a_{i, F}: \quad$ Actividad del componente $i$ en la fase $F$

Para una misma temperatura en las dos fases los potenciales químicos del disolvente $A$ en las fases concentrada (1) y diluida (2) son respectivamente:

$$
\begin{aligned}
& \mu_{A, 1}=\mu_{A, 1}^{\mathrm{o}}\left(T, P^{\mathrm{o}}\right)+R \cdot T \cdot \ln a_{A, 1}+v_{A, 1} \cdot\left(P_{1}-P^{\mathrm{o}}\right) \\
& \mu_{A, 2}=\mu_{A, 2}^{\mathrm{o}}\left(T, P^{\mathrm{o}}\right)+R \cdot T \cdot \ln a_{A, 2}+v_{A, 2} \cdot\left(P_{2}-P^{\mathrm{o}}\right)
\end{aligned}
$$

Por tratarse del mismo disolvente los potenciales del componente puro a la temperatura y presión de referencia en cada fase $\mu_{A, 1}^{o}$ y $\mu_{A, 2}^{o}$ son iguales, entonces, de la igualdad de potenciales en el equilibrio y considerando que el volumen específico es aproximadamente constante, se deduce:

$$
\left(P_{1}-P_{2}\right)=-\frac{R \cdot T}{v_{A}} \cdot\left(\ln a_{A, 1}-\ln a_{A, 2}\right)
$$

Si definimos la presión osmótica en una fase genérica $F$ de la siguiente manera: 
Ec. 7: $\quad \pi_{F}=-\frac{R_{u} \cdot T}{v_{A}} \cdot \ln a_{A, F}$

Entonces en el equilibrio la diferencia de presión entre las dos estará compensada por una diferencia de presión osmótica:

Ec. 8:

$$
\Delta \pi=\pi_{2}-\pi_{1}=-\frac{R \cdot T}{v_{A}} \cdot\left(\ln a_{A, 2}-\ln a_{A, 1}\right)
$$

Para disoluciones diluidas los coeficientes de actividad tienden a uno, y si consideramos un único soluto $S$, se tiene:

Ec. 9:

$$
\ln a_{A, F}=\ln \left(\gamma_{A, F} \cdot x_{A, F}\right) \approx \ln x_{A, F} \approx \ln \left(1-x_{S, F}\right) \approx-x_{S, F}
$$

Además, para una disolución diluida se cumplirá aproximadamente:

Ec. 10:

$$
x_{S, F}=\frac{n_{S, F}}{n_{A, F}+n_{S, F}} \approx \frac{n_{S, F}}{n_{A, F}}
$$

A partir de las anteriores relaciones puede deducirse que la presión osmótica de la fase $F, \pi_{F}$, puede ser calculada de manera aproximada, a partir de la concentración molar de soluto, mediante la ecuación de Van't Hoff:

Ec. 11:

$$
\pi_{F}=C_{S, F} \cdot R \cdot T
$$

Presión osmótica de las disoluciones de electrolitos:

Si el soluto sufre disociación o asociación la ecuación de Van’t Hoff debe modificarse multiplicándola por un factor " $n_{i}$ " comprendido entre 1 y el número de iones generados. Este factor será más cercano a uno cuanto más diluida sea la disolución. 
Ec. 12:

$$
\pi_{F}=n_{i} \cdot C_{S, F} \cdot R \cdot T
$$

El hecho de que $n_{i}$ no coincida exactamente con el número de iones es explicado por la teoría de Debye-Hückel, según la cual las interacciones electrostáticas reducen el potencial químico de los iones. Sin embargo, para disoluciones muy diluidas este efecto es despreciable. Como ejemplo considérense las disoluciones patrón de 2000 ppm de cloruro sódico utilizadas. En ellas al originar cada molécula de sal dos iones al disociarse se tiene $n_{i}=2$ en la Ec. 12, obteniéndose un incremento de presión osmótica respecto del agua pura de 1.69 bar, prácticamente igual al experimental.

Presión osmótica de otros tipos de disolución:

La ecuación de Van’t Hoff suele cumplirse de forma bastante aproximada para solutos no iónicos de bajo peso molecular. Para productos de mayor peso molecular, el resultado de la ecuación de Van’t Hoff debe ser multiplicado por un factor dependiente de la concentración (tal es el caso de las disoluciones poliméricas), o bien debe acudirse a expresiones empíricas como la relación de Thijssen, en el caso de zumos o disoluciones de sacarosa.

\section{Fenómeno de ósmosis inversa (OI).}

Si se aplica, en cambio, una presión superior a la presión osmótica en el lado de la disolución salina, se establecerá un flux $J_{w}$ hacia la fase con bajo contenido en sal (Ilustración 7). Además, si la membrana presenta una baja permeabilidad hacia la sal, el agua pasará prácticamente desprovista de ésta. Este fenómeno se conoce como ósmosis inversa.

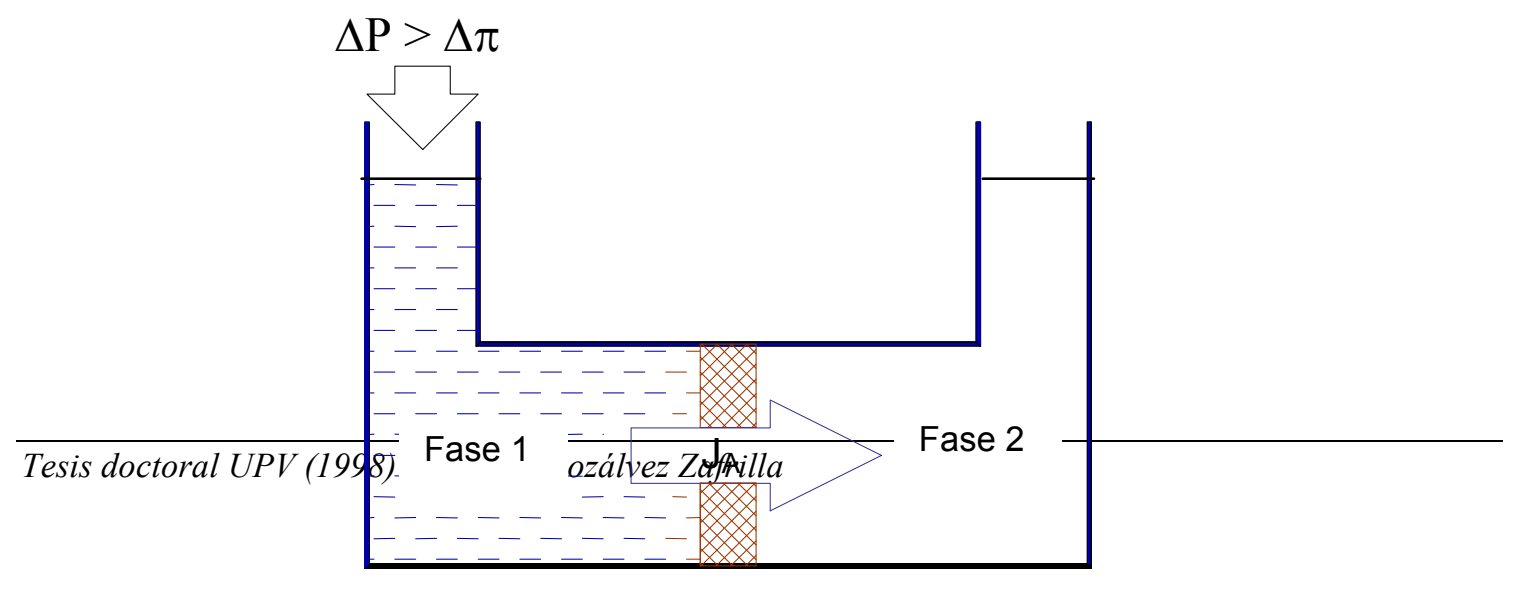




\section{Ilustración 7. Fenómeno de ósmosis inversa}

\section{Selectividad y transporte en las membranas de ósmosis inversa}

El mecanismo de transporte característico de estas membranas es el de "disolucióndifusión". En este mecanismo las sustancias deben disolverse en la membrana y luego difundir a través de ella en el sentido de los potenciales químicos decrecientes. La selectividad de una membrana de ósmosis inversa va a depender esencialmente de su naturaleza química, ya que las sustancias solubles en la membrana son las únicas susceptibles de atravesarla. El material de la membrana deberá mostrar una adecuada afinidad hacia el componente que queremos que constituya el permeado (normalmente el disolvente principal) para permitir que se disuelva en ella pero sin que quede excesivamente ligado. Si el disolvente es agua, la membrana deberá mostrar un adecuado carácter hidrófilo. En este caso, según la teoría de Gibbs sobre los fenómenos de adsorción, se formará un film de agua pura sobre las superficies de material hidrófilo ( 0.2 a $0.5 \mathrm{~nm}$ para membranas muy hidrófilas). En la superficie de una membrana de ósmosis inversa para desalación se forma pues una interfase de agua pura que tiende a excluir las impurezas que no tienen afinidad por la membrana. Asimismo las moléculas de agua tenderán a disolverse en el material de la membrana por la afinidad que muestran hacia él. Cuando existe una fuerza impulsora, en este caso un gradiente de potencial químico originado por la presión, el agua difunde a través de la membrana, formando y rompiendo enlaces con el material sucesivamente (véase Ilustración 9). Los enlaces del disolvente con la membrana deberán ser débiles (puentes de hidrógeno en el caso del agua) ya que de lo contrario se requeriría una enorme fuerza impulsora para desplazar las moléculas. 
Al no ser nunca la separación de la membrana completamente ideal, los solutos, aunque en menor proporción que el disolvente, atravesarán ésta, dependiendo la selectividad de la membrana hacia éstos dos factores, el coeficiente de reparto o distribución entre la membrana y la disolución, que marca la afinidad del soluto por el material de la membrana y el coeficiente de difusión del soluto en la membrana (que suele ser menos preponderante que el anterior).

Algunas indicaciones sobre la selectividad para diferentes solutos extraídas de Maurel (1993) y Dickson (1988) se muestran a continuación:

- Los ácidos y bases débiles son más rechazados en los valores de pH en los que la especie toma la forma iónica.

- Las proteínas son más retenidas para valores de $\mathrm{pH}$ alejados del punto isoeléctrico.

- Algunos iones bivalentes formando parte de un complejo son mucho menos rechazados que en su forma iónica libre.

- Los alcoholes tienen propiedades de permeación similares a las del agua, aumentando su rechazo con el peso molecular.

- Los iones más solvatados (véase Ilustración 8) los cuales tienen energía de hidratación más elevada, son los más rechazados.

- Para una misma valencia es rechazado el ion de menor masa molecular (más solvatado)

- El rechazo de la membrana es mayor hacia los iones con mayor valencia (más solvatados).
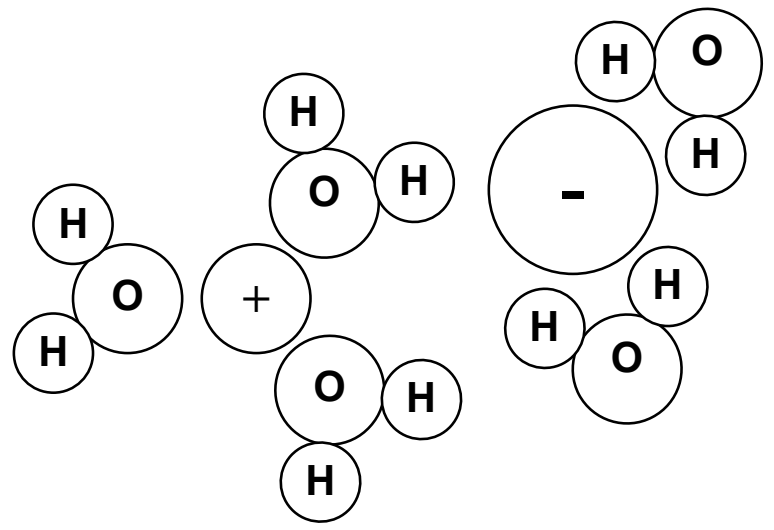
Ilustración 8. Hidratación de iones en disolución. 


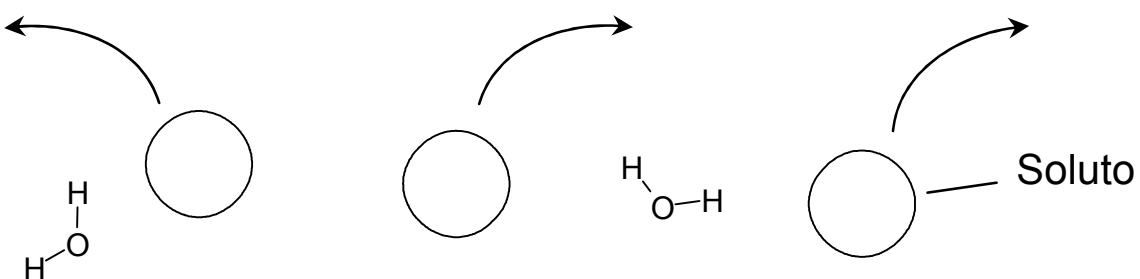

$\mathrm{H}^{\mathrm{O}-\mathrm{H}} \mathrm{H}^{-\mathrm{O}^{-}}$

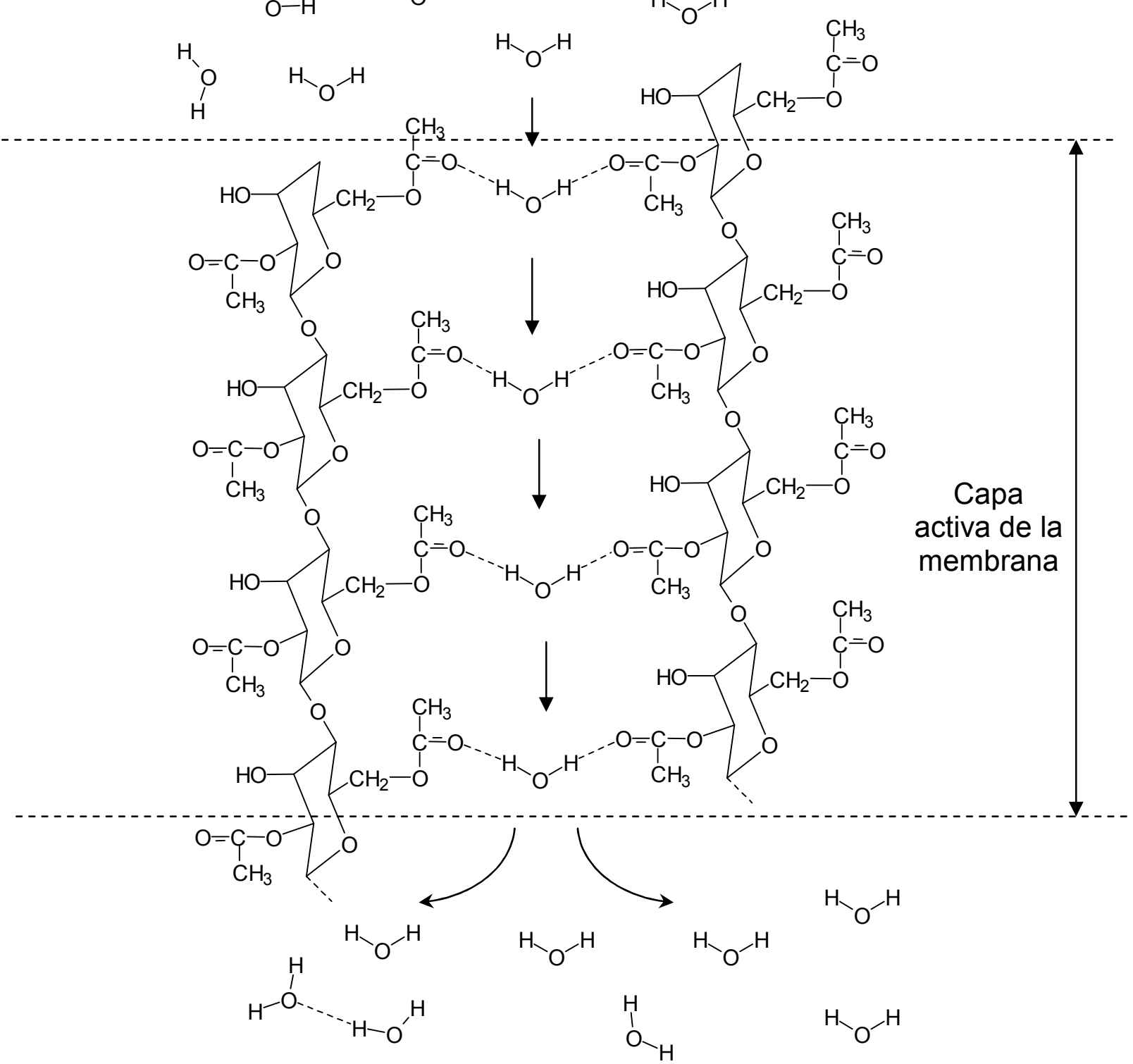

Ilustración 9. Transferencia de materia a través de una membrana semipermeable 


\subsubsection{Nanofiltración}

Como nanofiltración se conoce una nueva técnica intermedia entre la ósmosis inversa y ultrafiltración. Inicialmente las membranas con características de nanofiltración se catalogaban algunas veces como de ultrafiltración y la mayoría como de ósmosis inversa. Tanto es así que inicialmente la nanofiltración era referida en inglés como una clase de ósmosis inversa "loose reverse osmosis". Sin embargo se constató que existían determinadas membranas cuya asignación a uno u otro tipo no resultaba clara ya que participaban de las características separadoras de ambos procesos.

Las características definitorias de las membranas de nanofiltración son:

- Baja retención hacia las sales iónicas monovalentes, y alta para las multivalentes.

- Baja retención de los compuestos orgánicos de peso molecular inferior a $200 \mathrm{~g} / \mathrm{mol}$ (300 g/mol para otros autores) y alta retención para compuestos de peso molecular superior.

- Mecanismos de transferencia intermedios entre los de la ósmosis inversa (disolución - difusión) y la ultrafiltración (tamizado, flujo capilar).

\section{Selectividad y transporte en las membranas de nanofiltración}

En las membranas de ósmosis inversa las moléculas del material que constituye la capa activa de la membrana están tan juntas que no existen poros físicos detectables (diámetro $>0.5 \mathrm{~nm}$ ), debiéndose considerar la membrana como una estructura densa, no porosa en la que el disolvente se disuelve y difunde. En las membranas de nanofiltración ya se puede considerar la existencia de poros. Estos poros son del orden del tamaño de la película de disolvente casi puro adsorbido con lo que es de esperar un rechazo de impurezas sin afinidad por el material de la membrana importante. Como una parte del permeado atraviesa la membrana en flujo convectivo o capilar, sin formar ya puentes de 
hidrógeno con el material, el flux de permeado será mayor y el rechazo hacia los solutos no llegará a ser tan alto como en ósmosis inversa. Sin embargo, el rechazo hacia los solutos será mayor que en ultrafiltración y microfiltración donde el flujo es claramente convectivo (véase Ilustración 10).

En cuanto a la selectividad de las membranas de nanofiltración frente a compuestos no iónicos hay que comentar que un mayor tamaño de la partícula implica probablemente un mayor rechazo, si bien también pueden tener importancia los factores comentados en la página 37 sobre la selectividad de la ósmosis inversa.

En cuanto a la selectividad frente a especies iónicas son válidos los comentarios hechos sobre la selectividad de la ósmosis inversa, siendo en el caso de la nanofiltración el efecto de la carga de los iones mucho más patente. Hay que tener en cuenta que en nanofiltración se emplean muchas veces membranas cargadas por lo que la selectividad frente a los distintos iones puede verse afectada por el efecto de Donnan. Por ejemplo, en una membrana positivamente cargada se obtendría mayor rechazo para catión bivalente que para catión monovalente con el mismo contraión, pero para un mismo catión se obtiene mayor rechazo para el anión con menos valencia.

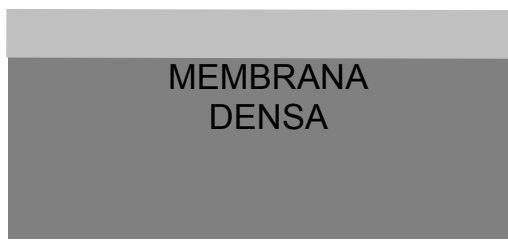

ÓSMOSIS INVERSA

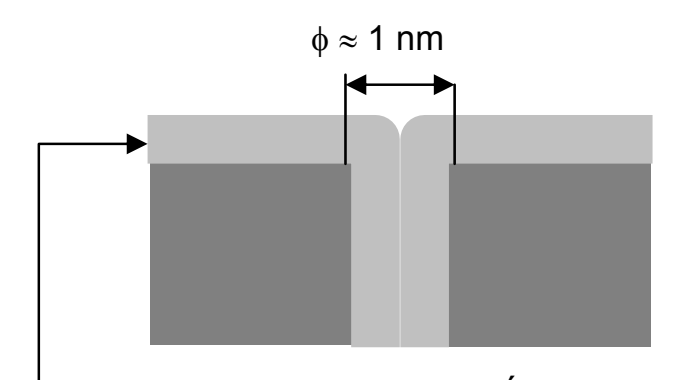

NANOFILTRACIÓN

\section{Película de agua}

$0.2-0.5 \mathrm{~nm}$

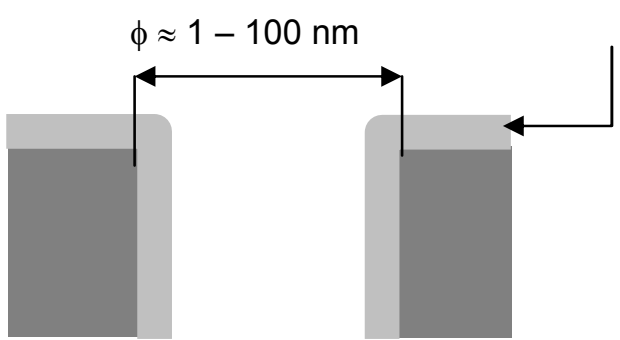

ULTRAFILTRACIÓN

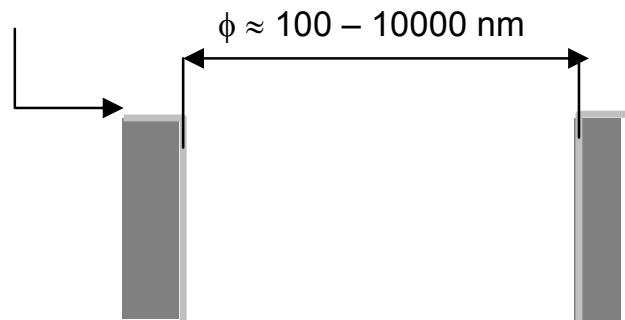

MICROFILTRACIÓN 
Ilustración 10. Influencia de la película de agua. Modelo de transferencia de Sourirajan 


\subsubsection{Modelos de transporte para membranas de ósmosis inversa y nanofiltración}

\section{Necesidad de los modelos de transporte}

El propósito general de los modelos de transporte aplicados a membranas es relacionar las características de comportamiento (flux y selectividad) con las condiciones operativas. Las condiciones operativas incluidas en la modelización suelen ser términos de fuerza impulsora del transporte, usualmente presión y concentración de soluto, aunque también pueden incluirse en modelos más completos parámetros influyentes sobre las propiedades permeoselectivas de la membrana, tales como la temperatura o el $\mathrm{pH}$.

Hay que tener en cuenta que un modelo es siempre una simplificación y por tanto no va a reproducir exactamente el funcionamiento de la membrana. El modelo será tanto más poderoso cuanto mejor prediga el comportamiento de la membrana bajo diferentes condiciones operativas. El elevar la complejidad del modelo para lograr una mayor exactitud no es siempre eficaz pues los datos de los parámetros que lo ajusten pueden ser de obtención dificultosa y poco exacta. Muchas veces son preferibles modelos sencillos y de fácil interpretación.

Una consideración importante es que los modelos deben incluir parámetros que se correspondan con propiedades que tengan interpretación física con posibilidad de ser ajustados a partir de datos experimentales. Ello permitirá que el modelo pueda utilizarse para evaluar el comportamiento bajo otras condiciones de operación. De lo contrario, en modelos basados en parámetros matemáticos se corre el riesgo de que éstos se ajusten bien para una experiencia determinada pero que no nos permitan extrapolar a otras condiciones ni sacar conclusiones sobre el comportamiento de la membrana.

Los modelos basados en parámetros relacionables con propiedades físicas de la membrana pueden ser aptos para un tipo particular de membrana pero fallar en la descripción del comportamiento de otros tipos de membrana basadas en otros mecanismos separadores donde otros parámetros físicos han pasado a ser importantes.

La utilización de los modelos de transporte en la presente Tesis pretende además poder interpretar el efecto de las condiciones de fabricación sobre las propiedades de la membrana. Para ello se relacionan las condiciones de fabricación con parámetros físicos de 
los modelos, con lo cual la información obtenida es de validez más general que si se obtiene la relación con el flux y rechazo obtenidos bajo condiciones muy específicas.

\section{Efectos dinámicos: Concentración por polarización}

En un proceso de membrana donde tenga lugar una cierta separación, el soluto es llevado hacia la membrana mediante flujo convectivo por el disolvente. El disolvente atraviesa la membrana en mayor grado y por tanto aumenta la concentración de soluto cerca de la membrana. En zonas con turbulencia el soluto es homogeneizado rápidamente a la concentración del seno del fluido (mezcla completa), mientras que en zonas incluidas en la capa límite el aumento de concentración de soluto cerca de la membrana origina un flujo difusivo de soluto en sentido contrario al flujo convectivo buscando disminuir la concentración. Cuando parte el proceso de una situación estática predomina el flujo convectivo, pero transcurrido un cierto tiempo se habrá acercado a las condiciones estacionarias en las que el flujo convectivo y el difusivo de soluto se habrán igualado; se tendrá entonces una concentración estacionaria de soluto en las cercanías de la membrana $C_{a, m}$ superior a la existente en el seno del fluido $C_{a}$. Este fenómeno conocido como concentración por polarización y la relación $C_{a, m} / C_{a}$ es el módulo de concentración por polarización.

Basándonos en la situación mostrada en la Ilustración 11 se tiene que para un flux volumétrico determinado $J_{v}$ la ecuación diferencial que rige el fenómeno en la capa límite laminar es:

Ec. 13:

$$
J_{v} \cdot C_{p}=J_{v} \cdot C(x)-D_{S A} \cdot \frac{d C(x)}{d x}
$$

Una condición de contorno para esta ecuación es que el máximo de concentración que queremos determinar $C_{a, m}$ se da en la pared de la membrana en contacto con el alimento (coordenada $x=0$ ) y la otra es que tenemos una concentración homogénea en el seno del líquido, $C_{a}$, fuera de la capa límite laminar a partir del espesor de esta última (coordenada $x=\delta$ ). Aplicando estas condiciones se llega a:

Ec. 14: $\quad \frac{C_{a, m}-C_{p}}{C_{a}-C_{p}}=\exp \left(\frac{J_{v}}{k}\right) \quad$ con $\quad k=\frac{D_{A S}}{\delta}$ 


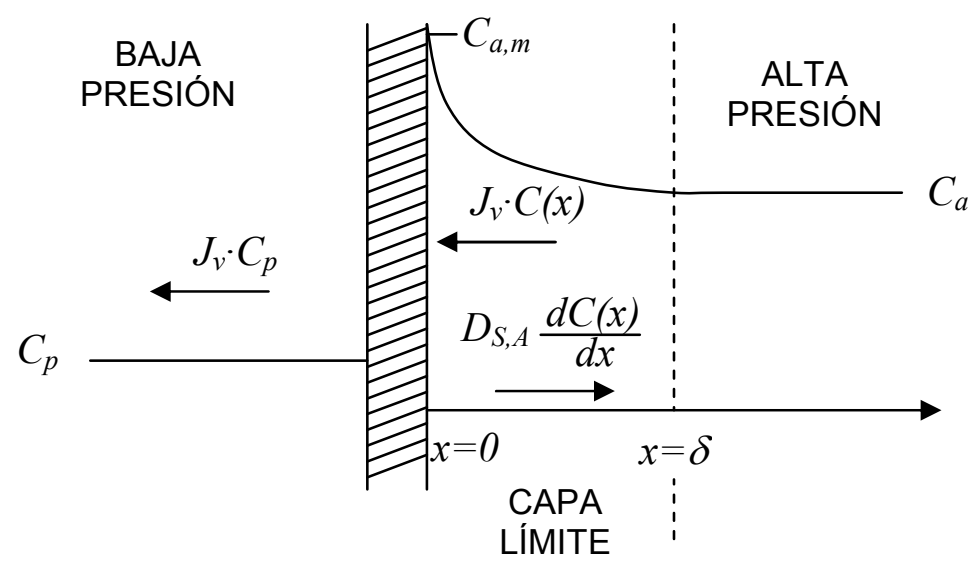

\section{Ilustración 11. Perfil de concentraciones estacionario en la polarización por concentración}

La Ec. 14 permite obtener $C_{a, m}$ y por tanto cuantifica el fenómeno de concentración por polarización. En la ecuación $k$ es el coeficiente de transferencia de masa, el cual, cuando aumenta su valor $C_{a, m}$ tiende a igualarse a la concentración en el seno de la zona de alta presión. Este aumento del coeficiente de transferencia puede producirse mediante una disminución del espesor de capa límite originado por un aumento de la turbulencia en la zona de alta presión.

La ecuación anterior se puede poner en función del rechazo observado $R_{a} \mathrm{y}$ el rechazo basado en la concentración en la cara de la membrana $R_{m}$.

Ec. 15: $\quad R_{m}=\frac{C_{a, m}-C_{p}}{C_{a, m}}$

Ec. 16: $\quad R_{a}=\frac{C_{a}-C_{p}}{C_{a}}$

Ec. 17:

$$
\begin{aligned}
& R_{a}=\left(1+\left(\frac{1}{R_{m}}-1\right) \cdot \exp \left(\frac{J_{v}}{k}\right)\right)^{-1} \\
& R_{m}=\left(1+\left(\frac{1}{R_{a}}-1\right) \cdot \exp \left(-\frac{J_{v}}{k}\right)\right)^{-1}
\end{aligned}
$$


El fenómeno de concentración por polarización trae como consecuencia que el rechazo observado sea menor que el basado en la concentración en la cara de la membrana, coincidiendo ambos sólo bajo condiciones de mezcla perfecta.

Para poder relacionar el rechazo real $R_{m}$ y el rechazo observado $R_{a}$ es necesario el conocimiento del coeficiente de transferencia de masa $k$ que va a ser función de las condiciones hidrodinámicas (geometría de módulo y velocidad de circulación de la alimentación) así como de la difusividad del componente. Para determinar $k$ diversos autores han utilizado correlaciones en función de los números de Sherwood y Schmidt de la siguiente forma:

Ec. 18: $\quad S h=\frac{k \cdot d_{h}}{D_{S A}}=a \cdot R e^{b} \cdot S c^{c}$

En la ecuación $d_{h}$ es el diámetro hidráulico (en módulos planos se toma dos veces el espesor de la separación por la que transcurre el alimento), el cual también debe utilizarse en el cálculo del número de Reynolds.

Se pueden ajustar los coeficientes $a$ y $b$ para un módulo concreto realizando ensayos con una disolución de $\mathrm{NaCl}$ como alimento y variando las condiciones hidrodinámicas. Para ello también se puede fijar $c$ en un valor de 1/3.

Schirg et al. (1992) consideran muy apropiada para ensayos de nanofiltración en un módulo plano sin promotor de turbulencia la siguiente particularización de la Ec. 18 proporcionada por Shaw y Hanratty:

$\begin{array}{llllll}\text { Ec. 19: } & \operatorname{Re}>2300 \quad S c>2000 & a=0,0177 \quad b=0,875 & c=0,296 \\ & 2300<\operatorname{Re}<10^{4} & S c<2000 & a=0,0177 \cdot \frac{\operatorname{Re}-100}{\operatorname{Re}} \quad b=0,875 \quad c=0,296\end{array}$

El valor de $k$ obtenido para el soluto y temperatura de referencia se puede modificar para hacerlo válido para otras condiciones de temperatura $\mathrm{u}$ otros solutos mediante el nuevo valor del coeficiente de difusión bajo esas condiciones: 
Ec. 20:

$$
k=k_{r e f}\left(\frac{D_{S A}}{D_{\text {SAref }}}\right)^{1-c}
$$

\section{Clasificación de los modelos de transporte}

Atendiendo a las características principales de los modelos podemos subdividir los modelos aplicables dentro del campo de la ósmosis inversa y la nanofiltración dentro de los siguientes grandes grupos:

\section{A. Modelos fenomenológicos.}

No consideran información sobre el mecanismo de transporte. Están basados en la Teoría Termodinámica de Procesos Irreversibles y relacionan directamente flux y fuerza impulsora a través de una constante de proporcionalidad.

B. Modelos de transporte en membranas no porosas.

Asumen una naturaleza no porosa para la membrana, por lo que explican el transporte a través de mecanismos de disolución y difusión. Sin embargo, algunos modelos pueden considerar un transporte no difusivo a través de imperfecciones.

C. Modelos de transporte en membranas porosas.

Asumen una naturaleza porosa para la membrana, por lo que los mecanismos de transporte son los de flujo convectivo a través de capilares en el caso del solvente. Sin embargo, en algún caso se puede suponer una naturaleza difusiva para el transporte de algún componente. 


\section{Tabla 7. Clasificación de los modelos de transporte}

\begin{tabular}{|l|l}
\hline Tipos y ejemplos & Aplicabilidad
\end{tabular}

A. Modelos fenomenológicos

- Relación de transporte fenomenológica

General

- Relación de Kedem-Spiegler (RKS)

OI, NF

- Modificación RKS de Linder y Perry

NF

B. Modelos de transporte en membranas densas

- Modelo de disolución-difusión (DD)

OI

- Modelo de disolución-difusión con imperfecciones (DDI)

OI, NF

- Modelo de disolución-difusión ampliado

OI

C. Modelos de transporte en membranas porosas

- Análisis de Kimura-Sourirajan (AKS)

OI, NF

- Modelos de red capilar

OI, NF

- Modelos bidimensionales

OI, NF

- Modelos para membranas cargadas

NF

- Exclusión electrostática de Donnan

- Teoría de Nernst-Planck extendida 


\section{A. Modelos fenomenológicos}

Como en otros muchos fenómenos físicos en los que un flujo es originado por una diferencia de potencial, se puede acudir a una relación fenomenológica que exprese la proporcionalidad entre el potencial o fuerza impulsora y el flux de componente a través del medio resistente. La fuerza impulsora estaría relacionada con la diferencia de una propiedad respecto de su valor en el equilibrio y se haría cero cuando se alcanzara éste.

Ec. 21: $\quad($ Flux de componente $)=($ Factor de proporcionalidad $) \times($ Fuerza impulsora $)$

\section{A-1. Relación de transporte fenomenológica}

Premisas del modelo:

Este modelo establece una linealidad entre fuerzas impulsoras $X_{j}$ y flux de componentes $J_{i}$ utilizando coeficientes de proporcionalidad supuestos válidos en toda la membrana. Se considera que el flux de un componente influye a su vez en el flux de los otros, por lo que de manera general se tiene:

Ec. 22:

$$
J_{i}=L_{i, j} \cdot X_{j}
$$

Formulación matemática:

A continuación se expone la formulación matemática para el caso de la separación de un soluto $(S)$ de un disolvente $(A)$.

En nuestro caso las fuerzas impulsoras que gobiernan la transferencia de materia a través de la membrana son diferencias de presión y diferencias de concentración de componente entre ambas fases. Ambas fuerzas quedan englobadas por un potencial 
químico termodinámico que considere la presión. De esta manera se tiene entre las fases situadas a cada lado de la membrana:

Ec. 23: $\Delta \mu_{A}=\mu_{A, 2}-\mu_{A, 1}=v_{A} \cdot\left(P_{2}-P_{1}\right)+R \cdot T \cdot\left(\ln a_{A, 2}-\ln a_{A, 1}\right)=v_{A} \cdot(\Delta P-\Delta \pi)$

Ec. 24: $\Delta \mu_{S}=\mu_{S, 2}-\mu_{S, 1}=v_{S} \cdot\left(P_{2}-P_{1}\right)+R \cdot T \cdot\left(\ln a_{S, 2}-\ln a_{S, 1}\right)=v_{S} \cdot \Delta P+\frac{\Delta \pi}{C_{S, l m}}$

Estando la media logarítmica de concentraciones definida como

Ec. 25:

$$
C_{S, l m}=\frac{C_{S, 1}-C_{S, 2}}{\ln \left(\frac{C_{S, 1}}{C_{S, 2}}\right)}
$$

La Ec. 24 se ha obtenido aplicando a la Ec. 6 la ley de Henry (actividad proporcional a la concentración de soluto para bajas concentraciones de éste), junto con la expresión para el cálculo de la presión osmótica (Ec. 12).

Las ecuaciones fenomenológicas para un sistema de dos componentes (disolvente $A$ y soluto $S$ ) con fuerzas impulsoras dadas por los gradientes de potencial de componente en el sentido de la fase 1 a la fase 2 son:

Ec. 26: $\quad J_{A}=L_{A A} \cdot\left(-\frac{d \mu_{A}}{d x}\right)+L_{A S}\left(-\frac{d \mu_{S}}{d x}\right)$

Ec. 27: $\quad J_{S}=L_{S A} \cdot\left(-\frac{d \mu_{A}}{d x}\right)+L_{S S}\left(-\frac{d \mu_{S}}{d x}\right)$

Según Onsager se cumplen las siguientes relaciones entre los coeficientes fenomenológicos:

$\begin{array}{ll} & L_{A S}=L_{S A} \\ \text { Ec. 28: } & L_{A A} \geq 0 \quad L_{S S} \geq 0 \\ & L_{A A} \cdot L_{S S} \geq L_{A S}\end{array}$


Interesa sin embargo que aparezca como fuerzas impulsoras la diferencia de presión aplicada y de presión osmótica entre ambas fases, para ello es necesario utilizar el flux volumétrico total y el difusivo, definidos como:

Ec. 29:

$$
J_{V}=J_{A} \cdot v_{A}+J_{S} \cdot v_{S}
$$

Ec. 30:

$$
J_{d}=\frac{J_{S}}{C_{S, l m}}-J_{A} \cdot C_{A}
$$

Tras reordenar se llega a las siguientes ecuaciones fenomenológicas equivalentes:

Ec. 31:

$$
J_{v}=L_{v P} \cdot \Delta P+L_{v \pi} \cdot \Delta \pi
$$

Ec. 32:

$$
J_{d}=L_{d P} \cdot \Delta P+L_{d \pi} \cdot \Delta \pi
$$

Un experimento de medida del flujo de la membrana cuando no hay presión osmótica (disolvente puro) mostraría una relación de linealidad entre flux y presión aplicada a presiones no excesivamente elevadas, lo cual determinaría el primer parámetro, la permeabilidad al disolvente puro $L_{p}$.

Ec. 33:

$$
L_{p}=L_{v P}=\left(\frac{J_{v}}{\Delta P}\right)_{\Delta \pi=0}
$$

Cuando no hay presión aplicada, a bajas presiones osmóticas aparece una relación de linealidad entre flujo de difusión y la diferencia de presión osmótica entre fases para presiones osmóticas no excesivamente elevadas. El parámetro de la relación es conocido como permeabilidad osmótica.

$$
\text { Ec. 34: } \quad L_{d \pi}=\left(\frac{J_{d}}{\Delta \pi}\right)_{\Delta P=0}
$$

De las relaciones de Onsager se extrae que tres parámetros son suficientes para el modelo, por lo que los dos coeficientes que quedan deben obtenerse a partir de un único 
parámetro. Este parámetro se conoce como el coeficiente de reflexión $\sigma$ y representa la relación existente entre las diferencias de presión y presión osmótica cuando el flux volumétrico es nulo.

Ec. 35: $\quad L_{v \pi}=L_{d p}$

Ec. 36:

$$
\sigma=\left(\frac{\Delta \pi}{\Delta P}\right)_{J_{v}=0}=-\frac{L_{v \pi}}{L_{v P}}
$$

Este coeficiente describe el efecto de la fuerza impulsora de presión sobre el flux de soluto para la membrana considerada. Se tiene $\sigma=1$ cuando la membrana rechaza totalmente al soluto, pues en este caso no hay flujo difusivo y se debe cumplir la igualdad entre presión osmótica y presión aplicada para flux volumétrico nulo. Para el caso de una membrana que no retiene al soluto se tiene $\sigma=0$.

Combinando las ecuaciones y teniendo en cuenta $v_{s} \cdot C_{S, l m}<<1$ se llega a las ecuaciones finales del modelo fenomenológico:

Ec. 37:

$$
J_{v}=L_{p} \cdot(\Delta P-\sigma \cdot \Delta \pi)
$$

Ec. 38:

$$
J_{S}=C_{S, l m} \cdot(1-\sigma) \cdot J_{v}+\omega \cdot \Delta \pi
$$

Siendo:

Ec. 39:

$$
\omega=\left(\frac{L_{d \pi}}{L_{P}}-\sigma^{2}\right) \cdot L_{P} \cdot C_{S, l m}
$$

\section{Obtención de los parámetros del modelo:}

Los tres parámetros de este modelo son $L_{p}, L_{v \pi} \mathrm{y} \sigma$. Algunos autores consideran el uso de $\omega$ en vez del coeficiente de permeabilidad osmótica $L_{v \pi}$ como parámetro del modelo. Como ya se ha indicado el coeficiente de permeabilidad de la membrana $L_{p}$ se determina realizando experiencias con disolvente puro midiendo el flux obtenido para diferentes presiones. Mientras que los dos coeficientes restantes son obtenidos con ensayos a diferentes concentraciones, para un ajuste lineal de los datos a la siguiente modificación 
de la Ec. 38, obteniéndose $\sigma$ del valor de la pendiente y $\omega$ directamente en la intersección en el origen.

Ec. 40 :

$$
\frac{J_{S}}{\Delta \pi}=\cdot(1-\sigma) \cdot J_{v} \frac{C_{S, l m}}{\Delta \pi}+\omega
$$

Donde:

Ec. 41:

$$
C_{p}=\frac{J_{S}}{J_{v}}
$$

Se puede deducir la siguiente relación entre el rechazo $R_{m}$ referido a la concentración en la cara de la membrana en contacto con el alimento $C_{a, m}$ (que se corresponde con $\pi_{a, m}$ ) y los parámetros del modelo $L_{p}, L_{\pi} \mathrm{y} \sigma$. A su vez el rechazo referido a la cara interna de la membrana puede ser relacionado con el rechazo observado a través de la Ec. 17.

Ec. 42:

$$
\frac{1}{R_{m}}=\frac{1}{\sigma}+\left(\frac{L_{\pi}}{L_{p}}-\sigma^{2}\right) \cdot\left(\frac{L_{P}}{\sigma}\right) \cdot \pi_{a, m} \cdot\left(\frac{1}{J_{v}}\right)
$$

Después de la utilización de la Ec. 37 los dos parámetros restantes se obtienen por ajuste de la Ec. 42 para diferentes condiciones de operación.

\section{Utilidad del modelo en ósmosis inversa y nanofiltración:}

Los modelos de transporte fenomenológicos presentan la desventaja de que sus coeficientes son dependientes de las concentraciones. Ello es debido a que si las diferencias de concentración o de presión a través de la membrana son elevadas las leyes lineales ya no se cumplen a lo largo de toda la membrana. Esto suele ocurrir en ósmosis inversa, sin embargo, para otros procesos con diferencias de concentración no demasiado elevadas, el modelo podría ser aplicable.

Otra desventaja es que, al considerar la membrana como una caja negra, no describen el mecanismo de transporte, sin embargo, esto le confiere una gran generalidad pudiéndose usar en ósmosis inversa, nanofiltración e incluso ultrafiltración. 


\section{A-2. Relación de Kedem-Spiegler}

Premisas del modelo:

Este modelo expresa las ecuaciones de partida del modelo anterior en forma diferencial en vez de asumir una ley lineal para el espesor total.

Formulación matemática:

Las ecuaciones diferenciales para flux de disolvente y de soluto son:

Ec. 43: $\quad J_{v}=p_{A} \cdot\left(\frac{d P}{d x}-\sigma \cdot \frac{d \pi}{d x}\right)$

Ec. 44:

$$
J_{S}=p_{S} \cdot \frac{d C_{S}(x)}{d x}+(1-\sigma) \cdot C_{S}(x) \cdot J_{v}
$$

Con las condiciones de contorno:

$$
\begin{aligned}
& P(0)=P_{1} \quad C_{S}(0)=C_{a, m} \quad \pi(0)=\pi_{a, m} \\
& P(\Delta x)=P_{2}
\end{aligned}
$$

Donde:

$x$ : $\quad$ Coordenada de integración a través del espesor de la membrana

$\Delta x: \quad$ Espesor efectivo de la membrana

$p_{A}, p_{B}: \quad$ Permeabilidades del disolvente y del soluto.

$\sigma . \quad$ Coeficiente de reflexión.

Si consideramos $p_{A}, p_{B}$ y $\sigma$ constantes a lo largo de la membrana las ecuaciones pueden ser integradas a lo largo de todo el espesor efectivo de la membrana llegándose a:

Ec. 45:

$$
J_{v}=\frac{p_{A}}{\Delta x} \cdot(\Delta P-\sigma \cdot \Delta \pi)
$$


Ec. 46:

$$
\frac{1}{1-R_{m}}=\frac{1}{1-\sigma} \cdot\left\{1-\exp \left[-\frac{(1-\sigma) \cdot J_{v}}{\left(p_{S} / \Delta x\right)}\right]\right\}
$$

Obtención de los parámetros del modelo:

Los tres coeficientes del modelo son $p_{A} / \Delta x, p_{S} / \Delta x$ y $\sigma$. La forma de ajustar parte de trabajar con diferentes presiones para obtener el primero de ellos con la Ec. 45 para después trabajando a diferentes concentraciones ajustar los dos restantes con la Ec. 46.

\section{Utilidad del modelo en ósmosis inversa y nanofiltración:}

Este modelo es más apropiado que el anterior para la descripción de la ósmosis inversa y ha sido utilizado por diversos autores.

En nanofiltración Schirg et al.(1992) indican que la permeabilidad del soluto depende significativamente de la concentración por lo que proponen que no se ajuste la permeabilidad del soluto como un parámetro constante, debiéndose expresar como:

Ec. 47 :

$$
p_{S} / \Delta x=\alpha \cdot C_{m}^{\beta}
$$

Estos autores resaltan que en nanofiltración el coeficiente de reflexión del soluto es menor que uno. Así, para $\mathrm{NaCl}$ y membranas de acetato de celulosa se tendría $\sigma=0.86$ y para polisulfona y poliamida $\sigma=0.94$.

Si bien se considera el efecto de la variación de la concentración a lo largo de la membrana, no se está teniendo en cuenta la estructura de ésta, por lo que podría no resultar adecuado para membranas asimétricas donde no exista un espesor de capa activa definido.

Recordemos que este modelo, al igual que el anterior, es de tipo fenomenológico y por tanto no utiliza información sobre el mecanismo de transporte. 


\section{A-3. Modificación de la relación de Kedem-Spiegler por Linder y Perry.}

Premisas del modelo:

Esta modificación del modelo RKS desarrollada por Perry y Linder (1989) considera que el soluto una vez atravesado el primer diferencial de membrana se encuentra a una concentración que está en equilibrio iónico de Donnan con su concentración en el alimento.

Formulación matemática:

Aplicando las ecuaciones del equilibrio de Donnan junto con la Ec. 47 se tiene para una concentración molar de cargas negativas en la membrana $C_{m, R}$ :

Ec. 48:

$$
\frac{1}{1-R_{m}}=\frac{1}{\left(1-\sigma_{\mathrm{NaCl}}\right) \cdot \sqrt{1+\frac{v^{-} \cdot C_{m, C l-}}{C_{m, R-}}}} \cdot\left\{1-\exp \left[-\frac{\left(1-\sigma_{\mathrm{NaCl}}\right) \cdot J_{v}}{\left(\alpha \cdot C_{m, \mathrm{Cl}-}\right)}\right]\right\}
$$

En la ecuación se puede tomar $v^{-}=2$ por estar el soluto completamente disociado.

Para membranas cargadas positivamente se puede obtener una expresión análoga.

Utilidad del modelo en ósmosis inversa y nanofiltración:

Cuando las membranas poseen carga se debe de utilizar este modelo en lugar del RKS. La expresión mostrada puede usarse también para el cálculo de la selectividad entre el $\mathrm{NaCl}$ y una sal de la forma $\mathrm{R}^{-} \mathrm{M}^{+}$. 


\section{B. Modelos de transporte en "membranas densas"}

Se ha considerado más adecuado el uso del término "membranas densas" frente a "membranas no porosas" ya que los modelos que se explican en este apartado son también aplicables a membranas que no son estrictamente "no porosas". Por membranas densas entendemos aquí aquellas en las que los poros son de orden molecular. El transporte queda descrito por el mecanismo de difusión al ser éste predominante sobre el flujo convectivo. Esta descripción puede ser adecuada para la osmosis inversa y combinándola con el transporte convectivo también para la nanofiltración.

Ec. 49: $\quad($ Permeabilidad $)=($ Solubilidad $) \times($ Difusividad $)$

La fuerza impulsora de la difusión es también el gradiente de potencial químico, el cual origina una velocidad de difusión $u_{i}$. El parámetro que relaciona velocidad y gradiente es la movilidad de la especie, la cual a su vez tiene la siguiente relación con el coeficiente de difusión termodinámico.

Ec. 50:

$$
u_{i}=-\operatorname{mov}_{i} \cdot \frac{d \mu_{i}}{d x}=-\frac{D_{T i}}{R \cdot T} \cdot \frac{d \mu_{i}}{d x}
$$

Ec. 51:

$$
J_{i}=u_{i} \cdot C_{i}=-\frac{D_{T i} \cdot C_{i}}{R \cdot T} \cdot \frac{d \mu_{i}}{d x}
$$

Utilizando la expresión del potencial termodinámico del componente $i$ (Ec. 6) se llega a:

Ec. 52:

$$
J_{i}=\frac{D_{T_{i}} \cdot C_{i}}{R \cdot T}\left[R \cdot T \cdot \frac{d \ln a_{i}}{d x}+v_{i} \cdot \frac{d P}{d x}\right]
$$




\section{B-1. Modelo de disolución-difusión (DD)}

Premisas del modelo:

Este modelo considera un mecanismo de tipo difusivo en el que todas las especies (solutos y disolvente) se disuelven en la membrana y difunden a través de ella de manera similar a como la harían a través de un sólido o de un líquido bajo la acción de un gradiente de concentración o de presión.

Cuando las concentraciones de soluto son bajas, el coeficiente de difusión termodinámico tiende al valor del coeficiente de difusión observado y se considera independiente de la concentración. Adicionalmente se considera que las propiedades de la membrana se consideran independientes de la presión.

Formulación matemática:

Bajo las hipótesis mencionadas (las cuales no son del todo rigurosas) la Ec. 52 puede ser integrada conduciendo a las expresiones del modelo siguientes:
Ec. 53:
$J_{v}=A \cdot(\Delta P-\Delta \pi)$
$A=\frac{D_{A, m} \cdot C_{A, m} \cdot v_{A}}{R \cdot T \cdot \Delta x}$
Ec. 54:
$J_{S}=B \cdot\left(C_{S, a m}-C_{S, p}\right)$
$B=\frac{D_{S, m} \cdot K}{\Delta x}$

Siendo en las anteriores ecuaciones $\mathrm{C}_{\mathrm{S}, \mathrm{am}}-\mathrm{C}_{\mathrm{S}, \mathrm{p}}$ la diferencia de concentraciones de soluto entre la cara del alimento y la del permeado a través de la membrana.

El modelo tiene dos coeficientes, relacionables con parámetros físicos de la membrana y del fenómeno de transporte:

- Coeficiente de permeabilidad del disolvente A:

Coincide con el parámetro $L_{p}$ del modelo fenomenológico y depende de: 
$D_{A, m}: \quad$ Difusividad del disolvente en la membrana.

$C_{A, m}: \quad$ Concentración del disolvente en la membrana.

$\Delta x: \quad$ Espesor efectivo de la membrana.

$v_{A}$ : $\quad$ Volumen molar parcial del agua en la disolución.

- Coeficiente de permeabilidad del soluto B:

Dependiente de:

$D_{S, m}$ : Difusividad del soluto en la membrana.

$\Delta x: \quad$ Espesor efectivo de la membrana.

K: Coeficiente de partición entre la membrana y la disolución.

Este coeficiente marca la capacidad de solubilidad del soluto en la membrana y está definido como:

$$
K=\frac{\mathrm{kg} \text { de soluto } / \mathrm{m}^{3} \text { de membrana }}{\mathrm{kg} \text { de soluto } / \mathrm{m}^{3} \text { de disolución }}
$$

En la práctica la membrana puede ser algo permeable a los solutos de bajo peso molecular por lo que la presión osmótica efectiva a lo largo de la membrana no es $\Delta \pi$ sino $\sigma \cdot \Delta \pi$, donde $\sigma$ es el coeficiente de reflexión de la membrana hacia el soluto en cuestión, ya mencionado en el modelo fenomenológico. Se puede modificar la Ec. 53, añadiendo este tercer parámetro para definir con mayor exactitud el flux volumétrico:

Ec. 55:

$$
J_{v}=A \cdot(\Delta P-\sigma \cdot \Delta \pi)
$$

La ecuación es formalmente igual a la del modelo fenomenológico; pero en este modelo el coeficiente de permeabilidad se expresa en función de términos con significado físico.

Obtención de los parámetros del modelo: 
Realizando ensayos con disolvente puro, en la misma forma que en el modelo fenomenológico, se puede obtener el coeficiente de permeabilidad del disolvente $A$.

Considerando la Ec. 41 se llega a que el rechazo basado en la cara en contacto con el alimento se expresa como:

Ec. 56:

$$
\frac{1}{R_{m}}=1+\frac{B}{J_{v}}=1+\frac{B}{A \cdot(\Delta P-\Delta \pi)}
$$

De esta ecuación se puede extraer el coeficiente $B$.

Una vez conocidos los parámetros $A$ y $B$ se puede obtener el resto de términos físicos que los constituyen determinando experimentalmente $D_{A, m}, D_{S, m} \mathrm{o} K$.

El valor de A es una función del coeficiente de distribución (solubilidad) y de la difusividad, en ósmosis inversa oscila entre $5 \cdot 10^{-3}$ y $5 \cdot 10^{-5} \mathrm{~m}^{3} \cdot \mathrm{m}^{-2} \cdot \mathrm{h}^{-1} \cdot \mathrm{bar}^{-1}$ (disminuyendo su valor al ser la membrana más densa).

Los valores de B para cloruro sódico se encuentran dentro del rango de $5 \cdot 10^{-3} \mathrm{a}$ $0.1 \cdot 10^{-3} \mathrm{~m} \cdot \mathrm{h}^{-1}$, dándose el valor más bajo para membranas de alto rechazo.

\section{Utilidad del modelo en ósmosis inversa y nanofiltración:}

El modelo de disolución-difusión se aplica relativamente bien al caso de la ósmosis inversa, no siendo apto para la nanofiltración donde una parte importante del transporte se lleva a cabo por mecanismos no difusivos. Este modelo y el de KedemSpiegler coinciden en sus predicciones para valores del coeficiente de reflexión cercanos a la unidad, sin embargo, como ya se ha comentado en el apartado concerniente al modelo de Kedem-Spiegler algunas sales presentan en estas membranas coeficientes de reflexión bajos.

Las hipótesis simplificativas empleadas en el modelo le restan capacidad de predicción. Por ejemplo, de la Ec. 56 se desprende que un aumento de la presión aumentaría siempre el flux y con ello el índice de rechazo tendería a valer 1.0 (100\%). La experiencia demuestra, sin embargo, que esto no es exacto y que el índice de rechazo tiende, más bien, asintóticamente hacia un valor inferior a 1.0. Ello es debido a que los 
términos $A$ y $B$ son en realidad dependientes de la presión y a la presencia de imperfecciones.

De las ecuaciones también se deduce que el flux de soluto es prácticamente independiente de la presión y que sólo depende de la diferencia de concentración a través de la membrana. Por tanto, para conseguir una separación eficaz a una presión de trabajo establecida, nos interesa tener una membrana que posea un coeficiente $A$ lo más alto posible (alta afinidad por el disolvente) mientras que el coeficiente $B$ debe ser lo más bajo posible (poca afinidad por el soluto a separar). Esto implica que la elección del material es muy importante porque determina las propiedades intrínsecas de la membrana.

\section{B-2. Modelo de disolución-difusión con imperfecciones (DDI)}

\section{Premisas del modelo:}

Este modelo considera la posible existencia de imperfecciones en la capa no porosa de una membrana. En la estructura densa el transporte sería por disolución-difusión mientras que las imperfecciones se comportarían como pequeños canales en los que el flujo sería predominantemente convectivo. Estas imperfecciones se producen en el proceso de fabricación y se corresponden con poros que ya no son de orden molecular.

Formulación matemática:

Se considera que las imperfecciones transportan disolución desde la cara del alimento a la del permeado sin modificar su composición $\left(C_{S a}\right)$ y que este flujo tal y como se detalla en los modelos para membranas porosas es proporcional a la fuerza impulsora de presión aplicada. Por ello, el modelo corrige las ecuaciones del anterior modelo de disolución-difusión con dos términos dependientes de la presión:

Ec. 57:

$$
J_{v}=A^{\prime} \cdot(\Delta P-\Delta \pi)+C^{\prime} \cdot \Delta P
$$


Ec. 58: $\quad J_{S}=B^{\prime} \cdot \Delta \pi+C^{\prime} \cdot \Delta P \cdot C_{S a}$

Los parámetros $A^{\prime}$ y $B^{\prime}$ tienen significados análogos a los del modelo de disolución-difusión, mientras que el parámetro $C$ ' es representativo del flujo a través de las imperfecciones asimiladas a poros. 
Obtención de los parámetros del modelo:

Considerando la Ec. 41 se llega a que el rechazo basado en la cara en contacto con el alimento se expresa como:

Ec. 59:

$$
\frac{1}{R_{m}}=\left(1+\frac{C^{\prime} / A^{\prime}}{1-\frac{\Delta \pi}{\Delta P}}\right)+\frac{B^{\prime} / A^{\prime}}{1-\frac{\Delta \pi}{\Delta P}} \cdot \frac{R \cdot T}{\Delta P}
$$

El modelo predice un límite asintótico teórico para el rechazo de valor:

$$
\frac{1}{1+\frac{C^{\prime}}{A^{\prime}}}
$$

Como todos los coeficientes por su naturaleza son positivos el valor teórico del rechazo límite es inferior a 1.0 (menor del 100 \%). Claramente el efecto de las imperfecciones (representado por $C^{\prime}$ ) empeora el rechazo obtenido.

Cuando se conoce que el transporte se realiza por un mecanismo de disolucióndifusión se debe de tratar de ajustar primero el modelo que no considera imperfecciones. Si los parámetros no ajustan bien o las membranas presentasen una baja separación respecto de la esperada se debe considerar la utilización del presente modelo.

Mediante experimentos con disolvente puro se determinaría la suma de los parámetros $A^{\prime}$ y $C^{\prime}$ tras aplicar Ec. 57. Si además, la presión osmótica es despreciable frente al incremento de presión aplicado, la Ec. 59 permite, tras un ajuste lineal, la obtención de un sistema que lleva a la obtención de cada uno de los tres parámetros.

Utilidad del modelo en ósmosis inversa y nanofiltración:

El modelo es de aplicación muy general en diferentes tipos de membranas. Parece sin embargo más adecuado para ósmosis inversa ya que mantiene el mecanismo de 
disolución-difusión como el principal. En nanofiltración podría llegar a ajustar bien, pero las conclusiones obtenidas de la aplicación del modelo deben interpretarse con cuidado, ya que si bien en la nanofiltración el mecanismo de disolución-difusión y el de flujo de poro se combinan, estrictamente no podemos describir una membrana de nanofiltración como una membrana "densa" con unas cuantas imperfecciones.

Una importante desventaja del modelo es que el coeficiente $C$ ' no es independiente de la concentración y de la presión aplicadas.

\section{B-3. Modelo de disolución-difusión ampliado}

Premisas del modelo:

En la formulación matemática del modelo de disolución-difusión no se ha contemplado el término de presión en la expresión del incremento del potencial químico del soluto entre ambas caras de la membrana. Si se incluye ahora este término se tiene:

$$
\Delta \mu_{S}=v_{S} \cdot \Delta P+R \cdot T \cdot \ln \frac{a_{S, 2}}{a_{S, 1}}=v_{S} \cdot \Delta P+\frac{\Delta \pi}{C_{S, l m}}
$$

Para el caso de una disolución de cloruro sódico se tiene $v_{S} \cong 2 \cdot 10^{-5} \cdot m^{3} \cdot m o l^{-1}$, con lo cual es aceptable despreciar el término de presión. Sin embargo para solutos orgánicos el término puede ser significativo por lo que no es aconsejable despreciarlo.

Formulación matemática:

Incluyendo el término de presión mencionado se llega a:
Ec. 53:
$J_{v}=A \cdot(\Delta P-\Delta \pi)$
$A=\frac{D_{A, m} \cdot C_{A, m} \cdot v_{A}}{R \cdot T \cdot \Delta x}$ 
Ec. 60: $\quad J_{S}=B \cdot\left(C_{S, a m}-C_{S, p}\right)+L_{S P} \cdot \Delta P \quad B=\frac{D_{S, m} \cdot K}{\Delta x}$ 
Obtención de los parámetros del modelo:

Podemos expresar el rechazo basado en la membrana mediante la siguiente ecuación:

Ec. 61:

$$
\frac{1}{R_{m}}=\left(1-\frac{L_{S, P} / A}{C_{S, m}} \cdot \frac{\Delta P}{\Delta P-\Delta \pi}\right)^{-1} \cdot\left(1+\frac{B / A}{\Delta P-\Delta \pi}\right)
$$

Se necesitarían ensayos con disolvente puro para evaluar el término $A$, posteriormente para diferentes presiones de trabajo, y si el término de presión osmótica es despreciable frente al de presión aplicada, los términos $L_{S, P}$ y $B$ pueden extraerse de los grupos obtenidos tras un ajuste lineal.

Utilidad del modelo en ósmosis inversa y nanofiltración:

Como ya se ha mencionado el modelo es conveniente para disoluciones de compuestos orgánicos en agua en los que, debido al elevado volumen parcial de los compuestos orgánicos, el término de presión en el potencial químico del soluto no sea despreciable. Por considerarse exclusivamente un mecanismo de disolución-difusión el modelo es apto para ósmosis inversa pero no para nanofiltración. 


\section{Modelos de transporte en "membranas porosas"}

Se considera que el transporte principal en la membrana se está dando a través de poros físicos de tamaño bastante mayor que las moléculas de disolvente, por lo que el flujo de éste será primordialmente de carácter convectivo. Sin embargo se pueden considerar también interacciones químicas entre disolvente y membrana. Si se considerasen únicamente interacciones de carácter estérico entre soluto y membrana este tipo de modelos no sería de utilidad para la ósmosis inversa, sin embargo, en este caso consideraremos el transporte de soluto como difusivo, con lo que los modelos pueden aplicarse en nanofiltración y ósmosis inversa.

El flux de disolvente se describe teniendo en cuenta que la fuerza impulsora de presión origina un flujo a través de una red de capilares, de ahí que la geometría de la membrana tendrá ahora importancia. Además, una característica de este flujo es la de ser laminar con lo que es proporcional a la fuerza impulsora, en este caso el gradiente de presión efectiva.

Ec. 62:

$$
J_{v}=L_{P}^{\prime} \cdot \frac{\Delta P}{\Delta x}
$$

Si agrupamos $L_{p}=L_{p}^{\prime} / \Delta x$ esta ecuación es análoga a la ecuación fenomenológica ya referida.

Ec. 37:

Sin embargo, en la ecuación fenomenológica el parámetro $L_{p}$ no tenía sentido físico y ahora se puede expresar en términos de la geometría de la membrana y de la viscosidad $\eta$ del fluido.

$$
L_{P}=f(\text { geometría }) \cdot \frac{1}{\eta}
$$


Según la estructura de la membrana la dependencia con la geometría deberá expresarse de una forma $u$ otra.

Considerando la membrana como una red ideal de capilares de longitud $\lambda$, radio $r$ y tortuosidad $\tau$, los cuales presentan una determinada porosidad superficial $\varepsilon_{S}$ se cumplirá la expresión de Hagen-Poiseuille:

Ec. 63: $\quad L_{P}=\frac{\varepsilon_{s} \cdot r^{2}}{8 \cdot \tau \cdot \lambda} \cdot \frac{1}{\eta}$

Mientras que si se tiene una estructura nodular, como ocurre en ocasiones en las capas superiores de membranas obtenidas por inversión de fase, el flux es descrito mejor por la ecuación de Kozeny-Karman:

Ec. 64:

$$
L_{P}=\frac{\varepsilon^{3}}{C_{K} \cdot S^{2} \cdot(1-\varepsilon)^{2} \cdot \Delta x} \cdot \frac{1}{\eta}
$$

En donde ahora aparece la porosidad volumétrica $\varepsilon$ y la superficie interna $S$ y la constante $C_{K}$ es función de la forma de los poros y la tortuosidad.

Las membranas obtenidas por inversión de fase poseen normalmente una estructura esponjosa que no se corresponde con las dos mencionadas. A pesar de ello, se puede describir de manera aproximada el flux utilizando alguna de las dos expresiones anteriores.

\section{C-1. Análisis de Kimura-Sourirajan (AKS) (Modelo de sorción capilar preferencial)}

Premisas del modelo:

El fenómeno físico que pretende modelizar es el mecanismo de flujo en presencia de absorción capilar preferencial. La membrana se considera microporosa y el transporte se da exclusivamente a través de poros. Cuando el material de la membrana 
presenta una atracción preferente hacia el agua se produce una capa de agua pura adsorbida en los poros. La aplicación de presión como fuerza impulsora fuerza al agua a pasar a través de los poros. La separación resultante es consecuencia, pues, de la interacción físico-química entre el soluto, el disolvente y la membrana, así como del tamaño, número y distribución de los poros.

Formulación matemática:

El flujo del disolvente es de tipo convectivo y por tanto proporcional a la fuerza impulsora. Sin embargo, el flujo de soluto se considera difusivo y dado por el gradiente de concentración.

Ec. 65:

$$
J_{v}=L_{p} \cdot(\Delta P-\Delta \pi)
$$

Ec. 66:

$$
J_{S}=B \cdot\left(C_{S, a m}-C_{S, p}\right) \quad B=\frac{D_{S, p m} \cdot K_{p}}{\lambda}
$$

$\begin{array}{ll}D_{S, p m} & \text { Difusividad del soluto en la estructura porosa de la membrana } \\ \lambda & \text { Longitud efectiva de poro } \\ K_{p} & \text { Coeficiente de partición basado en los poros }\end{array}$

Obtención de los parámetros del modelo:

Los parámetros del modelo son $L_{p}$ y el grupo $\frac{D_{S, p m} \cdot K_{p}}{\lambda}$.

Se obtiene una relación análoga al modelo de disolución-difusión y el ajuste de parámetros se realiza de la misma manera.

Ec. 67: $\quad \frac{1}{R_{m}}=1+\frac{D_{S, p m} \cdot K_{p}}{\lambda} \cdot \frac{1}{J_{v}}$

Al igual que en este último modelo se predice un rechazo tendiente hacia 1.0 (100\%) para fluxes altos, lo cual no es cierto para muchos solutos. 
Utilidad del modelo en ósmosis inversa y nanofiltración:

Este modelo es adecuado cuando la membrana presenta rechazos hacia el soluto cercanos al 100\%. Puede utilizarse para ósmosis inversa o nanofiltración si esta condición se cumple aproximadamente.

\section{C-2. Modelos unidimensionales de red capilar}

Premisas del modelo:

Este modelo considera la membrana constituida como un sistema de capilares interconectados que penetran en la estructura rígida del material.

Se basa en un balance entre fuerzas aplicadas y fricción en un poro teniendo en cuenta como única dimensión importante su longitud.

Formulación matemática:

El modelo parte de la teoría de los procesos termodinámicos irreversibles relacionando fuerzas generalizadas con fluxes generalizados en una formulación inversa a la de la Ec. 22.

Ec. 68:

$$
X_{i}=r_{i, k} \cdot J_{k}
$$

En el estado estacionario las fuerzas termodinámicas actuantes sobre cada componente $X_{i}$ estarán equilibradas por las fuerzas de fricción entre parejas soluto membrana, disolvente - membrana y soluto - disolvente $F_{i j}$. Estas fuerzas de fricción 
presentarán una relación de proporcionalidad con las velocidades a través de factores de fricción $f_{i j}$.

Ec. 69:

$$
\begin{aligned}
& F_{S m}=-f_{S m} \cdot\left(\bar{u}_{S}\right) \\
& F_{S A}=-f_{S A} \cdot\left(\bar{u}_{S}-\bar{u}_{A}\right) \\
& F_{A m}=-f_{A m} \cdot\left(\bar{u}_{A}\right)
\end{aligned}
$$

Donde las velocidades promedio en los capilares se han calculado como:

Ec. 70: $\quad \bar{u}_{m}=0 \quad \bar{u}_{i}=\frac{J_{i}}{\varepsilon \cdot C_{i}}$

El equilibrio de fuerzas se expresa como:

Ec. 71: $\quad X_{S}=F_{S m}+F_{S A}$

$$
X_{A}=F_{A m}+F_{A S}
$$

Ec. 72: $\quad X_{i}=-\frac{\partial \mu_{i}}{\partial x}$

Los siguientes parámetros aparecen en el desarrollo matemático subsiguiente:

Parámetro de fricción: $\quad b=\frac{X_{S A}+X_{S m}}{X_{S A}}=1+\frac{f_{S m}}{f_{S A}}=\frac{D_{S A}}{D_{S m}}$

Difusividad del soluto en el disolvente: $\quad D_{S A}=\frac{R \cdot T}{f_{S A}}$

Considerando $b$ y $f_{S A}$ independientes de la concentración de soluto se obtiene las dos ecuaciones del modelo:

Ec. 73: $\quad J_{v}=L_{p} \cdot(\Delta P-\Delta \pi)$ 
Ec. 74: $\quad \frac{1}{1-R_{m}}=\frac{b}{K_{S}^{\prime}}+\left(\frac{K_{S}^{\prime \prime}}{K_{S}^{\prime}}-\frac{b}{K_{S}^{\prime}}\right) \cdot \exp \left(-\frac{\Delta x}{\varepsilon_{s}} \cdot \frac{1}{D_{S A}} \cdot J_{v}\right)$

$\Delta x=\tau \cdot \lambda \quad$ Espesor efectivo de membrana

$K_{S}{ }_{S} K^{\prime}{ }_{S} \quad$ Coeficientes de partición en la cara de la alimentación y la del permeado

Obtención de los parámetros del modelo:

Puesto que $D_{S A}$ se puede encontrar en la bibliografía, los parámetros del modelo a ajustar a partir de los resultados de flux y rechazo de la membrana son $b / K{ }_{S}, K^{\prime}{ }_{S} / K_{S}{ }_{S}$ y $\Delta \mathrm{x} / \varepsilon_{\mathrm{s}}$ además de $L_{p}$.

Si se asume la simplificación $K^{\prime \prime}{ }_{S}=K_{S}$ el modelo se simplifica pasando a tener solo tres parámetros con lo que su ajuste resulta más sencillo.

Utilidad del modelo en ósmosis inversa y nanofiltración:

Este modelo ha sido aplicado por diversos autores a membranas de ósmosis inversa. También puede utilizarse para describir la nanofiltración.

\section{C-3. Modelos de flujo bidimensional en poros}

Estos modelos estudian el transporte de soluto y disolvente a través de poros considerados cilíndricos. Con ello se logra una descripción del fenómeno de transporte más precisa que con los anteriores modelos que consideraban una o ninguna dimensión. Sin embargo, el modelo adquiere mayor complejidad.

Utilidad del modelo en ósmosis inversa y nanofiltración: 
Los modelos de flujo bidimensional en poros han sido aplicados por diversos autores en membranas de electrodiálisis, ósmosis inversa y ultrafiltración. 


\section{C- 4. Modelos para membranas cargadas}

Muchas de las membranas de nanofiltración pueden presentar carga negativa o positiva debido a su composición. Se puede asumir que las membranas de nanofiltración son similares a una red de capilares cilíndricos con parámetros estructurales (como radio de poro, porosidad y espesor de membrana) que tienen, en algunos casos, propiedades eléctricas (tales como la densidad de carga). Como modelos de este tipo ya se comentó la modificación del modelo RKS que consideraba equilibrio de Donnan. A continuación se comentan otros dos modelos no fenomenológicos (Wang et al. 1994, 1995) que resultan muy apropiados para el estudio de las membranas de nanofiltración.

\section{Modelo de carga fija de Teorell - Meyer - Sievers (TMS):}

Este modelo ha sido empleado con éxito para estudiar membranas de intercambio iónico y también para describir el rechazo de membranas cargadas de ósmosis inversa y ultrafiltración.

Este modelo se basa en la teoría de exclusión electrostática de Donnan y la ecuación de Nernst-Planck para transporte iónico o la ecuación de Nernst-Planck extendida (si se considera contribución del flux volumétrico al flux iónico). El modelo TMS asume una distribución de carga fija y no está basado en parámetros estructurales, sin embargo considera una variación espacial de la concentración del ion móvil y del potencial en la dirección del flux.

\section{Modelo de carga espacial (MCE):}

Es un modelo más aproximado a la realidad que el anterior ya que asume una estructura de capilares rectos con una distribución espacial de carga en su interior. Además de la ecuación de Nernst-Planck, considera la ecuación de Poisson-Boltzmann para la distribución del potencial eléctrico y de la concentración de iones, así como la ecuación de 
Navier-Stokes o alguna de sus simplificaciones para explicar el flux. Los resultados que proporciona son más precisos que los del modelo TMS, sin embargo el cálculo resulta muy complicado y los parámetros son difíciles de obtener. 


\subsection{TÉCNICAS DE FABRICACIÓN DE MEMBRANAS}

\subsubsection{Antecedentes}

Las membranas comenzaron a estudiarse desde el punto de vista científico a finales del siglo pasado, sin embargo los comienzos de su fabricación industrial y utilización como técnica debemos situarlos a mediados de este siglo XX. También a partir de mediados de siglo comienza la comprensión de los mecanismos de transporte de las membranas y de los de su formación. Se observa antes de estas fechas un gran periodo de latencia entre los descubrimientos y la fabricación industrial. También que el desarrollo de la fabricación de membranas ha estado ligado al desarrollo de los conocimientos sobre materiales.

En la Tabla 8 se explica el desarrollo de las membranas celulósicas hasta 1963, año en el que Loeb y Sourirajan fabrican la primera membrana asimétrica de utilidad en desalación de agua de mar (Sourirajan, 1970; Loeb, S. 1980). Se observa en esta tabla como los materiales basados en acetato de celulosa sustituyen a los materiales nitrocelulósicos.

Aunque ya a finales de los años 40 se empezaron a utilizar las membranas microporosas, es en los 70 cuando comienza el desarrollo de las aplicaciones de las membranas tras su fabricación en continuo. En esta década de los 70, la ósmosis inversa se consolida, se desarrolla la fabricación de fibras huecas y de membranas ultrafinas para diversas aplicaciones. Los 80 es la década en la que comienza la fabricación industrial de membranas inorgánicas. Es en la década de los 90 cuando las aplicaciones de las membranas se diversifican, las membranas de nanofiltración encuentran nuevas aplicaciones y los módulos en espiral para pervaporación entran en el mercado. 


\begin{tabular}{|c|c|}
\hline Año & Referencia \\
\hline 1872 & $\begin{array}{l}\text { Primeras membranas de nitrocelulosa fabricadas por inversión de } \\
\text { fase }\end{array}$ \\
\hline 1917 & $\begin{array}{l}\text { Membranas porosas de nitrato de celulosa y acetato de celulosa } \\
\text { producidas por la técnica hinchamiento/precipitación (Gran } \\
\text { Bretaña) }\end{array}$ \\
\hline 1923 & Producción de membranas de nitrocelulosa en continuo (Francia) \\
\hline 1936 & $\begin{array}{l}\text { Membranas de acetato de celulosa producidas por inversión de fase } \\
\text { a partir de disoluciones saturadas de perclorato magnésico (Francia) }\end{array}$ \\
\hline 1963 & $\begin{array}{l}\text { Membranas asimétricas de acetato de celulosa apta para ósmosis } \\
\text { inversa. S. Loeb and S. Sourirajan (U.S.A.) }\end{array}$ \\
\hline
\end{tabular}

\subsubsection{Descripción de las técnicas de fabricación de membranas}

\section{Materiales empleados en las distintas técnicas}

En el apartado 1.1.1 ya se indicaron las distintas morfologías que podían presentar las membranas. Para un determinado proceso de membrana será necesaria una determinada morfología. Por ejemplo, serán necesarias membranas de una naturaleza porosa para microfiltración y no porosa para la capa activa de membranas de pervaporación. 
Tabla 9. Polímeros utilizados en las membranas comerciales

(Datos extraídos de Bernaola, 1995; Cabasso, 1987 y Mulder, 1992)

\begin{tabular}{|c|c|c|c|c|c|c|c|}
\hline Polímeros & $D$ & $M F$ & $U F$ & $N F$ & $O I$ & $P G$ & $P V$ \\
\hline Acetato de celulosa (AC, CA) & $\mathrm{x}$ & $\mathrm{x}$ & $\mathrm{x}$ & $\mathrm{x}$ & $\mathrm{x}$ & $\mathrm{x}$ & $\mathrm{x}$ \\
\hline Triacetato de celulosa (TAC, CTA) & & $\mathrm{x}$ & $\mathrm{x}$ & $\mathrm{x}$ & $\mathrm{x}$ & $\mathrm{x}$ & \\
\hline Mezclas de acetatos y triacetatos de celulosa & $\mathrm{x}$ & & & & $\mathrm{x}$ & $\mathrm{x}$ & \\
\hline Ésteres de celulosa mezclados & $\mathrm{x}$ & $\mathrm{x}$ & $\mathrm{x}$ & & & & \\
\hline Nitrato de celulosa & & $\mathrm{x}$ & & & & & \\
\hline Celulosa regenerada & $\mathrm{x}$ & $\mathrm{x}$ & $\mathrm{x}$ & & & & \\
\hline Gelatina & & $\mathrm{x}$ & & & & & \\
\hline Poliamidas aromáticas & $\mathrm{x}$ & $\mathrm{x}$ & $\mathrm{x}$ & $\mathrm{x}$ & $\mathrm{x}$ & & \\
\hline Poliamidas alifáticas & & & $\mathrm{x}$ & & & & \\
\hline Poliimida (PI) & & & $\mathrm{x}$ & & $\mathrm{x}$ & & \\
\hline Polieterimida (PEI) & & $\mathrm{x}$ & $\mathrm{x}$ & & & & \\
\hline Polibencimidazol (PBI) & & & & & $\mathrm{x}$ & & \\
\hline Polibencimidiazolona (PBIL) & & & & & $\mathrm{x}$ & & \\
\hline Poliacrilonitrilo (PAN) & $\mathrm{x}$ & & $\mathrm{x}$ & & & & \\
\hline Copolímeros de PAN y cloruro de polivinilo & & $\mathrm{x}$ & $\mathrm{x}$ & & & & \\
\hline Copolímeros de PAN y metalil sulfonato & $\mathrm{x}$ & & & & & & \\
\hline Polisulfonas (PSf) & $\mathrm{x}$ & $\mathrm{x}$ & $\mathrm{x}$ & & & $\mathrm{x}$ & \\
\hline Polietersulfona (PES) & & $\mathrm{x}$ & $\mathrm{x}$ & & & & \\
\hline Polisulfonas sulfonadas & & & $\mathrm{x}$ & & $\mathrm{x}$ & & \\
\hline Óxido de polidimetilfenileno (PPO) & & & $\mathrm{x}$ & & & $\mathrm{x}$ & \\
\hline Policarbonato & & $\mathrm{x}$ & & & & & \\
\hline Poliéster & & $\mathrm{x}$ & & & & & \\
\hline Politetrafluoretileno (PTFE) & & $\mathrm{x}$ & & & & & \\
\hline Polifluoruro de vinilideno (PVF) & & $\mathrm{x}$ & $\mathrm{x}$ & & & & \\
\hline Derivados de polivinilalcohol (PVA) & & & $\mathrm{x}$ & $\mathrm{x}$ & & & $\mathrm{x}$ \\
\hline Polipropileno (PP) & & $\mathrm{x}$ & & & & & \\
\hline Polielectrolitos complejos & & & $\mathrm{x}$ & & & & \\
\hline Polimetil metacrilato (PMMA) & $\mathrm{x}$ & & $\mathrm{x}$ & & & & \\
\hline Polidimetil siloxano (PDMS) & & & & & & $\mathrm{x}$ & \\
\hline Goma de silicona (SR) & & & & & & $\mathrm{x}$ & $\mathrm{x}$ \\
\hline
\end{tabular}


La elección del material es muy importante ya que condiciona en la mayoría de los casos las propiedades de transporte de la membrana. En algunos casos esta influencia será menor, en otros será drástica. Considérese por ejemplo, la influencia de la afinidad del material hacia los diferentes solutos y el disolvente en el mecanismo de disolución-difusión de las membranas de ósmosis inversa.

No solo eso, la elección del material también condiciona las técnicas preparativas que se pueden emplear y las morfologías que es posible alcanzar. Posteriormente, morfología, material y método de fabricación influirán también en las propiedades mecánicas, termo y quimiorresistentes del material.

La diversidad de materiales que se pueden emplear en la fabricación de membranas es muy amplia. Sin considerar las membranas líquidas, atendiendo al tipo de material utilizado ya hemos comentado que podemos clasificar las membranas en dos grandes grupos:

- membranas orgánicas (materiales poliméricos)

- membranas inorgánicas

En la Tabla 9 se exponen diferentes materiales poliméricos que se utilizan en la fabricación de membranas comerciales. Se ha experimentado también con otros polímeros que no aparecen en la tabla, pero estos no han alcanzado desarrollo comercial. Obsérvese que el acetato de celulosa, material estudiado en esta Tesis, se emplea prácticamente en todas las técnicas de membrana.

\section{Técnicas generales de fabricación de membranas}

A continuación se describe el conjunto de técnicas empleadas normalmente en la fabricación de membranas con vistas a enmarcar el proceso de fabricación por inversión de fase utilizado en la presente Tesis.

Algunas de las técnicas expuestas a continuación pueden utilizarse tanto para la fabricación de membranas orgánicas como inorgánicas. La mayor parte de las membranas fabricadas en el mundo son orgánicas, siendo los procesos de inversión de 
fase los más empleados para producirlas, ya sea para producir la membrana en sí o bien una parte de su estructura (como ocurre en las membranas compuestas).

Tenemos pues las siguientes técnicas generales:

- Sinterización (Término en Inglés: Sintering):

En este proceso se realiza la compresión de partículas de tamaño lo más homogéneo posible, calentándose posteriormente hasta una temperatura donde se produzca una fusión parcial que las aglutine.

Es aplicable a la fabricación de membranas de microfiltración, tanto inorgánicas como orgánicas (normalmente con PTFE).

Tamaños de poro: $\quad 0.1-10 \mu \mathrm{m}$

Porosidad: $\quad 10-20 \%$, metálicos $80 \%$

- Proceso sol-gel (Término en Inglés: Template leaching):

Para la fabricación de membranas inorgánicas se realiza una mezcla homogénea de materiales inorgánicos a alta temperatura para posteriormente enfriar con lo que se separan las dos fases. La fase más soluble es lixiviada mediante un ácido.

Para fabricar membranas orgánicas se dispersa un agente formador de poros constituyendo un film polimérico y luego se lixivia.

Tamaños de poro: $\quad>0.05 \mu \mathrm{m}$

- Estiramiento (Término en Inglés: Stretching):

Una hoja de material polimérico cristalino que ha sido producida por extrusión se somete a un esfuerzo perpendicular a la dirección de extrusión. El esfuerzo produce rupturas obteniéndose una estructura porosa.

Tamaños de poro: $\quad 0.1-3 \mu \mathrm{m}$

Porosidad: $\quad$ cercana al $90 \%$

- Ataque químico de trazas de ionización (Término en Inglés: Track-etching):

En este proceso, una hoja de material polimérico de superficie lisa es sometida a un bombardeo de partículas de alta energía, produciéndose trazas de ionización. Una 
inmersión en un baño mordiente, ácido o alcalino, produce el desarrollo en las trazas de poros cilíndricos rectos.

$\begin{array}{ll}\text { Tamaños de poro: } & 0.02-10 \mu \mathrm{m} \\ \text { Porosidad: } & <10 \%\end{array}$

- Inversión de fase (Término en Inglés: Phase inversion):

En un proceso de inversión de fase, una disolución de polímero en un disolvente orgánico (colodión), que ha sido depositada sobre un soporte, sufre una precipitación para dar lugar a dos fases, una fase sólida y una líquida. La fase sólida constituye la membrana con sus poros rellenados por la fase líquida. La precipitación puede ser inducida de varias maneras, las cuales se detallan en el apartado 1.5.

Es el proceso más empleado en la fabricación de membranas y también el más versátil, permitiendo la obtención de membranas de diferentes morfologías aplicables a diversos usos.

- Formación de membranas compuestas mediante aplicación de recubrimientos:

Las membranas compuestas poseen una estructura asimétrica constituida por un soporte poroso, que puede haber sido fabricado por alguna de las técnicas anteriores, junto una capa superficial densa de otro material. La gran ventaja de este tipo de membranas sobre las anteriores es que cada capa puede ser optimizada por separado, especialmente la capa densa que se puede realizar más uniforme y con menos imperfecciones. El método permite la utilización en esta capa de otros materiales no válidos para los otros métodos.

Entre las técnicas de recubrimiento están:

- Recubrimiento en baño: La membrana porosa es introducida en un baño que contiene una disolución muy diluida del material que constituirá la capa superior. La retirada del disolvente en un horno producirá entrecruzamiento.

- Polimerización de plasma: Consiste en la ionización de monómero gas mediante descargas eléctricas, el cual forma una capa ultrafina sobre la membrana presente en el reactor. 
- Introducción de grupos y de puntos activos de polimerización: Se pueden introducir grupos químicos (generalmente iónicos) mediante ataque directo por reactivos. Otra variante es irradiar la superficie de membrana para generar puntos activos donde iniciar una polimerización cuando ésta se sumerja en un baño de monómero.

- Policondensación interfacial: Este método ha desplazado a las membranas integrales en bastantes aplicaciones. En éste, una membrana de ultrafiltración o de microfiltración es sumergida en una disolución acuosa de un monómero, embebiendo la disolución en sus poros superficiales. Posteriormente es introducida en un segundo baño de disolvente inmiscible en agua que contiene un segundo monómero. Ambos monómeros reaccionan en la interfase entre ambas disoluciones originando una capa muy fina $(0.05-1 \mu \mathrm{m})$ sobre la superficie de la membrana porosa. Es normalmente necesario completar la reacción mediante un tratamiento térmico para producir entrecruzamiento entre ambos monómeros.

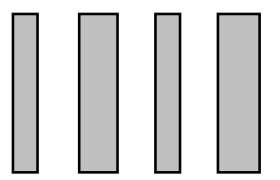

1) Membrana porosa

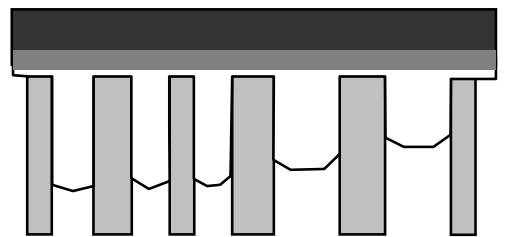

3) Inmersión en disolución orgánica que contiene monómero $B$. Inicio de la reacción interfacial

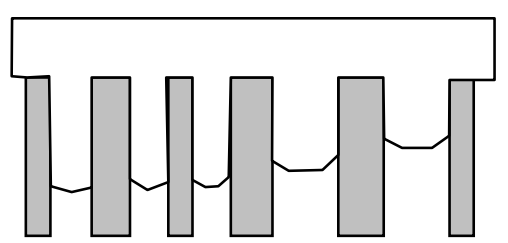

2) Inmersión en disolución acuosa que contiene monómero $\mathrm{A}$

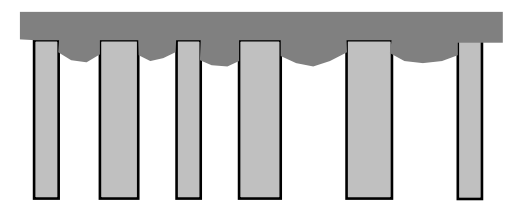

4) Finalización en horno del entrecruzamiento entre monómeros $A$ y $B$

Ilustración 12. Fases de la policondensación interfacial 
Últimamente las membranas inorgánicas están adquiriendo gran desarrollo en los campos de microfiltración, ultrafiltración y se está investigando también en nanofiltración. Los materiales utilizados para fabricar membranas inorgánicas pueden ser clasificados en tres grandes grupos:

- Cerámicos: Son una combinación de metal con un no-metal. Las membranas son producidas mediante sinterización o procesos sol-gel)

- Vidrios: El más empleado es el óxido de silicio. Las membranas son producidas por lixiviación.

- Metálicos: Se utiliza sinterización casi exclusivamente.

En la Ilustración 13 se clasifican los procesos de fabricación de membranas atendiendo a la estructura de la membrana producida y el mecanismo de separación. La versatilidad del método de inversión de fase permite su utilización en la formación de estructuras tanto simétricas como asimétricas. Asimismo se puede utilizar en la formación de membranas porosas, como base de las membranas compuestas y para obtener membranas densas que utilizan el mecanismo de disolución - difusión.

Otros métodos están limitados, sin embargo, a un tipo concreto de membrana. Ejemplos son el ataque químico a trazas de ionización que solo es capaz de producir membranas porosas simétricas, o la utilización directa de películas poliméricas obtenidas por extrusión que constituyen por sí mismas membranas simétricas no porosas.

Tanto en las membranas de ósmosis inversa como en las de nanofiltración se busca en la fabricación la obtención de estructuras lo más asimétricas posible con vistas a aumentar el flux de la membrana, estando los mecanismos selectivos limitados a una capa activa lo más pequeña posible. Ello es debido a la gran resistencia al flux existente en estas dos técnicas. Las membranas de ósmosis inversa son fabricadas hoy en día por el método de inversión de fase o por policondensación interfacial. Las membranas de nanofiltración se realizan con técnicas parecidas a las de las membranas de ósmosis inversa, aunque también es posible producirlas con técnicas propias de las membranas de ultrafiltración, e incluso hacerlas inorgánicas (Larbot et al., 1994). 


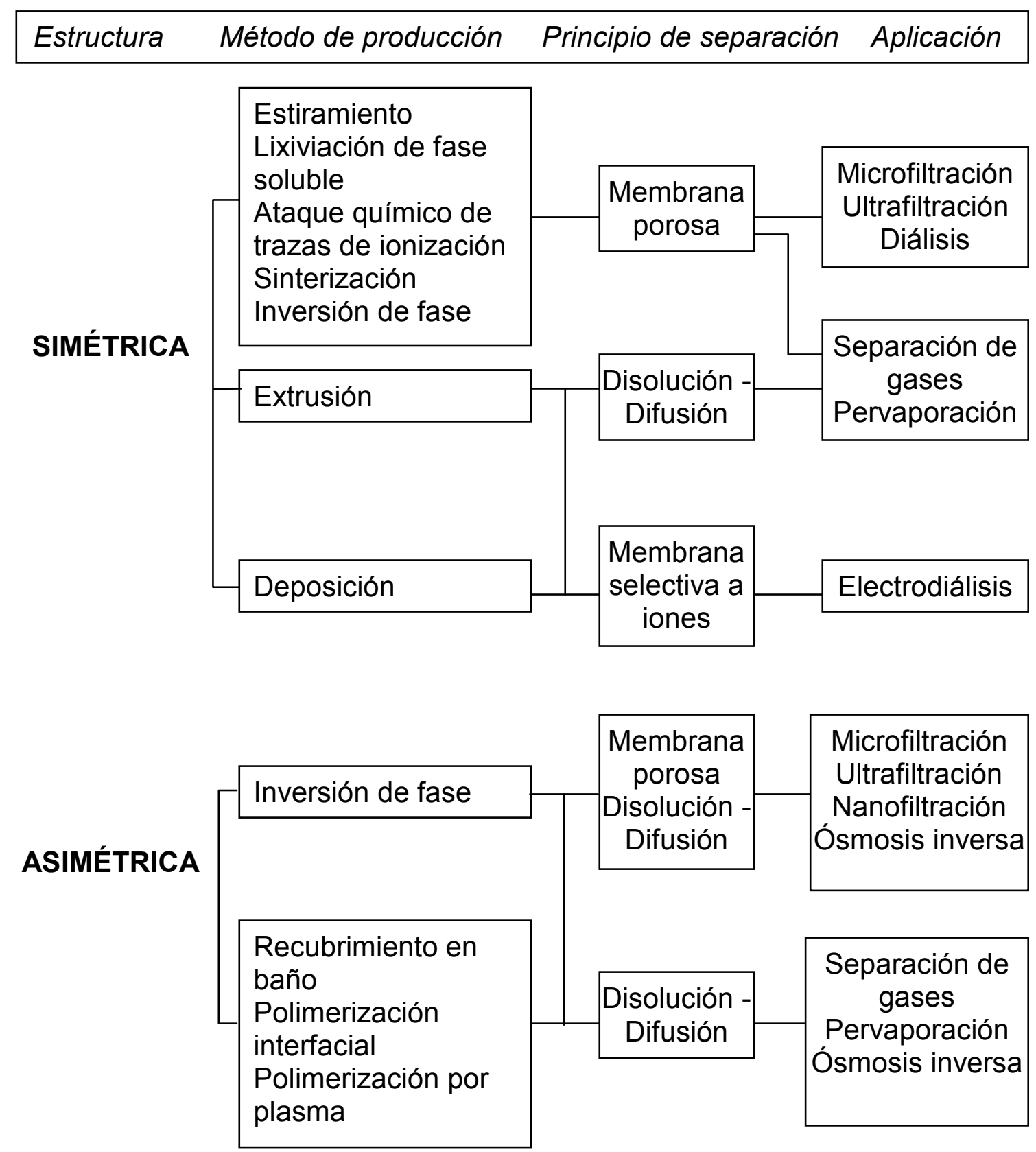

Ilustración 13. Esquema de clasificación de las técnicas de fabricación de membranas 


\subsection{PROCESOS DE PREPARACIÓN DE MEMBRANAS POR INVERSIÓN DE FASE}

\subsubsection{Aspectos generales de las técnicas de inversión de fase}

Los distintos procesos de inversión de fase tienen en común que en ellos una disolución de dos o más componentes se separa en dos fases. Esta disolución llamada colodión tiene generalmente como componentes principales uno o varios polímeros y uno o varios disolventes. La separación de fases se produce al hacerse termodinámicamente inestable la composición del colodión mediante uno de los dos siguientes mecanismos:

- Inducción de separación por difusión de componente: En este mecanismo se produce una variación de la composición del colodión producida por la difusión de un componente desde otra fase ajena al colodión, por pérdida de un componente del colodión, o bien por una combinación de ambos mecanismos.

- Inducción de separación por descenso de la temperatura: La disolución inicialmente estable a una temperatura alta se desestabiliza al disminuir la temperatura.

\section{Descripción del diagrama de fases polímero / disolvente / no-disolvente}

En la separación de fases producida según el primer mecanismo intervienen al menos tres componentes (1) Disolvente (sustancia disolvente del polímero); (2) Nodisolvente (sustancia que no disuelve al polímero pero que es miscible con el disolvente) y (3) Polímero. El sistema más sencillo que se puede estudiar es pues un sistema ternario.

Para representar la composición en sistemas ternarios se suele utilizar el diagrama triangular equilátero, donde cada punto se corresponde biunívocamente con una composición en fracciones de cada uno de los tres componentes. Las composiciones 
representadas en un diagrama deben ser para la misma presión y temperatura. En la Ilustración 14 queda reflejado como se sitúa una composición correspondiente a fracciones $x_{p}$ (polímero), $x_{d}$ (disolvente), $x_{n}$ (no-disolvente) cuando los lados del triángulo valen la unidad. Los vértices del triángulo se corresponden con composiciones puras de los componentes y los lados con composiciones bifásicas. En nuestro caso se utilizarán normalmente diagramas que consideren fracciones en peso de cada componente expresadas como $\left(x_{d}, x_{n}, x_{p}\right)$ o bien bajo la notación equivalente $\left(x_{1}, x_{2}, x_{3}\right)$. La presencia de más componentes (aditivos) haría que las fracciones reales no sumaran la unidad. No obstante, las cantidades de éstos suelen ser bastante más pequeñas que el resto de los componentes. Por ello se pueden utilizar fracciones respecto de una base másica desprovista de aditivos, estudiándose las modificaciones que introduce su efecto en el diagrama.

DISOLVENTE (1)

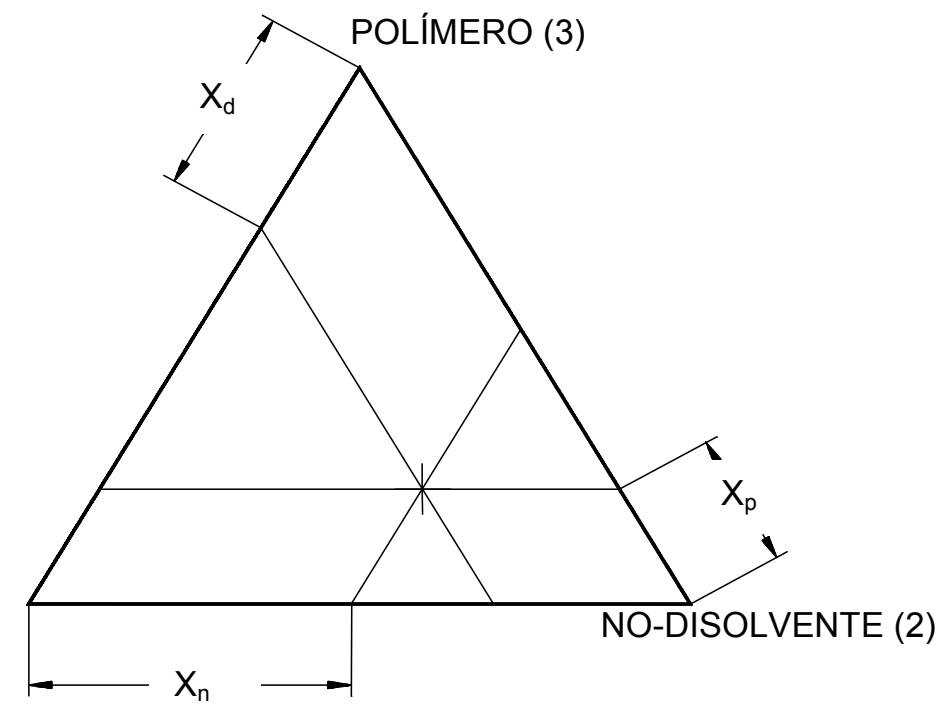

\section{Ilustración 14. Coordenadas en el diagrama de tres componentes}

En un sistema polímero/disolvente/no-disolvente típico no todos los puntos del diagrama se corresponderse con una única fase termodinámicamente estable (véase Ilustración 15). Es bastante frecuente la existencia de una zona (zona de insolubilidad) en la que no puede existir una única fase por lo que cuando la composición de la mezcla se encuentra en esta zona se produce una separación en dos fases. La curva en el diagrama que representa las composiciones estables y en equilibrio resultantes de esta 
descomposición es conocida como binodal y las líneas que unen las dos composiciones se conocen como rectas de reparto. La curva binodal separa pues la zona de insolubilidad de la región donde los tres componentes pueden formar una mezcla homogénea y cualquier composición que caiga en una recta de reparto se separará en dos composiciones en equilibrio correspondientes a los puntos extremos situados en la binodal. Una de las composiciones será una fase rica en polímero con algo de disolvente y no-disolvente y la otra rica en no-disolvente y disolvente pero bastante pobre en polímero.

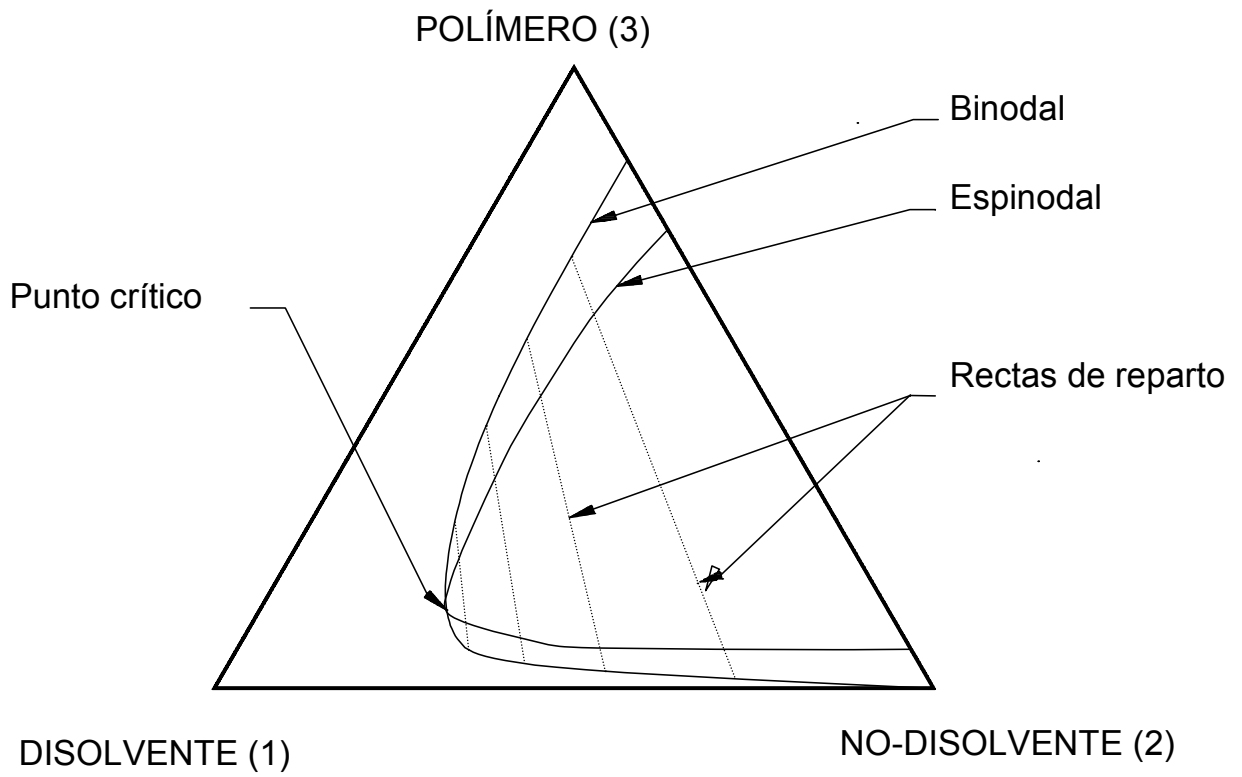

Ilustración 15. Diagrama de un sistema polímero/disolvente/no-disolvente típico

La zona de insolubilidad aparece a partir de una determinada concentración de nodisolvente y las composiciones en equilibrio son más cercanas conforme la fracción de disolvente es mayor. Las rectas de reparto correspondientes tienden a converger en un punto (punto crítico) a partir del cual ya se tiene una única fase.

Para altas concentraciones de polímero las cadenas pueden engancharse entre sí formando una estructura tridimensional, a modo de red y con viscosidad infinita, conocida como gel (Ilustración 16). Se conoce como zona de gelación las composiciones donde se produce el estado de gel y como recta de reparto sólida la primera recta, a partir de una composición de no-disolvente, con un punto de su composición en la región de gel. 


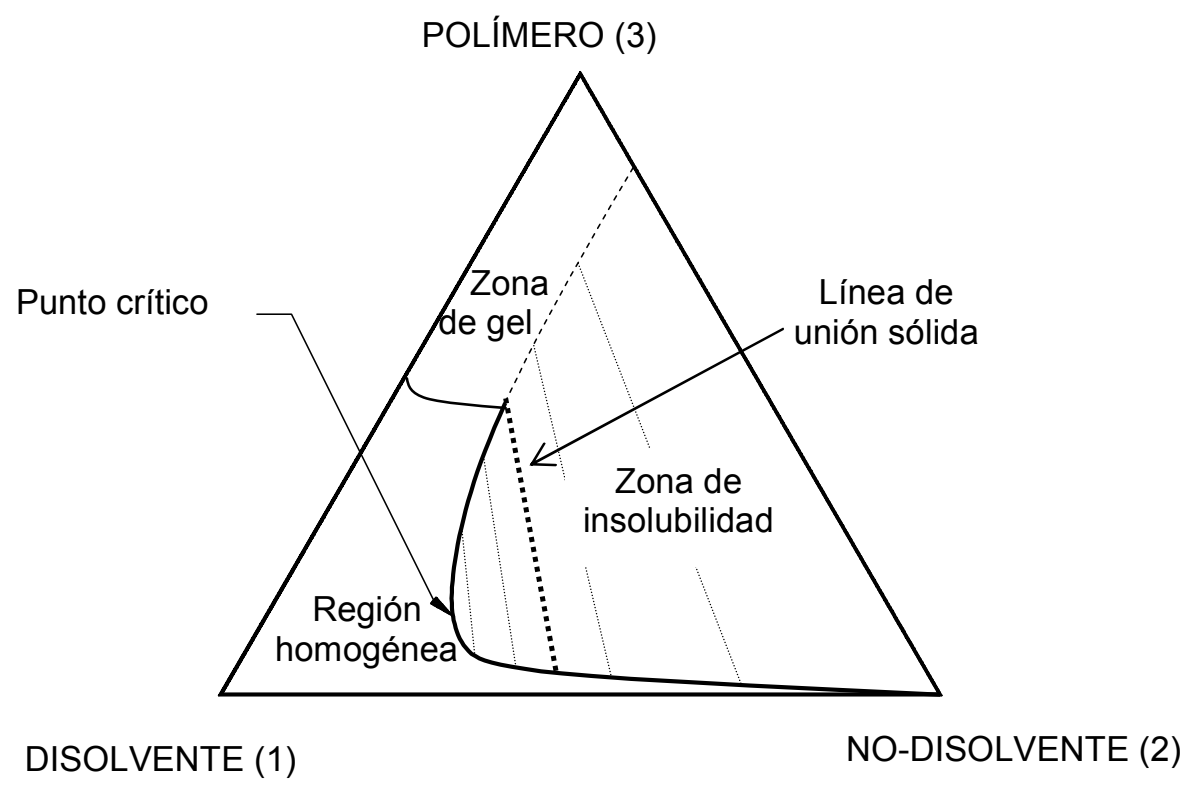

\section{Ilustración 16. Diagrama de un sistema polímero/disolvente/no-disolvente con región de gelación}

\section{Descripción de los diagramas temperatura - composición}

Al aumentar la temperatura, debido al aumento de la solubilidad entre los distintos componentes que se produce, la zona de insolubilidad entre las tres fases se reduce, llegando incluso a desaparecer. Dicha situación en un diagrama espacial que considere la temperatura queda representada en la Ilustración 17.

La superficie binodal representada en Ilustración 17 para una temperatura fijada origina la curva binodal de las anteriores representaciones. Para un sistema binario disolvente - polímero también originaría una curva sobre un plano de representación composición - temperatura tal como el de la Ilustración 18. La recta de reparto en este diagrama es una línea horizontal. 


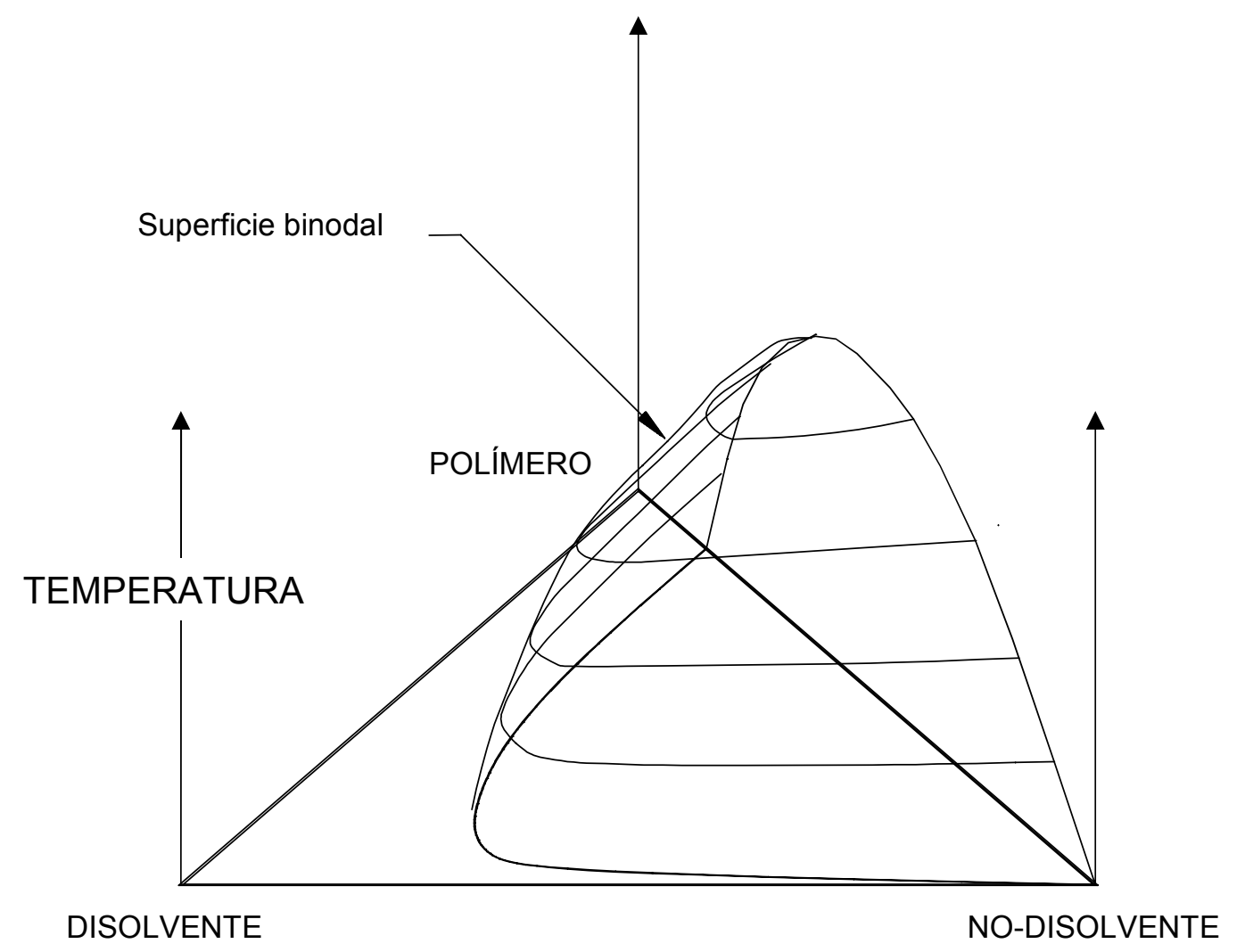

Ilustración 17. Diagrama ternario composición - temperatura

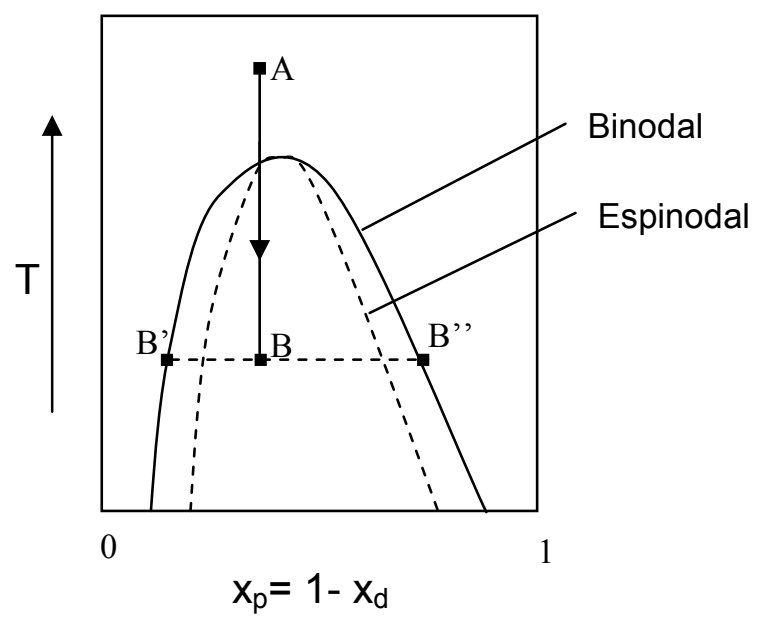

Ilustración 18. Diagrama binario polímero/disolvente - Temperatura 


\section{Aspectos termodinámicos de la separación de fases}

El parámetro más importante para describir la miscibilidad entre componentes es la energía libre de mezcla definida a partir de la entropía y entalpía de mezcla como

Ec. 75

$$
\Delta G_{m}=\Delta H_{m}-T \cdot \Delta S_{m}
$$

La entropía y entalpía de mezcla son la diferencia de entalpía existente entre el valor de las funciones de estado para la mezcla y la suma de los valores para los componentes por separado. Los componentes se mezclarán espontáneamente cuando $\Delta G_{m}<0$ y se separarán cuando la energía libre de los componentes por separado sea menor que la energía libre de la mezcla.

La Ilustración 19 representa una situación típica que presenta una zona de separación. Las composiciones comprendidas entre $B^{\prime}$ y $B^{\prime \prime}$ tienen la posibilidad de separarse en otras dos composiciones que suman una energía libre menor. Las composiciones que suman la menor energía libre posible son precisamente las de los puntos $B$ ' y $B$ '. Las composiciones a la izquierda de $B$ ' o a la derecha de $B$ "' no pueden dar lugar a dos fases de menor energía libre por lo que permanecerán como una fase homogénea.

Los puntos $B$ ' y $B$ ' 'se encuentran en la tangente a la curva de energía libre. Como la definición de potencial químico respecto del componente $i$ es:

Ec. $76 \quad \mu_{i}=\left(\frac{\partial G_{m}}{\partial x_{i}}\right)_{T, P}$

Ambos puntos tendrán el mismo potencial químico al tener la misma derivada de energía libre respecto de la composición.

Ec. $77 \quad \mu_{i}\left(B^{\prime}\right)=\mu_{i}\left(B^{\prime \prime}\right)$ 


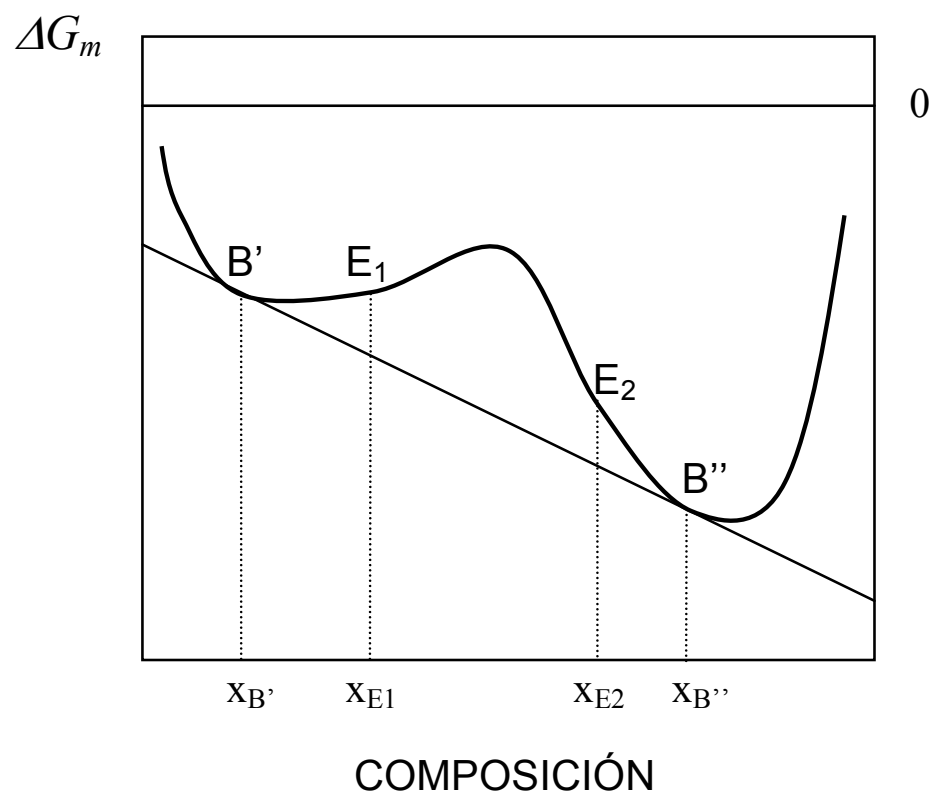

\section{Ilustración 19. Variación de la energías libre con la composición a lo largo de una recta de reparto}

En un sistema ternario la curva expuesta en la Ilustración 19 es una superficie tridimensional, los puntos pertenecientes a una zona de insolubilidad se separarán en puntos de la binodal que, de manera análoga, cumplen una igualdad entre los potenciales químicos para cada componente. Todas las composiciones que se separan en ambos puntos caerán dentro de una misma línea de reparto.

Los puntos $E 1$ y E2 de la Ilustración 19 son puntos de inflexión en los que la curva de energía libre pasa de cóncava a convexa, estos puntos cumplen además que la segunda derivada respecto de la variación de la composición a lo largo de la línea de reparto es nula. Estos puntos formarán en la superficie de energía libre la curva espinodal que dividirá el interior de la binodal en dos zonas: zona metaestable (formada por puntos comprendidos entre $B^{\prime}$ y $E_{1}$ y entre $E_{2}$ y $B^{\prime \prime}$ ) y zona inestable (puntos entre $E_{1}$ y $E_{2}$ ).

En las regiones comprendidas entre la curva espinodal y la binodal (zonas $B^{\prime}-E_{1}$ y $E_{2}-B^{\prime \prime}$ ) la segunda derivada es mayor que cero, lo que quiere decir que una pequeña variación en la composición no produce una disminución de la energía libre, a pesar de que hay un estado posible de menor energía libre. Estas regiones constituyen una zona metaestable en la que la composición puede permanecer homogénea si no hay bruscas 
variaciones en la composición. No obstante, si existen núcleos de separación formados se producirá la separación hacia composiciones en la binodal.

En la región interior a la curva espinodal (zona $E_{1}-E_{2}$ ) se tiene que la segunda derivada respecto de la composición es menor que cero por lo que la mezcla se separa espontáneamente.

El punto crítico (véase Ilustración 20) se corresponde con un punto límite de la binodal en el que las composiciones que se separan son infinitesimalmente cercanas. Dicho punto pertenece también a la curva espinodal.

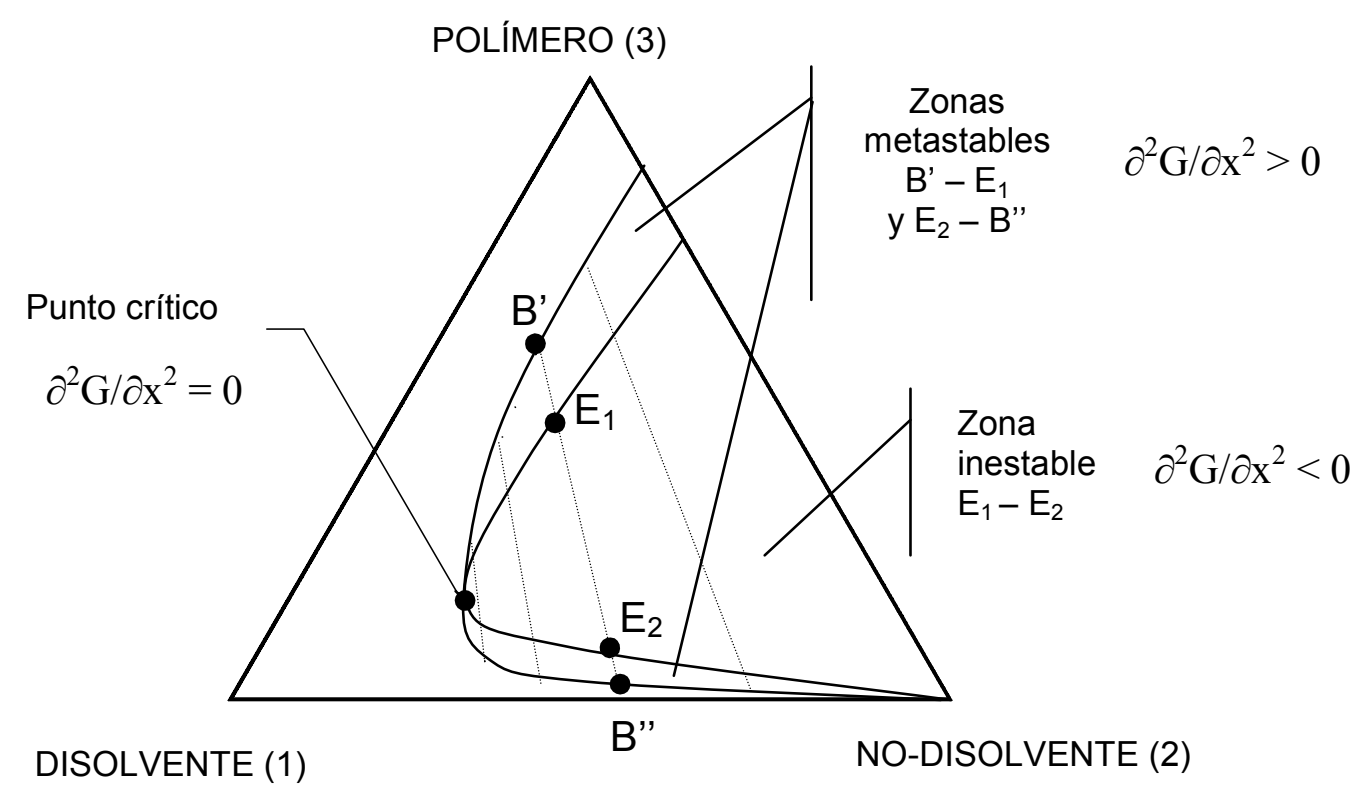

Ilustración 20. Zonas inestable, metaestable e inestable

El tratamiento teórico para el ajuste matemático de la curvas binodal y espinodal, se encuentra realizado en el anexo de esta Tesis "Programa para la determinación teórica del diagrama ternario". 


\section{Tipos de separación de fase}

Podemos distinguir entre dos tipos de separación de fases:

1. Separación líquido-líquido

2. Cristalización

1. Separación líquido-líquido:

En la separación líquido-líquido una fase termodinámicamente inestable se separa en dos fases de diferente composición. En la Ilustración 21 se puede ver como el cambio de composición originado por la adición de no-disolvente provoca que se alcance la binodal.

Si la trayectoria alcanza la binodal en un punto $B^{\prime}$ (por encima del punto crítico) empiezan a originarse núcleos de composición $B$ ". Estos núcleos crecerán posteriormente pudiéndose llegar a entrelazar. Al ser la composición $B$ " pobre en polímero y líquida si los núcleos no llegan a desarrollarse lo suficiente la estructura generada será muy poco porosa.

Si la trayectoria alcanza la binodal en un punto $B^{\prime \prime}$ (por debajo del punto crítico) los núcleos que empezarán a formarse serán de composición $B$ " rica en polímero. La estructura rica en polímero tendrá que crecer en una fase líquida. Si la expansión posterior de estos núcleos no llega a entrelazarse, la estructura resultante puede ser inconsistente.

Las dos posibilidades expuestas son conocidas como cinéticas de nucleación, con separación de fase sólida en el primer caso y líquida en el segundo caso. Existe un tercer tipo de cinética de descomposición conocida como espinodal. Ésta se da cuando el proceso de cambio de composición es tan rápido que ésta queda en un punto intermedio entre $E_{1} \mathrm{y}$ $E_{2}$ que ha atravesado la línea espinodal. En este caso la disolución se separa espontáneamente originándose una estructura entrelazada. Este tipo de descomposición es, sin embargo, poco probable en disoluciones poliméricas. 
POLÍMERO (3)

(2)

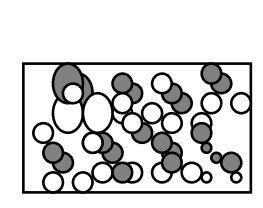

(3)

(1)

(2)

DISOLVENTE (1)
(1)

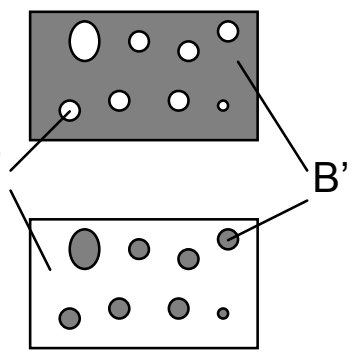

Ilustración 21. Nucleaciones de fase (1), (3) y descomposición espinodal (2)

\section{Cristalización:}

Al disminuir la energía libre y entrar la composición de la disolución en una zona termodinámicamente inestable es posible la formación de estructuras ordenadas o cristalinas. La formación de estas estructuras cristalinas depende del tiempo de que dispone el polímero para cristalizar. La separación líquido - líquido es un proceso mucho más rápido que compite fuertemente con la cristalización por lo que en la mayoría de los casos no llegan a formarse o se forman cristales de orden de tamaño microscópico. Por otra parte, el aumento de la concentración de polímero favorece la velocidad de nucleación. Por ello, el fenómeno de gelación, que aunque es un proceso de solidificación no es un proceso de inversión de fase, suele ir acompañado en el caso de polímeros semicristalinos por una fase inicial con formación de pequeñas estructuras microcristalinas. 


\subsubsection{Clasificación de los procesos de fabricación por inversión de fase}

Las técnicas generales de producción de membranas por inversión de fase son las siguientes:

- Precipitación por evaporación

- Precipitación inducida por difusión desde fase vapor

- Precipitación inducida por intercambio de difusión con fase líquida (Precipitación por inmersión)

- Precipitación inducida por descenso de temperatura

Las tres primeras están basadas en la modificación de la composición del colodión mediante difusión de uno varios componentes, bien desde la disolución polimérica (colodión) hacia un medio o bien desde un medio hacia el colodión hasta alcanzar una zona termodinámicamente inestable donde se produce separación de fases. La última es sustancialmente diferente al producirse la separación por efecto exclusivo de la temperatura sin modificación de la composición.

Se detalla a continuación los rasgos más característicos de estas técnicas:

\section{- Precipitación por evaporación:}

La disolución polimérica o colodión se deposita en un soporte apropiado y se evapora en una atmósfera inerte (desprovista de humedad). Existen dos variantes:

En la primera el colodión de partida es fundamentalmente polímero y disolvente y el sistema presenta insolubilidad para una determinada relación polímero/disolvente, por lo que al perderse disolvente el polímero precipita obteniéndose una membrana muy densa.

La segunda variante consiste en el uso de una disolución de polímero en una mezcla de disolvente y no-disolvente (véase Ilustración 22). Una mayor evaporación de disolvente llevaría a una relación polímero/no-disolvente que alcanza la curva binodal con lo que se produce una separación de fases. Las membranas que se obtienen son asimétricas con capa densa. 
- Precipitación inducida por difusión desde la fase vapor:

En este caso la deposición de colodión se pone en contacto con una fase vapor de naturaleza no-disolvente del polímero que se encuentra saturada en el disolvente, con ello se impide el paso de disolvente hacia la fase vapor. La separación se produce entonces por difusión de no-disolvente hacia colodión obteniéndose una estructura microporosa asimétrica sin capa densa (véase Ilustración 22).

- Inmersión - precipitación:

En este caso el soporte con el colodión depositado es introducido en un baño de coagulación que contiene no-disolvente. Se produce entonces un intercambio de disolvente y no-disolvente entre el baño y el colodión. La estructura de la membrana dependerá de la relación de intercambio disolvente/no-disolvente así como de las propiedades del sistema en cuanto a la separación de fases (véase Ilustración 22).

Este método es el empleado en la fabricación de las membranas de esta Tesis y es el más utilizado debido a su sencillez y versatilidad.

- $\quad$ Precipitación inducida por descenso de temperatura:

En este proceso se realiza una disolución del polímero en un disolvente o una mezcla de disolventes capaz de disolver al polímero únicamente a altas temperaturas. Un lento descenso de la temperatura permite que la disolución sobrepase la curva binodal correspondiente a esa composición haciéndose la disolución termodinámicamente inestable y produciéndose la separación de fases. De esta forma se obtiene una estructura polimérica y una fase líquida que debe ser extraída con un disolvente que no disuelva al polímero. Esto queda ilustrado en la Ilustración 18, donde la composición estable $A$ al enfriarse cae en el punto $B$ dentro de la zona de insolubilidad, por lo que se descompone en las composiciones $B^{\prime}$ y $B^{\prime}$ '. 
La estructura obtenida con este procedimiento suele ser completamente isotrópica, incluso para grandes espesores de membrana. Sin embargo, puede ser obtenida una capa densa superficial mediante la realización de una evaporación previa al enfriamiento.

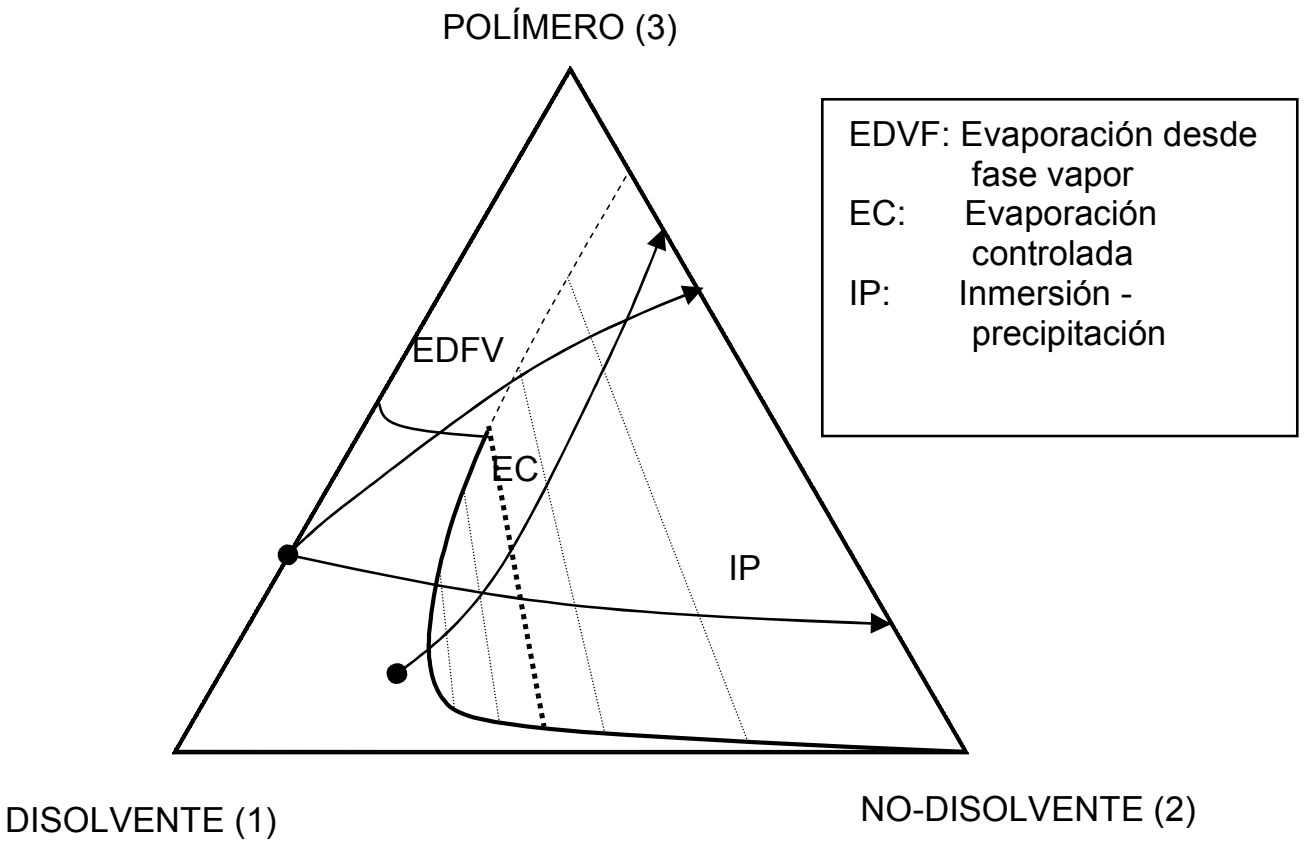

\section{Ilustración 22. Transiciones de fase correspondientes a distintas técnicas de inversión de fase}

Las técnicas que se han expuesto pueden presentar distintas variantes y combinaciones tal y como se muestra en la Ilustración 23 . 


\section{DEPOSICIÓN \\ EVAPORACIÓN \\ DIFUSIÓN \\ DESCENSO DE TEMPERATURA}

1. Separación de fases inducida por evaporación

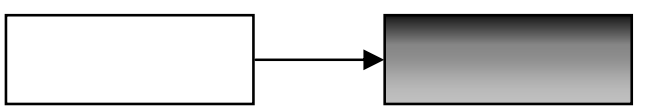

2. Separación de fases inducida por difusión

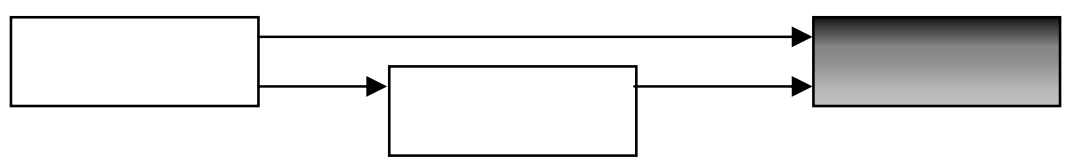

3. Separación de fases inducida por evaporación y difusión

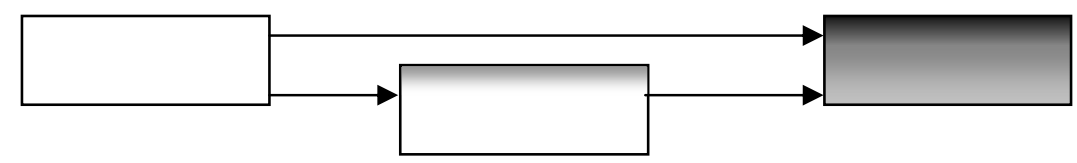

4. Separación de fases inducida por descenso de temperatura

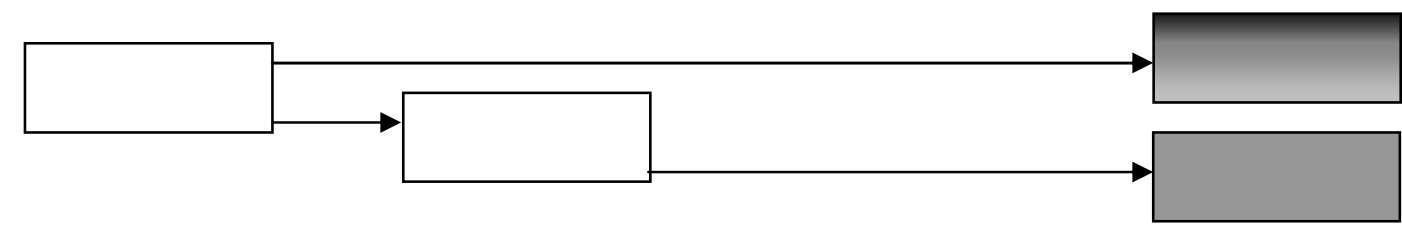

Ilustración 23. Clasificación de los procedimientos de inversión de fase 


\subsubsection{Técnica de inversión de fase por inmersión- precipitación}

Como ya se ha mencionado, en esta técnica el soporte con el colodión depositado (disolución de polímero, disolvente y aditivos) es introducido en un baño que contiene nodisolvente (baño de coagulación). Se producen entonces mecanismos de difusión que inducen a la separación. Por una parte, la difusión de disolvente hacia el baño y por otra la de no-disolvente hacia la membrana en formación. Dichos mecanismos conducen a la formación de la estructura de la membrana y se engloban dentro de una etapa conocida como coagulación. Como el polímero precipita mucho más rápido en la superficie que en el substrato inferior se produce normalmente una capa superior densa sobre un substrato microporoso.

Si bien la etapa de coagulación es la parte central de la técnica de inmersión precipitación suelen ser necesarias otras etapas para conseguir un determinado tipo de estructura. En la Ilustración 24 se puede ver un ejemplo de aplicación de la técnica a la fabricación de una de las primeras membranas asimétricas empleadas en ósmosis inversa.

$22.2 \%$ Ac. Celulosa

$66.7 \%$ Acetona

$10.0 \%$ Agua

$1.1 \%$ Perclorato magnésico

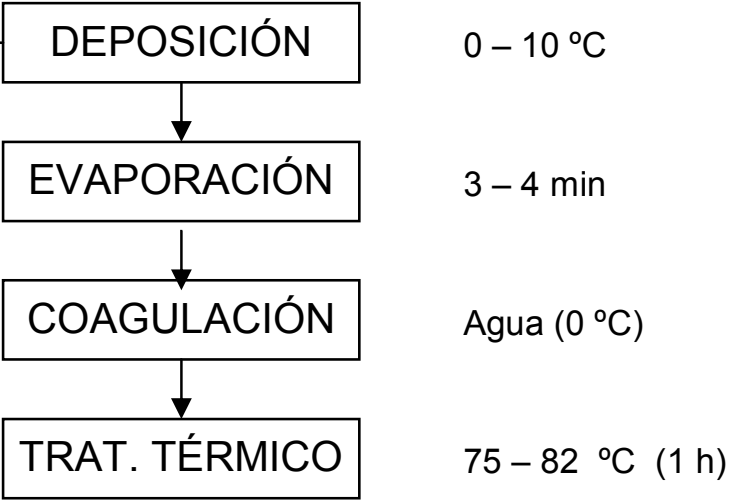

Ilustración 24. Proceso de fabricación de membranas para desalación de Loeb y Sourirajan (Sourirajan, 1970) 
El colodión deberá presentar unas características que faciliten su deposición sobre el soporte. En las membranas no integrales se utiliza un soporte mucho más poroso que la estructura asimétrica de membrana que cumpla funciones de resistencia estructural. Con ello se obtienen estructuras compuestas mucho más eficaces que las membranas integrales que requerirían un gran espesor de membrana, con la consiguiente pérdida de carga, para lograr la resistencia estructural necesaria.

La etapa de evaporación se utiliza cuando se busca aumentar la concentración de polímero en la superficie para lograr una estructura superior más densa que la inferior. Ello implica que se debe eliminar disolvente del colodión sometiéndolo a un ambiente a una temperatura determinada durante un tiempo dado.

Posteriormente a la completa coagulación, se obtiene una estructura de membrana, sin embargo la coagulación puede no proporcionar la estructura o propiedades requeridas por lo que se hacen necesarios tratamientos adicionales. Los tratamientos térmicos (calentamientos en baño, con vapor, por radiación infrarroja, etc.) son los más utilizados, permitiendo modificar la estructura superior haciéndola más cerrada.

\section{Mecanismo de separación de fase en la inmersión-precipitación}

La entrada de la composición del colodión en una zona de inmiscibilidad por efecto de la adición de no-disolvente trae como consecuencia una separación de fases que se produce en fracciones de segundo. Los procesos difusivos a lo largo del espesor de la membrana que llevan a la difusión de disolvente y no-disolvente pueden llegar a completarse al cabo de unos minutos. Podemos, por tanto, considerar la evolución de la composición durante la fase de coagulación como una secuencia de estados de equilibrio a lo largo de la membrana.

Para explicar el proceso de formación de la membrana durante la coagulación se debe tener en cuenta la situación reflejada por los puntos $A, B, C$ y $D$ de la Ilustración 25 y sus composiciones en la Ilustración 26 para un pequeño intervalo de tiempo.

En la zona del baño de coagulación en contacto con la membrana en formación se tiene desde el instante inicial de introducción de la deposición una zona donde se 
establece un gradiente de concentraciones de disolvente y no-disolvente (capa límite de difusión). Este gradiente origina un gradiente de potencial químico que es la fuerza impulsora del proceso de difusión, de manera que se establece un flux de disolvente desde la membrana en formación (mayor concentración de disolvente) hacia el seno del baño, que podemos suponer con concentración despreciable o constante en disolvente. Si el potencial químico del no-disolvente es mayor en el baño que en el colodión tenderá a difundir hacia éste.

En la zona $D-C$, para tiempos superiores al instante de introducción en el baño, tendremos estructura de membrana ya formada, constituida por una fase sólida rica en polímero que ya no varía apreciablemente su composición en el tiempo y a través de la que se está dando transporte de disolvente y no-disolvente.

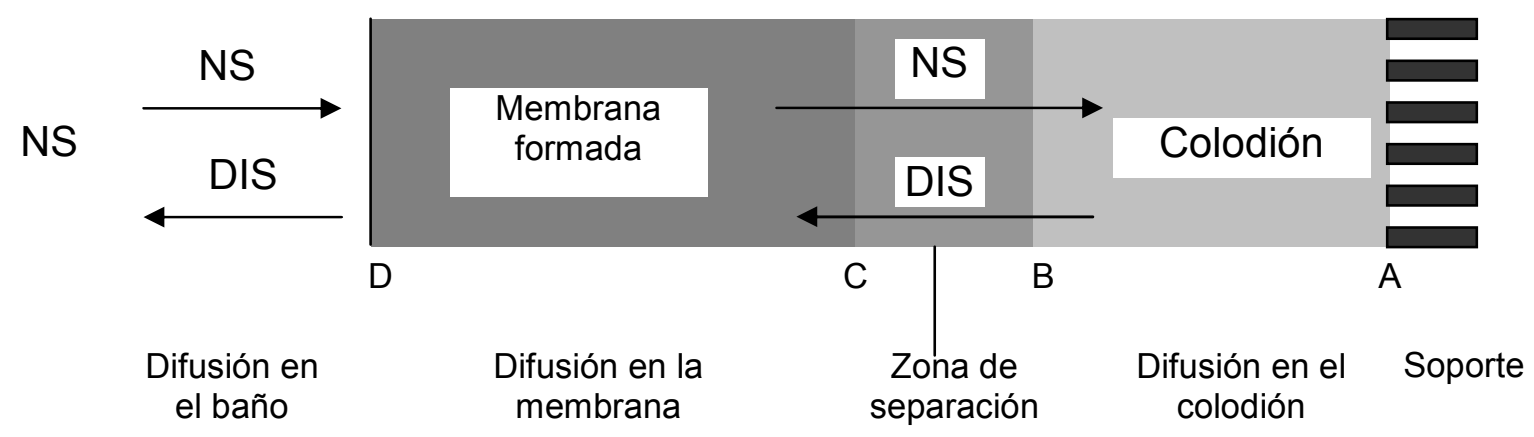

\section{Ilustración 25. Formación de la membrana y difusión de disolvente (DIS) y no- disolvente (NS)}

En la zona $C-B$ se está dando la separación de fases en una fase rica en polímero y una fase líquida prácticamente desprovista de polímero. En el diagrama ternario de la Ilustración 26 se puede apreciar la evolución de composición que sufre la fase rica en polímero cuando la zona de separación se desplaza hacia la derecha pasando a representar la composición de $B$ la situación que antes representaba el punto $C$.

Dentro de la separación líquido-líquido debemos distinguir dos situaciones:

- Separación líquido-líquido instantánea

- Separación líquido-líquido retrasada 
La separación líquido-líquido instantánea se daría para una situación como la representada Ilustración 26, el no-disolvente difundiendo a través del colodión origina que el recorrido de composición de $B$ a $C$ sobrepase la binodal originándose la separación de forma continua.

La separación líquido-líquido con retraso se produce si el recorrido de composición no penetra en la curva binodal sino que llega a $C$ atravesando la zona de gel la separación de fases se producirá con retraso en los puntos $C$ y $C^{\prime}$ e incluso puede no producirse. Las estructuras obtenidas serán en este caso de naturaleza densa y casi homogénea.

En la zona $A-B$ existirá una difusión continua de disolvente hacia la zona $C-B$ y una recepción de no-disolvente desde esta zona.

La curva de recorrido de composición $B-C$ no es una curva estática en el tiempo y es válida solamente para el intervalo corto de tiempo en el que se produce la debido a los cambios de composición.

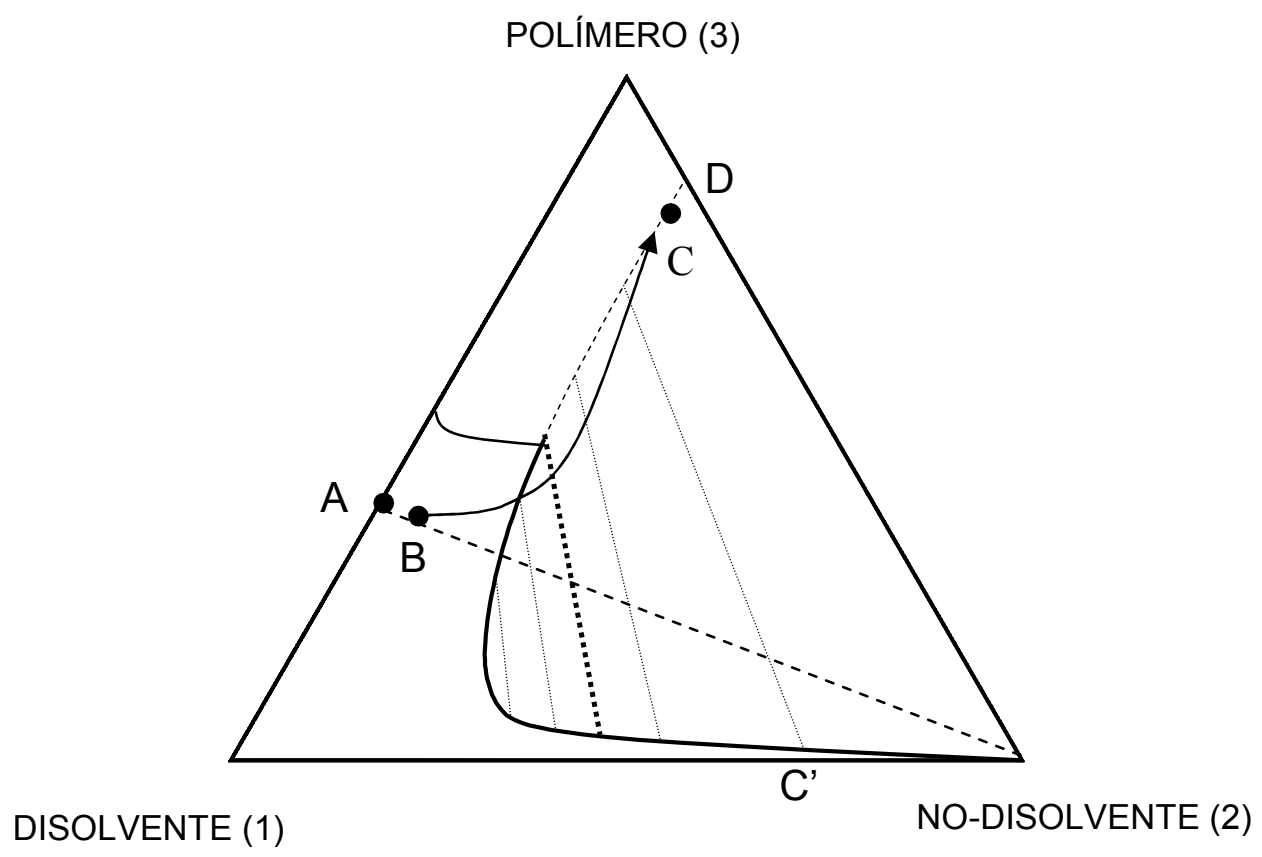

Ilustración 26. Evolución de las composiciones en la membrana en formación 



\section{OBJETIVOS}





\section{OBJETIVOS}

Los objetivos de la presente Tesis Doctoral son:

1. La determinación de las variables influyentes en la preparación mediante el método de inversión de fase por inmersión - precipitación de membranas de Acetato de Celulosa dentro de los rangos de ósmosis inversa y nanofiltración.

2. Establecer las bases para la fabricación en máquina de membranas compuestas de acetato de celulosa a partir de los resultados obtenidos utilizando un método manual de fabricación de membranas en el laboratorio.

El trabajo busca complementar la línea de preparación de membranas del Departamento de Ingeniería Química y Nuclear de la Universidad Politécnica de Valencia centrándose en el acetato de celulosa (AC). Otras tesis realizadas en nuestro departamento con otros materiales son las de Lora (1987), Alcaina (1991), e Iborra (1993) utilizando los materiales polisulfona y poliamida. La elección del acetato de celulosa como material base para esta Tesis viene determinada por el hecho de que es un material relativamente barato que resulta útil para contrastar y optimizar los métodos de fabricación y que por tanto es adecuado para introducir en la línea de investigación del Departamento la comparación con la fabricación en máquina con un dispositivo presente en nuestro laboratorio.

La elección del rango de ósmosis inversa enlazará con experiencias previas de este laboratorio y permitirá introducirse también en la novedosa línea de la nanofiltración. Los rangos de trabajo de ósmosis inversa y nanofiltración van a permitir una caracterización rápida de las disoluciones de alimento lo que agilizará el estudio de los factores de fabricación. Con ello se pretende más que fabricar membranas por inversión de fase altamente optimizadas el revisar la metodología de fabricación manual como un método auxiliar para la obtención de datos de una futura fabricación en máquina. 
Para conseguir los objetivos el trabajo se ha organizado en las siguientes fases:

1) Revisión y estudio bibliográfico:

La revisión bibliográfica ha abarcado varios aspectos:

- Modelos de comportamiento para membranas de ósmosis inversa y nanofiltración con vistas a relacionar los parámetros más oportunos que definen el funcionamiento con los parámetros de fabricación

- Información sobre métodos de fabricación

- Materiales y sus propiedades

- Condiciones para la formación de membranas

- Modelos termodinámicos y cinéticos útiles para el estudio de la formación de membranas

- Patentes y métodos existentes

2) Estudio y selección de materiales:

Se seleccionaron los disolventes, tipos de acetato de celulosa, aditivos y soportes adecuados. En la selección no solo se tuvieron en cuenta criterios científicos sino también criterios técnicos, económicos y de seguridad.

3) Estudio de las disoluciones de polímero (colodiones):

Se establecieron concentraciones de polímero y aditivos adecuados para obtener los resultados de fabricación requeridos.

Se realizaron además estudios sobre las propiedades de los colodiones interesantes para la fabricación industrial, tales como tiempo de formación y viscosidad. 
4) Determinación y estudio de los diagramas de fases:

Al estar el proceso de fabricación de membranas basado en una separación de fases, va a ser necesario obtener información sobre el equilibrio de separación de fases para comprender los mecanismos de formación de la membrana.

Para determinar los diagramas de fase se obtendrán datos experimentales. Para el posterior estudio de los diagramas se procederá en primer lugar al ajuste de los datos experimentales y datos obtenidos de la bibliografía a un modelo teórico que permitirá determinar datos como las líneas de reparto y curva espinodal, muy difíciles de obtener de forma experimental en este caso.

El efecto de la variación de las condiciones sobre el diagrama se estudiará de forma experimental, realizando la obtención de datos experimentales para diferentes condiciones, y de forma teórica, modificando los valores de los parámetros ajustados obtenidos.

5) Determinación de las variables influyentes en la preparación de membranas de AC y estudio de su efecto:

Para determinar cómo influyen las distintas variables de fabricación en el método de inversión de fase mediante inmersión - precipitación se utilizó un método manual con el que se realizaban las distintas etapas de fabricación a pequeña escala. El método, por su carácter artesanal, introduce una gran dispersión en los resultados y muchas veces existe baja reproducibilidad. Sin embargo, permite obtener información de manera más económica y con mayor flexibilidad en las condiciones de fabricación que la utilización de la máquina de producción disponible en el laboratorio del Departamento.

La variación de los parámetros de funcionamiento se realizaba en paralelo con su caracterización para introducir modificaciones en función de los resultados obtenidos. 
6) Caracterización de las membranas formadas:

Las membranas obtenidas se caracterizaban en cuanto a flux y rechazo. Las disoluciones patrón empleadas eran principalmente de cloruro sódico en agua y en alguna ocasión de sales con cationes bivalentes. Para realizar las medidas de flux se utilizó el método de aforo en la determinación del caudal por su fiabilidad y precisión. Las medidas de rechazo se efectuaron por conductimetría que permitía un rápido y fiable análisis.

7) Diseño de experimentos:

Como un ejemplo de las posibilidades de aplicación del método manual a la obtención de datos se realizó un diseño de experimentos para describir el efecto de las condiciones de fabricación dentro de un rango. Esta descripción permite hallar unas condiciones óptimas trasladables a la fabricación en máquina.

\section{8) Estudios de Microscopía electrónica:}

Se seleccionaron membranas para el análisis de su estructura en el microscopio electrónico, así como para el estudio de la adherencia del material de acetato de celulosa a los soportes. Se puso para ello a punto un método de preparación de muestras para su visualización en el microscopio electrónico.

9) Consideraciones sobre la viabilidad de la fabricación en máquina:

El enfoque de investigación se realiza con el fin de obtener conclusiones útiles para futuras investigaciones de fabricación en máquina. 


\section{METODOLOGÍA}





\section{METOdOLOGÍA}

\subsection{REVISION BIBLIOGRÁFICA}

La elaboración de la metodología de esta Tesis ha sido realizada basándose en fuentes muy diversas debido a la variedad de los contenidos tratados.

Los aspectos organizativos de la Tesis han seguido bastantes de los consejos del libro de Sierra, R. (1988).

La revisión bibliográfica para la selección de materiales y diagramas de fases se ha efectuado basándose en bibliografía general sobre polímeros o específica sobre membranas (Lloyd, 1984)

En lo referente al proceso de formación se ha basado en la experiencia previa de fabricación en el laboratorio de Ingeniería Química y Nuclear recogida en diferentes artículos, informes y Tesis, así como transmitida de forma oral. Se ha consultado una amplia bibliografía sobre el tema, así como numerosos artículos de la publicación Journal of Membrane Science, los cuales constituyen sin duda la fuente de referencia más importante sobre el tema.

La información sobre procesos industriales de fabricación en máquina es escasa, destacando Mulder, 1992; GKSS, 1993. En lo referente a este tema se consultaron diversas patentes.

Para el manejo de productos desde el punto de seguridad se han consultado manuales de seguridad, así como las normas de manejo de los productos indicadas por las mismas casas.

Para el tratamiento estadístico de los datos bastó la consulta de la bibliografía disponible en la UPV (Romero 1993 y 1993a) así como los manuales del programa estadístico Statgraphics (C) (Manugistics, Inc 1992). 


\subsection{SELECCIÓN DE MATERIALES. CARACTERÍSTICAS Y NORMAS DE SEGURIDAD EN SU UTILIZACIÓN}

Para la fabricación de las membranas va a ser necesario seleccionar los materiales más adecuados dentro de las siguientes clases:

- Polímeros

- Material soporte

- Disolventes

- Medio no-disolvente

- Aditivos

Adicionalmente va a ser necesario seleccionar las sustancias empleadas para la caracterización de las membranas.

La decisión más crítica a la hora de fabricar una membrana para un proceso concreto son los materiales que van a constituir ésta, en nuestro caso los polímeros y el material soporte. Los polímeros conferirán a la membrana sus propiedades permeoselectivas, mientras que el soporte conferirá las propiedades de resistencia estructural. Los factores que determinarán la selección provendrán de las características que le exija a la membrana el proceso concreto donde se va a aplicar ésta. En nuestro caso se tienen en cuenta también factores económicos al buscarse una clase de materiales relativamente baratos para la fabricación en máquina. Además para acotar los objetivos de trabajo se fijarán materiales aptos para los procesos de ósmosis inversa y nanofiltración, con capacidad permeoselectiva frente a disoluciones salinas y que sean capaces de resistir los rangos de presión de los anteriores procesos.

El método de fabricación estudiado en la presente Tesis requiere la utilización de un disolvente (o una mezcla de ellos) y un medio no-disolvente. La elección de ambos viene determinada por aspectos físico-químicos, debiendo realizarse en conjunto y teniendo en cuenta el material polimérico seleccionado. El sistema constituido por polímero/disolvente/no-disolvente deberá presentar un diagrama de fases con una zona de insolubilidad que cumpla unas determinadas características necesarias para la producción del tipo de membrana que se desea. 
La elección de los aditivos buscará la obtención de determinadas propiedades en la disolución polimérica que faciliten su formación o manejo. También se buscará aquellos capaces de modificar el diagrama de fases o de actuar en el proceso de formación.

\subsubsection{Polímeros utilizados}

La selección del material de la membrana es la más importante que hay que realizar, especialmente en los procesos donde existe mecanismo de transporte por disolución - difusión ya que va a determinar la permeación de los diferentes componentes a través de la membrana.

En un proceso de membrana la velocidad de permeación está gobernada por los siguientes factores:

- La naturaleza química del material de la membrana y la de los compuestos que permean

- La estructura de la membrana

La elección del material también es importante en la estructura de la membrana. La macroestructura depende del proceso de fabricación pero este está a veces condicionado por el material. La microestructura (capa densa) depende del proceso de formación y la naturaleza química del polímero. Además, tanto estructura como naturaleza del material serán importantes a efectos de resistencia mecánica de la membrana.

Otros aspectos no menos importantes a la hora de elegir el material son la resistencia química de éste y su resistencia al ensuciamiento.

La influencia de la naturaleza de la membrana sobre la permeación va a depender principalmente de efectos de equilibrio (partición de soluto entre membrana y disolución) y efectos cinéticos (difusión en la membrana). Entre los efectos fisico-químicos que se pueden establecer entre la membrana y los compuestos se encuentran las fuerzas polares (dipolos), fuerzas dispersivas (fluctuaciones de la nube electrónica) y puentes de 
hidrógeno. Además debemos incluir los efectos estéricos. Los tres primeros efectos mencionados se resumen en el parámetro de solubilidad o de energía cohesiva de Hansen.

Para el acetato de celulosa se tiene:

$$
\delta_{d}=7.9 ; \quad \delta_{p}=3.5 ; \quad \delta_{h}=6.3 ; \quad \delta^{2}=\delta_{d}^{2}+\delta_{p}^{2}+\delta_{h}^{2} \rightarrow \quad \delta=10.7
$$

Cuanto mayor sea la similitud química entre dos especies mayor será su solubilidad mutua y menor será la diferencia entre sus parámetros de solubilidad. Para una membrana podemos expresar esto mediante un factor de afinidad entre el material de la membrana $M$ y el componente de la disolución $D$ :

Ec. 78

$$
\Delta_{D M}^{2}=\left(\delta_{d D}-\delta_{d M}\right)^{2}+\left(\delta_{p D}-\delta_{p M}\right)^{2}+\left(\delta_{h D}-\delta_{h M}\right)^{2}
$$

Una excesiva afinidad entre membrana y el compuesto que se desea que permee no es deseable ya que quedaría inmovilizado en la membrana, podría hincharla excesivamente o incluso disolverla.

La selección del material y el procedimiento de fabricación representan un compromiso. La ósmosis inversa, nanofiltración y ultrafiltración requieren polímeros semicristalinos, mientras que para microfiltración se suelen emplear polímeros altamente cristalinos con regiones semicristalinas o amorfas. Por debajo de la temperatura de transición vítrea un polímero presentará cierta cristalinidad (aunque ésta nunca será total), y por encima éste será amorfo (comportándose como un líquido viscoso de cadenas flexibles). Los polímeros cristalinos deberán optimizarse en su microestructura, existiendo un compromiso entre resistencia mecánica (aportada por la cristalinidad) y tamaño de los corredores entre las cadenas que proporcionen permeabilidad (zonas amorfas). La cristalinidad será controlable durante los tratamientos de evaporación y térmicos, en polímeros con temperatura de transición vítrea superior a la temperatura ambiente (como es el caso del acetato de celulosa).

En resumen, aunque muchos polímeros se prestan para la obtención de estructuras asimétricas, no todos son útiles para la obtención de membranas de ósmosis inversa y nanofiltración, ya que deben presentar propiedades físico-químicas adecuadas respecto del disolvente y solutos que se quieren separar. Así, para las operaciones de desalación son 
necesarios materiales con un adecuado balance hidrófilo - hidrófobo (con alto valor del parámetro $A$ del modelo de disolución - difusión) y con una baja permeabilidad hacia el soluto o solutos que se van a separar (valores de parámetro $B$ bajos).

El material estudiado en esta Tesis es el acetato de celulosa, el cual ha sido el material históricamente más utilizado en la fabricación de membranas y ha sido el más investigado en los últimos cuarenta años. Aunque presenta ciertas desventajas frente a otros materiales (véase Tabla 10) se ha elegido por las siguientes razones:

- Es material de referencia para muchos procesos.

- Presenta características óptimas para su utilización en ósmosis inversa, es hidrofílico, menos afín a las sales que al agua y semicristalino.

- Se dispone de gran cantidad de datos sobre él.

- Permite su utilización en el método de inversión de fase y el estudio de los diferentes parámetros de este proceso. Permite, asimismo, la obtención de todo tipo de estructuras densas, porosas y asimétricas.

- Es un polímero bastante barato, lo que lo hace adecuado para su utilización en grandes cantidades para la fabricación en máquina.

Todo ello lo hace adecuado para estudiar y contrastar los métodos de fabricación manual y en máquina de las membranas compuestas por el método de inversión de fase.

\section{Materiales celulósicos y características de las membranas basadas en ellos}

Una importante clase de materiales ya empleados desde los comienzos de la ósmosis inversa son los ésteres de celulosa, sobre todo los pertenecientes a la familia de los acetatos. Actualmente se usan comercialmente mezclas de diacetatos y triacetatos de celulosa para obtener un índice de acetilo óptimo para la aplicación deseada, estableciéndose un compromiso entre obtener mayor flux o mayor rechazo.

Las membranas basadas en el acetato pueden llegar a poseer buenas características para desalación debido a su alta permeabilidad hacia el agua acompañada de una baja solubilidad para la sal. Sin embargo, su resistencia química o frente a los microorganismos y su estabilidad frente a la temperatura no son buenas. En contrapartida se trata de 
polímeros bastante baratos. Estas características pueden observarse comparadas en la Tabla 10 con la de otra clase de materiales competidores de los acetatos de celulosa en aplicaciones de ósmosis inversa, las poliamidas aromáticas. Las poliamidas presentan alta selectividad hacia las sales con un flux menor que el acetato de celulosa, tienen sin embargo mayor resistencia química y bacteriana, salvo su gran sensibilidad hacia el cloro libre que degrada los grupos amida. Por otra parte, la selectividad de las membranas de acetato de celulosa hacia las moléculas orgánicas es bastante baja, salvo hacia algunos carbohidratos.

Tabla 10. Características de trabajo de las membranas de acetato de celulosa y de poliamida

\begin{tabular}{|c|c|c|c|}
\hline \multirow[t]{2}{*}{ Variable } & \multicolumn{2}{|c|}{ Rango de trabajo } & \multirow[t]{2}{*}{ Comentarios } \\
\hline & Ac. celulosa & Poliamida & \\
\hline$p H$ & $5-7$ & $5-10$ & $\begin{array}{l}\text { Los acetatos necesitan un rango óptimo } \\
\text { para evitar la hidrólisis del polímero } \\
\text { (mayor resistencia en triacetatos que en } \\
\text { diacetatos). }\end{array}$ \\
\hline Temperatura & $<40^{\circ} \mathrm{C}$ & $<60^{\circ} \mathrm{C}$ & \\
\hline $\begin{array}{l}\text { Resistencia } \\
\text { bacteriana }\end{array}$ & baja & alta & $\begin{array}{l}\text { Los acetatos presentan una degradación } \\
\text { biológica más alta que los triacetatos. }\end{array}$ \\
\hline $\begin{array}{l}\text { Resistencia al } \\
\text { cloro libre }\end{array}$ & alta & baja & $\begin{array}{l}\text { En las poliamidas se produce } \\
\text { degradación del grupo -NH-CO. }\end{array}$ \\
\hline
\end{tabular}

\section{Estructura del acetato de celulosa}

La celulosa es el material de partida para la fabricación del acetato de celulosa. La celulosa es un polisacárido compuesto por unidades monoméricas de glucosa (Dglucopiranosa - Ilustración 27) que forman cadenas largas y sin ramificaciones. Los enlaces entre las distintas unidades que componen la celulosa son glicosídicos en 
posición $\beta$ 1,4 (Ilustración 28). Ello hace que las cadenas tiendan a ser lineales, no mostrando tendencia a enrollarse tal y como sucede por ejemplo con el almidón y glucógeno con sustituciones $\alpha$ 1,4. La disposición lineal hace que los grupos hidroxilo de distintas cadenas se enfrenten y queden unidos por puentes de hidrógeno formando con ello un polímero rígido, fibroso e insoluble.

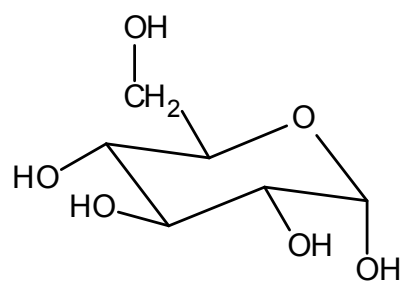

(axial)

$\alpha-D-(+)-g l u c o p i r a n o s a$

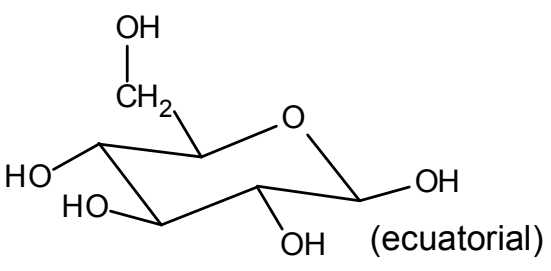

$\beta$-D-(+)-glucopiranosa

\section{Ilustración 27. Estructuras de la glucosa}

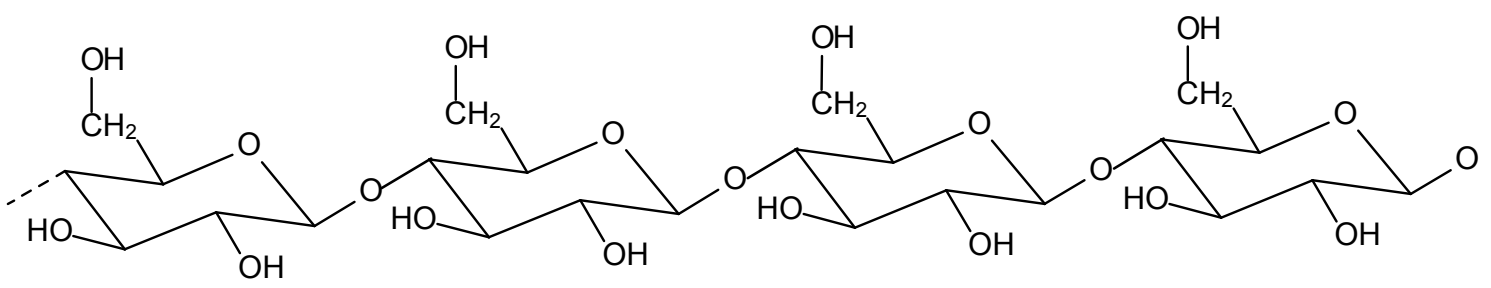

Ilustración 28. Estructura de una cadena de celulosa

La mayoría de los derivados comerciales de la celulosa son compuestos en los que los grupos hidroxilo libres son convertidos en ésteres o éteres. Cuando la celulosa es tratada con anhídrido acético se obtienen los acetatos de celulosa, normalmente diacetatos y triacetatos (véase Tabla 11). Las cadenas de acetatos ya no presentan una unión tan rígida entre sí por medio de puentes de hidrógeno. Ello hace que su solubilidad en compuestos orgánicos aumente substancialmente. 


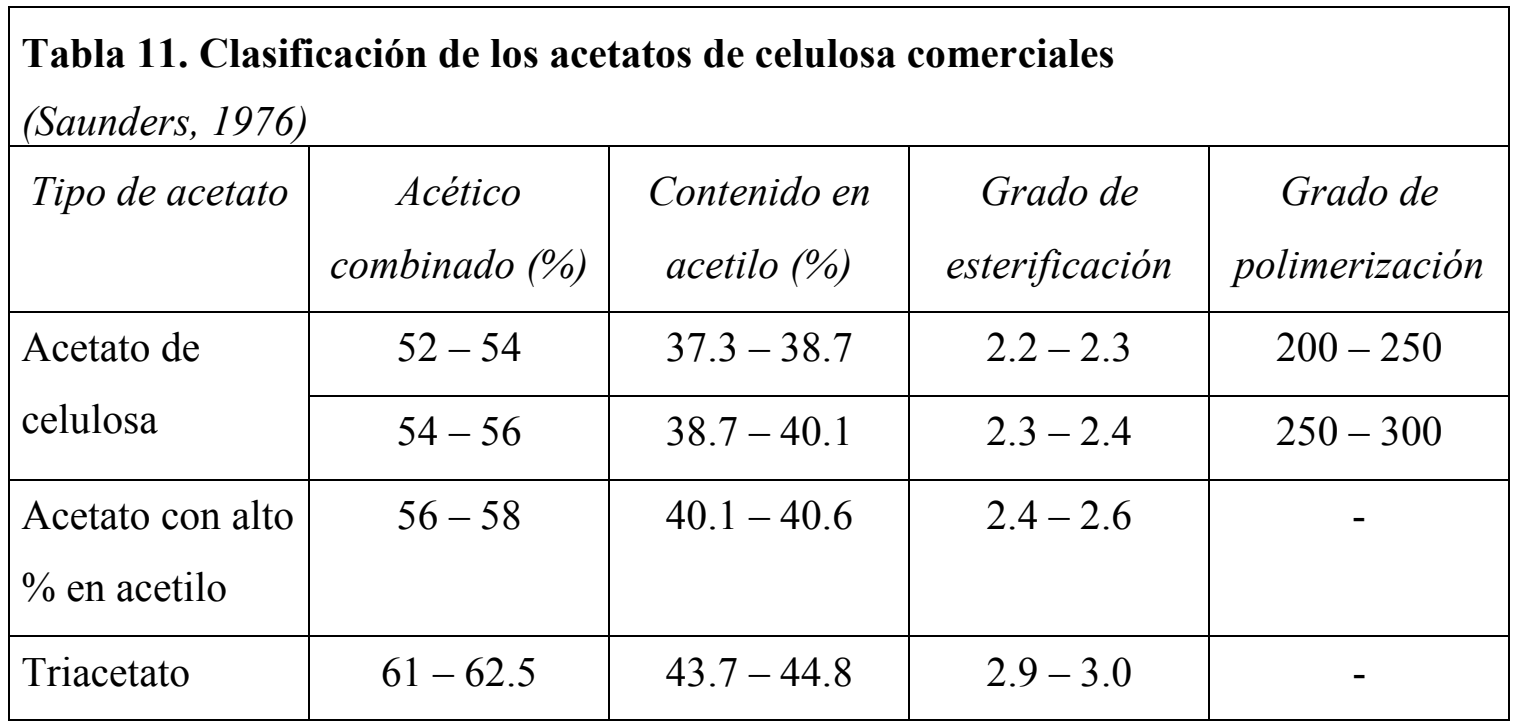

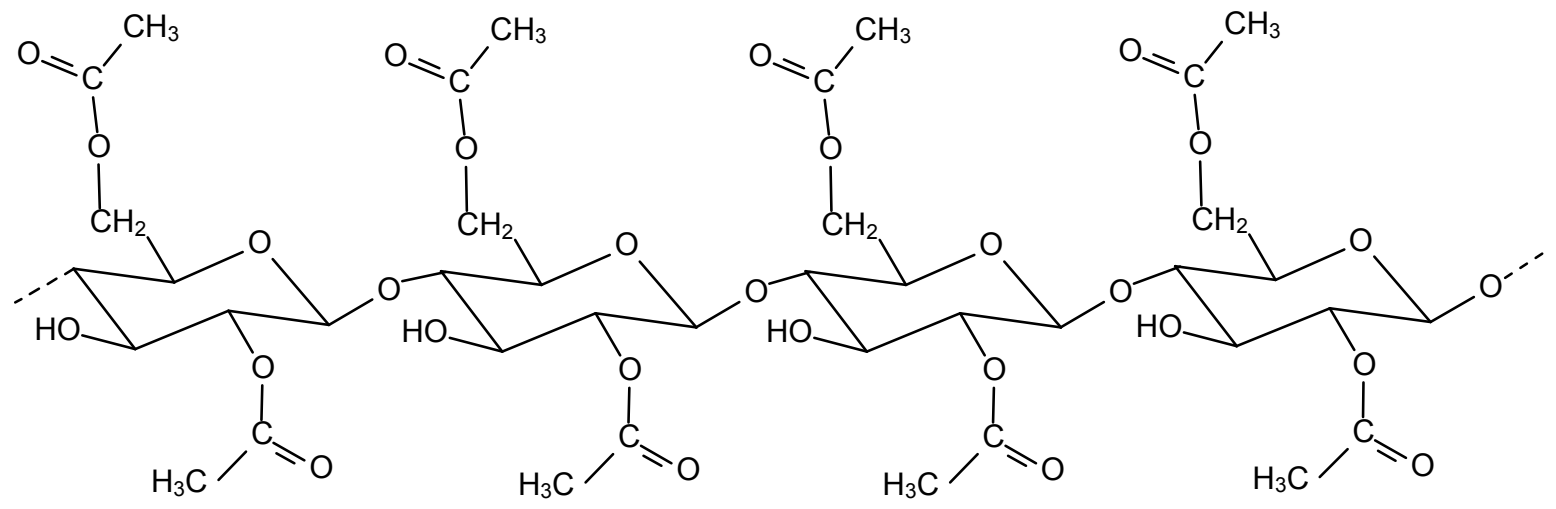

Ilustración 29. Estructura de un acetato de celulosa

Compuestos celulósicos utilizados en la fabricación de las membranas en el laboratorio. 
Los acetatos de celulosa fueron los compuestos principales seleccionados en la fabricación. Sus propiedades quedan reflejadas en la Tabla 12.

También se utilizaron en alguna ocasión ésteres mixtos de celulosa productos de reacción con los ácidos acético y propiónico o butírico (Tabla 13). Estos compuestos son materiales menos hidrofílicos, y por tanto de menor permeabilidad al agua, aunque con mayor solubilidad en disolventes por lo se consideró su mezcla con acetatos para obtener disoluciones concentradas.

\section{Tabla 12. Características de los acetatos de celulosa utilizados}

\begin{tabular}{lll}
\hline AC3 & Uso industrial, bajo daño a la salud \\
& Calidad: & Polvo \\
Presentación: & Kodak Eastman ${ }^{\circledR}$ CA 398-3. Ref. 4644 \\
Referencia: & $39.8 \pm 0.5 \%$ \\
Contenido en acetilo: & $3.5 \%$ \\
Conc. de hidroxilos: & $1.31 \mathrm{~g} / \mathrm{cm}^{3}$ \\
Densidad: & $3 \pm 1$ seg. $(11.4$ P) \\
Viscosidad ASTM-D: & $230-250{ }^{\circ} \mathrm{C}$ \\
Temperatura de fusión: & $180{ }^{\circ} \mathrm{C}$ \\
Tra. de transición vitrea: & Uso industrial, bajo daño a la salud \\
Calidad: & Polvo \\
Presentación: & Kodak Eastman ${ }^{\circledR}$ CA398-6. Ref. 60311 \\
Referencia: & $39.8 \pm 0.5 \%$ \\
Contenido en acetilo: & $6 \pm 1$ seg. \\
Viscosidad ASTM-D: & Uso industrial, bajo daño a la salud \\
Calidad: & Escamas \\
Presentación: & INACSA S.A. \\
Referencia: & $39.8 \pm 0.5 \%$ \\
Contenido en acetilo: & $0.009 \%$ \\
Acidez libre: & 10 seg. aprox. \\
Viscosidad ASTM-D: &
\end{tabular}




\section{Tabla 13. Características de los otros compuestos celulósicos utilizados}

\begin{tabular}{|lll|}
\hline PAC & Tipo de compuesto: & Propionato Acetato de celulosa \\
& Calidad: & Uso industrial \\
& Presentación: & Polvo \\
& Referencia: & Kodak Cellulose Acetate Propionate. Ref. 57992 \\
\hline BAC & Tipo de compuesto: & Butirato Acetato de celulosa \\
& Calidad: & Uso industrial \\
& Presentación: & Polvo \\
& Referencia: & Kodak Cellulose Acetate Propionate. Ref. 57991 \\
\hline
\end{tabular}

\section{Precauciones en el uso y almacenamiento de los polímeros:}

Para la manipulación y almacenamiento de estos productos se han tenido en cuenta las situaciones de peligro indicadas por el SEPS (Standard on Explosion Prevention Systems) y las correspondientes reglas de seguridad:

1) Peligro: Mezclar ésteres de celulosa en un hidrocarburo no polar, como tolueno o xileno, puede producir deflagración o explosión originadas por la electricidad estática.

Precaución: Cuando se añadan ésteres de celulosa a cualquier líquido inflamable se debería emplear una atmósfera de gas inerte en la vasija. (Referencia NFPA 69. SEPS).

2) Peligro: Los acetatos en polvo, como muchos otros materiales inorgánicos son capaces de producir una explosión seca.

Precaución: Minimizar en lo posible generación de polvo o acumulación. (Referencia NFPA folleto $\mathrm{n}^{\mathrm{o}} 654$ sobre prevención de fuegos y explosiones en las industrias químicas, del tintado, farmacéuticas y de plásticos) 
3) Peligro: Aún no siendo productos muy tóxicos en algún caso pueden originar problemas sobre la salud. Los productos más peligrosos son los que se presentan en forma de polvo muy fino que puede llegar hasta los pulmones. Los butiratos y propionatos son los más perjudiciales.

Precaución: Manipular con ventilación adecuada preferiblemente bajo campana de gases. Buscar auxilio médico si se presentan síntomas respiratorios.

En lugar de la regla de precaución indicada en el apartado 1 se tomaron otras equivalentes. La utilización de un gas inerte durante el proceso de mezcla no se llevó a cabo por la complejidad adicional que suponía al proceso de elaboración y por considerarse no necesaria al ser las cantidades manipuladas pequeñas. En su lugar se establecieron una serie de precauciones indicadas más adelante en el apartado 3.2.1. Sin embargo, para la mezcla de colodiones en cantidades industriales se debería emplear estrictamente la regla de seguridad indicada.

\subsubsection{Soportes no-tejidos}

En las membranas "integrales" constituidas por un único material, éste debe cumplir las funciones permeoselectivas, así como de resistencia estructural frente a los esfuerzos a los que pudiera ser sometida la membrana. En algunos procesos la resistencia mecánica de la membrana no necesita ser elevada, pero en otros sí lo es, tal es el caso de la ultrafiltración, nanofiltración y ósmosis inversa en los que la membrana debe soportar grandes presiones y en consecuencia grandes tensiones. En estos procesos, el soporte sobre el cual apoya la membrana puede ser un material perforado o acanalado. Aunque la distancia entre agujeros y canales es relativamente grande para poder soportar las altas presiones, las membranas se ven obligadas a soportar grandes esfuerzos. Por otra parte los materiales semipermeables de la membrana no poseen mucha resistencia mecánica. Ello hace necesario un soporte poroso con gran resistencia al esfuerzo tensil. 
La utilización de membranas "compuestas", que utilicen capas de materiales diferentes, busca optimizar por separado cada una de las capas. Así, la capa superior se optimizará para ejercer las funciones permeoselectivas, mientras que la inferior deberá ser capaz de servir de soporte a la superior y de hacer frente a los esfuerzos axiales que se generan durante la aplicación del proceso. Ambas capas deberán presentar una resistencia química adecuada para que los fluidos de trabajo o las disoluciones de limpieza no les afecten en las funciones que deben cumplir.

La primera decisión que se debe realizar en cuanto al soporte es el tipo de estructura que va a tener. En general, podemos clasificarla en los siguientes tipos:

- porosa no basada en fibras

- fibra tejida

- $\quad$ fibra no tejida (no-tejido)

Bajo la primera denominación quedarían englobadas las membranas mismas cuando son utilizadas como base para otra capa más densa de otro material, así como otros tipos de materiales no basados en fibras. Los soportes basados en fibras quedarían divididos en dos clases: "Soportes de fibra tejida o telas" constituidos por fibras poliméricas entralazadas ordenadamente, los cuales a su vez pueden ser monofilamento o multifilamento y "soportes de fibra no tejida (no-tejido)" constituidos por fibras poliméricas más finas y con una estructura similar a la del papel, produciéndose normalmente la conformación del material por medios térmicos.

La elección entre un tipo de soporte u otro vendrá condicionada por la técnica de fabricación de la membrana. Por ejemplo, la policondensación interfacial requerirá una capa microporosa (generalmente de polisulfona) para lograr una capa activa uniforme, mientras que para las membranas obtenidas por inversión de fase basta un soporte de mayor porosidad, con menor resistencia al flux. Para membranas de inversión de fase resultan pues aptos los soportes basados en fibras poliméricas, los cuales son deseables por presentar propiedades mecánicas superiores a los demás. Los soportes basados en fibras han sido estudiados en diversas Tesis del Departamento de Ingeniería Química (Soriano, 1983; Lora, 1987 Iborra, 1993) como medios para el estudio de las propiedades de las membranas. También han sido estudiados soportes porosos (Alcaina, 1991). Sin embargo, en esta Tesis se estudiarán, incluso a escala de laboratorio, únicamente soportes no-tejidos siguiendo las tendencias actuales de la fabricación industrial. 
Las principales ventajas de los soportes no-tejidos frente a los tejidos son:

- Van a permitir una deposición de menor espesor y más uniforme.

- Presentarán menor percolación de colodión

- Presentarán isotropía frente a los esfuerzos mecánicos de tensión

Como contrapartida los soportes no-tejidos presentan la desventaja de poseer una resistencia a la tracción y al desgarramiento inferior a la de los soportes tejidos.

\section{Vertido correcto (sin apoyar)}
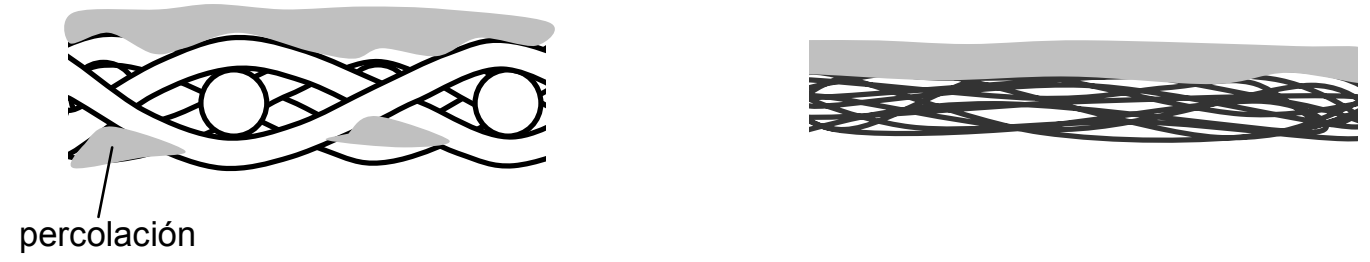

Vertido incorrecto (apoyando)

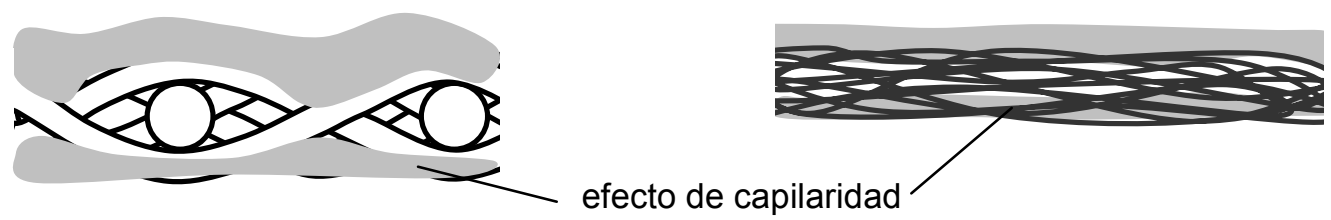

\section{Ilustración 30. Comparación en cuanto a la deposición de los tipos de soporte tejido y no-tejido}

Una vez elegido el tipo de soporte la elección recae en el tipo de material que lo constituye. El material deberá satisfacer los requerimientos de resistencia mecánica en funcionamiento, debiendo además presentar una resistencia química adecuada (véase Tabla 14). Las propiedades de resistencia física y química de los soportes son en la mayoría de los casos muy superiores a las del polímero activo que soportan. En concreto, los soportes basados en poliéster presentan unas propiedades adecuadas para el uso como soportes de membrana en procesos que no requieran condiciones especialmente agresivas, como ácidos o álcalis en caliente. 


\begin{tabular}{|c|c|c|c|c|c|}
\hline \multicolumn{2}{|l|}{ Agente } & Polietileno & Poliamida & Polipropileno & Poliéster \\
\hline \multicolumn{2}{|l|}{ Abrasión } & Regular & Muy buena & $\begin{array}{l}\text { Buena a muy } \\
\text { buena }\end{array}$ & $\begin{array}{l}\text { Buena a muy } \\
\text { buena }\end{array}$ \\
\hline \multicolumn{2}{|l|}{ Temperatura } & $-100^{\circ} \mathrm{C}$ & $-40^{\circ} \mathrm{C}-115^{\circ} \mathrm{C}$ & $-120^{\circ} \mathrm{C}$ & $-75^{\circ} \mathrm{C}-150^{\circ} \mathrm{C}$ \\
\hline \multirow[t]{2}{*}{$\begin{array}{l}\text { Ácidos muy } \\
\text { fuertes }\end{array}$} & Frío & Regular & $\begin{array}{l}\text { Regular o Mala } \\
(\mathrm{HCl})\end{array}$ & Regular & Buena \\
\hline & Caliente & Mala & Mala & Mala & Mala \\
\hline \multirow{2}{*}{$\begin{array}{l}\text { Ácidos } \\
\text { orgánicos } \\
\text { fuertes }\end{array}$} & Frío & Regular & Regular & Regular & Buena \\
\hline & Caliente & $\begin{array}{l}\text { Mala, depende } \\
\text { de la } \\
\text { concentración }\end{array}$ & $\begin{array}{l}\text { Mala, depende } \\
\text { de la } \\
\text { concentración }\end{array}$ & $\begin{array}{l}\text { Mala, depende } \\
\text { de la } \\
\text { concentración }\end{array}$ & $\begin{array}{l}\text { Buena, depende } \\
\text { de la } \\
\text { concentración }\end{array}$ \\
\hline \multirow[t]{2}{*}{ Álcalis } & Frío & Buena & Buena & Buena & Regular \\
\hline & Caliente & Regular & Mala & Regular & Mala \\
\hline \multicolumn{2}{|l|}{$\begin{array}{l}\text { Resistencia a } \\
\text { disolventes }\end{array}$} & $\begin{array}{l}\text { Buena, Regular } \\
\text { (acetona, } \mathrm{CCl}_{4} \text { ) }\end{array}$ & Buena & $\begin{array}{l}\text { Buena, incluso } \\
\text { a alta } \\
\text { temperatura }\end{array}$ & Buena \\
\hline
\end{tabular}

Interesa a efectos del procesado que el material sea hidrófobo ya que un soporte excesivamente hidrófilo absorbería agua inmediatamente al ser sumergido originando con ello un nuevo frente de coagulación indeseado en la zona del colodión en contacto con el soporte.

Otras características deseadas para el soporte van a depender tanto de la estructura y composición química de éste, así como de la forma en que ha sido fabricado. Estas características se encuentran detalladas en la Tabla 15. Teniendo en cuenta estas características (excepto las referidas a la capa activa) junto con los requerimientos de resistencia física y química del material se seleccionaron como soportes comerciales a estudiar los presentados en la Tabla 16, los cuales poseen características mecánicas adecuadas para ósmosis inversa y nanofiltración.

Posteriormente, en el transcurso del trabajo experimental estos soportes se analizaron desde el punto de vista de su interacción con la capa polimérica de acetato de celulosa que deben soportar. Los mejores resultados se obtuvieron para el soporte FO- 
2402, con el cual existía mejor adherencia, uniformidad de capa y menor resistencia al flux. Sin embargo, los resultados no deben generalizarse a otros tipos de polímero o de membrana, por ejemplo, el soporte FO-2431 resultó con mejores propiedades para la fabricación de membranas de ultrafiltración de polisulfona. Muy importante es además el hecho de que estos soportes son capaces de resistir sin pérdida importante de propiedades mecánicas los disolventes empleados en los colodiones (dimetilacetamida y acetona).

\section{Tabla 15. Características deseables en los soportes}

A) En relación con la capa activa que deben mantener:

- Buena adherencia al polímero orgánico

- No presencia de fibras sobresalientes o de partículas

- Superficies lisas sin apelmazamientos

- Porosidad uniforme

B) Para el procesado:

- Elevada resistencia mecánica longitudinal y transversal

- Resistencia sin pérdida de propiedades mecánicas a los disolventes empleados en el colodión

- Alta homogeneidad

- Flexibilidad, poca tendencia a formar arrugas y deformaciones

- Resistencia al tratamiento térmico

- Hidrófobo

C) En funcionamiento:

- Resistencia química a las disoluciones a tratar y a las de lavado

- Gran resistencia al esfuerzo tensil

- No se debe comprimir apenas bajo la presión

- Buena permeabilidad

- Distribución uniforme del permeado

- Mínima deformación

D) Económicas:

- Precio asequible

- Disponibilidad 


\section{Tabla 16. Datos técnicos de los soportes no-tejidos utilizados}

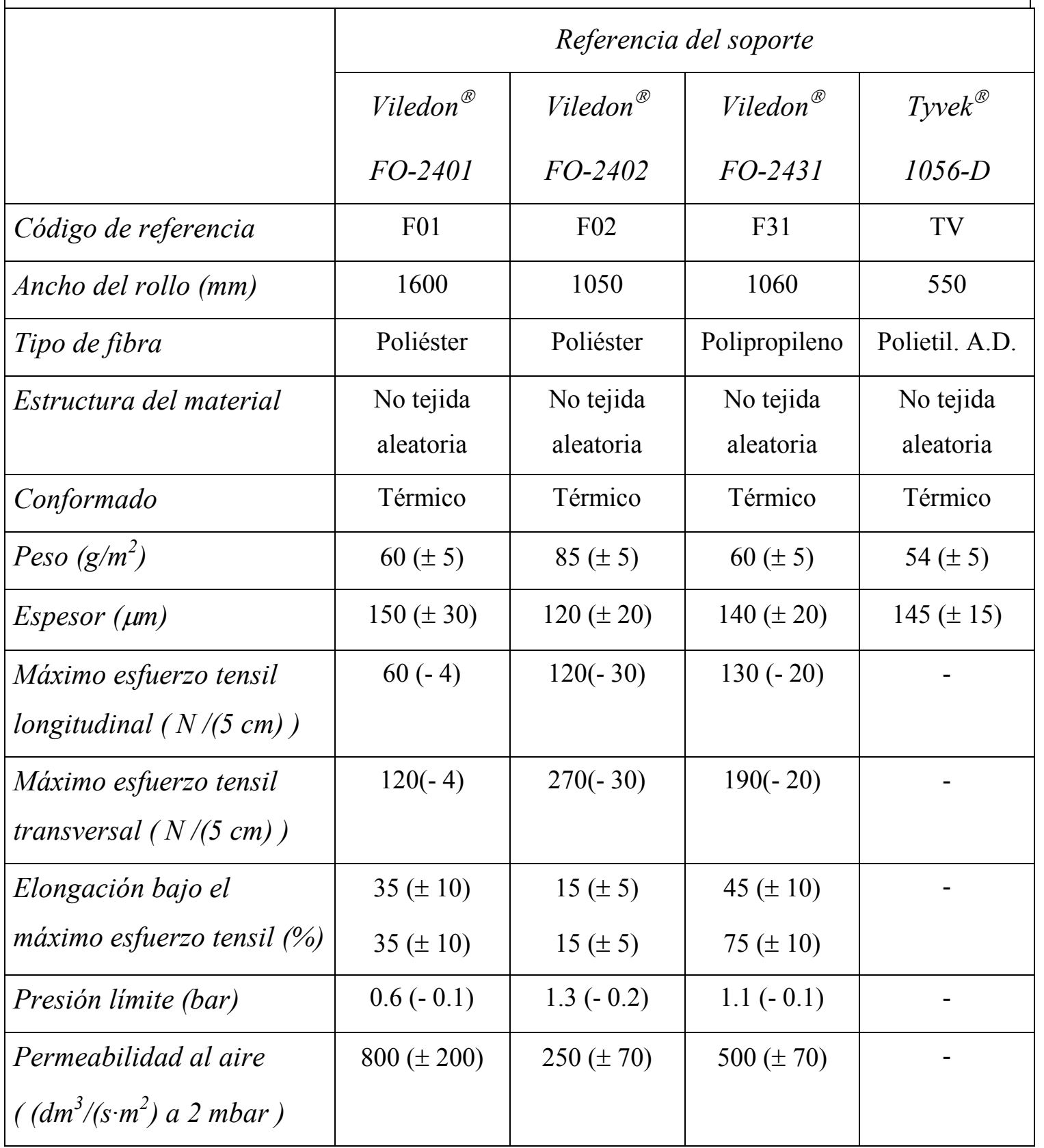




\subsubsection{Disolventes utilizados}

Una vez fijado el polímero debe elegirse una pareja disolvente - no-disolvente adecuada. El medio no-disolvente que se utilizó contenía siempre agua como componente principal y en la mayoría de los casos como componente único, lo cual se justificará en el siguiente apartado. Por tanto, la elección del disolvente vendrá determinada por las dos condiciones siguientes:

1) Deberá ser un disolvente orgánico que presente fuerte afinidad por el polímero, formando disoluciones homogéneas con él y de una viscosidad adecuada.

2) Deberá presentar una cierta polaridad para ser soluble en el agente coagulante empleado (agua en este caso)

En la mayoría de los casos se utilizará un único disolvente, sin embargo es posible utilizar dos o más disolventes con vistas a lograr un efecto de cosolvencia en el que la mezcla de ambos disolventes pudiera ser más afectiva que los disolventes por separado.

Desde un punto de vista teórico la afinidad entre disolvente y polímero, es decir la solubilidad de un polímero en un disolvente puede estudiarse mediante el incremento de energía libre de mezcla.

Ec. 75:

$$
\Delta G_{m}=\Delta H_{m}-T \cdot \Delta S_{m}
$$

Para que la mezcla sea posible la energía libre de mezcla debe ser negativa. Como para cualquier sistema aislado se cumple que el incremento de entropía en la mezcla es mayor que cero, la entalpía de mezcla deberá ser lo más pequeña posible para ser menor que la contribución del término entrópico. La entalpía libre de mezcla a su vez es proporcional en muchos sistemas poliméricos a la diferencia de parámetros de solubilidad entre polímero y disolvente.

Ec. 79

$$
\Delta H_{m} \propto\left(\delta_{\text {polimero }}-\delta_{\text {disolvente }}\right)^{2}
$$


La obtención de estos parámetros en la bibliografía sobre polímeros nos va a permitir efectuar una primera selección de disolventes adecuados. Cuando la diferencia entre los dos parámetros de solubilidad es pequeña (gran afinidad entre polímero y disolvente) se tiene $\Delta H_{m} \approx 0$ e $\Delta G_{m}<0$ con lo que el polímero y el disolvente son miscibles con bastante probabilidad. En la Tabla 17 se tienen datos de parámetros de solubilidad para el acetato de celulosa y varios disolventes observándose como disolventes con parámetros de solubilidad muy diferentes de los del acetato de celulosa no son disolventes de éste. Debe tenerse en cuenta, sin embargo, que el criterio expuesto puede no ser aproximado en el caso de disolventes polares.

Tabla 17. Solubilidad de los acetatos de celulosa en disolventes ordenados según el parámetro de solubilidad.

[Champetier y George; (1973); Saunders (1976) y experimental(*)]

\begin{tabular}{|lc|c|c|c|}
\hline \multicolumn{1}{|c|}{ Disolvente } & $\delta_{\text {disolvente }}$ & $\begin{array}{c}\text { Acetato de } \\
\text { celulosa } \\
(\delta=10.7)\end{array}$ & $\begin{array}{c}\text { Acetato de } \\
\text { celulosa de alto } \\
\% \text { de acetilo }\end{array}$ & Triacetato \\
\hline Benceno & 9.1 & Insoluble & Insoluble & Insoluble \\
\hline Cloroformo & 9.3 & Hincha $\left(^{*}\right)$ & Poco Soluble & Soluble \\
\hline Acetato de etilo & 9.3 & Hincha $\left(^{*}\right)$ & Hincha & Insoluble \\
\hline Ác. Acético & 9.8 & Soluble & Soluble & Hincha \\
\hline Acetona & 10.0 & Soluble & Hincha & Insoluble \\
\hline Dioxano & 12.6 & Insoluble & Insoluble & Insoluble \\
\hline Nitrometano & & & Poco Soluble & Insoluble \\
\hline
\end{tabular}

Los disolventes capaces de disolver un polímero dado pueden ser varios. Yanagishita et al. (1994) proponen un método para seleccionar los más adecuados entre ellos. Establecen que durante el proceso de disolución, el tiempo necesario para alcanzar un nivel estable de viscosidad del colodión es dependiente de la velocidad de disolución. 
Aquellos que, para una misma concentración volumétrica de polímero, antes alcancen en un sistema agitado una viscosidad estable serán los mejores disolventes.

La segunda condición referente a la solubilidad en el no-disolvente limita aún más el espectro de disolventes adecuados. En la Tabla 18 se encuentran disolventes de los polímeros acetato de celulosa y polisulfona que permiten la utilización del agua como medio no-disolvente. En particular los disolventes dimetilacetamida y dimetilformamida son disolventes completamente miscibles con el agua con gran capacidad de disolución para muchos polímeros, además de los dos considerados.

\begin{tabular}{|c|c|c|c|c|}
\hline \multirow[t]{2}{*}{ Disolvente } & \multicolumn{2}{|c|}{ Disolvente de } & \multicolumn{2}{|c|}{$\begin{array}{c}\text { Solubilidad en } \\
(\text { s. }=\text { soluble } ; \infty=\text { inf. sol. })\end{array}$} \\
\hline & A. Celulosa & Polisulfona & Agua & Etanol \\
\hline Acetona $(\mathrm{ACN})$ & $\mathrm{x}$ & & $\infty$ & $\infty$ \\
\hline Dioxano & $\mathrm{x}$ & & $\infty$ & s. \\
\hline Tetrahidrofurano (THF) & $\mathrm{x}$ & & s. & s. \\
\hline Acido acético $(\mathrm{AcH})$ & $\mathrm{x}$ & & $\infty$ & $\infty$ \\
\hline Dimetilformamida (DMF) & $\mathrm{x}$ & $\mathrm{x}$ & $\infty$ & $\infty$ \\
\hline Dimetilacetamida (DMA) & $\mathrm{x}$ & $\mathrm{x}$ & $\infty$ & $\infty$ \\
\hline Dimetilsulfoxida (DMSO) & $\mathrm{x}$ & $\mathrm{x}$ & s. & \\
\hline Formilpiperidina (FP) & & $\mathrm{x}$ & $\infty$ & $\infty$ \\
\hline Morfolina (MP) & & $\mathrm{x}$ & s. & \\
\hline N- metilpirrolidona (NMP) & & $\mathrm{x}$ & $\infty$ & $\infty$ \\
\hline
\end{tabular}

Para seleccionar entre los disolventes presentados en la Tabla 18 debe tenerse en cuenta ahora el tipo de membrana que se quiere obtener. Conviene, entonces, la realización de estudios de diagrama de fases como el mostrado en el anexo de esta Tesis. Esta información debe combinarse con el conocimiento aproximado de la relación de 
intercambio disolvente/no-disolvente que se va a establecer. Radovanovic et al. (1992) indican que para una terna polímero/disolvente/no-disolvente dada existirán dos regiones determinadas por la concentración de los colodiones de partida. Por encima de una determinada concentración, la relación de intercambio disolvente/no-disolvente será tal que las membranas obtenidas serán de tipo 1 (separación líquido-líquido retrasada) y por debajo serán de tipo 2 (separación líquido-líquido instantánea y asimétricas). Ya se comentó que ambos mecanismos de separación conducían a estructuras de membrana diferentes (tipo 1: pervaporación, intercambio de gases; tipo 2: ósmosis inversa y ultrafiltración).

El estudio de las posibilidades de formación de un tipo de membrana dado por un disolvente puede realizarse mediante el método de Frommer (1972).

El método utiliza un microscopio óptico para estudiar de forma visual y de manera dinámica el proceso de precipitación. Para ello una pequeña gota de colodión y otra de medio coagulante son colocadas a una distancia de menos de $1 \mathrm{~cm}$ sobre un cristal portaobjetos. Sobre ellas se coloca un cubreobjetos y se presiona hasta que las dos fases entran en contacto. A partir de la interfase se empieza a generar una estructura y teniendo en cuenta el campo óptico aplicado se puede estudiar la velocidad de precipitación.

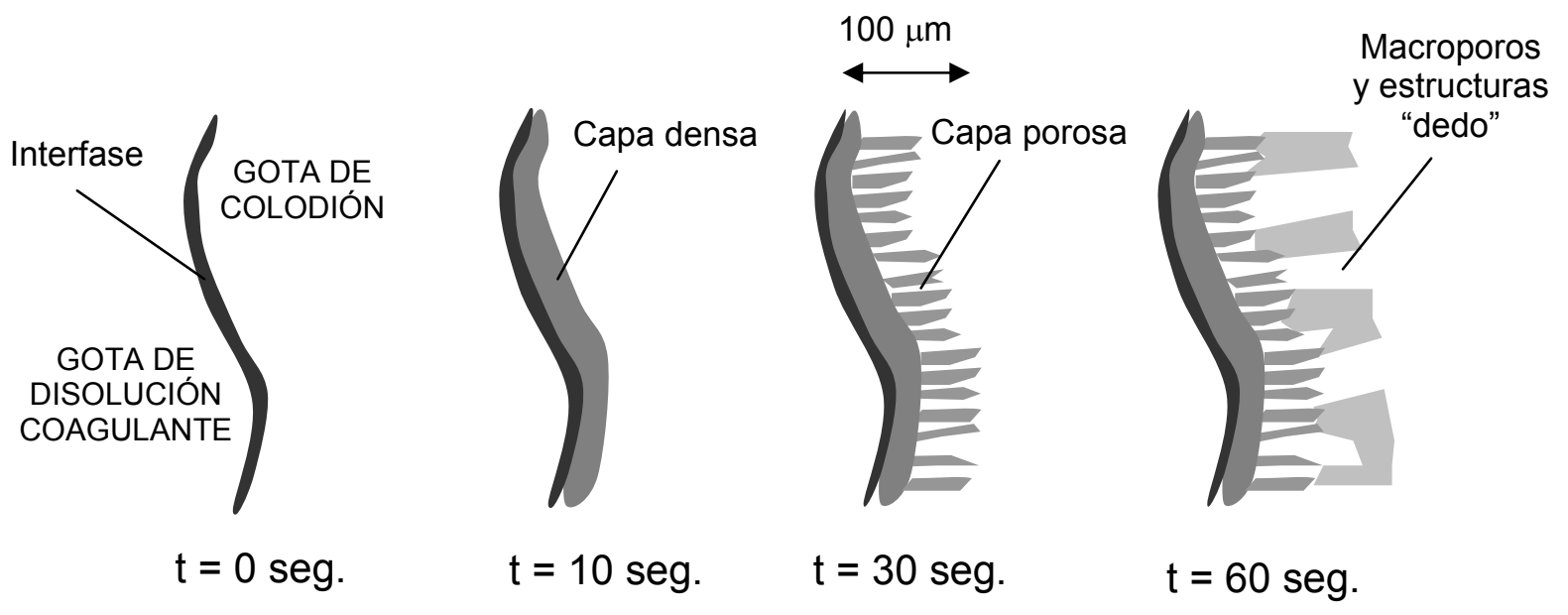

\section{Ilustración 31. Estructuras de precipitación visualizadas en microscopio óptico siguiendo el método de Frommer (Colodión: AC(20\%)/DMA, precipitante: Agua)}

Mediante el método de Frommer se estudiaron colodiones de acetona y dimetilacetamida observándose que estos eran capaces de producir capas densas 
adecuadas para las membranas de ósmosis inversa y nanofiltración cuando las concentraciones de polímero eran superiores al $19 \%$.

Otros factores relacionados con la seguridad y la producción en máquina también ayudaron a decidir el disolvente más adecuado.

El tetrahidrofurano no resulta conveniente en la mezcla con polímeros por su tendencia a formar peróxidos explosivos y el dioxano es agente cancerígeno, lo que los descartó al no existir los medios de seguridad adecuados para su manejo, además proporcionan capas activas excesivamente densas.

Los sistemas DMF/Agua/Acetato de celulosa y DMSO/Agua/Acetato de celulosa proporcionan membranas de ultrafiltración (Mulder, 1992) por lo que se descartaron.

Finalmente, teniendo en cuenta las consideraciones anteriores, las necesidades para la fabricación en máquina de forma económica y segura se escogió la dimetilacetamida como disolvente principal a estudiar y la acetona como disolvente secundario. A continuación se indican de manera comparada las propiedades de la dimetilacetamida y la acetona interesantes desde el punto de vista de la fabricación:

Propiedades de la dimetilacetamida en cuanto a fabricación:

- Tiene una toxicidad menor (excepto la acetona y el ácido acético).

- Los colodiones pueden depositarse a temperatura ambiente.

- Posibilidad de suministro en grandes cantidades a bajo precio.

- Permite la obtención de membranas con una fase de evaporación corta.

- Está reflejado en la bibliografía como un disolvente adecuado para la formación de membranas de ósmosis inversa y ultrafiltración.

- Se constata experimentalmente que no se produce una coagulación con la humedad ambiental.

- La viscosidad de las disoluciones puede resultar algo alta para la fabricación en máquina por lo que se hace necesario incluir aditivos en la composición del colodión. 
Propiedades respecto de la fabricación de la acetona:

- Proporciona membranas con una capa activa excesivamente densa para su uso en ósmosis inversa.

- Es el disolvente menos tóxico de todos.

- Los colodiones son de baja viscosidad a temperatura ambiente, sin embargo la deposición se debe realizar en algunos casos a baja temperatura lo que puede aumentar bastante la viscosidad.

- Es un disolvente muy barato.

- El bajo punto de inflamación lo hace peligroso en la producción en máquina.

- En la fase de deposición se presentan graves problemas al coagular los colodiones en presencia de humedad ambiente.

- Algunos aditivos requeridos por los colodiones, como el perclorato magnésico, resultan peligrosos.

\section{N,N'-dimetilacetamida (DMA)}

Estructura química y propiedades:

Las amidas son compuestos acílicos que resultan de la sustitución del grupo hidroxilo del ácido carboxílico por un átomo de nitrógeno unido a hidrógenos o a grupos alquílicos, indicándose en la nomenclatura las sustituciones realizadas en el nitrógeno mediante $\mathrm{N}$ - o bien $\mathrm{N}, \mathrm{N}$ - cuando la sustitución es doble.

Cuando el átomo de nitrógeno está enlazado con hidrógenos, éstos son capaces de formar puentes de hidrógeno con el oxígeno del grupo acílico restante. En consecuencia los compuestos presentan puntos de fusión y de ebullición muy elevados.

En el caso de la N,N'-dimetilacetamida los dos hidrógenos han sido sustituidos por grupos metilo, por lo que no puede formar enlaces de hidrógeno fuertes. Ello confiere un punto de ebullición y fusión bajos a este compuesto y características de buen disolvente orgánico (Solomons, 1988). 
<smiles>CNC(C)=O</smiles>

Acetamida o etanamida

P.F.: $82^{\circ} \mathrm{C}$, P.E.: $221^{\circ} \mathrm{C}$<smiles>CC(=O)N(C)C</smiles>

N,N' - Dimetilacetamida

P.F.: $-20^{\circ} \mathrm{C}$ P.E.: $165^{\circ} \mathrm{C}$

Ilustración 32. Estructura de dos acetamidas

\section{Tabla 19. Propiedades de la N,N'-dimetilacetamida}

\begin{tabular}{|ll|l|}
\hline Peso molecular: & $87.12 \mathrm{~g} / \mathrm{mol}$ & Conc. de saturación: $12 \mathrm{~g} / \mathrm{m}^{3}$ \\
\hline Densidad a $20^{\circ}:$ & $0.940-0.942 \mathrm{~g} / \mathrm{cm}^{3}$ & Límite de explosión: $2-11.5 \%$ en vol. \\
\hline Punto de fusión: $\quad-20^{\circ} \mathrm{C}$ & Temp. de ignición: $\quad 490^{\circ} \mathrm{C}$ \\
\hline Punto de ebullición: $\quad 165^{\circ} \mathrm{C}$ & Miscible sin limitación con el agua \\
\hline P. de vapor a $20^{\circ} \mathrm{C}: \quad 3 \mathrm{hPa}$ & Higroscópica \\
\hline
\end{tabular}

Utilización:

Para el manejo de la N-N'-dimetilacetamida se tuvieron en cuenta las propiedades de la Tabla 19 y las indicaciones de la Tabla 20. Además se exigía las siguientes prestaciones a la dimetilacetamida comercial para su utilización como producto en la fabricación de membranas:

- Pureza superior al 99\%

- Contenido en agua inferior al $0.3 \%$

Se utilizó dimetilacetamida suministrada por ERTISA S.A. y también por MERCK cumpliéndose en ambos casos las especificaciones de pureza. 


\section{Tabla 20. Cuestiones de seguridad y almacenamiento relativas a la N-N'- dimetilacetamida}

\section{Riesgos:}

R 20/21: Nocivo por inhalación y en contacto con la piel.

R 36: Irrita los ojos

Reglas de seguridad:

S 26: En caso de contacto con los ojos lávense inmediata y abundantemente con agua y acúdase a un médico.

S 28.1: En caso de contacto con la piel, lávese inmediata y abundantemente con agua.

S 36: Usar indumentaria protectora adecuada

\section{Eliminación:}

Por incineración

Almacenamiento:

Como líquido combustible

\section{Acetona (ACN)}

La acetona es un compuesto carboxílico con capacidad de formar puentes de hidrógeno con el agua, por lo que es completamente miscible con ella. Además es capaz de disolver diversas sustancias orgánicas.

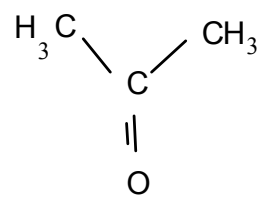

Acetona

Ilustración 33. Estructura de la acetona 


\section{Tabla 21. Propiedades de la acetona}

\begin{tabular}{|ll|l|}
\hline Peso molecular: & $58.08 \mathrm{~g} / \mathrm{mol}$ & Conc. de saturación: $533 \mathrm{~g} / \mathrm{m}^{3}$ \\
\hline Densidad a $20^{\circ}:$ & $0.789-0.791 \mathrm{~g} / \mathrm{cm}^{3}$ & Limite de explosión: $2.2-12.8 \%$ en vol. \\
\hline Punto de fusión: $\quad-95^{\circ} \mathrm{C}$ & Temp. de ignición: $\quad 540^{\circ} \mathrm{C}$ \\
\hline Punto de ebullición: $\quad 56^{\circ} \mathrm{C}$ & Viscosidad a $25^{\circ} \mathrm{C}: \quad 0.31 \mathrm{mPa} \cdot \mathrm{s}$ \\
\hline Punto inflamación: $\quad-20^{\circ} \mathrm{C}$ & Miscible sin limitación con el agua \\
\hline P. de vapor a $20^{\circ} \mathrm{C}:$ & $233 \mathrm{hPa}$ & \\
\hline
\end{tabular}

\section{Utilización:}

Para el manejo de la acetona se tuvieron en cuenta las propiedades de la Tabla 21 y las indicaciones de la Tabla 22. Además se exigía las siguientes prestaciones a la dimetilacetamida comercial para su utilización como producto en la fabricación de membranas:

- $\quad$ Pureza superior al 99\%

- Contenido en agua inferior al $0.3 \%$

Se utilizó acetona suministrada por MERCK que cumplía las especificaciones de pureza.

\section{Tabla 22. Cuestiones de seguridad y almacenamiento relativas a la acetona}

Riesgos:

R 11 Fácilmente inflamable

Reglas de seguridad:

S 9: Mantener el recipiente en lugar bien ventilado

S16: Conservar alejado de toda llama o fuente de chispas

S 23.2: No respirar los vapores

S33: Evítese la acumulación de cargas electrostáticas

\section{Eliminación:}

Evacuación por las cañerías con gran cantidad de agua

Almacenamiento:

Como líquido combustible 


\subsubsection{Componentes del baño de coagulación}

En el anterior apartado ya se comentó que el disolvente y el medio no-disolvente debían seleccionarse conjuntamente para una polímero dado. En nuestro caso se seleccionó el agua como componente principal o exclusivo, que es el medio coagulante por excelencia por su bajo coste y sus marcadas características de no-disolvente de los polímeros, ampliamente utilizado en la fabricación de membranas. Ello viene también condicionado porque el estudio está destinado a la fabricación en máquina y en ésta se necesita disponer de grandes cantidades de medio coagulante.

Sin embargo, aún manteniendo el agua como componente principal del baño de coagulación se consideró la posibilidad de adicionar aditivos a éste.

Yanagishita et al. (1994) indican que el mejor medio de coagulación es aquel que presenta calores de mezcla menores en el punto de coagulación. Los calores de mezcla bajos se relacionan con velocidades de coagulación lentas lo que trae consigo la formación de estructuras esponjosas en el substrato de la capa activa. Estas estructuras proporcionan membranas con mejores características que las estructuras en forma de "dedos" con presencia de macroporos. Esto indica que para disminuir el calor de mezcla se puede actuar sobre la composición del colodión o sobre la del baño de coagulación. También un descenso de la temperatura producirá una disminución de la velocidad de coagulación.

Una posibilidad de actuar sobre la estructura de la membrana es pues añadir disolvente al baño de coagulación. Diversos autores indican que el efecto de añadir disolvente al baño de coagulación origina una disminución de la velocidad de coagulación y en consecuencia una tendencia a formar capas cada vez más gruesas de estructuras tipo 1 no porosas debido a la aparición de retraso en el proceso de separación. Radovanovic et al. (1992) puntualizan más, e indican que no siempre es así; por ejemplo, para el sistema polisulfona/dimetilacetamida/agua la adición de disolvente origina para pequeñas cantidades una tendencia hacia la separación líquido-líquido instantánea y para cantidades mayores aparece la tendencia a retrasarla. Los mismos autores indican por otra parte que para sistemas que incluyen el acetato de celulosa el 
adicionar disolvente al baño de coagulación siempre va a retrasar la separación líquidolíquido y en consecuencia hará la capa activa cada vez más espesa.

La adición de disolvente al baño en cantidades inferiores al $25 \%$ no se consideró en el trabajo experimental con vistas a lograr estructuras tipo 1, no adecuadas para ósmosis inversa y nanofiltración, sino buscando la posibilidad de lograr una subcapa esponjosa con menor presencia de macroporos. El retraso en el tiempo de coagulación y la formación de una capa no porosa más densa se constató visualmente por el método de Frommer detallado en el apartado 3.2.3.

Como disolventes añadidos al baño se han utilizado:

- Dimetilacetamida

- Acetona

- Dimetilacetamida/Acetona 1:1

\subsubsection{Aditivos del colodión}

Este apartado incluye aquellas sustancias diferentes de los polímeros y de los disolventes principales que se añaden al colodión para conseguir alguno de los siguientes efectos:

- Permitir una más fácil disolución del polímero.

- Proporcionar al colodión una característica adecuada, por ejemplo más baja viscosidad.

- Favorecer la formación de una estructura adecuada en la membrana.

Los aditivos del colodión utilizados se pueden clasificar en función de su interacción con el par polímero/disolvente según se indica en la Tabla 23.

Los aditivos más empleados forman parte del grupo de las sales. Con su adición se busca aumentar la solubilidad del polímero en el disolvente y disminuir la viscosidad del colodión. El perclorato magnésico se incluyó como componente de los colodiones basados en acetona. El cloruro de litio y el nitrato de litio son empleados en las composiciones que incluyen dimetilacetamida. El efecto de aumento de la solubilidad es 
producido por la capacidad de solvatación de los iones $\mathrm{Li}^{+}$que al tratarse de un ión pequeño es muy grande. El nitrato de litio apenas se utilizó, ya que se consideró que la utilización de un compuesto comburente en forma directa podría resultar excesivamente peligrosa en los colodiones. Por ello, la sal utilizada en casi todas las composiciones fue el cloruro de litio.

\begin{tabular}{|c|c|c|}
\hline Grupo & Compuesto o producto & $\begin{array}{l}\text { Rangos de porcentaje } \\
\text { en peso utilizados. }\end{array}$ \\
\hline \multirow[t]{2}{*}{ Sales } & $\mathrm{LiCl}, \mathrm{LiNO}_{3}$ & $0.5-6 \%$ \\
\hline & Perclorato magnésico & \\
\hline \multirow[t]{2}{*}{ Tensioactivos: } & Tritón X-100 & $0.5-1 \%$ \\
\hline & Woolite ${ }^{\circledR}$ & $0.5-1 \%$ \\
\hline \multirow[t]{3}{*}{ No-disolventes: } & Agua & $<2 \%$ \\
\hline & Glicerina & \\
\hline & Alcohol & \\
\hline $\begin{array}{l}\text { Disolventes en } \\
\text { pequeña cantidad: }\end{array}$ & Ácido acético & \\
\hline
\end{tabular}

Los tensioactivos se añadieron con vistas a disminuir la viscosidad de los colodiones y al igual que con la presencia de sales se esperaba una disminución de la tendencia a formar macroporos tal y como indica Mulder (1992). Esto se comprobó mediante el método de Frommer tal y como se indica en la Ilustración 34.

Los sustancias no-disolventes del polímero se añadieron con vistas a modificar la estructura de la membrana. Wang, D. et al. (1994) indican varias sustancias nodisolventes que pueden añadirse, las cuales al acelerar el proceso de coagulación y afectar a la relación de intercambio disolvente/no-disolvente permiten la obtención de membranas con una capa activa más fina y estructura más uniforme.

Se exigió a los aditivos únicamente purezas superiores al $99 \%$ no importando el contenido en agua en la composición inicial para las sales ya que éstas eran desecadas antes de su uso. 


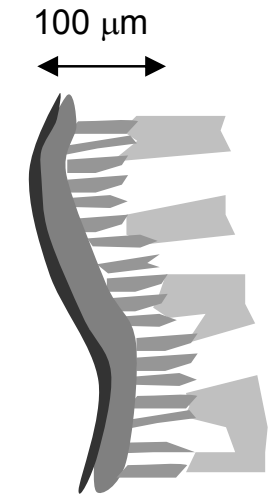

AC(20\%) / DMA

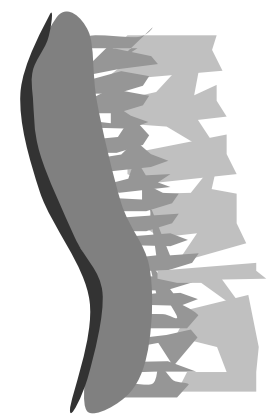

AC(20\%) / DMA / Tritón X-100 (1\%)

Ilustración 34. Efecto de un aditivo en las estructuras de precipitación visualizadas en microscopio óptico siguiendo el método de Frommer (precipitante: $\left.\mathrm{H}_{2} \mathrm{O}\right)$

Tabla 24. Propiedades del cloruro de litio y reglas de seguridad

\begin{tabular}{|ll|l|}
\hline Peso molecular: & $42.39 \mathrm{~g} / \mathrm{mol}$ & Solubilidad en agua a $20^{\circ} \mathrm{C}: 820 \mathrm{~g} /$ litro \\
\hline Densidad a $20^{\circ}:$ & $2.07 \mathrm{~g} / \mathrm{cm}^{3}$ & Higroscópico \\
\hline Punto de fusión: & $614^{\circ} \mathrm{C}$ & \\
\hline
\end{tabular}

Riesgos:

R22: Nocivo por ingestión.

R36/38: Irrita los ojos y la piel.

\section{Eliminación:}

Recipiente colector I o D para sus disoluciones neutras

Almacenamiento:

Como sustancia sólida que no presenta peligro de incendio 
Tabla 25. Propiedades del nitrato de litio y reglas de seguridad

\begin{tabular}{|ll|l|}
\hline Peso molecular: & $68.95 \mathrm{~g} / \mathrm{mol}$ & Solubilidad en agua a $20^{\circ} \mathrm{C}: 522 \mathrm{~g} /$ litro \\
\hline Densidad a $20^{\circ}:$ & $2.38 \mathrm{~g} / \mathrm{cm}^{3}$ & Descomposición térmica sobre $600{ }^{\circ} \mathrm{C}$ \\
\hline Punto de fusión: & $255^{\circ} \mathrm{C}$ & Comburente \\
\hline
\end{tabular}

Riesgos:

R8: Peligro de fuego en contacto con materias combustibles.

S24/25: Evítese el contacto con los ojos y la piel.

\section{Eliminación:}

Recipiente colector I o D para sus disoluciones neutras

Almacenamiento:

Por su carácter comburente se debe almacenar alejado de sustancias combustibles

\section{Tabla 26. Propiedades del perclorato magnésico hidratado $\left(\mathrm{MgClO}_{4}\right)_{2} \cdot \mathrm{xH}_{2} \mathrm{O}$ y reglas de seguridad}

\begin{tabular}{|ll|l|}
\hline Peso molecular: & $223.21 \mathrm{~g} / \mathrm{mol}$ & Solubilidad en agua a $25^{\circ} \mathrm{C}: 500 \mathrm{~g} /$ litro \\
\hline Densidad a $20^{\circ}:$ & $2.60 \mathrm{~g} / \mathrm{cm}^{3}$ & Higroscópico, Comburente, Irritante \\
\hline Punto de fusión: & $146^{\circ} \mathrm{C}$ & Se descompone a partir de $250^{\circ} \mathrm{C}$ \\
\hline
\end{tabular}

Riesgos:

R8: Peligro de fuego en contacto con materias combustibles.

R 36/37/38: Irrita los ojos, la piel y las vías respiratorias.

\section{Eliminación:}

Introduciendo los restos en una disolución de tiosulfato sódico puede transformarse en un producto de reducción menos peligroso.

Almacenamiento:

Por su carácter comburente se debe almacenar alejado de sustancias combustibles 


\subsubsection{Sales para caracterización}

Para evaluar las propiedades retentivas de las membranas se utilizó como sal principal el cloruro sódico $(\mathrm{NaCl})$, ya que es habitual en las membranas de ósmosis inversa proporcionar el rechazo de éstas frente a disoluciones de esta sustancia, debido a su uso principal en desalación. Se fijó una concentración de referencia de 2000 ppm.

En algunas de las membranas que no presentaban características de ósmosis inversa (bajo rechazo hacia el cloruro sódico) se consideró evaluar el rechazo que ofrecían frente a sales de cationes bivalentes para determinar si eran válidas como membranas de ósmosis inversa. Se pensó en sales que poseyeran los cationes magnesio y calcio por ser los más comunes en los ensayos además del sodio. Como anión de las sales bivalentes se pensó en el anión cloruro para poder comparar el efecto del catión con el cloruro sódico. Finalmente se escogió la forma hexahidratada de las sales cálcicas y magnésicas por su estabilidad, buena solubilidad y baja higroscopicidad. Además de estas sales también se utilizó sulfato magnésico y nitrato sódico.

Tabla 27. Propiedades de los cloruros empleados en la caracterización

\begin{tabular}{|l|c|c|c|}
\hline \multicolumn{1}{|c|}{ Sal } & $\begin{array}{c}\text { Masa molecular } \\
(\mathrm{g} / \mathrm{mol})\end{array}$ & $\begin{array}{c}\text { Densidad } \\
\left(\mathrm{g} / \mathrm{cm}^{3}\right)\end{array}$ & $\begin{array}{c}\text { Solubilidad en agua } \\
\text { a 20 }{ }^{\circ} \mathrm{C}(\mathrm{g} / 100 \mathrm{~g})\end{array}$ \\
\hline $\mathrm{NaCl}$ & 58.45 & 2.16 & 36.5 \\
\hline $\mathrm{MgCl}_{2} \cdot 6 \mathrm{H}_{2} \mathrm{O}$ & 203.3 & 1.56 & 74.5 \\
\hline $\mathrm{CaCl}_{2} \cdot 6 \mathrm{H}_{2} \mathrm{O}$ & 219.1 & 1.68 & 54.5 \\
\hline
\end{tabular}




\subsection{METODOLOGÍA DE DESCRIPCIÓN DEL PROCESO TEÓRICO DE SEPARACIÓN DE FASES}

Para poder interpretar mejor los resultados del proceso de separación de fases es muy conveniente la utilización de un diagrama de composición ternario. En dicho diagrama se consideran los tres componentes principales polímero/disolvente/nodisolvente del colodión. La influencia del resto de componentes del colodión se puede observar como una modificación en las curvas del diagrama. El diagrama permitirá establecer conclusiones aproximadas sobre cómo se va a producir la separación de fases para una composición de colodión y condiciones determinadas, así como el tipo de membranas que pueden ser obtenidas. Resulta, por tanto, una herramienta importante en la formulación de colodiones.

La curva binodal del diagrama puede ser obtenida de forma directa experimentalmente, ya que el punto de precipitación puede ser apreciado con cierta aproximación. Sin embargo, las curvas de reparto, así como la curva espinodal, no pueden ser determinadas de forma directa debido a la imposibilidad de realizar medidas exactas de la composición de las fases nacientes. Por ello, se optó por utilizar un modelo teórico que utiliza tres parámetros, llamados parámetros de interacción binarios, siendo dos de ellos obtenidos a través de experimentos indirectos y el tercer parámetro ajustando el modelo a los datos experimentales de la binodal. Una vez ajustado el modelo se pueden obtener tanto las curvas de reparto como la espinodal, existiendo además la ventaja adicional de poderse estudiar de forma teórica el efecto de variaciones pequeñas de los parámetros. Hay que tener en cuenta, no obstante, que el modelo es aproximado al no considerar interacciones ternarias o de orden superior. 


\subsubsection{Determinación experimental de las curvas binodales para el sistema Acetato de celulosa/dimetilacetamida/agua}

Como componentes del estudio se utilizaron los acetatos de celulosa, dimetilacetamida y agua de características idénticas a los utilizados en la fabricación de membranas y que se encuentran reseñados en el apartado 3.2.

Cada determinación de curva binodal se realizó a temperatura constante. En nuestro caso se consideraron tres temperaturas diferentes: $2{ }^{\circ} \mathrm{C}$ (como temperatura típica de los baños de coagulación de membranas que suele dar buenos resultados), $25^{\circ} \mathrm{C}$ (como representativa de la temperatura ambiente) y una temperatura intermedia $12^{\circ} \mathrm{C}$ para ver la influencia de la temperatura en la modificación de las curvas.

El proceso experimental que se expone a continuación es una adaptación del proceso establecido por Mulder(1984).

\section{Proceso experimental seguido}

Se realizaron colodiones disolviendo polímero desecado de acetato de celulosa en dimetilacetamida tal y como se detalla en 3.4.1 y 3.4.2. Los porcentajes en polímero de las disoluciones de partida se encontraron entre $0.5 \%$ y $14 \%$. Con cada una de estas concentraciones se obtuvieron sucesivamente puntos de las curvas binodales correspondientes a las temperaturas de $2{ }^{\circ} \mathrm{C}, 12^{\circ} \mathrm{C}$ y $25^{\circ} \mathrm{C}$.

En cada muestra se pesaban unos $20 \mathrm{~g}$ de colodión en la balanza de precisión (Tabla 28) dentro de matraces Erlenmeyer de $50 \mathrm{ml}$, anotándose la cantidad exactamente pesada. Posteriormente se iban añadiendo con un cuentagotas pequeñas cantidades de agua destilada al contenido del Erlenmeyer pesándose minuciosamente la masa de agua introducida por diferencia con la masa ya existente. Las tres primeras adiciones eran de 0.5 g y las posteriores de $0.1 \mathrm{~g}$ o una cantidad inferior. Después de añadir cada pequeña porción de agua se cerraba herméticamente el matraz y se sometía el contenido a agitación mediante un agitador magnético. Cada adición de agua podía formar localmente un coágulo blanquecino que desaparecía al disolverse a temperatura ambiente. Una vez hecho esto el recipiente se termostataba en un baño a la temperatura inferior de $2{ }^{\circ} \mathrm{C}$ durante un 
tiempo no inferior a 2 h, manteniéndose agitado (Ilustración 35). Si transcurridos ese tiempo, por comparación con una muestra de colodión original guardada en un recipiente similar se apreciaba una débil turbiedad blanquecina, se consideraba que el colodión había coagulado para esa fracción másica de agua. Es decir, se había producido una separación en dos fases inmiscibles, siendo una de ellas una pequeña cantidad de fase rica en polímero en suspensión en el polímero. Si no se apreciaba separación de fases se llevaba de nuevo el colodión a la temperatura ambiente para añadirle una nueva cantidad de agua. El motivo de tener que llevar el colodión cada vez a temperatura ambiente era el evitar la condensación de agua sobre las paredes, lo cual hubiera producido un error de pesada, así como para acelerar la velocidad de disolución.

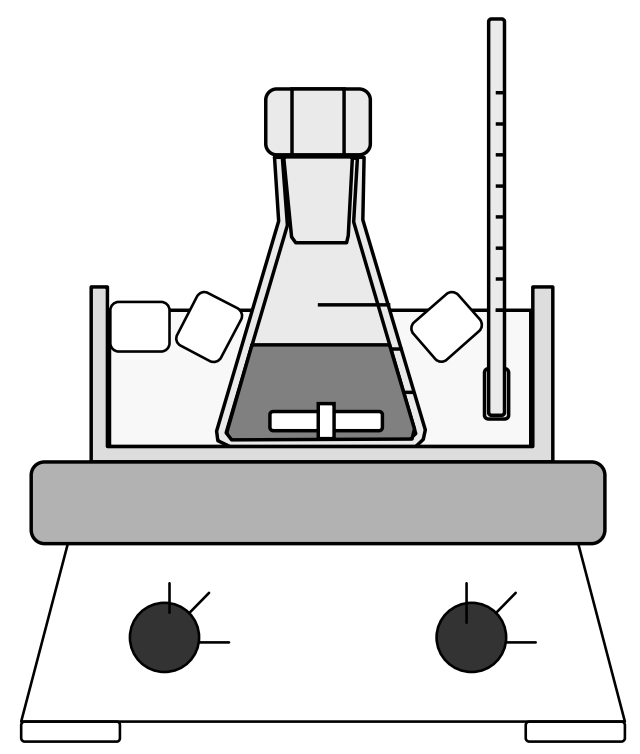

\section{Ilustración 35. Montaje para termostatación del colodión}

Como la solubilidad aumenta con la temperatura una temperatura mayor se corresponde con una curva binodal más desplazada hacia la derecha por lo que el punto verdadero de precipitación se suele sobrepasar (Ilustración 36 - punto $\mathrm{P}_{1}$ ). Por ello se procedía a retroceder añadiendo pequeñas cantidades de disolvente hasta observar la desaparición de la turbiedad con lo cual se había alcanzado de forma muy aproximada la composición de un punto de la binodal (punto $\mathrm{B}_{1}$ ). Como las cantidades totales de los 
diferentes compuestos son conocidas se puede ya obtener para ese punto las fracciones másicas y representarlo sobre el diagrama.

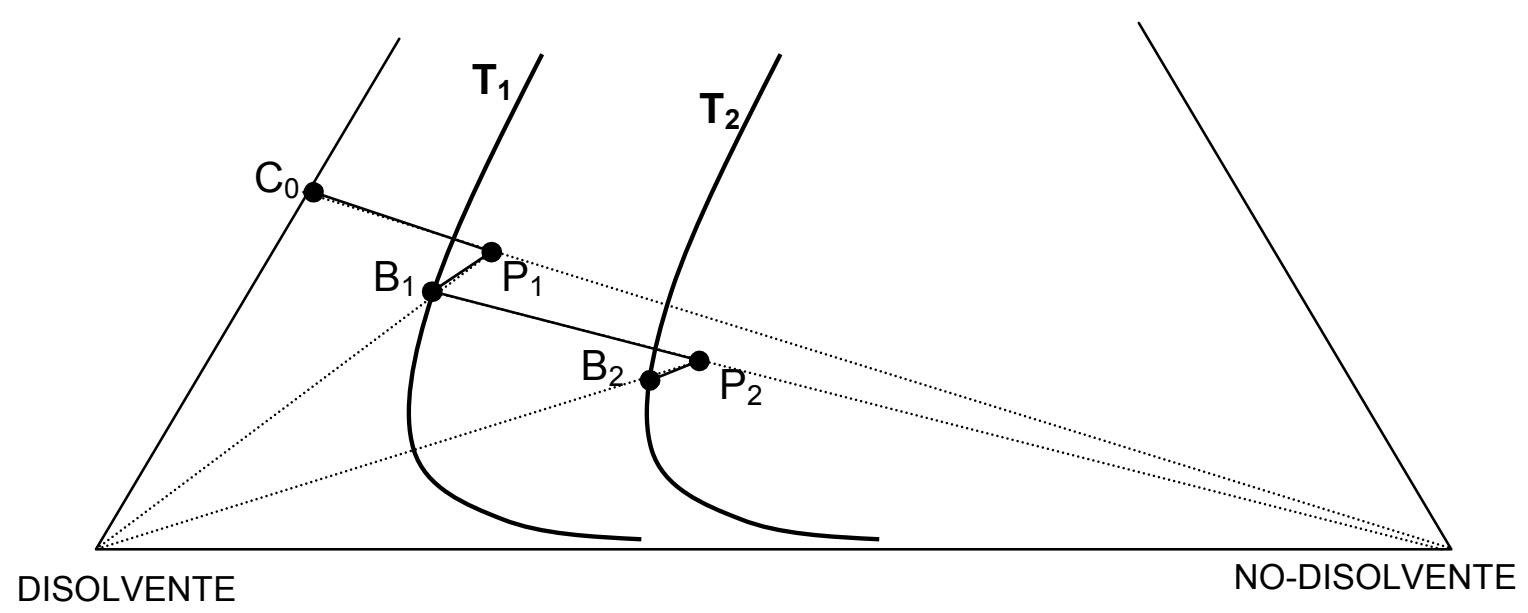

\section{Ilustración 36. Evolución de composiciones en la obtención experimental de la binodal}

El punto determinado a $2{ }^{\circ} \mathrm{C}$ era el punto de partida para la determinación de un punto de la binodal a $12^{\circ} \mathrm{C}$ siguiendo el mismo proceso (puntos $\mathrm{P}_{2} \mathrm{y}_{2}$ ). De manera análoga se determina a partir de éste el punto a $25^{\circ} \mathrm{C}$, pero sin necesidad de llevar el colodión a temperatura ambiente durante el proceso de pesada. 


\subsubsection{Obtención de parámetros de interacción binarios y ajuste del modelo}

La energía libre de mezcla de un sistema ternario puede expresarse en función de las fracciones molares $x_{i}$ y volumétricas $\phi_{i}$ de cada componente mediante la siguiente expresión:

Ec. 80:

$\frac{\Delta G_{m}}{R \cdot T}=x_{1} \cdot \ln \left(\phi_{1}\right)+x_{2} \cdot \ln \left(\phi_{2}\right)+x_{3} \cdot \ln \left(\phi_{3}\right)+\chi_{12} \cdot \frac{v_{1}}{v_{1}} \cdot x_{1} \cdot \phi_{2}+\chi_{23} \cdot \frac{v_{2}}{v_{1}} \cdot x_{2} \cdot \phi_{3}+\chi_{13} \cdot \frac{v_{3}}{v_{1}} \cdot x_{3} \cdot \phi_{1}$

En la expresión aparecen los volúmenes moleculares de las sustancias $v_{i}$, así como los coeficientes de interacción binarios de Flory-Huggins $\chi_{\mathrm{ij}}$, los cuales se pueden suponer independientes de la composición o determinarse su variación con ésta en ciertos casos. Para un sistema ternario disolvente (1) / no-disolvente (2) / polímero (3) se tendrán que determinar los siguientes coeficientes:

$-\chi_{12}$ Coeficiente de interacción disolvente - no-disolvente

- $\chi_{13}$ Coeficiente de interacción disolvente - polímero

- $\chi_{23}$ Coeficiente de interacción no-disolvente - polímero

Una vez averiguados los coeficientes es posible determinar matemáticamente tal y como se detalla en el anexo "Programa para la determinación teórica del diagrama ternario" incluido en esta Tesis:

- La curva binodal ajustada.

- Las líneas de reparto igualando los potenciales químicos entre dos fases obtenidos a partir de la primera derivación respecto de la composición de la expresión anterior para la energía libre de mezcla.

- La curva espinodal a partir de la derivada segunda de la expresión mencionada. 


\section{Determinación experimental del coeficiente de interacción no-disolvente - polímero $\chi_{23}$}

La forma más común de obtener el parámetro de interacción entre polímero y nodisolvente es a través de la medida del equilibrio de hinchamiento del polímero con el nodisolvente. También se podría hacer mediante cromatografía de gases pero los parámetros obtenidos a alta concentración polimérica para elevada temperatura podrían no ser extrapolables.

Cuando el polímero se introduce en el medio no-disolvente (en nuestro caso agua) se produce absorción de éste como consecuencia de las fuerzas de afinidad química que se van a establecer entre determinados grupos del polímero y el agua que tenderán a mezclar los componentes hinchando el polímero pero sin disolverlo al no ser lo suficientemente fuertes. A su vez la energía elástica del polímero se opone a su hinchamiento. El equilibrio se alcanzará cuando se cumpla cuando el incremento de energía libre total suma de los incrementos de energía libre de mezcla y elástica es cero (Champetier y George; 1973):

Ec. 81

$$
\ln \left(1-\phi_{3}\right)+\phi_{3}+\chi_{13} \cdot \phi_{3}^{2}+\frac{\phi_{2} \cdot\left(\phi_{3}^{1 / 3}-1 / 2 \cdot \phi_{3}\right)}{\phi_{3} \cdot M_{c}}=0
$$

Como para este polímero el peso molecular de cada segmento es de $265 \mathrm{~g} / \mathrm{mol}$ y la masa molecular promedio entre entrecruzamientos de la red $M_{c}$ va a ser mayor aún por lo que el parámetro de interacción binario puede ser obtenido a partir de la fracción volumétrica de polímero en el polímero hinchado por agua, $\phi_{3}$, mediante la siguiente expresión:

Ec. 82

$$
\chi_{23}=-\frac{\ln \left(1-\phi_{3}\right)+\phi_{3}}{\phi_{3}^{2}}
$$

El coeficiente en nuestro caso se va a obtener a partir de la medida de la absorción de agua por una fina capa de preparada de acetato de celulosa. La capa debe estar desprovista de porosidad para que la absorción de agua sea debida exclusivamente a la interacción físico-química entre los dos materiales. 
Para obtener tiras de acetato celulosa desprovistas de poros se partió de un colodión concentrado al $25 \%$ de polímero en dimetilacetamida. Sobre una superficie de vidrio de 25 $\times 25 \mathrm{~cm}$ se colocaron en los bordes de la placa tiras de cinta adhesiva de un espesor aproximado de $0.1 \mathrm{~mm}$. En el espacio entre ellas se depositó el colodión y se enrasó con el enrasador de cuchilla C4 (Tabla 31), con lo que se obtuvo una deposición de espesor inicial semejante a $0.2-0.3 \mathrm{~mm}$.

Las placas de vidrio con el colodión depositado se introdujeron en una estufa de ventilación forzada durante un tiempo del orden de $8 \mathrm{~h}$ a una temperatura de $60{ }^{\circ} \mathrm{C}$ para no dañar excesivamente el polímero. Se despegó el acetato de celulosa ya solidificado, se cortó en tiras de tamaño aproximado de $6 \times 1 \mathrm{~cm}$ y se siguió manteniéndolo en estufa de vacío (Tabla 28) durante un tiempo superior a $48 \mathrm{~h}$ para terminar de extraer totalmente el disolvente. Con ello se obtuvieron tiras de acetato de celulosa de unos $0.05 \mathrm{~mm}$ de espesor totalmente transparentes y exentas de porosidad.

Una vez extraídas del horno de vacío las tiras de celulosa fueron pesadas e introducidas en un recipiente cerrado de $200 \mathrm{ml}$, lleno hasta el borde con agua destilada para ser llevadas a un baño termostatado a la temperatura de medida durante un tiempo de $48 \mathrm{~h}$.

Posteriormente las tiras fueron extraídas del recipiente y comprimidas entre papeles de filtro para eliminar las gotas exteriores pasando a ser pesadas rápidamente para determinar el agua absorbida.

Las mismas tiras podían ser utilizadas para obtener datos de absorción en baños con temperaturas diferentes.

\section{Determinación del coeficiente de interacción disolvente - no-disolvente $\chi_{12}$}

El parámetro de interacción binario entre disolvente y no-disolvente puede ser obtenido a partir de datos de la energía libre de exceso. Se encontraron datos de entalpía de mezcla (Christensen et al. 1982), aunque no de entropía de mezcla los cuales son necesarios para determinar la energía libre de exceso. Si se pudiera conocer los datos de la energía libre de exceso el parámetro se podría calcular en función de la composición como: 
Ec. 83: $\quad \chi_{12}=\frac{1}{x_{1} \cdot \phi_{2}}\left[x_{1} \cdot \ln \frac{x_{1}}{\phi_{1}}+x_{2} \cdot \ln \frac{x_{2}}{\phi_{2}}+\frac{\Delta G^{E}}{R \cdot T}\right]$

\section{Determinación del coeficiente de interacción disolvente - polímero $\chi_{13}$}

El parámetro de interacción entre polímero y solvente es determinable a partir de medidas de presión de vapor o a través de osmometría de membrana.

Sin embargo, no existía posibilidad en el laboratorio de obtener de forma exacta datos experimentales sobre éste ni se encontraron datos bibliográficos por lo que se optó por ajustar el parámetro a partir de la información derivada de la forma de la binodal.

\section{Ajuste de los parámetros en el modelo}

Los valores de los coeficientes de interacción binarios relacionados con el disolvente no pudieron ser obtenidos experimentalmente de forma directa, ni a través de la bibliografía. Sin embargo, también existe información derivada de la obtención experimental de la binodal que permite ajustarlos utilizando el programa detallado en el anexo. Para ello se introducía el dato experimental del coeficiente polímero/nodisolvente y se modificaba el valor del parámetro disolvente/no-disolvente hasta lograr que el valor de la curva teórica calculada por el modelo alcanzase a los puntos experimentales de la binodal. Posteriormente se modificaba el parámetro disolvente/polímero hasta lograr que se reprodujese la forma de la curva binodal experimental. Una vez hecho esto el programa calculaba las líneas de reparto, así como la curva espinodal. 


\subsection{METODOLOGÍA DE PREPARACIÓN Y CARACTERIZACIÓN DE COLODIONES}

El procedimiento de preparación es común a la elaboración manual y en máquina, existiendo diferencias solamente en cuanto a las cantidades producidas de colodión.

Las fases que se siguen en la preparación son:

1) Preparación de los materiales

Purificación de los polímeros

Secado de los polímeros y aditivos

Filtración del disolvente

2) Mezcla de los componentes

3) Estandarización de los colodiones

Maduración

Filtrado del colodión

Eliminación de aire

Centrifugado

Una vez realizados los colodiones se efectuaba la operación de etiquetado y opcionalmente su caracterización. 
Tabla 28. Aparatos utilizados en la preparación y control de colodiones.

\begin{tabular}{|c|c|c|c|c|}
\hline$N^{o}$ & Aparato & Marca & Modelo & Características \\
\hline 1 & $\begin{array}{l}\text { Balanza de alta } \\
\text { precisión }\end{array}$ & & & $\begin{array}{l}\text { Precisión : } \\
0.00010 \text { g a } 150 \text { g máx. } \\
0.00001 \text { g a } 20 \text { g máx. }\end{array}$ \\
\hline 2 & Balanza de precisión & & & $\begin{array}{l}\text { Precisión: } \\
\pm 0.01 \mathrm{~g}(\text { de } 0 \text { a } 200 \mathrm{~g}) \\
\pm 0.1 \mathrm{~g} \quad(\text { de } 200 \mathrm{a} 400 \mathrm{~g})\end{array}$ \\
\hline 3 & Horno de vacío & Selecta & Vaciotem & $\begin{array}{l}\text { Temperatura entre la del } \\
\text { ambiente y } 200^{\circ} \mathrm{C}\end{array}$ \\
\hline 4 & Viscosímetro & Brookfield & DV-II & Viscosidades hasta $10^{6}$ Poise \\
\hline 5 & Centrífuga & Selecta & Ref. S-240 & $\begin{array}{l}\text { Velocidad de giro } \\
\text { hasta } 10000 \mathrm{rpm}\end{array}$ \\
\hline 6 & Agitador magnético & $\begin{array}{l}\text { Selecta } \\
\text { / SBS - } 1\end{array}$ & Agimatic-E & $\begin{array}{l}60-1600 \mathrm{rpm} \\
\text { Termostatación } 50-350{ }^{\circ} \mathrm{C}\end{array}$ \\
\hline 7 & Filtros de vidrio poroso & & & $\begin{array}{l}\text { Números según tamaño de } \\
\text { poro decreciente: } 0,1 \text { y } 2\end{array}$ \\
\hline
\end{tabular}




\subsubsection{Preparación previa de materiales}

\section{Purificación previa de los polímeros}

Los acetatos de celulosa Eastman Kodak $®$ utilizados se presentan como polvos y en forma de escamas en el caso de los acetatos de INACSA. Para eliminar la posible presencia de impurezas se ideó un procedimiento de purificación basado en los siguientes pasos:

1. Disolución del polímero (colodión).

2. Filtración de partículas insolubles.

3. Coagulación del colodión en agua destilada.

4. Secado y almacenamiento del material coagulado.

Con ello se buscaba eliminar partículas insolubles en disolvente en la fase de filtración. Los posibles restos de ácido acético, sales solubles, cadenas poliméricas muy cortas u otros productos químicos pasarían en la fase de coagulación al agua.

\section{1) Disolución del polímero:}

Se realizan disoluciones de polímero (no necesariamente desecado) al $12 \%$ en N,N'-dimetilacetamida o al $15 \%$ en acetona (colodiones) en un matraz Erlenmeyer de capacidad 1 litro. El pesado de los productos no requiere exactitud pues los porcentajes anteriores son aproximados. Conviene apoyar el proceso de disolución con una leve agitación magnética. Con ello, el tiempo de disolución requerido es inferior a una hora, siendo un tiempo bajo debido a la poca concentración en polímero empleada.

\section{2) Filtración de partículas insolubles:}

Se dispone en un matraz Erlenmeyer un filtro de lecho de vidrio poroso (Tabla 28: filtro número 1) para realizar una filtración a vacío tal y como se indica en la Ilustración 37. El empleo de colodiones de polímero y acetona frente a los de dimetilacetamida está 
justificado por el menor coste y nocividad de la acetona, así como menor viscosidad de los colodiones de acetona, lo cual facilita bastante la filtración. Sin embargo, utilizando acetona la operación debe realizarse con rapidez por la mayor higroscopía de estos colodiones, lo que hace que estos absorban agua de la humedad ambiental aumentando mucho su viscosidad o coagulando.

El protocolo de la operación es el siguiente:

Una vez conectada la bomba de vacío, se va vertiendo colodión sobre el lecho poroso. Acabada la filtración de todo el material se vierte disolvente sobre el lecho para limpiarlo. El disolvente, junto con los restos extraídos, puede caer sobre la disolución filtrada, pudiendo ser homogeneizados con el resto mediante una varilla de vidrio limpia.

Las posteriores limpiezas del filtro con otros disolventes se deberían realizar sin verter sobre la disolución filtrada. Las partículas retenidas por el filtro pueden ser eliminadas mediante el empleo de mezcla crómica.

La operación de filtrado se realiza de forma más eficaz si la disolución previamente se ha calentado a una temperatura no mayor de $45^{\circ} \mathrm{C}$. Todo el proceso debe realizarse dentro de una campana de extracción de gases debido a los vapores de disolvente que se desprenden.

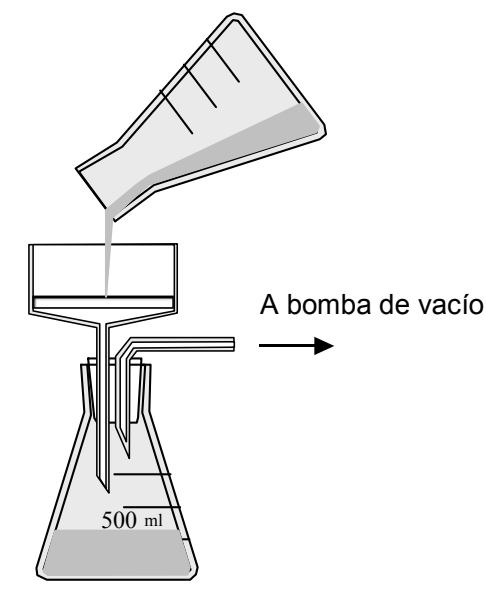

Ilustración 37. Montaje para la filtración del colodión 
3) Coagulación del polímero en agua destilada:

Se dispone un recipiente de unos 25 litros de capacidad conteniendo agua destilada o desionizada. El colodión filtrado se vierte lentamente sobre el recipiente inclinando progresivamente el matraz de forma que un fino hilo de colodión discurra desde la boca del matraz hasta el líquido. El hilo de colodión que cae en el agua coagula progresivamente y adquiere consistencia. Conviene imprimir con el brazo un movimiento circular sobre el recipiente de manera que los hilos sean lo más largos posibles y no se formen grumos. Con ello, el producto purificado adquirirá mayor manejabilidad. Se mantendrá el producto coagulado junto con el agua un tiempo de una hora hasta su completa coagulación. Transcurrido este tiempo se cambiará el líquido del recipiente por agua destilada o desionizada y se mantendrá unas 24 horas para extraer de los hilos sales y disolventes. El producto se lava posteriormente con agua destilada sobre un cedazo provisto de tela filtrante.

4) Secado y almacenamiento del material coagulado:

El producto coagulado se mantiene en una estufa con ventilación forzada de aire a una temperatura de unos $40{ }^{\circ} \mathrm{C}$ durante un tiempo de unas 24 horas. Una vez secado el producto se recoge en una bolsa o recipiente con cierre hermético para su conservación.

Los resultados obtenidos con este método de purificación fueron idénticos a los obtenidos utilizando directamente el producto en polvo para fabricar el colodión de trabajo, siempre y cuando se centrifugara el colodión. Ello refleja la poca importancia de los compuestos solubles en el polímero y la ocasional presencia de impurezas no insolubles, las cuales son muy perjudiciales para la calidad de la membrana al poder constituir imperfecciones en la capa activa.

Aún no pareciendo ser necesario este método de purificación en los productos utilizados en la elaboración de esta tesis, conviene utilizarlo para prever posibles variaciones en la calidad de los productos. Especialmente las derivadas de un exceso de acidez libre. 


\section{Secado de los polímeros y aditivos}

Los acetatos de celulosa debido a su carácter higroscópico, aún conservados en un recipiente cerrado, presentaban una cantidad variable de un 5 a $6 \%$ en peso de agua. Para normalizar la composición de los acetatos de celulosa, aún en las composiciones de colodión que incluían agua, el método normal de trabajo ha sido proceder siempre a su secado en un horno de vacío (Tabla $28-\mathrm{n}^{\circ} 3$ ).

También todas las sales empleadas presentaban una elevada higroscopía, por lo que era necesario proceder a su secado.

El protocolo de secado empleado previamente a la mezcla del colodión ha sido, en todos los casos, el siguiente:

1) Pesado del polímero y aditivos:

Las cantidades pesadas de polímero y aditivos fueron ligeramente superiores (p.e.: 10\%) a las que se va a necesitar para formar el colodión. Los productos se pesaron en recipientes de vidrio perfectamente limpios que podían ser cerrados por rosca o tapón a presión sellado para la preservación de la humedad durante el tiempo de manipulación. La boca de los recipientes era ancha para permitir la extracción del material mediante cucharilla. Dependiendo de las cantidades que se pesaban se escogía un dispositivo de pesada u otro (Tabla $28-\mathrm{n}^{\mathrm{o}} 1 \mathrm{y} \mathrm{n}^{\mathrm{o}} 2$ ).

\section{2) Secado de las sales en el horno de vacío:}

Las sales eran introducidas en el horno de vacío con el recipiente abierto. Primeramente se realizaba la extracción de aire de la cámara con una bomba de vacío hasta lograr una presión manométrica negativa cercana a -1.0 bar. La temperatura del horno se establecía a unos $110^{\circ} \mathrm{C}$ en el caso del cloruro de litio, lo que facilitaba un buen secado de la sal sin apelmazarse. En el caso del nitrato de litio y perclorato magnésico la temperatura tomada era de $90{ }^{\circ} \mathrm{C}$ por su menor punto de fusión. El tiempo de secado a la temperatura establecida era superior a 2 horas. 
3) Secado de los polímeros en el horno de vacío:

En este caso también se realizaba extracción de aire hasta una presión manométrica negativa del orden de -1.0 bar. Sin embargo, la temperatura de secado establecida para los acetatos de celulosa era de $55^{\circ} \mathrm{C}$, no siendo mayor para no producir una destrucción de los grupos responsables de la permeabilidad de la membrana o cambios en la estructura polimérica. Debido a la menor temperatura el tiempo mínimo de secado era de 24 horas.

A diferencia del caso anterior, la cantidad de agua existente en el polímero y que pasa a la atmósfera enrarecida del interior del horno era significante debido a la mayor masa de polímero introducida. Ello provoca un aumento de la presión manométrica en el interior de la cámara del horno que puede llegar subir hasta -0.6 bar. Por ello, para favorecer la extracción transcurridas de seis a ocho horas se realizaba una nueva extracción de los gases que pudieran haber sido desprendidos. Si se producía elevación de la presión significativa ( 0.1 bar) transcurridas las 24 horas se volvía a realizar vacío y se prolongaba el tiempo de secado hasta que fuera necesario. Raramente era necesario, constatándose que tiempos de secado mayores no se correspondían con disminuciones significativas de peso por pérdida de humedad.

El matraz con su contenido era pesado para obtener datos de cuanta humedad tenía el material. Los matraces se tapaban y se sellaban con plástico sellador si no se iba a realizar la preparación del colodión inmediatamente.

\section{Filtración del disolvente}

El disolvente que se utilizaba se filtraba en un filtro poroso (Tabla $28-\mathrm{n}^{\mathrm{o}} 7$ : filtro tipo 1) y se guardaba hasta su uso en frascos de vidrio con rosca. El recipiente debía almacenarse en un sitio oscuro y fresco. Los recipientes (de medio litro) se etiquetaban con su contenido, procedencia y fecha de filtración. 


\subsubsection{Mezcla de los componentes}

$\underline{\text { Recipientes empleados: }}$

Los recipientes de mezcla empleados en todos los casos eran matraces Erlenmeyer con tapón de vidrio esmerilado. El mismo recipiente donde se formaba el colodión se utilizaba para la conservación de éste.

Para impedir en la medida de lo posible que la boca del matraz quedara ensuciada por partículas o gotas se prefería utilizar boca ancha de cierre universal 29/32, excepto en los tamaños por debajo de $100 \mathrm{ml}$ donde este tipo de anchos de boca no era posible.

El tamaño del matraz estaba en función de la cantidad que se iba a preparar, de manera que el volumen de colodión debía estar entre $1 / 4$ y $1 / 3$ de la capacidad nominal del matraz. Se estimaba para ello que la densidad relativa al agua de los colodiones era cercana a 1 . Un tamaño superior a $1 / 3$ de la capacidad del matraz redundaba en que la acción de la varilla magnética agitadora no era efectiva.

Dispositivo de agitación empleado:

El dispositivo de agitación era una varilla magnética agitadora recubierta de teflón y preferiblemente con valona. La varilla introducida en el agitador era accionada por un dispositivo de agitación magnética con placa calefactora (Tabla $28-n^{\circ} 6$ ). El tamaño de la varilla debía de ser acorde con la base del matraz Erlenmeyer (longitud entre y $\frac{1}{2}$ y $\frac{1}{3}$ del diámetro de ésta). Longitudes mayores no eran prácticas con colodiones viscosos y longitudes menores no afectaban de manera eficaz al contenido del matraz. 
$\underline{\text { Riesgos a tener en cuenta durante la mezcla: }}$

El perclorato magnésico y el nitrato de litio son comburentes muy potentes, especialmente el primero. Su adición al disolvente y posterior agitación violenta puede originar una explosión, especialmente cuando el combustible es acetona. Esto hace que en la realización de las composiciones de colodión que los incluyen se deba extremar las precauciones.

El proceso de mezcla y pesado se debería realizar bajo campana de gases debido a la nocividad de los disolventes, especialmente la dimetilacetamida $\mathrm{y}$ dimetilformamida. La utilización de la campana perturbaba la medida por las corrientes de aire que origina. Por ello el proceso de medida se realizaba rápidamente en las cantidades pequeñas, manejando poco disolvente. O bien, para la realización de cantidades mayores, superiores a $100 \mathrm{ml}$, se realizaba bajo la campana de gases, conectándola después del pesado de componentes.

Problemas de la mezcla simultánea de componentes:

Se realizaron al principio algunos colodiones mediante la mezcla simultánea de todos los componentes durante la pesada y realizando una agitación con varilla de teflón magnética. La mezcla simultánea no resultaba adecuada en algunos casos ya que el tiempo hasta una perfecta disolución podía llegar a ser grande.

La evolución de las mezclas realizadas de esta forma se observaba visualmente, encontrándose los siguientes casos:

A. Presencia de grumos alrededor de pequeños terrones de sal que tardan en disolverse

B. Gotas coaguladas en zonas ricas de no-disolvente que incluso llegan a no disolverse

C. Formación de una mezcla tan viscosa que inactiva el agitador

D. Presencia de espuma

El caso A se producía sobre todo cuando no se había tenido la precaución de triturar la sal con la cucharilla, y aún así no se tenía completa seguridad de la mezcla íntima de la sal, desaprovechándose la capacidad de solvatación del polímero por la sal, 
ya que la presencia de ésta en cantidades moderadas favorece la disolución del polímero.

El caso B se daba en composiciones que incluían no-disolvente del polímero, especialmente agua y etanol, y en menor grado con los tensioactivos. La introducción conjunta de polímero, disolvente y no-disolvente puede llevar a que polímero disuelto coagule al interaccionar con una zona rica en no-disolvente y que el disolvente ya no tenga suficiente poder de disolución como para poder redisolverlo.

El caso C se presentaba en la mayoría de las ocasiones, sobre todo cuando se empleaba un agitador poco potente o con mala regulación de velocidad. Casi siempre transcurridas más de 4 horas la mezcla perdía viscosidad y podía llegar a agitarse, aunque con dificultad. El problema se presentaba sobre todo en colodiones de dimetilacetamida con cantidades de CA-398-3 superiores al 23\% o de CA-398-6 y ACE superiores al $20 \%$. La adición directa de sales a la mezcla (por encima de 2\%) dificultaba aún más la agitación.

El caso D se presentaba sobre todo en los polímeros purificados según el procedimiento explicado en 3.4.1. Ello es debido a la elevada presencia de aire contenido en la estructura esponjosa del propio polímero coagulado, así como el atrapado entre los propios hilos. Al cabo de un tiempo de unas 48 horas estas espumas desaparecían completamente.

La forma habitual de pesado tenía como primer paso medir previamente el peso de un matraz perfectamente limpio en la balanza de alta precisión. Posteriormente se introducía el polímero con un embudo al efecto procurando que no quedaran restos de este en la boca o en el exterior.

\section{Procedimiento empleado en la mezcla de componentes:}

Teniendo en cuenta los problemas explicados se diseñó un procedimiento de mezcla, basado en las siguientes reglas:

- Si el agua entra en la composición las sales se deben disolver en ésta de manera que guarden la misma relación en peso con el agua que presentarán en el colodión. Esto se hará siempre que la disolución resultante no quede saturada en sales, en cuyo caso se procede a añadir las sales restantes al disolvente. La disolución formada se puede 
conservar indefinidamente en un frasco cerrado. En el caso de los percloratos siempre aparece el agua en la composición, por lo que se debe proceder obligatoriamente así.

- Los disolventes se manipulan fríos (unos $5^{\circ} \mathrm{C}$ ) para disminuir el riesgo de explosión cuando se emplean sales comburentes y para minimizar su evaporación durante la pesada.

- Si el agua no entra en la composición o queda saturada en sales, las sales se añadirán al disolvente del polímero menos volátil de todos los que aparezcan en la composición. Con esto podemos asegurar mediante una comprobación visual una disolución total. En el caso de haber sales comburentes, éstas se añadirán sobre el disolvente en cantidades de alrededor de 0.2 gramos anotando la pesada, cerrando el envase y procediendo a disolver hasta que la cantidad total añadida guarde la proporción en peso necesaria con el disolvente. La disolución formada se debe conservar en nevera. En el caso de las disoluciones de cloruro de litio en disolvente no existe tanto riesgo de explosión. Se introduce primero el disolvente, se pesa, tara y se introducen de una sola vez las sales de forma que guarden la proporción deseada con el disolvente. El recipiente se cierra, sella y posteriormente se agita magnéticamente hasta la completa disolución de las sales. Se puede preparar disolución suficiente para otros colodiones que empleen el cloruro de litio en la misma proporción o inferior. La disolución puede conservarse en sitio fresco y oscuro.

- Una vez realizada la disolución de sales con el disolvente menos volátil (p.e.: dimetilacetamida frente a acetona) se procede a añadir el resto de disolventes. Con ello se pretende disminuir la evaporación de disolventes durante la pesada.

- Las disoluciones de sal en disolvente o agua y el resto de no-disolventes pueden mezclarse atendiendo a las proporciones deseadas.

- Una vez perfectamente mezclados los anteriores componentes, puede pasarse a la introducción del polímero o polímeros. 
$\underline{\text { Sellado del recipiente: }}$

Cuando todos los componentes y la varilla agitadora estaban introducidos se procedía a sellar el tapón con un plástico especial arrollado exteriormente a la junta, permaneciendo el recipiente bajo agitación magnética.

\subsubsection{Estandarización de los colodiones}

\section{Maduración}

Muchos de los colodiones que habían llegado a parecer visualmente homogéneos dentro del recipiente no se encontraban perfectamente disueltos en la realidad. Ello podía apreciarse por la aparición de grumos de diferente viscosidad al resto si el colodión se vertía. Esta mala disolución se presentaba sobre todo en los colodiones más viscosos. Para asegurar una perfecta disolución de todos los colodiones se estableció un periodo de maduración de 48 horas de agitación magnética suave a partir del momento en que se apreciaba homogeneidad visual, no utilizándose los colodiones en la formación de membranas antes de que hubiese transcurrido este tiempo.

\section{Filtrado del colodión}

El procedimiento de filtración de los colodiones ya formados fue tal y como se ha explicado en el apartado 3.4.1. El filtrado del colodión una vez formado se debe realizar cuando se parte de polímeros no purificados o cuando se detectan impurezas visualmente. Se corre, sin embargo, el riesgo de que la composición varíe debido a la evaporación del disolvente, por lo que este procedimiento apenas se utilizó, prefiriéndose utilizar el centrifugado de los colodiones. 


\section{Eliminación del aire ocluido}

Durante el proceso de formación del colodión puede llegar a quedar aire ocluido en el colodión en forma de minúsculas burbujas o bien disuelto, especialmente en los colodiones que forman espumas durante su formación. En el caso de los colodiones muy viscosos las burbujas de aire, debido a su pequeño tamaño, pueden tardar bastante en ascender.

Para intentar eliminar este aire, fuente de posibles defectos en la estructura de la membrana, los colodiones se sometían a una presión de vacío moderada -0.9 bar en el mismo matraz donde se formaron. Al aplicar el vacío, las pequeñas burbujas aumentaban de tamaño, uniéndose entre ellas y ascendiendo. La aplicación del vacío se suspendía transcurridos $60 \mathrm{~s}$. desde el comienzo de su aplicación, ya que no se deseaba perder una cantidad significativa de disolvente en forma de vapor, con una consiguiente modificación de la composición. El resto de pequeñas burbujas que puedan quedar se eliminan en la fase de centrifugación.

\section{Centrifugado}

El objetivo de esta etapa es la eliminación de aire en forma de minúsculas burbujas y de pequeñas partículas presentes en el colodión.

Cuando se preveía utilizar una cierta cantidad de colodión, se llenaban tubos de ensayo de vidrio provistos de rosca, o bien de cierre de tapón esmerilado. Los tubos utilizados eran de una capacidad de $10 \mathrm{ml}$ (suficiente para una hoja de membrana de $40 \times$ $22 \mathrm{~cm}$ ) y un diámetro de boca nunca inferior a $0.8 \mathrm{~cm}$ para permitir un llenado fácil con las disoluciones más viscosas y una deposición del contenido lo suficientemente rápida.

En disoluciones muy viscosas a temperatura ambiente se procedía a termostatar el colodión en el Erlenmeyer a unos $30^{\circ} \mathrm{C}$. Los tubos de ensayo, una vez llenos y cerrados, se termostataban a una temperatura superior $\left(50{ }^{\circ} \mathrm{C}\right)$ para disminuir en lo posible su viscosidad y facilitar el proceso de centrifugación.

La velocidad de giro en la centrífuga utilizada (Tabla $28-\mathrm{n}^{0}$ 5) se establecía en 8000 rpm durante un tiempo de 1 hora.

Los tubos de ensayo que no iban a ser utilizados a continuación se conservaban en un recipiente hermético conteniendo gel de sílice. 


\subsubsection{Etiquetado y almacenamiento}

Una vez realizada la mezcla de los componentes y sellado el recipiente se colocaba una etiqueta con los datos sobre el colodión (Tabla 29 - datos 1 a 5). Incidencias posteriores (dato 6) se anotaban en la misma etiqueta o en una reproducción de ésta si el colodión se cambiaba de recipiente. Los datos de la etiqueta se consignaban en las hojas de control del cuaderno de laboratorio.

\begin{tabular}{|l}
$\begin{array}{c}\text { Tabla 29. Datos incluidos en la etiqueta asignada a los } \\
\text { colodiones }\end{array}$ \\
\hline 1. Nombre de la persona que prepara \\
2. Código de referencia asignado al colodión \\
3. Porcentajes de los componentes \\
4. Masa total inicial \\
5. Fecha del mezclado \\
6. Tratamiento especial efectuado (p.e. filtrado)
\end{tabular}

Los tubos de ensayo de $10 \mathrm{ml}$ que se usaban comúnmente en la elaboración de membranas por el método manual se etiquetaban con el dato del código de referencia asignado al colodión.

Para almacenar los colodiones hasta su uso durante un tiempo relativamente corto (inferior a una semana), estos se sellaban con un plástico especial alrededor del cuello y el tapón.

Si se preveían tiempos de almacenamiento largos se utilizaba un sello de cinta de teflón y grasa de silicona tipo B.

Los colodiones realizados se guardaban siempre fuera de la acción de la luz, en un lugar no expuesto a altas temperaturas. En el caso de los colodiones que incluían sales comburentes se guardaban en nevera por cuestiones de seguridad. 


\subsubsection{Métodos de caracterización de los colodiones}

\section{Apreciación visual}

Como ya se ha comentado, éste era el método empleado para determinar la correcta disolución y establecer a partir de cuándo se debía contar el tiempo de maduración. También se anotaba cualquier información visual que se consideraba interesante (color, turbiedad, presencia de grumos no disueltos, etc.)

\section{Medida de la viscosidad}

De algunos de los colodiones formados con volumen suficiente se extraía una cantidad de unos $25 \mathrm{ml}$ para su medida en un viscosímetro (Tabla $28-\mathrm{n}^{\circ} 4$ ).

Este aparato transforma en dato de viscosidad el par resistente ofrecido por la disolución a una varilla metálica que gira introducida en ella.

La medida de viscosidad se aplicaba a colodiones centrifugados y sin presencia de burbujas que pudiesen causar interferencias.

Los pasos a seguir en la medida viscosimétrica eran los siguientes:

- Termostatación en un baño del recipiente del colodión, así como el tubo que lo contendrá en el viscosímetro a una temperatura de $25^{\circ} \mathrm{C}$. También el dispositivo de termostatación del viscosímetro se establece a la misma temperatura.

- Realización del autocero del viscosímetro sin cilindro de medida ("spindle").

- Ajuste del cilindro de medida ("spindle"). Para las viscosidades utilizadas el no 4.

- Introducción del colodión en el tubo de medida, en cantidad suficiente para llegar al enrase situado a unos $2 \mathrm{~mm}$ del borde.

- Introducción del tubo con colodión en el tubo de termostatación, situado de manera que el cilindro de medida se sumerge en el colodión.

- En modo "visualización de porcentaje en el rango" se realiza un ajuste de la velocidad a 3, 6 ó 12 rpm según la viscosidad del colodión, de manera que el 
porcentaje que represente la medida dentro del rango total esté situado entre $20 \%$ y $80 \%$.

- En modo "medida", toma del dato de viscosidad en centipoises.

\section{Medida de la densidad}

La medida de la densidad de los colodiones se realizaba termostatándo el recipiente de almacenamiento a $25{ }^{\circ} \mathrm{C}$. Debido a la elevada viscosidad no podía emplearse el picnómetro, por ello se realizaba de forma aproximada midiendo el peso de $25 \mathrm{ml}$ de colodión en una probeta estrecha previamente tarada en peso. 


\subsection{METODOLOGÍA DE PREPARACIÓN MANUAL DE MEMBRANAS}

\subsubsection{Fases en la preparación.}

La preparación de membranas por el método manual expuesto a continuación y su posterior caracterización en planta permite de una forma rápida y sencilla evaluar el efecto que sobre el comportamiento de la membrana tienen las condiciones de fabricación. Adicionalmente se pretende modelizar, en la medida de lo posible, las condiciones del proceso de fabricación en máquina.

El método empleado es apto para la fabricación de pequeñas áreas de membrana (100 a $\left.1000 \mathrm{~cm}^{2}\right)$ a partir de pequeñas cantidades de colodión $(10 \mathrm{ml})$. Un fabricante experto emplearía unos 30 min para producir una membrana.

Las fases empleadas en la producción en el orden en el que se realizan están expuestas en la Tabla 30.

\begin{tabular}{|l}
$\begin{array}{c}\text { Tabla 30. Fases de la fabricación de membranas mediante } \\
\text { inmersión - precipitación }\end{array}$ \\
\hline 1) Formulación del colodión \\
2) Deposición del colodión \\
Preparación del soporte \\
Deposición \\
3) Evaporación \\
4) Coagulación \\
5) Tratamiento térmico \\
6) Tratamientos conservativos
\end{tabular}

La fase de deposición ya fue explicada en el apartado 3.4, el resto de fases se explica a continuación. 


\subsubsection{Deposición}

Una vez fabricado el colodión, el primer paso en la fabricación de una membrana es la deposición de éste sobre un soporte o una superficie.

Atendiendo al soporte empleado tendríamos los siguientes casos:

- Soporte no-tejido

- Soporte tejido

- Sin soporte (Deposición sobre placa)

El estudio de la deposición sobre soporte tejido (tela de finos filamentos) no se trata en esta Tesis, pudiéndose encontrarse información en las tesis de Lora (1987); Alcaina (1991) e Iborra (1993).

La deposición de colodión sobre placa tiene actualmente interés desde el punto de vista experimental para realizar membranas integrales con las que evaluar las propiedades de transporte de la membrana sin tener en cuenta la influencia del soporte.

El tipo de soporte no-tejido (los usados se referencian en 3.2.2) presenta muchas ventajas sobre el no-tejido; la más importante es que permite una deposición más uniforme, de menor espesor que la que se realizaría en un soporte tejido. Otra ventaja es que presenta menor percolación de colodión y que los materiales hidrófobos pueden sumergirse sin absorber agua y originar una doble coagulación. Por ello los soportes notejidos son cada vez más usados.

Los soportes no-tejidos deben de mantenerse tensos y extendidos durante la deposición para que ésta se realice de forma adecuada. Para ello es necesario colocar el soporte una estructura que lo mantenga tensionado, el bastidor.

Para realizar la deposición sobre el soporte existen las siguientes variantes:

- Enrasado

- Pincelado

- Pulverización

- Otras menos usuales. 
El procedimiento de deposición elegido en este caso va a ser siempre por enrasado, por su sencilla aplicación, homogeneidad y similitud de la forma de deposición del colodión con las condiciones de enrasado en máquina. Para ello se tensa el soporte sobre un bastidor, se deposita el colodión en un extremo y posteriormente se utiliza un enrasador para extenderlo. La zona de soporte sobre la que se va a depositar no debe apoyar sobre ninguna superficie para que el colodión no percole y llegue a la otra cara, lo cual produciría una coagulación indeseable en ambas caras.

Bastidores utilizados:

En la elaboración de membranas con soporte tejido, resulta práctico utilizar un bastidor diseñado en el laboratorio de Ingeniería Química y Nuclear (Ilustración 38). Se trata de un soporte circular con un hueco en su centro de forma rectangular con rebordes. Un aro de diámetro ligeramente mayor que el del cuerpo del bastidor permite atrapar la tela tensionándola en todas sus direcciones de manera que apoya en los rebordes del rectángulo. La deposición se efectúa en la zona rectangular.

Este tipo de bastidor no resulta práctico para el soporte no-tejido debido a los pliegues que se originan y el deficiente tensionado. Por ello se optó por emplear exclusivamente un bastidor de marco rectangular (Ilustración 38) que permite tensionar la tela uniformemente en una dirección. En este caso dos barras tensionan al soporte el cual apoya sobre dos cilindros. La utilización de este enrasador permite acercarse a las condiciones en las que se encuentra el soporte no-tejido durante la fabricación en máquina, así como un área de deposición mayor. 

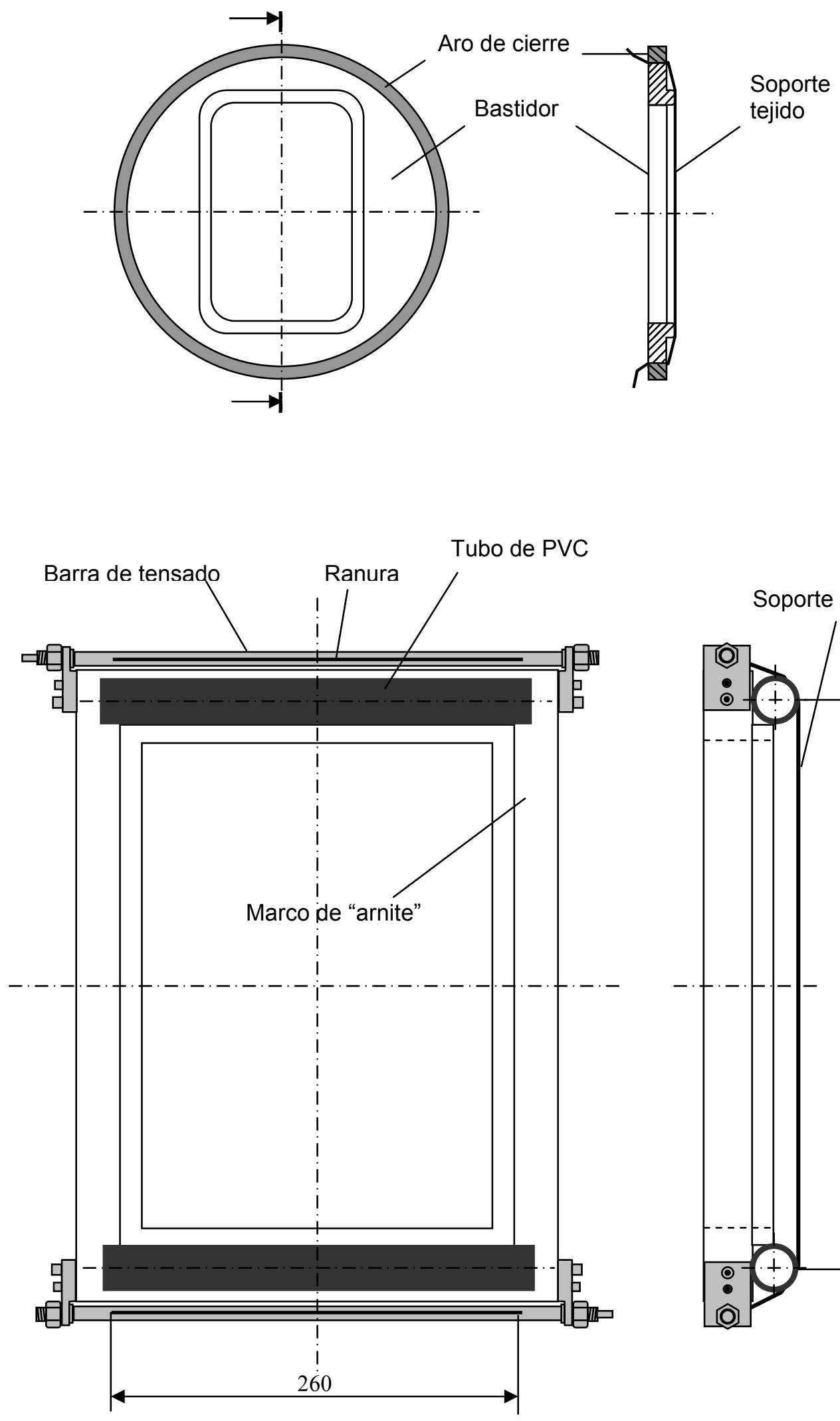

Ilustración 38. Bastidor de marco circular y bastidor rectangular construido en “arnite” y acero inoxidable. (Diseño: Arnal, J.M. Dpto. de Ingeniería Química Nuclear, 1986) 
Enrasadores utilizados:

Para realizar el enrasado se han utilizado dos tipos de enrasadores:

- enrasador de cuchilla

- enrasador de estrías

El enrasador de cuchilla (Ilustración 39, Tabla 31) es un elemento de acero inoxidable que tiene como base un prisma de base cuadrada. Sobre este prisma se ha tallado un ángulo que termina en forma de cuchilla roma. La holgura que queda entre el lado del prisma y la cuchilla tallada se corresponde con el espesor de deposición nominal de este elemento. Las muestras de membrana que se pueden preparar con este enrasador son pequeñas $(10 \times 18 \mathrm{~cm})$ viniendo el ancho limitado por el largo de la zona de cuchilla. Este elemento de enrase se emplea usualmente para la preparación de muestras de membranas de soporte tejido en un bastidor circular especial. Sin embargo, en esta tesis se ha empleado en la elaboración de pequeñas muestras de membranas sobre soporte no-tejido apoyadas sobre una placa de vidrio.

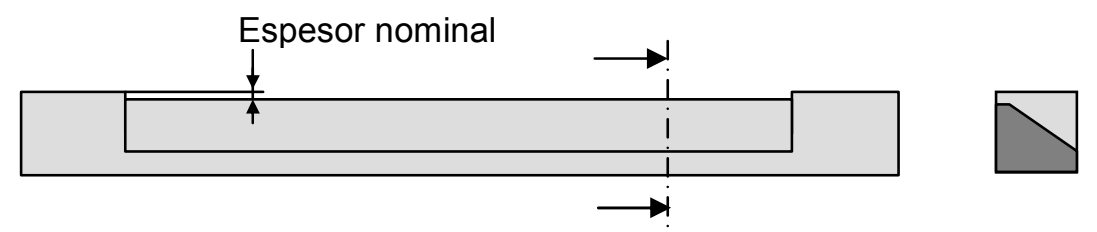

\section{Ilustración 39. Enrasador de cuchilla}

El enrasador de estrías (Ilustración 40, Tabla 31) es un elemento cilíndrico de acero inoxidable y estriado a modo de tornillo con una estría de acabado sinusoidal. El enrasador lleva a su vez un mango y un cilindro de sujeción para realizar con facilidad el enrase. Este tipo de enrasadores se utiliza con el bastidor rectangular y han sido los principalmente utilizados. Las muestras de membrana que pueden ser obtenidas pueden llegar hasta $25 \mathrm{~cm}$ de ancho. 


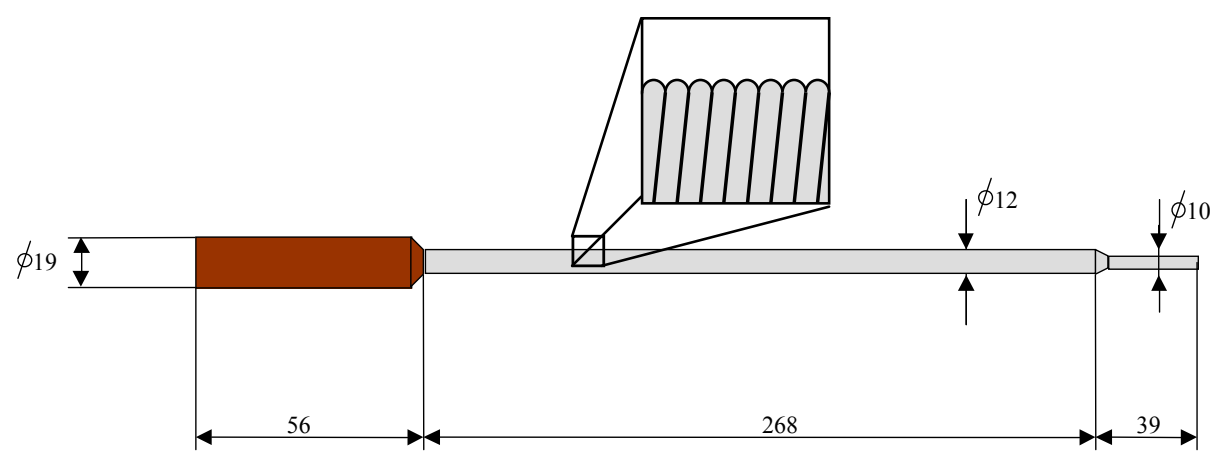

Ilustración 40. Enrasador de estrías. (Acotación en mm y detalle)

Tabla 31. Características de los enrasadores utilizados

\begin{tabular}{|c|c|c|c|}
\hline Tipo & $\begin{array}{l}\text { Código de } \\
\text { referencia }\end{array}$ & $\begin{array}{c}\text { Estrías por } \\
\text { centímetro } \\
\left(\mathrm{cm}^{-1}\right)\end{array}$ & $\begin{array}{c}\text { Espesor de } \\
\text { deposición } \\
\text { nominal } \\
\text { (micras) }\end{array}$ \\
\hline \multirow[t]{6}{*}{ de estrías } & Rojo (R) & 55 & 18 \\
\hline & Negro (N) & 20 & 36 \\
\hline & Amarillo (A) & 15 & 50 \\
\hline & Naranja (Na) & 13 & 60 \\
\hline & Marrón (M) & 10 & 75 \\
\hline & Azul (Az) & 7.5 & 100 \\
\hline \multirow[t]{4}{*}{ de cuchilla } & $\mathrm{C} 1$ & NO & 100 \\
\hline & $\mathrm{C} 2$ & NO & 50 \\
\hline & $\mathrm{C} 3$ & NO & 10 \\
\hline & $\mathrm{C} 4$ & $\mathrm{NO}$ & 300 \\
\hline
\end{tabular}




\section{Preparación de los materiales y equipos}

\section{Colocación del soporte no-tejido en el bastidor de marco:}

Previamente se recortaba una porción de soporte no-tejido de $55 \mathrm{~cm}$ de largo por $22 \mathrm{~cm}$ de ancho. El soporte no-tejido comercial se presenta en forma de rollos en los que la cara más satinada y protegida es la interior. Se tenía, pues, especial precaución al disponer el soporte en el bastidor de manera que esta cara interior fuese la que quedara arriba lista para efectuar la deposición sobre ella.

El bastidor se dispone frente al operario de manera que este puede agarrar ambos extremos de una de las varillas de tensado. En la ranura de la varilla de tensado es introducido el soporte dejando sobresalir aproximadamente $0.5 \mathrm{~cm}$ y procurando el máximo paralelismo posible. Con la mano derecha y ayudado de una llave especial adosada a la varilla se imprimían dos vueltas en sentido horario a la varilla de tensado, bloqueándola posteriormente con las tuercas de cada extremo. Posteriormente, se introducían los dos tubos entre el soporte y el bastidor manteniendo una ligera tensión sobre éste con la mano izquierda e introduciéndolo por arriba a través de la ranura de la varilla de tensado del otro extremo. Se daba una vuelta a todo el bastidor de manera que la otra varilla de tensado quedara cerca del operario y se giraba ésta con la llave en sentido horario hasta lograr tensar el soporte. En ese momento se terminaba de tensar cerrando la tuerca derecha en sentido horario y bloqueando con ello la varilla de tensado. Posteriormente se tensaba la otra tuerca.

El tensado debía ser tal que el soporte no cediese apenas al hacer presión el enrasador, pero no tan fuerte que se produjeran estrías. Si esto último sucedía la hoja soporte debía de colocarse de nuevo, o bien desecharla por una nueva si había quedado deformada.

\section{Limpieza del enrasador:}

Antes de cada nuevo uso los enrasadores debían de ser limpiados.

El enrasador tipo cuchilla es de una fácil limpieza cuando se utilizan colodiones de acetato de celulosa, pues basta dejar el enrasador manchado de colodión en un baño de 
agua durante unos minutos, con lo que los restos de colodión coagulan pudiéndose eliminar con agua y jabón fácilmente.

En el caso del enrasador de estrías es fácil que siguiendo solo este proceso queden restos de polímero fuertemente adheridos y que podrían ser causa de deposiciones defectuosas en los siguientes usos. Por ello, después de cada uso se sigue el siguiente protocolo de limpieza:

1) Introducción del enrasador en una probeta con agua durante unos dos minutos.

2) Eliminación manual del polímero coagulado de fácil extracción

3) Secado con papel secante

4) Introducción en una probeta que contiene dimetilacetamida durante dos minutos

5) Nueva introducción en probeta con agua

6) Escurrido y posterior secado con aire caliente

\section{Deposición mediante enrasado}

El colodión, bien a unos $2{ }^{\circ} \mathrm{C}$ en el caso de los colodiones que utilizan sólo acetona o bien a temperatura ambiente, se deposita lo más rápidamente posible formando una línea paralela y cercana en uno de los extremos sobre los que esta tensado el soporte.

A continuación, se extiende con velocidad constante y efectuando sobre el soporte una ligera presión con el enrasador. La velocidad debe ser tal que se observe una deposición correcta y homogénea y dependiendo de la viscosidad del colodión. Los tiempos de enrasado típicos son de 4 - 7 segundos, superando raramente los 10 segundos. 


\subsubsection{Fase de evaporación}

El parámetro más importante es el “tiempo de evaporación”, el cual se empezaba a contar desde el instante en que se terminaba el enrase y terminaba cuando se sumergía el soporte en el baño de coagulación. Se trata pues de un tiempo de evaporación mínimo, debiendo tenerse en cuenta que en la membrana oscilará entre este valor y el mismo valor más el tiempo de enrasado.

Usualmente el tiempo de evaporación se establecía entre 30 y 90 segundos. En todo caso no conviene que este tiempo sea inferior a 30 segundos para dar tiempo a que la capa de colodión se reparta bien y se logre homogeneidad en la membrana.

La evaporación se realizó en todos los casos a la temperatura acondicionada de laboratorio (unos $20^{\circ} \mathrm{C}$ ). Se procuraba evitar corrientes de aire alrededor del colodión depositado para tener en la medida de lo posible condiciones de evaporación no turbulentas. También se controlaba la humedad relativa ambiental realizándose membranas entre el 50 y $60 \%$.

Aunque se consideró la posibilidad del estudio de la evaporación en horno o mediante exposición a rayos infrarrojos, éstas se descartaron por incompatibilidad con la planta de fabricación.

\subsubsection{Fase de coagulación}

Para realizar la fase de coagulación se empleaba una bandeja como las utilizadas en el revelado de películas fotográficas de $5 \mathrm{~cm}$ de profundidad y sección trapezoidal. El ancho de bandeja escogido era el adecuado para que el bastidor cuando se disponía invertido sobre ésta apoyara sobre sus lados sin tocar el fondo. La cantidad de líquido coagulante añadido a la bandeja debía ser de unos 6 litros de manera que el soporte quedara sumergido completamente. 
Composición de los baños:

Los baños de coagulación en laboratorio han estado constituidos en la mayoría de los casos por agua de red (unos 700 ppm de sales) por similitud a los empleados en máquina. Se realizaron también experiencias con agua desionizada, no detectándose en las membranas así obtenidas grandes diferencias con las preparadas en baño de agua de red.

También se realizaron pruebas añadiendo disolventes al baño, expresándose la cantidad de disolvente añadida como porcentaje en volumen respecto del total antes de mezcla. Normalmente se añadía dimetilacetamida como único disolvente al baño, ya que era el mismo disolvente utilizado en los colodiones, además de poseer baja volatilidad. También se experimentó con acetona o mezclas de acetona y dimetilacetamida.

\section{Temperatura del baño:}

Se hicieron pruebas con temperaturas de baño de coagulación entre $0{ }^{\circ} \mathrm{C}$ y temperatura ambiente (hasta $30^{\circ} \mathrm{C}$ ). El interés de trabajar a temperaturas cercanas a $0{ }^{\circ} \mathrm{C}$ estaba basado en los mejores resultados observados a estas temperaturas, sin embargo se realizaron pruebas a temperaturas cercanas a la ambiente por compatibilidad con la fabricación en máquina.

El baño se mantenía agitado para homogeneizar la temperatura hasta que se encontraba a la temperatura adecuada.

Forma de coagular:

Con el agitador ya desconectado y el baño a la temperatura óptima la coagulación se realizaba introduciendo el bastidor con la superficie de la membrana inclinada ligeramente respecto de la superficie del agua. Ello se realizaba a una velocidad constante de forma que se formase un frente continuo de coagulación avanzando sobre la membrana. El interrumpir la velocidad de introducción era causa de imperfecciones en forma de estrías que se podían visualizar. Las membranas que las presentaban eran rechazadas si no se podía realizar un recorte de prueba que no contuviese al frente de coagulación interrumpido. 
Tiempo de coagulación:

El dato de tiempo de coagulación se consideraba desde el instante en el que la membrana se apartaba de las condiciones del baño hasta que se separaba del bastidor para retirarse a otro baño con agua a temperatura ambiente o a bolsas para su conservación.

Sólo influía cuando era demasiado corto para que la membrana no hubiera eliminado casi todo su disolvente, en cuyo caso las membranas obtenidas eran defectuosas.

Para tiempos de coagulación mayores de 5 minutos la membrana se podía considerar coagulada totalmente y tiempos de permanencia mayores ya no influían. Sin embargo, para normalizar resultados se decidió tomar como tiempo de coagulación 10 ó más minutos.

$\underline{\text { Retirada de la membrana del bastidor: }}$

Para prevenir desgarros en la capa activa de la membrana siempre se destensaba el soporte y posteriormente se recortaba la zona con deposición correcta. A continuación la membrana se depositaba en un medio húmedo a temperatura ambiente. 


\subsubsection{Tratamiento térmico}

Tratamiento térmico para aumentar el rechazo:

Principalmente se utilizó el tratamiento térmico de las membranas para conseguir aumentar la característica de rechazo de éstas a costa de disminuir el flux.

Lo anterior era casi siempre necesario en las membranas en las que el disolvente que predominaba era la dimetilacetamida. En las membranas producidas utilizando acetona el tratamiento térmico eliminaba casi por completo el flux.

Se probaron distintas formas de tratamiento térmico, tales como exposición a vapor o a rayos IR, pero la única eficaz resultó ser la inmersión en agua destilada caliente en un recipiente termostatado.

Una vez que se observaba que la temperatura del baño variaba en menos de $0.5^{\circ} \mathrm{C}$ se introducía la membrana. El dato de tiempo de tratamiento térmico se tomaba desde el instante de introducción de la membrana hasta su retirada. Una vez extraída la membrana del baño se dejaba disminuir su temperatura en el aire durante unos 30 segundos previamente a su introducción en un medio húmedo, ello con vistas a evitar tensiones térmicas.

En el método de exposición al vapor se mantenía la cara activa de la membrana a $2 \mathrm{~cm}$ de un baño de agua caliente durante el tiempo de tratamiento térmico. 


\subsubsection{Tratamientos de conservación}

Tratamiento de conservación:

Las membranas de acetato de celulosa son muy sensibles a la acción bacteriana. Para preservar las membranas de su destrucción por la actividad biológica las membranas, una vez concluidos los tratamientos se conservaban en bolsas con cierre estanco con la cantidad suficiente de disolución acuosa de formaldehido al $4 \%$ para empaparlas de forma que quede algo de líquido remanente. Las membranas podían así conservarse en bolsas etiquetadas, varios meses incluso, hasta el momento de su prueba.

Otro tratamiento adicional se realiza con vistas a impedir una rápida desecación de las membranas en contacto con el aire. El acetato de celulosa al perder humedad se vuelve frágil pudiendo cuartearse la capa activa. Una pequeña cantidad de glicerina en la disolución acuosa facilita su manipulación durante el montaje en el módulo al mantenerlas elásticas durante más tiempo. 


\subsection{METODOLOGÍA DE FABRICACIÓN DE MEMBRANAS EN MÁQUINA.}

La optimización de la fabricación en máquina no forma parte del contenido central de la Tesis por lo que solamente se han realizado unas pocas pruebas en máquina. A continuación se describe el método de fabricación que se empleó en las pruebas preliminares con vistas a comentar en el apartado de conclusiones las modificaciones a realizar derivadas a partir de la información obtenida por el método manual.

\subsubsection{Preparación del colodión}

La fase de preparación del colodión no presenta diferencias con la preparación de colodiones para la fabricación manual, excepto en las cantidades que se preparan. 


\subsubsection{Fabricación en máquina}

\section{Descripción de la máquina}

La máquina para realizar las experiencias finales de fabricación de membranas se encuentra ubicada en el laboratorio de plantas piloto perteneciente a la sección de Ingeniería Química II del Departamento de Ingeniería Química y Nuclear de la UPV. Es una planta de escala industrial que ha permanecido inactiva hasta el presente año debido a obras de reforma en el Departamento, por lo que hasta el momento sólo se ha utilizado en periodo de pruebas.

En la Ilustración 41 se puede observar un esquema simplificado de la planta. Las partes principales de la planta son:

- El sistema de movimiento de la cinta soporte que mediante los motores desbobinador, tensor y bobinador mueve la cinta a través de un sistema de rodillos.

- El sistema de deposición del colodión que utiliza nitrógeno seco para crear la presión necesaria para que el colodión fluya hacia la cuchilla de enrase.

- El baño de coagulación.

- La unidad extractora de vapores.

La unidad extractora cumple principalmente funciones de seguridad y ningún elemento de la máquina se activa si ésta no está funcionando.

Durante el proceso de fabricación el soporte es desenrollado merced al motor desbobinador (punto 1) y llevado hasta el punto de enrasado (punto 2) donde la cuchilla enrasadora deposita y enrasa el colodión sobre el soporte. Entre este punto y la inmersión dentro del baño de coagulación (punto 3) se produce la fase de evaporación. El soporte con el colodión permanece el tiempo suficiente en el baño para coagular completamente antes de su salida (punto 4). Finalmente la membrana es enrollada por el motor bobinador (punto 8). 


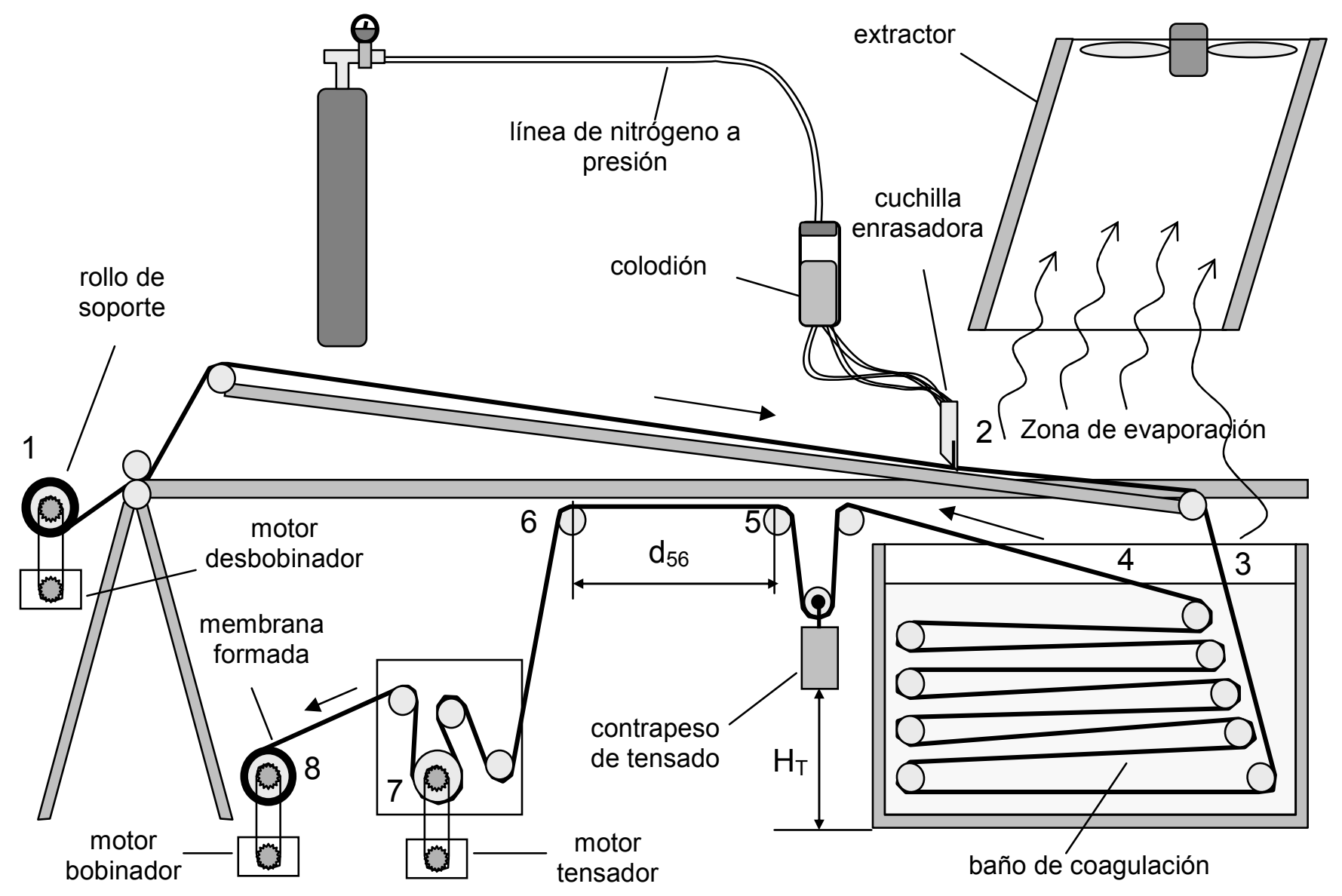

Ilustración 41. Esquema simplificado de la máquina de fabricación de membranas del DIQN. (Diseñada por Arnal J.M. y Lora J. 1990). 


\section{Preparación de la máquina}

Colocación del soporte y retirada de membrana fabricada:

Para colocar un nuevo soporte se corta la cinta de soporte colocada (punto 1) antes de su entrada en el sistema de rodillos, el nuevo soporte se conecta al anterior utilizando cinta adhesiva de un ancho igual o superior a $5 \mathrm{~cm}$.

Para retirar membrana fabricada se corta el soporte (punto 8) retirando el rodillo bobinador con la membrana fabricada. Se instala otro rodillo bobinador y con cinta adhesiva de ancho $5 \mathrm{~cm}$ se conecta el nuevo soporte al soporte antiguo.

Hay que tener en cuenta que para realizar una limpieza integral del baño de coagulación y los rodillos es necesaria la retirada total del soporte del sistema.

Limpieza del sistema de inyección del colodión:

Antes de iniciarse la producción de membrana con un nuevo colodión es necesario proceder a la limpieza del sistema de enrase. Para ello se trata de eliminar presurizando con nitrógeno el máximo colodión posible manteniendo la cinta de soporte desplazándose. Una vez hecho esto se introduce, ya sin presión, dimetilacetamida en el recipiente contenedor del colodión. Para una limpieza más eficaz se puede desmontar las dos cuchillas del sistema enrasador y limpiarlas con el mismo disolvente o acetona. También conviene retirar el elemento distribuidor de colodión para una mejor limpieza.

Adaptación del dispositivo enrasador:

El dispositivo representado seccionado en la Ilustración 42 ocupa todo el ancho de cinta y puede ser extraído en la máquina.

Con el dispositivo en posición horizontal y una vez introducidas las cuchillas se puede ajustar el ancho de boquilla $a_{B}$ mediante una galga, así como la diferencia de alturas $d_{C}$ entre la cuchilla de enrase y la cuchilla reguladora de la deposición mediante un tornillo 
micrométrico. Ambas magnitudes influyen sobre la cantidad depositada de colodión a una presión dada.

Para lograr una distribución de colodión uniforme en colodiones de baja viscosidad (tales como los utilizados en la fabricación de membranas de ultrafiltración con concentraciones de polímero inferiores al 18\%) resulta conveniente la presencia de un distribuidor interno. Sin embargo, en las pruebas realizadas, éste se retiró por la elevada resistencia al paso de colodión que establecía.

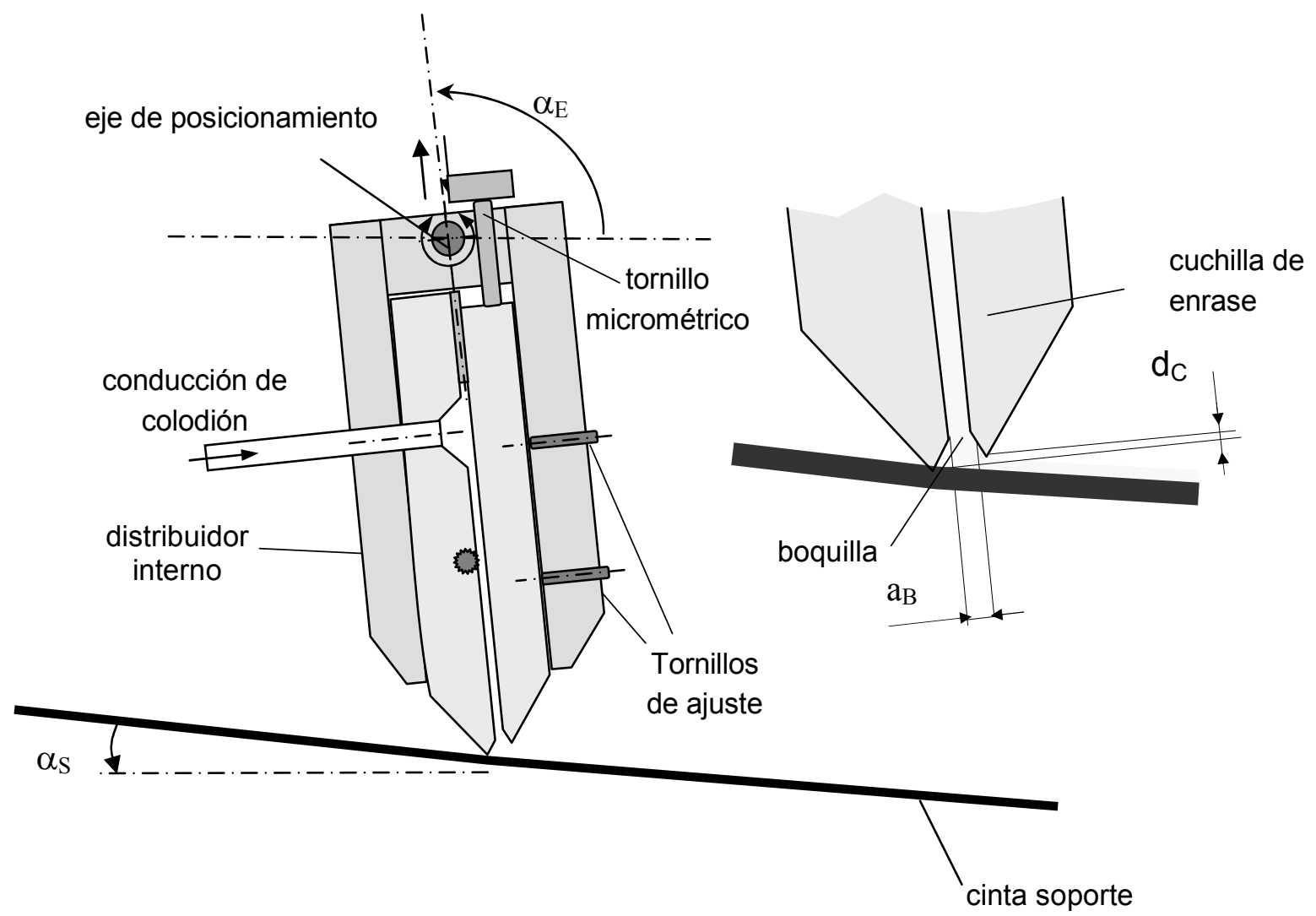

Ilustración 42. Sección esquemática del dispositivo enrasador 
Una vez realizados los ajustes anteriores y girando el dispositivo de enrase sobre su eje de posicionamiento se puede conseguir un determinado ángulo de éste con la respecto de la horizontal $\alpha_{\mathrm{E}} \mathrm{y}$ desplazándolo sobre unas guías conseguir que el soporte presente un determinado ángulo $\alpha_{S}$ respecto de la horizontal. La resta de ambos ángulos constituye el ángulo del enrasador sobre el soporte, el cual influye sobre la deposición.

$\underline{\text { Renovación del baño de coagulación: }}$

El baño de coagulación contiene unos 1500 litros de líquido por lo que se estima que puede utilizarse sin renovarse durante 5 cargas de colodión. La máquina dispone de conducciones para aportación de agua de red, así como para su vaciado. El nivel de líquido final en el baño de coagulación se fija normalmente en unos $10 \mathrm{~cm}$ por debajo del borde superior.

\section{Llenado del recipiente de colodión:}

El recipiente de colodión se puede llenar por su parte superior con cargas de colodión de 300 a $1000 \mathrm{ml}$ Antes de proporcionar presión de nitrógeno es necesario esperar a la desaparición de las burbujas de aire que inevitablemente se forman al introducirlo. 


\section{Regulación en funcionamiento}

Una vez conectada la planta se puede actuar sobre la velocidad de la cinta soporte actuando sobre las revoluciones de bobinador y desbobinador, las cuales se encuentran coordinadas. Como el radio de la membrana enrollada en la bobina va aumentando progresivamente, la velocidad de giro debe modificarse para obtener una velocidad lineal de cinta constante. La velocidad lineal de cinta se mide cronometrando el tiempo que tarda una marca en desplazarse entre los puntos 5 y 6 representados en la Ilustración 41. La velocidad lineal de cinta influye claramente sobre el espesor de deposición al obtenerse menor espesor cuando se aumenta la velocidad de enrasado, pero también influye sobre el tiempo de evaporación que es el empleado por la cinta para recorrer la distancia entre los puntos 2 y 3 . La influencia sobre el tiempo de coagulación no es importante ya que la permanencia del soporte en el baño de coagulación está sobredimensionada para cualquier velocidad de cinta permisible.

Otro parámetro que se puede controlar es la tensión de la cinta sobre el dispositivo de enrase. Para lograr un rango de presiones determinado se puede aumentar o disminuir el contrapeso de tensado antes de conectar el sistema, y también bajar la altura del dispositivo de enrasado (Ilustración 42). Una vez en funcionamiento se puede lograr mayor o menor presión moviendo la altura $H_{T}$ respecto del suelo mediante mayor o menor porcentaje de carga del motor tensador. Esta tensión influye sobre la calidad de la deposición.

La presión de nitrógeno produce la inyección de colodión sobre el soporte, una mayor presión de nitrógeno aumenta la cantidad de colodión aportada. Esta cantidad producirá un mayor o menor espesor según la velocidad de cinta que se tenga.

Es importante tener en cuenta que la planta, tras la modificación de las condiciones mencionadas, necesita un cierto tiempo para lograr estabilidad. Por ello tras modificar alguna condición se realiza una marca de final de condiciones antes del enrase y transcurridos 2 minutos se realiza una nueva marca indicando el comienzo de nuevas condiciones. 


\subsubsection{Tratamiento térmico}

Actualmente la máquina de producción de membranas del DIQN no posee un tratamiento térmico continuo posterior al baño de coagulación. En un futuro se podría desarrollar un tratamiento continuo en que la membrana coagulada enrollada se desenrollara para hacerla pasar por un baño de tratamiento térmico. Otra posibilidad menos aconsejable sería el tratamiento de porciones del rollo en autoclave.

El tratamiento térmico efectuado en la parte experimental de esta Tesis ha sido llevado a cabo sobre recortes en la misma forma que en el método manual, tal y como se explica en 3.5.5.

\subsubsection{Tratamientos de conservación}

La conservación de recortes de membrana no presenta ninguna diferencia en la conservación respecto de los recortes del método manual explicado en 3.5.6. La conservación de rollos de membrana es también básicamente igual, sólo que no se debe descuidar la estanqueidad de las bolsas que contengan los rollos, ni la cantidad de líquido. Ello es debido a que al encontrarse la membrana arrollada sobre sí misma un desecamiento elevado puede ocasionar que la capa activa se pegue a la parte inferior del soporte desgarrándose al desplegar la membrana. Por ello, para periodos largos de conservación conviene incluir glicerina en el líquido conservante. 


\subsection{METODOLOGÍA DE CARACTERIZACIÓN DE MEMBRANAS.}

En este apartado se detallan los métodos utilizados para obtener información relevante, para el proceso de fabricación, sobre la estructura de la membrana. También se explica la evaluación del comportamiento de la membrana en los campos de aplicación de ósmosis inversa y nanofiltración seleccionados.

\subsubsection{Caracterización de propiedades estructurales}

La caracterización de las propiedades aquí indicadas va a obtener datos importantes desde el punto de vista de la fabricación, como son: la estructura microporosa existente debajo de la capa activa, la presencia de defectos, la homogeneidad de la distribución de polímero, etc.

\section{Microscopía electrónica}

Se realizaron cortes transversales con vistas a estudiar la estructura microporosa de la membrana, así como la interconexión entre polímero y soporte no poroso.

Para ello se utilizó el microscopio electrónico de barrido CRIOSEM perteneciente al Servicio de Microscopía de la Universidad Politécnica de Valencia.

Las muestras a observar se obtenían de tiras de membrana de un ancho de $7 \mathrm{~mm}$ aproximadamente y después de cortadas debían tener un alto de $4 \mathrm{~mm}$. Las muestras habían estado mantenidas en agua para que la estructura de la membrana se encontrase hinchada.

El corte con bisturí de la muestra a temperatura ambiente producía una deformación plástica en la estructura de la membrana no apareciendo una fractura 
limpia que mostrase sin desplazamientos la sección transversal. Por ello se utilizó la posibilidad de llevar la muestra a temperaturas criogénicas con el equipo auxiliar presente en el laboratorio de microscopía. Para ello se preparaba nieve de nitrógeno sólido disminuyendo la presión en un recipiente que contenía nitrógeno líquido y presurizando a presión ambiente una vez formada. Se introducían entonces tiras de un ancho de $7 \mathrm{~mm}$ durante 3 a 5 minutos para que su temperatura se acercase a la del equilibrio entre nitrógeno sólido y líquido.

El equipo CRIOSEM permite metalizar in situ la muestra después de haberla fracturado mediante un golpe con una varilla. Sin embargo, los materiales de los soportes no porosos no eran lo suficientemente frágiles, incluso a tan baja temperatura, como para fracturarse por golpe, observándose que la muestra se desgarraba con separación de la capa polimérica. Se optó por realizar un corte limpio de la muestra criogenizada con unas tijeras especiales como las empleadas en cirugía y posteriormente recubrir las muestras con una fina capa de oro en un equipo metalizador.

Una vez metalizadas las muestras se colocaban en un portaobjetos cilíndrico y se fijaban con pasta de carbono conductora dentro de la ranura del portaobjetos con la sección transversal fracturada dispuesta lo más paralelamente posible a la base del portaobjetos. Para asegurar una distribución adecuada del flujo electrónico en la muestra durante su observación es importante la realización de un puente eléctrico entre los dos bordes de la ranura de manera que cubra la muestra en los laterales tal y como se indica en la Ilustración 43.

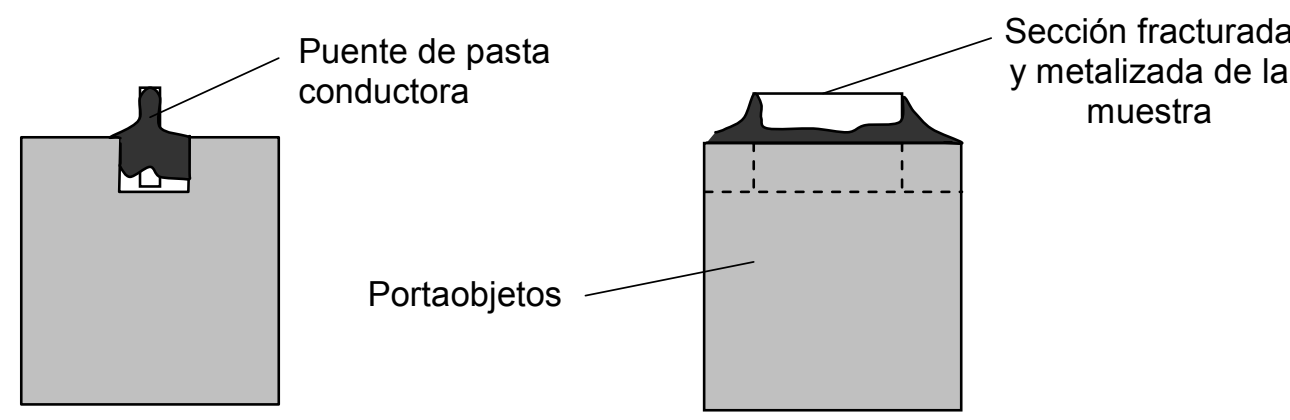

Ilustración 43. Colocación de la muestra en el portaobjetos 
Se pueden introducir en una sesión cuatro portaobjetos con una muestra cada uno en la placa del microscopio. Una vez dentro se efectúa el vacío. Tras haber el operador ajustado los parámetros de intensidad del microscopio, el zoom del microscopio y el posicionador de muestras se pueden ajustar para explorar la muestra. El equipo posee dispositivo fotográfico y digitalizador de imágenes para conservar las vistas interesantes de la muestra. Se debe efectuar un ajuste de brillo y contraste en el zoom inmediatamente superior previo al registro fotográfico o digital en el zoom de la vista.

\section{Medida del espesor}

El espesor de la capa de polímero depositada se obtiene como la diferencia entre el espesor total y el espesor del soporte. Las medidas de espesor se realizan mediante un tornillo micrométrico (referencia Zwick 73-9036).

Los espesores de los soportes no-tejidos presentaban una dispersión de valores con valores máximos y mínimos que podían llegar hasta un $30 \%$ por encima o debajo de la media, tanto a lo ancho como a lo largo del rollo de soporte. Por ello la medida más adecuada del espesor medio obtenido debía realizarse restando a la medida de espesor obtenida la medida del soporte en el mismo punto. La medida del espesor del soporte se podía realizar antes de la preparación de la membrana en un punto situado a una distancia determinada de un borde marcado. También se podía realizar un ensayo destructivo de medida del soporte en membranas que ya habían sido probadas eliminando con acetona el polímero depositado.

Aún después de haber restado el espesor de soporte, las medidas realizadas en diferentes posiciones solían presentar dispersión significativa (especialmente en el método manual de fabricación) por lo que se realizaban varias medidas para calcular un valor medio y la desviación típica. Los puntos de medida en los recortes periféricos se dividían en centrales y periféricos tal y como se indica en Ilustración 44. 


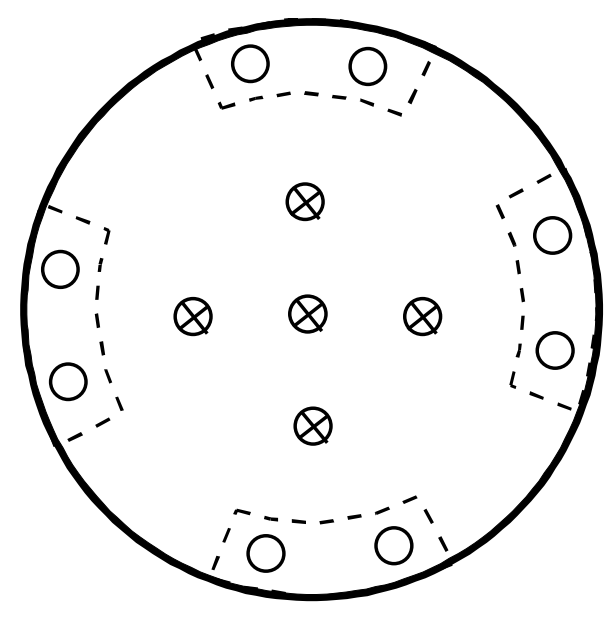

Ilustración 44. Disposición de las medidas de espesor

Atendiendo a la forma y momento de la realización de la medida era posible obtener:

- “espesor después de coagulación"

- "espesor húmedo después de tratamiento térmico"

- "espesor seco después de tratamiento térmico"

- "espesor húmedo después de prueba"

La comparación de medidas de "espesor húmedo después de prueba" y "espesor húmedo después de tratamiento térmico" sirve para obtener una medida de la compactación de la membrana del proceso, pero es difícilmente realizable por la deformación que sufre la membrana al adaptarse al soporte metálico. 


\section{Medida de la cantidad de polímero depositada y capacidad de absorción de agua por unidad de área de membrana}

Con este ensayo se busca relacionar el tipo de colodión y el espesor de enrasador utilizado con la cantidad de polímero depositado por unidad de superficie. Las pruebas se realizan con recortes de membrana sobrantes en la caracterización.

El procedimiento experimental constó de las siguientes fases:

\section{Recorte y marcado de la muestra:}

- Se recorta un rectángulo de muestra anotando el dato de "área recortada". El recorte debe incluir exclusivamente zonas con polímero depositado desprovistas de defectos. Conviene tomar la mayor área posible que quepa en los tubos de ensayo destinados a contenerlo.

- Se marca un tubo de ensayo con el número de hoja correspondiente a la muestra recortada y se introduce la muestra correspondiente junto con unos $2 \mathrm{ml}$ aproximadamente de agua para que no se seque.

- Se sella la boca del tubo de ensayo.

2. Eliminación de gotas exteriores y pesada de la muestra húmeda:

- Se saca la muestra de su tubo de ensayo con unas pinzas y con papel absorbente se eliminan las gotas exteriores.

- Se pesa en una balanza de precisión, anotándose el valor de medida transcurridos 5 seg después de depositar la muestra y se anota como dato de "peso en húmedo".

- Se retira el agua del tubo de ensayo y se devuelve a él la muestra. 
3. Secado de la muestra en horno y pesada en seco:

- Las muestras se llevan en sus tubos de ensayo correspondientes, sin tapar y sin agua, al horno de aire para su secado. Es muy importante que la muestra quede enrollada de forma que la cara que contiene polímero quede dispuesta internamente.

- Se realiza un vacío inferior a $100 \mathrm{mmHg}$ y se establece la temperatura del horno a $100^{\circ} \mathrm{C}$, manteniéndose las muestras en él durante $30 \mathrm{~min}$.

- Se realiza un nuevo proceso de vacío, se apaga la temperatura del horno y se mantienen las muestras otros $30 \mathrm{~min}$.

- Se realiza la pesada de las muestras sobre un vidrio de reloj, teniendo cuidado al extraer las muestras para que no se desprendan esquirlas de polímero seco. Se anota el dato como "peso en seco".

- Una vez pesadas, se devuelven las muestras a sus tubos.

4. Eliminación con disolvente del polímero depositado en el soporte:

- Se introduce acetona en los tubos de manera que las muestras queden cubiertas y se sellan.

- Transcurridos unos $30 \mathrm{~min}$, se vacía la acetona con polímero disuelto y se vuelve a añadir nueva acetona, sellándose de nuevo.

- Se repite el procedimiento mientras se observen restos de polímero.

- Se retira la acetona.

- Se secan las muestras en estufa de aire a $60^{\circ} \mathrm{C}$.

- Se realiza un procedimiento de pesada de la muestra anotándose el resultado como dato de "peso del soporte". 


\subsubsection{Caracterización en planta de propiedades permeoselectivas}

La evaluación del comportamiento se realiza en condiciones estandarizadas ya que no se busca realizar estudios completos de comportamiento bajo condiciones muy diversas, sino de disponer de un método rápido de caracterización para evaluar el proceso de fabricación.

\section{Descripción de las plantas pilotos empleadas}

Para la realización de los ensayos de caracterización en planta se dispuso de dos plantas pilotos pertenecientes al Departamento de Ingeniería Química y Nuclear de la Universidad Politécnica de Valencia.

Unidad 1: Planta de módulos individuales en paralelo:

El diagrama de esta planta puede observarse en la Ilustración 47. Puede trabajar a presiones entre 10 y 60 bar, disponiendo de termómetro de alimentación común y manómetros de medida de la presión a la entrada de cada módulo.

Esta planta dispone de cuatro módulos cilíndricos con un diámetro interno de 4 $\mathrm{cm}$ dispuestos en paralelo como los representados en la Ilustración 45. Permite la caracterización de pequeños recortes circulares de membrana (ver Tabla 32). Los módulos presentan la desventaja de una mayor concentración por polarización debido a que la velocidad del fluido no es alta en las cercanías de la membrana. La muestra de membrana debe tener un diámetro de $5.5 \mathrm{~cm}$ y apoya sobre una placa metálica agujerada uniformemente existente en la base del módulo. El cierre se efectúa mediante un tornillo que ejerce presión sobre el casquillo hueco del módulo, el cual a su vez comprime la membrana contra la base. Es conveniente el recubrimiento del extremo del 
casquillo y de la base con sendas coronas circulares de plástico adhesivo para lograr una estanqueidad perfecta.

Es una planta apta para hacer evaluaciones rápidas y que permite el remplazamiento de un módulo que presente una membrana fallida sin interrumpir la experiencia.

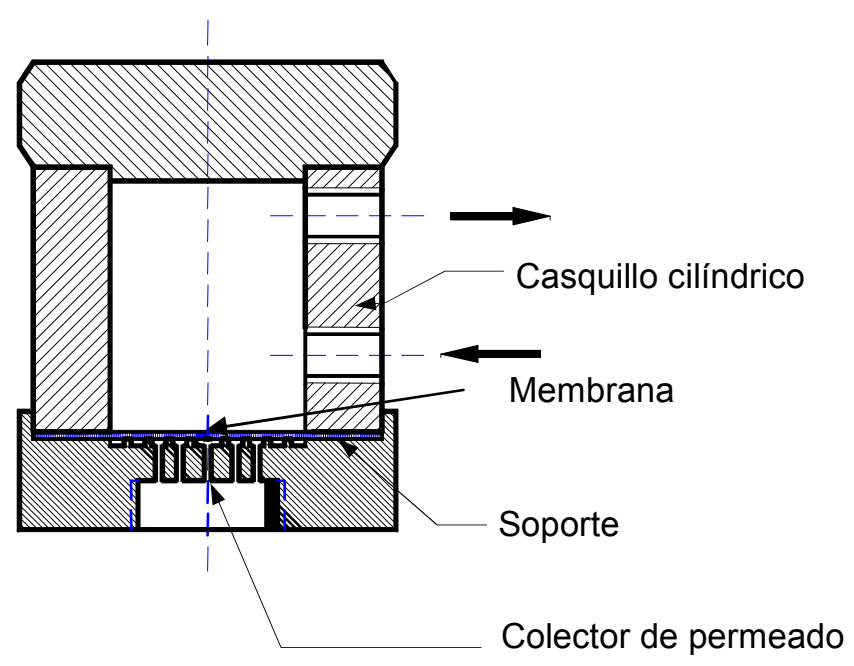

Ilustración 45. Módulo cilíndrico individual

Unidad 2: Planta de módulos de placas en serie.

El diagrama de esta planta puede observarse en la Ilustración 48. Puede trabajar a presiones entre 5 y 60 bar y utiliza un módulo de placas en serie con un diámetro interno de $10 \mathrm{~cm}$ con posibilidad de montar 4, 6 u 8 membranas de la forma indicada en la Ilustración 46. La planta dispone de un manómetro de entrada a los módulos y uno de salida. El dato de presión para esta planta se toma como el promedio de ambos. Las membranas deben recortarse con un diámetro de unos $12 \mathrm{~cm}$ y deben perforarse en posiciones determinadas correspondientes a las aberturas de entrada y salida de alimentación de cada placa, así como en la posición de los tetones de sujeción de cada anillo. Si la perforación de la membrana se ajusta a las áreas de abertura, la pérdida de carga en el módulo será inferior a 1 bar. Las membranas también apoyan sobre una placa con distribución uniforme de agujeros, apoyando esta a su vez sobre una placa 
recolectora de permeado. Las placas se mantienen presionadas mediante un gato de 15 Tm de fuerza y es recomendable el uso de coronas circulares de plástico adhesivo o de teflón para lograr un mejor sellado entre los casquillos, la membrana y las bases.

Es una planta apta para hacer ensayos largos y que permite evaluar mayores superficies de membrana que la anterior. Otra de sus ventajas es que posee poca concentración por polarización.

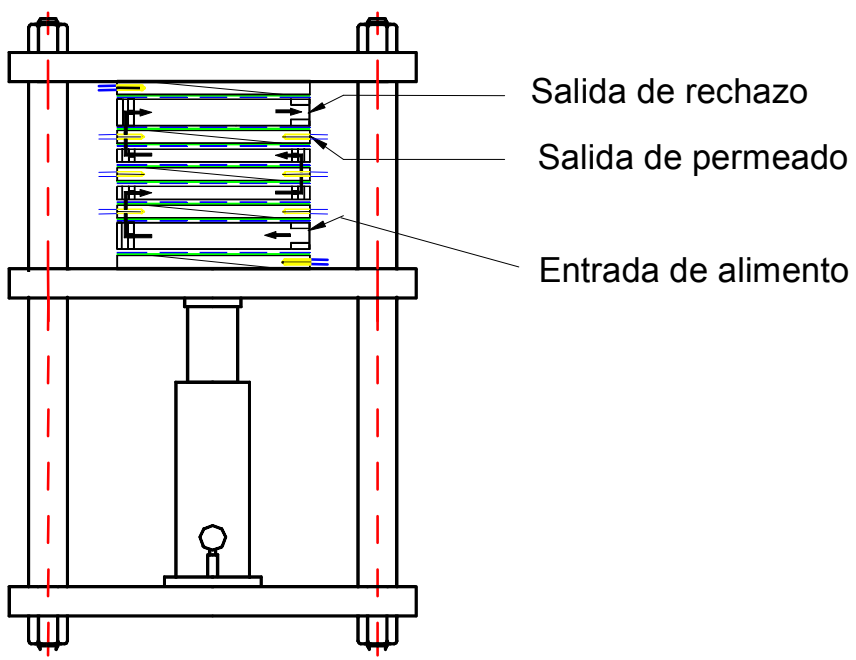

Ilustración 46. Módulo de placas cilíndricas

Operación y mantenimiento de las plantas:

Las plantas disponen de bomba centrífuga cebadora y filtros antes de pasar por la bomba de pistones que es la que produce la mayor parte de la presión. En particular es importante la limpieza periódica de filtros, debiéndose controlar su estado con el manómetro auxiliar instalado para detectar cavitación. Los filtros son de tela y pueden limpiarse con una disolución al 10\% de ácido acético.

Las plantas precisan también la renovación del aceite de las bombas de pistones cada 3 meses de uso.

Es muy importante arrancar las plantas con las válvulas completamente abiertas para irlas cerrando gradualmente con vistas a evitar el deterioro de la planta o daños a las membranas. 

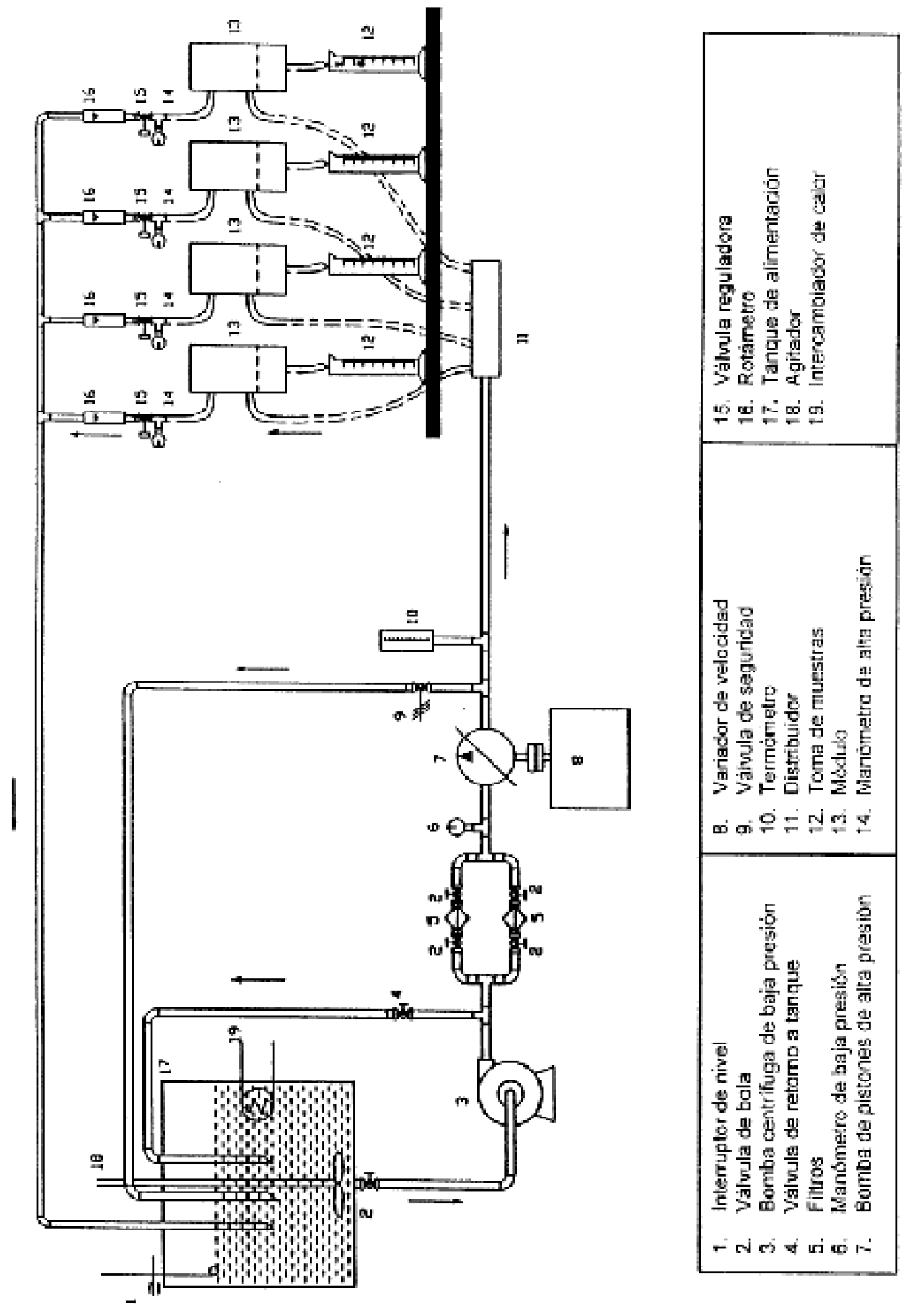

Ilustración 47. Planta piloto (unidad $n^{\circ} 1$ ) para pruebas en osmosis inversa y nanofiltración. 

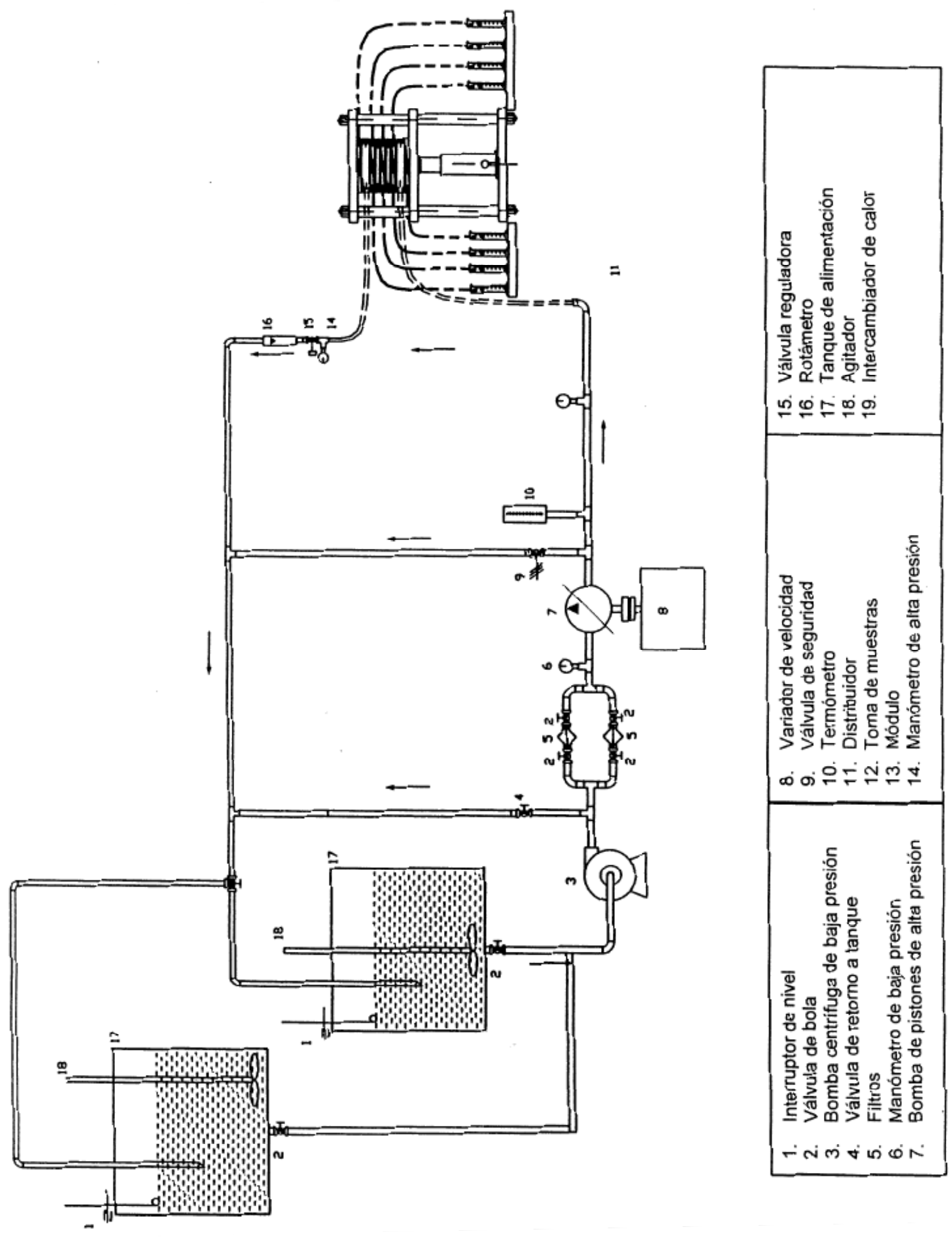

Ilustración 48. Planta piloto (unidad $n^{\circ}$ 2) para pruebas en osmosis inversa $y$ nanofiltración. 


\section{Condiciones experimentales}

Como ya se ha indicado se pretende tener unas condiciones de caracterización estandarizadas por lo que se fijaron los siguientes parámetros:

Concentración estándar del alimento:

Como alimento estándar para comparación se fijó el cloruro sódico con una concentración de 2000 ppm.

Devolución de permeados al tanque de alimentación para mantener la concentración:

La devolución de permeados al tanque de alimentación se realiza con el fin de mantener la composición del alimento constante durante el experimento. Esto se realizaba de manera continua a través de un sistema de recolección del permeado cuando no se estaba tomando muestras. Los permeados analizados también se retornaban al tanque de alimentación. Inevitablemente se pierde algo de permeado y también agua por evaporación, por lo que el tanque era renovado al detectarse un aumento de su conductividad superior al $10 \%$ o ensuciamiento del alimento.

\section{Temperatura:}

Se buscaba mantener la temperatura del alimento entre 20 y $25^{\circ} \mathrm{C}$ controlándose su valor durante la experiencia y anotándose ésta en el momento de las medidas de flux y rechazo. Al funcionar el sistema como un circuito cerrado el alimento se calienta progresivamente por lo que se utilizaba un serpentín refrigerador para mantenerla dentro del rango fijado. 
Flujo de alimentación:

Para la unidad 1 se fijó un flujo de alimentación de trabajo de $80 \mathrm{~L} \cdot \mathrm{h}^{-1}$ por módulo individual.

Para la unidad 2 el flujo de alimentación fue de $400 \mathrm{~L} \cdot \mathrm{h}^{-1}$ transcurriendo por los módulos de placas en serie.

Índice de $\mathrm{pH}$ de trabajo:

El pH de trabajo se fijó dentro de un rango comprendido entre 5.5 y 6.0, valores entre los cuales el comportamiento permeoselectivo del acetato de celulosa es óptimo.

Presiones de trabajo:

Las presiones de trabajo estudiadas fueron 10, 20, 30 y 40 bar, considerándose 30 bar como el valor de referencia.

Tiempos de ensayo:

En un ensayo típico la planta se arranca con las válvulas abiertas y se mantiene 10 min a una presión de 1 a 2 bar observando la existencia de posibles fugas en el módulo y dejando que la membrana se adapte lentamente a la base del módulo.

Transcurrido el tiempo inicial se tiene un mínimo de 2 hora a 10 bar, tiempo tras el cual se pueden tomar medidas correspondientes a esta presión. A partir de la medida de presión a 10 bar se puede pasar a otras presiones en orden creciente, funcionando a la presión a la que se va a medir al menos 2 horas. 


\section{Procedimiento de medida del flux}

La medida del flux se realizaba a partir de una medición de los caudales de permeado por el método de aforo. Cada salida del permeado correspondiente a una membrana concreta se encontraba conectada a un tubo de silicona. Aunque los tubos de silicona se seleccionaron con un diámetro pequeño para evitar la presencia de burbujas de aire que al ser arrastradas pudieran falsear la medida, éstas aparecían ocasionalmente. Comprobada la no presencia de burbujas cada tubo de silicona se introducía en una probeta limpia y seca para llenar un volumen de 10 a $15 \mathrm{ml}$, midiéndose el tiempo necesario para ello. El dato de flux característico de la membrana se obtenía a partir de las constantes del módulo de la Tabla 32 como:

Ec. 84

$$
\text { Flux }\left(L \cdot m^{-2} \cdot \text { día }^{-1}\right)=\frac{\text { Volumen }(\mathrm{ml})}{\text { Tiempo }(\mathrm{min})} \times \text { Constante del módulo }
$$

\section{Tabla 32. Constantes de los módulos}

\begin{tabular}{|l|c|c|}
\hline \multicolumn{1}{|c|}{ Módulo } & $\begin{array}{c}\text { Área efectiva de membrana } \\
\left(\mathrm{cm}^{2}\right)\end{array}$ & $\begin{array}{c}\text { Constante del módulo } \\
\left(\mathrm{L} \cdot \mathrm{m}^{-2} \cdot \mathrm{dia}^{-1}\right) /\left(\mathrm{ml}^{\prime} \mathrm{min}^{-1}\right)\end{array}$ \\
\hline CILINDRO INDIVIDUAL & 12.57 & 1146.00 \\
\hline PLACAS & 78.54 & 183.35 \\
\hline
\end{tabular}

\section{Procedimiento de medida del índice de rechazo}

Como método analítico para determinar la concentración de los permeados se escogió la conductimetría. Para ello se introducía una sonda conductimétrica lavada en agua destilada en las muestras de permeado recogidas en la medida del flux junto con una sonda de temperatura y se apuntaba el dato de medida una vez estabilizado. Una vez analizados los permeados, también se analizaba una muestra de la disolución alimento recogida en el mismo tiempo en el que estos se obtuvieron. El aparato disponía de 
corrección interna de la conductividad para referir las medidas a una temperatura de 25 ${ }^{\circ} \mathrm{C}$. Previamente a las mediciones, éste se calibraba y se ajustaba la constante de celda.

Al no ser las concentraciones excesivamente elevadas se cumplía una relación de linealidad bastante aproximada entre la conductividad a una misma temperatura y la concentración, tal y como se puede observar en la Ilustración 49. De esta forma el índice de rechazo aparente se podía evaluar como:

Ec. $85 \quad R_{a}=\frac{C_{a}-C_{p}}{C_{a}} \approx \frac{\Lambda_{a}-\Lambda_{p}}{\Lambda_{a}}$

CONCENTRACIÓN (ppm)

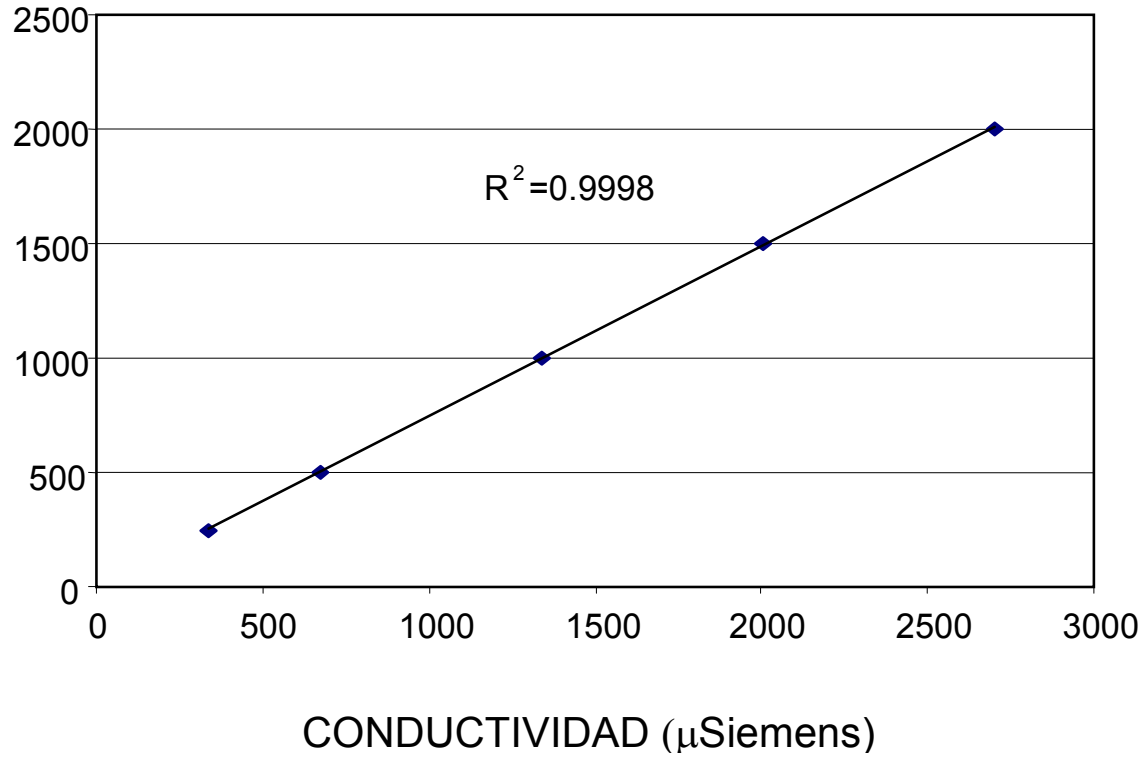

Ilustración 49. Curva de calibrado del conductímetro Crison utilizado para la medida de concentraciones de $\mathrm{NaCl}$. Conductividad corregida a $25^{\circ} \mathrm{C}$ 


\section{Otras variables experimentales}

En la caracterización en planta, además del flux y el rechazo bajo unas condiciones dadas, se puede obtener información adicional sobre otras características de la membrana.

Ensuciamiento:

Debido a la naturaleza del alimento utilizado, en principio no debería producirse. Sin embargo en ensayos largos se producirá casi inevitablemente ensuciamiento de la membrana por la presencia en la disolución de trazas de aceite proveniente de la bomba, restos de degradación de las conducciones y otros elementos, materia orgánica e inorgánica ya presente en el agua o llegada en forma de polvo al tanque.

El ensuciamiento era patente tras la retirada de las membranas. Si bien se observó mayor tendencia a ensuciarse en las membranas de mayor flux, sin embargo no se hicieron estudios sobre el ensuciamiento, utilizándose esta información a efectos de mantenimiento de la planta y de renovación de las disoluciones ya que el ensuciamiento afecta a los resultados de flux.

\section{Degradación físico-química y biológica:}

Las membranas de acetato de celulosa presentan cierta resistencia al cloro libre disuelto en el agua, sin embargo la degradación biológica sí que puede darse, siendo apreciada como una pérdida de la selectividad. No obstante, la permanencia de las membranas en el módulo, nunca superior a 7 días impedía la percepción de una degradación biológica apreciable. 
Acomodamiento y compactación:

Al cambiar bruscamente la presión de trabajo actuante sobre la membrana, no se obtenía instantáneamente la respuesta de régimen correspondiente a las nuevas condiciones, observándose un transitorio en el flux y el rechazo. Si bien la membrana presenta una cierta elasticidad, para tiempos de ensayo largos se puede producir compactación de la membrana lo cual se aprecia como una disminución del flux producido y un pequeño aumento del rechazo.

\section{Obtención de los parámetros de transporte}

Los parámetros de transporte se van a estimar a partir de la medida del flux y rechazo de la membrana utilizados. En particular se obtendrán los parámetros de permeabilidad al agua $A$ y el factor de paso de sal $B$ y se interpretarán desde el punto de vista del análisis de Kimura - Sourirajan presentado en la Introducción de esta Tesis, buscándose obtener información sobre espesor de capa activa o presencia de imperfecciones.

En la interpretación de los parámetros hay que tener en cuenta la influencia de la concentración por polarización haciendo que el rechazo real y el observado no coincidan. En nuestro caso, el efecto de la concentración por polarización depende en última instancia de la geometría del módulo al haberse fijado el estado de turbulencia del alimento, la temperatura y la concentración de trabajo.

Para obtener los parámetros a partir del flux volumétrico $J_{v} \mathrm{y}$ el rechazo observado $R_{a}$ se utilizarán las siguientes transformaciones matemáticas:

Ec. 86

$$
A=\frac{J_{v}}{\Delta P-\Delta \pi}=\frac{J_{v}}{\Delta P-2 / M_{\mathrm{NaCl}} \cdot R \cdot T \cdot \Delta C_{s}}=\frac{J_{v}}{\Delta P-2 / M_{\mathrm{NaCl}} \cdot R \cdot T \cdot \mathrm{Ca} \cdot R_{a}}
$$

Ec. 87

$$
B=\frac{J_{s}}{\Delta C_{s}}=\frac{J_{s}}{J_{v}} \cdot \frac{J_{v}}{(C a-C p)}=C p \cdot \frac{J_{v}}{\frac{C p}{1-R_{a}}-C p}=J_{v} \cdot \frac{1-R_{a}}{R_{a}}
$$




\subsection{DISEÑO DE EXPERIMENTOS.}

\section{Planificación experimental}

Dentro de la realización experimental de la Tesis podemos distinguir las siguientes fases (Ilustración 50):

- Búsqueda de información y planificación: Estudio bibliográfico previo, selección de materiales y definición del método.

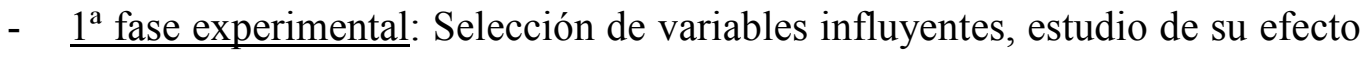
y determinación de rangos de trabajo utilizando el método manual de fabricación de membranas.

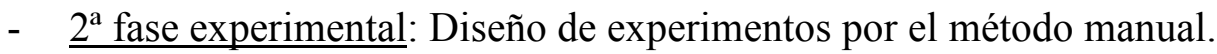

En la primera fase experimental se realizan experimentos y se analizan para estudiar el efecto de las variables y plantear nuevos experimentos con vistas a determinar las variables más importantes.

En la segunda fase se utilizan las variables seleccionadas en la anterior con vistas a estudiar la optimización mediante el método manual. Adicionalmente se realizan experiencias de fabricación en máquina. 


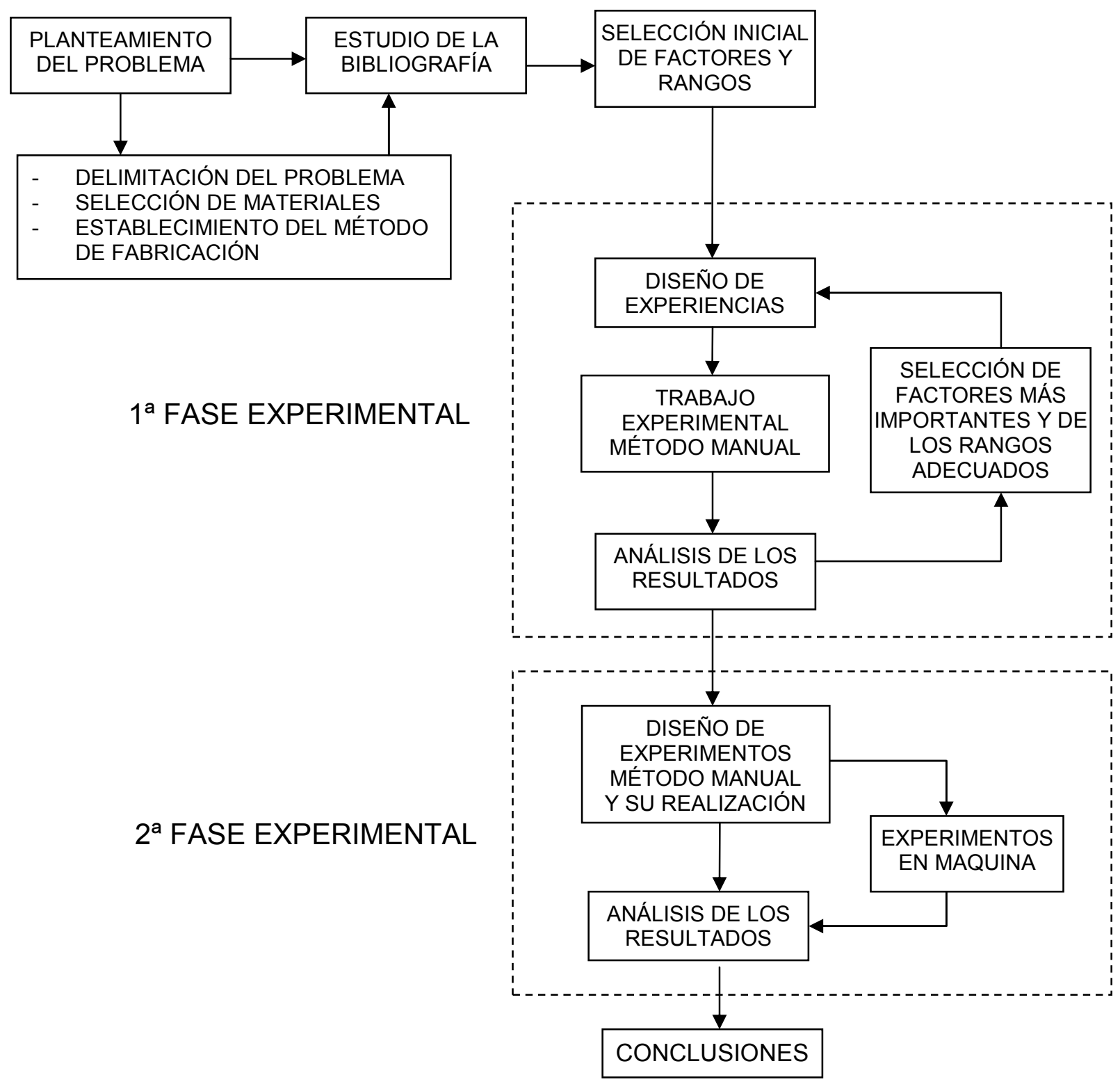

Ilustración 50. Planificación metodológica de la Tesis 


\section{Metodología de organización de la información.}

Para la elaboración de membranas por el método de inversión de fase, se siguieron los pasos detallados en la Tabla 30. Analizando el proceso de fabricación se observó que existía libertad para decidir entre determinadas opciones o fijar unos valores de parámetros que influían sobre variables que se pretendían estudiar. Estas variables o decisiones que podemos controlar en el diseño de la experiencia son denominadas "factores controlables" y las variables sobre las que pretendemos estudiar el efecto de los valores de las anteriores son conocidas como "variables respuesta". Las variables respuesta pueden verse también influidas por "variables no controladas", las cuales pueden ser conocidas o desconocidas. Muchas de estas variables no controladas son aleatorias y su efecto crea dispersión de los resultados cuando los pretendemos explicar a partir de los factores controlables.

Tanto los factores como las variables respuesta pueden ser clasificados como cualitativos o cuantitativos. Las variables cualitativas son decisiones o condiciones que no pueden ser expresadas numéricamente como una variable continua dentro de un determinado rango a diferencia de las variables cuantitativas que sí pueden serlo.

Como el número posible de factores a estudiar era muy grande, el estudio se centró en unos cuantos factores significativos, los cuales se seleccionaron teniendo en cuenta los aspectos referentes a la formación de membranas expuestos en la Introducción de esta Tesis. Aquellos factores de fabricación con probabilidad de ejercer influencia en las características finales de la membrana fabricada se seleccionaron como "factores de fabricación referentes al colodión y al proceso" (Tabla 33, Tabla 34 y Tabla 35) y se apuntaron como descriptivos de una membrana concreta. Los "factores de caracterización en planta" (Tabla 36) también influyen en los resultados, pero puesto que el objetivo principal de esta Tesis es la influencia de las variables de caracterización, se estandarizaron en la medida de lo posible. Otros factores distintos a los presentados en las tablas (principalmente de tipo cualitativo) han sido incluidos cuando se ha considerado conveniente como anotaciones, por si pudieran explicar algún tipo de comportamiento diferente al esperado de la consideración de los otros factores. 


\begin{tabular}{|c|c|}
$\begin{array}{c}\text { Tabla 33. Factores cualitativos de fabricación } \\
\text { significativos }\end{array}$ \\
\hline 1. Tipo de polímero \\
2. Tipo de disolvente \\
3. Tipo de aditivos o su ausencia \\
4. Tipo de soporte no-tejido \\
5. Tipo de enrasador empleado \\
6. Tipo de aditivos empleados en el baño \\
7. Tipo de tratamiento térmico empleado
\end{tabular}

Tabla 34. Factores cuantitativos de fabricación referentes al colodión y sus rangos estudiados

\begin{tabular}{|l|c|}
\hline \multicolumn{1}{|c|}{ Factor } & Rango estudiado \\
\hline 1. Relación polímero A / polímero B & $1: 01: 1$ \\
2. Concentración de polímero total & $18-25 \%$ \\
3. Concentración de aditivo & $0-2 \%$ \\
\hline
\end{tabular}

Tabla 35. Factores cuantitativos de fabricación referentes al proceso de fabricación y rangos estudiados

\begin{tabular}{|l|c|}
\hline \multicolumn{1}{|c|}{ Factor } & Rango estudiado \\
\hline 4. Espesor de deposición & $30-100$ micras \\
5. Temperatura de evaporación & Ambiente \\
6. Tiempo de evaporación & $15-120 \mathrm{seg}$ \\
7. Concentración de disolvente en el baño de & $0 \%$ (usual) $-30 \%$ \\
coagulación & \\
8. Temperatura de coagulación & $10 \mathrm{~min}$ \\
9. Tiempo de coagulación & $75^{\circ} \mathrm{C}-100^{\circ} \mathrm{C}$ \\
10. Temperatura de tratamiento térmico & $30-600 \mathrm{seg}$ \\
11. Tiempo de tratamiento térmico & \\
\hline
\end{tabular}


Tabla 36. Factores de la caracterización en planta

\begin{tabular}{|l|c|}
\hline \multicolumn{1}{|c|}{ Factor } & Rango estudiado \\
\hline 1. Presión manométrica media entre la entrada y & $10,20,30,40 \mathrm{bar}$ \\
salida del módulo & \\
2. Temperatura de trabajo & $15-30{ }^{\circ} \mathrm{C}$ (usual $20^{\circ} \mathrm{C}$ ) \\
3. pH de trabajo & $5.5-6.0$ \\
4. Caudal de alimentación & $400 \mathrm{~L}^{-1} \mathrm{~h}^{-1}$ \\
5. Tiempo de prueba & $>2 \mathrm{~h}$ \\
\hline
\end{tabular}

Las variables respuesta principales seleccionadas (Tabla 37) fueron el flux y el rechazo referido al componente seleccionado que era en la mayoría de los casos cloruro sódico. Estas variables son las más interesantes desde el punto de vista de la utilidad de la membrana. Sin embargo conviene combinarlas matemáticamente utilizando los modelos descritos en la Introducción para obtener variables relacionables con parámetros físico - químicos de la membrana.

\begin{tabular}{|l|}
\hline Tabla 37. Variables respuesta estudiadas \\
Variables principales de la caracterización en planta: \\
1. Flux de la membrana \\
2. Rechazo a las sales de la membrana \\
3. Transformaciones matemáticas de las anteriores \\
variables: \\
A: Permeabilidad al disolvente \\
B: Factor de paso de soluto \\
A ${ }^{2}$ B: Nivel de comportamiento \\
Variables morfológicas de la membrana: \\
4. Espesor depositado \\
5. Masa de polímero depositada \\
6. Etc.
\end{tabular}




\section{Metodología de diseño de experiencias para su análisis}

En el estudio de la influencia de los factores en la membrana no se consideraron todos los factores a la vez, sino que se seleccionaron un grupo pequeño de factores ("factores clave") elegidos entre los más influyentes con vistas a simplificar los estudios.

En la primera fase experimental se estudió el efecto de factores influyentes descritos en la bibliografía modificándolos, manteniendo constante el resto de variables. También se investigaron posibles nuevos factores, así como factores cualitativos.

La estrategia de diseño de experimentos típica de las primeras etapas de la investigación utiliza usualmente diseños factoriales de $2^{\mathrm{k}}$ experiencias para reducir el número de factores relevantes a partir de un número relativamente elevado de posibles factores. Sin embargo debido al elevado número de experiencias realizadas en la primera fase experimental de la Tesis, se utilizaron las conclusiones derivadas de estas experiencias para fijar un reducido número de variables clave y sus rangos utilizando posteriormente la técnica de diseño de superficie de respuesta.

En la segunda fase se empleóla metodología de diseño de superficies de respuesta, la cual aproxima un polinomio de segundo grado y permite la localización de máximos para las variables respuesta. Se encontró como diseño más adecuado el diseño de Box-Behnken, el cual se puede utilizar cuando se tienen tres o más factores. Al igual que los diseños factoriales utiliza para los factores los valores inferior, superior y central de los rangos predefinidos. Aunque para más de cuatro factores requiere mayor número de experiencias que otros diseños posibles (Draper-Lin, cubo-estrella, etc.) presenta la ventaja respecto de estos de utilizar solamente los valores inferior, superior y central de los rangos, lo cual nos interesa en particular en el factor "Espesor de enrasador manual" donde no disponemos de valores continuos. Los diseños factoriales también presentan la anterior ventaja y tienen más grados de libertad pero requieren un mayor número de experiencias. El diseño de Box-Behnken constituye pues un compromiso aceptable para la comparación de los resultados de fabricación manual y los de máquina. 


\section{RESULTADOS Y DISCUSIÓN}





\section{RESULTADOS Y DISCUSIÓN}

En este capítulo se presentan los resultados experimentales marcados en los objetivos de esta Tesis. Para su obtención se han seguido las pautas establecidas en la sección de metodología.

Los resultados se presentan divididos en las siguientes secciones:

1. Estudio de los diagramas de composición ternarios

2. Preparación y caracterización de colodiones

3. Preparación y caracterización de membranas

4. Estudios de viabilidad para la fabricación en máquina

En la primera sección se presentan los resultados obtenidos en cuanto a diagramas de composición, los cuales resultan útiles para la interpretación de los resultados de formación de membranas. Se utiliza en esta sección el modelo teórico junto con una serie de datos extraídos de la bibliografía que son difíciles de determinar en el laboratorio.

En la segunda sección se describe de forma breve los resultados encontrados durante la preparación de los colodiones empleados.

La tercera sección es la más amplia de todas. En ella se incluyen las condiciones de fabricación de las membranas y la caracterización de éstas en planta piloto. Se busca establecer la influencia de las variables de fabricación en las características de las membranas.

Finalmente se presentan algunos resultados de fabricación en máquina obtenidos atendiendo a las conclusiones derivadas del anterior apartado. Las experiencias realizadas en este apartado tuvieron que limitarse bastante debido al elevado consumo de materiales empleados en una sesión de fabricación. 


\subsection{DIAGRAMAS DE COMPOSICIÓN}

El estudio de los diagramas de composición se ha basado en los datos experimentales obtenidos, así como en la utilización del modelo físico-matemático presentado en el Anexo de esta Tesis. Los datos más importantes son los concernientes a la curva binodal, ya que nos indican cuando se va a producir la separación de fases. Esta curva se ha estudiado experimentalmente para las distintas variedades de acetato de celulosa utilizadas en la fabricación de membranas y para los disolventes dimetilacetamida y acetona con el fin de estudiar los efectos de una modificación de los materiales.

También se ha podido determinar experimentalmente el equilibrio entre agua y polímero, lo que ha permitido determinar el coeficiente de interacción binario acetato de celulosa - agua. Fijado este parámetro se han modificado los otros dos hasta lograr aproximar la curva binodal calculada mediante el modelo de cálculo del Anexo de esta Tesis a la curva binodal experimental.

El modelo se ha utilizado posteriormente para corroborar la información obtenida de los datos experimentales.

\subsubsection{Datos experimentales de la curva binodal}

En la Tabla 38 quedan resumidas las condiciones en las que se apreció el punto de separación entre fases cuando se partía de disoluciones poco concentradas en polímero AC3 y se añadían pequeñas cantidades de agua como agente precipitante.

Los datos se encuentran representados en la Ilustración 51 para las temperaturas de $25^{\circ} \mathrm{C}, 12{ }^{\circ} \mathrm{C}$ y $2{ }^{\circ} \mathrm{C}$ que es la mínima temperatura práctica que se puede alcanzar en el baño de coagulación sin problemas de formaciones locales de cristales de hielo. 
Como era de esperar un aumento de temperatura aumenta la solubilidad entre componentes reduciéndose la zona de separación de fases. Esto se aprecia como un desplazamiento de las curvas hacia la derecha. La diferencia entre las curvas para los rangos de temperatura estudiados no es muy acusada. Se observa además que la distancia entre las curvas binodales correspondientes a 2 y $12^{\circ} \mathrm{C}$ es menor que la existente entre la de 12 y $25^{\circ} \mathrm{C}$, por lo que el efecto de la temperatura no es lineal.

\begin{tabular}{|c|c|c|c|c|c|c|c|c|c|}
\hline $\mathrm{T}^{\mathrm{a}}:$ & & $2^{\circ} \mathrm{C}$ & & & $12^{\circ} \mathrm{C}$ & & & $25^{\circ} \mathrm{C}$ & \\
\hline$\%$ Pol. & $x_{p}$ & $x_{d}$ & $x_{n}$ & $x_{p}$ & $x_{d}$ & $x_{n}$ & $x_{p}$ & $x_{d}$ & $x_{n}$ \\
\hline 15.2 & 0.1311 & 0.7302 & 0.1401 & 0.1290 & 0.7282 & 0.1429 & 0.1283 & 0.7170 & 0.1552 \\
\hline 12.0 & 0.1023 & 0.7502 & 0.1475 & 0.1020 & 0.7485 & 0.1495 & 0.1007 & 0.7383 & 0.1610 \\
\hline 10.0 & 0.0850 & 0.7600 & 0.1550 & 0.0847 & 0.7573 & 0.1580 & 0.0838 & 0.7499 & 0.1663 \\
\hline 8.0 & 0.0671 & 0.7710 & 0.1619 & 0.0669 & 0.7681 & 0.1650 & 0.0661 & 0.7590 & 0.1749 \\
\hline 6.0 & 0.0498 & 0.7795 & 0.1707 & 0.0497 & 0.7774 & 0.1729 & 0.0493 & 0.7705 & 0.1802 \\
\hline 4.0 & 0.0350 & 0.7845 & 0.1805 & 0.0350 & 0.7830 & 0.1820 & 0.0346 & 0.7749 & 0.1905 \\
\hline 2.0 & 0.0161 & 0.7902 & 0.1937 & 0.0160 & 0.7885 & 0.1955 & 0.0159 & 0.7820 & 0.2021 \\
\hline
\end{tabular}

En la Ilustración 52 se representa la comparación de la curva binodal obtenida con el polímero AC3 a $25{ }^{\circ} \mathrm{C}$ con datos experimentales del resto de polímeros utilizados. Tal y como se indica en el apartado 4.1.4 para un polímero dado una mayor cadena polimérica trae como consecuencia una curva binodal desplazada paralelamente hacia la izquierda. Sin embargo, las curvas no siguen claramente la secuencia de masas moleculares derivadas de la viscosidad que es ACE > AC6 > AC3, lo cual puede ser debido a que los acetatos empleados son en realidad distribuciones amplias de pesos moleculares, o bien puede ser indicativo de pequeñas diferencias en la constitución química de los polímeros. 


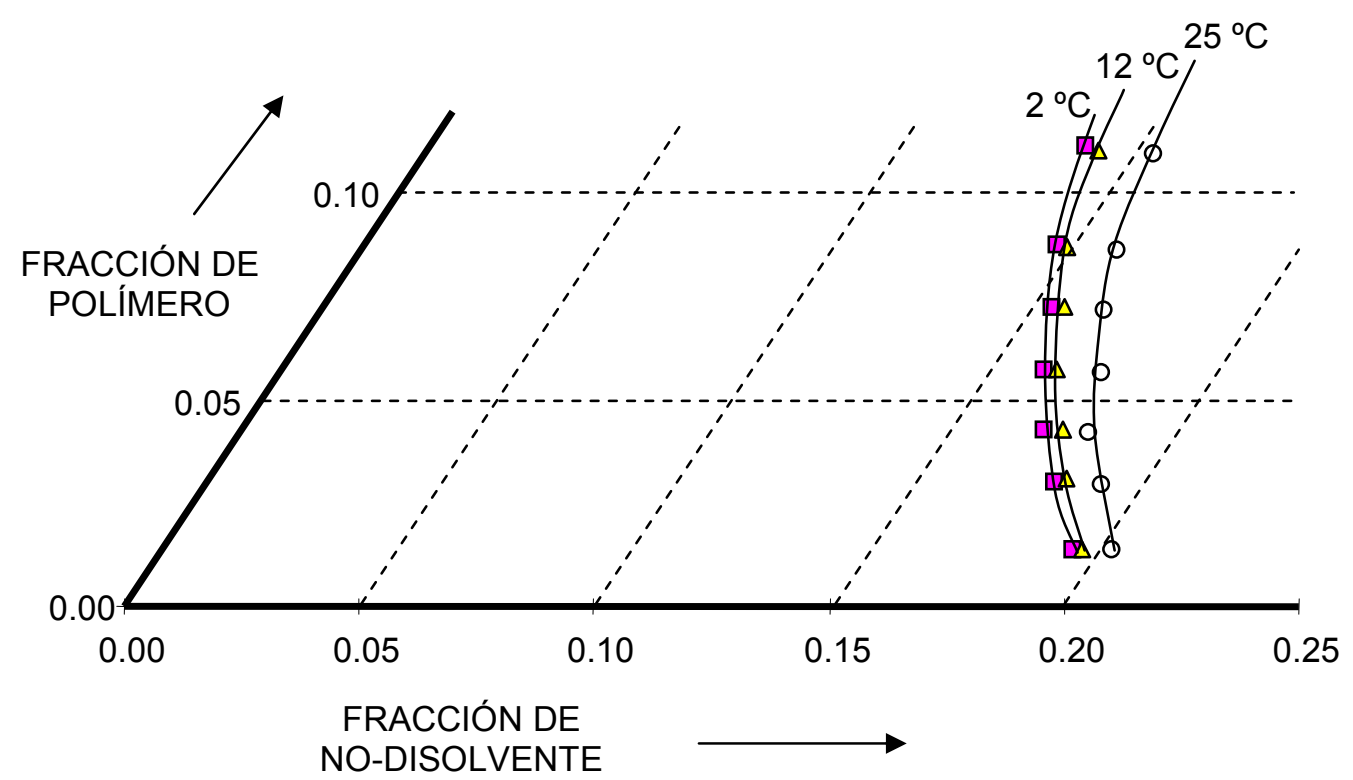

Ilustración 51. Curvas binodales experimentales para tres temperaturas diferentes correspondientes al sistema $\mathrm{AC3} / \mathrm{DMA} / \mathrm{H}_{2} \mathrm{O}$

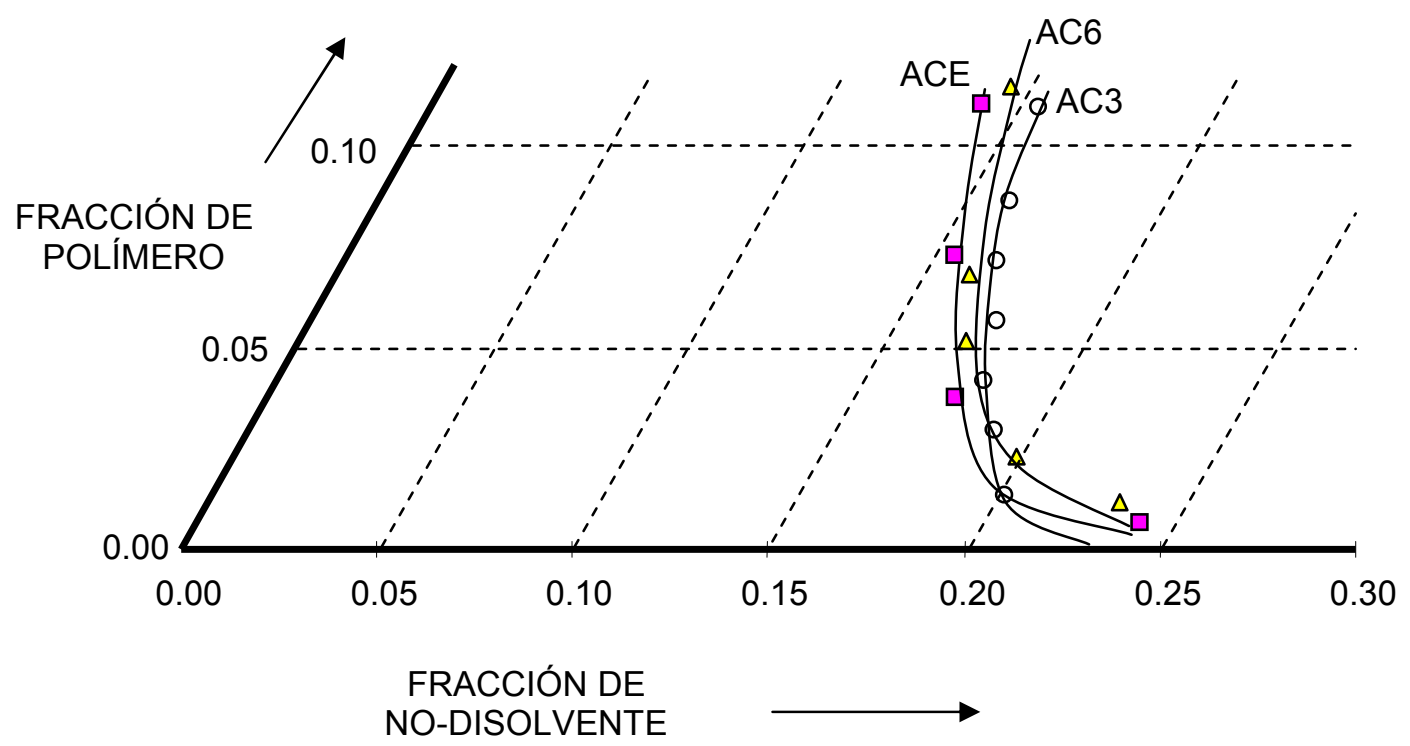

Ilustración 52. Curvas binodales experimentales de sistemas $\mathrm{AC} / \mathrm{DMA} / \mathrm{H}_{2} \mathrm{O}$ a la temperatura de $25^{\circ} \mathrm{C}$ para tres acetatos de celulosa diferentes 
En la Ilustración 53 se representan comparados los datos experimentales obtenidos para los disolventes dimetilacetamida y acetona. La utilización de la acetona produce un curva binodal bastante más desplazada hacia la derecha que la obtenida para la dimetilacetamida. Una combinación de ambos disolventes en la misma proporción produce una curva más cercana a la obtenida para acetona, desplazándose incluso más a la izquierda de ésta para valores bajos de concentración de polímero debido probablemente a un efecto de cosolvencia.

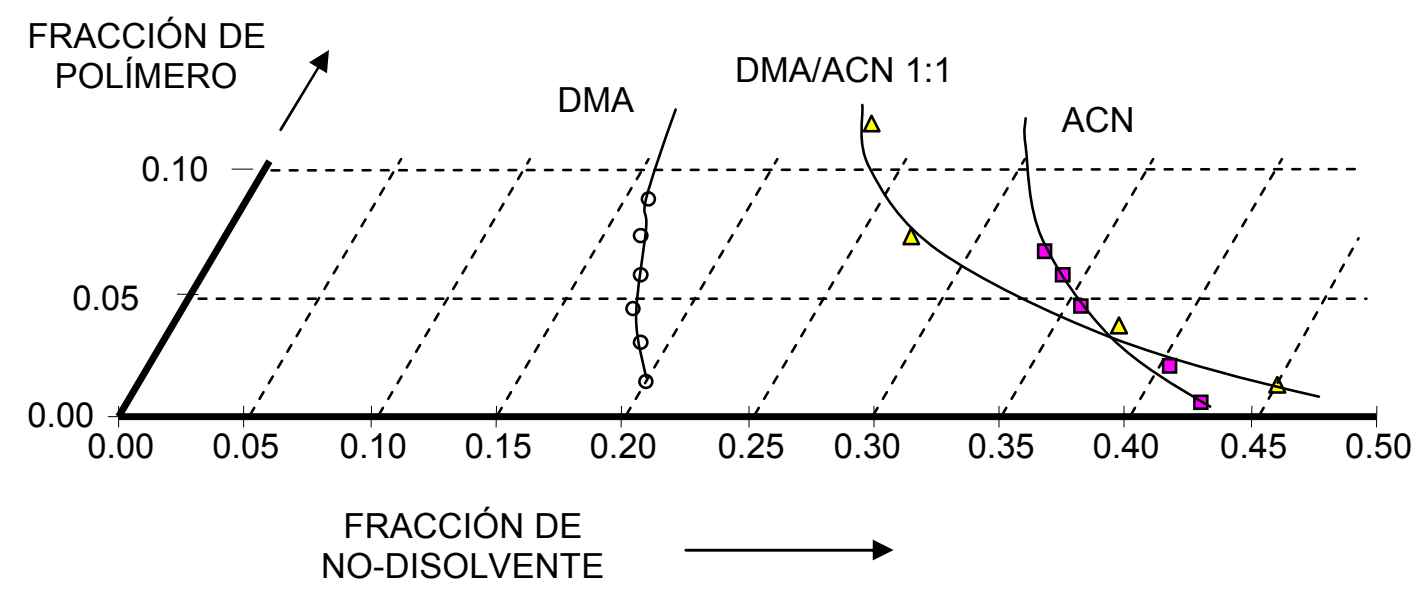

Ilustración 53. Curvas binodales experimentales de sistemas $\mathrm{AC} 3 /$ disolvente $/ \mathrm{H}_{2} \mathrm{O}$ a la temperatura de $25{ }^{\circ} \mathrm{C}$ para los disolventes dimetilacetamida (DMA) y acetona $(A C N)$

Las curvas obtenidas utilizando acetona como disolvente son similares a las presentadas en (Strathmann, 1984; p.182) y (Mulder, 1992; p. 98) para el mismo sistema. Tal y como indican Kang et al. (1991) una binodal más desplazada hacia la izquierda significa una menor tolerancia hacia el no-disolvente y una pequeña cantidad de no-disolvente origina que el polímero se separe rápidamente en dos fases. Esta rapidez en la separación origina según se comentó en el apartado 3.2.3 la formación de membranas tipo 2 asimétricas formadas por una fina capa densa sobre una estructura porosa apta para ósmosis inversa y nanofiltración. Las membranas obtenidas a partir de la dimetilacetamida al estar la binodal más desplazada hacia la izquierda presentarán una asimetría más marcada pero también más alta porosidad en la capa superior por lo 
cual serán necesarios tratamientos térmicos para corregirlo. Las membranas obtenidas con acetona presentarán una capa superior más densa. Kang et al. también indican que una menor tolerancia al disolvente va a ser positiva al permitir la obtención de estructuras con menos defectos y macroporos.

Todo lo mencionado llevó, en resumen, a las siguientes conclusiones que se tuvieron en cuenta en el resto de la investigación:

- La temperatura de coagulación influye relativamente poco comparada con otras variables en el diagrama de fases, si bien se utilizaron baños de coagulación a baja temperatura con vistas a disminuir la cinética del proceso, lo cual es beneficioso desde el punto de vista de formación de la membrana.

- El uso de la dimetilacetamida parece más adecuado que el de la acetona al conseguirse una capa densa de menor espesor, siempre y cuando el tratamiento térmico sea capaz de cerrar los poros.

- La dimetilacetamida comparada con la acetona disminuye el riesgo de formación de macroporos, si bien se emplearán aditivos con vistas a disminuir su posible formación y lograr una estructura inferior esponjosa.

- Los polímeros utilizados parecen no presentar diferencias significativas en cuanto a su comportamiento en el proceso de separación de fases. Las diferencias en su comportamiento se derivarán de su diferente peso molecular lo que origina diferente viscosidad de las disoluciones poliméricas.

- La introducción máxima posible de no-disolvente en los colodiones está alrededor del $10 \%$ en masa. 


\subsubsection{Datos experimentales y bibliográficos de coeficientes binarios}

La obtención del coeficiente de interacción binario polímero - no-disolvente se realizó para el polímero más utilizado (AC3). Los datos promedio de varias experiencias se muestran resumidos en la Tabla 39. Se puede observar que no se obtuvo una dependencia significativa del coeficiente binario con la temperatura.

\section{Tabla 39. Obtención del coeficiente de interacción binario entre polímero (3) y no-disolvente (2) para tres temperaturas diferentes}

\begin{tabular}{|c|c|c|c|c|}
\hline $\begin{array}{c}\text { Temperatura } \\
\text { de absorción } \\
\left({ }^{\circ} \mathrm{C}\right)\end{array}$ & $\begin{array}{c}\text { Densidad del } \\
\text { polímero seco } \\
\left(\mathrm{g} / \mathrm{cm}^{3}\right)\end{array}$ & $\begin{array}{c}\text { Razón másica } \\
\text { de agua } \\
\text { absorbida }\end{array}$ & $\begin{array}{c}\text { Fracción } \\
\text { volumétrica de } \\
\text { polímero } \phi_{p}\end{array}$ & $\begin{array}{c}\text { Coeficiente } \\
\text { binario } \chi_{23}\end{array}$ \\
\hline 2 & 1.31 & 0.1480 & 0.838 & 1.397 \\
\hline 12 & 1.31 & 0.1483 & 0.837 & 1.396 \\
\hline 25 & 1.31 & 0.1462 & 0.839 & 1.404 \\
\hline
\end{tabular}

El coeficiente de interacción disolvente - no-disolvente está relacionado con la energía libre de mezcla entre ambas substancias. Este coeficiente binario no se puede considerar constante ya que la entalpía de mezcla depende fuertemente de la composición como se desprende de la siguiente correlación en función de la fracción másica de agua proporcionada por Christensen et al. (1982):

Ec. 88: $\quad \Delta H_{m}=x \cdot(1-x) \cdot\left[-10.323+6551 \cdot(1-2 \cdot x)-3918 \cdot(1-2 \cdot x)^{2}\right]$

(Medida por calorimetría directa, desviación estándar $=71.75 \mathrm{~J} / \mathrm{mol}$ )

Para obtener la energía libre de exceso en función de la composición se obtuvo un diagrama de equilibrio líquido-vapor a temperatura constante con el programa CHEMCAD - III. El modelo termodinámico escogido fue el UNIQUAC y la energía libre de exceso se calculó a partir de las siguientes ecuaciones: 
Ec. 89: $\quad \gamma_{1}=\frac{P}{P_{\text {sat }}^{25^{\circ} \mathrm{C}}} \cdot \frac{y_{1}}{x_{1}} \quad \gamma_{2}=\frac{P}{P_{\text {sat }}^{25^{\circ} \mathrm{C}}} \cdot \frac{y_{2}}{x_{2}}$

Ec. 90: $\quad \frac{\Delta G^{e x}}{R \cdot T}=x_{1} \cdot \ln \left(\gamma_{1}\right)+x_{2} \cdot \ln \left(\gamma_{2}\right)$

El parámetro de interacción binario se obtuvo a partir de la energía libre de exceso aplicando la Ec. 83. Los resultados alrededor del punto crítico se encuentran en la Tabla 40 .

\begin{tabular}{|c|c|c|c|c|c|}
\hline $\begin{array}{c}P \\
(m m H g)\end{array}$ & $X_{\text {agua }}$ & $Y_{\text {agua }}$ & $G^{e x} / R T$ & $u_{\text {agua }}$ & $\chi_{12}$ \\
\hline 5.815 & 0.200 & 0.727 & 0.095 & 0.954 & 6.634 \\
\hline 6.847 & 0.250 & 0.783 & 0.083 & 0.939 & 5.836 \\
\hline 7.911 & 0.300 & 0.826 & 0.072 & 0.923 & 5.298 \\
\hline 9.004 & 0.350 & 0.859 & 0.062 & 0.905 & 4.907 \\
\hline 10.126 & 0.400 & 0.885 & 0.053 & 0.885 & 4.609 \\
\hline 11.275 & 0.450 & 0.906 & 0.045 & 0.862 & 4.370 \\
\hline 12.447 & 0.500 & 0.924 & 0.038 & 0.837 & 4.172 \\
\hline 13.638 & 0.550 & 0.938 & 0.032 & 0.808 & 4.005 \\
\hline 14.843 & 0.600 & 0.950 & 0.028 & 0.774 & 3.857 \\
\hline
\end{tabular}




\subsubsection{Datos obtenidos del ajuste del diagrama}

Introduciendo en el modelo del Anexo de esta Tesis la información obtenida sobre los coeficientes binarios se pudo modificar las coordenadas asignadas al punto crítico hasta lograr un ajuste adecuado entre los datos experimentales de la binodal y la binodal calculada. Ello permitió obtener la siguiente información:

- Se pudo obtener la situación aproximada del punto crítico. En este punto tienden a converger las líneas de reparto y se encuentra a la vez en la binodal y la espinodal. Resulta interesante para estimar previamente las estructuras que se van a formar, así, si la binodal se alcanza por encima de éste se formarán obtener estructuras consistentes formadas por una fase rica en polímero reticulada. En nuestro caso, parece estar situado a una composición correspondiente a $7-10 \%$ de porcentaje másico de polímero y $15-18 \%$ de no-disolvente. En relación con diagramas de acetato de celulosa / acetona / agua expuestos por otros autores (Mulder, 1992; Strathmann, 1984) el punto crítico se encuentra situado más hacia la izquierda y más bajo debido a la menor solubilidad relativa del polímero en la dimetilacetamida, lo que origina menor tolerancia al no-disolvente.

- Las rectas de reparto permiten determinar las composiciones de las fases formadas. En nuestro caso tienen una inclinación tal que la fase rica en polímero presenta una fracción de disolvente mayor que la fase acuosa. Por lo tanto, tras la coagulación, hace falta un tiempo para que la membrana alcance la composición definitiva es necesario un tiempo para que el disolvente difunda siendo reemplazado por el nodisolvente.

- La región entre la binodal y la espinodal no resulta excesivamente grande por lo que los equilibrios metaestables se darán con mucha improbabilidad, iniciándose la separación de fases una vez atravesada la binodal. Ello hace pensar que la separación de fases va a ocurrir de forma bastante rápida. 


\subsubsection{Efectos calculados de la modificación de parámetros sobre la binodal}

A continuación se presentan los efectos en el diagrama que origina la modificación de los valores de los coeficientes:

\section{Efecto de un cambio del parámetro de interacción (no-disolvente) - disolvente $\chi_{12}$ :}

El efecto de un aumento de este coeficiente como consecuencia de un cambio de disolvente o no-disolvente produce un desplazamiento de la curva binodal hacia la izquierda. Ello se puede apreciar en la Ilustración 54 donde se muestra un cambio de $\chi_{12}$ de 2.13 a 2.23 para $\chi_{13}=0.40 ; \chi_{23}=1.40$ constantes.

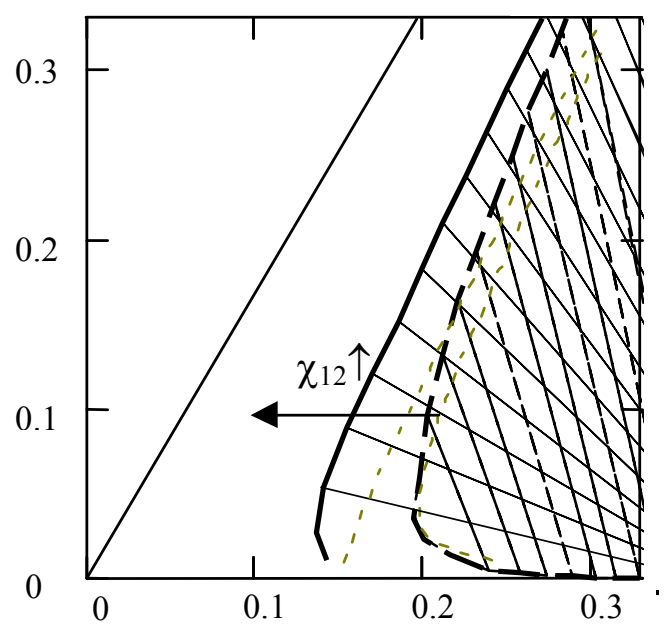

Ilustración 54. Efecto del coeficiente de interacción disolvente - (no-disolvente)

Un mayor valor del coeficiente se corresponde con la utilización de un disolvente de propiedades físico-químicas muy diferentes a las del no-disolvente con tamaño molecular diferente y con energía libre de mezcla con él elevada, tal y como se 
desprende la Ec. 83. Este resultado está de acuerdo con las conclusiones derivadas de la comparación de resultados experimentales entre la dimetilacetamida y la acetona.

\section{Efecto de un cambio del parámetro de interacción disolvente - polímero} $\chi_{13:}$

El efecto de un aumento de este coeficiente como consecuencia de un cambio de disolvente produce un desplazamiento de la curva binodal hacia la derecha. En la Ilustración 55 se muestra el efecto de cambiar $\chi_{13}$ de 0.4 a 0.0 para $\chi_{12}=2.13$ y $\chi_{23}=1.40$. El efecto de este parámetro sobre el desplazamiento de la binodal es menor que el de $\chi_{12} \mathrm{y}$ además la pendiente de las rectas de reparto no se modifica sustancialmente.

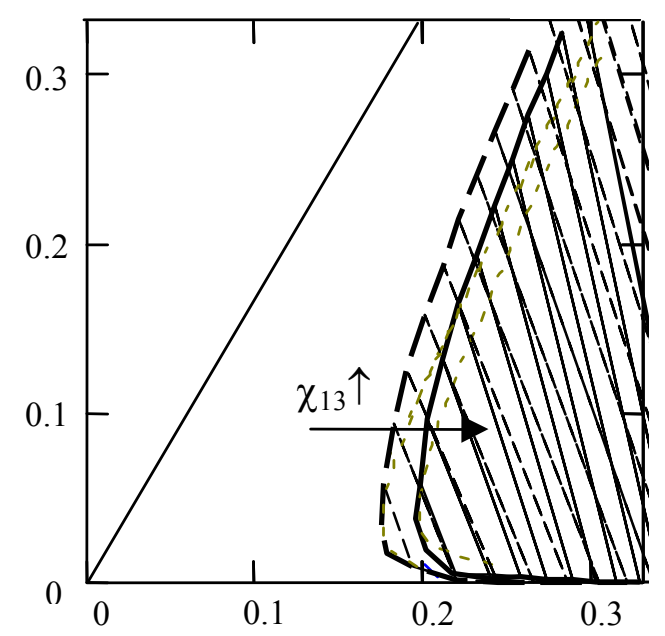

Ilustración 55. Efecto del coeficiente de interacción disolvente - (no-disolvente) 


\section{Efecto de un cambio del parámetro de interacción (no-disolvente) - polímero $\chi_{23}$ :}

El efecto de un aumento de este coeficiente como consecuencia de un cambio de disolvente produce un desplazamiento de la curva binodal hacia la izquierda. En la Ilustración 56 se muestra el efecto de cambiar $\chi_{23}$ de 1.40 a 1.20 para $\chi_{12}=2.13$ y $\chi_{13}$ $=0.40$. El efecto de este parámetro sobre el desplazamiento de la binodal es también menor que el de $\chi_{12}$. La modificación de la pendiente de las rectas de reparto es aún menor que la que se produce variando $\chi_{13}$.

Como se deduce de la Ec. 82 una menor afinidad del polímero hacia el medio no-disolvente origina un aumento de éste parámetro de interacción. Si este efecto predomina sobre la interacción con el disolvente la binodal se desplazará hacia la izquierda favoreciendo una rápida separación de fases.

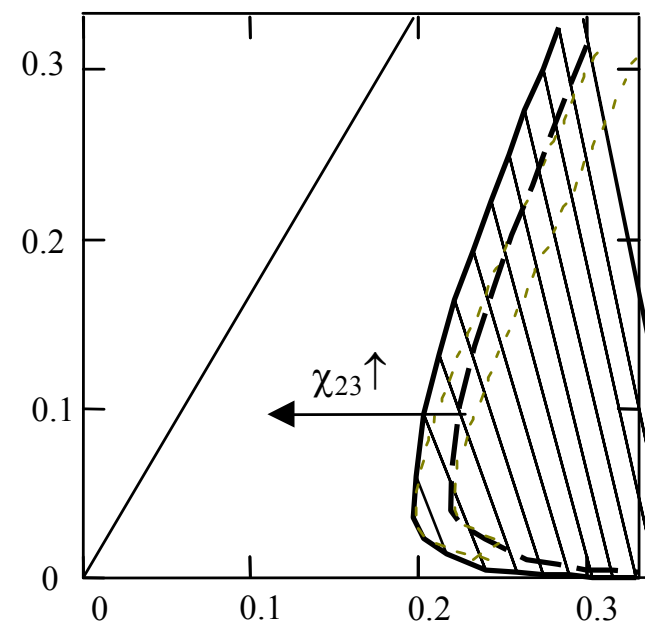

Ilustración 56. Efecto del coeficiente de interacción disolvente - (no-disolvente) 


\section{Efecto de un aumento de la longitud de la cadena polimérica}

Una mayor longitud de las cadenas poliméricas trae consigo un aumento de la masa molecular proporcional al número $\mathrm{n}$ de unidades monoméricas (Para el acetato de celulosa se tendría $\left.\mathrm{M}_{3}=\mathrm{n} \times 265 \mathrm{~g} / \mathrm{mol}\right)$. Se puede considerar además para pesos moleculares grandes una relación lineal aproximada entre masa molecular y volumen de la molécula.

El efecto de un aumento de la longitud de la cadena del polímero en el diagrama se puede apreciar en la Ilustración 57. El aumento apenas desplaza la binodal hacia la izquierda para puntos por encima del punto crítico. Por debajo del punto crítico se observa que la zona cercana al eje disolvente - no-disolvente se desplaza significativamente hacia la izquierda para valores bajos de peso molecular, pero para pesos moleculares altos apenas lo hace, siendo los valores muy cercanos al valor límite teórico para peso molecular infinito. En la Ilustración 57 se presentan los resultados para $\mathrm{n}=10$ y $\mathrm{n}=100$ con $\chi_{12}=$ $2.13, \chi_{13}=0.40, \mathrm{y} \chi_{23}=1.42$.

Zeman y Fraser (1993) obtuvieron mediante técnicas cromatográficas una longitud media de cadena $\mathrm{n}=360$ para el polímero CA-398-3 y $\mathrm{n}=512$ para CA-398-6. Ambas longitudes son lo suficientemente grandes para producir en el modelo teórico curvas binodales muy cercanas entre sí y ya muy próximas al calor teórico para una cadena de longitud infinita.

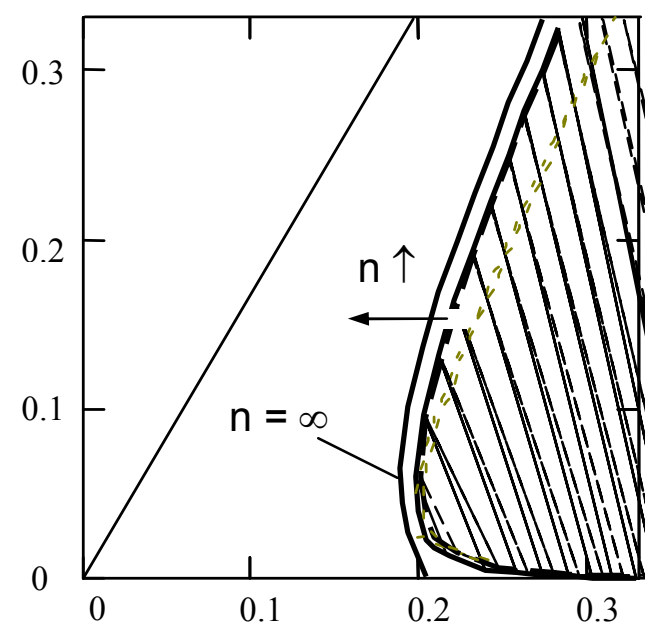

Ilustración 57. Efecto de la longitud de la cadena polimérica 


\subsection{CARACTERIZACIÓN DE COLODIONES}

\section{Resultados concernientes a la fabricación de colodiones}

Los acetatos son un material higroscópico por lo que inevitablemente absorben agua a lo largo del tiempo quedándose en equilibrio de absorción con la humedad ambiental. Aún conservándose en bolsas cerradas siempre han presentado un porcentaje de agua absorbida entre $4-6.5 \%$. No se deben emplear pues en las formulaciones de colodiones sin desecarlos.

\section{TIEMPO DE DISOLUCIÓN (horas)}

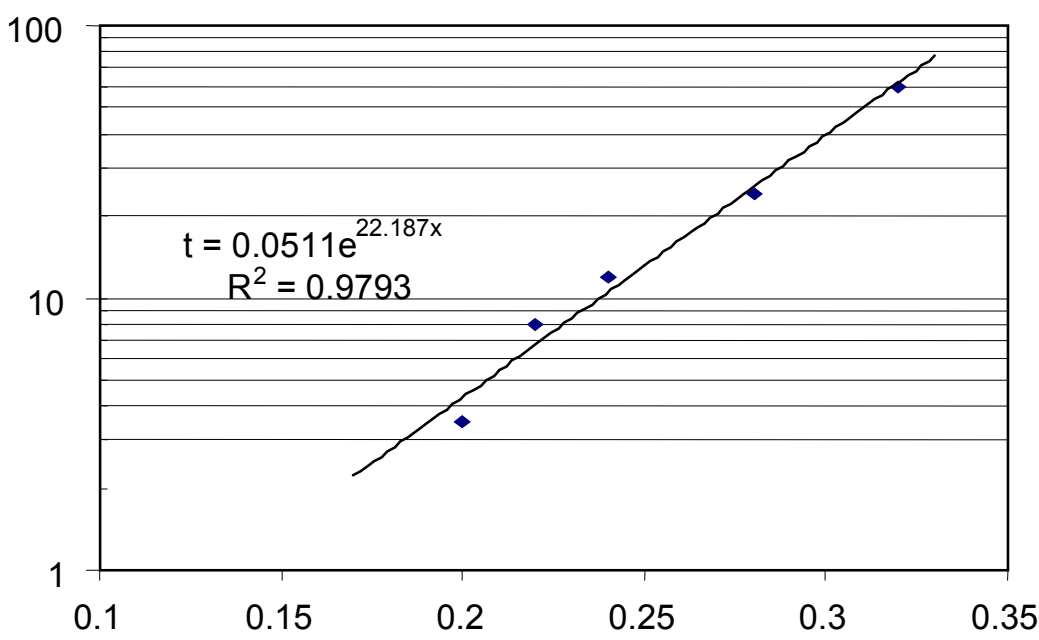

FRACCIÓN MÁSICA DE POLÍMERO

Ilustración 58. Tiempo de disolución completa de disoluciones de acetato de celulosa AC3 en disoluciones de dimetilacetamida (2.5\% de LiCl; Temperatura ambiente).

A la hora de realizar las disoluciones se observó que el tiempo hasta conseguir una homogeneidad visual aparente aumentaba bastante con la concentración tal y como se observa en la Ilustración 58. Para una misma concentración de polímero los tiempos de disolución mayores se corresponden con el polímero ACE y los menores con el AC3, 
encontrándose que a mayor viscosidad de la disolución final mayor tiempo de homogeneización.

No se produjeron problemas de conservación en colodiones cerrados adecuadamente. Los colodiones empleados inmediatamente después de su homogeneización parecieron producir más membranas defectuosas por lo que esto llevó a respetar un tiempo de maduración de dos días en los colodiones antes de su utilización.

\section{Propiedades de los colodiones}

Se estudió la viscosidad y la densidad como posibles factores influyentes en la cantidad de polímero que deposita un enrasador determinado. Algunos valores para colodiones seleccionados se muestran en la Tabla 41.

Se observó que la densidad de los colodiones fabricados dependía principalmente del tipo de polímero. Para los rangos de concentración estudiados $(20-$ $24 \%$ ) las densidades de colodiones en dimetilacetamida del polímero AC3 fueron las más altas con valores de densidad relativa semejantes a 1 . Los colodiones fabricados con AC6 produjeron valores cercanos a 0.91 y los de ACE fueron ligeramente inferiores. Al ser la densidad semejante en todos los colodiones de dimetilacetamida fabricados ésta no resulta una variable importante en la deposición.

La viscosidad final que alcanzan los colodiones resulta en cambio un factor importante en la fabricación de estos (tal y como se ha comentado en el anterior apartado) así como en su manejabilidad y deposición, tanto en el método manual como en la fabricación en máquina. Valores de viscosidad mayores de $15000 \mathrm{cP}$ resultan poco prácticos para conseguir una deposición homogénea. El cloruro de litio, componente añadido en la mayoría de colodiones tiene un fuerte efecto sobre la viscosidad y aumenta la solubilidad del polímero por la solvatación que produce. Este efecto beneficioso puede observarse en la Ilustración 59.

Los colodiones fabricados con acetona produjeron viscosidades a temperatura ambiente inferiores a $5000 \mathrm{cP}$ aún con concentraciones altas (24\%) de polímero. 


\begin{tabular}{|l|c|ccc|c|c|}
\hline \multicolumn{1}{|c|}{ Tabla 41. Propiedades de colodiones típicos en función de la composición } \\
\hline Colodión & Tipo de & Polímero & LiCl & DMA & Viscosidad & Densidad \\
& polímero & $(\%)$ & $(\%)$ & $(\%)$ & $(\boldsymbol{c P})$ & $\left(\boldsymbol{g} \cdot \boldsymbol{c m}^{-3}\right)$ \\
\hline C0 (971201) & ACE & 16.10 & 4.70 & 79.20 & 5591 & 1.004 \\
C1 (980118) & AC6 & 22.00 & 4.68 & 73.32 & 5909 & 0.913 \\
C2 (980119) & AC6 & 22.00 & 6.00 & 72.00 & 7200 & 1.005 \\
C3 (980120) & AC3 & 22.00 & 4.68 & 73.32 & 6095 & 1.009 \\
C4 (971017) & AC3 & 22.00 & 3.12 & 74.88 & 6775 & 1.023 \\
C5 (971020) & AC3 & 22.00 & 1.56 & 76.44 & 7528 & 1.033 \\
C6 (971105) & AC3 & 22.00 & 0.00 & 78.00 & 9694 & 1.013 \\
C7 (980119) & AC3 & 16.84 & 0.00 & 83.16 & 5189 & 1.004 \\
C8 (971205) & AC3/AC6 1:1 & 20.00 & 0.00 & 80.00 & 6437 & 1.012 \\
C9 (980101) & AC3/AC6 1:1 & 17.80 & 1.90 & 80.30 & 2810 & 0.999 \\
\hline
\end{tabular}

\section{VISCOSIDAD (cP)}

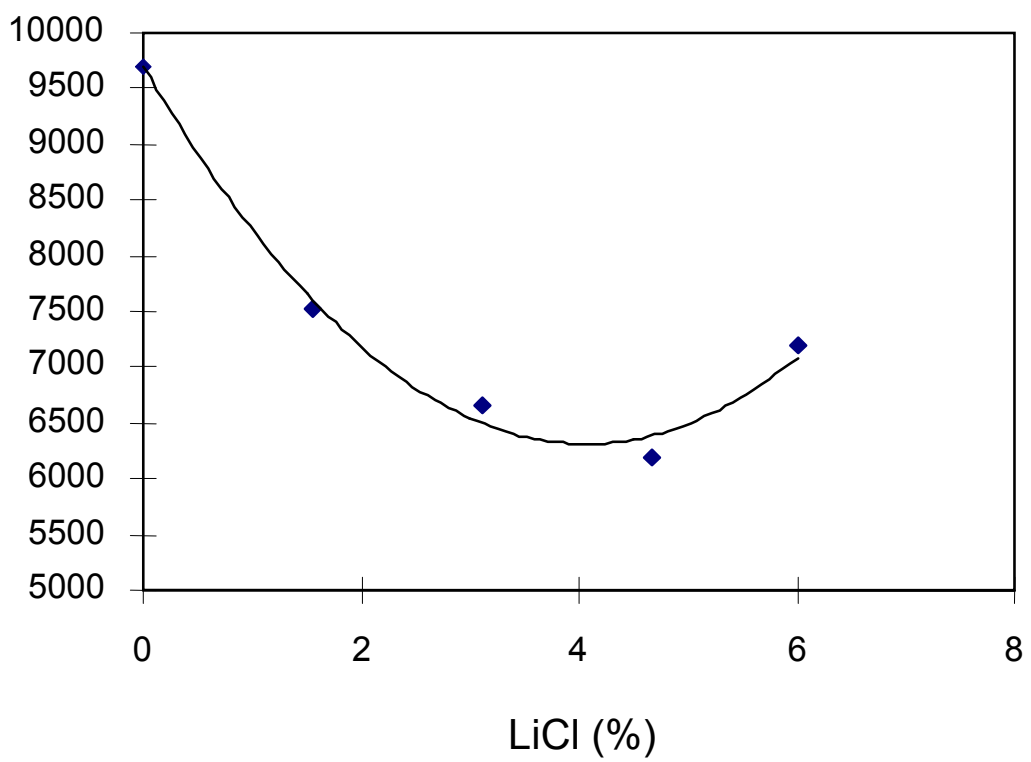

Ilustración 59. Influencia del cloruro de litio en la viscosidad (a $\left.25^{\circ} \mathrm{C}\right)$ de colodiones de $22 \%$ de AC3 en dimetilacetamida 


\subsection{RESULTADOS OBTENIDOS EN LAS MEMBRANAS FABRICADAS EN EL LABORATORIO.}

En esta parte se presentan primero los resultados de evaluación del método de caracterización empleado. Posteriormente se presentan ensayos específicos preliminares basados en composiciones de colodiones semejantes a los encontrados en la bibliografía. A continuación se presenta el cuerpo de ensayos específicos realizados para la determinación de variables influyentes en el proceso de fabricación. Finalmente se presenta un diseño de experimentos realizado para explicar el efecto de las variables seleccionadas.

Las condiciones de fabricación y caracterización de las membranas fabricadas se encuentran expresadas en forma de tablas a lo largo de este apartado y en el apartado 6 (Apéndice I). Dichas tablas contienen los valores de los factores y variables seleccionadas mencionados en la sección de Metodología. Los códigos utilizados para las variables quedan reflejados en Tabla 42 y Tabla 43.

Las variables medidas en el ensayo han sido el flux o flujo por unidad de área de membrana $J_{v}$ y el rechazo observado $R_{a}$, los cuales están siempre referidos a la presión de trabajo a la que han sido obtenido. Estos han sido transformados para cada presión en la permeabilidad volumétrica $A$ y el factor de paso de sal $B$ mediante la Ec. 86 y la Ec. 87.

Estos nuevos parámetros son más independientes de la presión que los anteriores de flux y rechazo, siendo más representativos de las características físicas de la membrana explicables según el modelo de disolución-difusión o el modelo KSA explicado en el punto C-1 del apartado 1.3.3.

Para resumir el comportamiento de la membrana frente a disoluciones salinas usaremos tal y como proponen Chen et al. (1983) el parámetro $A^{2} / B\left(\mathrm{~L} \cdot \mathrm{m}^{-2} \cdot \mathrm{dí}^{-1} \cdot \mathrm{bar}^{-2}\right)$ al que denominaremos "nivel de comportamiento". Cuanto más alto sea el valor de esta variable mejor es el comportamiento de la membrana. Su valor relaciona flux y rechazo a una presión dada de la siguiente forma:

Ec. 91

$$
\frac{A^{2}}{B}=J_{v} \cdot \frac{R_{a}}{1-R_{a}} \cdot \frac{1}{\Delta P}
$$




\section{Tabla 42. Códigos utilizados para las variables de fabricación}

\begin{tabular}{|c|c|c|}
\hline Código & Variable & Tipos / (Unidad de medida) \\
\hline$M E M$ & Marca asignada a la membrana & Referencia serie - Referencia específica \\
\hline$P$ & Polímero utilizado & $\begin{array}{l}\text { AC3, AC6, ACE (acetatos); BAC, PAC } \\
\text { (según Tabla } 12 \text { y Tabla 13) }\end{array}$ \\
\hline$X P$ & Fracción en peso de polímero & $(\%)$ \\
\hline$D$ & Disolvente utilizado & $\begin{array}{l}\text { DMA (dimetilacetamida); ACN (acetona) } \\
\text { (según Tabla } 19 \text { y Tabla 21) }\end{array}$ \\
\hline$X D$ & Fracción de disolvente & $(\%)$ \\
\hline$A 1$ & Aditivo 1 & $\begin{array}{l}\mathrm{LiCl} ; \mathrm{NO}_{3} \mathrm{Li} ; \mathrm{MgPC} \\
\text { (según Tabla 23) }\end{array}$ \\
\hline$X A 1$ & Fracción en peso de aditivo 1 & $(\%)$ \\
\hline$A 2$ & Aditivo 2 & $\begin{array}{l}\text { H2O (agua); T1, TX (tensoactivos) } \\
\text { (según Tabla 23) }\end{array}$ \\
\hline$X A 2$ & Fracción en peso de aditivo 2 & $(\%)$ \\
\hline$S P$ & Soporte utilizado & $\begin{array}{l}\text { F02 (FO-2402); TV; PPS } \\
\text { (según Tabla 16) }\end{array}$ \\
\hline$E N$ & Espesor nominal de deposición & $(\mu \mathrm{m})$ \\
\hline$T R E$ & Temperatura de evaporación & $\left({ }^{\circ} \mathrm{C}\right)$ \\
\hline$T P E$ & Tiempo de evaporación & (min.) \\
\hline$T R C$ & Temperatura de coagulación & $\left({ }^{\circ} \mathrm{C}\right)$ \\
\hline$T P C$ & Tiempo de coagulación & (min.) \\
\hline$T R T$ & Temperatura de tratamiento & $\left({ }^{\circ} \mathrm{C}\right)$ \\
\hline$T P T$ & Tiempo de tratamiento & (min.) \\
\hline
\end{tabular}


Tabla 43. Significado de las claves de variables de ensayo y calculadas

\begin{tabular}{|c|l|c|}
\hline Clave & \multicolumn{1}{|c|}{ Significado } & Tipos /(Unidad de medida) \\
\hline MEM & Marca de la membrana & \\
\hline$M O D$ & Módulo utilizado & $\mathrm{P}($ placas $) ; \mathrm{C}$ (cilíndrico) \\
\hline Fnn & Flux a nn bar de presión & $\mathrm{L} \cdot \mathrm{m}^{-2} \cdot \mathrm{día}^{-1}$ \\
\hline$R n n$ & Rechazo a nn bar de presión & $\mathrm{L} \cdot \mathrm{m}^{-2} \cdot \mathrm{día}^{-1}$ \\
\hline Ann & Permeabilidad a nn bar & $\mathrm{L} \cdot \mathrm{m}^{-2} \cdot \mathrm{día}^{-1} \cdot \mathrm{bar}^{-1}$ \\
\hline$B n n$ & Factor de paso de sal a $\mathrm{nn}$ bar & $\mathrm{L} \cdot \mathrm{m}^{-2} \cdot \mathrm{día}^{-1}$ \\
\hline
\end{tabular}

\subsubsection{Evaluación del método de caracterización}

En este apartado se busca estimar la influencia que sobre el comportamiento de las membranas tienen los módulos utilizados, así como la idoneidad de las condiciones de trabajo establecidas.

\section{Evaluación de la influencia de los módulos en el comportamiento de las membranas}

Se realizó una prueba con membranas comerciales de las cuales se conocía su flux y rechazo nominal en módulo espiral. Se escogieron dos membranas diferentes (una basada en poliamida de polimerización interfacial y una membrana de inversión de fase de acetato de celulosa) de las cuales se extrajeron 6 recortes para prueba promediándose los resultados. El experimento se realizó con los fluxes de alimentación establecidos en la Metodología mantenidos constantes ya que para estos el funcionamiento de la planta era el más estable. Los resultados presentados en la Tabla 44 muestran que el flux en los módulos puede ser hasta un $20 \%$ del valor en módulo 
espiral, siendo los resultados de flux inferiores en el módulo cilíndrico. Los resultados de rechazo pueden ser hasta un 5\% inferiores. Ello puede explicarse porque la membrana asienta sobre un soporte metálico con pocos orificios de recogida de permeado por centímetro cuadrado lo que origina que el fluido tenga que atravesar soporte no-tejido. La menor turbulencia existente en las cercanías de la membrana debida a la mayor sección de paso, unida a la presencia de zonas de flujo muertas, puede crear una elevada concentración por polarización lo que explicaría el menor rechazo en los módulos de prueba.

\section{Tabla 44. Influencia del módulo en el comportamiento de membranas comerciales}

Alimento: 2000 ppm de $\mathrm{NaCl}$ Presión: 30 bar

Flujo de alimento: 400 lph (módulo de placas); 80 lph (por módulo cilíndrico)

\begin{tabular}{|l|c|c|c|c|c|}
\hline \multicolumn{1}{|c|}{ Membranas } & $\begin{array}{c}\text { MÓDULO } \\
\text { ESPIRAL }\end{array}$ & \multicolumn{2}{|c|}{$\begin{array}{c}\text { MÓDULO } \\
\text { CILÍNDRICO }\end{array}$} & \multicolumn{2}{c|}{$\begin{array}{c}\text { MÓDULO } \\
\text { DE PLACAS }\end{array}$} \\
\cline { 2 - 6 } & $\begin{array}{c}\text { Flux } \\
\left(\mathrm{L} / \mathrm{m}^{2} \cdot \text { dia }\right)\end{array}$ & $\begin{array}{c}\text { Flux } \\
\left(\mathrm{L}^{2} \mathrm{~m}^{2} \cdot \text { dia }\right)\end{array}$ & $\begin{array}{c}\text { Variación } \\
(\%)\end{array}$ & $\begin{array}{c}\text { Flux } \\
\left(\mathrm{L} / \mathrm{m}^{2} \cdot \text { dia }\right)\end{array}$ & $\begin{array}{c}\text { Variación } \\
(\%)\end{array}$ \\
\hline PA interfacial & 1700 & 1506 & -11 & 1446 & -15 \\
\hline Acetato de Celulosa & 550 & 451.5 & -18 & 435.3 & -20 \\
\hline & Rechazo & Rechazo & Diferencia & Rechazo & Diferencia \\
$(\%)$ & $(\%)$ & $(\%)$ & $(\%)$ & -2.4 \\
\hline PA interfacial & 90 & 84.9 & -5.1 & 87.6 & -2 \\
\hline Acetato de Celulosa & 92 & 88.1 & -3.9 & 88.1 & -2 \\
\hline
\end{tabular}

Los resultados observados de flux y rechazo en la caracterización de las membranas son pues límites inferiores de los que se pueden alcanzar cuando la membrana funcione en módulo, más cercanos al flux y rechazo máximos teóricos de la membrana. Sin embargo, los valores observados se podrán utilizar para optimizar las variables de fabricación ya que mayores rechazos observados se corresponden con mayores valores teóricos. 


\section{Influencia del tiempo de ensayo}

En las fases iniciales de la investigación se realizaron ensayos de larga duración para ver cómo podía afectar el tiempo de ensayo al flux y rechazo de la membrana. Las membranas nuevas introducidas se compactaban al transcurrir el tiempo de ensayo, disminuyendo el flux y aumentando el rechazo. Al cambiar a una presión superior se producía un brusco aumento de flux, descendiendo este como consecuencia de un nuevo acomodamiento de la membrana la presión superior (hasta un 10\% de descenso en algún caso). El efecto sobre el rechazo no era tan instantáneo como el efecto sobre el flux aumentando éste lentamente hacia el valor final (hasta un $20 \%$ de aumento relativo en membranas muy abiertas). Cuando después de un ensayo largo se pasaba a una presión inferior las membranas producían en los primeros instantes un flux inferior y un rechazo superior al que habían proporcionado anteriormente en las mismas condiciones de presión, estabilizándose en valores de flux ligeramente inferiores y de rechazo ligeramente superiores, prueba de que se producía cierta compactación irreversible de la membrana y que el acomodamiento a las nuevas condiciones no era total (Ilustración $60)$.

En los ensayos se observó que la mayor compactación se producía en la primera hora observándose descensos máximos de flux del $10 \%$ y aumentos relativos de rechazo máximos del $15 \%$. En la segunda hora de ensayo la membrana se encontraba por lo general estabilizada no variando por lo general flux y rechazo en más del $1 \%$ en membranas de alto rechazo. Sin embargo, en algunos casos el rechazo aumentaba algo más debido a que la compactación cerraba algunas imperfecciones.

Se consideró pues como representativas de una presión determinada las medidas de la membrana realizadas transcurrido un tiempo de ensayo superior a dos horas, teniéndose en cuenta que en membranas de bajo rechazo el rechazo estabilizado podría ser algo superior. 


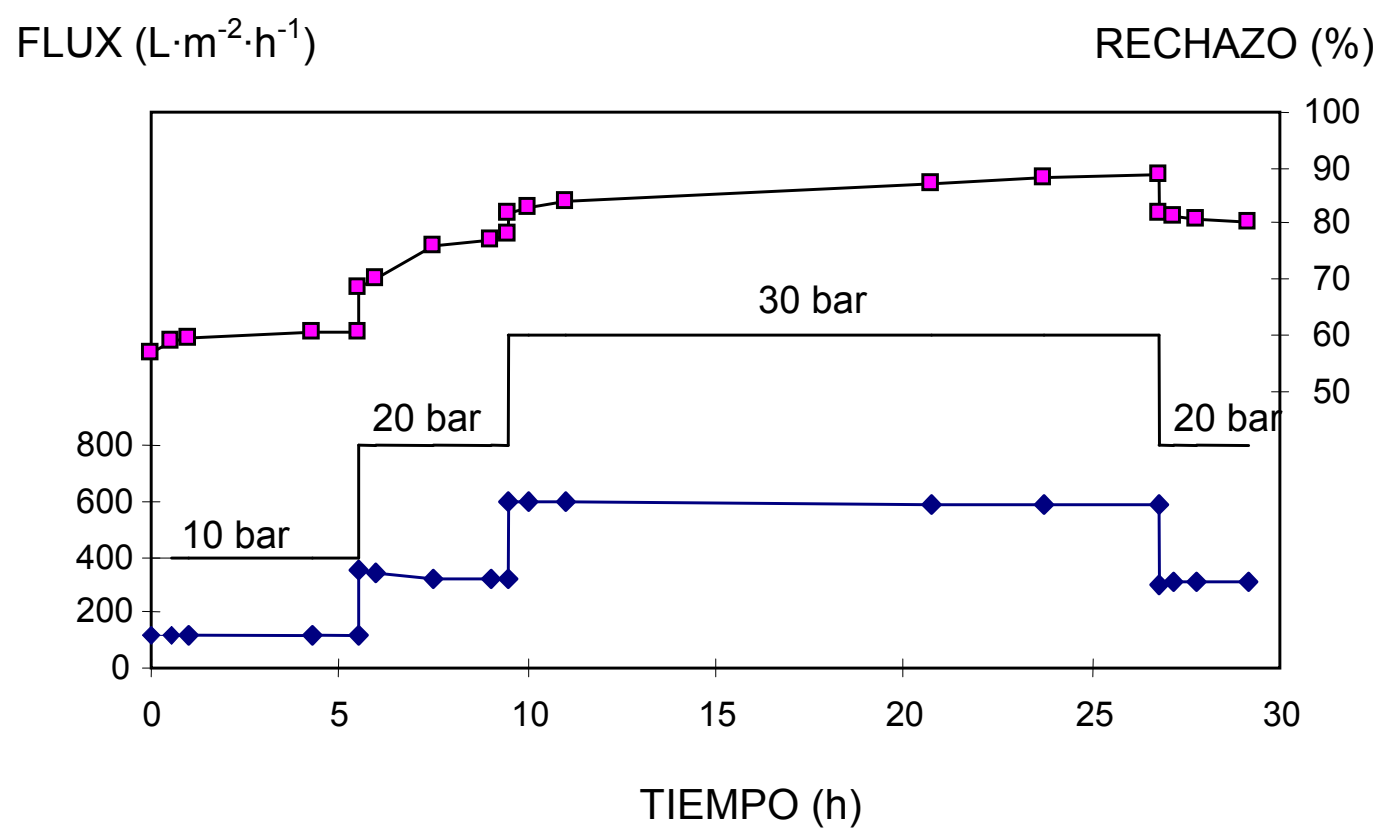

Ilustración 60. Estabilización de la membrana 60726-6 en módulo de placas (Alimento: $2000 \mathrm{ppm}$ de $\mathrm{NaCl}$; Temperatura: $20-26^{\circ} \mathrm{C}$ )

\section{Evaluación del efecto del pH en las membranas de acetato de celulosa}

Para el acetato de celulosa el pH óptimo de trabajo está situado entre 5.5 y 6 , lo cual se constató en el experimento que se refleja en la Ilustración 61 donde se puede observar que para ese rango el rechazo alcanza valores máximos y el flux tiene valores altos. 


$$
\operatorname{FLUX}\left(\mathrm{L} \cdot \mathrm{m}^{-2} \cdot \mathrm{día}^{-1}\right) \quad \text { RECHAZO (\%) }
$$

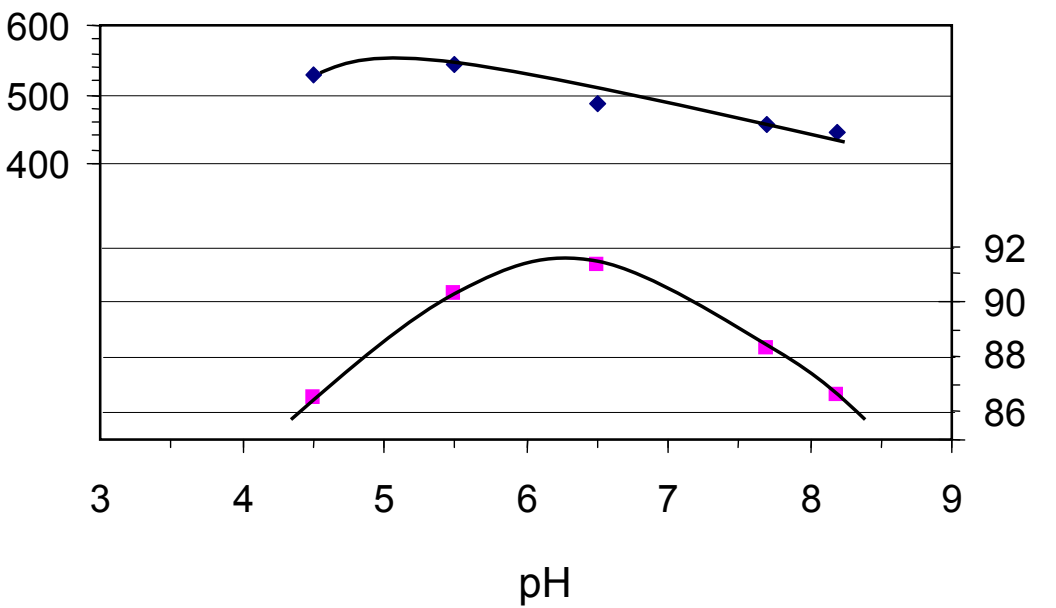

Ilustración 61. Efecto de la modificación del pH con $\mathrm{HCl}$ sobre el flux y rechazo de la membrana 21006-513. (Alimento: 2000 ppm de NaCl; Presión: 30

bar; Tra.: 24-25 ${ }^{\circ} \mathrm{C}$; Tiempo de ensayo: $24 \mathrm{~h}$ )

\subsubsection{Evaluación de la reproducibilidad del método de fabricación}

Los resultados obtenidos en la caracterización de las membranas fabricadas han presentado siempre una elevada dispersión originada por variables no controladas, lo que ha dificultado la interpretación de los resultados y la obtención de relaciones claras entre las variables de fabricación y el comportamiento permeoselectivo.

Teniendo en cuenta que en el método manual se obtiene en cada proceso completo una única hoja de membrana, aparecen dos tipos de dispersión de resultados:

- Dispersión interhojas (diferentes propiedades entre hojas)

- Dispersión intrahoja (diferentes propiedades para cada membrana recortada)

En ambos tipos de dispersión influye decisivamente la fase de deposición, donde la dispersión proviene de las irregularidades propias del soporte, diferencias en el tensado y diferencias en la presión de aplicación y velocidad de enrasado por la persona (el factor más crítico). También la dispersión puede provenir de las impurezas de los 
productos o del tratamiento térmico donde la membrana puede estar expuesta a gradientes térmicos no homogéneos. La dispersión interhojas, además de los factores mencionados puede deberse a errores de fabricación en los colodiones, cambios de composición e impurezas en el baño de coagulación, velocidad de introducción en el baño y cambios en la temperatura ambiental.

Para estudiar cual de las dos dispersiones tenía más importancia se realizaron tres hojas de membrana con las mismas condiciones de fabricación en días diferentes. El tratamiento térmico se realizó de forma individual para cada uno de los recortes de membrana. Los resultados mostrados en la Ilustración 62 reflejan que ambos tipos de variabilidad pueden llegar a ser muy importantes, llegando a ser incluso mayor la variabilidad intramembranal. El elevado valor de ambas variabilidades hace que con el método manual propuesto las tendencias no se puedan predecir de forma clara.

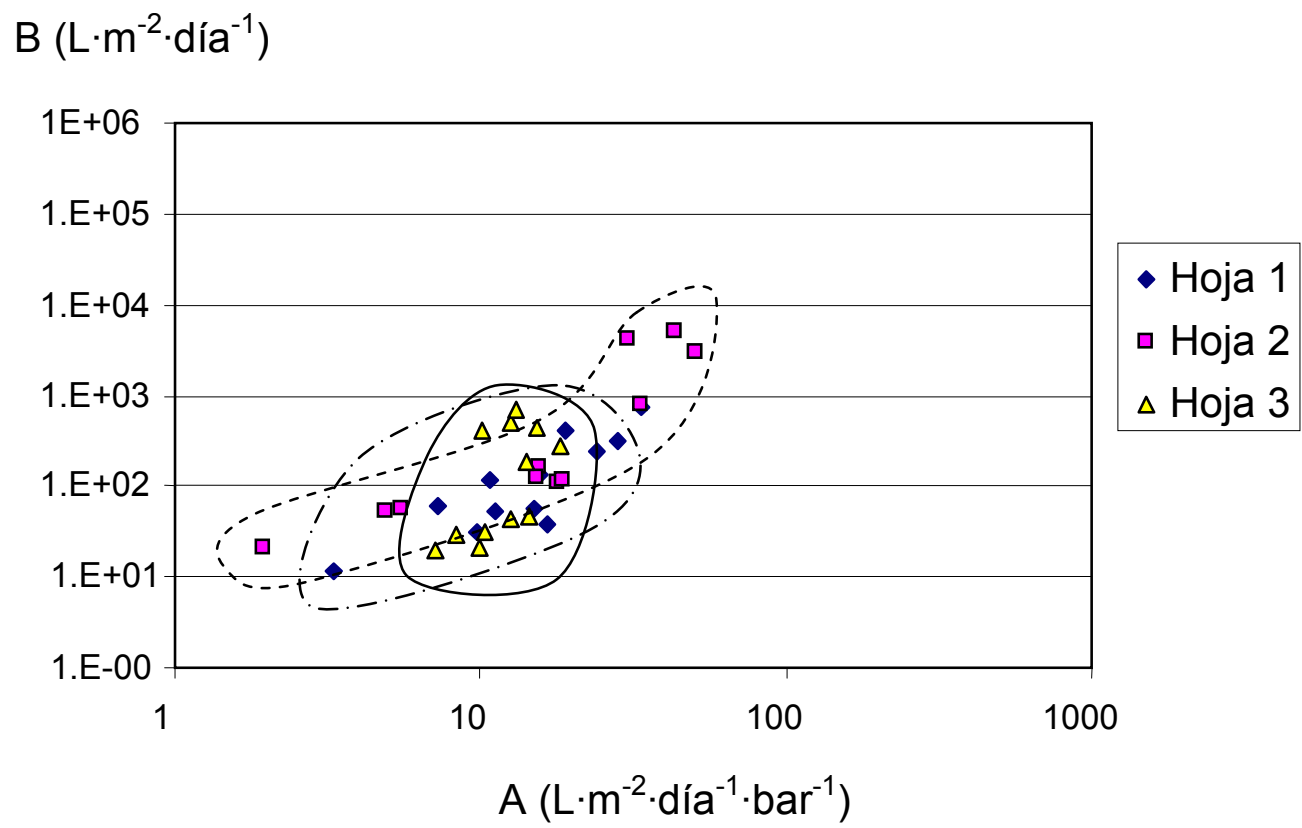

Ilustración 62. Efecto de la variabilidad en serie 31001 (30 bar) 


\subsubsection{Experimentos preliminares para la selección de composiciones}

En las primeras fases de la investigación se realizaron diferentes series de membranas basadas en la utilización de diferentes polímeros, disolventes y aditivos, realizándose dentro de una serie modificaciones de las variables dentro de amplios rangos. La elección de las composiciones y condiciones se basó en la experiencia previa del laboratorio de Tecnología de Membranas del DIQN, los resultados experimentales del diagrama ternario, así como en la información proporcionada en la bibliografía. En base a esta información se consideró:

1) Estudiar los tres acetatos de celulosa disponibles

2) Utilizar concentraciones superiores al $18 \%$ para obtener membranas cerradas aptas para ósmosis inversa y nanofiltración

3) Utilizar como disolvente principal la dimetilacetamida (DMA), estudiar también si la acetona ( $\mathrm{ACN}$ ) es un disolvente adecuado para el proceso de fabricación propuesto

4) Estudiar el efecto de la adición de disolvente al baño

5) Estudiar el efecto de sales, y no-disolventes en el colodión

Las series realizadas se encuentran numeradas en la Tabla 45. Las membranas de cada serie se ensayaron a 30 bar bajo las condiciones de ensayo establecidas en la Metodología. Las condiciones óptimas de fabricación correspondientes a las membranas que presentaron mejores resultados quedan reflejadas en la Tabla 46 y los resultados de flux y rechazo que proporcionaron a 30 bar se representan en la Ilustración 63. 


\section{Tabla 45. Series preliminares y rangos estudiados}

\begin{tabular}{|c|c|c|c|c|c|c|c|c|c|c|c|c|c|}
\hline SERIE & $P$ & $X P$ & $D$ & $A 1$ & $X A 1$ & $A 2$ & $X A 2$ & $S P$ & $E N$ & TPE & $T R C$ & $T R T$ & $T P T$ \\
\hline 1 & $\mathrm{AC} 3$ & $20-23$ & DMA & $\mathrm{LiCl}$ & $1-4$ & $\mathrm{~T} 1$ & $0-0.5$ & $\begin{array}{l}\text { F02 } \\
\text { TV }\end{array}$ & $\begin{array}{l}50- \\
100\end{array}$ & 20 & -20 & $0-97$ & $\begin{array}{r}60- \\
300 \\
\end{array}$ \\
\hline 2 & AC6 & $20-23$ & DMA & $\mathrm{LiCl}$ & $1-4$ & $\mathrm{~T} 1$ & $0-0.5$ & $\begin{array}{l}\text { F02 } \\
\text { TV }\end{array}$ & $\begin{array}{l}50- \\
100 \\
\end{array}$ & 20 & $2-20$ & $85-97$ & $\begin{array}{r}60- \\
300 \\
\end{array}$ \\
\hline 3 & $\mathrm{ACE}$ & 19 & DMA & $\mathrm{LiCl}$ & $1-6$ & $\mathrm{~T} 1$ & $0-0.5$ & $\begin{array}{c}\mathrm{F} 02 \\
\mathrm{TV} \\
\end{array}$ & 75 & 20 & $2-10$ & $90-97$ & $\begin{array}{l}60- \\
600 \\
\end{array}$ \\
\hline 4 & $\mathrm{AC} 3$ & 23 & DMA & & & & & F02 & $50^{(1)}$ & $\begin{array}{c}20- \\
100^{(2)} \\
\end{array}$ & $2-5$ & $75-90$ & $\begin{array}{l}30- \\
330 \\
\end{array}$ \\
\hline 5 & $\begin{array}{l}\text { AC3- } \\
\text { BAC/ } \\
\text { PAC } \\
\end{array}$ & $\begin{array}{c}20-23 \\
5-8\end{array}$ & DMA & & & & & $\begin{array}{l}\text { F02 } \\
\text { TV }\end{array}$ & $\begin{array}{c}50- \\
100^{(1)}\end{array}$ & 20 & $2-5$ & $75-95$ & $\begin{array}{l}30- \\
330\end{array}$ \\
\hline 6 & $\mathrm{AC} 3$ & 23 & $\mathrm{ACN}$ & $\mathrm{MgPC}$ & $1-2$ & & & F02 & 50 & 20 & $2-5$ & $75-95$ & $\begin{array}{r}30- \\
330 \\
\end{array}$ \\
\hline 7 & $\mathrm{AC} 3$ & $20-23$ & $\begin{array}{c}\mathrm{ACN} \\
\underset{(3)}{\mathrm{DMA}}\end{array}$ & & & & & $\begin{array}{l}\text { F02 } \\
\text { TV }\end{array}$ & $\begin{array}{c}50- \\
100^{(1)}\end{array}$ & $\begin{array}{l}10- \\
100\end{array}$ & 2 & $\begin{array}{l}85- \\
100\end{array}$ & $\begin{array}{l}20- \\
330\end{array}$ \\
\hline 8 & $\mathrm{AC} 3$ & $20-22$ & DMA & & & Etanol & $4-7.5$ & F02 & $\begin{array}{c}50- \\
100^{(1)}\end{array}$ & $\begin{array}{l}90- \\
330\end{array}$ & 5 & 90-98 & 60 \\
\hline 9 & $\mathrm{AC} 3$ & $20-22$ & DMA & & & Agua & $2-5$ & F02 & $\begin{array}{c}50- \\
100^{(1)}\end{array}$ & $\begin{array}{l}90- \\
330 \\
\end{array}$ & 5 & $90-98$ & 60 \\
\hline
\end{tabular}

(1) Enrasador liso

(2) Coagulación en baño de DMA al 30\%
(3) Relaciones de volumen ACN/DMA entre 0.3 y 1.5 
Tabla 46. Rangos óptimos a 30 bar de las series preliminares

\begin{tabular}{|c|c|c|c|c|c|c|c|c|c|c|c|c|c|}
\hline SERIE & $P$ & $X P$ & $D$ & $A 1$ & $X A 1$ & $A 2$ & $X A 2$ & $S P$ & $E N$ & $T P E$ & $T R C$ & $T R T$ & $T P T$ \\
\hline 1 & $\mathrm{AC} 3$ & 23 & DMA & $\mathrm{LiCl}$ & 4 & & 0 & F02 & 50 & 20 & $2-5$ & 95 & 180 \\
\hline 2 & AC6 & 20 & DMA & $\mathrm{LiCl}$ & 4 & & 0 & F02 & $50-75$ & 20 & $2-3$ & 95 & $\begin{array}{c}120- \\
180 \\
\end{array}$ \\
\hline 3 & $\mathrm{ACE}$ & 19 & DMA & $\mathrm{LiCl}$ & 2 & $\mathrm{~T} 1$ & 0.5 & F02 & 75 & 20 & 2 & 97 & 180 \\
\hline 4 & $\mathrm{AC} 3$ & 23 & DMA & & & & & F02 & $50^{(1)}$ & $60^{(2)}$ & 2 & 85 & 180 \\
\hline 7 & $\mathrm{AC} 3$ & 20 & $\begin{array}{c}\mathrm{ACN} \\
\mathrm{DMA}\end{array}$ & & & & & F02 & $100^{(1)}$ & 60 & 2 & 85 & 20 \\
\hline 8 & $\mathrm{AC} 3$ & 22 & $\begin{array}{c}\text { DMA } \\
\text { (4) }\end{array}$ & & & Etanol & 7.5 & F02 & $100^{(1)}$ & 330 & 5 & 95 & 60 \\
\hline 9 & $\mathrm{AC} 3$ & 22 & DMA & & & Agua & 3 & F02 & 50 & 90 & 5 & 90 & 60 \\
\hline \multicolumn{6}{|c|}{ (1) Enrasador liso } & \multicolumn{8}{|c|}{ (3) Relación de volumen ACN/DMA: 0.4} \\
\hline (2) $\mathrm{Co}$ & agulac & ón en & baño de & DMA & al $30 \%$ & & (4) $\mathrm{Di}$ & olven & e DMA & $: 62 \%$ & $\mathrm{ACN}$ : & $3.1 \%$ & \\
\hline
\end{tabular}

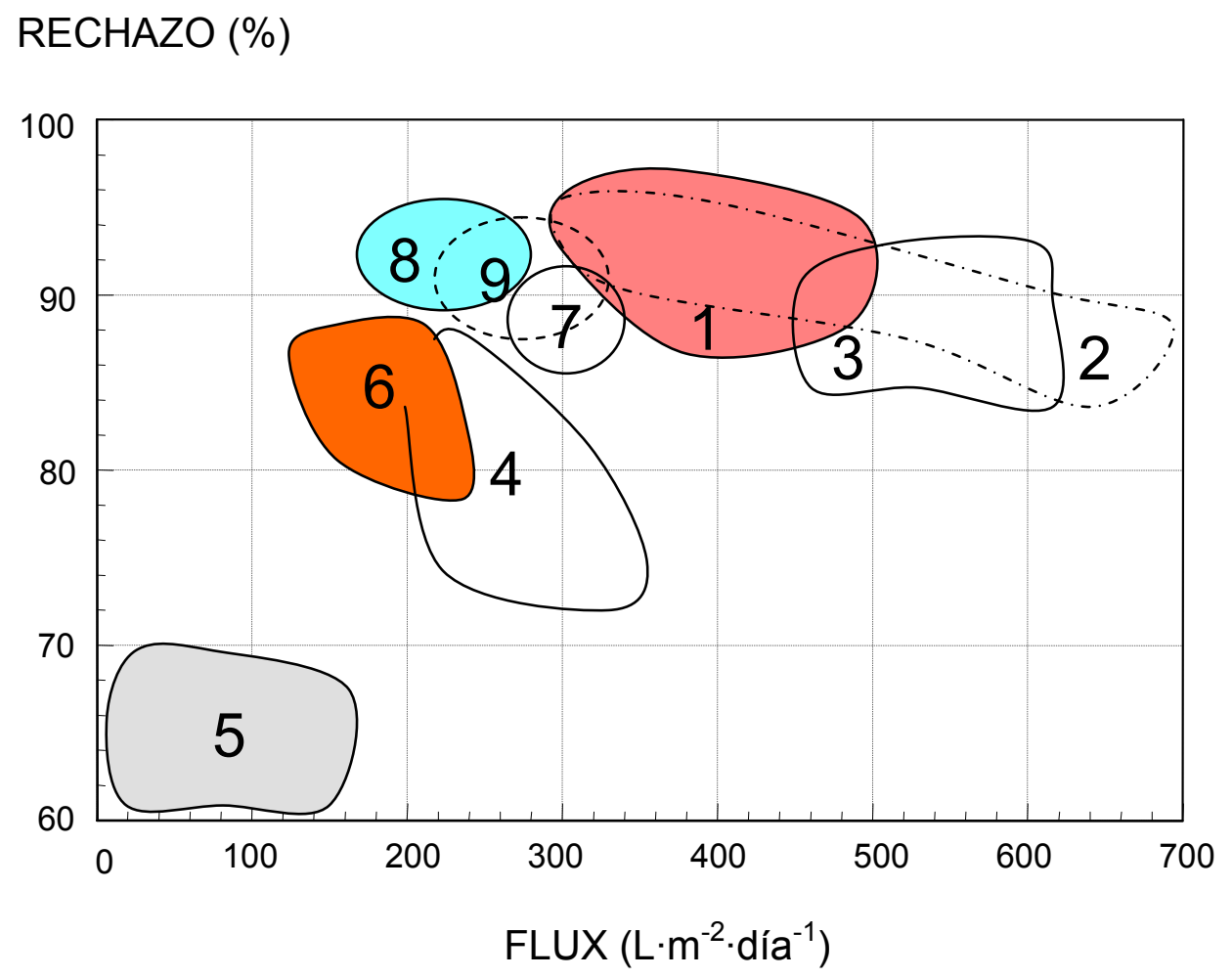

Ilustración 63. Comportamiento de las distintas series de membranas expuestas en la Tabla 8. (Alimentación 2000 ppm de NaCl; Presión: 30 bar) 
A continuación se comentan los resultados obtenidos para las distintas series, habiéndose fabricado unas 10 membranas en cada una de ellas:

- Serie 1: Acetato de celulosa CA-398-3 (AC3) como polímero base. Adición de LiCl. Tratamiento térmico a alta temperatura.

La baja viscosidad del polímero AC3 permitió utilizar rangos de concentración de polímero más altos que los de los otros polímeros. Para obtener viscosidad que permitieran el manejo del colodión de forma aceptable se limitó el porcentaje de polímero a un $23 \%$ y el de $\mathrm{LiCl}$ a no más del 6\%. Ello permitió obtener rechazos altos, observándose que para obtener resultados de rechazo superiores al 90\% había que utilizar temperaturas altas de al menos $95^{\circ} \mathrm{C}$ durante más de tres minutos. Bajo estas condiciones se obtuvieron los siguientes resultados:

$$
\begin{array}{ll}
\text { Fluxes: } & 300-450 \mathrm{~L} \cdot \mathrm{m}^{-2} \cdot \mathrm{dí}^{-1} \\
\text { Rechazos: } & 95-91 \%
\end{array}
$$

Los resultados de rechazo obtenidos son más altos que para los otros dos polímeros base (AC6 y ACE) aunque los fluxes son inferiores. La adición de LiCl aumentaba el rechazo a costa de una pequeña disminución en el flux. El calentamiento aumentaba el rechazo a costa de disminuir el flux.

- Serie 2: Acetato de celulosa CA-398-6 (AC6) como polímero base. Adición de LiCl. Tratamiento térmico a alta temperatura.

Debido a la mayor viscosidad de los colodiones estos tuvieron que limitarse finalmente a un $20 \%$. También se observaron los mejores resultados de rechazo para temperaturas de $95^{\circ} \mathrm{C}$ y tres minutos. Sin embargo, tiempos inferiores de calentamiento produjeron fluxes bastante más altos con rechazos inferiores.

a) tiempo de tratamiento: $180 \mathrm{~s}$

$$
\begin{array}{ll}
\text { Fluxes: } & 300-370 \mathrm{~L} \cdot \mathrm{m}^{-2} \cdot \mathrm{dí}^{-1} \\
\text { Rechazos: } & 96-90 \%
\end{array}
$$


b) tiempo de tratamiento: $120 \mathrm{~s}$

$$
\begin{array}{ll}
\text { Fluxes: } & 570-700 \mathrm{~L} \cdot \mathrm{m}^{-2} \cdot \mathrm{dí}^{-1} \\
\text { Rechazos: } & 90-85 \%
\end{array}
$$

De manera similar a la serie anterior la adición de $\mathrm{LiCl}$ aumentaba el rechazo obtenido y el tratamiento térmico aumentaba el rechazo a costa de disminuir el flux.

- Serie 3: Acetato de celulosa en escamas de Inacsa (ACE) como polímero base. Adición de LiCl. Tratamiento térmico a alta temperatura.

Aunque los resultados de rechazo son inferiores a los obtenidos con los otros materiales la permeabilidad de este material parece ser bastante mayor, ya que proporciona un flux más elevado. Los colodiones presentaban una alta viscosidad lo que hacía muy difícil trabajar con concentraciones de polímero superiores al 19\%.

Se observaron los mejores resultados de rechazo para temperaturas mayores de $95^{\circ} \mathrm{C}$. Sin embargo, el efecto del tratamiento térmico en el aumento de rechazo era menos acusado que con los anteriores polímeros. Los valores medios obtenidos fueron:

$\begin{array}{ll}\text { Fluxes: } & 570 \mathrm{~L} \cdot \mathrm{m}^{-2} \cdot \mathrm{dí}^{-1} \\ \text { Rechazos: } & 90 \%\end{array}$

- Serie 4: Acetato de celulosa CA-398-3 (AC3) como polímero base. Adición de disolvente al baño. Tratamiento térmico a temperaturas bajas y medias.

Esta serie de membranas presentó unos fluxes inferiores a los de la Serie 1 debido a que la presencia del disolvente en el baño induce a la formación de una capa activa más gruesa. Los resultados de rechazo empeoraban drásticamente para fluxes mayores de 250 $\mathrm{L} /\left(\mathrm{m}^{2} \cdot\right.$ día $)$. El tratamiento térmico si bien aumentaba el rechazo producía una disminución fuerte del flux, especialmente para los tratamientos térmicos de temperaturas más altas.

$\begin{array}{ll}\text { Fluxes: } & 250 \mathrm{~L} \cdot \mathrm{m}^{-2} \cdot \mathrm{dí}^{-1} \\ \text { Rechazos: } & 75 \%\end{array}$


- Serie 5: Adición de propionato de celulosa (PAC) y butirato de celulosa (BAC) al acetatato de celulosa CA-398-3 (AC3) como polímero base.

El comportamiento en cuanto a permeabilidad de los propionatos y butiratos de acetato de celulosa usados puros es inferior al de los diacetatos y triacetatos de celulosa. Se buscaba, sin embargo, combinarlos en poca cantidad con los acetatos para obtener un efecto importante en la disminución de la viscosidad y con ello aumentar al máximo posible la concentración de polímero total. De este modo partiendo de un $20 \%$ de polímero AC3 se pudo llegar añadiendo PAC hasta obtener un colodión de un 30\% de polímero total en peso.

Las membranas dieron sin embargo bajos fluxes $\left(<150 \mathrm{~L} \cdot \mathrm{m}^{-2} \cdot \mathrm{dí}^{-1}\right)$ y rechazos inferiores al $60 \%$ sin tratamiento térmico y fluxes casi nulos cuando se efectuaba el tratamiento térmico.

Las membranas fabricadas con colodión de alta concentración daban fluxes bajos probablemente por el gran espesor de la capa activa formada.

Las membranas realizadas a más baja concentración daban peores resultados que las fabricadas con AC3 puro de la misma concentración.

- Serie 6: Acetato de celulosa CA-398-3 (AC3) como polímero base. Utilización de acetona.

Estas membranas están basadas en las composiciones clásicas de colodión propuestas por Sourirajan (1970). Se buscaba ver si el método propuesto de fabricación proporcionaba buenos resultados para ese tipo de colodiones. Sin embargo, los colodiones de esta serie resultaron ser muy problemáticos pues coagulaban rápidamente con la humedad ambiental dando membranas con un rechazo bajo y muy poco flux debido al mayor espesor de capa activa formada a pesar de que la deposición se efectuaba a $5{ }^{\circ} \mathrm{C}$ para prevenir una excesiva pérdida de acetona.

- Serie 7: Acetato de celulosa CA-398-3 (AC3) como polímero base. Utilización conjunta de acetona y dimetilacetamida. 
Se buscaba corregir el elevado tiempo de retraso de coagulación que produce la acetona (lo cual originaba una capa activa demasiado espesa y poco flux), así como su elevada volatilidad. Los resultados fueron intermedios entre los de las series 1 y 6 . Los rechazos más altos se correspondieron con fluxes bastante bajos. Los resultados medios obtenidos fueron:

$$
\begin{array}{ll}
\text { Fluxes: } & 310 \mathrm{~L} \cdot \mathrm{m}^{-2} \cdot \mathrm{dí}^{-1} \\
\text { Rechazos: } & 87 \%
\end{array}
$$

- Serie 8: Acetato de celulosa CA-398-3 (AC3) como polímero base. Adición de Etanol al colodión.

Se buscaba el efecto de la adición de un no-disolvente (etanol) en la composición para crear una capa activa más cerrada. Los rechazos podían llegar a ser altos pero disminuía el flux considerablemente. Para fluxes superiores a $300 \mathrm{~L} \cdot \mathrm{m}^{-2} \cdot \mathrm{día}^{-1} \mathrm{sin}$ tratamiento térmico los rechazos eran bajos (40\%).

Los mejores resultados a 30 bar de presión se obtuvieron para la siguiente combinación:

$$
\begin{array}{ll}
\text { Fluxes obtenidos } & 210 \mathrm{~L} \cdot \mathrm{m}^{-2} \cdot \mathrm{dí}^{-1} \\
\text { Rechazos obtenidos } & 93 \%
\end{array}
$$

- Serie 9: Acetato de celulosa CA-398-3 (AC3) como polímero base. Adición de agua al colodión.

La adición de agua como no-disolvente proporcionaba fluxes algo más altos que los de la Serie 8 que adicionaba etanol y rechazos del mismo orden. Para concentraciones cercanas al 5\% de agua los colodiones eran bastante viscosos. 


\subsubsection{Experimentos de fabricación manual para la determinación de la influencia de las variables}

A la vista de los resultados preliminares obtenidos para el método de fabricación manual empleado se decidió centrar la investigación en membranas similares a las de las series 1,2 y 3 del apartado anterior que permitían mayores fluxes, estudiando la posibilidad de aumentar el factor de rechazo.

Utilizaremos el factor de nivel de comportamiento definido, así como gráficas $\log A-\log B$ para comparar las distintas modificaciones realizadas en el proceso de fabricación realizado con los tres materiales seleccionados.

\section{Tipo de polímero}

Con los diferentes tipos de acetato de celulosa se pudieron obtener membranas de comportamiento muy variado. Sin embargo, el polímero CA-398-3 permitía obtener membranas de mayor rechazo (menores valores de factor de paso de sal $B$ ) con un flujo algo menor utilizando tratamiento térmico. Las membranas de ACE mostraron menos tendencia a aumentar el rechazo mediante tratamiento térmico. Los niveles de comportamiento máximos que se pudieron alcanzar quedan reflejados en la Ilustración 64.

En la Ilustración 65 se muestran los resultados de membranas obtenidas variando tratamientos térmicos, temperaturas de coagulación y adición de cloruro de litio para los tres materiales seleccionados. Se observa que los puntos experimentales tienden a situarse sobre una curva potencial que en coordenadas logarítmicas aparece como una recta. Los exponentes para los materiales AC3 y AC6 son más elevados por lo que mediante las anteriores modificaciones es posible aumentar el nivel de comportamiento. En cambio el exponente de comportamiento de las membranas fabricadas en ACE es similar a 2 por lo que el efecto de los tratamientos sobre su comportamiento es menor. 
$A^{2} / B\left(L \cdot m^{-2} \cdot d i^{-1} \cdot b^{-2}\right)$

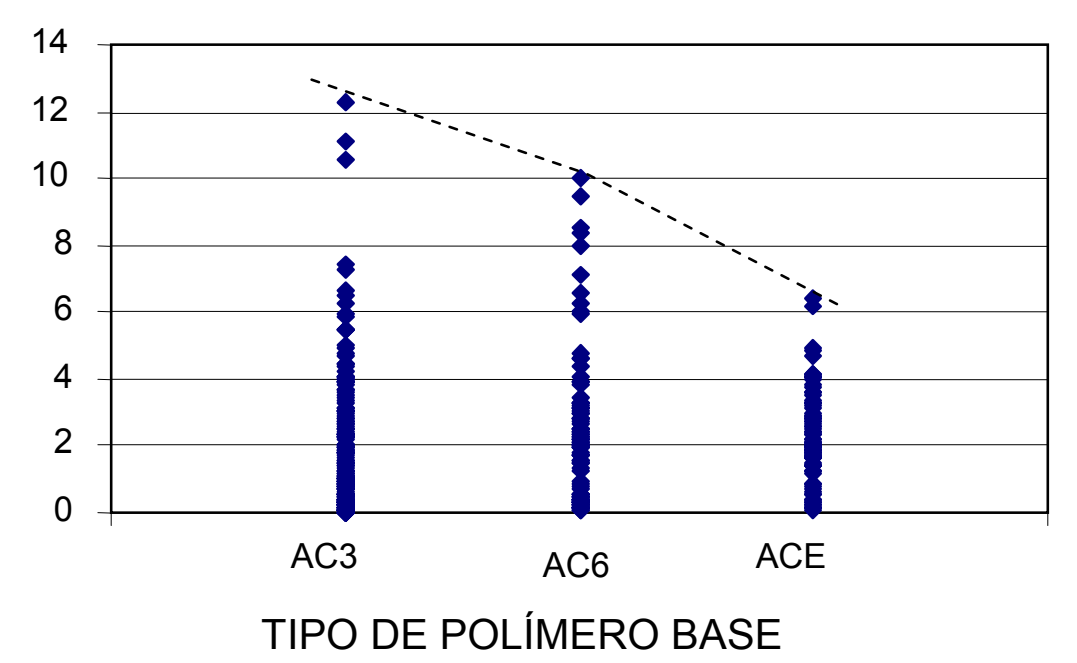

Ilustración 64. Rangos de nivel de comportamiento a 30 bar para membranas fabricadas con los polímeros estudiados

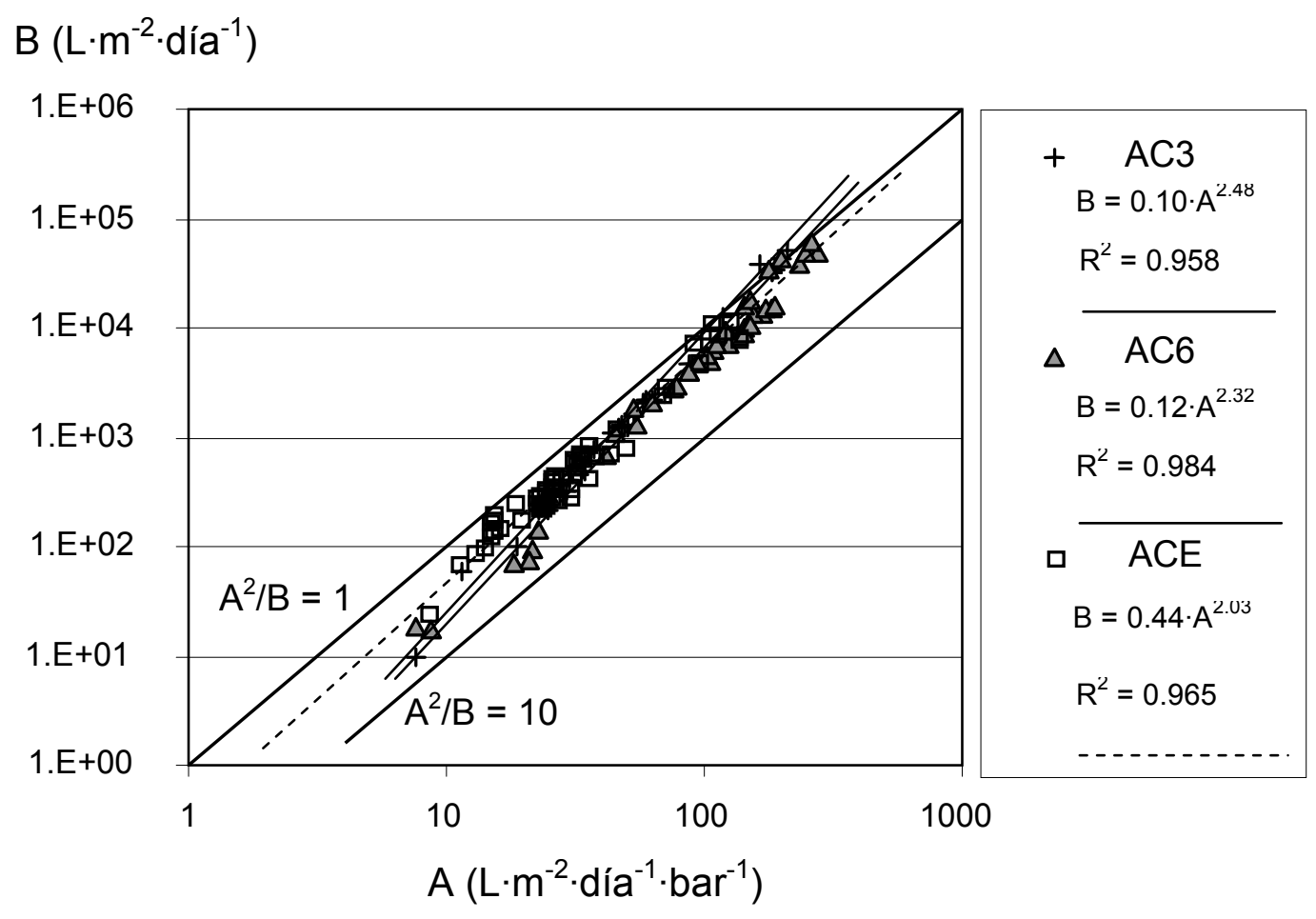

Ilustración 65. Resultados de parámetros permeoselectivos a 20 bar 


\section{Tipo de soporte}

Se realizaron membranas empleando en la casi totalidad de ellas soportes notejidos. Los tipos utilizados en las experiencias previas fueron los soportes FO-2401 y FO-2402 (poliéster), FO-2431 (polipropileno) y Tyvek (polietileno de alta densidad).

Torres et al. (1993) compararon las características de membranas de ultrafiltración de polisulfona que fabricaron con los soportes FO-2401 y FO-2431 obteniendo membranas de mayor flujo y rechazo con el soporte FO-2431. Esto se achacó a la elevada porosidad del soporte de poliéster FO-2401 (permeabilidad al aire de $800 \mathrm{dm}^{3} \cdot \mathrm{s}^{-1} \cdot \mathrm{m}^{-2}$ a 2 mbar para un espesor de $150 \mu \mathrm{m}$ ) frente al soporte de polipropileno FO-2431 (500 dm $\mathrm{dm}^{3} \cdot \mathrm{s}^{-1} \cdot \mathrm{m}^{-2}$ a 2 mbar para un espesor de $\left.140 \mu \mathrm{m}\right)$. La menor porosidad del soporte FO-2431 aseguraba en ese caso una capa ultrafiltrante independiente del soporte con menor penetración de polímero.

Para el acetato de celulosa se realizaron deposiciones sobre los soportes FO2401 y FO-2431. Las membranas obtenidas presentaron muy bajo rechazo a 30 bar (menor del 20\% excepto en las membranas 30721-09 y 30721-10) y tendencia a la descamación (tal y como se puede observar en la Ilustración 100). La porosidad del FO-2431 no resulta adecuada en este caso. Los soportes de menor porosidad FO-2402 (permeabilidad al aire $250 \mathrm{dm}^{3} \cdot \mathrm{s}^{-1} \cdot \mathrm{m}^{-2}$ a 2 mbar para un espesor de $120 \mu \mathrm{m}$ ) y Tyvek (muy baja permeabilidad y $145 \mu \mathrm{m}$ ) resultaron más adecuados para la fabricación de membranas de acetato de celulosa por su menor porosidad y mejores propiedades mecánicas. El soporte Tyvek probablemente condujo a deposiciones de acetato más uniformes, sin embargo presentó el problema de una mayor resistencia al flujo, así como una tendencia muy fuerte a arrugarse durante los tratamientos térmicos. 


\section{Efecto de la adición de LiCI}

La adición de cloruro de litio ha resultado beneficiosa en la mayoría de las membranas fabricadas, ya que la disminución del paso de sal que originaba era más importante relativamente que el descenso en el flujo con lo que aumentaba el nivel de comportamiento. Los valores óptimos de fracción de cloruro de litio desde el punto de vista de aumento del parámetro $A^{2} / B$ se situaron entre 2 y $4 \%$. Como ya se ha dicho, la adición de $\mathrm{LiCl}$ produce una disminución de la viscosidad lo que resulta beneficioso desde el punto de vista de la aplicabilidad del colodión al soporte no-tejido. Han y Bhattacharyya (1991) indican que los colodiones de mayor viscosidad tienen tendencia a producir membranas con menos macroporos. Sin embargo, en este caso el cloruro de litio añadido provoca probablemente la aparición de una estructura microporosa debido a que el efecto de mejora que produce aumentando la solubilidad del polímero en el disolvente es más importante que el efecto de disminución de viscosidad.

- $A\left(L \cdot \mathrm{m}^{-2} \cdot d \mathrm{di}^{-1} \cdot \mathrm{bar}^{-1}\right)$

ㅁ $B\left(L \cdot m^{-2} \cdot d i ́ a{ }^{-1}\right)$

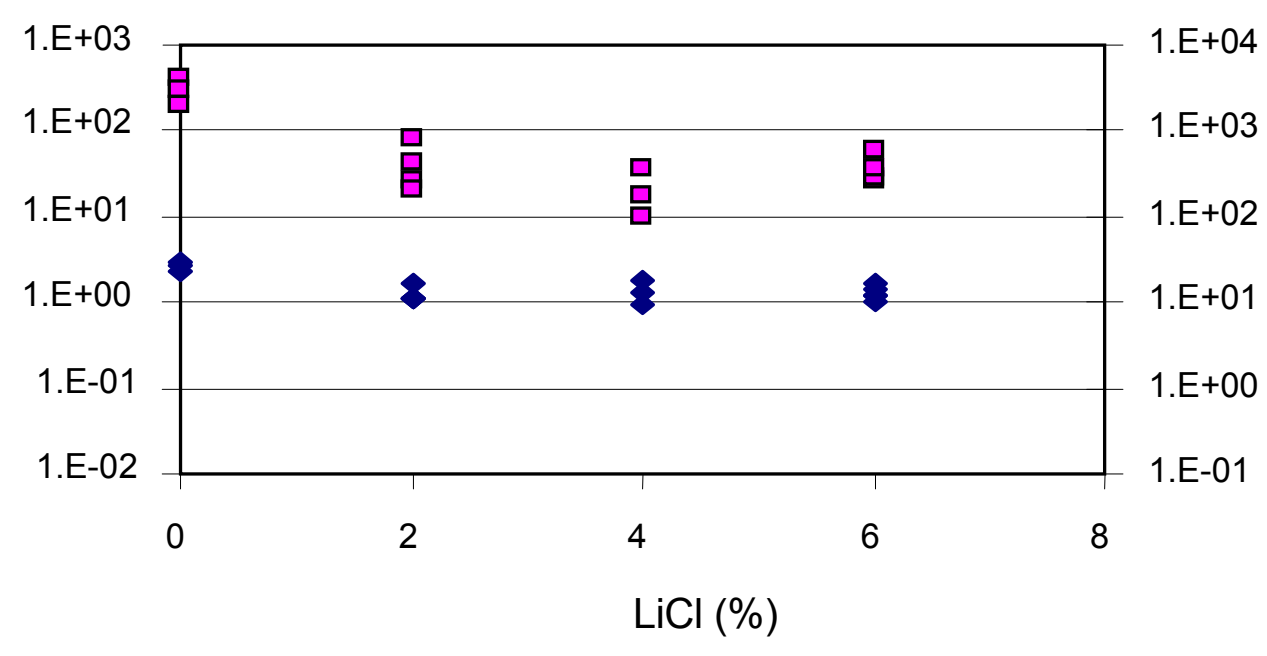
Ilustración 66. Influencia de la incorporación de LiCl al colodión en las series
610081 y 610082 


\section{Efecto de los tensoactivos}

En membranas de alto flujo la adición de tensoactivo mejoró bastante el nivel de comportamiento tal y como puede observarse en la Ilustración 67. Ello era debido a que la adición de tensoactivo producía una disminución importante del factor de paso de sal $B$ con relación a la disminución de $A$. Observando la Ilustración 68 se puede ver que el cambio no se produce a lo largo de la misma curva potencial $\log A-\log B$ tal y como sucede al aplicar un tratamiento térmico en el que la ganancia de $\log B$ es proporcional a la pérdida de $\log A$ al cerrarse la estructura porosa inicial. Al incluir el tensoactivo en la composición los resultados se sitúan sobre una nueva curva $\log A-\log B$ paralela a la anterior. Ello es significativo de que se ha produce un cambio en las propiedades de la membrana previamente al tratamiento térmico. Este efecto se podría explicar teniendo en cuenta la observación hecha por Paulsen et al., (1994) en el sistema acetato de celulosa/acetona/agua. Este indica que la adición de tensoactivos en el colodión podría prevenir la formación de macroporos y conseguirse una estructura porosa inicial más uniforme. Paulsen et al. resaltan también que el efecto es dependiente del sistema concreto. Si este fuera el hecho también para el sistema acetato de celulosa/dimetilacetamida/agua, explicaría la mejora en nivel de comportamiento y la menor dispersión de resultados que se observa tras la adición de tensoactivo.

Es de destacar también que en membranas de bajo flujo y alto rechazo la adición de tensoactivo no mejoró, en cambio, significativamente el comportamiento. 
$A^{2} / B\left(L \cdot m^{-2} \cdot\right.$ día $^{-1} \cdot$ bar $\left.^{-2}\right)$

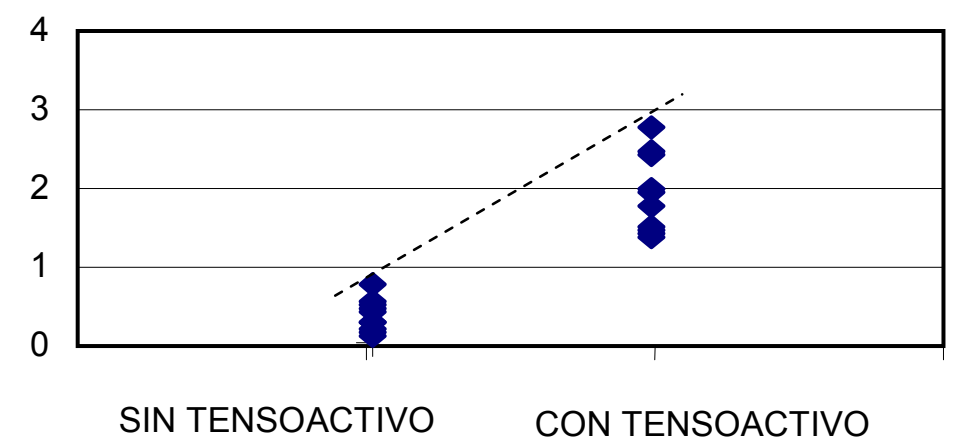

Ilustración 67. Efecto de la adición de 0.5\% de tensoactivo Tritón X-100 sobre el nivel de comportamiento de membranas de AC6 (Series 60715 vs 60916)

$B\left(L \cdot m^{-2} \cdot d i a^{-1}\right)$

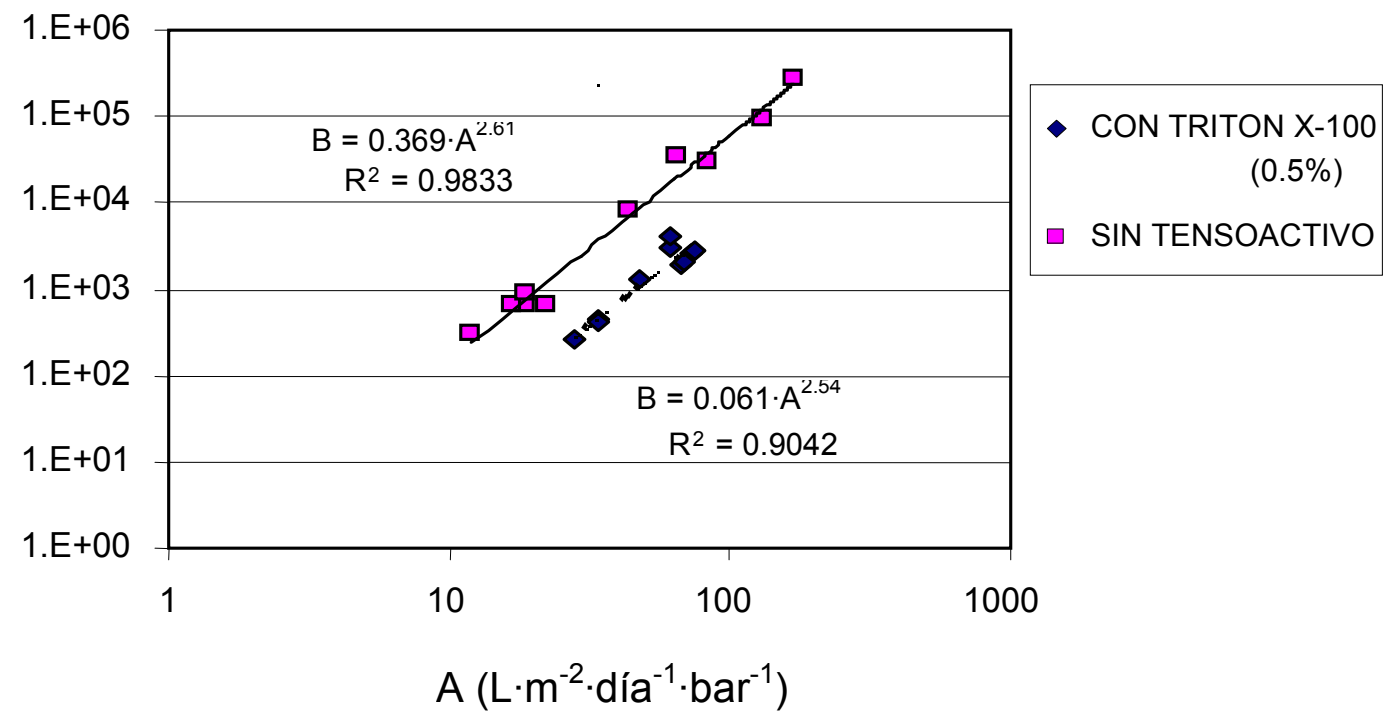

Ilustración 68. Efecto de la adición de 0.5\% de tensoactivo Tritón X-100 sobre los parámetros de permeoselectivos de membranas de AC6 (Series 60715 vs 60916) 


\section{Efecto de la temperatura del baño de coagulación}

Se realizaron membranas variando la temperatura de coagulación en baños de agua destilada. Las membranas fabricadas a menores temperaturas de coagulación eran más cerradas con rechazos de sal más altos (menores valores de $B$ ) pero a costa de tener flujos más bajos (menores valores de $A$ ), tal y como se puede ver en la Ilustración 69 . Las membranas producidas a $2{ }^{\circ} \mathrm{C}$ presentaban un aspecto brillante en contraposición a las fabricadas a temperatura ambiente de aspecto mate y blanquecino.

Han y Bhattacharyya (1991) explican que las temperaturas altas de coagulación inducen en las membranas de acetato de celulosa / acetona a la formación de macroporos originando estructuras más abiertas debido a que la temperatura más elevada acelera la velocidad de coagulación. Para las membranas de acetato de celulosa / dimetilacetamida podemos establecer una conclusión similar.

B $\left(L \cdot \mathrm{m}^{-2} \cdot d i^{-1}\right)$

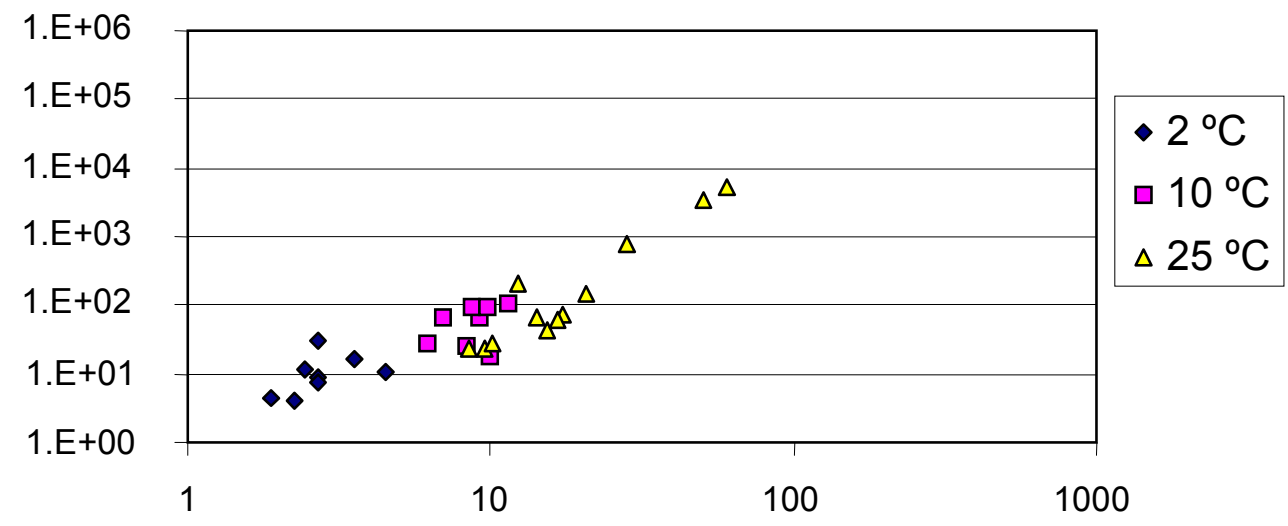

A $\left(L \cdot \mathrm{m}^{-2} \cdot \mathrm{dí}^{-1} \cdot \mathrm{bar}^{-1}\right)$

Ilustración 69. Efecto de la temperatura de coagulación en el comportamiento de membranas de AC3 (serie 31006 a 30 bar) 


\section{Efecto del tratamiento térmico}

Las membranas que no han recibido tratamiento térmico han mostrado por lo general altos fluxes $\left(>1000 \mathrm{~L} \cdot \mathrm{m}^{-2} \cdot \mathrm{dí}^{-1}\right)$ y bajos rechazos de soluto $(<20 \%)$. Esto es indicativo de que la superficie de una membrana no tratada es bastante porosa. Un tratamiento térmico puede cerrar más la estructura. Así, la separación de soluto se ha incrementado tras un tratamiento térmico, pasando por ejemplo desde un $30 \%$ de rechazo hasta más del 90\%. Por otra parte, al aumentar el rechazo mediante tratamiento térmico el flux disminuye, en alguna ocasión hasta en un orden de magnitud. La explicación del efecto del tratamiento térmico es que éste induce cambios en la conformación de las cadenas poliméricas. En el proceso de inversión de fase la rápida coagulación produce una gran cantidad de conformaciones alejadas del equilibrio termodinámico. El calentamiento del acetato de celulosa proporciona la energía suficiente para que se produzcan movimientos en los segmentos de cadena hacia la obtención de configuraciones más estables de la red polimérica. Según Sourirajan (1970) esto lleva a que las cadenas se entrelacen, los segmentos de la red polimérica tridimensional de la capa activa se acerquen más y disminuyan los espacios capilares. La subestructura de poros, si bien disminuye, se mantiene.

Lo anterior se puede explicar también teniendo en cuenta que la temperatura de transición vítrea del acetato de celulosa se encuentra alrededor de 56 a $60{ }^{\circ} \mathrm{C}$. Cuando calentamos por encima de estas temperaturas se produce un paso gradual de las estructuras cristalinas hacia estructuras amorfas. Estas estructuras son mucho más flexibles que las cristalinas por lo que se pueden reordenar las posiciones de sus segmentos. Las zonas amorfas pueden aumentar la permeabilidad del agua respecto del soluto cuando los espacios entre cadenas toman una separación adecuada.

El tratamiento térmico utilizado principalmente fue la inmersión en agua caliente. También se aplicó un tratamiento de exposición de la cara activa de la membrana a vapor caliente buscando conseguir una acción selectiva sobre la superficie, sin embargo no se obtuvieron mejores resultados que con el tratamiento de inmersión.

Un efecto beneficioso adicional que se ha constatado ha sido una mejor resistencia al secado de las membranas que han sufrido tratamiento térmico. Las membranas que habían sido expuestas al aire y perdido completamente el agua que contenían proporcionaban al ensayarse pérdida de las propiedades permeoselectivas, lo cual se pudo observar ensayando en el módulo cilíndrico membranas ya caracterizadas en el módulo de 
placas de mayor área. Este efecto ha sido mayor en membranas no tratadas térmicamente (pérdida relativa de rechazo de un $20 \%$ ) frente a las membranas tratadas térmicamente (pérdida relativa de rechazo inferior al 5\%). Esta pérdida de propiedades ha sido explicada por Han y Bhattacharyya (1991), según estos autores el secado al aire de membranas de acetato de celulosa puede causar un colapso de la estructura debido a la presión capilar. En las membranas tratadas térmicamente la reorganización molecular disminuye la movilidad de las moléculas de acetato de celulosa haciendo la estructura activa más resistente.

El efecto del tratamiento térmico puede apreciarse desde Ilustración 70 a Ilustración 79. Para una temperatura de tratamiento dada existe un óptimo para de tiempo de tratamiento térmico en el cual se alcanza un máximo de nivel de comportamiento. Por debajo de ese tiempo óptimo las membranas darán mucho flujo y retendrán poco, por encima serán membranas muy cerradas con un flujo muy bajo. En la Ilustración 70 se puede observar en línea discontinua como el máximo de tratamiento térmico a una temperatura de tratamiento de $76^{\circ} \mathrm{C}$ (una temperatura de tratamiento bastante baja) se sitúa a unos 10 minutos. Para temperaturas de tratamiento más altas los tiempos óptimos son menores, así para temperaturas entre 95 y $97{ }^{\circ} \mathrm{C}$ los tiempos óptimos se encuentran entre 3 y 5 minutos.

Para el material AC3 la temperatura de tratamiento óptima es cercana a los $95{ }^{\circ} \mathrm{C}$ tal y como se aprecia en la Ilustración 71. Por encima de esta temperatura se produce una caída muy fuerte de la permeabilidad $A$, mientras que el factor de paso de sal $B$ se mantiene (véase Ilustración 71 e Ilustración 72). El material AC6 no varía $A$ y $B$ significativamente a temperaturas inferiores a los $90{ }^{\circ} \mathrm{C}$, presentando su mejor comportamiento sobre los $95{ }^{\circ} \mathrm{C}$ (Ilustración 75). Por encima de esta temperatura el flujo aumenta algo, pero el factor de paso de sal lo hace en una proporción mayor, lo que se interpreta como un deterioro de las propiedades de la membrana. El material ACE presenta un comportamiento similar al del material AC6 aunque con el óptimo situado entre 95 y 97 ${ }^{\circ} \mathrm{C}$ y variaciones menores de $\log A$ y $\log B$. 


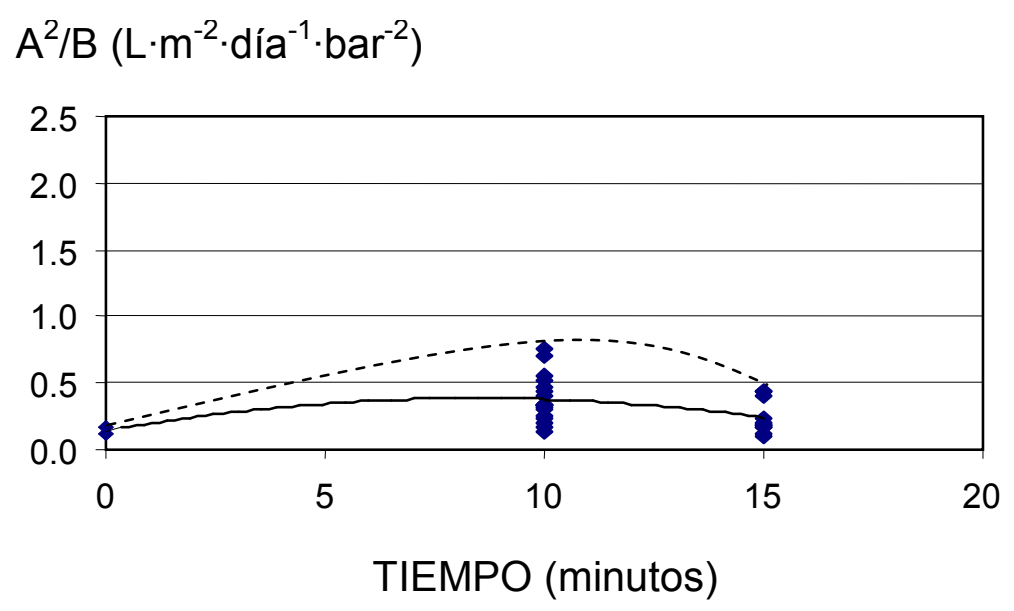

Ilustración 70. Efecto del tiempo de tratamiento térmico por inmersión en agua a 76 ${ }^{o} \mathrm{C}$ sobre el nivel de comportamiento en las series 60916 y 60921 


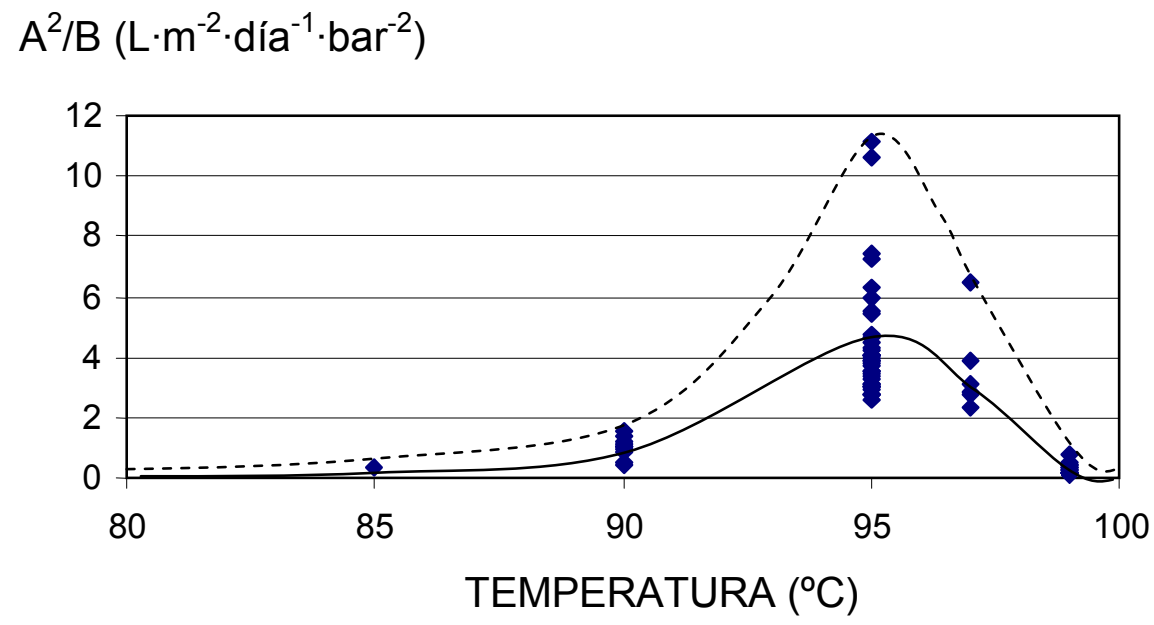

Ilustración 71. Efecto de la temperatura de tratamiento térmico sobre el nivel de comportamiento de membranas fabricadas con $A C 3$

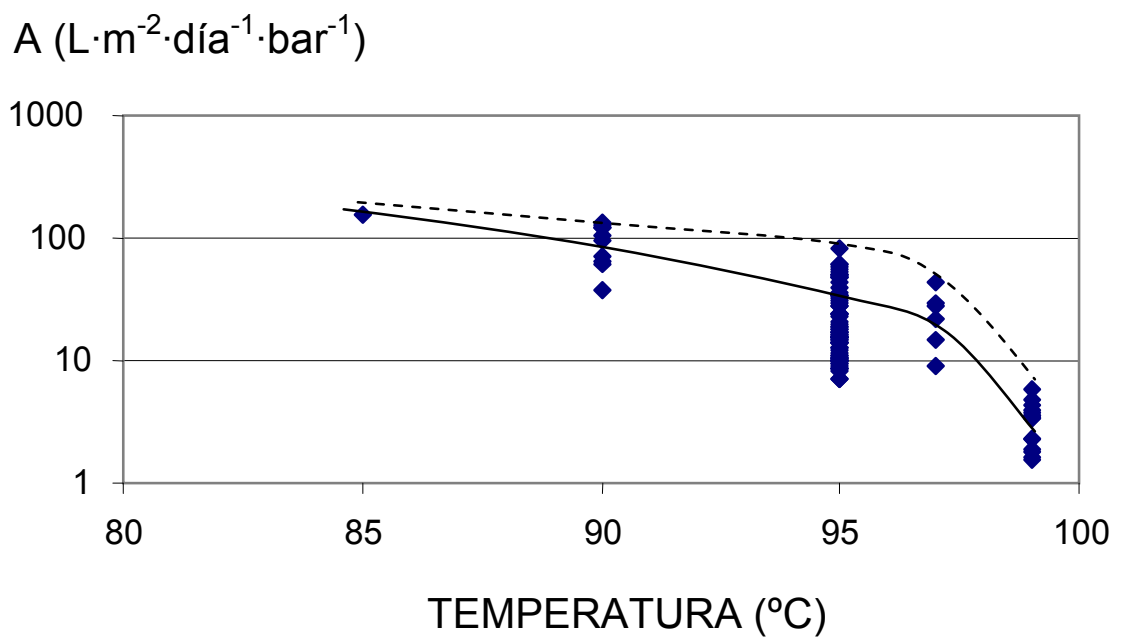

Ilustración 72. Efecto de la temperatura de tratamiento térmico sobre la permeabilidad a 30 bar de membranas fabricadas con AC3

$B\left(L \cdot m^{-2} \cdot d i ́ a a^{-1}\right)$

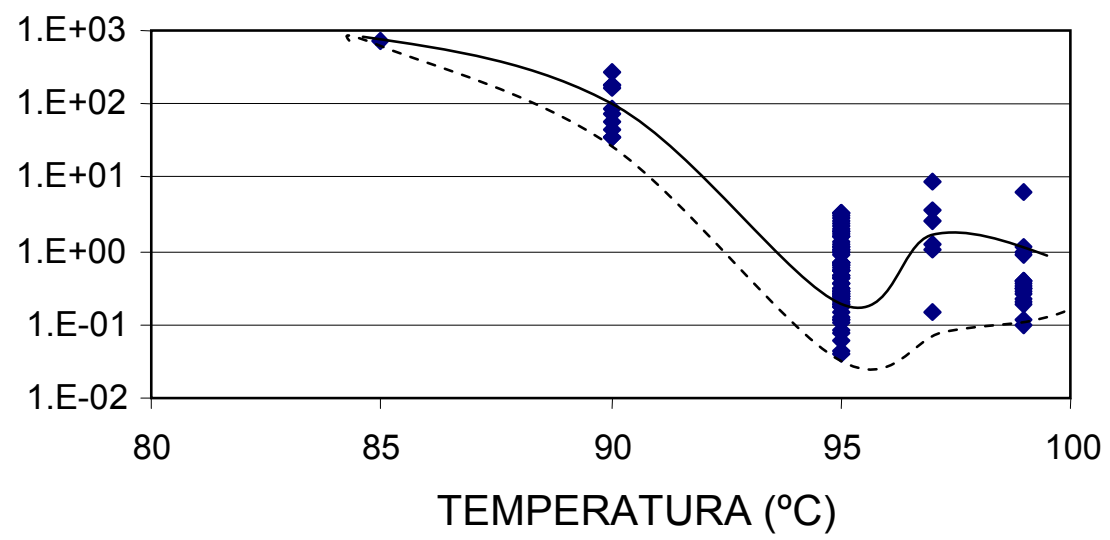

Ilustración 73. Efecto de la temperatura de tratamiento térmico sobre el factor de paso de sal a 30 bar de membranas fabricadas con $A C 3$ 
$A^{2} / B\left(L \cdot m^{-2} \cdot d i^{-1} \cdot\right.$ bar $\left.^{-2}\right)$

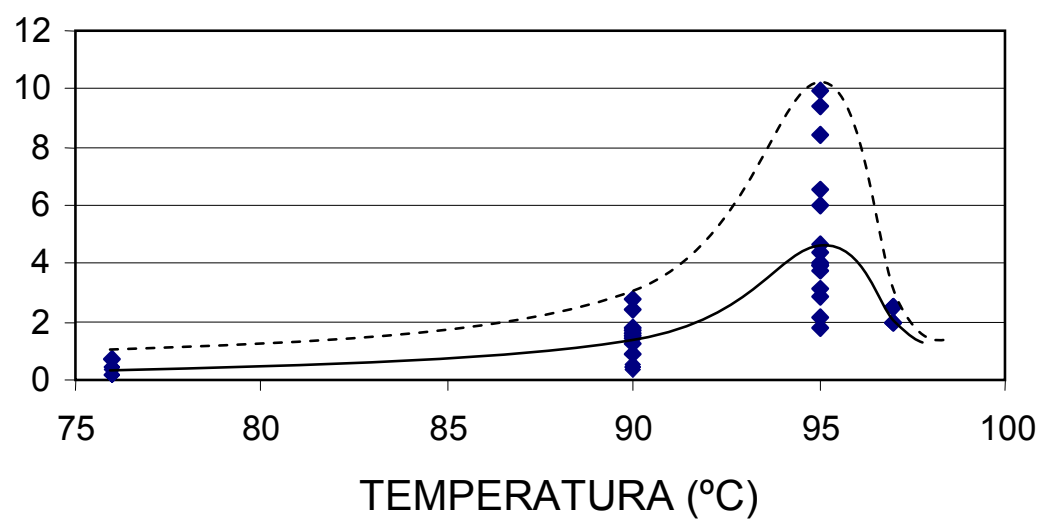

Ilustración 74. Efecto de la temperatura de tratamiento térmico sobre el nivel de comportamiento de membranas fabricadas con AC6

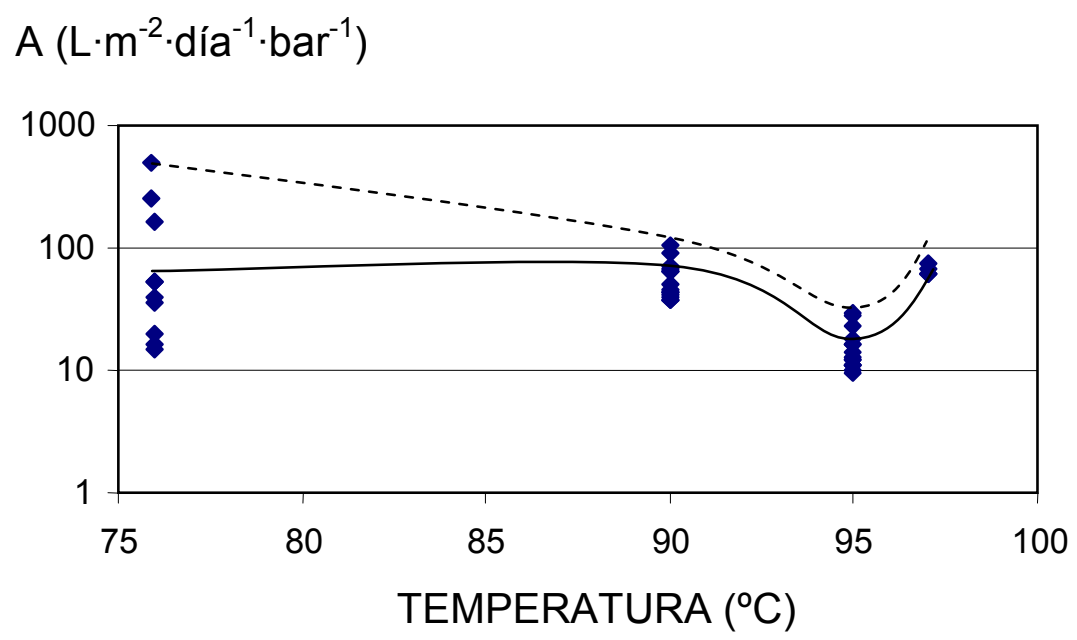

Ilustración 75. Efecto de la temperatura de tratamiento térmico sobre la permeabilidad a 30 bar de membranas fabricadas con AC6 $\mathrm{B}\left(\mathrm{L} \cdot \mathrm{m}^{-2} \cdot \mathrm{dí}^{-1}\right)$

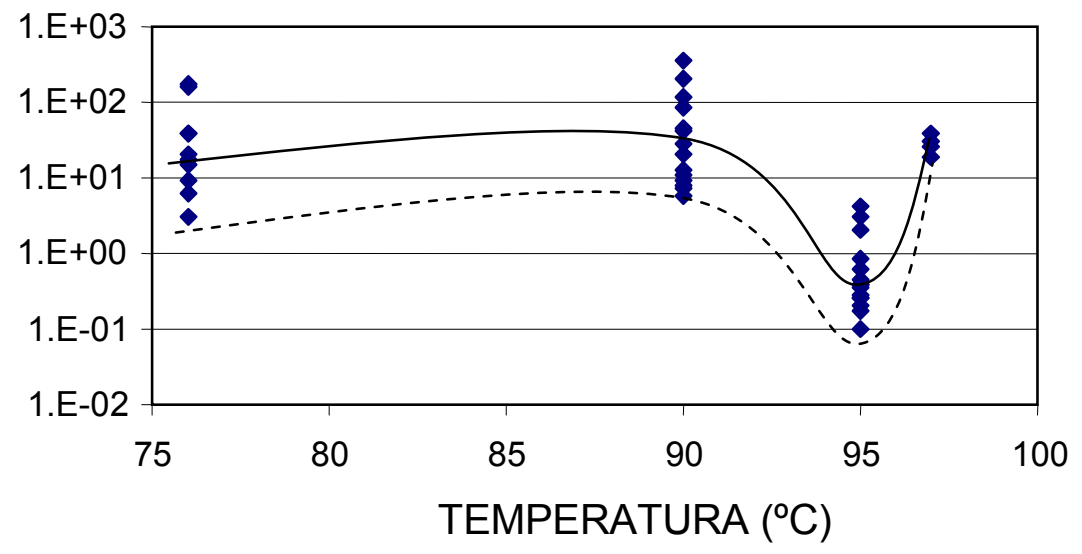

Ilustración 76. Efecto de la temperatura de tratamiento térmico sobre el factor de paso de sal a 30 bar de membranas fabricadas con AC6 


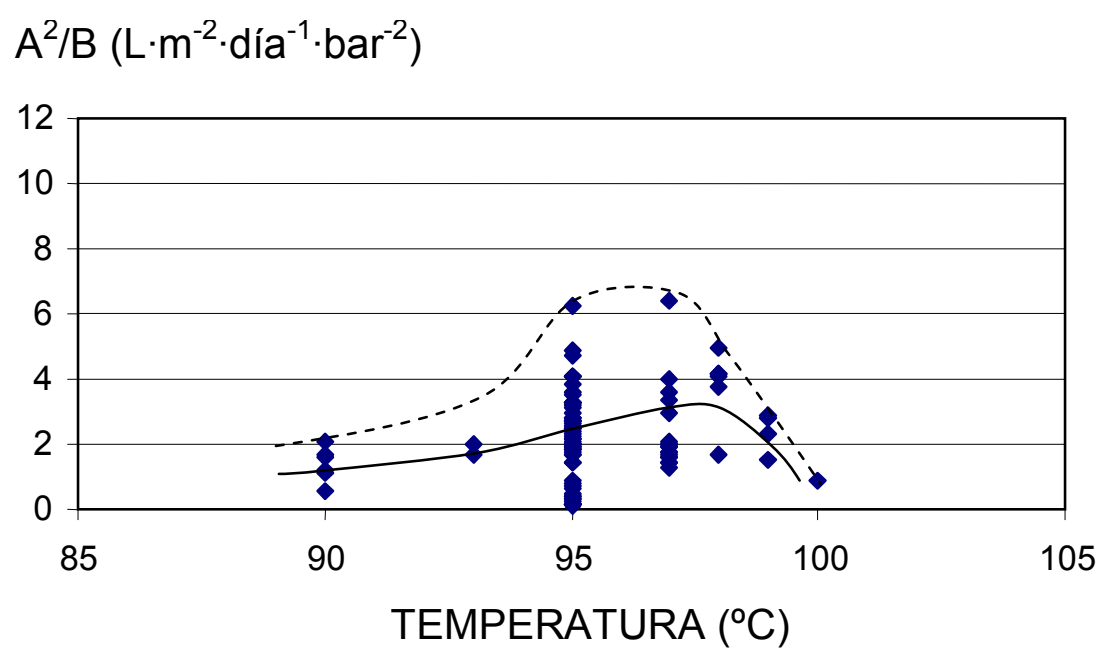

Ilustración 77. Efecto de la temperatura de tratamiento térmico sobre el nivel de comportamiento de membranas fabricadas con $A C E$

$A\left(L \cdot \mathrm{m}^{-2} \cdot \mathrm{día}^{-1} \cdot \mathrm{bar}^{-1}\right)$

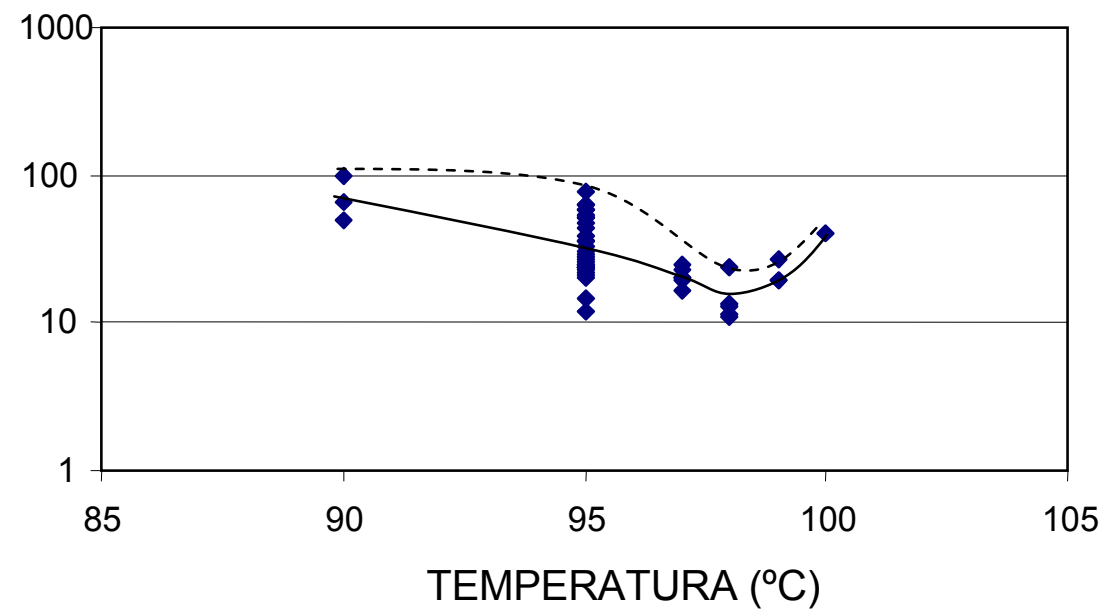

Ilustración 78. Efecto de la temperatura de tratamiento térmico sobre la permeabilidad a 30 bar de membranas fabricadas con $A C E$

$\mathrm{B}\left(\mathrm{L} \cdot \mathrm{m}^{-2} \cdot \mathrm{dí}^{-1}\right)$

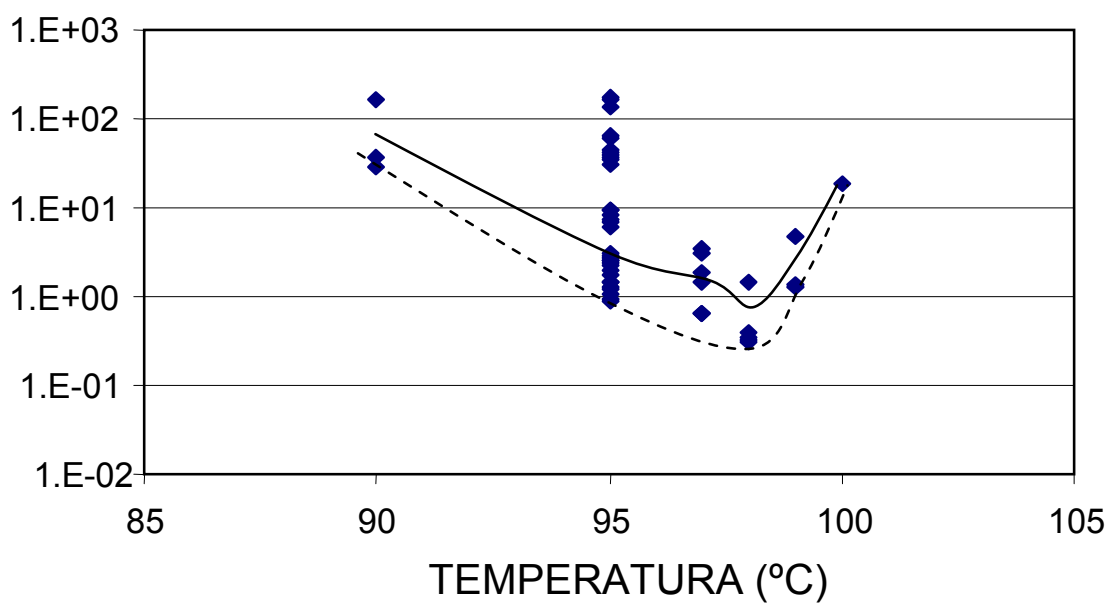

Ilustración 79. Efecto de la temperatura de tratamiento térmico sobre el factor de paso de sal a 30 bar de membranas fabricadas con $A C E$ 


\subsubsection{Serie de experimentos para el estudio de la interacción entre los factores de fabricación seleccionados}

Con vistas a estudiar el efecto de las variables seleccionadas se realizó un diseño de experimentos con el programa Statgraphics v. 2.0. con vistas a poder realizar estudios de superficie de respuesta con un número de experimentos óptimo. Se consideraron unos rangos para las variables seleccionadas para el estudio y se fijaron el resto de variables en valores que proporcionaron membranas adecuadas en los estudios anteriores (Tabla 47). Se escogió un diseño de Box-Behnken cuyo sumario se presenta en la Tabla 48. La elección de este diseño se debió a que proporcionaba rangos de factores a estudiar que no incluían números negativos.

\begin{tabular}{|ll|}
\hline $\begin{array}{l}\text { Tabla 47. Características de las membranas empleadas } \\
\text { en el experimento }\end{array}$ \\
\hline Polímero: & Mezcla de AC3 y AC6 1:1 \\
Aditivo: & Cloruro de Litio (2\%) \\
Disolvente: & Dimetilacetamida \\
Temperatura de evaporación: & Ambiente \\
Temperatura de coagulación: & $25^{\circ} \mathrm{C}$ \\
Temperatura de tratamiento & \\
térmico: & $95^{\circ} \mathrm{C}$ \\
\hline
\end{tabular}

Se fabricaron membranas atendiendo a las distintas combinaciones de factores en Tabla 50 y se midieron las cantidades de polímero depositadas por unidad de área de membrana ( Tabla 49). La forma de fabricar las membranas no fue completamente aleatoria ya que se utilizó el mismo colodión y se trató de utilizar la misma hoja para obtener membranas de diferentes tratamientos térmicos, siguiendo la técnica de Mukherjee et al. (1994) con vistas a disminuir el efecto de la variabilidad inter-hojas. 
Las experiencias de caracterización correspondientes a cada combinación de factores se realizaron siguiendo un orden aleatorio con vistas a proteger el experimento de posibles efectos de variables no controladas. También se han mantenido lo más constantes posible las condiciones de caracterización para conseguir que los efectos sobre los resultados sean debidos a los factores de fabricación.

\section{Tabla 48. Sumario del diseño de experimentos}

Clase de diseño: Superficie de respuesta. Diseño de Box-Behnken en un solo bloque Número de factores experimentales: 4

\begin{tabular}{|c|}
\hline Número de bloques: 1 \\
\hline Grados de libertad de error: 12 \\
\hline Número de ensayos: 27 \\
\hline
\end{tabular}
Número de respuestas estudiadas: 3 Número de puntos centrales por bloque: 3

\begin{tabular}{|c|l|c|c|c|c|}
\hline \multicolumn{2}{|c|}{ Factor del experimento } & $\begin{array}{c}\text { Valor } \\
\text { alto }\end{array}$ & $\begin{array}{c}\text { Valor } \\
\text { intermedio }\end{array}$ & $\begin{array}{c}\text { Valor } \\
\text { bajo }\end{array}$ & Continuo \\
\hline$X P$ & Polímero en el colodión $(\%)$ & 20.0 & 22.0 & 24.0 & Sí \\
\hline$E N$ & Espesor de enrasador $(\mu \mathrm{m})$ & 36.0 & 55.5 & 75.0 & Sí \\
\hline$T P E$ & Tpo. evaporación $(\mathrm{s})$ & 30.0 & 60.0 & 90.0 & Sí \\
\hline$T P T$ & $\begin{array}{l}\text { Tiempo de tratamiento } \\
\text { térmico (s) }\end{array}$ & 60.0 & 150.0 & 240.0 & Sí \\
\hline & Variables estudiadas & & Unidades & Continua \\
\hline$A$ & Permeabilidad & litro $\cdot \mathrm{m}^{-2} \cdot \mathrm{día}^{-1} \cdot \mathrm{bar}^{-1}$ & Sí \\
\hline$B$ & Factor de paso de sal & $\left(\mathrm{mol} \cdot \mathrm{m}^{-2} \cdot \mathrm{día}^{-1}\right) /\left(\mathrm{mol}^{2} \cdot \mathrm{litro}{ }^{-1}\right)$ & Sí \\
\hline$A^{2} / B$ & Factor de comportamiento & litro $\cdot \mathrm{m}^{-2} \cdot \mathrm{día}^{-1} \cdot \mathrm{bar}^{-2}$ & Sí \\
\hline
\end{tabular}


Una vez fabricadas las membranas se obtuvieron resultados de flux y rechazo a tres presiones diferentes, reflejados también en la Tabla 50, los cuales se transformaron en las variables permeabilidad $A$ y factor de paso de sal $B$ (Tabla 51). Las variables $A$ y $B$ no se han obtenido en este caso de forma independiente a cada presión sino como las pendientes de ajustes lineales del flux volumétrico frente a la presión efectiva y del flux de soluto frente a la diferencia de concentración. Estas variables resultan más adecuadas para su utilización en el análisis estadístico que las variables flux y rechazo que son diferentes para cada presión, además la variable rechazo al estar doblemente acotada podía originar resultados ajustados ilógicos con valores de rechazo superiores al 100\%.

Tabla 49. Deposición de polímero AC $\left(\mathrm{mg} / \mathrm{cm}^{2}\right)$

\begin{tabular}{|c|c|c|c|c|c|c|c|c|}
\hline Membrana & $\begin{array}{c}E N \\
(\mu \mathrm{m})\end{array}$ & $\begin{array}{c}\text { Deposición } \\
\left(\mathrm{mg} / \mathrm{cm}^{2}\right)\end{array}$ & Membr. & $\begin{array}{c}E N \\
(\mu \mathrm{m})\end{array}$ & $\begin{array}{c}\text { Deposición } \\
\left(\mathrm{mg} / \mathrm{cm}^{2}\right)\end{array}$ & Membrana & $\begin{array}{c}\text { EN } \\
(\mu \mathrm{m})\end{array}$ & $\begin{array}{c}\text { Deposición } \\
\left(\mathrm{mg} / \mathrm{cm}^{2}\right)\end{array}$ \\
\hline 1 & 75 & 1.245 & 10 & 50 & 1.168 & 19 & 50 & 1.028 \\
\hline 2 & 50 & 0.889 & 11 & 75 & 1.400 & 20 & 75 & 1.402 \\
\hline 3 & 36 & 0.800 & 12 & 50 & 1.032 & 21 & 50 & 1.030 \\
\hline 4 & 36 & 1.000 & 13 & 50 & 0.898 & 22 & 50 & 0.905 \\
\hline 5 & 50 & 1.025 & 14 & 50 & 0.975 & 23 & 36 & 0.905 \\
\hline 6 & 36 & 0.936 & 15 & 75 & 1.475 & 24 & 50 & 1.159 \\
\hline 7 & 75 & 1.564 & 16 & 75 & 1.727 & 25 & 50 & 1.011 \\
\hline 8 & 50 & 1.034 & 17 & 50 & 0.950 & 26 & 50 & 1.040 \\
\hline 9 & 36 & 1.030 & 18 & 36 & 0.900 & 27 & 50 & 1.053 \\
\hline
\end{tabular}


Tabla 50. Condiciones de fabricación y resultados de caracterización para el experimento manual

Factores:

$X P: \quad$ Fracción de polímero (\%)

$E N$ : Enrasador utilizado (micras)

TPE: Tiempo de evaporación (s)

$T P T$ : Tiempo de tratamiento térmico a la temperatura de $95^{\circ} \mathrm{C}(\mathrm{s})$

\begin{tabular}{|c|c|c|c|c|c|c|c|c|c|c|}
\hline \multirow[t]{3}{*}{$\begin{array}{l}\text { Mem- } \\
\text { brana }\end{array}$} & \multicolumn{4}{|c|}{ Factores de fabricación } & \multicolumn{6}{|c|}{$\begin{array}{c}\text { Variables caracterizadas } \\
\text { Flux }\left(L /\left(m^{2} \cdot \text { dia }\right)\right) \text { Rechazo }(\%)\end{array}$} \\
\hline & \multirow{2}{*}{$\begin{array}{l}X P \\
(\%)\end{array}$} & \multirow{2}{*}{$\begin{array}{c}E N \\
(\mu m)\end{array}$} & \multirow{2}{*}{$\begin{array}{l}T P E \\
(s)\end{array}$} & \multirow{2}{*}{$\begin{array}{l}T P T \\
(s)\end{array}$} & \multicolumn{2}{|c|}{$20 \mathrm{bar}$} & \multicolumn{2}{|c|}{30 bar } & \multicolumn{2}{|c|}{40 bar } \\
\hline & & & & & Flux & $R(\%)$ & Flux & $R(\%)$ & Flux & $R(\%)$ \\
\hline 1 & 20 & 75 & 60 & 150 & 1158 & 22.3 & 1618 & 36.9 & 1897 & 38.5 \\
\hline 2 & 20 & 55.5 & 60 & 60 & 1539 & 19.8 & 1833 & 27.6 & 2116 & 38.6 \\
\hline 3 & 20 & 36 & 60 & 150 & 710 & 38.1 & 957 & 44.7 & 1264 & 54.7 \\
\hline 4 & 24 & 36 & 60 & 150 & 212 & 82.0 & 335 & 86.7 & 462 & 87.2 \\
\hline 5 & 24 & 55.5 & 90 & 150 & 239 & 82.3 & 381 & 88.1 & 512 & 89.3 \\
\hline 6 & 22 & 36 & 60 & 240 & 965 & 36.1 & 1410 & 56.1 & 1930 & 41.2 \\
\hline 7 & 24 & 75 & 60 & 150 & 295 & 75.3 & 425 & 83.4 & 585 & 83.4 \\
\hline 8 & 22 & 55.5 & 60 & 150 & 367 & 56.4 & 507 & 67.3 & 675 & 72.3 \\
\hline 9 & 22 & 36 & 60 & 60 & 643 & 44.4 & 1183 & 46.9 & 1528 & 46.9 \\
\hline 10 & 24 & 55.5 & 60 & 240 & 166 & 83.3 & 248 & 87.9 & 308 & 90.4 \\
\hline 11 & 22 & 75 & 90 & 150 & 803 & 43.1 & 1048 & 47.6 & 2142 & 65.9 \\
\hline 12 & 20 & 55.5 & 60 & 240 & 880 & 30.0 & 1146 & 37.2 & 1325 & 44.0 \\
\hline 13 & 20 & 55.5 & 90 & 150 & 611 & 41.5 & 857 & 50.1 & 1134 & 58.6 \\
\hline 14 & 22 & 55.5 & 30 & 60 & 414 & 64.7 & 591 & 73.4 & 1225 & 84.8 \\
\hline 15 & 22 & 75 & 30 & 150 & 400 & 66.7 & 579 & 70.9 & 1197 & 84.6 \\
\hline 16 & 22 & 75 & 60 & 240 & 705 & 44.8 & 943 & 51.3 & 1931 & 68.6 \\
\hline 17 & 22 & 55.5 & 60 & 150 & 306 & 69.2 & 444 & 76.2 & 925 & 87.1 \\
\hline 18 & 22 & 36 & 30 & 150 & 712 & 45.1 & 1000 & 53.9 & 622 & 77.8 \\
\hline 19 & 22 & 55.5 & 30 & 240 & 531 & 49.5 & 887 & 53.9 & 1146 & 52.5 \\
\hline 20 & 22 & 75 & 60 & 60 & 759 & 37.8 & 1038 & 50.1 & 1279 & 56.3 \\
\hline 21 & 22 & 55.5 & 90 & 240 & 655 & 50.8 & 957 & 57.0 & 1068 & 56.9 \\
\hline 22 & 20 & 55.5 & 30 & 150 & 1222 & 22.9 & 1528 & 31.1 & 1865 & 32.8 \\
\hline 23 & 22 & 36 & 90 & 150 & 430 & 65.5 & 622 & 71.5 & 1286 & 84.4 \\
\hline 24 & 24 & 55.5 & 60 & 60 & 417 & 54.4 & 618 & 64.5 & 710 & 64.8 \\
\hline 25 & 22 & 55.5 & 60 & 150 & 458 & 47.3 & 595 & 59.6 & 719 & 69.6 \\
\hline 26 & 24 & 55.5 & 30 & 150 & 186 & 82.5 & 281 & 87.4 & 373 & 88.0 \\
\hline 27 & 22 & 55.5 & 90 & 60 & 167 & 74.0 & 258 & 76.0 & 356 & 77.2 \\
\hline
\end{tabular}

Condiciones del ensayo:

Planta: $\quad$ Planta 2 con módulo de 6 placas Alimento: $\mathrm{NaCl} 2000$ ppm en agua desionizada Temperatura: $20^{\circ} \mathrm{C}$ 
Tabla 51. Parámetros $A$ y $B$ calculados

\begin{tabular}{|c|r|r|r|r|r|r|r|}
\hline Membrana & \multicolumn{1}{|c|}{$A$} & \multicolumn{1}{|c|}{$B$} & \multicolumn{1}{|c|}{$A^{2} / B$} & Membrana & \multicolumn{1}{|c|}{$A$} & \multicolumn{1}{|c|}{$B$} & $A^{2} / B$ \\
\hline 1 & 80.7 & 3279.0 & 1.99 & 15 & 37.4 & 218.2 & 6.39 \\
\hline 2 & 94.3 & 4806.2 & 1.85 & 16 & 60.9 & 882.5 & 4.20 \\
\hline 3 & 51.4 & 1127.7 & 2.34 & 17 & 28.9 & 137.5 & 6.09 \\
\hline 4 & 18.7 & 55.3 & 6.32 & 18 & 41.1 & 633.1 & 2.67 \\
\hline 5 & 21.0 & 54.7 & 8.06 & 19 & 45.2 & 779.3 & 2.62 \\
\hline 6 & 75.2 & 1855.1 & 3.05 & 20 & 54.1 & 1093.1 & 2.67 \\
\hline 7 & 24.0 & 99.0 & 5.83 & 21 & 47.4 & 722.2 & 3.11 \\
\hline 8 & 27.7 & 262.6 & 2.93 & 22 & 79.4 & 3769.6 & 1.67 \\
\hline 9 & 58.7 & 1290.7 & 2.67 & 23 & 40.1 & 237.0 & 6.79 \\
\hline 10 & 13.2 & 33.4 & 5.26 & 24 & 31.1 & 358.4 & 2.69 \\
\hline 11 & 67.9 & 1106.7 & 4.16 & 25 & 31.5 & 409.5 & 2.42 \\
\hline 12 & 58.1 & 1892.5 & 1.79 & 26 & 15.6 & 43.6 & 5.55 \\
13 & 45.8 & 838.6 & 2.50 & 27 & 14.1 & 81.9 & 2.44 \\
\hline 14 & 38.3 & 219.8 & 6.67 & & & & \\
\hline
\end{tabular}

\section{Estudio de la deposición}

El único factor de los estudiados en el experimento que puede tener influencia sobre la deposición es el espesor nominal del enrasado $(E N)$. Una mayor cantidad de polímero depositada conduce a un mayor espesor de capa activa de membrana. Este espesor a su vez bajo unas mismas condiciones de formación de la membrana, y siempre que esta esté libre de imperfecciones, influirá en el flux y la selectividad de la membrana.

Para estudiar si el espesor nominal del enrasador tenía una relación directa con el espesor depositado se midió para todas las membranas de la Tabla 50 el acetato de celulosa depositado según se indica en el apartado 3.7.1. Los resultados aparecen tabulados en la Tabla 49 y representados en la Ilustración 80. 


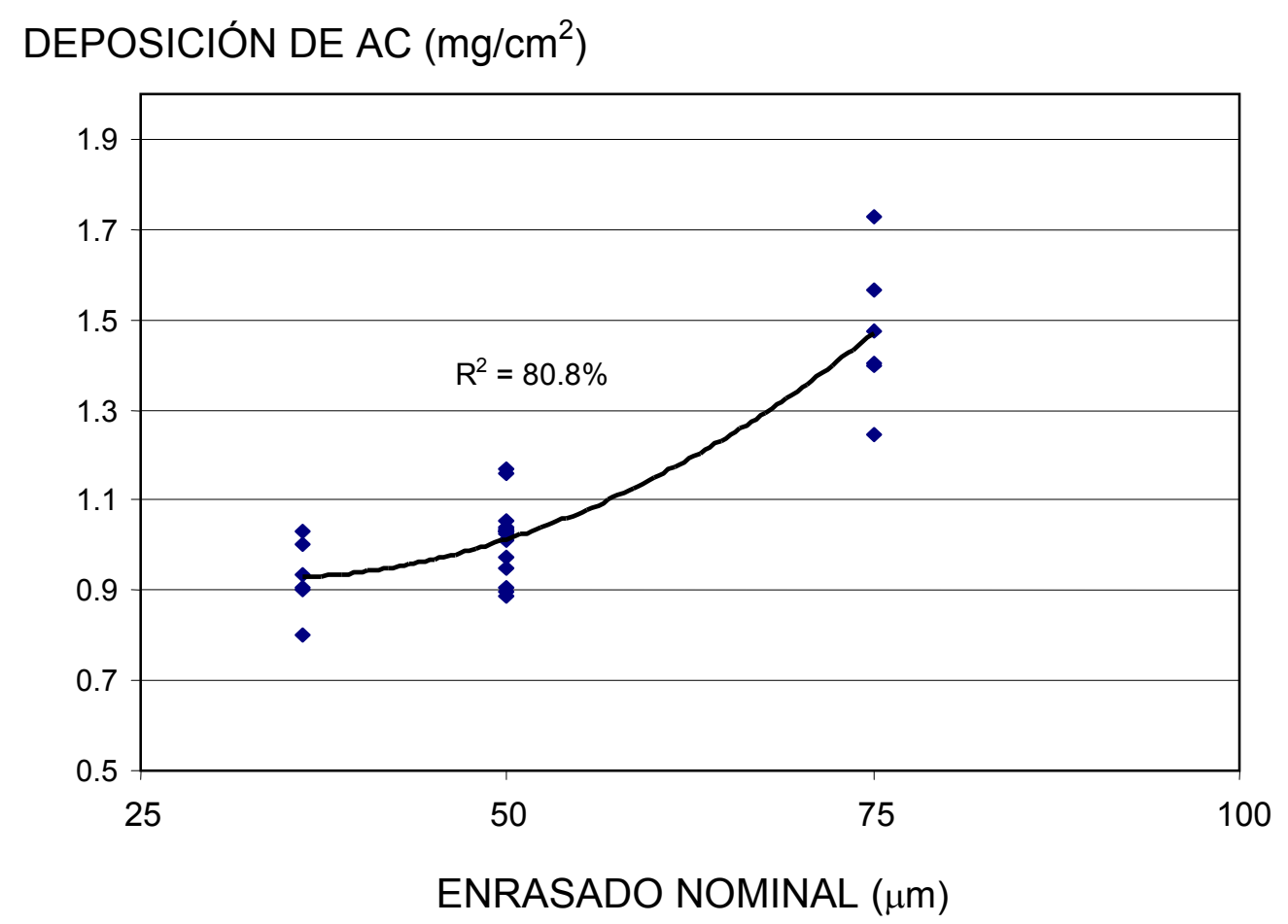

\section{Ilustración 80. Cantidad de acetato de celulosa depositada en función del espesor nominal de enrasado}

En la Ilustración 80 se puede ver que no existe una relación lineal entre el espesor nominal de enrasado y la cantidad realmente depositada, si bien los valores medios de deposición son mayores cuanto mayor es el espesor nominal de enrasado. Se observa también que debido a la elevada dispersión de resultados algunos valores de cantidad depositada son mayores para el enrasador de $36 \mu \mathrm{m}$ que para el de $50 \mu \mathrm{m}$.

\section{Estudio del efecto de los factores en la permeabilidad al disolvente (parámetro $A$ )}

Se estimaron los efectos de los factores sobre el parámetro $A$ y los errores basados en un error total para 12 grados de libertad. En el análisis normal de la varianza de la Tabla 52 se expresa la variabilidad de $A$ separada para los distintos efectos de los factores. La significación estadística de cada efecto viene expresada por comparación del cuadrado medio residual con el cuadrado medio del factor. En nuestro caso los factores $X P$ (fracción de polímero en el colodión) y $E N$ (enrasado nominal) tienen 
valores $\mathrm{P}$ inferiores a 0.05 , lo cual indica que son significativamente diferentes de cero con un $95 \%$ de nivel de confianza. El coeficiente de correlación $R^{2}$ nos indica que el modelo explica un $78.1 \%$ de la variabilidad de $A$; sin embargo, para comparar con el ajuste de los otras variables resulta más adecuado considerar el coeficiente $R^{2}$ ajustado con valor $52.5 \%$. El error estándar de la estimación mostró una desviación de los errores residuales de 15.2185 , mientras que el error medio absoluto de 8.26975 es el valor medio de los residuos.

Tabla 52. Análisis de la varianza para $A$

\begin{tabular}{|c|c|c|c|c|c|}
\hline Fuente & $\begin{array}{c}\text { Cuadrado } \\
\text { medio factor }\end{array}$ & $G . L$. & $\begin{array}{c}\text { Cuadrado } \\
\text { medio residual }\end{array}$ & F-Ratio & Valor P \\
\hline$X P$ & 6821.100 & 1 & 6821.100 & 29.45 & 0.0002 \\
\hline$E N$ & 132.003 & 1 & 132.003 & 0.57 & 0.4648 \\
\hline$T P E$ & 35.708 & 1 & 35.708 & 0.15 & 0.7015 \\
\hline$T P T$ & 7.363 & 1 & 7.363 & 0.03 & 0.8615 \\
\hline$X P^{*} X P$ & 165.763 & 1 & 165.763 & 0.72 & 0.4141 \\
\hline$X P^{*} E N$ & 144.000 & 1 & 144.000 & 0.62 & 0.4457 \\
\hline$X P^{*} T P E$ & 380.250 & 1 & 380.250 & 1.64 & 0.2243 \\
\hline$X P * T P T$ & 83.723 & 1 & 83.723 & 0.36 & 0.5589 \\
\hline$E N^{*} E N$ & 1230.190 & 1 & 1230.190 & 5.31 & 0.0399 \\
\hline$E N^{*} T P E$ & 248.063 & 1 & 248.063 & 1.07 & 0.3211 \\
\hline$E N^{*} T P T$ & 23.522 & 1 & 23.523 & 0.10 & 0.7554 \\
\hline$T P E^{*} T P E$ & 1.763 & 1 & 1.763 & 0.01 & 0.9319 \\
\hline$T P E^{*} T P T$ & 174.240 & 1 & 174.240 & 0.75 & 0.4028 \\
\hline$T P T^{*} T P T$ & 865.301 & 1 & 865.301 & 3.74 & 0.0772 \\
\hline Residuo & 2779.230 & 12 & 231.603 & & \\
\hline Total (corr.) & 12675.600 & 26 & & & \\
\hline \multicolumn{3}{|l|}{$R^{2}: 0.7812$} & \multicolumn{3}{|c|}{$R^{2}$ (ajustado por g.l.): 0.5254} \\
\hline \multicolumn{3}{|c|}{ Error estándar de la estimación: 15.2185} & \multicolumn{3}{|c|}{ Error medio absoluto: 8.26975} \\
\hline \multicolumn{3}{|c|}{ Estadístico de Durbin-Watson: 2.34} & & & \\
\hline
\end{tabular}


El parámetro estadístico de Durbin-Watson con un valor mayor de 1.4 determina que no existe ninguna autocorrelación seria entre los residuos y el modelo planteado resulta válido no siendo necesario utilizar interacciones entre factores de orden superior.

La información permitió construir el diagrama de Pareto de la Ilustración 81 donde se observa que el factor $X P$ y la interacción $E N^{*} E N$ tienen efectos significativos por encima del error estándar, lo cual se aprecia porque sobrepasan la línea discontinua correspondiente a un $95 \%$ de nivel de confianza.

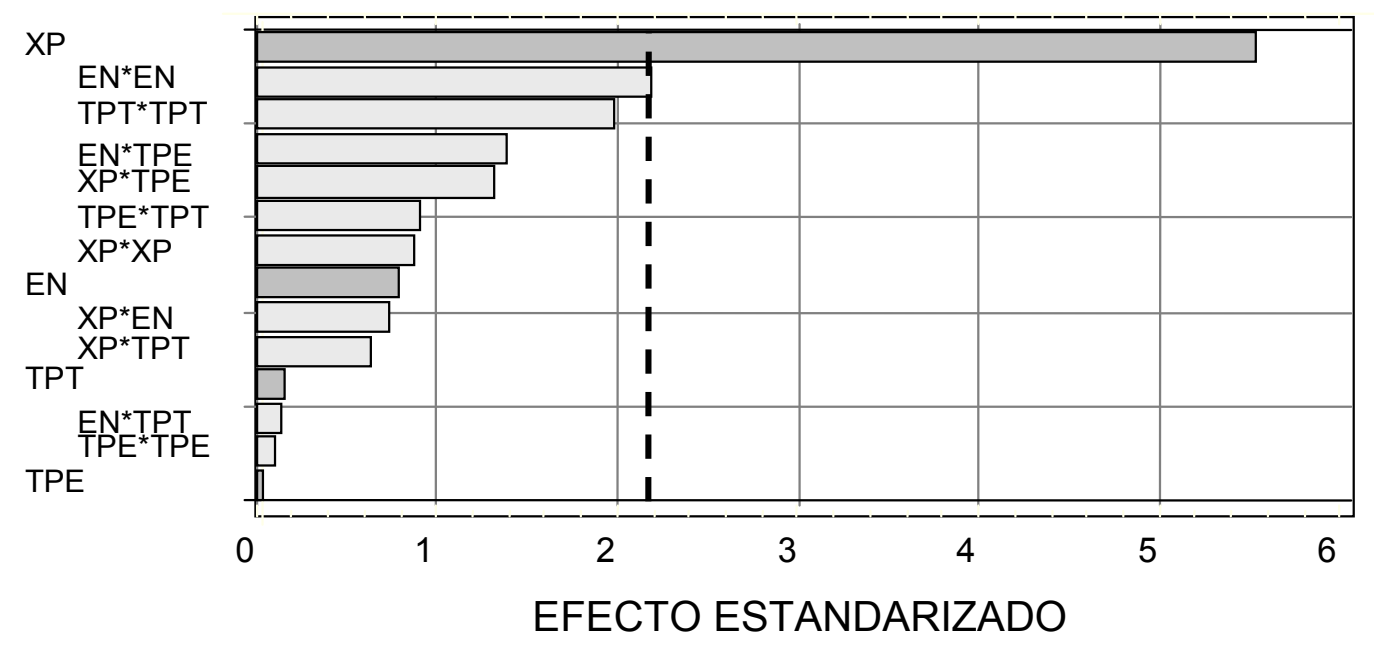

Ilustración 81. Diagrama de Pareto para la variable A

Los efectos de los factores poco significativos que se comportan como ruido desde el punto de vista estadístico se sitúan en una curva de probabilidad normal centrada en cero. En la Ilustración 82 esta curva aparece transformada en recta, quedando el efecto de la concentración de polímero (factor $X P$ ) claramente distanciado de ésta al ser significativo. 


\section{PROPORCIÓN}

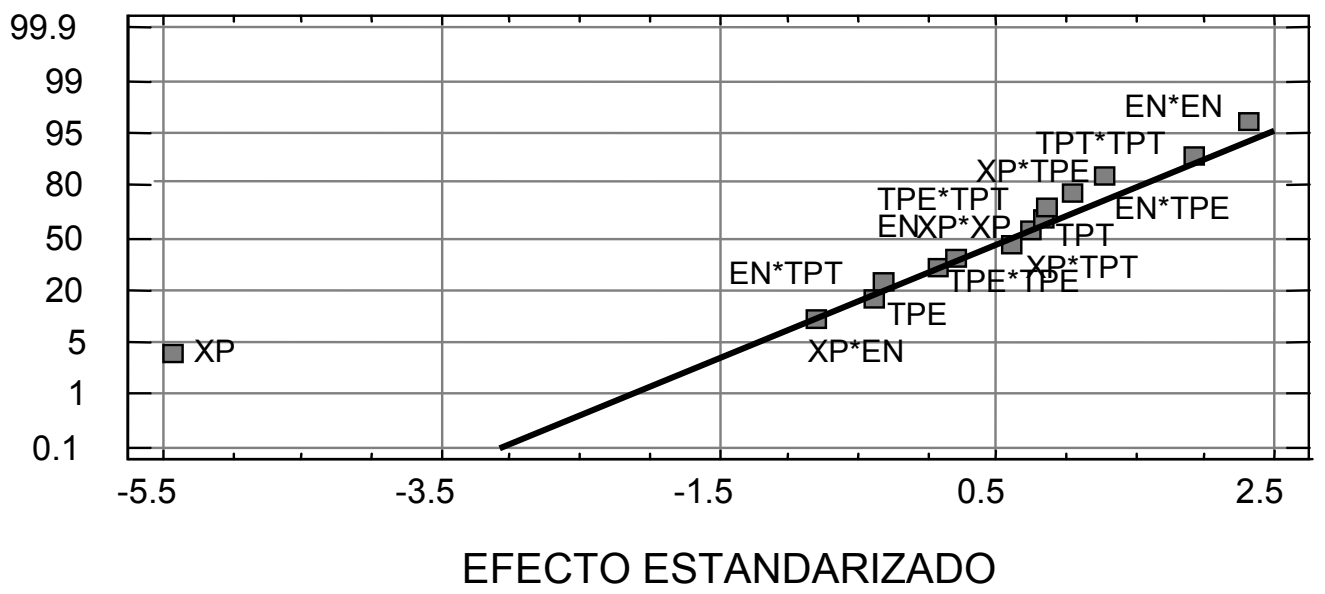

Ilustración 82. Efecto de los factores sobre A en gráfico de probabilidad normal

En la Ilustración 83 se muestra el efecto que sobre la variable $A$ tiene la variación de los diferentes factores cuando el resto de factores se mantiene en su valor central. Se puede observar que el porcentaje de polímero $(X P)$ disminuye la permeabilidad fuertemente. El tiempo de evaporación $(T P E)$ no tiene apenas influencia. Ello puede explicarse considerando que en el rango de tiempos estudiado la capa superior ha tenido tiempo para estabilizarse y la temperatura no es lo suficientemente elevada para producir una concentración superficial de polímero significativa.

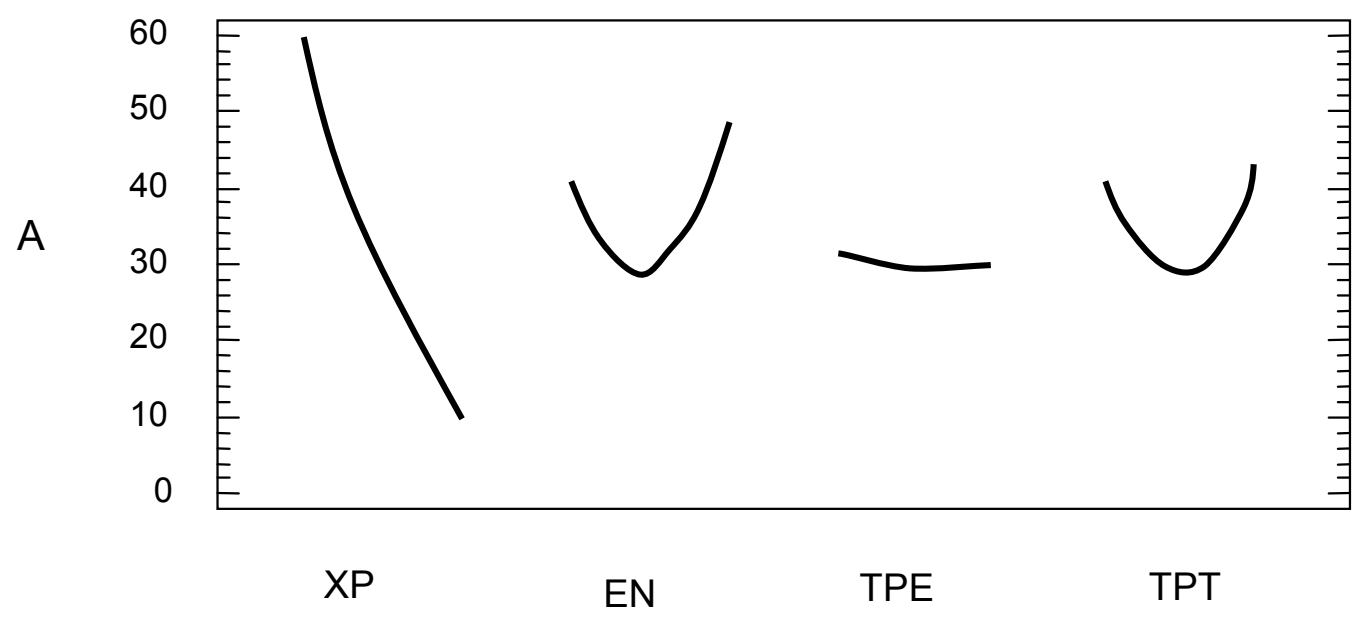

Ilustración 83. Representación de efectos principales para la variable A 
En la Ilustración 84 se representan para parejas de factores el efecto de cada factor manteniendo el segundo a un nivel bajo (curva -) y a un nivel alto (curva + ) mientras que el resto de factores permanece en su nivel medio. Se puede observar que el efecto de la concentración de polímero (factor $X P$ ) sobre $A$ no se ve casi afectado por los otros factores.

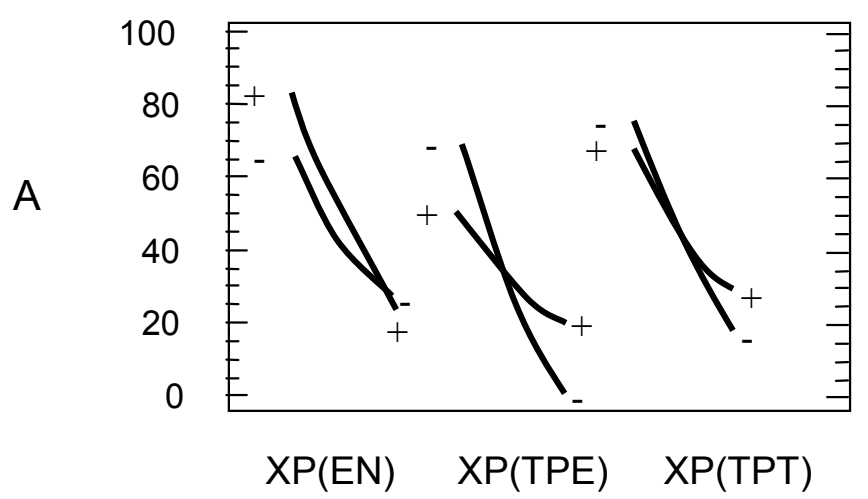

Ilustración 84. Efectos cruzados de los factores

En la Ilustración 85 se representa la superficie de respuesta obtenida en función de los dos factores más influyentes. En ella se aprecia que los valores más altos de permeabilidad $A$ se obtienen para porcentajes bajos de polímero en el colodión. El espesor nominal de enrase $(E N)$ que parece proporcionar menores valores de $A$ parece situarse sobre los $50 \mu \mathrm{m}$ y no sobre los valores más altos como cabe esperar.

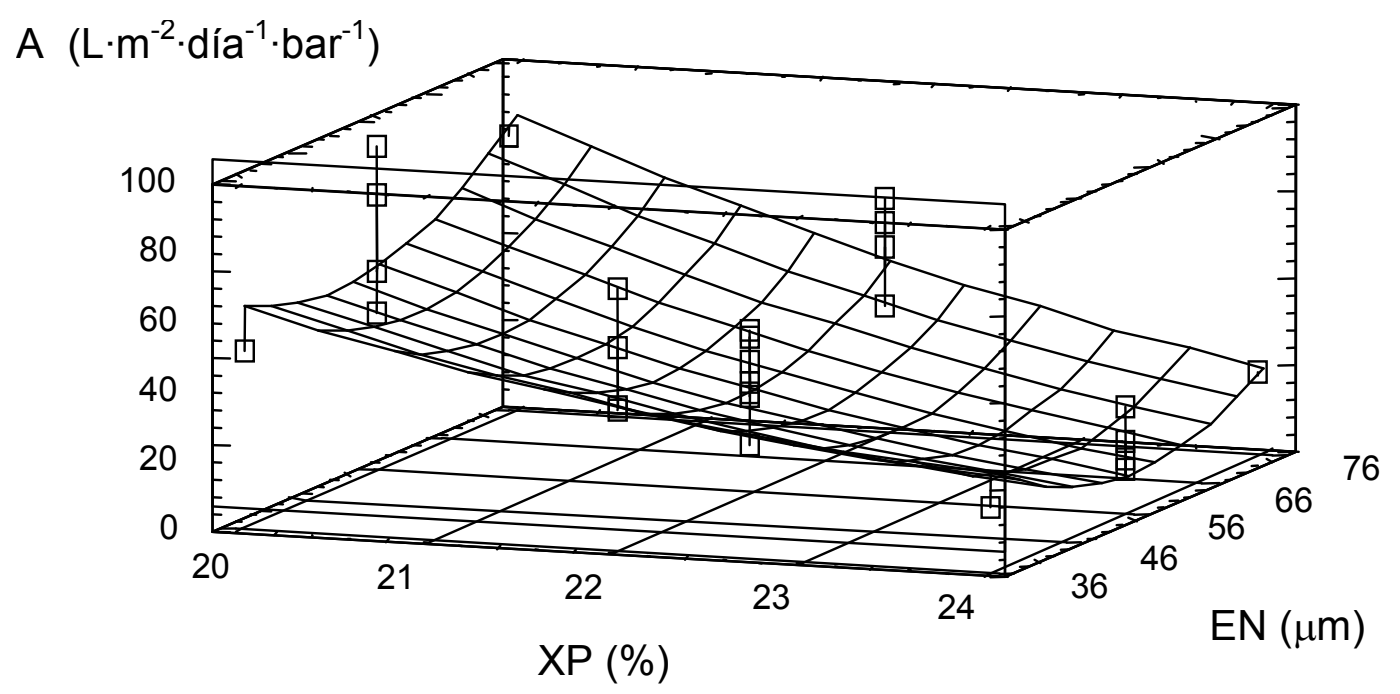

Ilustración 85. Superficie de respuesta del parámetro A frente a los factores XP y EN con TPE y TPT en sus valores medios. 


\section{Estudio del efecto de los factores en el factor de paso de soluto (parámetro $B$ )}

Para este parámetro también se realizó un análisis normal de la varianza (Tabla 53) para expresar la variabilidad de $B$ separada para los distintos efectos de las factores.

\section{Tabla 53. Análisis de la varianza para $B$}

\begin{tabular}{|c|c|c|c|c|c|}
\hline Fuente & $\begin{array}{l}\text { Cuadrado } \\
\text { medio factor }\end{array}$ & G. $L$. & $\begin{array}{c}\text { Cuadrado } \\
\text { medio residual }\end{array}$ & F-Ratio & Valor P \\
\hline$X P$ & 18923400 & 1 & 18923400 & 30.88 & 0.0001 \\
\hline$E N$ & 182435 & 1 & 182435 & 0.30 & 0.5953 \\
\hline$T P E$ & 573126 & 1 & 573126 & 0.94 & 0.3526 \\
\hline$T P T$ & 236630 & 1 & 236630 & 0.39 & 0.5459 \\
\hline$X P^{*} X P$ & 3837480 & 1 & 3837480 & 6.26 & 0.0278 \\
\hline$X P^{*} E N$ & 1110490 & 1 & 1110490 & 1.81 & 0.2031 \\
\hline$X P^{*} T P E$ & 2163990 & 1 & 2163990 & 3.53 & 0.0847 \\
\hline$X P^{*} T P T$ & 1675340 & 1 & 1675340 & 2.73 & 0.1241 \\
\hline$E N^{*} E N$ & 442906 & 1 & 442906 & 0.72 & 0.4119 \\
\hline$E N^{*} T P E$ & 412549 & 1 & 412549 & 0.67 & 0.4279 \\
\hline$E N^{*} T P T$ & 150156 & 1 & 150156 & 0.25 & 0.6295 \\
\hline$T P E^{*} T P E$ & 62684 & 1 & 62684 & 0.10 & 0.7546 \\
\hline$T P E^{*} T P T$ & 1632 & 1 & 1632 & 0.00 & 0.9597 \\
\hline$T P T^{*} T P T$ & 1645090 & 1 & 1645090 & 2.68 & 0.1272 \\
\hline Residuo & 7352580 & 12 & 612715 & & \\
\hline Total (corr.) & $3.84217 \mathrm{E} 7$ & 26 & & & \\
\hline \multicolumn{3}{|l|}{$R^{2}: 0.8094$} & \multicolumn{3}{|c|}{$R^{2}$ (ajustado por g.l.): 0.5853} \\
\hline \multicolumn{3}{|c|}{ Error estándar de la estimación: 782.76} & \multicolumn{3}{|c|}{ Error medio absoluto: 428.214} \\
\hline \multicolumn{3}{|c|}{ Estadistico de Durbin-Watson: 2.00} & & & \\
\hline
\end{tabular}


En este caso el factor $X P$ tiene un valor $P$ muy inferior a 0.05 y también resulta inferior a este valor la interacción $X P^{*} X P$. La importancia de este factor sobre el parámetro $B$ se puede apreciar también en Ilustración 86 y Ilustración 87.

El coeficiente de correlación $R^{2}$ nos indica que el modelo explica un $80.9 \%$ de la variabilidad de $B$. El valor de coeficiente $R^{2}$ ajustado es de $58.5 \%$ por lo que los factores seleccionados explican ligeramente mejor el comportamiento de $\mathrm{B}$ que el comportamiento del parámetro $A$ (con un valor de coeficiente ajustado de $52.5 \%$ ). El estadístico de Durbin-Watson da en este caso también un valor mayor de 1.4 por lo que tampoco existe ninguna autocorrelación importante entre los residuos.

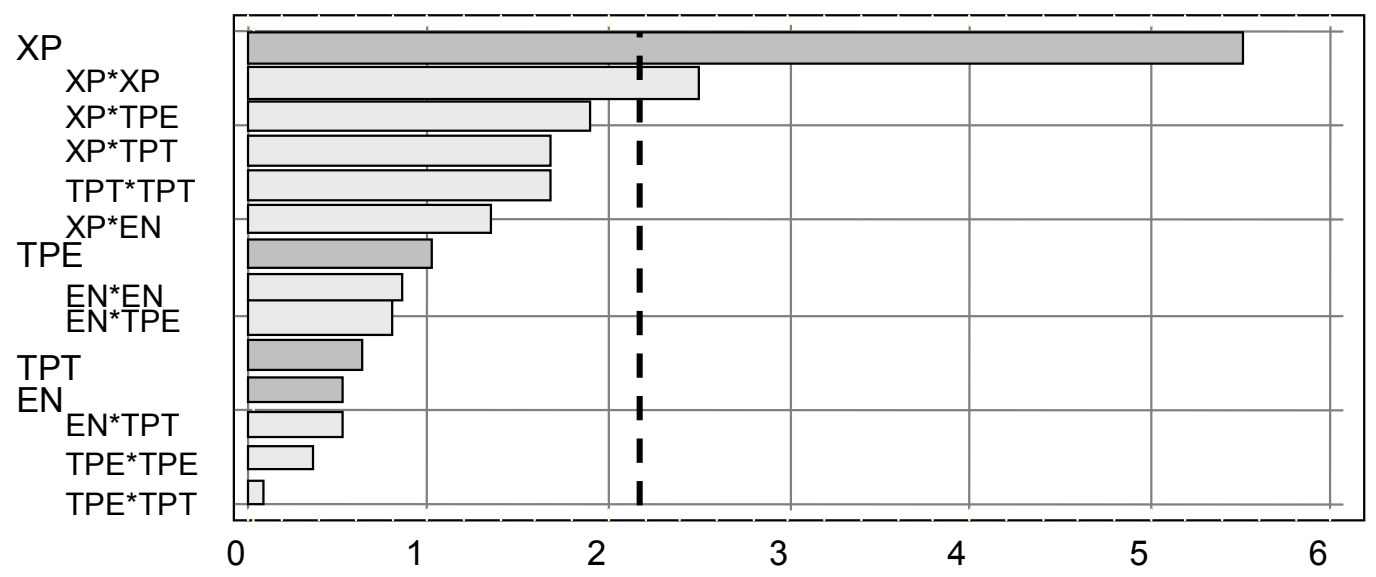

Ilustración 86. Diagrama de Pareto para la variable B

\section{PROPORCIÓN}

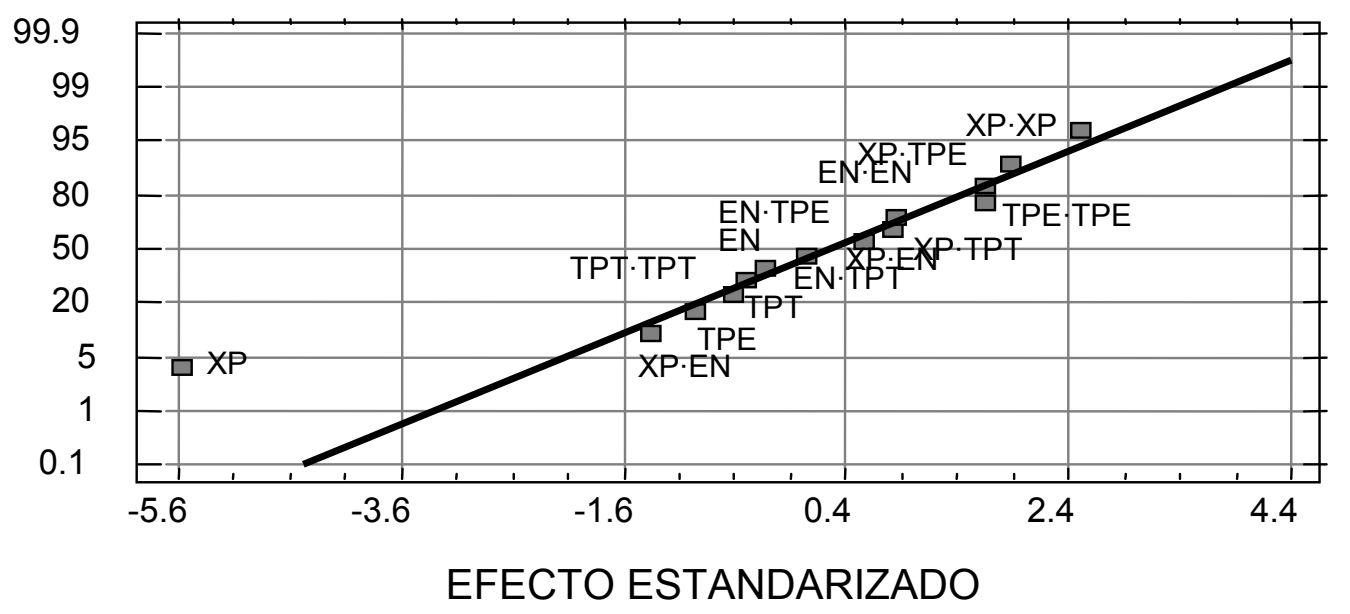

Ilustración 87. Efecto de los factores sobre B en gráfico de probabilidad normal 
Analizando los efectos principales de los factores en la Ilustración 88 se observa la gran influencia del factor fracción másica de polímero $X P$, también constatada por diversos autores recopilados en Lora et al. (1989). La disminución de $B$ que se produce al pasar desde una fracción del 20 al 22\% es mucho mayor que la producida al pasar de 22 a $24 \%$, lo cual resulta indicativo de que por encima del $22 \%$ ya se logra una estructura cerrada en la que el paso de sal se produce por el fenómeno de disolucióndifusión. Respecto a la influencia del enrasado nominal se aprecia una tendencia análoga a la del parámetro $A$; existe un valor cercano a las $50 \mu \mathrm{m}$ para el cual se produce un mínimo. El tiempo de evaporación actúa disminuyendo $B$ ya que se crea una capa superior menos porosa debido a la concentración superficial en polímero por pérdida de disolvente en la fase de evaporación. Se encuentra también un óptimo de tratamiento térmico a $95^{\circ} \mathrm{C}$ alrededor de los 3 minutos, lo cual también se ha apreciado en las membranas anteriores realizadas con polímeros AC3 y AC6 puros.

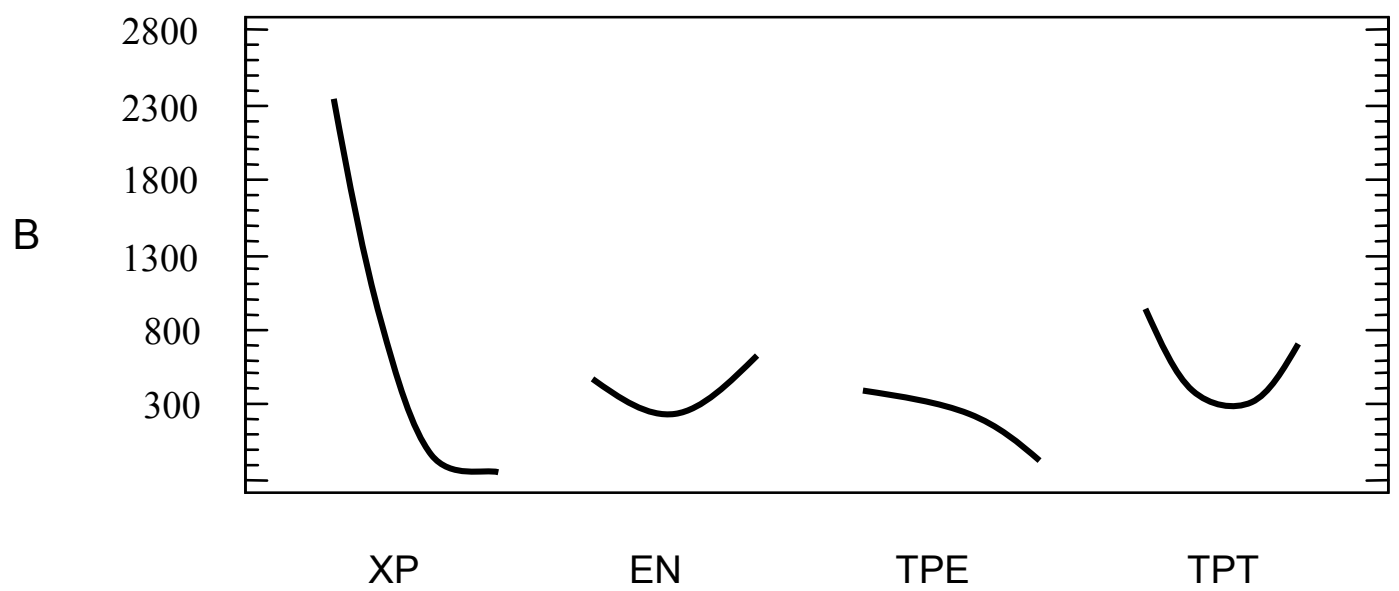

Ilustración 88. Representación de efectos principales para la variable B

El factor espesor nominal de enrasador no tiene un efecto tan significativo como el que tenía sobre el parámetro $A$ ya que las propiedades selectivas están determinadas por la estructura de la capa activa superior, la cual depende de las fases de evaporación (tiempo de evaporación TPE) y tratamiento térmico (tiempo de tratamiento TPT). La 
Ilustración 89 explica el efecto de dichos factores de fabricación para diferentes valores del factor fracción de polímero $X P$.

A concentraciones bajas de polímero (20\%) se obtienen valores bastantes grandes de $B$. El incremento del tiempo de evaporación disminuye el valor de $B$ al crearse una estructura más cerrada por la concentración de polímero originada por la pérdida de disolvente. A concentraciones de polímero medias (22\%) se obtienen ya valores bastante bajos de $B$ observándose también descenso de $B$ con el tiempo de evaporación. En cambio a concentraciones altas (24\%) los valores de $B$ ya no descienden con el tiempo de evaporación, probablemente porque el colodión ya no tiene capacidad para concentrarse más en la superficie a temperatura ambiente. Se observa también que los valores de tiempo de tratamiento térmico en los cuales se alcanzan los mínimos valores de $B$ son más bajos cuanto mayor es la concentración de polímero. 

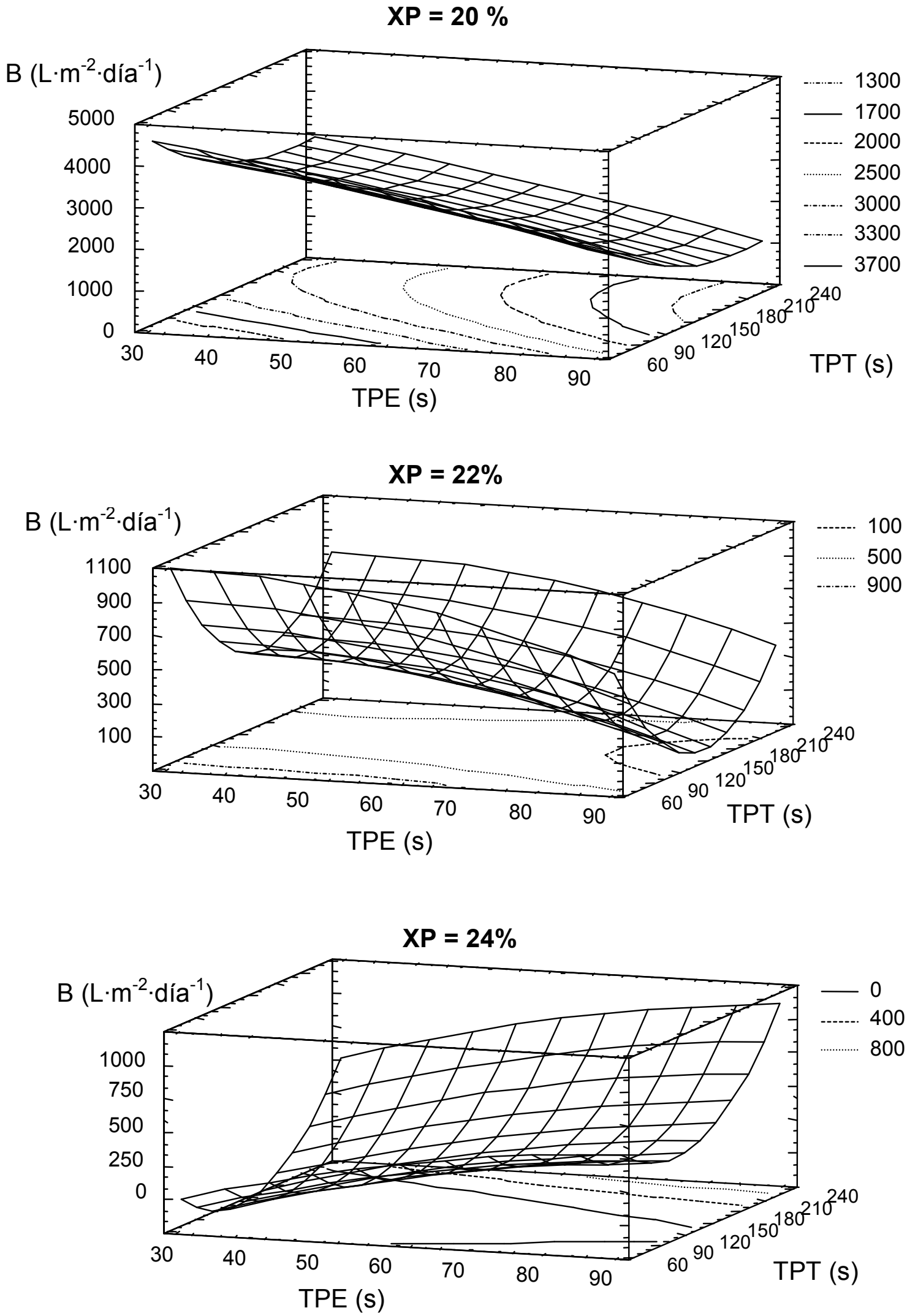

Ilustración 89. Superficie de respuesta del parámetro B frente a los factores TPE y TPT para diferentes valores de XP y valores medios de EN. 


\section{Estudio del efecto de los factores en el nivel de comportamiento (parámetro $A^{2} / B$ )}

Analizamos ahora la influencia de los factores sobre el nivel de comportamiento para estudiar la variación relativa de las propiedades de flujo y rechazo.

En este caso el modelo estadístico creado explicó un $74.3 \%$ de la variabilidad del parámetro $A^{2} / B$, sin embargo el valor de correlación ajustada es del $44.3 \%$ por lo que comparativamente con los otros modelos el ajuste es peor. El parámetro estadístico de Durbin-Watson al resultar menor que 1.4 indica que no existe correlación importante para los valores residuales. El resultado del análisis normal de la varianza proporcionó un diagrama de Pareto que muestra que también en este caso el factor más influyente es la fracción de polímero en el colodión XP. También resulta importante sobre la influencia conjunta los factores de tiempo de evaporación TPE y de tratamiento térmico $T P T$.

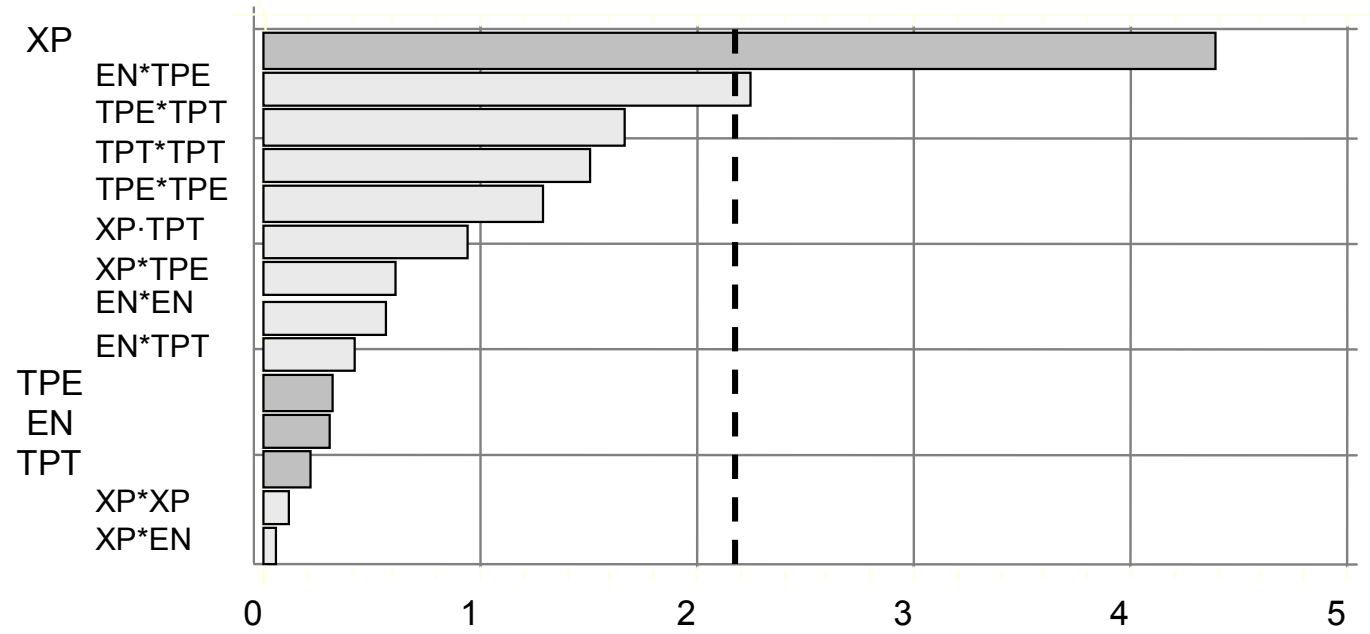

Ilustración 90. Diagrama de Pareto para la variable $A^{2} / B$

Después de descartar los factores menos influyentes la ecuación obtenida para el modelo fue:

$$
A^{2} / B=-8.70431+0.350924 \cdot X P-0.00271114 \cdot E N^{*} T P E+0.000436366 \cdot T P E^{*} T P T
$$


En la Ilustración 91 se observa que el aumentar la concentración de polímero dentro del rango mejora el nivel de comportamiento ya que el aumento de selectividad que se consigue al cerrar los poros resulta mucho más importante que el descenso de flux. El efecto del enrasador no se puede analizar por separado del tiempo de evaporación, para espesores de enrasados bajos el nivel de comportamiento aumenta con el tiempo de evaporación, mientras que para enrasados altos disminuye con él.

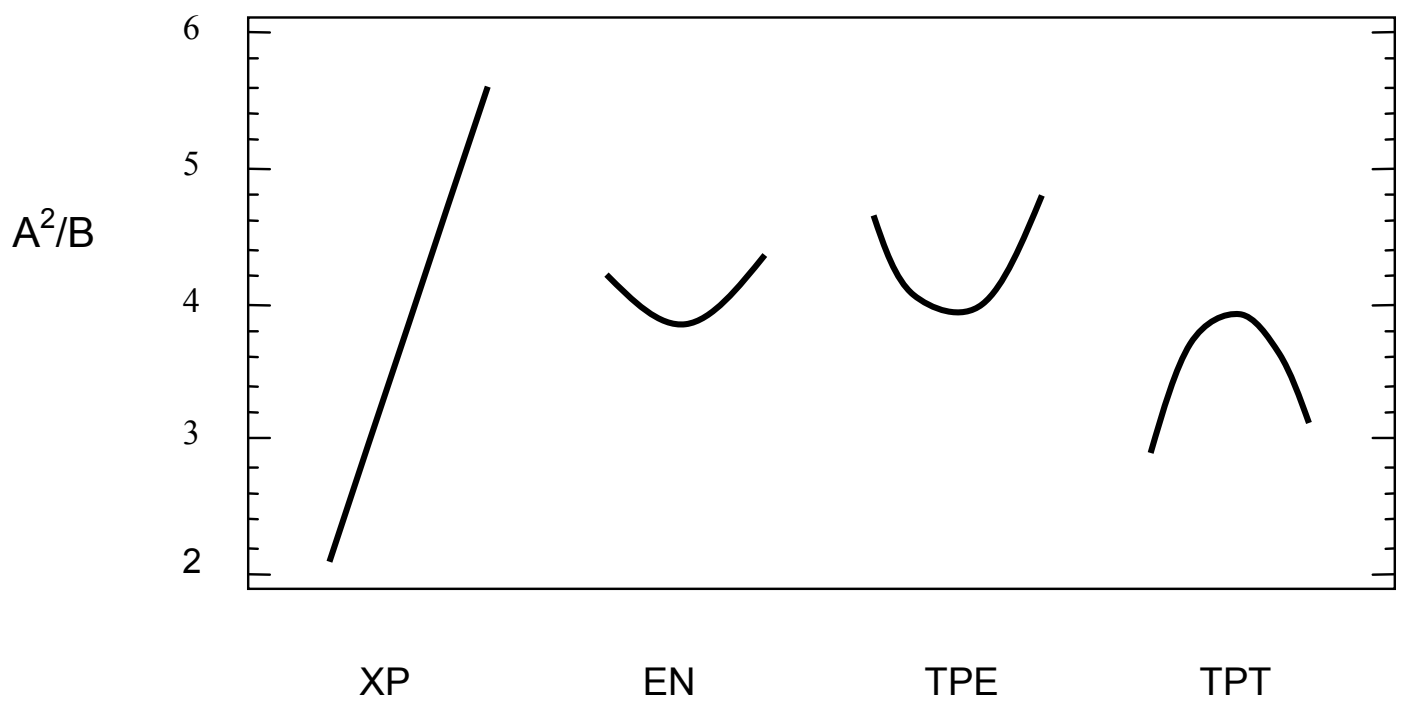

Ilustración 91. Representación de efectos principales para la variable $A^{2} / B$

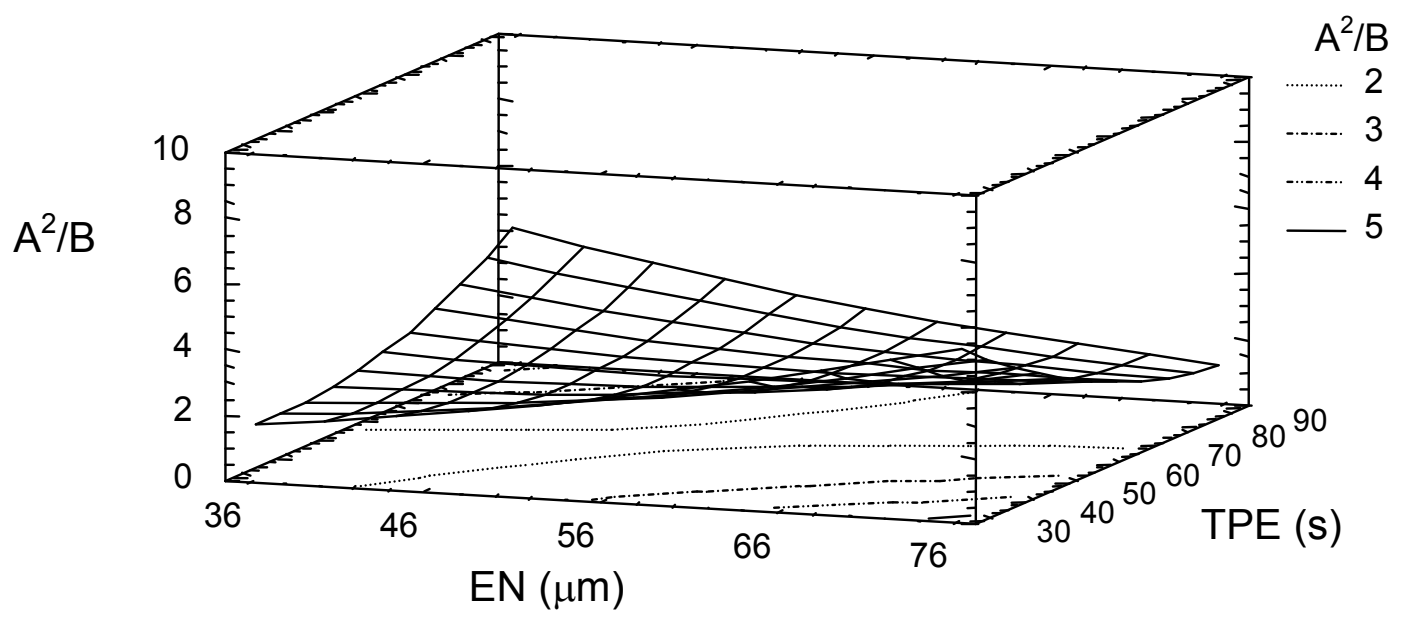

Ilustración 92. Superficie de respuesta del parámetro $A^{2} / B\left(L \cdot m^{-2} \cdot d i a^{-1} \cdot b a r^{-2}\right)$ frente a los factores TPE y EN con XP y TPT en su valor medio. 

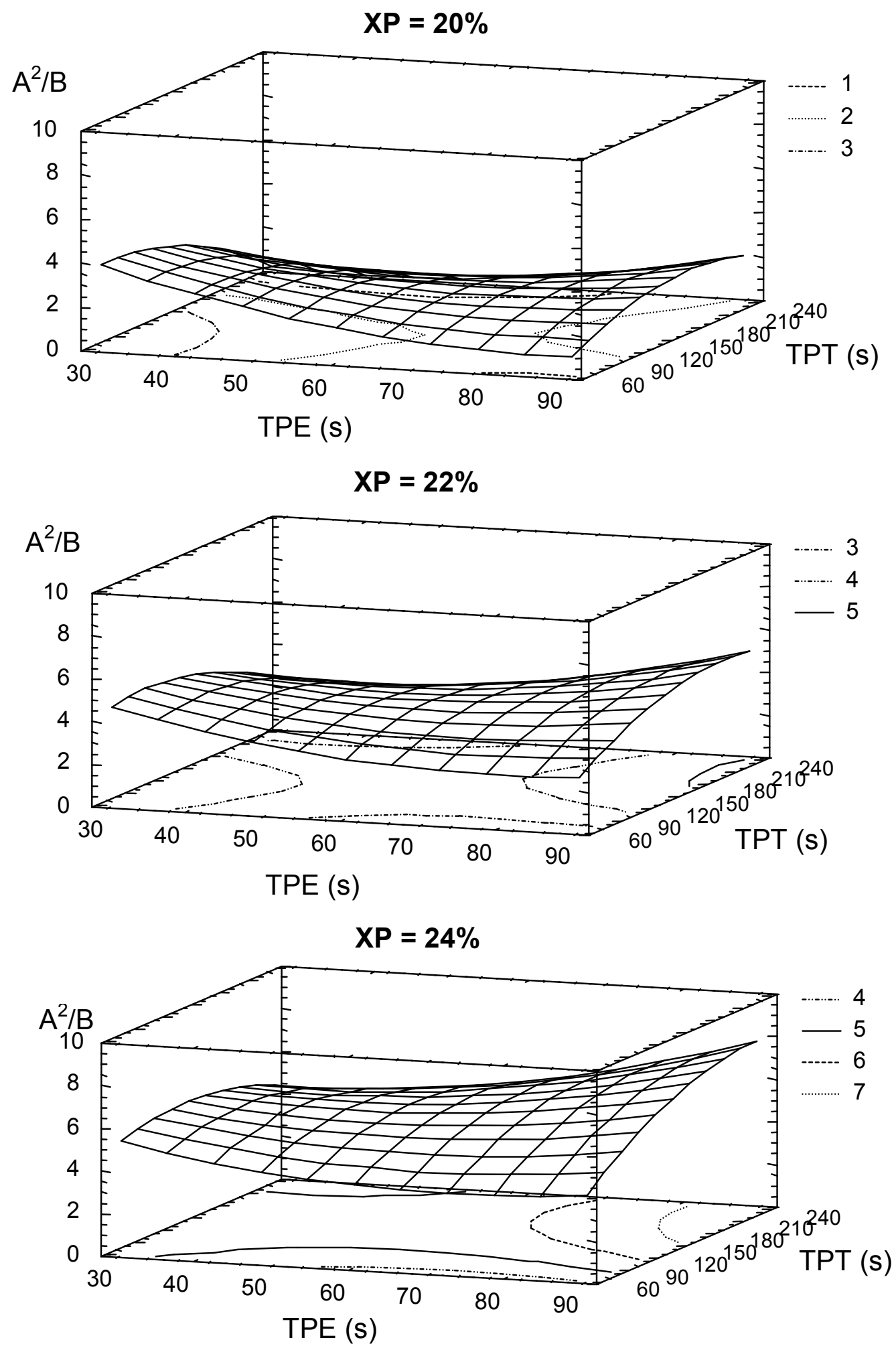

Ilustración 93. Superficies de respuesta del parámetro $A^{2} / B\left(L \cdot m^{-2} \cdot d i a^{-1}\right)$ frente a los factores TPE y TPT y EN en su valor medio. 
Las superficies de respuesta de la Ilustración 93 muestran como el nivel de comportamiento aumenta al aumentar la fracción de polímero. Para tiempos de evaporación bajos el máximo nivel de comportamiento se sitúa en tiempos de tratamiento térmico cortos, mientras que para tiempos de evaporación más altos se requiere mayor tiempo de tratamiento térmico para alcanzar el máximo, situándose en valores en el rango de 3 a 4 minutos tal y como se observó en las experiencias con polímeros AC3 y AC6 puros.

\section{Relaciones entre los parámetros de respuesta en las membranas del experimento}

Al representar para las membranas (basadas en la mezcla de AC3 y AC6) el parámetro $B$ frente al parámetro $A$ en escala logarítmica en la Ilustración 94 los puntos experimentales se situaron aproximadamente en una recta, de exponente intermedio entre las obtenidas para membranas basadas en AC3 y AC6 puros. Esta recta marca el único intercambio posible de mejora de selectividad a costa de pérdida de flux. Debido al exponente del ajuste logarítmico parece que la única forma de aumentar el nivel de comportamiento es perdiendo flux mediante el tratamiento térmico o trabajando con mayores porcentajes de polímero. Las membranas así fabricadas quedarían comparadas con las comerciales dentro de un comportamiento bajo, tal y como se puede observar en la Ilustración 95. 
B $\left(\mathrm{mol} \cdot \mathrm{m}^{-2} \cdot \mathrm{di}^{-1}\right) /\left(\mathrm{mol} \cdot \mathrm{L}^{-1}\right)$

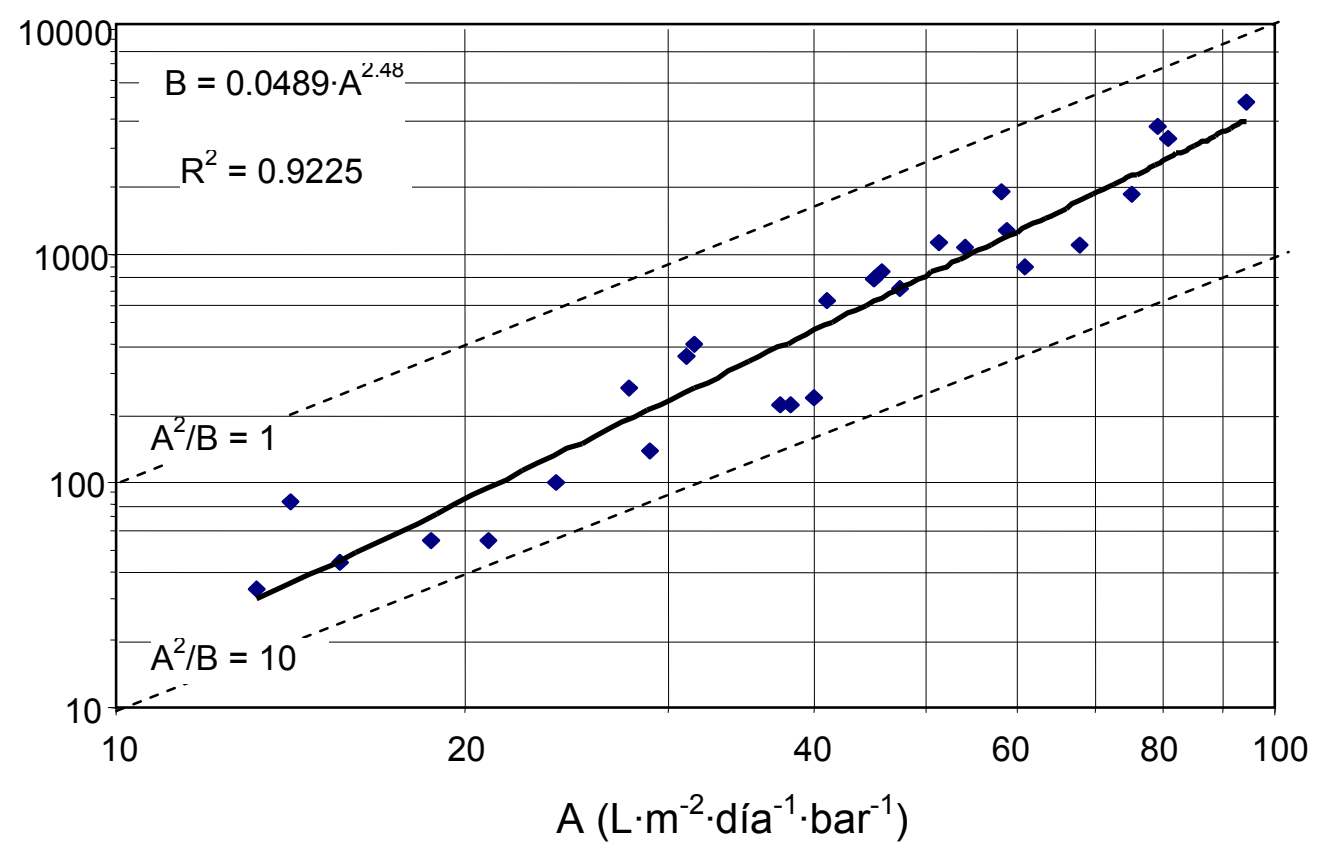

Ilustración 94. Relación entre parámetros A y B para las membranas fabricadas

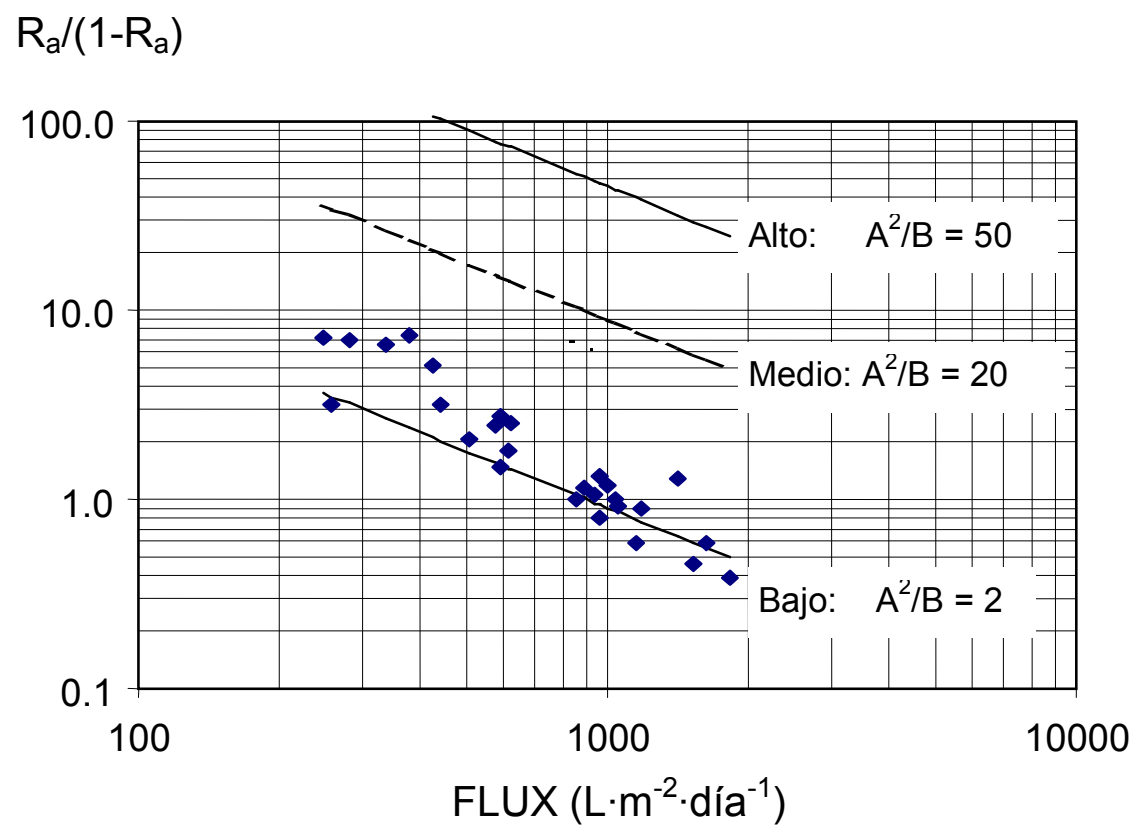

Ilustración 95. Nivel de comportamiento $\left(L \cdot m^{-2} \cdot d i a^{-1} \cdot b a r^{-2}\right)$ de las membranas fabricadas 


\subsubsection{Análisis de la estructura mediante microscopía}

Para estudiar el efecto de las condiciones de fabricación sobre la estructura de las membranas se realizaron los recortes de membrana de la Tabla 54 y se utilizaron también recortes correspondientes a membranas de ultrafiltración.

\begin{tabular}{|c|c|c|c|c|c|}
\hline \multicolumn{6}{|c|}{ Polímero: $\quad$ Acetato de celulosa (AC6) } \\
\hline \multicolumn{6}{|c|}{ Concentración: $\quad 24 \%$} \\
\hline \multicolumn{6}{|c|}{ N,N-dimetilacetamid } \\
\hline \multicolumn{6}{|c|}{ Temperatura de coagulación: $\quad 10^{\circ} \mathrm{C}$} \\
\hline \multicolumn{6}{|c|}{ Tiempo de coagulación: } \\
\hline \multicolumn{6}{|c|}{ Temperatura de tratamiento térmico: $95{ }^{\circ} \mathrm{C}$} \\
\hline Muestra & Soporte & $\begin{array}{c}\text { Tiempo de } \\
\text { evaporación } \\
\text { (seg) }\end{array}$ & $\begin{array}{c}\text { Espesor de } \\
\text { deposición } \\
\text { (micras) }\end{array}$ & $\begin{array}{l}\text { Tiempo de } \\
\text { tratamiento } \\
\text { térmico } \\
\text { (min) }\end{array}$ & $\begin{array}{c}\text { DMA en } \\
\text { baño de } \\
\text { coagulación } \\
(\%)\end{array}$ \\
\hline 1 & FO-2402 & 15 & 100 & 0 & 0 \\
\hline 2 & FO-2402 & 15 & 100 & 5 & 0 \\
\hline 3 & FO-2402 & 15 & 100 & 3 & 0 \\
\hline 4 & FO-2402 & 15 & 100 & 1 & 0 \\
\hline 5 & FO-2401 & 15 & 100 & 0 & 0 \\
\hline 6 & FO-2401 & 15 & 100 & 3 & 0 \\
\hline 7 & Tyvek & 15 & 100 & 0 & 0 \\
\hline 8 & Tyvek & 15 & 100 & 3 & 0 \\
\hline 9 & FO-2402 & 120 & 100 & 0 & 0 \\
\hline 10 & FO-2402 & 120 & 100 & 3 & 0 \\
\hline 11 & FO-2402 & 120 & 50 & 0 & 0 \\
\hline 12 & FO-2402 & 120 & 50 & 3 & 0 \\
\hline 13 & FO-2402 & 120 & 36 & 0 & 0 \\
\hline 14 & FO-2402 & 120 & 36 & 3 & 0 \\
\hline 15 & FO-2402 & 30 & 50 & 0 & 10 \\
\hline 16 & FO-2402 & 30 & 50 & 3 & 10 \\
\hline 17 & FO-2402 & 30 & 50 & 0 & 20 \\
\hline 18 & FO-2402 & 30 & 50 & 3 & 20 \\
\hline 19 & FO-2402 & 30 & 50 & 0 & 30 \\
\hline 20 & FO-2402 & 30 & 50 & 3 & 30 \\
\hline
\end{tabular}


En general no se pueden observar poros en la parte superior de la capa activa incluso para los aumentos mayores, debido a que nos encontramos en los rangos de nanofiltración y ósmosis inversa donde los poros son del orden de nanómetros o inexistentes. En la capa inmediatamente inferior a la capa activa se pueden apreciar estructuras porosas lo que demuestra que las membranas fabricadas son asimétricas. En las vistas de ampliación inferior a 100X se puede ver que las capas poliméricas tiene un espesor comprendido entre 20 y $50 \mu \mathrm{m}$, mientras que el soporte mide entre 100 y 150 $\mu \mathrm{m}$. Existe además una zona de 10 - $30 \mu \mathrm{m}$ de penetración del polímero en el soporte.

En las vistas 6-75X (Ilustración 100), 17-75X (Ilustración 101) y 7-100X (Ilustración 102) se pueden apreciar las diferencias entre los distintos soportes notejidos utilizados. La mayor porosidad del soporte FO-2401 (muestra 6-75X) trae como consecuencia una deficiente deposición lo cual origina una descamación de la capa polimérica. La adherencia del acetato de celulosa a los soportes FO-2402 y Tyvek resulta adecuada. Además, a diferencia de lo que ocurre con el soporte FO-2401, la penetración del colodión en el soporte no es excesiva por lo que la capa polimérica activa tiene un espesor definido y uniforme, tal y como se puede apreciar en las vistas 2500X y 8-500X (Ilustración 103 e Ilustración 104). Sin embargo, el soporte Tyvek presenta, como se puede observar en las vistas, una menor porosidad y un mayor espesor lo que origina una resistencia adicional al flujo de agua.

En las vistas 10-500X (Ilustración 105), 11-500X (Ilustración 106) y 13-500X (Ilustración 107) se comparan membranas fabricadas con diferentes espesores nominales de enrase. Dentro de una mismas membranas se observa una irregularidad en el espesor de la capa polimérica atribuible a la falta de uniformidad del espesor de los soportes. También se puede ver que para todos los recortes estudiados el espesor de la capa polimérica es menor que la medida nominal del enrasador como consecuencia de la penetración de polímero en el soporte. Así, las membranas realizadas con el enrasador de $100 \mu \mathrm{m}$ presentan espesores de capa polimérica de 40 - $50 \mu \mathrm{m}$, las realizadas con el enrasador de $50 \mu \mathrm{m}$ tienen espesores de $30-50 \mu \mathrm{m}$ y las realizadas con el enrasador de $36 \mu \mathrm{m}$ tienen espesores de $20-30 \mu \mathrm{m}$.

El efecto de la evaporación y del tratamiento térmico sobre el espesor final sobre el espesor no es significativo, al menos para los rangos de trabajo. Ello se puede observar en las vistas de las membranas 2, 8 y 10 dónde se ha realizado una deposición de 100 micras. 
Las estructuras de grandes macroporos con formaciones "dedo" (Inglés: fingers) no son usuales. Los grandes huecos que aparecen en las ilustraciones son debidos en la mayoría de los casos a desgarros del soporte no tejido originados en el corte de la muestra. Sin embargo las formaciones de la vista TV-2000X (Ilustración 109) podrían ser estructuras “dedo". En la vista 6-2000X (Ilustración 113) se puede ver en la superficie de la membrana una estructura de grandes poros típica de ultrafiltración. Las estructuras de ultrafiltración obtenidas son sin embargo más cerradas que las de membranas comerciales (Ilustración 114 e Ilustración 115)

En la vista 10 - 2000x (Ilustración 111) se aprecia como un elevado tiempo de evaporación conduce a una estructura densa muy poco permeable, mientras que un tiempo de evaporación corto origina una estructura más porosa (vista 1-2000x, Ilustración 110). Esta estructura puede ser cerrada mediante un tratamiento térmico, tal y como se puede ver en $2-2000 x$ (Ilustración 112). Finalmente se puede observar a 50000X la diferencia entre la estructura de la capa superior de una membrana de ultrafiltración - nanofiltración (Ilustración 116) y una de ósmosis inversa desprovista de poros Ilustración 117). 


\subsubsection{Estudios sobre la deposición}

Se midieron espesores de membrana observándose una gran dispersión de espesores debido a la falta de uniformidad de espesor de los soportes no-tejidos.

También se intentó correlacionar el espesor depositado con las características de la membrana no obteniéndose conclusiones claras al ser las propiedades principalmente determinadas por las características de la capa activa formada y no depender éstas significativamente del espesor depositado.

\section{Comparación entre la deposición sobre soporte tejido y sobre no-tejido}

\section{Soporte tejido:}

Precisa más cantidad de colodión (ya que se tienen que cubrir los huecos existentes entre los filamentos). En consecuencia aparecen zonas de mucho espesor trayendo como consecuencia una baja permeabilidad.

Soporte no-tejido:

Los huecos entre filamentos son de magnitud despreciable frente al espesor de la deposición. Por encima de viscosidades correspondientes a 15\% en acetato de celulosa. La viscosidad del polímero hace que éste no atraviese el soporte. 


\subsubsection{Evaluación del comportamiento de nanofiltración}

\section{Rechazo de otros solutos diferentes del $\mathrm{NaCl}$}

El parámetro $B$ de las distintas variantes de los modelos de disolución-difusión así como del modelo de Kimura-Sorirajan puede ser obtenido a partir de los resultados del comportamiento de la membrana frente a disoluciones de referencia de $\mathrm{NaCl}$. Este parámetro puede ser estimado a su vez para otros solutos diferentes del $\mathrm{NaCl}$ con lo que se puede, introduciendo el nuevo valor de $B$ en el modelo, estimar el rechazo frente a los nuevos solutos.

El procedimiento está basado en el hecho de que el parámetro de transporte está relacionado con la energía libre necesaria para mover los iones desde la disolución alimento a la membrana, energía que viene expresada mediante unos parámetros de energía libre propios del material y del ion considerado. Algunos de valores para el acetato de celulosa vienen referidos en la Tabla 55.

A partir de $B$ y de los parámetros de energía libre para los iones $\mathrm{Cl}^{-}$y $\mathrm{Na}^{+}$se puede obtener mediante la ecuación de Born, tal y como plantea Dickson (1988), un nuevo parámetro $B^{*}$ representativo de la membrana e independiente de los iones.

Ec. 92: $\quad \ln \left(B_{\mathrm{NaCl}}\right)=\ln \left(B^{*}{ }_{\mathrm{NaCl}}\right)+1 \cdot I_{\mathrm{Na}^{+}}+1 \cdot I_{\mathrm{Cl}^{-}}$

El valor de $B$ para otras sales puede ser obtenido a partir de $B^{*}$ si son conocidos los parámetros de energía libre para los nuevos iones.

Ec. 93:

$$
\ln \left(B_{M_{m} X_{x}}\right)=\ln \left(B^{*}{ }_{N a C l}\right)+m \cdot I_{M^{x+}}+1 \cdot I_{X^{m-}}
$$




\begin{tabular}{|c|r|r|r|r|r|}
\hline \multicolumn{6}{|c|}{ Tabla 55. Parámetros de energía libre $\mathbf{I}=-\Delta \mathbf{\Delta G} / \mathbf{R T}$ de } \\
diferentes iones en membranas de acetato de celulosa \\
\hline Catión & $I\left(\mathrm{M}^{+}\right)$ & $E_{\text {hidrat }}$ & Anión & \multicolumn{1}{|c|}{$I(X)$} & $E_{\text {hidrat }}$ \\
\hline$H^{+}$ & 6.34 & & $\mathrm{OH}$ & -6.18 & \\
\hline $\mathrm{Na}^{+}$ & 5.79 & 454 & $\mathrm{Cl}^{-}$ & -4.42 & 325 \\
\hline $\mathrm{K}^{+}$ & 5.91 & 363 & $\mathrm{NO}_{3}{ }^{-}$ & -3.66 & 310 \\
\hline $\mathrm{Mg}^{2+}$ & 8.72 & & $\mathrm{SO}_{4}{ }^{2-}$ & -13.20 & 1047 \\
\hline $\mathrm{Ca}^{2+}$ & 8.88 & 1615 & $\mathrm{CO}_{3}{ }^{2-}$ & -13.22 & \\
\hline
\end{tabular}

Se estudió el comportamiento frente a diferentes sales para las membranas de la Tabla 56. Los resultados de caracterización frente a diferentes sales, así como el resultado teórico de las otras sales predicho a partir del resultado obtenido para $\mathrm{NaCl}$ se encuentran en la Ilustración 96 y la Ilustración 97. Se observa que los resultados de rechazo obtenidos para las sales bivalentes son menores, si bien similares a los predichos para el modelo. La explicación puede encontrarse en el hecho de que el modelo es adecuado para un comportamiento de disolución-difusión en la capa activa de la membrana y en nuestro caso puede existir flujo convectivo importante a través de poros grandes.

\section{Tabla 56. Membranas 9804 caracterizadas frente a diferentes sales}

Polímeros: AC3 (50\%) AC6 (50\%); Aditivo: $\mathrm{LiCl}$ (2\%); Disolvente: Dimetilacetamida

Temperatura de evaporación: $20^{\circ} \mathrm{C}$; Temperatura de coagulación: ${ }^{\circ} \mathrm{C}$

\begin{tabular}{|c|c|c|c|c|}
\hline Membrana & Polímero & Enrasador & $\begin{array}{c}\text { Tiempo de } \\
\text { evaporación } \\
(\mathrm{seg})\end{array}$ & $\begin{array}{c}\text { Tratamiento } \\
\text { térmico a } 95{ }^{\circ} \mathrm{C} \\
(\mathrm{seg})\end{array}$ \\
\hline $9804-05$ & 24 & 50 & 90 & 150 \\
\hline $9804-21$ & 22 & 50 & 90 & 240 \\
\hline
\end{tabular}




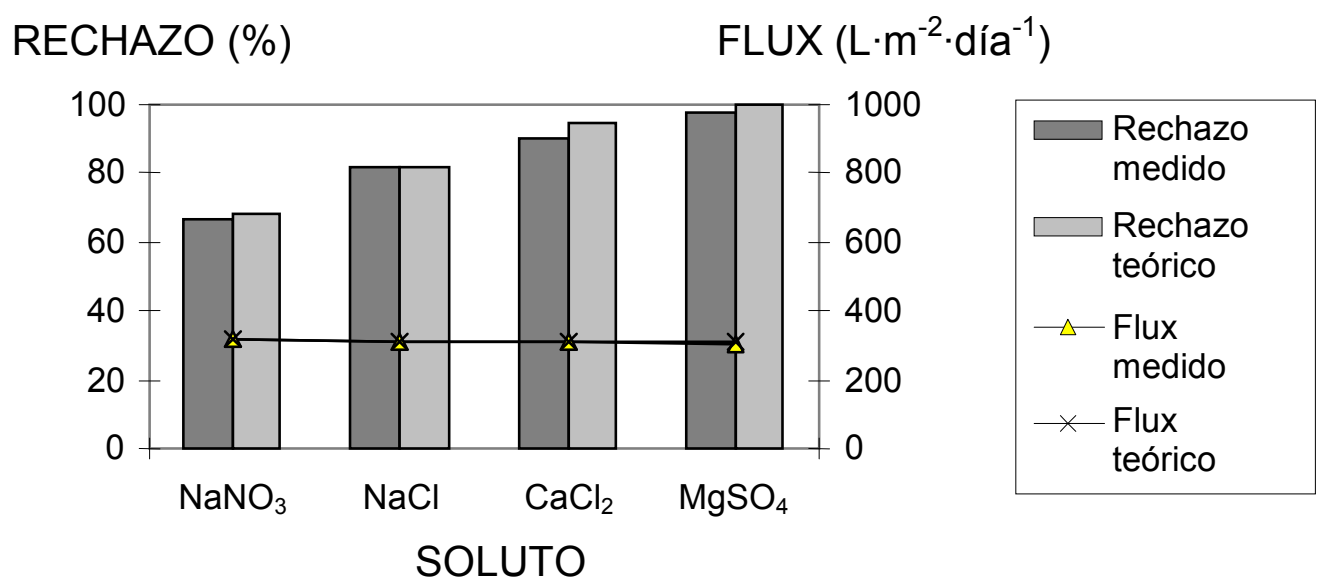

Ilustración 96. Resultados de caracterización de la membrana 980105 para diversas sales y su comparación con el resultado teórico obtenido a partir del rechazo al NaCl (Alimentación: 2000 ppm; Presión: 15 bar).

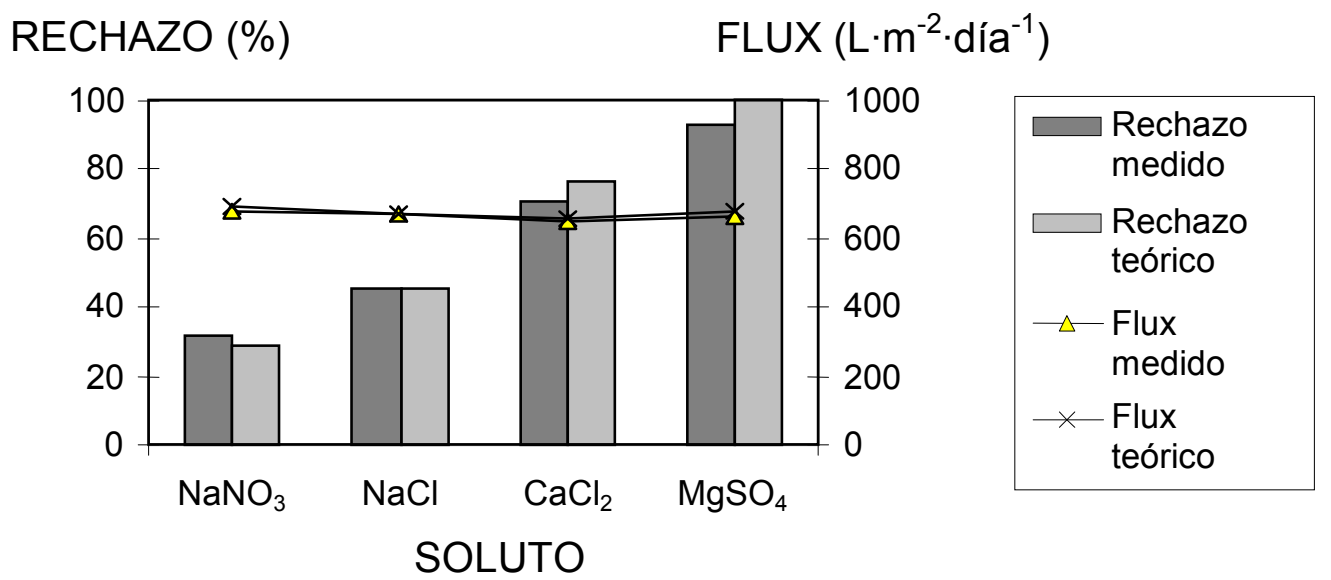

Ilustración 97. Resultados de caracterización de la membrana 980121 para diversas sales y su comparación con el resultado teórico obtenido a partir del rechazo al NaCl (Alimentación: 2000 ppm; Presión: 15 bar).

Para algunas membranas fabricadas con material ACE se comparó el rechazo frente el $\mathrm{NaCl}$ con el de algunos compuestos orgánicos (Ilustración 98). Para las membranas con rechazo de sal inferior al 20\% las características de nanofiltración no son muy pronunciadas ya que los rechazos frente a la glucosa y sacarosa son bastante 
pobres, comportándose como membranas de ultrafiltración. Las que rechazan el $\mathrm{NaCl}$ por encima de un $40 \%$ ya separan la glucosa y sacarosa en mayor grado y el rechazo es casi total para compuestos de un peso molecular superior a $600 \mathrm{~g} / \mathrm{mol}$.

\section{RECHAZO (\%)}

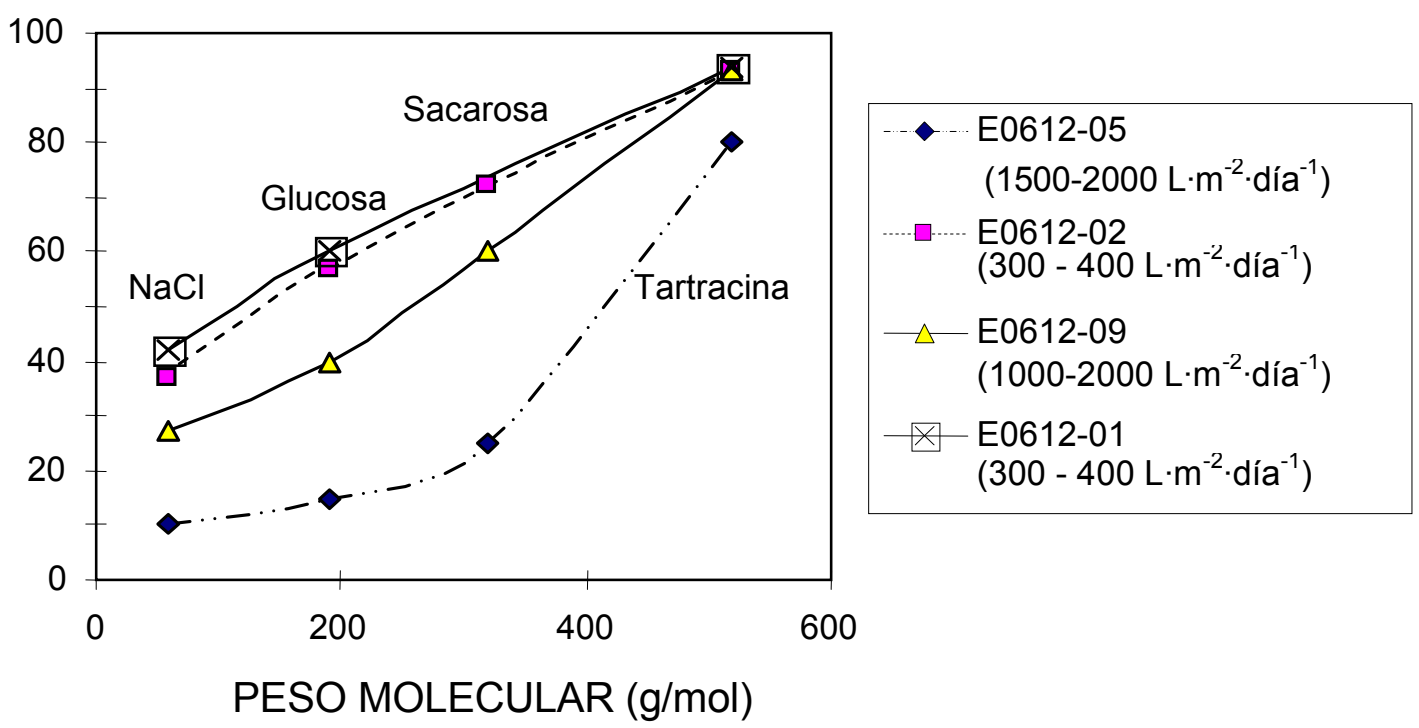

Ilustración 98. Comportamiento de nanofiltración de membranas de ACE frente a solutos de diferente peso molecular. (Alimento: 2000 ppm; Presión: 10 bar) 


\subsection{ESTUDIO DE LA VIABIALIDAD DE UTILIZAR LOS RESULTADOS DEL MÉTODO MANUAL EN LA FABRICACIÓN EN MÁQUINA}

La optimización de la fabricación en máquina será un importante objetivo dentro de las futuras investigaciones del Departamento. Para que este se lleve a cabo serán necesarios una serie de ajustes y modificaciones en la máquina de producción.

Debido a los costes de material, necesario en la puesta a punto y en la estabilización posterior, el número de ensayos se ha limitado a un número muy pequeño, pretendiéndose con ellos demostrar la posibilidad de utilizar el método de fabricación manual como una forma de realización de experiencias previas que tienen por fin ahorrar ensayos en máquina durante el proceso de búsqueda de unas condiciones de optimas de fabricación. El método de fabricación manual utilizado permite obtener resultados indicativos del efecto de los factores de fabricación en el comportamiento de la membrana.

Los resultados del método de fabricación manual indican una gran dispersión, que está principalmente derivada del hecho de que la deposición efectuada es normalmente poco uniforme. En cambio, en la fabricación en máquina se puede obtener una deposición más uniforme. Sin embargo, la información derivada de los resultados medios obtenidos por el método manual puede ser el punto de inicio de una posterior optimización de las condiciones de fabricación en máquina.

\section{Condiciones de fabricación utilizadas}

De acuerdo con los resultados obtenidos se eligen los colodiones CM1 y CM2 para su ensayo en máquina. La composición de estos colodiones se encuentra reflejada en la Tabla 57. El colodión CM1 tiene la composición de uno de los tres colodiones utilizados en el diseño de experimentos del apartado 4.3.5. El colodión CM2 tiene la misma composición que la mayor parte de los colodiones utilizados en la preparación manual de membranas con base en el polímero ACE. 
Con los colodiones se realizaron pruebas en la máquina manteniendo las condiciones de fabricación indicadas en la Tabla 58 en diferentes tramos de soporte. La abertura de boquilla escogida inicialmente fue de $200 \mu \mathrm{m}$.

\begin{tabular}{|c|c|c|c|}
\hline \multicolumn{3}{|c|}{ Tabla 57. Colodiones utilizados en las pruebas de fabricación en máquina } \\
\hline Colodión & Polímero & Disolvente & Aditivos \\
\hline CM1 & $\begin{array}{c}\text { CA-398-3 / CA-398-6 }=1: 1 \\
(22 \%)\end{array}$ & dimetilacetamida & $\mathrm{LiCl}(2 \%)$ \\
\hline CM2 & $\begin{array}{c}\text { Acetato de INACSA } \\
(19 \%)\end{array}$ & dimetilacetamida & $\begin{array}{c}\mathrm{LiCl}(6 \%) \\
\text { Tritón X-100 }(0.5 \%)\end{array}$ \\
\hline
\end{tabular}

\begin{tabular}{|c|c|c|c|c|c|c|}
\hline \multicolumn{3}{|c|}{ Temperatura de evaporación: $22^{\circ} \mathrm{C}$} & \multicolumn{4}{|c|}{$\begin{array}{l}\text { Temperatura de coagulación: } 20^{\circ} \mathrm{C} \\
\text { Tiempo de coagulación: > } 10 \mathrm{~min}\end{array}$} \\
\hline $\begin{array}{c}\text { Tramo } \\
\text { (Colodión-x) }\end{array}$ & Soporte & $\begin{array}{c}\text { Abertura } \\
\text { de boquilla } \\
a_{B}(\mu \mathrm{m})\end{array}$ & $\begin{array}{l}\text { Presión de } \\
\text { nitrógeno } \\
\Delta P \text { (bar) }\end{array}$ & $\begin{array}{l}\text { Velocidad } \\
\text { de cinta } \\
u_{S}(\mathrm{~cm} / \mathrm{s})\end{array}$ & $\begin{array}{c}\text { Tiempo de } \\
\text { evaporación } \\
\text { TPE (s) }\end{array}$ & $\begin{array}{c}\text { Deposición } \\
\text { media } \\
D\left(\mathrm{mg} / \mathrm{cm}^{2}\right)\end{array}$ \\
\hline CM1-1 & F02 & 200 & 1.5 & 0.93 & 135 & 0.265 \\
\hline CM1-2 & F02 & 200 & 2.1 & 0.93 & 135 & 0.358 \\
\hline CM1-3 & F02 & 200 & 1.5 & 0.63 & 200 & 0.384 \\
\hline CM1-4 & F02 & 200 & 2.1 & 0.63 & 200 & 0.538 \\
\hline CM2-1 & TV & 400 & 2.1 & 1.06 & 120 & 0.925 \\
\hline
\end{tabular}

Como al cambiarse las condiciones de velocidad de la cinta soporte o de la presión de nitrógeno se produce un transitorio en el comportamiento de la máquina, se ha despreciado, a efectos de caracterización, el primer metro de membrana a partir del punto de cambio de condiciones. 


\section{Estudio de la homogeneidad de la deposición}

El colodión impulsado por la presión de nitrógeno debe pasar a través de una serie de elementos que oponen resistencia al flujo (véase Ilustración 41). Los elementos que producen una pérdida distribuida de carga son los tubos de conducción $\left(N_{t}\right.$ tubos de diámetro $d_{t}$ y longitud $L_{t}$ ) y la boquilla (de longitud $L_{B}$ y abertura variable $a_{B}$ ). A estos elementos debemos de añadir las pérdidas de carga puntuales, especialmente el coeficiente de descarga en el soporte. El flujo de colodión al ser la viscosidad tan alta es claramente laminar, por lo que la expresión teórica para la pérdida de carga proporciona en ese caso:

$$
\frac{\Delta P_{c o l}}{\rho_{c o l} \cdot g}=\left[K+\frac{128 \cdot L_{t}}{N_{t} \cdot \pi \cdot d_{t}^{4}}+\frac{16 \cdot L_{B}}{a_{B}^{3} \cdot A_{B}}\right] \cdot \frac{\dot{m}_{c o l} \cdot \mu_{c o l}}{\rho_{c o l}{ }^{2} \cdot g}
$$

En la expresión aparecen el coeficiente $K$ indicativo de todas las pérdidas de carga puntuales y el ancho del enrasador $A_{B}$. En su deducción se ha despreciado la energía cinética del fluido en la salida y la diferencia de cotas entre el depósito sometido a presión y la descarga en el soporte por lo que sólo aparece la presión manométrica a la que se somete el depósito. Con ello puede ser calculada la masa depositada por unidad de superficie de membrana $D$ como:

$$
D=\frac{\dot{m}_{c o l}}{A_{B} \cdot u_{S}}=\frac{\Delta P_{c o l} \cdot \rho_{c o l}}{u_{S} \cdot \mu_{c o l}} \cdot \frac{1}{\left[A_{B} \cdot\left(K+\frac{128 \cdot L_{t}}{N_{t} \cdot \pi \cdot d_{t}^{4}}\right)+\frac{16 \cdot L_{B}}{a_{B}^{3}}\right]}
$$

La expresión para $K=0$ predice resultados de deposición más altos de los obtenidos, por lo que las pérdidas de carga puntuales son importantes. Sin embargo se cumple de forma bastante aproximada la relación de proporcionalidad con la presión y la relación inversa con la velocidad de desplazamiento del soporte $u_{S}$, tal y como se puede deducir de los valores de deposición de masa indicados en la Tabla 58.

Los valores de deposición por unidad de área se midieron mediante el método descrito en el apartado 3.7.1. Las muestras cuadradas de membrana de un área de $490 \mathrm{~cm}^{2}$ se tomaron tanto a lo ancho de la cinta de membrana (muestras transversales) como a lo largo de ésta (muestras longitudinales), tal y como se indica en la Ilustración 99. 
La dispersión de los resultados de deposición de las muestras transversales fue bastante elevada (la desviación típica representaba de un 5\% a $20 \%$ del valor medio), lo cual se puede achacar a deficiencias de ajuste de los rodillos de la máquina debidas a su traslado reciente. Sin embargo, la dispersión longitudinal a lo largo de una misma posición fue inferior a un 3\%. Esta dispersión resultó ser mucho menor que la obtenida con el procedimiento de fabricación manual (de un $5 \%$ a un $30 \%$ del valor medio en la membrana).

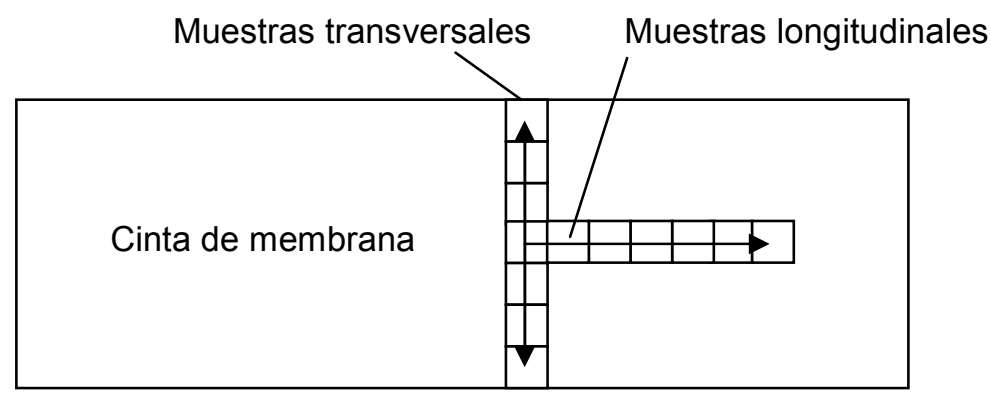

Ilustración 99. Posiciones de las muestras del análisis de deposición 


\section{Resultados de caracterización de las membranas fabricadas en máquina}

Las membranas obtenidas con el colodión CM1 presentaron, una vez estabilizada la máquina, una deposición muy fina y uniforme. Sin embargo, se produjo una diferencia sustancial con la fabricación manual. En este caso, la deposición efectuada sobre el soporte FO-2402 penetró bastante dentro del soporte debido a la presión del colodión sobre éste. La capa que se logró fue demasiado fina para recubrir las imperfecciones superficiales del soporte por lo que la capa activa no se formó y las membranas no presentaron rechazos. Ello queda también confirmado por los datos de deposición por unidad de área que son del orden de la tercera o cuarta parte de los menores depositados con el enrasador manual. Se necesita, por tanto, una mayor abertura de boquilla para poder depositar mayor cantidad de polímero.

Para trabajar con el colodión el colodión CM2 se aumentó la abertura de boquilla y se trabajó con el soporte Tyvek, el cual presenta una menor porosidad superficial. Ello permitió la formación de una capa activa adecuada, obteniéndose membranas comparables a las de las series fabricadas manualmente (E1026-3nn en Tabla 62 y Tabla 65). Los resultados de caracterización en planta de membranas obtenidas del tramo fabricado presentaron menor dispersión respecto de los valores medios, tanto en flujo como en rechazo, que las membranas fabricadas manualmente a partir de diversas hojas (véase Tabla 59).

Tabla 59. Comparación entre membranas fabricadas manualmente y en máquina

\begin{tabular}{|c|c|c|c|c|c|c|}
\hline Membrana & $\begin{array}{c}\text { Fluxes } \\
\text { a } 30 \text { bar } \\
\left(L \cdot m^{-2} \cdot d a^{-1}\right)\end{array}$ & $\begin{array}{c}\text { Rechazos } \\
\text { a } 30 \text { bar } \\
\text { (\%) }\end{array}$ & $\begin{array}{c}\text { Permeabilidad } \\
\text { media } \\
\bar{A} \\
\left(L \cdot m^{-2} \cdot \operatorname{dia}^{-1} \cdot b a r^{-1}\right)\end{array}$ & $\begin{array}{l}\text { Factor de } \\
\text { paso de sal } \\
\text { medio } \bar{B} \\
\left(L \cdot m^{-2} \cdot \text { dia }^{-1}\right)\end{array}$ & $\begin{array}{c}\text { Dispersión } \\
\text { de } A \\
\stackrel{\sigma_{A} / \bar{A}}{ }\end{array}$ & $\begin{array}{c}\text { Dispersión } \\
\text { de } B \\
\sigma_{B} / \bar{B}\end{array}$ \\
\hline $\begin{array}{l}\text { Manuales } \\
\text { (E1026-3) }\end{array}$ & $683-802$ & $73.7-88.0$ & 25.4 & 2.1 & $6.3 \%$ & $34 \%$ \\
\hline $\begin{array}{l}\text { Máquina } \\
\text { (CM21) }\end{array}$ & $760-831$ & $76.2-87.0$ & 27.2 & 2.0 & $4.2 \%$ & $20 \%$ \\
\hline
\end{tabular}




\section{CONCLUSIONES}





\section{CONCLUSIONES}

A la vista de los resultados podemos establecer las siguientes conclusiones:

1) El acetato de celulosa resulta un material óptimo para la realización de pruebas preliminares. La utilización de dimetilacetamida como disolvente en el colodión permite la obtención de membranas muy variadas, así como la utilización de agua como medio no-disolvente. Los polímeros CA-398 fabricados por Kodak Chemical ${ }^{\circledR}$ resultan ser, por su homogeneidad, materiales adecuados para la fabricación de membranas.

2) Los soportes no-tejidos resultan adecuados para la fabricación de membranas siempre que presenten espesores uniformes, superficies libres de defectos y una porosidad adecuada. De todos los soportes estudiados, el que presentó mejores prestaciones fue el Viledon ${ }^{\circledR}$ FO-2402. Los estudios de microscopía mostraron una adherencia adecuada del polímero al soporte.

3) El comportamiento permeoselectivo de las membranas obtenidas por el método propuesto es típico de membranas de nanofiltración en la mayoría de los casos. Si bien, también es posible la producción de membranas con características de ósmosis inversa con un flujo relativamente bajo.

4) Desde un punto de vista de optimización de las condiciones de fabricación, la técnica de diseño de experimentos resulta mucho más adecuada que el estudio individual del efecto de los distintos factores. Esto se debe a que los efectos de los factores de fabricación influyentes sobre las propiedades de la membrana están íntimamente relacionados.

5) Un tiempo de ensayo cercano a 4 horas resulta adecuado para la caracterización de membranas nuevas ya que produce resultados cercanos al comportamiento estacionario 
de la membrana. Para tiempos inferiores los efectos de la compactación de la membrana pueden ser significativos.

6) El comportamiento de las membranas fabricadas puede ser estudiado mediante los parámetros $A$ (permeabilidad de la membrana) y $B$ (factor de paso de sal). En particular para expresar los resultados son de sumo interés las gráficas $\log A-\log B$. Los parámetros $A$ y $B$ pueden ser interpretados físicamente según los modelos de KimuraSourirajan (para membranas poco cerradas) o disolución-difusión (en membranas de alto rechazo). El uso de estos parámetros permite eliminar en parte la influencia de las condiciones de caracterización, resultando más adecuados para el análisis estadístico que los correspondientes de flux y rechazo.

7) La determinación experimental de la curva binodal resulta de gran importancia a la hora de escoger las composiciones de trabajo. El programa de cálculo propuesto permite determinar de forma aproximada el diagrama ternario teórico.

8) La adición de tensoactivos al colodión conviene especialmente en membranas de alto flujo ya que produce una mejora de las características de rechazo y mayor uniformidad de comportamiento. Además, facilita la extensión del colodión sobre el soporte al disminuir la tensión superficial. Sin embargo, los efectos de su adición dependen del sistema coagulante concreto, por lo que se debería incluir como un factor más dentro del diseño de experimentos.

9) La adición de sales de cloruro de litio mejora las propiedades permeoselectivas cuando se utilizan en una concentración entre 2 y $4 \%$. Además aumentan la solubilidad del polímero en el colodión y disminuyen la viscosidad del colodión final en el rango expuesto.

10) Desde el punto de vista de la retención de sales monovalentes interesa aumentar la concentración de polímero, ya que es el parámetro con más influencia. La concentración de polímero en el colodión no se puede aumentar por encima del $24 \%$ ya que aparecen problemas en el manejo y deposición del colodión. El aumentar la concentración también produce una disminución muy fuerte de la permeabilidad ya que la disminución de la porosidad se produce en toda la capa activa depositada. 
11) Existe una gran variabilidad en el comportamiento de las membranas fabricadas según el método manual propuesto achacable principalmente a factores de tipo humano, de materiales (por las imperfecciones del soporte principalmente) y ambientales. Los factores de tipo humano son los más difíciles de controlar. Los más influyentes son la falta de uniformidad de la presión del enrasador sobre el soporte y la velocidad durante el enrasado, así como variaciones en la velocidad de inmersión en el baño de coagulación. Otros factores son achacables en parte a los materiales, como por ejemplo las deficiencias en el tensado del soporte, o bien totalmente, como es el caso de la poca uniformidad de espesor del soporte.

12) El factor ambiental no controlado más importante es probablemente la humedad ambiental.

13) Los colodiones, bien conservados, no incrementan la variabilidad en los resultados.

14) Los espesores de deposición óptimos se situaron entre 36 y $50 \mu \mathrm{m}$ si bien el elemento depositador utilizado es causante de una elevada dispersión de resultados.

15) En todos los casos un tiempo de coagulación superior a 10 minutos resultaba suficiente.

16) El tratamiento térmico mediante inmersión produce una disminución del factor de paso de sal $B$ a costa de una perdida de permeabilidad al agua $A$. La variación es de tipo potencial, apareciendo las sucesivas membranas sobre una misma línea cuando se representan ambos parámetros en coordenadas logarítmicas. Se puede utilizar este tratamiento para modificar las características de la membrana, si bien las posibilidades de modificación dependerán de la membrana de partida.

17) Los materiales CA-398-3 y CA-398-6 de fabricados por Kodak Chemical ${ }^{\circledR}$ sobre soporte Viledon FO-2402 tuvieron unos rangos óptimos, en la producción de membranas de alto rechazo, cercanos a los siguientes:

- Porcentaje de polímero: $\quad 24 \%$ 
- Porcentaje de LiCl:

- Temperatura de coagulación:

- Temperatura de tratamiento:

- Tiempo de tratamiento:
$2-4 \%$

$2{ }^{\circ} \mathrm{C}$

$95^{\circ} \mathrm{C}$

$3 \mathrm{~min}$

18) El soporte FO-2402, que resultó ser el más adecuado para la fabricación manual, no ofreció buenos resultados en la fabricación en máquina. Ello se considera debido a una porosidad del soporte demasiado elevada para la fabricación en máquina lo que impedía una deposición de capa desprovista de defectos cuando los espesores de deposición eran pequeños. Es decir un soporte que puede funcionar bien en el método de fabricación manual puede no serlo en la fabricación en máquina.

19) Los resultados obtenidos en máquina presentan una dispersión de la deposición mucho menor de la obtenida por el método manual. Ello se traduce en la obtención de membranas con una menor dispersión en sus resultados de flujo y rechazo que los de las membranas fabricadas manualmente.

En definitiva, el método manual es válido para la obtención de conclusiones de tipo cualitativo pero no resulta del todo conveniente para una investigación sistemática y optimización de un proceso de fabricación, por ello se proponen las siguientes mejoras:

1) Al ser la fase de enrasado y la evaporación las etapas más críticas, el factor humano debería evitarse mediante un dispositivo aplicador automático situado bajo una campana de atmósfera controlable.

2) El método propuesto actualmente con tiempos cortos de evaporación a temperatura ambiente no resulta adecuado para producir membranas de alto rechazo con un flujo razonable. Si esto último es lo que se desea conviene va a ser necesario incluir en la máquina de fabricación una zona de evaporación que utilice aire caliente forzado con vistas a aumentar la evaporación de disolvente y crear un gradiente de concentraciones dentro de la membrana que favorezca una estructura más asimétrica durante la coagulación. 
3) El sistema de tratamiento térmico puede ser mejorado mediante automatización. En la fabricación en máquina la solución más adecuada sería efectuarlo como una etapa sucesiva a la coagulación. 



\section{ANEXO I: Tablas de datos de fabricación de membranas y caracterización en planta}





\section{ANEXO I: Tablas de datos de fabricación de membranas y caracterización en planta}

En este apéndice se presentan las condiciones de fabricación de membranas en una tabla por cada polímero base utilizado (Tabla 60, Tabla 61 y Tabla 62). Cada membrana fabricada tiene en la columna $M E M$ un código de referencia único. La caracterización en planta de las membranas se encuentra en Tabla 63, Tabla 64 y Tabla 65, viniendo las membranas referidas por el mismo código de referencia.

Los códigos de las variables de fabricación vienen explicados exhaustivamente en la Tabla 42 siendo:
$P, X P$ :
Polímero utilizado y su fracción
$D, X D$ :
Disolvente utilizado y su fracción
$A 1, A 2, X A 1, X A 2$ :
Aditivos utilizados y su fracción
$S P$ :
Soporte utilizado $(\mathrm{F} 02=2402, \mathrm{TV}=$ Tyvek $)$
$E N$ :
Espesor nominal de deposición $(\mu \mathrm{m})$
TRE, TRC, TRT:
Temperaturas de evaporación, coagulación y de tratamiento térmico $\left({ }^{\circ} \mathrm{C}\right)$
TPE, TPC, TPT: $\quad$ Tiempos de evaporación (seg), de coagulación (min) y tratamiento térmico (min)
TTT:
Tipo de tratamiento térmico $(\mathrm{I}=$ inmersión $)$

Los códigos para de las variables de caracterización en planta vienen explicados exhaustivamente en la Tabla 42 siendo:
MOD:
Tipo de módulo utilizado $(\mathrm{P}=$ placas, $\mathrm{C}=$ cilíndrico $)$
Fnn:
Flux a nn bar de presión $\left(\mathrm{L} \cdot \mathrm{m}^{-2} \cdot \mathrm{dí}^{-1}\right)$
Rnn:
Rechazo a nn bar de presión (\%)
Ann:
Permeabilidad a nn bar de presión $\left(\mathrm{L} \cdot \mathrm{m}^{-2} \cdot \mathrm{dí}^{-1} \cdot \mathrm{bar}^{-1}\right)$
Bnn:
Factor de paso de sal a nn bar de presión $\left(\mathrm{L} \cdot \mathrm{m}^{-2} \cdot\right.$ día $\left.^{-1}\right)$ 
Tabla 60. Condiciones de fabricación de membranas que utilizan como polímero base AC3 (CA-398-3)

\begin{tabular}{|c|c|c|c|c|c|c|c|c|c|c|c|c|c|c|c|c|}
\hline MEM & $P$ & $X P$ & $D$ & $X D$ & $A 1$ & $X A 1$ & $A 2$ & $X A 2$ & $S P$ & $E N$ & $T R E$ & $T P E$ & $T R C$ & $T R T$ & $T P T$ & TTT \\
\hline $30511-1 \mathrm{~A}$ & AC3 & 25 & DMA & 74.5 & - & & $\mathrm{T} 1$ & 0.5 & PPS & 36 & 25 & 30 & 10 & & 0 & - \\
\hline 30511-1B & AC3 & 25 & DMA & 74.5 & - & & $\mathrm{T} 1$ & 0.5 & PPS & 36 & 25 & 30 & 10 & & 0 & - \\
\hline $30511-2 A$ & AC3 & 25 & DMA & 74.5 & - & & $\mathrm{T} 1$ & 0.5 & F02 & 75 & 25 & 30 & 10 & & 0 & - \\
\hline $30511-2 B$ & AC3 & 25 & DMA & 74.5 & - & & $\mathrm{T} 1$ & 0.5 & F02 & 75 & 25 & 30 & 10 & & 0 & - \\
\hline $30511-3 A$ & AC3 & 25 & DMA & 74.5 & - & & $\mathrm{T} 1$ & 0.5 & F02 & 50 & 25 & 30 & 10 & & 0 & - \\
\hline $30511-3 B$ & AC3 & 25 & DMA & 74.5 & - & & $\mathrm{T} 1$ & 0.5 & F02 & 50 & 25 & 30 & 10 & & 0 & - \\
\hline $30511-4 \mathrm{~A}$ & AC3 & 25 & DMA & 74.5 & - & & T1 & 0.5 & F02 & 36 & 25 & 15 & 10 & & 0 & - \\
\hline 30511-4B & AC3 & 25 & DMA & 74.5 & - & & $\mathrm{T} 1$ & 0.5 & F02 & 36 & 25 & 15 & 10 & & 0 & - \\
\hline $30512-01$ & AC3 & 25 & DMA & 75 & - & & - & & F02 & 75 & 25 & 30 & 10 & & 0 & - \\
\hline $30512-02$ & AC3 & 25 & DMA & 75 & - & & - & & F02 & 75 & 25 & 30 & 10 & & 0 & - \\
\hline $30512-03$ & AC3 & 25 & DMA & 75 & - & & - & & F02 & 75 & 25 & 120 & 10 & & 0 & - \\
\hline $30512-04$ & AC3 & 25 & DMA & 75 & - & & - & & F02 & 75 & 25 & 120 & 10 & & 0 & - \\
\hline $30512-05$ & AC3 & 25 & DMA & 75 & - & & - & & F02 & 100 & 25 & 30 & 10 & & 0 & - \\
\hline $30512-06$ & AC3 & 25 & DMA & 75 & - & & - & & F02 & 100 & 25 & 30 & 10 & & 0 & - \\
\hline 30514-01 & AC3 & 25 & DMA & 75 & - & & - & & F02 & 75 & 25 & 30 & 22 & & 0 & - \\
\hline 30514-02 & AC3 & 25 & DMA & 75 & - & & - & & F02 & 75 & 25 & 30 & 22 & & 0 & - \\
\hline $30514-03$ & AC3 & 25 & DMA & 75 & - & & - & & F02 & 100 & 25 & 30 & 10 & & 0 & - \\
\hline $30514-04$ & AC3 & 25 & DMA & 75 & - & & - & & F02 & 100 & 25 & 30 & 10 & & 0 & - \\
\hline $30514-05$ & AC3 & 25 & DMA & 75 & - & & - & & F02 & 75 & 25 & 120 & 22 & & 0 & - \\
\hline 30514-07 & AC3 & 25 & DMA & 75 & - & & - & & F02 & 75 & 25 & 30 & 10 & & 0 & - \\
\hline $30514-08$ & AC3 & 25 & DMA & 75 & - & & - & & F02 & 75 & 25 & 30 & 10 & & 0 & - \\
\hline 30518-01 & AC3 & 23 & DMA & 77 & - & & - & & F02 & 50 & 25 & 15 & 10 & & 0 & - \\
\hline $30518-02$ & AC3 & 23 & DMA & 77 & - & & - & & F02 & 50 & 25 & 15 & 10 & & 0 & - \\
\hline 30518-03 & AC3 & 23 & DMA & 77 & - & & - & & F02 & 36 & 25 & 15 & 10 & & 0 & - \\
\hline 30518-04 & AC3 & 23 & DMA & 77 & - & & - & & F02 & 36 & 25 & 15 & 10 & & 0 & - \\
\hline $30518-05$ & AC3 & 25 & DMA & 75 & - & & - & & F02 & 100 & 25 & 15 & 22 & & 0 & - \\
\hline 30518-06 & AC3 & 25 & DMA & 75 & - & & - & & F02 & 100 & 25 & 15 & 22 & & 0 & - \\
\hline \begin{tabular}{|l|}
$30518-07$ \\
\end{tabular} & AC3 & 25 & DMA & 75 & - & & - & & F02 & 100 & 25 & 30 & 22 & & 0 & - \\
\hline $30518-08$ & AC3 & 25 & DMA & 75 & - & & - & & F02 & 100 & 25 & 30 & 22 & & 0 & - \\
\hline 30518-2' & AC3 & 22 & DMA & 78 & - & & - & & Nylon & 36 & 25 & 15 & 10 & & 0 & - \\
\hline $30519-01$ & AC3 & 25 & DMA & 74.5 & - & & $\mathrm{TX}$ & 0.5 & F02 & 75 & 25 & 15 & 22 & & 0 & - \\
\hline 30519-02 & AC3 & 25 & DMA & 74.5 & - & & $\mathrm{TX}$ & 0.5 & F02 & 75 & 25 & 15 & 22 & & 0 & - \\
\hline 30519-03 & AC3 & 25 & DMA & 74.5 & - & & TX & 0.5 & F02 & 100 & 25 & 15 & 22 & & 0 & - \\
\hline $30519-04$ & AC3 & 25 & DMA & 74.5 & - & & $\mathrm{TX}$ & 0.5 & F02 & 100 & 25 & 15 & 22 & & 0 & - \\
\hline 30519-05 & AC3 & 23 & DMA & 76.5 & - & & TX & 0.5 & F02 & 75 & 25 & 15 & 22 & & 0 & - \\
\hline $30519-06$ & AC3 & 23 & DMA & 76.5 & - & & $T X$ & 0.5 & F02 & 75 & 25 & 15 & 22 & & 0 & - \\
\hline 30519-07 & AC3 & 23 & DMA & 76.5 & - & & $\mathrm{TX}$ & 0.5 & F02 & 100 & 25 & 15 & 22 & & 0 & - \\
\hline 30519-08 & AC3 & 23 & DMA & 76.5 & - & & $\mathrm{TX}$ & 0.5 & F02 & 100 & 25 & 15 & 22 & & 0 & - \\
\hline $30522-01$ & AC3 & 23 & DMA & 76.5 & - & & $\mathrm{TX}$ & 0.5 & F02 & 100 & 25 & 15 & 11 & & 0 & - \\
\hline $30522-02$ & AC3 & 23 & DMA & 76.5 & - & & $T X$ & 0.5 & F02 & 100 & 25 & 15 & 11 & & 0 & - \\
\hline $30522-03$ & AC3 & 23 & DMA & 73 & $\mathrm{LiCl}$ & 4 & - & & F02 & 75 & 25 & 15 & 22 & & 0 & - \\
\hline 30522-04 & AC3 & 23 & DMA & 73 & $\mathrm{LiCl}$ & 4 & - & & F02 & 75 & 25 & 15 & 22 & & 0 & - \\
\hline $30522-05$ & AC3 & 23 & DMA & 73 & $\mathrm{LiCl}$ & 4 & - & & F02 & 100 & 25 & 15 & 11 & & 0 & - \\
\hline $30522-06$ & AC3 & 23 & DMA & 77 & - & & - & & F02 & 100 & 25 & 15 & 11 & & 0 & - \\
\hline 30528-01 & AC3 & 25 & DMA & 75 & - & & - & & F02 & 75 & 25 & 15 & 15 & & 0 & - \\
\hline $30528-04$ & AC3 & 23 & DMA & 73 & $\mathrm{LiCl}$ & 4 & - & & F02 & 100 & 25 & 15 & 13 & & 0 & - \\
\hline
\end{tabular}


Tabla 60 (Continuación)

\begin{tabular}{|c|c|c|c|c|c|c|c|c|c|c|c|c|c|c|c|c|}
\hline MEM & $P$ & $X P$ & $D$ & $X D$ & $A 1$ & $X A 1$ & A2 & $X A 2$ & $S P$ & $E N$ & $T R E$ & $T P E$ & $T R C$ & $T R T$ & $T P T$ & $T T T$ \\
\hline $30528-05$ & AC3 & 23 & DMA & 73 & $\mathrm{LiCl}$ & 4 & - & & F02 & 100 & 25 & 15 & 13 & & 0 & - \\
\hline $30528-06$ & C3 & 25 & DMA & 75 & 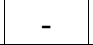 & & - & & F02 & 75 & 25 & 10 & 15 & & 0 & - \\
\hline $30528-07$ & AC3 & 25 & DMA & 75 & - & & - & & F02 & 75 & 25 & 10 & 15 & & 0 & - \\
\hline $30529-02$ & AC3 & 23 & DMA & 73 & $\mathrm{LiCl}$ & 4 & - & & F02 & 75 & 25 & 15 & 11 & & 0 & - \\
\hline $30529-03$ & AC3 & 25 & DMA & 70.5 & $\mathrm{LiCl}$ & 4 & TX & 0.5 & F02 & 75 & 25 & 15 & 12 & & 0 & - \\
\hline $30529-04$ & $\mathrm{C} 3$ & 25 & DMA & 74.5 & - & & $T X$ & 0.5 & F02 & 100 & 25 & 15 & 12 & & 0 & - \\
\hline $30529-05$ & AC3 & 23 & DMA & 76.5 & - & & $T X$ & 0.5 & F02 & 75 & 25 & 15 & 11 & & 0 & - \\
\hline $30529-06$ & AC3 & 22 & DMA & 76 & $\mathrm{LiCl}$ & 2 & - & & F02 & 75 & 25 & 15 & 12 & & 0 & - \\
\hline $30529-07$ & AC3 & 22 & DMA & 76 & $\mathrm{LiCl}$ & 2 & - & & F02 & 100 & 25 & 15 & 12 & & 0 & - \\
\hline $30529-08$ & AC3 & 23 & DMA & 73 & $\mathrm{LiCl}$ & 4 & - & & F02 & 100 & 25 & 15 & 22 & & 0 & - \\
\hline $30615-07$ & C3 & 22 & DMA & 77.5 & - & & $\mathrm{T} 1$ & 0.5 & F02 & 75 & 25 & 15 & 10 & 90 & 5 & 1 \\
\hline $30615-08$ & $\mathrm{C} 3$ & 22 & DMA & 77.5 & - & & $\mathrm{T} 1$ & 0.5 & F02 & 75 & 25 & 15 & 10 & 90 & 5 & I \\
\hline 30703-01 & AC3 & 23 & DMA & 72.5 & $\mathrm{LiCl}$ & 4 & $\mathrm{~T} 2$ & 0.5 & TV & 75 & 25 & 15 & 20 & 95 & 2 & I \\
\hline 30703-02 & AC3 & 23 & DMA & 72.5 & $\mathrm{LiCl}$ & 4 & $\mathrm{~T} 2$ & 0.5 & TV & 75 & 25 & 15 & 20 & 95 & 2 & $\mathrm{I}$ \\
\hline $30703-03$ & AC3 & 23 & DMA & 72.5 & $\mathrm{LiCl}$ & 4 & $\mathrm{~T} 2$ & 0.5 & TV & 50 & 25 & 15 & 20 & 95 & 2 & 1 \\
\hline 30703-04 & AC3 & 23 & DMA & 72.5 & $\mathrm{LiCl}$ & 4 & $\mathrm{~T} 2$ & 0.5 & TV & 50 & 25 & 15 & 20 & 95 & 2 & 1 \\
\hline $30705-01$ & AC3 & 18 & DMA & 82 & - & & - & & F02 & 50 & 25 & 180 & & & 0 & - \\
\hline $30705-02$ & A & 18 & DMA & 82 & - & & - & & $\mathrm{F}$ & 50 & 25 & 180 & & & 0 & 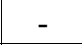 \\
\hline $30705-03$ & AC3 & 23 & DMA & 77 & - & & - & & $1+02$ & 75 & 25 & 180 & 10 & & 0 & - \\
\hline $30705-04$ & AC3 & 23 & DMA & 77 & - & & - & & F02 & 100 & 25 & 180 & 10 & & 0 & - \\
\hline $30705-05$ & $A C 3$ & 23 & DMA & 77 & - & & - & & F02 & 36 & 25 & 180 & 10 & & 0 & - \\
\hline $30705-06$ & $\mathrm{C} 3$ & 23 & DMA & 77 & - & & - & & $=02$ & 36 & 25 & 180 & 10 & & 0 & - \\
\hline $30705-07$ & C3 & 23 & DMA & 73 & $\mathrm{LiCl}$ & 4 & - & & TV & 50 & 25 & 15 & 20 & 90 & 3 & 1 \\
\hline $30705-08$ & C3 & 23 & DMA & 73 & $\mathrm{LiCl}$ & 4 & - & & TV & 50 & 25 & 15 & 20 & 90 & 3 & 1 \\
\hline $30705-09$ & AC3 & 23 & DMA & 73 & $\mathrm{LiCl}$ & 4 & - & & TV & 75 & 25 & 15 & 20 & 90 & 3 & 1 \\
\hline $30705-10$ & AC3 & 23 & DMA & 73 & $\mathrm{LiCl}$ & 4 & - & & TV & 75 & 25 & 15 & 20 & 90 & 3 & 1 \\
\hline $30705-2 \mathrm{~A}$ & AC3 & 23 & DMA & 76.5 & - & & $\mathrm{T}$ & 0.5 & F02 & 50 & 25 & 120 & 10 & & 0 & - \\
\hline $30705-2 B$ & AC3 & 23 & DMA & 76.5 & - & & $\mathrm{T}$ & 0.5 & $F$ & 50 & 25 & 120 & 4 & & 0 & - \\
\hline $30705-3 \mathrm{~A}$ & A & 23 & DMA & 76.5 & - & & $-T$ & 0.5 & $\mathrm{~F}$ & 36 & 25 & 120 & 1 & & 0 & - \\
\hline $30705-3 B$ & AC3 & 23 & DMA & 76.5 & - & & T & 0.5 & $F$ & 36 & 25 & 120 & 10 & & 0 & - \\
\hline $30705-4 \mathrm{~A}$ & AC3 & 23 & DMA & 76.5 & - & & $T$ & 0.5 & Fo & 36 & 25 & 15 & 10 & & 0 & - \\
\hline $30705-4 \mathrm{~B}$ & AC3 & 23 & DMA & 76.5 & - & & $\mathrm{T}$ & 0.5 & Fo & 36 & 25 & 15 & 10 & & 0 & - \\
\hline $30717-01$ & AC3 & 23 & DMA & 72.5 & $\mathrm{LiCl}$ & 4 & $\mathrm{~T} 2$ & 0.5 & $\mathrm{~T}$ & 75 & 25 & 15 & 20 & 97 & 5 & 1 \\
\hline $30717-02$ & AC3 & 23 & DMA & 72.5 & $\mathrm{Li}$ & 4 & $\mathrm{~T} 2$ & 0.5 & T & 75 & 25 & 15 & 2 & 97 & 5 & 1 \\
\hline $30717-03$ & AC3 & 23 & DMA & 72.5 & $\mathrm{LiCl}$ & 4 & $\mathrm{~T} 2$ & 0.5 & IV & 75 & 25 & 15 & 20 & 97 & 3 & I \\
\hline $30717-04$ & AC3 & 23 & DMA & 72.5 & $\mathrm{LiCl}$ & 4 & $\mathrm{~T} 2$ & 0.5 & TV & 75 & 25 & 15 & 20 & 97 & 3 & 1 \\
\hline 30717-05 & AC3 & 23 & DMA & 72.5 & $\mathrm{LiCl}$ & 4 & T2 & 0.5 & TV & 75 & 25 & 15 & 20 & 95 & 5 & 1 \\
\hline $30717-06$ & AC3 & 23 & DMA & 72.5 & $\mathrm{LiCl}$ & 4 & $\mathrm{~T} 2$ & 0.5 & TV & 75 & 25 & 15 & 20 & 95 & 5 & 1 \\
\hline $30717-07$ & $A C$ & 23 & DMA & 72.5 & $\mathrm{Li}$ & 4 & $\mathrm{~T} 2$ & 0.5 & TV & 75 & 25 & 15 & 20 & 95 & 3 & 1 \\
\hline $30717-08$ & AC3 & 23 & DMA & 72.5 & & 4 & $\mathrm{~T} 2_{2}$ & 0.5 & $\mathrm{~T}$ & 75 & 25 & 15 & 20 & 95 & 3 & I \\
\hline 307 & $\mathrm{AC}$ & 3 & DMA & 72.5 & & 4 & 12 & 0.5 & & 75 & 25 & 15 & 20 & 9 & 5 & I \\
\hline $30717-10$ & $A<3$ & 23 & DMA & 72.5 & $\mathrm{LiCl}$ & 4 & T2 & 0.5 & 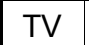 & 75 & 25 & 15 & 20 & 95 & 5 & 1 \\
\hline $30721-01$ & AC3 & 22 & DMA & 77.5 & 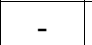 & & $\mathrm{T} 2$ & 0.5 & TV & 75 & 25 & 15 & 20 & 95 & 1 & 1 \\
\hline $30721-02$ & AC3 & 22 & DMA & 77.5 & - & & $\mathrm{T} 2$ & 0.5 & TV & 75 & 25 & 15 & 20 & 95 & 1 & I \\
\hline $30721-03$ & AC3 & 22 & DMA & 77.5 & - & & $\mathrm{T} 2$ & 0.5 & TV & 75 & 25 & 15 & 20 & 95 & 3 & 1 \\
\hline $30721-04$ & AC3 & 22 & DMA & 77.5 & - & & $\mathrm{T} 2$ & 0.5 & TV & 75 & 25 & 15 & 20 & 95 & 3 & 1 \\
\hline $30721-05$ & AC3 & 22 & DMA & 77.5 & - & & $\mathrm{T} 2$ & 0.5 & TV & 75 & 25 & 15 & 20 & 95 & 5 & I \\
\hline $30721-06$ & AC3 & 22 & DMA & 77.5 & - & & $\mathrm{T} 2$ & 0.5 & TV & 75 & 25 & 15 & 20 & 95 & 5 & 1 \\
\hline
\end{tabular}


Tabla 60 (Continuación)

\begin{tabular}{|c|c|c|c|c|c|c|c|c|c|c|c|c|c|c|c|c|}
\hline MEM & $P$ & $X P$ & $D$ & $X D$ & $A 1$ & $X A 1$ & $A 2$ & $X A 2$ & $S P$ & $E N$ & $T R E$ & TPE & $T R C$ & $T R T$ & $T P T$ & TTT \\
\hline 30721-07 & AC3 & 22 & DMA & 77.5 & - & & $\mathrm{T} 2$ & 0.5 & TV & 75 & 25 & 15 & 20 & 97 & 2 & 1 \\
\hline $30721-08$ & AC3 & 22 & DMA & 77.5 & - & & $\mathrm{T} 2$ & 0.5 & TV & 75 & 25 & 15 & 20 & 97 & 2 & I \\
\hline $30721-09$ & AC3 & 22 & DMA & 77.5 & - & & $\mathrm{T} 2$ & 0.5 & F01 & 75 & 25 & 15 & 20 & 95 & 3 & I \\
\hline $30721-10$ & AC3 & 22 & DMA & 77.5 & - & & $\mathrm{T} 2$ & 0.5 & F01 & 75 & 25 & 15 & 20 & 95 & 3 & I \\
\hline $30805-1 \mathrm{~A}$ & AC3 & 23 & DMA & 76.5 & - & & T & 0.5 & F02 & 75 & 25 & 15 & 10 & & 0 & - \\
\hline $30805-1 B$ & AC3 & 23 & DMA & 76.5 & - & & $T$ & 0.5 & F02 & 75 & 25 & 15 & 10 & & 0 & - \\
\hline $30922-11$ & AC3 & 23 & DMA & 77 & - & & - & & F02 & 50 & 20 & 15 & 2 & 99 & 1 & 1 \\
\hline $30922-12$ & AC3 & 23 & DMA & 77 & - & & - & & F02 & 50 & 20 & 15 & 2 & 99 & 1 & I \\
\hline $30922-13$ & AC3 & 23 & DMA & 77 & - & & - & & F02 & 50 & 20 & 15 & 2 & 99 & 1 & I \\
\hline $30922-14$ & AC3 & 23 & DMA & 77 & - & & - & & F02 & 50 & 20 & 15 & 2 & 99 & 1 & I \\
\hline 30923-01 & AC3 & 23 & DMA & 77 & - & & - & & F02 & 50 & 20 & 5 & 2 & 99 & 1.5 & I \\
\hline $30923-02$ & AC3 & 23 & DMA & 77 & - & & - & & F02 & 50 & 20 & 5 & 2 & 99 & 1.5 & I \\
\hline $30923-03$ & AC3 & 23 & DMA & 77 & - & & - & & F02 & 50 & 20 & 5 & 2 & 99 & 1.5 & 1 \\
\hline $30923-04$ & AC3 & 23 & DMA & 77 & - & & - & & F02 & 50 & 20 & 5 & 2 & 99 & 1.5 & 1 \\
\hline 30923-05 & AC3 & 23 & DMA & 77 & - & & - & & F02 & 50 & 20 & 5 & 2 & 99 & 1.5 & 1 \\
\hline 30924-01 & AC3 & 23 & DMA & 77 & - & & - & & F02 & 50 & 20 & 15 & 2 & 99 & 1.5 & 1 \\
\hline $30924-02$ & AC3 & 23 & DMA & 77 & - & & - & & F02 & 50 & 20 & 15 & 2 & 99 & 1.5 & 1 \\
\hline $30924-03$ & AC3 & 23 & DMA & 77 & - & & - & & F02 & 50 & 20 & 15 & 2 & 99 & 1.5 & 1 \\
\hline $30924-04$ & AC3 & 23 & DMA & 77 & - & & - & & F02 & 50 & 20 & 15 & 2 & 99 & 1.5 & 1 \\
\hline $30924-05$ & AC3 & 23 & DMA & 77 & - & & - & & F02 & 50 & 20 & 5 & 2 & 99 & 2 & 1 \\
\hline $30924-06$ & AC3 & 23 & DMA & 77 & - & & - & & F02 & 50 & 20 & 5 & 2 & 99 & 2 & 1 \\
\hline $30924-07$ & AC3 & 23 & DMA & 77 & - & & - & & F02 & 50 & 20 & 5 & 2 & 99 & 2 & 1 \\
\hline $30924-08$ & AC3 & 23 & DMA & 77 & - & & - & & F02 & 50 & 20 & 5 & 2 & 99 & 2 & 1 \\
\hline $31001-111$ & AC3 & 23 & DMA & 77 & - & & - & & F02 & 50 & 25 & 15 & 2 & 95 & 3 & 1 \\
\hline $31001-112$ & AC3 & 23 & DMA & 77 & - & & - & & F02 & 50 & 25 & 15 & 2 & 95 & 3 & 1 \\
\hline $31001-113$ & AC3 & 23 & DMA & 77 & - & & - & & F02 & 50 & 25 & 15 & 2 & 95 & 3 & 1 \\
\hline $31001-114$ & AC3 & 23 & DMA & 77 & - & & - & & F02 & 50 & 25 & 15 & 2 & 95 & 3 & 1 \\
\hline $31001-121$ & AC3 & 23 & DMA & 77 & - & & - & & F02 & 50 & 25 & 15 & 2 & 95 & 3 & 1 \\
\hline $31001-122$ & AC3 & 23 & DMA & 77 & - & & - & & F02 & 50 & 25 & 15 & 2 & 95 & 3 & 1 \\
\hline $31001-123$ & AC3 & 23 & DMA & 77 & - & & - & & F02 & 50 & 25 & 15 & 2 & 95 & 3 & 1 \\
\hline $31001-124$ & AC3 & 23 & DMA & 77 & - & & - & & F02 & 50 & 25 & 15 & 2 & 95 & 3 & 1 \\
\hline $31001-131$ & AC3 & 23 & DMA & 77 & - & & - & & F02 & 50 & 25 & 15 & 2 & 95 & 3 & 1 \\
\hline $31001-132$ & AC3 & 23 & DMA & 77 & - & & - & & F02 & 50 & 25 & 15 & 2 & 95 & 3 & 1 \\
\hline $31001-133$ & AC3 & 23 & DMA & 77 & - & & - & & F02 & 50 & 25 & 15 & 2 & 95 & 3 & 1 \\
\hline $31001-134$ & AC3 & 23 & DMA & 77 & - & & - & & F02 & 50 & 25 & 15 & 2 & 95 & 3 & 1 \\
\hline $31001-211$ & AC3 & 23 & DMA & 77 & - & & - & & F02 & 50 & 25 & 15 & 2 & 95 & 3 & 1 \\
\hline $31001-213$ & AC3 & 23 & DMA & 77 & - & & - & & F02 & 50 & 25 & 15 & 2 & 95 & 3 & 1 \\
\hline $31001-214$ & AC3 & 23 & DMA & 77 & - & & - & & F02 & 50 & 25 & 15 & 2 & 95 & 3 & 1 \\
\hline $31001-221$ & AC3 & 23 & DMA & 77 & - & & - & & F02 & 50 & 25 & 15 & 2 & 95 & 3 & 1 \\
\hline $31001-222$ & AC3 & 23 & DMA & 77 & - & & - & & F02 & 50 & 25 & 15 & 2 & 95 & 3 & I \\
\hline $31001-223$ & AC3 & 23 & DMA & 77 & - & & - & & F02 & 50 & 25 & 15 & 2 & 95 & 3 & 1 \\
\hline $31001-224$ & AC3 & 23 & DMA & 77 & - & & - & & F02 & 50 & 25 & 15 & 2 & 95 & 3 & 1 \\
\hline $31001-231$ & AC3 & 23 & DMA & 77 & - & & - & & F02 & 50 & 25 & 15 & 2 & 95 & 3 & 1 \\
\hline $31001-232$ & AC3 & 23 & DMA & 77 & - & & - & & F02 & 50 & 25 & 15 & 2 & 95 & 3 & 1 \\
\hline $31001-233$ & AC3 & 23 & DMA & 77 & - & & - & & F02 & 50 & 25 & 15 & 2 & 95 & 3 & 1 \\
\hline $31001-234$ & AC3 & 23 & DMA & 77 & - & & - & & F02 & 50 & 25 & 15 & 2 & 95 & 3 & 1 \\
\hline $31001-311$ & AC3 & 23 & DMA & 77 & - & & - & & F02 & 50 & 25 & 15 & 2 & 95 & 3 & 1 \\
\hline $31001-312$ & AC3 & 23 & DMA & 77 & - & & - & & F02 & 50 & 25 & 15 & 2 & 95 & 3 & 1 \\
\hline $31001-313$ & AC3 & 23 & DMA & 77 & - & & - & & F02 & 50 & 25 & 15 & 2 & 95 & 3 & 1 \\
\hline
\end{tabular}


Tabla 60 (Continuación)

\begin{tabular}{|c|c|c|c|c|c|c|c|c|c|c|c|c|c|c|c|c|}
\hline MEM & $P$ & $X P$ & $D$ & $X D$ & $A 1$ & $X A 1$ & $A 2$ & $X A 2$ & $S P$ & $E N$ & $T R E$ & TPE & $T R C$ & $T R T$ & $T P T$ & TTT \\
\hline $31001-314$ & AC3 & 23 & DMA & 77 & - & & - & & F02 & 50 & 25 & 15 & 2 & 95 & 3 & I \\
\hline $31001-321$ & AC3 & 23 & DMA & 77 & - & & - & & F02 & 50 & 25 & 15 & 2 & 95 & 3 & $\mathrm{I}$ \\
\hline $31001-322$ & AC3 & 23 & DMA & 77 & - & & - & & F02 & 50 & 25 & 15 & 2 & 95 & 3 & I \\
\hline $31001-323$ & AC3 & 23 & DMA & 77 & - & & - & & F02 & 50 & 25 & 15 & 2 & 95 & 3 & I \\
\hline $31001-324$ & AC3 & 23 & DMA & 77 & - & & - & & F02 & 50 & 25 & 15 & 2 & 95 & 3 & 1 \\
\hline $31001-331$ & AC3 & 23 & DMA & 77 & - & & - & & F02 & 50 & 25 & 15 & 2 & 95 & 3 & 1 \\
\hline $31001-332$ & AC3 & 23 & DMA & 77 & - & & - & & F02 & 50 & 25 & 15 & 2 & 95 & 3 & 1 \\
\hline $31001-333$ & AC3 & 23 & DMA & 77 & - & & - & & F02 & 50 & 25 & 15 & 2 & 95 & 3 & 1 \\
\hline $31001-334$ & AC3 & 23 & DMA & 77 & - & & - & & F02 & 50 & 25 & 15 & 2 & 95 & 3 & I \\
\hline $31006-111$ & AC3 & 23 & DMA & 73 & $\mathrm{LiCl}$ & 4 & - & & F02 & 75 & 25 & 15 & 25 & 95 & 3 & I \\
\hline $31006-112$ & AC3 & 23 & DMA & 73 & $\mathrm{LiCl}$ & 4 & - & & F02 & 75 & 25 & 15 & 25 & 95 & 3 & 1 \\
\hline $31006-113$ & AC3 & 23 & DMA & 73 & $\mathrm{LiCl}$ & 4 & - & & F02 & 75 & 25 & 15 & 25 & 95 & 3 & 1 \\
\hline $31006-114$ & AC3 & 23 & DMA & 73 & $\mathrm{LiCl}$ & 4 & - & & F02 & 75 & 25 & 15 & 25 & 95 & 3 & 1 \\
\hline $31006-121$ & AC3 & 23 & DMA & 73 & $\mathrm{LiCl}$ & 4 & - & & F02 & 75 & 25 & 15 & 25 & 95 & 3 & I \\
\hline $31006-122$ & AC3 & 23 & DMA & 73 & $\mathrm{LiCl}$ & 4 & - & & F02 & 75 & 25 & 15 & 25 & 95 & 3 & 1 \\
\hline $31006-123$ & AC3 & 23 & DMA & 73 & $\mathrm{LiCl}$ & 4 & - & & F02 & 75 & 25 & 15 & 25 & 95 & 3 & $\mathrm{I}$ \\
\hline $31006-124$ & AC3 & 23 & DMA & 73 & $\mathrm{LiCl}$ & 4 & - & & F02 & 75 & 25 & 15 & 25 & 95 & 3 & $\mathrm{I}$ \\
\hline $31006-131$ & AC3 & 23 & DMA & 73 & $\mathrm{LiCl}$ & 4 & - & & F02 & 75 & 25 & 15 & 25 & 95 & 3 & 1 \\
\hline $31006-132$ & AC3 & 23 & DMA & 73 & $\mathrm{LiCl}$ & 4 & - & & F02 & 75 & 25 & 15 & 25 & 95 & 3 & 1 \\
\hline $31006-133$ & AC3 & 23 & DMA & 73 & $\mathrm{LiCl}$ & 4 & - & & F02 & 75 & 25 & 15 & 25 & 95 & 3 & 1 \\
\hline $31006-134$ & AC3 & 23 & DMA & 73 & $\mathrm{LiCl}$ & 4 & - & & F02 & 75 & 25 & 15 & 25 & 95 & 3 & I \\
\hline $31006-221$ & AC3 & 23 & DMA & 73 & $\mathrm{LiCl}$ & 4 & - & & F02 & 75 & 25 & 15 & 2 & 95 & 3 & 1 \\
\hline $31006-222$ & AC3 & 23 & DMA & 73 & $\mathrm{LiCl}$ & 4 & - & & F02 & 75 & 25 & 15 & 2 & 95 & 3 & $\mathrm{I}$ \\
\hline $31006-223$ & AC3 & 23 & DMA & 73 & $\mathrm{LiCl}$ & 4 & - & & F02 & 75 & 25 & 15 & 2 & 95 & 3 & I \\
\hline $31006-224$ & AC3 & 23 & DMA & 73 & $\mathrm{LiCl}$ & 4 & - & & F02 & 75 & 25 & 15 & 2 & 95 & 3 & $\mathrm{I}$ \\
\hline $31006-231$ & AC3 & 23 & DMA & 73 & $\mathrm{LiCl}$ & 4 & - & & F02 & 75 & 25 & 15 & 2 & 95 & 3 & I \\
\hline $31006-232$ & AC3 & 23 & DMA & 73 & $\mathrm{LiCl}$ & 4 & - & & F02 & 75 & 25 & 15 & 2 & 95 & 3 & 1 \\
\hline $31006-233$ & AC3 & 23 & DMA & 73 & $\mathrm{LiCl}$ & 4 & - & & F02 & 75 & 25 & 15 & 2 & 95 & 3 & 1 \\
\hline $31006-234$ & AC3 & 23 & DMA & 73 & $\mathrm{LiCl}$ & 4 & - & & F02 & 75 & 25 & 15 & 2 & 95 & 3 & 1 \\
\hline $31006-411$ & AC3 & 23 & DMA & 73 & $\mathrm{LiCl}$ & 4 & - & & F02 & 75 & 25 & 15 & 10 & 95 & 3 & 1 \\
\hline $31006-412$ & AC3 & 23 & DMA & 73 & $\mathrm{LiCl}$ & 4 & - & & F02 & 75 & 25 & 15 & 10 & 95 & 3 & I \\
\hline $31006-413$ & AC3 & 23 & DMA & 73 & $\mathrm{LiCl}$ & 4 & - & & F02 & 75 & 25 & 15 & 10 & 95 & 3 & I \\
\hline $31006-414$ & AC3 & 23 & DMA & 73 & $\mathrm{LiCl}$ & 4 & - & & F02 & 75 & 25 & 15 & 10 & 95 & 3 & $\mathrm{I}$ \\
\hline $31006-421$ & AC3 & 23 & DMA & 73 & $\mathrm{LiCl}$ & 4 & - & & F02 & 75 & 25 & 15 & 10 & 95 & 3 & 1 \\
\hline $31006-422$ & AC3 & 23 & DMA & 73 & $\mathrm{LiCl}$ & 4 & - & & F02 & 75 & 25 & 15 & 10 & 95 & 3 & 1 \\
\hline $31006-423$ & AC3 & 23 & DMA & 73 & $\mathrm{LiCl}$ & 4 & - & & F02 & 75 & 25 & 15 & 10 & 95 & 3 & 1 \\
\hline $31006-424$ & AC3 & 23 & DMA & 73 & $\mathrm{LiCl}$ & 4 & - & & F02 & 75 & 25 & 15 & 10 & 95 & 3 & 1 \\
\hline $31006-511$ & AC3 & 23 & DMA & 73 & $\mathrm{LiCl}$ & 4 & - & & F02 & 50 & 25 & 15 & 2 & 95 & 3 & 1 \\
\hline $31006-512$ & AC3 & 23 & DMA & 73 & $\mathrm{LiCl}$ & 4 & - & & F02 & 50 & 25 & 15 & 2 & 95 & 3 & 1 \\
\hline $31006-513$ & AC3 & 23 & DMA & 73 & $\mathrm{LiCl}$ & 4 & - & & F02 & 50 & 25 & 15 & 2 & 95 & 3 & I \\
\hline $31006-514$ & AC3 & 23 & DMA & 73 & $\mathrm{LiCl}$ & 4 & - & & F02 & 50 & 25 & 15 & 2 & 95 & 3 & 1 \\
\hline $31006-521$ & AC3 & 23 & DMA & 73 & $\mathrm{LiCl}$ & 4 & - & & F02 & 50 & 25 & 15 & 2 & 95 & 3 & 1 \\
\hline $31006-522$ & AC3 & 23 & DMA & 73 & $\mathrm{LiCl}$ & 4 & - & & F02 & 50 & 25 & 15 & 2 & 95 & 3 & 1 \\
\hline $31006-523$ & AC3 & 23 & DMA & 73 & $\mathrm{LiCl}$ & 4 & - & & F02 & 50 & 25 & 15 & 2 & 95 & 3 & I \\
\hline $31006-524$ & AC3 & 23 & DMA & 73 & $\mathrm{LiCl}$ & 4 & - & & F02 & 50 & 25 & 15 & 2 & 95 & 3 & 1 \\
\hline $31006-611$ & AC3 & 23 & DMA & 73 & $\mathrm{LiCl}$ & 4 & - & & F02 & 75 & 25 & 15 & 2 & 90 & 3 & I \\
\hline $31006-612$ & AC3 & 23 & DMA & 73 & $\mathrm{LiCl}$ & 4 & - & & F02 & 75 & 25 & 15 & 2 & 90 & 3 & 1 \\
\hline $31006-613$ & AC3 & 23 & DMA & 73 & $\mathrm{LiCl}$ & 4 & - & & F02 & 75 & 25 & 15 & 2 & 90 & 3 & 1 \\
\hline
\end{tabular}




\begin{tabular}{|c|c|r|r|r|r|r|r|r|r|r|r|r|r|r|r|r|}
\hline MEM & $P$ & $X P$ & $D$ & $X D$ & $A 1$ & $X A 1$ & A2 & XA2 & SP & EN & TRE & TPE & TRC & TRT & TPT & TTT \\
\hline $31006-614$ & AC3 & 23 & DMA & 73 & LiCl & 4 & - & & F02 & 75 & 25 & 15 & 2 & 90 & 3 & I \\
\hline $31006-714$ & AC3 & 23 & DMA & 73 & LiCl & 4 & - & & F02 & 50 & 25 & 15 & 3 & 85 & 3 & 1 \\
\hline
\end{tabular}

Tabla 61. Condiciones de fabricación de membranas que utilizan como polímero base AC6 (CA-398-6)

\begin{tabular}{|c|c|c|c|c|c|c|c|c|c|c|c|c|c|c|c|c|}
\hline MEM & $P$ & $X P$ & $D$ & $X D$ & $A 1$ & $X A 1$ & $A 2$ & $X A 2$ & $S P$ & $E N$ & $T R E$ & $T P E$ & $T R C$ & $T R T$ & $T P T$ & TTT \\
\hline $60521-08$ & AC6 & 20 & DMA & 80 & - & & - & & F02 & 100 & 25 & 15 & & & 0 & - \\
\hline $60528-02$ & AC6 & 25 & DMA & 71 & $\mathrm{LiCl}$ & 4 & - & & F02 & 75 & 25 & 15 & 12 & & 0 & - \\
\hline $60528-03$ & AC6 & 23 & DMA & 73 & $\mathrm{LiCl}$ & 4 & - & & F02 & 75 & 25 & 60 & 12 & & 0 & - \\
\hline $60612-03$ & AC6 & 20 & DMA & 78 & $\mathrm{LiCl}$ & 2 & - & & F02 & 75 & 25 & 15 & 10 & 95 & 5 & 1 \\
\hline 60612-04 & AC6 & 20 & DMA & 78 & $\mathrm{LiCl}$ & 2 & - & & F02 & 75 & 25 & 15 & 10 & 95 & 5 & 1 \\
\hline 60615-01 & AC6 & 23 & DMA & 73 & $\mathrm{LiCl}$ & 4 & - & & F02 & 75 & 25 & 15 & 10 & 95 & 2 & 1 \\
\hline $60615-02$ & AC6 & 23 & DMA & 73 & $\mathrm{LiCl}$ & 4 & - & & F02 & 75 & 25 & 15 & 10 & 95 & 2 & 1 \\
\hline $60615-03$ & AC6 & 20 & DMA & 78 & $\mathrm{LiCl}$ & 2 & - & & F02 & 75 & 25 & 15 & 10 & 95 & 2 & 1 \\
\hline $60615-04$ & AC6 & 20 & DMA & 78 & $\mathrm{LiCl}$ & 2 & - & & F02 & 75 & 25 & 15 & 10 & 95 & 2 & 1 \\
\hline $60625-01$ & AC6 & 23 & DMA & 73 & $\mathrm{LiCl}$ & 4 & - & & F02 & 75 & 25 & 15 & 20 & 90 & 1 & 1 \\
\hline $60625-02$ & AC6 & 23 & DMA & 73 & $\mathrm{LiCl}$ & 4 & - & & F02 & 75 & 25 & 15 & 20 & 90 & 1 & 1 \\
\hline $60625-03$ & AC6 & 23 & DMA & 73 & $\mathrm{LiCl}$ & 4 & - & & F02 & 50 & 25 & 15 & 20 & 90 & 1 & 1 \\
\hline $60625-04$ & AC6 & 23 & DMA & 73 & $\mathrm{LiCl}$ & 4 & - & & F02 & 50 & 25 & 15 & 20 & 90 & 1 & 1 \\
\hline $60625-05$ & AC6 & 23 & DMA & 73 & $\mathrm{LiCl}$ & 4 & - & & F02 & 75 & 25 & 15 & 20 & 90 & 2 & 1 \\
\hline $60625-06$ & AC6 & 23 & DMA & 73 & $\mathrm{LiCl}$ & 4 & - & & F02 & 75 & 25 & 15 & 20 & 90 & 2 & 1 \\
\hline 60625-07 & AC6 & 23 & DMA & 73 & $\mathrm{LiCl}$ & 4 & - & & F02 & 75 & 25 & 15 & 20 & 90 & 3 & 1 \\
\hline $60625-08$ & AC6 & 23 & DMA & 73 & $\mathrm{LiCl}$ & 4 & - & & F02 & 75 & 25 & 15 & 20 & 90 & 3 & 1 \\
\hline 60625-09 & AC6 & 23 & DMA & 73 & $\mathrm{LiCl}$ & 4 & - & & F02 & 50 & 25 & 15 & 20 & 90 & 2 & 1 \\
\hline $60625-10$ & AC6 & 23 & DMA & 73 & $\mathrm{LiCl}$ & 4 & - & & F02 & 50 & 25 & 15 & 20 & 90 & 2 & 1 \\
\hline 60629-01 & AC6 & 23 & DMA & 73 & $\mathrm{LiCl}$ & 4 & - & & F02 & 50 & 25 & 15 & 20 & 90 & 3 & 1 \\
\hline 60629-02 & AC6 & 23 & DMA & 73 & $\mathrm{LiCl}$ & 4 & - & & TV & 50 & 25 & 15 & 20 & 90 & 3 & 1 \\
\hline 60629-03 & AC6 & 23 & DMA & 73 & $\mathrm{LiCl}$ & 4 & - & & NV & 75 & 25 & 15 & 20 & 90 & 1 & 1 \\
\hline 60629-04 & AC6 & 23 & DMA & 73 & $\mathrm{LiCl}$ & 4 & - & & NV & 75 & 25 & 15 & 20 & 90 & 1 & 1 \\
\hline 60629-05 & AC6 & 23 & DMA & 73 & $\mathrm{LiCl}$ & 4 & - & & NV & 50 & 25 & 15 & 20 & 90 & 1 & 1 \\
\hline $60629-06$ & AC6 & 23 & DMA & 73 & $\mathrm{LiCl}$ & 4 & - & & NV & 50 & 25 & 15 & 20 & 90 & 1 & 1 \\
\hline 60629-09 & AC6 & 23 & DMA & 73 & $\mathrm{LiCl}$ & 4 & - & & NV & 50 & 25 & 15 & 20 & 90 & 2 & 1 \\
\hline $60629-10$ & AC6 & 23 & DMA & 73 & $\mathrm{LiCl}$ & 4 & - & & NV & 50 & 25 & 15 & 20 & 90 & 2 & 1 \\
\hline $60702-03$ & AC6 & 23 & DMA & 77 & - & & - & & TV & 75 & 25 & 15 & 20 & 95 & 2 & V \\
\hline 60702-04 & AC6 & 23 & DMA & 77 & - & & - & & TV & 75 & 25 & 15 & 20 & 95 & 2 & V \\
\hline $60702-05$ & AC6 & 23 & DMA & 77 & - & & - & & TV & 75 & 25 & 15 & 20 & 95 & 2 & 1 \\
\hline $60702-06$ & AC6 & 23 & DMA & 77 & - & & - & & TV & 75 & 25 & 15 & 20 & 95 & 2 & 1 \\
\hline $60702-07$ & AC6 & 23 & DMA & 77 & - & & - & & TV & 75 & 25 & 15 & 20 & 95 & 2 & V \\
\hline 60702-08 & AC6 & 23 & DMA & 77 & - & & - & & TV & 75 & 25 & 15 & 20 & 95 & 2 & V \\
\hline 60715-01 & AC6 & 20 & DMA & 79.5 & - & & $\mathrm{TX}$ & 0.5 & TV & 75 & 25 & 15 & 22 & 97 & 5 & 1 \\
\hline $60715-02$ & AC6 & 20 & DMA & 79.5 & - & & $T X$ & 0.5 & TV & 75 & 25 & 15 & 22 & 97 & 5 & 1 \\
\hline $60715-03$ & AC6 & 20 & DMA & 79.5 & - & & TX & 0.5 & TV & 75 & 25 & 15 & 22 & 97 & 3 & 1 \\
\hline $60715-04$ & AC6 & 20 & DMA & 79.5 & - & & TX & 0.5 & TV & 75 & 25 & 15 & 22 & 97 & 3 & 1 \\
\hline $60715-05$ & AC6 & 20 & DMA & 79.5 & - & & $T X$ & 0.5 & TV & 75 & 25 & 15 & 20 & 95 & 5 & 1 \\
\hline $60715-06$ & AC6 & 20 & DMA & 79.5 & - & & $\mathrm{TX}$ & 0.5 & TV & 75 & 25 & 15 & 20 & 95 & 5 & 1 \\
\hline 60715-07 & AC6 & 20 & DMA & 79.5 & - & & $\mathrm{TX}$ & 0.5 & TV & 75 & 25 & 15 & 20 & 95 & 3 & 1 \\
\hline
\end{tabular}


Tabla 61 (Continuación)

\begin{tabular}{|c|c|c|c|c|c|c|c|c|c|c|c|c|c|c|c|c|}
\hline MEM & $P$ & $X P$ & $D$ & $X D$ & $A 1$ & $X A 1$ & $A 2$ & $X A 2$ & $S P$ & $E N$ & TRE & TPE & $T R C$ & $T R T$ & $T P T$ & TTT \\
\hline $60715-08$ & AC6 & 20 & DMA & 79.5 & - & & $T X$ & 0.5 & TV & 75 & 25 & 15 & 20 & 95 & 3 & I \\
\hline $60715-09$ & AC6 & 20 & DMA & 79.5 & - & & TX & 0.5 & TV & 75 & 25 & 15 & 20 & 95 & 5 & 1 \\
\hline $60715-10$ & AC6 & 20 & DMA & 79.5 & - & & TX & 0.5 & TV & 75 & 25 & 15 & 20 & 95 & 5 & 1 \\
\hline 60916-01 & AC6 & 20 & DMA & 80 & - & & - & 0 & F02 & 50 & 25 & 15 & 3 & 76 & 10 & 1 \\
\hline 60916-02 & AC6 & 20 & DMA & 80 & - & & - & 0 & F02 & 50 & 25 & 15 & 3 & 76 & 10 & 1 \\
\hline 60916-03 & AC6 & 20 & DMA & 80 & - & & - & 0 & F02 & 50 & 25 & 15 & 3 & 76 & 10 & 1 \\
\hline 60916-04 & AC6 & 20 & DMA & 80 & - & & - & 0 & F02 & 50 & 25 & 15 & 3 & 76 & 10 & 1 \\
\hline 60917-01 & AC6 & 20 & DMA & 80 & - & & - & 0 & F02 & 50 & 25 & 15 & 2 & 72 & 15 & 1 \\
\hline $60917-05$ & AC6 & 20 & DMA & 80 & - & & - & 0 & F02 & 50 & 25 & 15 & 3 & 76 & 15 & 1 \\
\hline 60917-06 & AC6 & 20 & DMA & 80 & - & & - & 0 & F02 & 50 & 25 & 15 & 3 & 76 & 15 & I \\
\hline 60917-07 & AC6 & 20 & DMA & 80 & - & & - & 0 & F02 & 50 & 25 & 15 & 3 & 76 & 15 & I \\
\hline 60917-08 & AC6 & 20 & DMA & 80 & - & & - & 0 & F02 & 50 & 25 & 15 & 3 & 76 & 15 & 1 \\
\hline 60917-09 & AC6 & 20 & DMA & 80 & - & & - & 0 & F02 & 50 & 25 & 15 & 3 & 76 & 10 & 1 \\
\hline 60917-10 & AC6 & 20 & DMA & 80 & - & & - & & F02 & 50 & 25 & 15 & 3 & 76 & 10 & 1 \\
\hline $60917-11$ & AC6 & 20 & DMA & 80 & - & & - & & F02 & 50 & 25 & 15 & 3 & 76 & 10 & 1 \\
\hline $60917-12$ & AC6 & 20 & DMA & 80 & - & & - & & F02 & 50 & 25 & 15 & 3 & 76 & 10 & 1 \\
\hline 60918-15 & AC6 & 20 & DMA & 80 & - & & - & & F02 & 50 & 25 & 15 & 3 & 76 & 10 & 1 \\
\hline 60918-16 & AC6 & 20 & DMA & 80 & - & & - & & F02 & 50 & 25 & 15 & 3 & & 0 & - \\
\hline 60918-17 & AC6 & 20 & DMA & 80 & - & & - & & F02 & 50 & 25 & 15 & 3 & 76 & 10 & 1 \\
\hline 60918-18 & AC6 & 20 & DMA & 80 & - & & - & & F02 & 50 & 25 & 15 & 3 & 76 & 10 & 1 \\
\hline 60918-19 & AC6 & 20 & DMA & 80 & - & & - & & F02 & 50 & 25 & 15 & 3 & 76 & 10 & 1 \\
\hline 60918-21 & AC6 & 20 & DMA & 80 & - & & - & & F02 & 50 & 25 & 15 & 3 & 76 & 10 & 1 \\
\hline 60918-23 & AC6 & 20 & DMA & 80 & - & & - & & F02 & 50 & 25 & 15 & 3 & 76 & 10 & 1 \\
\hline 60921-02 & AC6 & 21 & DMA & 79 & - & & - & & F02 & 50 & 25 & 15 & 3 & & 0 & - \\
\hline $60921-11$ & AC6 & 20 & DMA & 80 & - & & - & & F02 & 50 & 25 & 15 & 3 & 76 & 10 & 1 \\
\hline 60921-12 & AC6 & 20 & DMA & 80 & - & & - & & F02 & 50 & 25 & 15 & 3 & 76 & 10 & 1 \\
\hline $60921-13$ & AC6 & 20 & DMA & 80 & - & & - & & F02 & 50 & 25 & 15 & 3 & 76 & 10 & 1 \\
\hline 60921-14 & AC6 & 20 & DMA & 80 & - & & - & & F02 & 50 & 25 & 15 & 3 & 76 & 10 & 1 \\
\hline 60922-01 & AC6 & 20 & DMA & 80 & - & & - & & F02 & 50 & 25 & 15 & 3 & 76 & 15 & 1 \\
\hline 60922-02 & AC6 & 20 & DMA & 80 & - & & - & & F02 & 50 & 25 & 15 & 3 & 76 & 15 & 1 \\
\hline 60922-03 & AC6 & 20 & DMA & 80 & - & & - & & F02 & 50 & 25 & 15 & 3 & 76 & 15 & 1 \\
\hline 60922-04 & AC6 & 20 & DMA & 80 & - & & - & & F02 & 50 & 25 & 15 & 3 & 76 & 15 & 1 \\
\hline 60922-05 & AC6 & 20 & DMA & 80 & - & & - & & F02 & 50 & 25 & 15 & 3 & 76 & 15 & 1 \\
\hline 60922-06 & AC6 & 20 & DMA & 80 & - & & - & & F02 & 50 & 25 & 15 & 3 & 76 & 15 & 1 \\
\hline $61008-111$ & AC6 & 20 & DMA & 80 & $\mathrm{LiCl}$ & 0 & - & & F02 & 75 & 25 & 15 & 3 & 95 & 3 & 1 \\
\hline 61008-112 & AC6 & 20 & DMA & 80 & $\mathrm{LiCl}$ & 0 & - & & F02 & 75 & 25 & 15 & 3 & 95 & 3 & I \\
\hline $61008-113$ & AC6 & 20 & DMA & 80 & $\mathrm{LiCl}$ & 0 & - & & F02 & 75 & 25 & 15 & 3 & 95 & 3 & I \\
\hline $61008-114$ & AC6 & 20 & DMA & 78 & $\mathrm{LiCl}$ & 2 & - & & F02 & 50 & 25 & 15 & 3 & 95 & 3 & 1 \\
\hline $61008-121$ & AC6 & 20 & DMA & 78 & $\mathrm{LiCl}$ & 2 & - & & F02 & 50 & 25 & 15 & 3 & 95 & 3 & 1 \\
\hline 61008-123 & AC6 & 20 & DMA & 78 & $\mathrm{LiCl}$ & 2 & - & & F02 & 75 & 25 & 15 & 3 & 95 & 3 & 1 \\
\hline \begin{tabular}{|c|}
$61008-124$ \\
\end{tabular} & AC6 & 20 & DMA & 78 & $\mathrm{LiCl}$ & 2 & - & & F02 & 75 & 25 & 15 & 3 & 95 & 3 & 1 \\
\hline $61008-211$ & AC6 & 20 & DMA & 76 & $\mathrm{LiCl}$ & 4 & - & & F02 & 50 & 25 & 15 & 3 & 95 & 3 & 1 \\
\hline $61008-212$ & AC6 & 20 & DMA & 76 & $\mathrm{LiCl}$ & 4 & - & & F02 & 75 & 25 & 15 & 3 & 95 & 3 & 1 \\
\hline $61008-213$ & AC6 & 20 & DMA & 76 & $\mathrm{LiCl}$ & 4 & - & & F02 & 75 & 25 & 15 & 3 & 95 & 3 & 1 \\
\hline $61008-214$ & AC6 & 20 & DMA & 74 & $\mathrm{LiCl}$ & 6 & - & & F02 & 50 & 25 & 15 & 3 & 95 & 3 & 1 \\
\hline 61008-221 & AC6 & 20 & DMA & 74 & $\mathrm{LiCl}$ & 6 & - & & F02 & 50 & 25 & 15 & 3 & 95 & 3 & 1 \\
\hline $61008-222$ & AC6 & 20 & DMA & 74 & $\mathrm{LiCl}$ & 6 & - & & F02 & 50 & 25 & 15 & 3 & 95 & 3 & 1 \\
\hline 61008-223 & AC6 & 20 & DMA & 74 & $\mathrm{LiCl}$ & 6 & - & & F02 & 50 & 25 & 15 & 3 & 95 & 3 & I \\
\hline \begin{tabular}{|c|}
$61008-224$ \\
\end{tabular} & AC6 & 20 & DMA & 74 & $\mathrm{LiCl}$ & 6 & - & & F02 & 75 & 25 & 15 & 3 & 95 & 3 & 1 \\
\hline
\end{tabular}




\section{Tabla 61 (Continuación)}

\begin{tabular}{|c|c|r|c|c|c|c|c|r|r|r|r|r|r|r|r|r|}
\hline MEM & $P$ & $X P$ & $D$ & $X D$ & $A 1$ & $X A 1$ & A2 & $X A 2$ & $S P$ & $E N$ & $T R E$ & TPE & TRC & TRT & TPT & TTT \\
\hline $61008-312$ & AC6 & 20 & DMA & 80 & - & & - & & F02 & 75 & 25 & 15 & 4 & 90 & 3 & I \\
\hline $61008-313$ & AC6 & 20 & DMA & 80 & - & & - & & F02 & 75 & 25 & 15 & 4 & 90 & 3 & I \\
\hline $61008-314$ & AC6 & 20 & DMA & 80 & - & & - & & F02 & 75 & 25 & 15 & 4 & 90 & 3 & I \\
\hline $61008-321$ & AC6 & 20 & DMA & 80 & - & & - & & F02 & 75 & 25 & 15 & 4 & 90 & 3 & I \\
\hline $61008-322$ & AC6 & 20 & DMA & 80 & - & & - & & F02 & 75 & 25 & 15 & 4 & 90 & 3 & I \\
\hline $61008-323$ & AC6 & 20 & DMA & 80 & - & & - & & F02 & 75 & 25 & 15 & 4 & 90 & 3 & I \\
\hline $61008-324$ & AC6 & 20 & DMA & 80 & - & & - & & F02 & 75 & 25 & 15 & 4 & 90 & 3 & I \\
\hline $61008-511$ & AC6 & 20 & DMA & 80 & - & & - & & F02 & 50 & 25 & 15 & 2 & 90 & 3 & I \\
\hline $61008-513$ & AC6 & 20 & DMA & 80 & - & & - & & F02 & 50 & 25 & 15 & 2 & 90 & 3 & I \\
\hline $61008-514$ & AC6 & 20 & DMA & 80 & - & & - & & F02 & 50 & 25 & 15 & 2 & 90 & 3 & I \\
\hline $61008-521$ & AC6 & 20 & DMA & 80 & - & & - & & F02 & 50 & 25 & 15 & 2 & 90 & 3 & I \\
\hline $61008-522$ & AC6 & 20 & DMA & 80 & - & & - & & F02 & 50 & 25 & 15 & 2 & 90 & 3 & I \\
\hline $61008-523$ & AC6 & 20 & DMA & 80 & - & & - & & F02 & 50 & 25 & 15 & 2 & 90 & 3 & I \\
\hline $61008-524$ & AC6 & 20 & DMA & 80 & - & & - & & F02 & 50 & 25 & 15 & 2 & 90 & 3 & I \\
\hline
\end{tabular}

Tabla 62. Condiciones de fabricación de membranas que utilizan como polímero base ACE (Acetato en escamas de INACSA)

\begin{tabular}{|c|c|c|c|c|c|c|c|c|c|c|c|c|c|c|c|c|}
\hline MEM & $P$ & $X P$ & $D$ & $X D$ & $A 1$ & $X A 1$ & $A 2$ & $X A 2$ & $S P$ & $E N$ & $T R E$ & $T P E$ & $T R C$ & $T R T$ & $T P T$ & TTT \\
\hline $0612-01$ & ACE & 19 & DMA & 79 & $\mathrm{LiCl}$ & 2 & 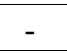 & & F02 & 75 & 25 & 15 & 10 & 95 & 5 & 1 \\
\hline E0612-02 & ACE & 19 & DMA & 79 & $\mathrm{LiCl}$ & 2 & - & & F02 & 75 & 25 & 15 & 10 & 95 & 5 & I \\
\hline E0612-05 & $A C E$ & 19 & DMA & 79 & $\mathrm{LiCl}$ & 2 & 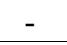 & & F02 & 75 & 25 & 15 & 10 & 95 & 2 & I \\
\hline $0612-06$ & ACE & 19 & DMA & 79 & $\mathrm{LiCl}$ & 2 & - & & F02 & 75 & 25 & 15 & 10 & 95 & 2 & 1 \\
\hline E0615-01 & ACE & 19 & DMA & 80.5 & - & & $\mathrm{T} 1$ & 0.5 & $\mathrm{~F}$ & 75 & 25 & 15 & 10 & 90 & 5 & I \\
\hline 0615 & ACE & 19 & D & 80.5 & - & & T1 & 0.5 & $\mathrm{~F}$ & $7 !$ & 25 & 15 & 1 & 90 & 5 & 1 \\
\hline 0615 & $A C$ & 19 & & & - & & $\mathrm{T} 1$ & t & $\mathrm{F}$ & $7 !$ & 25 & 15 & 1 & 90 & 2 & I \\
\hline$=0615-04$ & $\mathrm{ACE}$ & 19 & DMA & 80.5 & - & & 1 & 0.5 & $F$ & 7 & 25 & 15 & 1 & 95 & 2 & 1 \\
\hline E6615-05 & $\mathrm{ACl}$ & 19 & DMA & 80.5 & - & & $T$ & 0.5 & Fo & $7 !$ & 25 & 15 & 10 & 95 & 2 & I \\
\hline $0615-06$ & IACE & 19 & DMA & 80.5 & 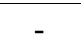 & & & 0.5 & Fo & $7 !$ & 25 & 15 & 10 & 95 & 2 & I \\
\hline 061 & ACE & 19 & DMA & 80.5 & & & 11 & 0.5 & Fo & 75 & 25 & 15 & 10 & 95 & 5 & I \\
\hline E061 & ACE & 19 & DMA & 80.5 & & & T1 & 0.5 & F02 & 75 & 25 & 15 & 10 & 95 & 5 & 1 \\
\hline E1026-121 & $\mathrm{CE}$ & 19 & DMA & 79 & $\mathrm{LiCl}$ & 2 & - & & TV & 75 & 25 & 15 & 2 & 95 & 5 & 1 \\
\hline E1026-122 & ACE & 19 & DMA & 79 & $\mathrm{LiCl}$ & 2 & - & & TV & 75 & 25 & 15 & 2 & 95 & 5 & 1 \\
\hline E1026-131 & ACE & 19 & DMA & 79 & $\mathrm{LiCl}$ & 2 & 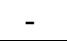 & & TV & 75 & 25 & 15 & 2 & 95 & 5 & 1 \\
\hline E1026-132 & $A C E$ & 19 & DMA & 79 & $\mathrm{Li}$ & 0 & 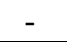 & & $\mathrm{T}$ & 75 & 25 & 15 & 2 & 95 & 5 & $\mathrm{I}$ \\
\hline E1026-211 & ACE & 19 & DMA & 79 & $\mathrm{Li}$ & 2 & - & & & 75 & 25 & 15 & & 95 & 3 & 1 \\
\hline E1026-212 & $I^{\prime}$ & 19 & D & 79 & $\mathrm{Li}$ & 2 & - & & & 75 & 25 & 15 & 4 & 95 & 3 & I \\
\hline E102 & & 19 & & 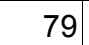 & $\mathrm{Li}$ & 2 & - & & & 75 & 25 & 15 & 21 & 95 & 3 & 1 \\
\hline E1026-222 & & 19 & DMA & 79 & $\mathrm{Li}$ & 2 & - & & & 15 & 25 & 15 & 2 & 95 & 3 & 1 \\
\hline E1026-223 & 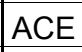 & 19 & DMA & 79 & $\mathrm{LiC}$ & 2 & - & & & 75 & 25 & 15 & 2 & 95 & 3 & 1 \\
\hline 1026-224 & & 19 & DN & 79 & $\mathrm{LiC}$ & 2 & - & & & & 25 & 15 & 4 & 95 & 3 & 1 \\
\hline 026-321 & $U E$ & 19 & DMA & 4 & $\mathrm{LiC}$ & 6 & - & & & & 25 & 15 & -1 & 95 & 10 & I \\
\hline 026-322 & ULE & 19 & DMA & 15 & $\mathrm{LiC}$ & 6 & - & & 1 & 15 & 25 & 15 & 2 & 95 & 10 & 1 \\
\hline $1026-323$ & $A C E$ & 19 & DMA & 75 & $\mathrm{LiCl}$ & 6 & - & & TV & 75 & 25 & 15 & 2 & 95 & 10 & I \\
\hline
\end{tabular}




\section{Tabla 62 (Continuación)}

\begin{tabular}{|c|c|c|c|c|c|c|c|c|c|c|c|c|c|c|c|c|}
\hline MEM & $P$ & $X P$ & $D$ & $X D$ & $A 1$ & $X A 1$ & $A 2$ & $X A 2$ & $S P$ & $E N$ & $T R E$ & TPE & $T R C$ & $T R T$ & $T P T$ & TTT \\
\hline E1026-331 & ACE & 19 & DMA & 75 & $\mathrm{LiCl}$ & 6 & - & & TV & 75 & 25 & 15 & 2 & 95 & 10 & I \\
\hline E1026-332 & $A C E$ & 19 & DMA & 75 & $\mathrm{LiCl}$ & 6 & - & & TV & 75 & 25 & 15 & 2 & 95 & 10 & $\mathrm{I}$ \\
\hline E1026-333 & $A C E$ & 19 & DMA & 75 & $\mathrm{LiCl}$ & 6 & - & & TV & 75 & 25 & 15 & 2 & 95 & 10 & I \\
\hline E1026-334 & ACE & 19 & DMA & 75 & $\mathrm{LiCl}$ & 6 & - & & TV & 75 & 25 & 15 & 2 & 95 & 10 & I \\
\hline E1026-411 & ACE & 19 & DMA & 75 & $\mathrm{LiCl}$ & 6 & - & & TV & 75 & 25 & 15 & 2 & 98 & 2 & 1 \\
\hline E1026-412 & ACE & 19 & DMA & 75 & $\mathrm{LiCl}$ & 6 & - & & TV & 75 & 25 & 15 & 2 & 98 & 2 & 1 \\
\hline E1026-413 & ACE & 19 & DMA & 75 & $\mathrm{LiCl}$ & 6 & - & & TV & 75 & 25 & 15 & 2 & 98 & 2 & I \\
\hline E1026-414 & $A C E$ & 19 & DMA & 75 & $\mathrm{LiCl}$ & 6 & - & & TV & 75 & 25 & 15 & 2 & 98 & 2 & 1 \\
\hline E1026-424 & $A C E$ & 19 & DMA & 75 & $\mathrm{LiCl}$ & 6 & - & & TV & 75 & 25 & 15 & 2 & 98 & 2 & I \\
\hline E1026-511 & ACE & 23 & DMA & 75 & $\mathrm{LiCl}$ & 2 & - & & TV & 75 & 25 & 15 & 3 & 97 & 2 & I \\
\hline E1026-512 & ACE & 23 & DMA & 75 & $\mathrm{LiCl}$ & 2 & - & & TV & 75 & 25 & 15 & 3 & 97 & 2 & I \\
\hline E1026-513 & ACE & 23 & DMA & 75 & $\mathrm{LiCl}$ & 2 & - & & TV & 75 & 25 & 15 & 3 & 97 & 2 & 1 \\
\hline E1026-514 & ACE & 23 & DMA & 75 & $\mathrm{LiCl}$ & 2 & - & & TV & 75 & 25 & 15 & 3 & 97 & 2 & I \\
\hline E1026-811 & $A C E$ & 19 & DMA & 79 & $\mathrm{LiCl}$ & 2 & - & & TV & 75 & 25 & 15 & 4 & 99 & 1 & I \\
\hline E1026-812 & ACE & 19 & DMA & 79 & $\mathrm{LiCl}$ & 2 & - & & TV & 75 & 25 & 15 & 4 & 99 & 1 & I \\
\hline E1026-813 & ACE & 19 & DMA & 79 & $\mathrm{LiCl}$ & 2 & - & & TV & 75 & 25 & 15 & 4 & 99 & 1 & 1 \\
\hline E1026-814 & ACE & 19 & DMA & 79 & $\mathrm{LiCl}$ & 2 & - & & TV & 75 & 25 & 15 & 4 & 99 & 1 & 1 \\
\hline E1029-1' & ACE & 19 & DMA & 79 & $\mathrm{LiCl}$ & 2 & - & & TV & 75 & 25 & 15 & 2 & 97 & 2 & 1 \\
\hline E1029-1" & ACE & 19 & DMA & 79 & $\mathrm{LiCl}$ & 2 & - & & TV & 75 & 25 & 15 & 2 & 97 & 2 & 1 \\
\hline \begin{tabular}{|l|} 
E1029-1"' \\
\end{tabular} & ACE & 19 & DMA & 79 & $\mathrm{LiCl}$ & 2 & - & & TV & 75 & 25 & 15 & 2 & 97 & 2 & I \\
\hline E1029-111 & ACE & 19 & DMA & 79 & $\mathrm{LiCl}$ & 2 & - & & TV & 75 & 25 & 15 & 2 & 97 & 2 & I \\
\hline E1029-112 & ACE & 19 & DMA & 79 & $\mathrm{LiCl}$ & 2 & - & & TV & 75 & 25 & 15 & 2 & 97 & 2 & 1 \\
\hline E1029-2' & ACE & 19 & DMA & 79 & $\mathrm{LiCl}$ & 2 & - & & TV & 75 & 25 & 15 & 2 & 97 & 3 & 1 \\
\hline E1029-2" & ACE & 19 & DMA & 79 & $\mathrm{LiCl}$ & 2 & - & & TV & 75 & 25 & 15 & 2 & 97 & 3 & 1 \\
\hline E1029-2"' & $A C E$ & 19 & DMA & 79 & $\mathrm{LiCl}$ & 2 & - & & TV & 75 & 25 & 15 & 2 & 97 & 3 & $\mathrm{I}$ \\
\hline E1029-211 & $A C E$ & 19 & DMA & 79 & $\mathrm{LiCl}$ & 2 & - & & TV & 75 & 25 & 15 & 2 & 97 & 3 & I \\
\hline E1029-3' & ACE & 19 & DMA & 79 & $\mathrm{LiCl}$ & 2 & - & & TV & 75 & 25 & 15 & 3 & 97 & 5 & 1 \\
\hline E1029-3" & ACE & 19 & DMA & 79 & $\mathrm{LiCl}$ & 2 & - & & TV & 75 & 25 & 15 & 3 & 97 & 5 & I \\
\hline E1029-3"' & ACE & 19 & DMA & 79 & $\mathrm{LiCl}$ & 2 & - & & TV & 75 & 25 & 15 & 3 & 97 & 5 & I \\
\hline E1029-311 & ACE & 19 & DMA & 79 & $\mathrm{LiCl}$ & 2 & - & & TV & 75 & 25 & 15 & 3 & 97 & 5 & I \\
\hline E1029-4' & ACE & 19 & DMA & 79 & $\mathrm{LiCl}$ & 2 & - & & TV & 75 & 25 & 15 & 4 & 90 & 15 & 1 \\
\hline E1029-4" & ACE & 19 & DMA & 79 & $\mathrm{LiCl}$ & 2 & - & & TV & 75 & 25 & 15 & 4 & 90 & 15 & I \\
\hline E1029-4"' & ACE & 19 & DMA & 79 & $\mathrm{LiCl}$ & 2 & - & & TV & 75 & 25 & 15 & 4 & 90 & 15 & 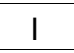 \\
\hline E1029-411 & ACE & 19 & DMA & 79 & $\mathrm{LiCl}$ & 2 & - & & TV & 75 & 25 & 15 & 4 & 90 & 15 & 1 \\
\hline E1029-5' & ACE & 19 & DMA & 79 & $\mathrm{LiCl}$ & 2 & - & & TV & 75 & 25 & 15 & 2 & 97 & 2 & I \\
\hline E1029-5" & ACE & 19 & DMA & 79 & $\mathrm{LiCl}$ & 2 & - & & TV & 75 & 25 & 15 & 2 & 98 & 3 & I \\
\hline E1029-5"' & ACE & 19 & DMA & 79 & $\mathrm{LiCl}$ & 2 & - & & TV & 75 & 25 & 15 & 2 & 99 & 4 & I \\
\hline E1029-511 & ACE & 19 & DMA & 79 & $\mathrm{LiCl}$ & 2 & - & & TV & 75 & 25 & 15 & 2 & 100 & 5 & 1 \\
\hline E1029-6' & ACE & 19 & DMA & 79 & $\mathrm{LiCl}$ & 2 & - & & TV & 75 & 25 & 15 & 2 & 95 & 10 & I \\
\hline E1029-6" & ACE & 19 & DMA & 79 & $\mathrm{LiCl}$ & 2 & - & & TV & 75 & 25 & 15 & 2 & 95 & 10 & I \\
\hline \begin{tabular}{|l|l} 
E1029-6"' \\
\end{tabular} & ACE & 19 & DMA & 79 & $\mathrm{LiCl}$ & 2 & - & & TV & 75 & 25 & 15 & 2 & 95 & 10 & 1 \\
\hline E1029-611 & ACE & 19 & DMA & 79 & $\mathrm{LiCl}$ & 2 & - & & TV & 75 & 25 & 15 & 2 & 95 & 10 & 1 \\
\hline E1029-612 & $A C E$ & 19 & DMA & 79 & $\mathrm{LiCl}$ & 2 & - & & TV & 75 & 25 & 15 & 2 & 95 & 10 & 1 \\
\hline E1029-613 & ACE & 19 & DMA & 79 & $\mathrm{LiCl}$ & 2 & - & & TV & 75 & 25 & 15 & 2 & 95 & 10 & I \\
\hline E1029-614 & ACE & 19 & DMA & 79 & $\mathrm{LiCl}$ & 2 & - & & TV & 75 & 25 & 15 & 2 & 95 & 10 & I \\
\hline E2109-11 & ACE & 19 & DMA & 78.5 & $\mathrm{LiCl}$ & 2 & $\mathrm{~T} 1$ & 0.5 & TV & 75 & 25 & 15 & 2 & 95 & 3 & 1 \\
\hline E2109-12 & ACE & 19 & DMA & 78.5 & $\mathrm{LiCl}$ & 2 & T1 & 0.5 & TV & 75 & 25 & 15 & 2 & 95 & 3 & 1 \\
\hline E2109-13 & ACE & 19 & DMA & 78.5 & $\mathrm{LiCl}$ & 2 & $\mathrm{~T} 1$ & 0.5 & TV & 75 & 25 & 15 & 2 & 95 & 3 & 1 \\
\hline
\end{tabular}




\section{Tabla 62 (Continuación)}

\begin{tabular}{|c|c|c|c|c|c|c|c|c|c|c|c|c|c|c|c|c|}
\hline MEM & $P$ & $X P$ & $D$ & $X D$ & A1 & $X A 1$ & A2 & $X A 2$ & $S P$ & $E N$ & $T R E$ & TPE & $T R C$ & $T R T$ & $T P T$ & TTT \\
\hline E2109-14 & ACE & 19 & DMA & 78.5 & $\mathrm{LiCl}$ & 2 & $\mathrm{~T} 1$ & 0.5 & TV & 75 & 25 & 15 & 2 & 95 & 3 & 1 \\
\hline E2109-2 & ACE & 19 & DMA & 78.5 & $\mathrm{LiCl}$ & 2 & $\mathrm{~T} 1$ & 0.5 & TV & 75 & 25 & 15 & 2 & 95 & 3 & 1 \\
\hline E2109-4 & ACE & 19 & DMA & 78.5 & $\mathrm{LiCl}$ & 2 & $\mathrm{~T} 1$ & 0.5 & TV & 75 & 25 & 15 & 2 & 95 & 3 & 1 \\
\hline E1104-1 & ACE & 19 & DMA & 79 & $\mathrm{LiCl}$ & 2 & & & TV & 75 & 25 & 15 & 2.5 & 95 & 15 & I \\
\hline E1104-2 & ACE & 19 & DMA & 79 & $\mathrm{LiCl}$ & 2 & & & TV & 75 & 25 & 15 & 2.5 & 93 & 15 & 1 \\
\hline E1104-3 & ACE & 19 & DMA & 79 & $\mathrm{LiCl}$ & 2 & & & TV & 75 & 25 & 15 & 3 & 93 & 20 & 1 \\
\hline E1105-1 & ACE & 19 & DMA & 75 & $\mathrm{LiCl}$ & 6 & & & TV & 75 & 25 & 15 & 4 & 95 & 3 & 1 \\
\hline E1105-2 & ACE & 19 & DMA & 75 & $\mathrm{LiCl}$ & 6 & & & TV & 75 & 25 & 15 & 2.5 & 95 & 2 & I \\
\hline E1105-3 & ACE & 19 & DMA & 75 & $\mathrm{LiCl}$ & 6 & & & TV & 75 & 25 & 15 & 2.5 & 95 & 3 & 1 \\
\hline E1105-4 & ACE & 19 & DMA & 75 & $\mathrm{LiCl}$ & 6 & & & TV & 75 & 25 & 15 & 2 & 95 & 4 & I \\
\hline E1105-5 & ACE & 19 & DMA & 75 & $\mathrm{LiCl}$ & 6 & & & TV & 75 & 25 & 15 & 2 & 95 & 5 & 1 \\
\hline E1109-11 & ACE & 19 & DMA & 78.5 & $\mathrm{LiCl}$ & 2 & T1 & 0.5 & TV & 75 & 25 & 15 & 2 & 95 & 3 & 1 \\
\hline E1109-12 & ACE & 19 & DMA & 78.5 & $\mathrm{LiCl}$ & 2 & $\mathrm{~T} 1$ & 0.5 & TV & 75 & 25 & 15 & 2 & 95 & 3 & 1 \\
\hline E1109-21 & ACE & 19 & DMA & 78.5 & $\mathrm{LiCl}$ & 2 & $\mathrm{TX}$ & 0.5 & TV & 75 & 25 & 15 & 2.5 & 95 & 3 & 1 \\
\hline E1109-22 & ACE & 19 & DMA & 78.5 & $\mathrm{LiCl}$ & 2 & $T X$ & 0.5 & TV & 75 & 25 & 15 & 2.5 & 95 & 3 & 1 \\
\hline E1109-31 & ACE & 19 & DMA & 78.5 & $\mathrm{LiCl}$ & 2 & $\mathrm{~T} 1$ & 0.5 & TV & 75 & 25 & 15 & 2 & 95 & 2 & I \\
\hline E1109-32 & ACE & 19 & DMA & 78.5 & $\mathrm{LiCl}$ & 2 & $\mathrm{~T} 1$ & 0.5 & TV & 75 & 25 & 15 & 2 & 95 & 2 & I \\
\hline E1109-41 & ACE & 19 & DMA & 78.5 & $\mathrm{LiCl}$ & 2 & $\mathrm{~T} 1$ & 0.5 & TV & 75 & 25 & 15 & 3 & 95 & 5 & I \\
\hline E1109-42 & ACE & 19 & DMA & 78.5 & $\mathrm{LiCl}$ & 2 & $\mathrm{~T} 1$ & 0.5 & TV & 75 & 25 & 15 & 3 & 95 & 5 & I \\
\hline E1109-51 & ACE & 19 & DMA & 78.5 & $\mathrm{LiCl}$ & 2 & $\mathrm{~T} 1$ & 0.5 & F02 & 75 & 25 & 15 & 3.5 & 95 & 3 & 1 \\
\hline E1109-52 & ACE & 19 & DMA & 78.5 & $\mathrm{LiCl}$ & 2 & $\mathrm{~T} 1$ & 0.5 & F02 & 75 & 25 & 15 & 3.5 & 95 & 3 & 1 \\
\hline E1109-61 & ACE & 19 & DMA & 79 & $\mathrm{LiCl}$ & 2 & $\mathrm{~T} 1$ & & F02 & 75 & 25 & 15 & 2.5 & 95 & 4 & I \\
\hline E1109-62 & ACE & 19 & DMA & 79 & $\mathrm{LiCl}$ & 2 & $\mathrm{~T} 1$ & & F02 & 75 & 25 & 15 & 2.5 & 95 & 4 & 1 \\
\hline E1109-71 & ACE & 19 & DMA & 79 & $\mathrm{LiCl}$ & 2 & $\mathrm{TX}$ & & F02 & 75 & 25 & 15 & 2 & 95 & 4 & 1 \\
\hline E1109-72 & ACE & 19 & DMA & 79 & $\mathrm{LiCl}$ & 2 & $\mathrm{TX}$ & & F02 & 75 & 25 & 15 & 2 & 95 & 4 & I \\
\hline
\end{tabular}


Tabla 63. Resultados de caracterización en planta para las membranas que utilizan como polímero base AC3 (CA-398-3)

\begin{tabular}{|c|c|c|c|c|c|c|c|c|c|c|c|c|c|c|c|c|c|}
\hline MEM & $M O D$ & $F 10$ & $R 10$ & A10 & $B 10$ & F20 & $R 20$ & A20 & $B 20$ & F30 & R30 & A30 & B30 & F40 & $R 40$ & $A 40$ & $B 40$ \\
\hline $30511-1 \mathrm{~A}$ & $P$ & & & & & & & & & & & & & 1902 & 5.0 & 48 & 361 \\
\hline $30511-1 \mathrm{~B}$ & $P$ & & & & & & & & & & & & & 1834 & 6.7 & 46 & 255 \\
\hline $30511-2 A$ & $P$ & & & & & & & & & & & & & 3789 & 12.3 & 95 & 270 \\
\hline $30511-2 B$ & $P$ & & & & & & & & & & & & & 3952 & 12.5 & 99 & 277 \\
\hline $30511-3 A$ & $P$ & & & & & & & & & & & & & 2037 & 15.4 & 51 & 112 \\
\hline $30511-3 B$ & $P$ & & & & & & & & & & & & & 3574 & 12.0 & 90 & 262 \\
\hline $30511-4 A$ & $P$ & & & & & & & & & & & & & 3125 & 10.1 & 78 & 278 \\
\hline $30511-4 B$ & $P$ & & & & & & & & & & & & & 2456 & 12.8 & 62 & 167 \\
\hline $30512-01$ & $P$ & & & & & & & & & & & & & 1628 & 4.3 & 41 & 367 \\
\hline $30512-02$ & $P$ & & & & & & & & & & & & & 1698 & 3.8 & 43 & 430 \\
\hline $30512-03$ & $P$ & & & & & & & & & & & & & 86 & 16.5 & 2 & 4 \\
\hline $30512-04$ & $P$ & & & & & & & & & & & & & 53.2 & 27.7 & 1 & 1 \\
\hline $30512-05$ & $P$ & & & & & & & & & & & & & 1775 & 5.2 & 44 & 324 \\
\hline $30512-06$ & $P$ & & & & & & & & & & & & & 1859 & 2.6 & 47 & 696 \\
\hline 30514-01 & $P$ & 2456 & 5.8 & 165 & 400 & & & & & & & & & 3200 & 9.8 & 80 & 295 \\
\hline $30514-02$ & $P$ & 2392 & 4.7 & 241 & 485 & & & & & & & & & 3481 & 10.4 & 87 & 301 \\
\hline 30514-03 & $P$ & 2670 & 3.5 & 269 & 736 & & & & & & & & & 4105 & 11.3 & 103 & 322 \\
\hline $30514-04$ & $P$ & 2523 & 7.1 & 255 & 331 & & & & & & & & & 4367 & 11.1 & 110 & 350 \\
\hline 30514-05 & $P$ & 2501 & 7.1 & 253 & 329 & & & & & & & & & 3719 & 6.4 & 93 & 541 \\
\hline $30514-07$ & $P$ & 2750 & 3.5 & 277 & 750 & & & & & & & & & 3929 & 6.2 & 98 & 596 \\
\hline 30514-08 & $P$ & 3057 & 3.1 & 307 & 966 & & & & & & & & & 4585 & 5.9 & 115 & 726 \\
\hline $30518-01$ & $P$ & 393 & 14.3 & 26.6 & 23.6 & & & & & & & & & & & & \\
\hline $30518-02$ & $P$ & 3711 & 9.2 & 377 & 366 & & & & & & & & & & & & \\
\hline 30518-03 & $P$ & 232 & 22.9 & 24.1 & 7.8 & & & & & & & & & & & & \\
\hline $30518-04$ & $P$ & 164 & 26.0 & 17.2 & 4.7 & & & & & & & & & & & & \\
\hline 30518-05 & $P$ & 3809 & 6.0 & 385 & 597 & & & & & & & & & & & & \\
\hline 30518-06 & $P$ & 3619 & 6.0 & 366 & 567 & & & & & & & & & & & & \\
\hline $30518-07$ & $P$ & 3048 & 6.2 & 308 & 461 & & & & & & & & & & & & \\
\hline $30518-08$ & $P$ & 3913 & 5.5 & 395 & 672 & & & & & & & & & & & & \\
\hline 30518-2' & $P$ & 209 & 18.5 & 21.6 & 9.2 & & & & & & & & & & & & \\
\hline $30519-01$ & $P$ & 890 & 27.0 & 61.2 & 24.1 & & & & & 1626 & 29.6 & 55.1 & 38.7 & & & & \\
\hline $30519-02$ & $P$ & 864 & 28.0 & 90.7 & 22.2 & & & & & 1556 & 32.6 & 52.8 & 32.2 & & & & \\
\hline $30519-03$ & $P$ & 3289 & 16.0 & 338 & 173 & & & & & 3327 & 13.4 & 112 & 215 & & & & \\
\hline $30519-04$ & $P$ & 2496 & 14.6 & 256 & 146 & & & & & 2984 & 10.4 & 100 & 257 & & & & \\
\hline $30519-05$ & $P$ & 2210 & 18.8 & 228 & 95.5 & & & & & 2585 & 18.3 & 87.1 & 115 & & & & \\
\hline $30519-06$ & $P$ & 2706 & 17.0 & 279 & 132 & & & & & 2924 & 16.7 & 98.4 & 146 & & & & \\
\hline $30519-07$ & $P$ & 1905 & 19.7 & 197 & 77.7 & & & & & 2113 & 21.0 & 71.3 & 79.5 & & & & \\
\hline $30519-08$ & $P$ & 2193 & 17.4 & 226 & 104 & & & & & 2210 & 16.7 & 74.4 & 110 & & & & \\
\hline $30522-01$ & $P$ & 1884 & 8.5 & 191 & 203 & & & & & & & & & & & & \\
\hline $30522-02$ & $P$ & 2053 & 7.2 & 208 & 266 & & & & & & & & & & & & \\
\hline 30522-03 & $P$ & 2724 & 6.6 & 275 & 384 & & & & & & & & & & & & \\
\hline $30522-04$ & $P$ & 2927 & 6.4 & 296 & 430 & & & & & & & & & & & & \\
\hline $30522-05$ & $P$ & 3199 & 7.4 & 324 & 399 & & & & & & & & & & & & \\
\hline $30522-06$ & $P$ & 3396 & 6.1 & 343 & 523 & & & & & & & & & & & & \\
\hline $30528-01$ & $P$ & 281 & 10.2 & 28.6 & 24.6 & 640 & 13.2 & 32 & 42 & & & & & & & & \\
\hline $30528-04$ & $P$ & 7435 & 3.4 & 748 & 2105 & 3987 & 8.3 & 201 & 440 & & & & & & & & \\
\hline
\end{tabular}




\section{Tabla 63 (continuación)}

\begin{tabular}{|c|c|c|c|c|c|c|c|c|c|c|c|c|c|c|c|c|c|}
\hline MEM & $M O D$ & F10 & $R 10$ & $A 10$ & $B 10$ & $F 20$ & $R 20$ & A20 & $B 20$ & F30 & R30 & A30 & B30 & $F 40$ & $R 40$ & A40 & $B 40$ \\
\hline $30528-05$ & $P$ & 7054 & 2.1 & 708 & 3289 & 3236 & 7.8 & 163 & 383 & & & & & & & & \\
\hline 30528-06 & $P$ & 899 & 3.3 & 90.4 & 263 & 1786 & 7.5 & 90 & 219 & & & & & & & & \\
\hline $30528-07$ & $P$ & 1487 & 3.4 & 150 & 421 & 1196 & 6.8 & 60 & 165 & & & & & & & & \\
\hline $30529-02$ & $P$ & 2751 & 3.7 & 277 & 715 & & & & & & & & & & & & \\
\hline 30529-03 & $P$ & 1647 & 3.2 & 166 & 502 & & & & & & & & & & & & \\
\hline 30529-04 & $P$ & 1342 & 2.6 & 135 & 494 & & & & & & & & & & & & \\
\hline 30529-05 & $P$ & 2645 & 2.6 & 266 & 973 & & & & & & & & & & & & \\
\hline 30529-06 & $P$ & 2331 & 4.2 & 235 & 527 & & & & & & & & & & & & \\
\hline $30529-07$ & $P$ & 1688 & 5.0 & 170 & 319 & & & & & & & & & & & & \\
\hline 30529-08 & $P$ & 2100 & 3.4 & 211 & 590 & & & & & & & & & & & & \\
\hline $30615-07$ & $P$ & & & & & 2319 & 15.2 & 117 & 129 & 3048 & 26.0 & 103 & 86.8 & 2202 & 34.9 & 56 & 41 \\
\hline $30615-08$ & $P$ & & & & & 1937 & 19.6 & 98.5 & 79.5 & 2796 & 32.0 & 94.9 & 59.4 & 2420 & 42.0 & 62 & 33 \\
\hline 30703-01 & $P$ & 664 & 16.8 & 68.4 & 32.9 & 1163 & 34.0 & 59.9 & 22.6 & 1494 & 48.9 & 51.2 & 15.6 & 1684 & 61.4 & 43 & 11 \\
\hline 30703-02 & $P$ & 328 & 35.2 & 34.9 & 6.0 & 650 & 57.5 & 34.2 & 4.8 & 959 & 71.7 & 33.3 & 3.8 & 1349 & 79.3 & 35 & 4 \\
\hline 30703-03 & $P$ & 663 & 16.3 & 68.1 & 34.0 & 1209 & 35.8 & 62.3 & 21.7 & 1579 & 52.4 & 54.2 & 14.3 & 2102 & 64.3 & 54 & 12 \\
\hline 30703-04 & $P$ & 267 & 34.9 & 28.4 & 5.0 & 574 & 58.1 & 30.2 & 4.1 & 842 & 73.1 & 29.3 & 3.1 & 1229 & 81.2 & 32 & 3 \\
\hline $30705-01$ & $P$ & & & & & & & & & & & & & 5331 & 11.2 & 134 & 423 \\
\hline $30705-02$ & $P$ & & & & & & & & & & & & & 5394 & 13.4 & 136 & 350 \\
\hline $30705-03$ & $P$ & & & & & & & & & & & & & 423 & 20.6 & 11 & 16 \\
\hline $30705-04$ & $P$ & & & & & & & & & & & & & 308 & 26.4 & 8 & 9 \\
\hline 30705-05 & $P$ & & & & & & & & & & & & & 375 & 39.5 & 10 & 6 \\
\hline $30705-06$ & $P$ & & & & & & & & & & & & & 320 & 15.0 & 8 & 18 \\
\hline $30705-07$ & $P$ & 2771 & 2.4 & 278 & 1127 & 3763 & 10.2 & 190 & 331 & 3763 & 16.8 & 127 & 186 & 3908 & 22.7 & 99 & 133 \\
\hline $30705-08$ & $P$ & 3110 & 1.2 & 312 & 2561 & 4119 & 7.5 & 207 & 508 & 3958 & 13.2 & 133 & 260 & 4064 & 18.6 & 102 & 178 \\
\hline 30705-09 & $P$ & 2605 & 2.5 & 262 & 1016 & 3586 & 9.9 & 181 & 326 & 3586 & 16.2 & 121 & 185 & 3672 & 22.4 & 93 & 127 \\
\hline $30705-10$ & $P$ & 2583 & 2.8 & 260 & 897 & 3586 & 10.3 & 181 & 312 & 3544 & 17.1 & 119 & 172 & 3586 & 23.3 & 91 & 118 \\
\hline $30705-2 A$ & $P$ & & & & & & & & & & & & & 3920 & 8.6 & 98 & 417 \\
\hline $30705-2 B$ & $P$ & & & & & & & & & & & & & 3930 & 10.1 & 99 & 350 \\
\hline $30705-3 \mathrm{~A}$ & $P$ & & & & & & & & & & & & & 4550 & 9.6 & 114 & 428 \\
\hline 30705-3B & $P$ & & & & & & & & & & & & & 4106 & 10.4 & 103 & 354 \\
\hline $30705-4 \mathrm{~A}$ & $P$ & & & & & & & & & & & & & 1704 & 14.4 & 43 & 101 \\
\hline 30705-4B & $P$ & & & & & & & & & & & & & 2259 & 10.1 & 57 & 201 \\
\hline 30717-01 & $P$ & 124 & 59.4 & 13.8 & 0.9 & 215 & 78.8 & 11.5 & 0.58 & 431 & 79.9 & 15.1 & 1.1 & 668 & 76.7 & 17 & 2 \\
\hline $30717-02$ & $P$ & 187 & 58.2 & 20.7 & 1.3 & 349 & 78.2 & 18.7 & 0.97 & 629 & 83.6 & 22.0 & 1.2 & 894 & 76.7 & 23 & 3 \\
\hline $30717-03$ & $P$ & 57.5 & 89.0 & 6.8 & 0.1 & 141 & 93.4 & 7.6 & 0.10 & 259 & 94.6 & 9.1 & 0.1 & 406 & 94.9 & 11 & 0 \\
\hline $30717-04$ & $P$ & 284 & 40.8 & 30.5 & 4.1 & 446 & 66.9 & 23.6 & 2.20 & 786 & 75.8 & 27.4 & 2.5 & 1077 & 81.2 & 28 & 2 \\
\hline $30717-05$ & $P$ & 332 & 34.4 & 35.2 & 6.3 & 551 & 62.6 & 29.1 & 3.29 & 947 & 74.3 & 32.9 & 3.3 & 1308 & 80.8 & 34 & 3 \\
\hline $30717-06$ & $P$ & 274 & 41.4 & 29.4 & 3.9 & 468 & 68.4 & 24.9 & 2.16 & 821 & 78.8 & 28.6 & 2.2 & 1146 & 84.1 & 30 & 2 \\
\hline $30717-07$ & $P$ & 926 & 15.3 & 95.1 & 51.3 & 1172 & 35.8 & 60.4 & 21.0 & 1825 & 49.6 & 62.6 & 18.5 & 2292 & 58.9 & 59 & 16 \\
\hline $30717-08$ & $P$ & 1458 & 10.5 & 148 & 124 & 1693 & 26.8 & 86.6 & 46.2 & 2400 & 37.7 & 81.7 & 39.7 & 2849 & 44.5 & 73 & 36 \\
\hline 30717-09 & $P$ & 656 & 18.5 & 67.7 & 28.9 & 913 & 41.5 & 47.3 & 12.9 & 1502 & 56.1 & 51.7 & 11.8 & 1929 & 64.9 & 50 & 10 \\
\hline $30717-10$ & $P$ & 623 & 18.5 & 64.4 & 27.5 & 849 & 43.6 & 44.1 & 11.0 & 1424 & 57.2 & 49.1 & 10.7 & 1836 & 65.4 & 47 & 10 \\
\hline $30721-01$ & $P$ & 348 & 20.6 & 36.0 & 13.4 & 717 & 48.3 & 37.4 & 7.68 & 1037 & 64.3 & 35.9 & 5.8 & 1516 & 73.4 & 39 & 5 \\
\hline $30721-02$ & $P$ & 608 & 14.9 & 62.4 & 34.7 & 1117 & 35.2 & 57.6 & 20.6 & 1431 & 51.0 & 49.1 & 13.7 & 1941 & 61.8 & 50 & 12 \\
\hline $30721-03$ & $P$ & 183 & 39.1 & 19.6 & 2.9 & 441 & 66.1 & 23.4 & 2.26 & 682 & 79.0 & 23.8 & 1.8 & 1077 & 84.4 & 28 & 2 \\
\hline $30721-04$ & $P$ & 179 & 36.4 & 19.0 & 3.1 & 437 & 63.4 & 23.1 & 2.52 & 682 & 77.0 & 23.8 & 2.0 & 1093 & 82.2 & 28 & 2 \\
\hline 30721-05 & $P$ & 190 & 38.7 & 20.3 & 3.0 & 427 & 66.7 & 22.6 & 2.13 & 657 & 79.5 & 22.9 & 1.7 & 1070 & 84.8 & 28 & 2 \\
\hline $30721-06$ & $P$ & 499 & 18.7 & 51.5 & 21.7 & 891 & 41.5 & 46.2 & 12.6 & 1172 & 57.6 & 40.4 & 8.6 & 1666 & 67.1 & 43 & 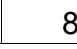 \\
\hline
\end{tabular}


Tabla 63 (continuación)

\begin{tabular}{|c|c|c|c|c|c|c|c|c|c|c|c|c|c|c|c|c|c|}
\hline MEM & $M O D$ & F10 & $R 10$ & A10 & $B 10$ & $F 20$ & $R 20$ & A2O & $B 20$ & $F 30$ & R30 & A30 & B30 & $F 40$ & $R 40$ & A40 & $B 40$ \\
\hline $30721-07$ & $P$ & 512 & 21.5 & 53.2 & 18.7 & 983 & 44.2 & 51.1 & 12.4 & 1286 & 60.2 & 44.4 & 8.5 & 1893 & 69.7 & 49 & 8 \\
\hline 30721-08 & $P$ & 285 & 31.3 & 30.1 & 6.3 & 591 & 55.8 & 31.0 & 4.68 & 847 & 70.4 & 29.4 & 3.6 & 1260 & 76.5 & 33 & 4 \\
\hline $30721-09$ & $P$ & 847 & 16.8 & 87.2 & 41.9 & 1343 & 34.6 & 69.2 & 25.4 & 1684 & 48.1 & 57.7 & 18.2 & 2628 & 46.3 & 67 & 30 \\
\hline $30721-10$ & $P$ & 580 & 21.5 & 60.1 & 21.2 & 1034 & 38.8 & 53.5 & 16.3 & 1386 & 49.2 & 47.5 & 14.3 & 2796 & 36.9 & 71 & 48 \\
\hline $30805-1 \mathrm{~A}$ & $P$ & & & & & & & & & & & & & 428 & 43.0 & 11 & 6 \\
\hline $30805-1 \mathrm{~B}$ & $P$ & & & & & & & & & & & & & 515 & \begin{tabular}{|l|}
55.4 \\
\end{tabular} & 13 & 4 \\
\hline $30922-11$ & $C$ & & & & & & & & & 102 & 71.4 & 3.5 & 0.4 & & & & \\
\hline $30922-12$ & $C$ & & & & & & & & & 102 & 78.6 & 3.6 & 0.3 & & & & \\
\hline $30922-13$ & $C$ & & & & & & & & & 127 & 77.3 & 4.4 & 0.4 & & & & \\
\hline $30922-14$ & $C$ & & & & & & & & & 52 & 81.9 & 1.8 & 0.1 & & & & \\
\hline 30923-01 & $C$ & & & & & & & & & 98.8 & 75.1 & 3.4 & 0.3 & & & & \\
\hline 30923-02 & $C$ & & & & & & & & & 46.1 & 71.2 & 1.6 & 0.2 & & & & \\
\hline 30923-03 & $C$ & & & & & & & & & 138 & 82.1 & 4.8 & 0.3 & & & & \\
\hline 30923-04 & $C$ & & & & & & & & & 55 & 71.8 & 1.9 & 0.2 & & & & \\
\hline $30923-05$ & C & & & & & & & & & 111 & 56.2 & 3.8 & 0.9 & & & & \\
\hline 30924-01 & $C$ & & & & & & & & & 27 & 72.5 & 0.9 & 0.1 & & & & \\
\hline $30924-02$ & $C$ & & & & & & & & & 96 & 78.0 & 3.3 & 0.3 & & & & \\
\hline $30924-03$ & $C$ & & & & & & & & & 114 & 53.7 & 3.9 & 1.0 & & & & \\
\hline 30924-04 & $C$ & & & & & & & & & 99 & 46.3 & 3.4 & 1.1 & & & & \\
\hline 30924-05 & $C$ & & & & & & & & & 46 & 53.7 & 1.6 & 0.4 & & & & \\
\hline 30924-06 & $C$ & & & & & & & & & 65 & 67.6 & 2.3 & 0.3 & & & & \\
\hline 30924-07 & $C$ & & & & & & & & & 65 & 76.2 & 2.3 & 0.2 & & & & \\
\hline 30924-08 & $C$ & & & & & & & & & 169 & 21.4 & 5.7 & 6.2 & & & & \\
\hline 31001-111 & $C$ & & & & & & & & & 275 & 90.1 & 9.7 & 0.3 & & & & \\
\hline $31001-112$ & $C$ & & & & & & & & & 469 & 92.6 & 16.5 & 0.4 & & & & \\
\hline $31001-113$ & $C$ & & & & & & & & & 692 & 74.2 & 24.1 & 2.4 & & & & \\
\hline $31001-114$ & $C$ & & & & & & & & & 969 & 57.1 & 33.4 & 7.3 & & & & \\
\hline $31001-121$ & $C$ & & & & & & & & & 430 & 88.5 & 15.1 & 0.6 & & & & \\
\hline $31001-122$ & $C$ & & & & & & & & & 806 & 71.8 & 28.0 & 3.2 & & & & \\
\hline $31001-123$ & $C$ & & & & & & & & & 448 & 76.6 & 15.6 & 1.4 & & & & \\
\hline $31001-124$ & $C$ & & & & & & & & & 322 & 85.6 & 11.3 & 0.5 & & & & \\
\hline $31001-131$ & C & & & & & & & & & 94 & 89.0 & 3.3 & 0.1 & & & & \\
\hline $31001-132$ & $C$ & & & & & & & & & 208 & 77.4 & 7.3 & 0.6 & & & & \\
\hline $31001-133$ & $C$ & & & & & & & & & 549 & 58.0 & 18.9 & 4.0 & & & & \\
\hline 31001-134 & $C$ & & & & & & & & & 309 & 72.5 & 10.7 & 1.2 & & & & \\
\hline $31001-211$ & $C$ & & & & & & & & & 509 & 82.6 & 17.8 & 1.1 & & & & \\
\hline $31001-213$ & $C$ & & & & & & & & & 968 & 55.0 & 33.3 & 7.9 & & & & \\
\hline 31001-214 & $C$ & & & & & & & & & 1295 & 20.8 & 43.7 & 49.3 & & & & \\
\hline $31001-221$ & $C$ & & & & & & & & & 56 & 73.1 & 1.9 & 0.2 & & & & \\
\hline $31001-222$ & $C$ & & & & & & & & & 158 & 74.1 & 5.5 & 0.6 & & & & \\
\hline 31001-223 & $C$ & & & & & & & & & 445 & 73.5 & 15.5 & 1.6 & & & & \\
\hline $31001-224$ & $C$ & & & & & & & & & 439 & 78.1 & 15.3 & 1.2 & & & & \\
\hline $31001-231$ & $C$ & & & & & & & & & 902 & 17.8 & 30.4 & 41.7 & & & & \\
\hline $31001-232$ & $C$ & & & & & & & & & 537 & 82.2 & 18.8 & 1.2 & & & & \\
\hline $31001-233$ & $C$ & & & & & & & & & 141 & 72.5 & 4.9 & 0.5 & & & & \\
\hline $31001-234$ & $C$ & & & & & & & & & 1490 & 32.7 & 50.6 & 30.7 & & & & \\
\hline $31001-311$ & $C$ & & & & & & & & & 370 & 42.8 & 12.6 & 4.9 & & & & \\
\hline $31001-312$ & $C$ & & & & & & & & & 355 & 89.0 & 12.5 & 0.4 & & & & \\
\hline $31001-313$ & $C$ & & & & & & & & & 407 & 89.9 & 14.3 & 0.5 & & & & \\
\hline
\end{tabular}


Tabla 63 (continuación)

\begin{tabular}{|c|c|c|c|c|c|c|c|c|c|c|c|c|c|c|c|c|c|}
\hline MEM & $M O D$ & F10 & $R 10$ & A10 & $B 10$ & F2O & $R 20$ & A20 & $B 20$ & F30 & R30 & A30 & B30 & $F 40$ & $R 40$ & A40 & B4O \\
\hline $31001-314$ & $C$ & & & & & & & & & 525 & 65.4 & 18.2 & 2.8 & & & & \\
\hline $31001-321$ & C & & & & & & & & & 284 & 93.0 & 10.0 & 0.2 & & & & \\
\hline $31001-322$ & $C$ & & & & & & & & & 407 & 69.0 & 14.1 & 1.8 & & & & \\
\hline 31001-323 & $C$ & & & & & & & & & 292 & 90.1 & 10.3 & 0.3 & & & & \\
\hline $31001-324$ & $C$ & & & & & & & & & 296 & 41.9 & 10.1 & 4.1 & & & & \\
\hline 31001-331 & $C$ & & & & & & & & & 235 & 89.1 & 8.2 & 0.3 & & & & \\
\hline $31001-332$ & $C$ & & & & & & & & & 384 & 36.2 & \begin{tabular}{|l|}
13.1 \\
\end{tabular} & 6.8 & & & & \\
\hline $31001-333$ & $C$ & & & & & & & & & 449 & 51.4 & 15.4 & 4.2 & & & & \\
\hline 31001-334 & $C$ & & & & & & & & & 202 & \begin{tabular}{|l|}
91.2 \\
\end{tabular} & 7.1 & 0.2 & & & & \\
\hline 31006-111 & $C$ & & & & & & & & & 433 & 91.1 & \begin{tabular}{|l|}
15.2 \\
\end{tabular} & 0.4 & & & & \\
\hline $31006-112$ & $C$ & & & & & & & & & 497 & 87.3 & 17.4 & 0.7 & & & & \\
\hline $31006-113$ & $C$ & & & & & & & & & 242 & 97.6 & 8.5 & 0.1 & & & & \\
\hline 31006-114 & $C$ & & & & & & & & & 301 & 95.2 & 10.6 & 0.2 & & & & \\
\hline $31006-121$ & $C$ & & & & & & & & & 240 & 91.1 & 8.4 & 0.2 & & & & \\
\hline 31006-122 & $C$ & & & & & & & & & 1788 & 24.6 & \begin{tabular}{|l|}
60.4 \\
\end{tabular} & 54.8 & & & & \\
\hline 31006-123 & $C$ & & & & & & & & & 407 & 85.8 & 14.3 & 0.7 & & & & \\
\hline $31006-124$ & $C$ & & & & & & & & & 591 & 79.5 & 20.6 & 1.5 & & & & \\
\hline 31006-131 & $C$ & & & & & & & & & 1483 & 29.8 & 50.3 & 34.9 & & & & \\
\hline $31006-132$ & $C$ & & & & & & & & & 270 & 92.3 & 9.5 & 0.2 & & & & \\
\hline $31006-133$ & $C$ & & & & & & & & & 287 & 91.5 & 10.1 & 0.3 & & & & \\
\hline 31006-134 & $C$ & & & & & & & & & 472 & 88.2 & \begin{tabular}{|l|}
16.6 \\
\end{tabular} & 0.6 & & & & \\
\hline $31006-221$ & $C$ & & & & & & & & & 77 & 72.6 & 2.7 & 0.3 & & & & \\
\hline $31006-222$ & $C$ & & & & & & & & & \begin{tabular}{|l|}
63.7 \\
\end{tabular} & 93.9 & 2.2 & 0.0 & & & & \\
\hline $31006-223$ & $C$ & & & & & & & & & 54 & 92.6 & 1.9 & 0.0 & & & & \\
\hline $31006-224$ & $C$ & & & & & & & & & \begin{tabular}{|l|}
69.4 \\
\end{tabular} & 85.8 & 2.4 & 0.1 & & & & \\
\hline $31006-231$ & $C$ & & & & & & & & & 102 & 85.9 & 3.6 & 0.2 & & & & \\
\hline $31006-232$ & $C$ & & & & & & & & & 127 & 92.0 & 4.5 & 0.1 & & & & \\
\hline $31006-233$ & $C$ & & & & & & & & & 76 & 89.9 & 2.7 & 0.1 & & & & \\
\hline 31006-234 & $C$ & & & & & & & & & 76 & 90.8 & 2.7 & 0.1 & & & & \\
\hline $31006-411$ & $C$ & & & & & & & & & 441 & \begin{tabular}{|l|}
63.6 \\
\end{tabular} & \begin{tabular}{|l|}
15.2 \\
\end{tabular} & 2.5 & & & & \\
\hline $31006-412$ & $C$ & & & & & & & & & 264 & 79.5 & 9.2 & 0.7 & & & & \\
\hline 31006-413 & $C$ & & & & & & & & & 235 & 90.4 & 8.3 & 0.2 & & & & \\
\hline $31006-414$ & $C$ & & & & & & & & & 250 & 72.8 & 8.7 & 0.9 & & & & \\
\hline $31006-421$ & $C$ & & & & & & & & & 198 & 75.4 & 6.9 & 0.6 & & & & \\
\hline $31006-422$ & $C$ & & & & & & & & & 283 & 94.0 & 10.0 & 0.2 & & & & \\
\hline $31006-423$ & $C$ & & & & & & & & & 177 & 86.1 & 6.2 & 0.3 & & & & \\
\hline $31006-424$ & $C$ & & & & & & & & & 281 & 74.9 & 9.8 & 0.9 & & & & \\
\hline $31006-511$ & $C$ & & & & & & & & & 485 & 84.0 & \begin{tabular}{|l|}
17.0 \\
\end{tabular} & 0.9 & & & & \\
\hline $31006-512$ & $C$ & & & & & & & & & 426 & 91.9 & 15.0 & 0.4 & & & & \\
\hline $31006-513$ & $C$ & & & & & & & & & 485 & 91.3 & 17.0 & 0.5 & & & & \\
\hline $31006-514$ & $C$ & & & & & & & & & 334 & 96.4 & \begin{tabular}{|l|}
11.8 \\
\end{tabular} & 0.1 & & & & \\
\hline $31006-521$ & $C$ & & & & & & & & & 402 & 95.5 & \begin{tabular}{|l|}
14.2 \\
\end{tabular} & 0.2 & & & & \\
\hline $31006-522$ & $C$ & & & & & & & & & 577 & 84.7 & 20.2 & 1.0 & & & & \\
\hline $31006-523$ & $C$ & & & & & & & & & 318 & 92.4 & $\mid 11.2$ & 0.3 & & & & \\
\hline $31006-524$ & $C$ & & & & & & & & & 284 & 92.1 & 10.0 & 0.2 & & & & \\
\hline $31006-611$ & $C$ & & & & & & & & & 2063 & 36.7 & \begin{tabular}{|l|}
70.2 \\
\end{tabular} & 35.6 & & & & \\
\hline $31006-612$ & $C$ & & & & & & & & & 1920 & 30.7 & 65.1 & \begin{tabular}{|l|}
43.3 \\
\end{tabular} & & & & \\
\hline $31006-613$ & $C$ & & & & & & & & & 1834 & 20.2 & 61.8 & 72.5 & & & & \\
\hline
\end{tabular}




\begin{tabular}{|c|c|c|c|c|c|c|c|c|c|c|c|c|c|c|c|c|c|}
\hline MEM & MOD & $F 10$ & $R 10$ & $A 10$ & B10 & F20 & R20 & $A 20$ & B20 & $F 30$ & $R 30$ & $A 30$ & B30 & F40 & $R 40$ & $A 40$ & $B 40$ \\
\hline $31006-614$ & $C$ & & & & & & & & & 1131 & 23.7 & 38.2 & 36.4 & & & & \\
\hline $31006-714$ & $C$ & & & & & & & & & 4584 & 6.1 & 153 & 706 & & & & \\
\hline
\end{tabular}

Tabla 64. Resultados de caracterización en planta para las membranas que utilizan como polímero base AC6 (CA-398-6)

\begin{tabular}{|c|c|c|c|c|c|c|c|c|c|c|c|c|c|c|c|c|c|}
\hline MEM & $O D$ & F10 & $R 10$ & A10 & B10 & $F 20$ & $R 20$ & A20 & $B 20$ & F30 & R30 & A30 & B30 & $F 40$ & R40 & A40 & $B 40$ \\
\hline & $P$ & 8 & & & & & & & & & & & & & & & \\
\hline & $F$ & 60 & 2.6 & 90 & 2916 & & 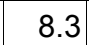 & 1 & & & & & & & & & \\
\hline & & & 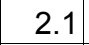 & 1.2 & 98.5 & 82 & .1 & 5 & 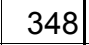 & & & & & & & & \\
\hline & & 1 & & .7 & 8 & 3 & 3.8 & 45.3 & 11.2 & 1191 & 59.6 & 41.1 & 8.1 & 1085 & 75.0 & & \\
\hline 4 & $P$ & 6 & .4 & 3 & 7.2 & 1214 & 37.4 & 62.7 & 20.3 & 1836 & 0.2 & 62.8 & 21.4 & 1847 & 1.7 & 47 & 17 \\
\hline 60615-01 & $P$ & & & & & 12 & 88.5 & 7.68 & 0.18 & 237 & 92.3 & 8.3 & 0.2 & 19 & 5.5 & & \\
\hline $60615-02$ & $P$ & & & & & 159 & 90.1 & 8.61 & 0.17 & 77 & 93.8 & .8 & ] & 56 & 6.7 & & \\
\hline 606 & $P$ & & & & & 399 & 80.7 & 21.4 & 0.95 & 77 & 88.0 & 23.8 & . & 55 & & & \\
\hline & $P$ & & & & & 393 & .7 & 21.2 & 0.77 & 9 & 3.0 & & .0 & & & & \\
\hline & $P$ & 32 & & 8 & 145 & 2308 & 22.0 & 8 & 82 & 3018 & .6 & 102 & 75.3 & 1 & & & 40 \\
\hline & $P$ & & & 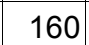 & 9 & 2057 & & & 1 & & & & & & & & 24 \\
\hline 6062 & $P$ & 327 & 12 & 238 & 166 & 3309 & 19.9 & 168 & 133 & 3763 & 29.6 & 28 & 89.5 & 3544 & & & \\
\hline 06. & $P$ & 74 & 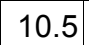 & 272 & 228 & 3586 & 9.1 & 32 & 152 & 008 & 28.3 & 32 & 99.0 & 3810 & & & 68 \\
\hline 06 & $F$ & 71 & 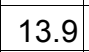 & & 97 & 2438 & 26.2 & 25 & 69 & 3278 & 37.4 & 2 & 9 & 3544 & & & \\
\hline & $P$ & 93 & 2.1 & 93 & 138 & 2822 & 22.3 & 44 & 98 & 04 & 3.5 & 9 & 69.6 & 3544 & & & 43 \\
\hline & $P$ & 7 & 14.2 & 40 & 83 & 2132 & 25.4 & 09 & 63 & 2876 & 36.9 & 97.9 & 49.2 & 3018 & 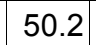 & & 30 \\
\hline 606 & $P$ & 2 & 9.7 & 15 & 197 & 3079 & 8.6 & 56 & 135 & 3629 & 28.6 & 123 & 90.6 & 87 & t & & 54 \\
\hline 6 & $P$ & 59 & 10.0 & 89 & 167 & 2032 & .2 & 84 & 57 & 3425 & \begin{tabular}{|l|}
30.7 \\
\end{tabular} & 16 & 7.3 & 3387 & 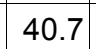 & & 49 \\
\hline & $P$ & 14 & 13.6 & 124 & 77 & 1847 & 27.9 & 94.6 & 47.7 & 2771 & 38.7 & 94.4 & 43.9 & 3048 & 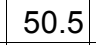 & & 30 \\
\hline & $P$ & 17 & & a & 21 & & & 43 & 88.1 & & & & .4 & & & & 56 \\
\hline & $F$ & & & 0 & 142 & & & & 05 & & & & & & & & 99 \\
\hline 606 & $P$ & 2 & & 56 & 232 & 3425 & ( & & 53 & & .8 & & & & & & 107 \\
\hline 606 & $F$ & 50 & & 270 & 231 & 3717 & & 1 & 158 & 11 & 26.0 & & & 4 & 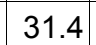 & & 04 \\
\hline 6062 & $P$ & 4 & & 41 & 756 & 4689 & 11.0 & 7 & 379 & 4 & 1 & 55 & 4 & 0 & 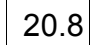 & & 193 \\
\hline 6062 & $P$ & $483 \varepsilon$ & & 488 & 981 & 5542 & \begin{tabular}{|l|}
10.2 \\
\end{tabular} & 0 & 488 & 5255 & 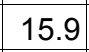 & & 8 & 4 & 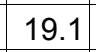 & 4 & 239 \\
\hline & $P$ & 4 & 4 & 404 & 813 & 4 & D & 4 & 472 & 49 & 4 & 3 & 50 & 0 & 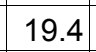 & 2 & 211 \\
\hline & $P$ & 4 & $\theta$ & 444 & 1150 & 5166 & 8 & 0 & 611 & 4763 & 13.3 & & 10 & 5166 & 17.3 & 30 & 247 \\
\hline & $P$ & 05 & 6 & 143 & 149 & 2796 & 15.1 & 42 & 157 & 3958 & 18.4 & 33 & 76 & & & & \\
\hline & $P$ & 1639 & 8.3 & 66 & 181 & 2988 & 4.4 & 51 & 178 & 4175 & \begin{tabular}{|l|}
18.1 \\
\end{tabular} & 41 & 89 & & & & \\
\hline & $P$ & 180 & 52.7 & & 1.6 & 429 & 75.4 & 22.9 & 1.40 & 27 & 84.2 & & 1.4 & 1006 & & & \\
\hline & $P$ & & & & 0.8 & 3 & & 4 & 0.69 & 3 & & & 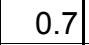 & & & & \\
\hline 607 & $P$ & & & & 0 & 2 & & 0 & 6.97 & 51 & 4 & & 9 & 1 & & & 14 \\
\hline & $F$ & & & & 9.0 & & & & 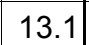 & & & & & & & & 30 \\
\hline & $F$ & 8 & & & 4 & 2177 & & & \begin{tabular}{|l|}
70.1 \\
\end{tabular} & 04 & 37.0 & & & & & & \\
\hline & $F$ & 21 & 10.3 & 165 & 141 & 2363 & 19.6 & 120 & 96.9 & 1825 & 31.5 & & 39.7 & 1847 & & & 32 \\
\hline & $F$ & 1062 & & 109 & 66 & 1712 & 29.8 & 87.8 & 40.3 & 2132 & 44.2 & 2.9 & 26.9 & 2849 & & & 26 \\
\hline & $P$ & & & 89 & 44 & 1 & 34.8 & 75.1 & 27.3 & 1954 & 50.1 & 0 & 9.5 & 051 & J.v & & 15 \\
\hline & $P$ & 1047 & 13.0 & 107 & 70 & 1712 & 30.1 & 87.8 & 39.8 & 2162 & 44.0 & 3.9 & 27.5 & 2822 & 2.4 & 2 & 26 \\
\hline & $P$ & 899 & & 92.4 & 47.6 & 1532 & 34.2 & 78.9 & 9.5 & \begin{tabular}{|l|}
1979 \\
\end{tabular} & 49.0 & 7.9 & 20.6 & 574 & 6.6 & 68 & 21 \\
\hline $7115-07$ & $P$ & 273 & 26.8 & 28.6 & 4 & 607 & 52.8 & 31.8 & 5.43 & 986 & 68.9 & 4.2 & 4.5 & 1516 & 4.9 & 39 & \\
\hline
\end{tabular}




\section{Tabla 64 (continuación)}

\begin{tabular}{|c|c|c|c|c|c|c|c|c|c|c|c|c|c|c|c|c|c|}
\hline MEM & $M O D$ & $F 10$ & R10 & A10 & B10 & $F 20$ & $R 20$ & A20 & $B 20$ & F30 & R30 & A30 & B30 & $F 40$ & R40 & A40 & $B 40$ \\
\hline 60715-08 & $P$ & 181 & 33.9 & 19.2 & 3.5 & 470 & 61.4 & 24.8 & 2.95 & 798 & 75.4 & 27.8 & 2.6 & 1308 & 77.2 & 34 & 4 \\
\hline 60715-09 & $P$ & 546 & 14.2 & 56.0 & 33.0 & 1044 & 35.7 & 53.8 & 18.8 & 1379 & 51.9 & 47.4 & 12.8 & 1920 & 60.8 & 49 & 12 \\
\hline $60715-10$ & $P$ & 273 & 24.8 & 28.5 & 8.3 & 615 & 53.5 & 32.2 & 5.34 & 980 & 70.1 & 34.0 & 4.2 & 1494 & \begin{tabular}{|c|}
76.7 \\
\end{tabular} & 39 & 5 \\
\hline 60916-01 & $C$ & & & & & & & & & 645 & 49.6 & 22.1 & 6.6 & & & & \\
\hline \begin{tabular}{|l|}
$60916-02$ \\
\end{tabular} & $C$ & & & & & & & & & 543 & 45.4 & 18.6 & 6.5 & & & & \\
\hline 60916-03 & $C$ & & & & & & & & & 491 & 42.8 & 16.8 & 6.6 & & & & \\
\hline 60916-04 & $C$ & & & & & & & & & 350 & 53.5 & 12.0 & 3.0 & & & & \\
\hline 60917-01 & $C$ & & & & & & & & & 3929 & 3.9 & 131 & 967 & & & & \\
\hline 60917-05 & $C$ & & & & & & & & & 552 & 39.0 & 18.8 & 8.6 & & & & \\
\hline 60917-06 & $C$ & & & & & & & & & 5014 & 1.8 & 167 & 2735 & & & & \\
\hline 60917-07 & $C$ & & & & & & & & & 1302 & 14.0 & 43.7 & 80.0 & & & & \\
\hline 60917-08 & $C$ & & & & & & & & & 1964 & 5.4 & 65.7 & 344 & & & & \\
\hline 60917-09 & $C$ & & & & & & & & & 2507 & 8.0 & 83.9 & 288 & & & & \\
\hline $60917-10$ & $C$ & & & & & & & & & 1300 & 18.2 & 43.8 & 58.4 & & & & \\
\hline 60917-11 & $C$ & & & & & & & & & 2095 & 9.3 & 70.2 & 204 & & & & \\
\hline $60917-12$ & $C$ & & & & & & & & & 4983 & 5.7 & 167 & 824 & & & & \\
\hline $60918-15$ & $C$ & & & & & & & & & 540 & 46.5 & 18.5 & 6.2 & & & & \\
\hline \begin{tabular}{|l|}
$60918-16$ \\
\end{tabular} & $C$ & & & & & & & & & 2483 & 3.9 & 82.9 & 612 & & & & \\
\hline \begin{tabular}{|l|}
$60918-17$ \\
\end{tabular} & $C$ & & & & & & & & & 1487 & 7.2 & 49.8 & 192 & & & & \\
\hline 60918-18 & $C$ & & & & & & & & & 1948 & 13.4 & 65.4 & 126 & & & & \\
\hline 60918-19 & $C$ & & & & & & & & & 1008 & 20.8 & 34.0 & 38.4 & & & & \\
\hline 60918-21 & $C$ & & & & & & & & & 927 & 23.3 & 31.3 & 30.5 & & & & \\
\hline 60918-23 & $C$ & & & & & & & & & 1243 & 12.6 & 41.7 & 86.2 & & & & \\
\hline 60921-02 & $C$ & & & & & & & & & 136 & 51.8 & 4.7 & 1.3 & & & & \\
\hline 60921-11 & $C$ & & & & & & & & & 1054 & 22.0 & 35.6 & 37.4 & & & & \\
\hline 60921-12 & $C$ & & & & & & & & & 424 & 58.2 & 14.6 & 3.0 & & & & \\
\hline $60921-13$ & $C$ & & & & & & & & & 1585 & 8.5 & 53.1 & 171 & & & & \\
\hline 60921-14 & $C$ & & & & & & & & & 1169 & 23.3 & 39.5 & 38.5 & & & & \\
\hline \begin{tabular}{|l|}
$60922-01$ \\
\end{tabular} & $C$ & & & & & & & & & 477 & 43.8 & 16.3 & 6.1 & & & & \\
\hline \begin{tabular}{|l|}
$60922-02$ \\
\end{tabular} & $C$ & & & & & & & & & 486 & 25.0 & \begin{tabular}{|l|}
16.4 \\
\end{tabular} & 14.6 & & & & \\
\hline \begin{tabular}{|l|}
$60922-03$ \\
\end{tabular} & $C$ & & & & & & & & & 596 & 38.7 & 20.3 & 9.4 & & & & \\
\hline \begin{tabular}{|l|}
$60922-04$ \\
\end{tabular} & $C$ & & & & & & & & & 1581 & 8.7 & 53.0 & 166 & & & & \\
\hline $60922-05$ & $C$ & & & & & & & & & 552 & 23.5 & 18.6 & 18.0 & & & & \\
\hline 60922-06 & $C$ & & & & & & & & & 565 & 21.4 & 19.1 & 20.8 & & & & \\
\hline 61008-211 & $C$ & & & & & & & & & 860 & 67.9 & 29.8 & 4.1 & & & & \\
\hline $61008-214$ & $C$ & & & & & & & & & 663 & 68.7 & 23.0 & 3.0 & & & & \\
\hline $61008-222$ & $C$ & & & & & & & & & 785 & 79.9 & 27.4 & 2.0 & & & & \\
\hline 61008-111 & $C$ & & & & & & & & & 462 & 84.8 & 16.2 & 0.8 & & & & \\
\hline 61008-112 & $C$ & & & & & & & & & 318 & 87.9 & 11.2 & 0.4 & & & & \\
\hline 61008-213 & $C$ & & & & & & & & & 307 & 92.0 & 10.8 & 0.3 & & & & \\
\hline 61008-223 & $C$ & & & & & & & & & 314 & 93.9 & 11.1 & 0.2 & & & & \\
\hline 61008-123 & $C$ & & & & & & & & & 275 & 96.5 & 9.7 & 0.1 & & & & \\
\hline $61008-221$ & $C$ & & & & & & & & & 502 & 93.1 & 17.7 & 0.4 & & & & \\
\hline 61008-224 & $C$ & & & & & & & & & 370 & 95.6 & 13.0 & 0.2 & & & & \\
\hline 61008-113 & $C$ & & & & & & & & & 287 & 91.7 & 10.1 & 0.3 & & & & \\
\hline $61008-114$ & $C$ & & & & & & & & & 344 & 90.2 & 12.1 & 0.4 & & & & \\
\hline 61008-121 & $C$ & & & & & & & & & 393 & 93.1 & 13.8 & 0.3 & & & & \\
\hline $61008-124$ & $C$ & & & & & & & & & 475 & 88.8 & 16.7 & 0.6 & & & & \\
\hline 61008-212 & $C$ & & & & & & & & & 348 & 90.4 & 12.2 & 0.4 & & & & \\
\hline
\end{tabular}


Tabla 64 (continuación)

\begin{tabular}{|c|c|c|c|c|c|r|r|r|r|r|r|r|r|r|r|r|r|}
\hline MEM & MOD & $F 10$ & R10 & $A 10$ & B10 & F20 & R20 & A20 & B20 & $F 30$ & $R 30$ & A30 & B30 & $F 40$ & $R 40$ & $A 40$ & $B 40$ \\
\hline $61008-312$ & $C$ & & & & & & & & & 1203 & 63.1 & 41.6 & 7.0 & & & & \\
\hline $61008-313$ & $C$ & & & & & & & & & 1261 & 22.8 & 42.6 & 42.7 & & & & \\
\hline $61008-314$ & $C$ & & & & & & & & & 1318 & 50.8 & 45.2 & 12.8 & & & & \\
\hline $61008-321$ & $C$ & & & & & & & & & 2139 & 15.0 & 71.9 & 121 & & & & \\
\hline $61008-322$ & $C$ & & & & & & & & & 1261 & 53.3 & 43.3 & 11.0 & & & & \\
\hline $61008-323$ & $C$ & & & & & & & & 1070 & 53.5 & 36.8 & 9.3 & & & & \\
\hline $61008-324$ & $C$ & & & & & & & & & 1070 & 58.4 & 36.9 & 7.6 & & & & \\
\hline $61008-511$ & $C$ & & & & & & & & & 3209 & 8.3 & 107 & 355 & & & & \\
\hline $61008-513$ & $C$ & & & & & & & & & 1910 & 29.6 & 64.8 & 45.4 & & & & \\
\hline $61008-514$ & $C$ & & & & & & & & 1146 & 66.9 & 39.7 & 5.7 & & & & \\
\hline $61008-521$ & $C$ & & & & & & & & & 1467 & 42.5 & 50.1 & 19.8 & & & & \\
\hline $61008-522$ & $C$ & & & & & & & & & 1879 & 41.0 & 64.1 & 27.0 & & & & \\
\hline $61008-523$ & $C$ & & & & & & & & & 1999 & 19.1 & 67.4 & 84.7 & & & & \\
\hline $61008-524$ & $C$ & & & & & & & & & 2750 & 12.0 & 92.3 & 202 & & & & \\
\hline
\end{tabular}

Tabla 65. Resultados de caracterización en planta para las membranas que utilizan como polímero base ACE (Acetato en escamas de Inacsa)

\begin{tabular}{|c|c|c|c|c|c|c|c|c|c|c|c|c|c|c|c|c|c|}
\hline MEM & $M O D$ & $F 10$ & $R 10$ & A10 & B10 & $F 20$ & $R 20$ & A20 & $B 20$ & F30 & R30 & A30 & B30 & $F 40$ & R40 & A40 & $B 40$ \\
\hline E0612-01 & $P$ & 325 & 39.6 & 34.8 & 5.0 & 840 & 55.8 & 44.1 & 6.65 & 1275 & 65.5 & 44.1 & 6.7 & 1155 & 71.0 & 30 & 5 \\
\hline E0612-02 & $P$ & 374 & 38.1 & 40.0 & 6.1 & 952 & 55.4 & 50.0 & 7.66 & 1379 & 66.0 & 47.8 & 7.1 & 1085 & 69.0 & 28 & 5 \\
\hline E0612-05 & $P$ & 1608 & 11.6 & 164 & 123 & 2706 & 25.4 & 138 & 79.5 & & & & & 4825 & 38.9 & 123 & 76 \\
\hline E0612-06 & $P$ & 1524 & 12.1 & 156 & 111 & 2706 & 26.2 & 138 & 76.2 & & & & & 6433 & 28.1 & 163 & 165 \\
\hline E0615-01 & $P$ & 1787 & 8.2 & 181 & 200 & 2519 & 18.7 & 128 & 110 & 1487 & 28.9 & 50.4 & 36.6 & 431 & 29.0 & 11 & 11 \\
\hline E0615-02 & $P$ & 1135 & 12.9 & 116 & 77 & 1893 & 29.3 & 97.1 & 45.7 & 1965 & 40.3 & 67.0 & 29.1 & 2002 & 41.1 & 51 & 29 \\
\hline E0615-03 & $P$ & 568 & 16.3 & 58.4 & 29.2 & 1412 & 33.8 & 72.7 & 27.7 & & & & & 5790 & 26.7 & 146 & 159 \\
\hline E0615-04 & $P$ & 597 & 16.8 & 61.5 & 29.6 & 1359 & 36.8 & 70.1 & 23.3 & & & & & 7423 & 22.0 & 187 & 263 \\
\hline E0615-05 & $P$ & & & & & 440 & 65.6 & 23.3 & 2.31 & 1037 & 78.8 & 36.2 & 2.8 & 1188 & \begin{tabular}{|l|}
83.8 \\
\end{tabular} & 31 & 2 \\
\hline E0615-06 & $P$ & & & & & 449 & 68.3 & 23.8 & 2.08 & 935 & 81.0 & 32.7 & 2.2 & 1073 & 85.5 & 28 & 2 \\
\hline E0615-09 & $P$ & & & & & 705 & 50.6 & 36.8 & 6.88 & 1458 & \begin{tabular}{|l|}
70.0 \\
\end{tabular} & 50.6 & 6.2 & 1588 & 77.3 & 41 & 5 \\
\hline E0615-10 & $P$ & & & & & 884 & 43.0 & 45.9 & 11.7 & 1675 & 63.9 & 57.9 & 9.5 & 1732 & 71.7 & 45 & 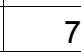 \\
\hline E1026-121 & $C$ & & & & & & & & & 1834 & 23.1 & 61.9 & 61.1 & & & & \\
\hline E1026-122 & $C$ & & & & & & & & & 1707 & 21 & 57.6 & 64.2 & & & & \\
\hline E1026-131 & $C$ & & & & & & & & & 77.1 & 46.5 & 2.6 & 0.9 & & & & \\
\hline E1026-132 & $C$ & & & & & & & & & 731 & 47.5 & 25.0 & 8.1 & & & & \\
\hline E1026-211 & C & & & & & & & & & 917 & 21.3 & 30.9 & 33.9 & & & & \\
\hline E1026-212 & $C$ & & & & & & & & & 353 & 26.7 & 11.9 & 9.7 & & & & \\
\hline E1026-221 & $C$ & & & & & & & & & 632 & 16.7 & 21.3 & 31.5 & & & & \\
\hline E1026-222 & $C$ & & & & & & & & & 869 & 17.2 & 29.3 & 41.8 & & & & \\
\hline E1026-223 & $C$ & & & & & & & & & 2328 & 12.2 & 78.1 & 168 & & & & \\
\hline E1026-224 & $C$ & & & & & & & & & 1862 & 28.9 & 63.1 & 45.8 & & & & \\
\hline E1026-321 & $C$ & & & & & & & & & 688 & 88.0 & 24.1 & 0.9 & & & & \\
\hline E1026-322 & $C$ & & & & & & & & & 802 & 73.9 & 27.9 & 2.8 & & & & \\
\hline E1026-323 & $C$ & & & & & & & & & 688 & 82.9 & 24.1 & 1.4 & & & & \\
\hline
\end{tabular}




\begin{tabular}{|c|c|c|c|c|c|c|c|c|c|c|c|c|c|c|c|c|c|}
\hline MEM & $M O D$ & F10 & $R 10$ & A10 & B10 & $F 20$ & $R 20$ & A20 & $B 20$ & F30 & R30 & A30 & B30 & F40 & $R 40$ & A40 & $B 40$ \\
\hline E1026-331 & $C$ & & & & & & & & & 683 & \begin{tabular}{|l|}
79.7 \\
\end{tabular} & 23.8 & 1.7 & & & & \\
\hline E1026-332 & $C$ & & & & & & & & & 780 & 75.0 & 27.2 & 2.6 & & & & \\
\hline E1026-333 & $C$ & & & & & & & & & 722 & 73.7 & 25.1 & 2.6 & & & & \\
\hline E1026-334 & $C$ & & & & & & & & & 731 & 75.8 & 25.5 & 2.3 & & & & \\
\hline E1026-411 & C & & & & & & & & & 326 & 91.2 & 11.5 & 0.3 & & & & \\
\hline E1026-412 & $C$ & & & & & & & & & 377 & 91.4 & 13.3 & 0.4 & & & & \\
\hline E1026-413 & $C$ & & & & & & & & & 314 & 90.7 & 11.0 & 0.3 & & & & \\
\hline E1026-414 & $C$ & & & & & & & & & 362 & 90.3 & 12.7 & 0.4 & & & & \\
\hline E1026-424 & $C$ & & & & & & & & & 688 & 82.9 & 24.1 & 1.4 & & & & \\
\hline E1026-511 & $C$ & & & & & & & & & 463 & 87.6 & 16.2 & 0.7 & & & & \\
\hline E1026-512 & $C$ & & & & & & & & & 722 & 66.9 & 25.0 & 3.6 & & & & \\
\hline E1026-513 & $C$ & & & & & & & & & 594 & 66.5 & 20.6 & 3.0 & & & & \\
\hline \begin{tabular}{|l|} 
E1026-514 \\
\end{tabular} & $C$ & & & & & & & & & 552 & 75.3 & 19.2 & 1.8 & & & & \\
\hline E1026-811 & $C$ & 398 & 75.5 & 45.7 & 1.3 & & & & & 550 & 82.1 & 19.2 & 1.2 & & & & \\
\hline E1026-812 & C & & & & & & & & & 764 & 62.3 & 26.4 & 4.6 & & & & \\
\hline E1026-813 & $C$ & & & & & & & & & 553 & 80.9 & 19.3 & 1.3 & & & & \\
\hline E1026-814 & $C$ & & & & & & & & & 550 & 80.6 & 19.2 & 1.3 & & & & \\
\hline E1029-1' & $P$ & & & & & 609 & 50.2 & 31.8 & 6.04 & & & & & & & & \\
\hline E1029-1" & $P$ & & & & & 614 & 53.3 & 32.2 & 5.38 & & & & & & & & \\
\hline E1029-1"' & $P$ & & & & & 512 & 53.8 & 26.8 & 4.40 & & & & & & & & \\
\hline E1029-111 & $C$ & & & & & 585 & 64.3 & 30.9 & 3.25 & & & & & & & & \\
\hline E1029-112 & $C$ & & & & & 573 & 67.8 & 30.4 & 2.72 & & & & & & & & \\
\hline E1029-2' & $P$ & & & & & 284 & 63.9 & 15.0 & 1.60 & & & & & & & & \\
\hline E1029-2" & $P$ & & & & & 284 & \begin{tabular}{|l|}
70.4 \\
\end{tabular} & 15.1 & 1.19 & & & & & & & & \\
\hline E1029-2"' & $P$ & & & & & 217 & 76.6 & 11.6 & 0.66 & & & & & & & & \\
\hline E1029-211 & $C$ & & & & & & & & & 573 & 90.1 & 20.1 & 0.6 & & & & \\
\hline E1029-3' & $P$ & & & & & 293 & 61.0 & 15.5 & 1.87 & & & & & & & & \\
\hline E1029-3" & $P$ & & & & & 293 & 68.4 & 15.6 & 1.35 & & & & & & & & \\
\hline E1029-3"' & $P$ & & & & & 244 & 74.0 & 13.0 & 0.86 & & & & & & & & \\
\hline E1029-311 & $C$ & & & & & & & & & 655 & 81.7 & 22.9 & 1.5 & & & & \\
\hline E1029-4' & $P$ & & & & & 2153 & 17.2 & 109 & 104 & & & & & & & & \\
\hline E1029-4" & $P$ & & & & & 2275 & 21.4 & 116 & 84 & & & & & & & & \\
\hline E1029-4"' & $P$ & & & & & 1828 & 20.6 & 93.0 & 70.5 & & & & & & & & \\
\hline E1029-411 & $C$ & & & & & & & & & 2906 & 15.0 & 97.7 & 165 & & & & \\
\hline E1029-5' & $P$ & & & & & 634 & 48.7 & 33.1 & 6.68 & & & & & & & & \\
\hline E1029-5" & $P$ & & & & & 601 & 51.1 & 31.4 & 5.75 & & & & & & & & \\
\hline E1029-5"' & $P$ & & & & & 741 & 53.3 & 38.8 & 6.49 & & & & & & & & \\
\hline E1029-511 & $C$ & & & & & & & & & 1179 & 38.8 & 40.2 & 18.6 & & & & \\
\hline E1029-6' & $P$ & & & & & 447 & 61.5 & 23.6 & 2.80 & & & & & & & & \\
\hline E1029-6" & $P$ & & & & & 427 & 64.5 & 22.6 & 2.35 & & & & & & & & \\
\hline E1029-6"' & $P$ & & & & & 526 & 67.9 & 27.9 & 2.49 & & & & & & & & \\
\hline E1029-611 & $C$ & & & & & & & & & 673 & 77.0 & 23.5 & 2.0 & & & & \\
\hline E1029-612 & $C$ & & & & & & & & & 662 & 81.6 & 23.1 & 1.5 & & & & \\
\hline E1029-613 & C & & & & & & & & & 579 & 84.3 & 20.3 & 1.1 & & & & \\
\hline E1029-614 & $C$ & & & & & & & & & 630 & 84.0 & 22.0 & 1.2 & & & & \\
\hline E2109-11 & $C$ & & & & & & & & & 1054 & 22.0 & 35.6 & 37.4 & & & & \\
\hline E2109-12 & $C$ & & & & & & & & & 424 & 58.2 & 14.6 & 3.0 & & & & \\
\hline E2109-13 & C & & & & & & & & & 1585 & 8.5 & 53.1 & 171 & & & & \\
\hline
\end{tabular}




\section{Tabla 65 (continuación)}

\begin{tabular}{|c|c|c|c|c|c|c|c|c|c|c|c|c|c|c|c|c|c|}
\hline MEM & $M O D$ & F10 & $R 10$ & A10 & B10 & $F 20$ & $R 20$ & A20 & $B 20$ & F30 & R30 & A30 & B30 & $F 40$ & $R 40$ & A40 & $B 40$ \\
\hline E2109-14 & $C$ & & & & & & & & & 1169 & 23.3 & 39.5 & 38.5 & & & & \\
\hline E2109-2 & $C$ & & & & & & & & & 136 & 51.8 & 4.7 & 1.3 & & & & \\
\hline E2109-4 & $C$ & & & & & & & & & 1549 & 10.1 & 51.9 & 138 & & & & \\
\hline E1104-1 & $P$ & & & & & 163 & 87.4 & 8.80 & 0.23 & & & & & & & & \\
\hline E1104-2 & $P$ & & & & & 636 & 49.2 & 33.2 & 6.57 & & & & & & & & \\
\hline E1104-3 & $P$ & & & & & 491 & 59.6 & 25.9 & 3.33 & & & & & & & & \\
\hline E1105-1 & $P$ & & & & & 475 & 60.3 & 25.0 & 3.13 & & & & & & & & \\
\hline E1105-2 & $P$ & & & & & 700 & 46.7 & 36.4 & 7.99 & & & & & & & & \\
\hline E1105-3 & $P$ & & & & & 533 & 56.4 & 28.0 & 4.12 & & & & & & & & \\
\hline E1105-4 & $P$ & & & & & 681 & 62.9 & 36.0 & 4.02 & & & & & & & & \\
\hline E1105-5 & $P$ & & & & & 305 & 68.3 & 16.2 & 1.42 & & & & & & & & \\
\hline E1109-11 & $P$ & & & & & 465 & 60.5 & 24.5 & 3.04 & & & & & & & & \\
\hline E1109-12 & $P$ & & & & & 501 & 56.9 & 26.3 & 3.79 & & & & & & & & \\
\hline E1109-21 & $P$ & & & & & 269 & \begin{tabular}{|l|}
73.6 \\
\end{tabular} & 14.3 & 0.96 & & & & & & & & \\
\hline E1109-22 & $P$ & & & & & 287 & 68.7 & 15.2 & 1.31 & & & & & & & & \\
\hline E1109-31 & $P$ & & & & & 495 & 55.2 & 26.0 & 4.02 & & & & & & & & \\
\hline E1109-32 & $P$ & & & & & 665 & 52.2 & 34.8 & 6.09 & & & & & & & & \\
\hline E1109-41 & $P$ & & & & & 293 & 63.8 & 15.5 & 1.66 & & & & & & & & \\
\hline E1109-42 & $P$ & & & & & 355 & 59.5 & 18.7 & 2.42 & & & & & & & & \\
\hline E1109-51 & $P$ & & & & & 447 & 67.2 & 23.7 & 2.18 & & & & & & & & \\
\hline E1109-52 & $P$ & & & & & 505 & 61.1 & 26.6 & 3.22 & & & & & & & & \\
\hline E1109-61 & $P$ & & & & & 466 & 67.3 & 24.7 & 2.26 & & & & & & & & \\
\hline E1109-62 & $P$ & & & & & 495 & 65.3 & 26.2 & 2.63 & & & & & & & & \\
\hline E1109-71 & $P$ & & & & & 377 & 68.5 & 20.0 & 1.73 & & & & & & & & \\
\hline E1109-72 & $P$ & & & & & 426 & 61.3 & 22.5 & 2.69 & & & & & & & & \\
\hline
\end{tabular}





\section{ANEXO II: Fotografías realizadas en el microscopio electrónico}





\section{ANEXO II: Fotografías realizadas en el microscopio electrónico}

A continuación se presentan las fotografías realizadas en el microscopio electrónico de las cuales se hace referencia principalmente en el apartado 4.3.6. Las fotografías fueron realizadas con el microscopio CRIOSEM de la UPV para diferentes aumentos sobre membranas preparadas con las condiciones de caracterización explicadas en la Tabla 54. 


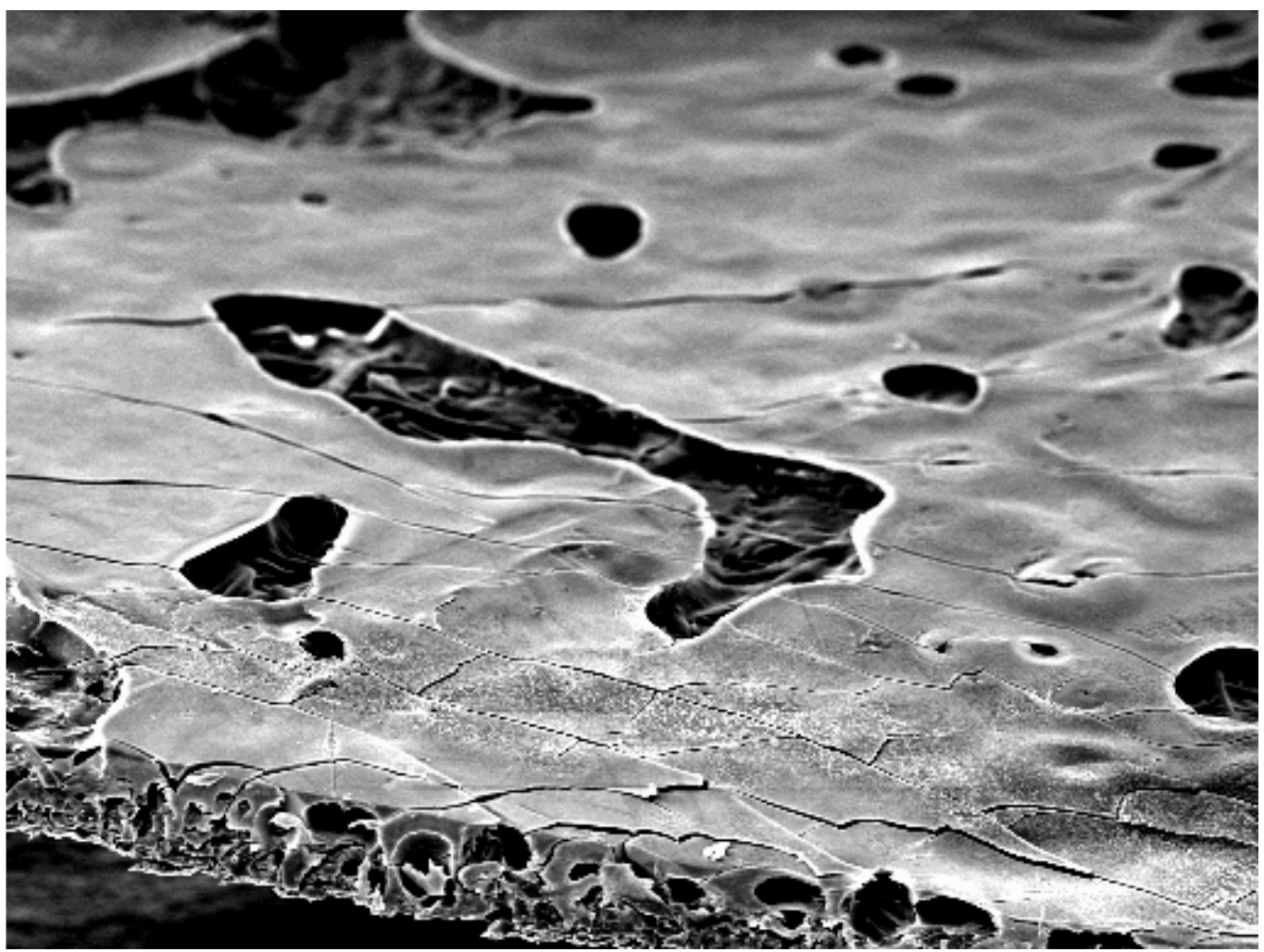

Ilustración 100. Muestra 6 - 75X. Despegue de la capa de acetato de celulosa en el soporte $\mathrm{FO}-2401$
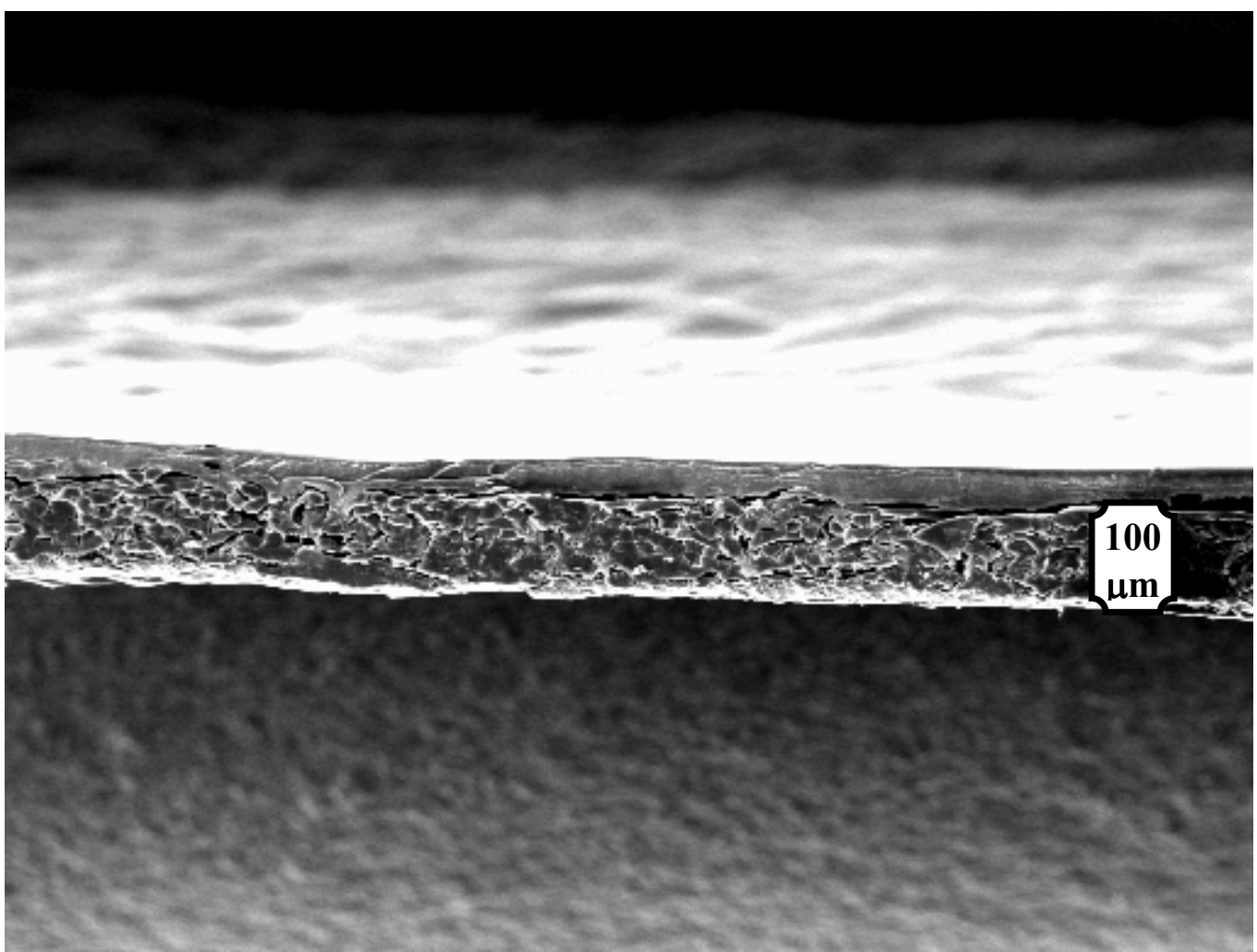

Ilustración 101. Muestra 17 - 75 X. Corte transversal de membrana fabricada con soporte FO-2402 

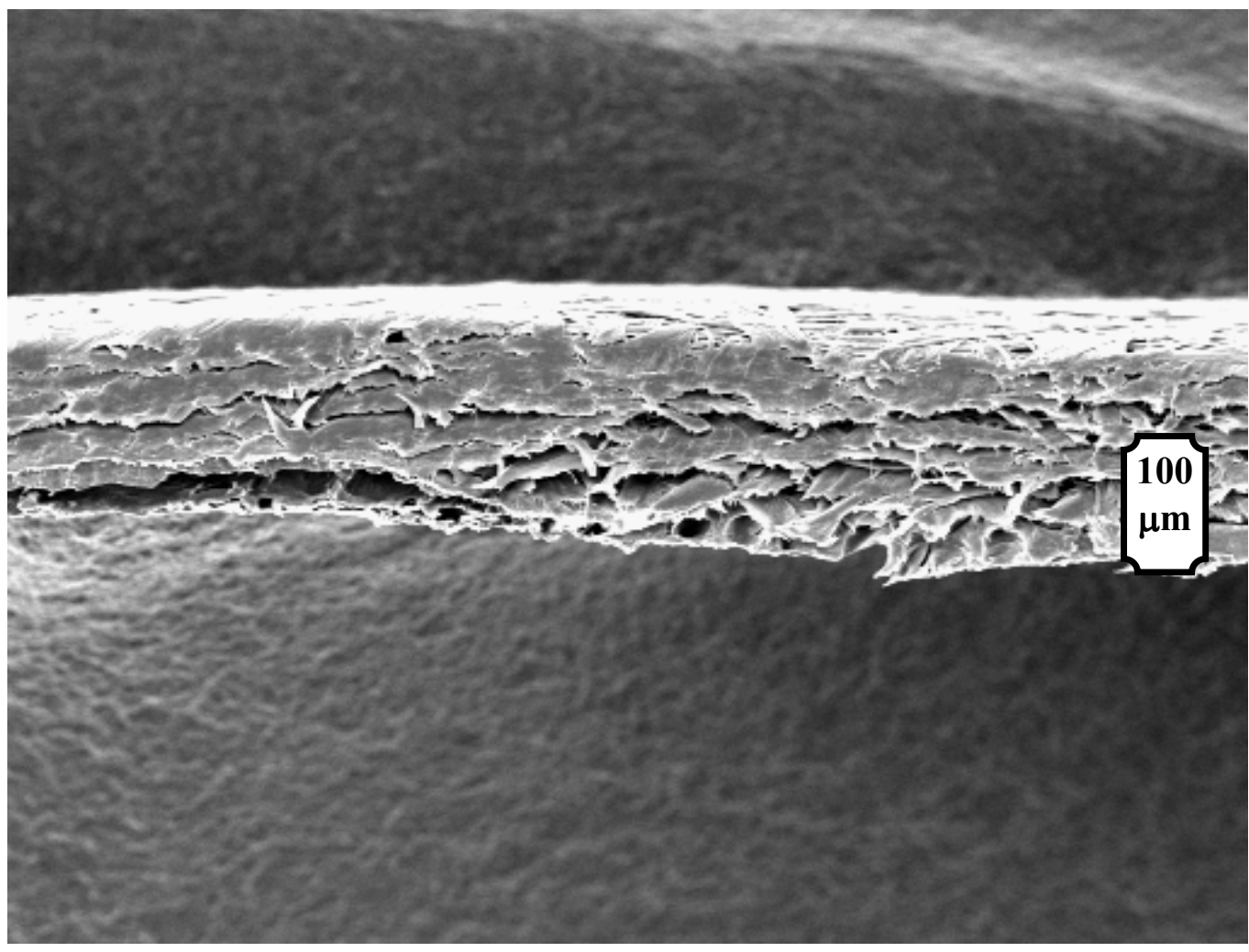

Ilustración 102. Muestra 7 - 100 X. Soporte Tyvek

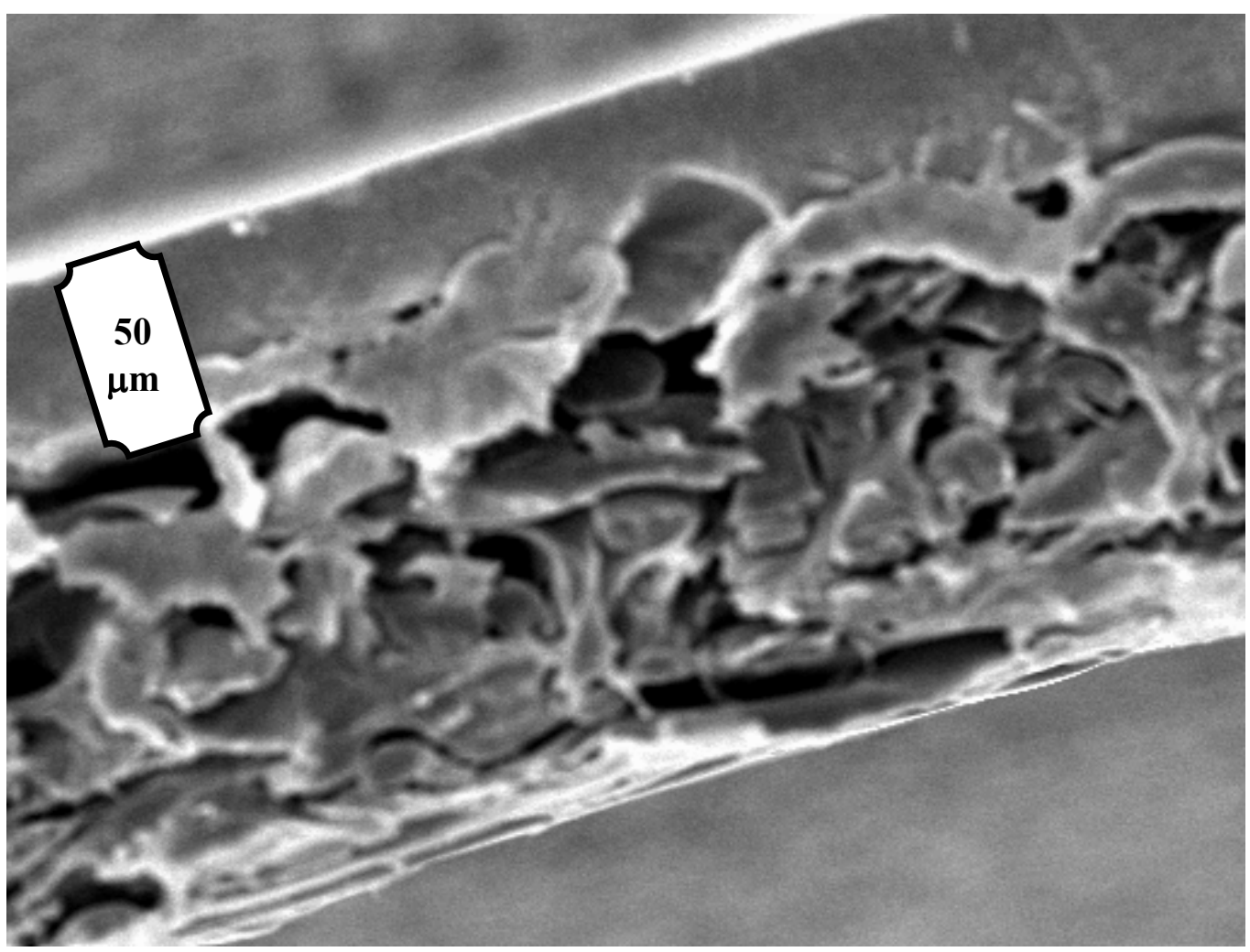

Ilustración 103. Muestra 2 - 500 X. Deposición de 100 micras sobre soporte FO-2402. Tiempo de evaporación: 15 seg. 


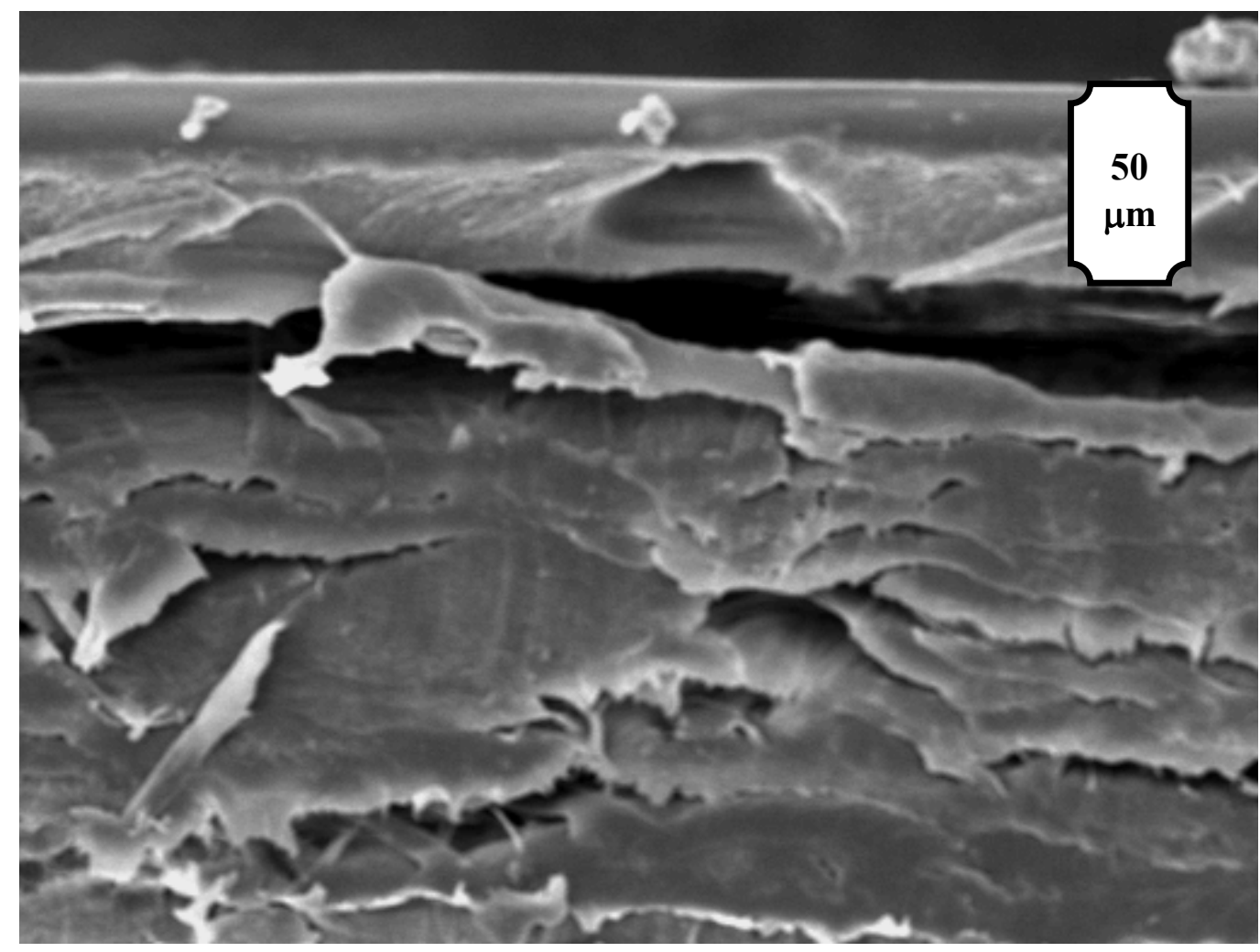

Ilustración 104. Muestra 8 - 500 X. Deposición de 100 micras sobre soporte Tyvek. Tiempo de evaporación $15 \mathrm{seg}$.

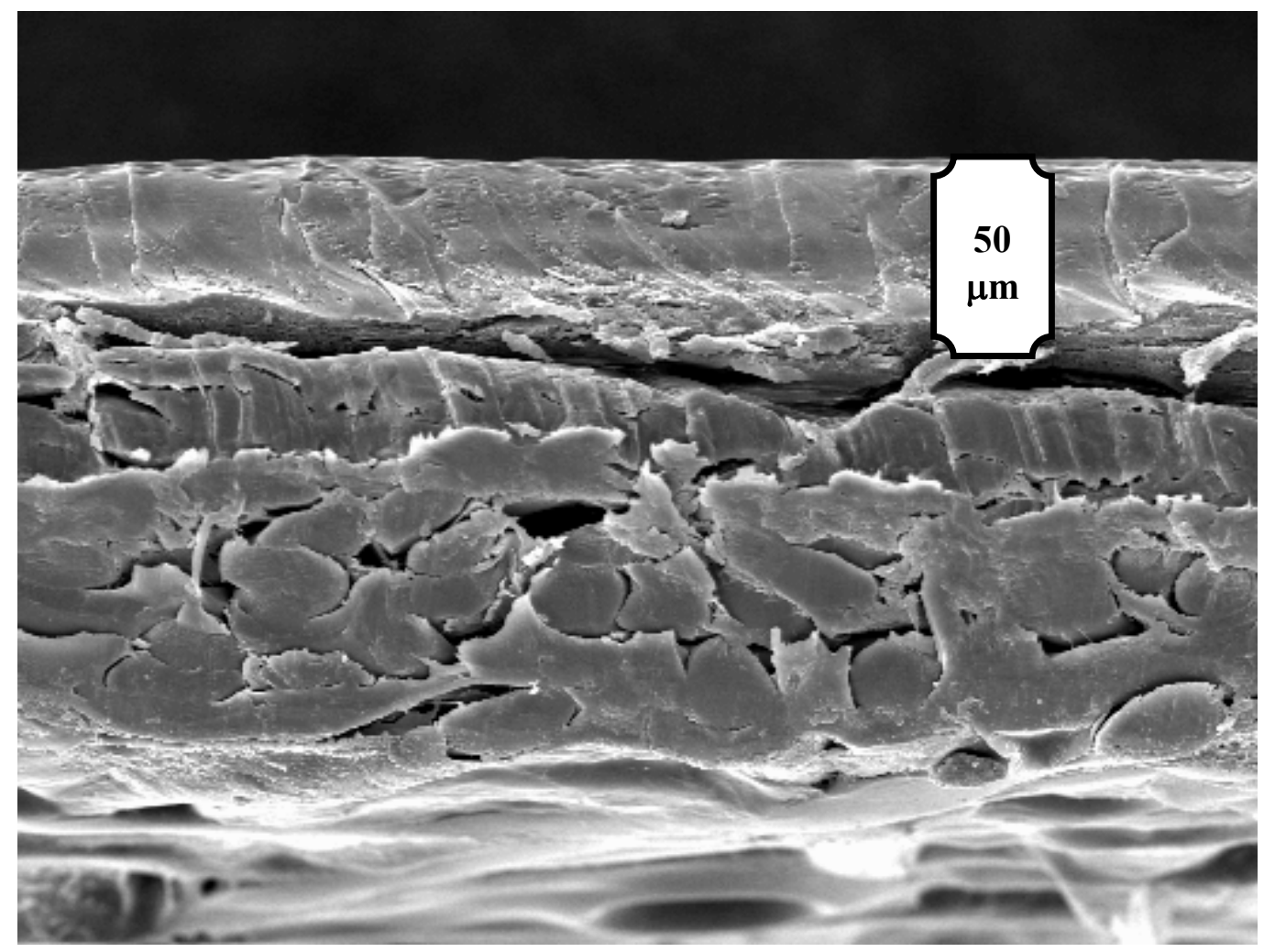

Ilustración 105. Muestra 10 - 500 X. Deposición de 100 micras sobre soporte FO2402. Tiempo de evaporación $120 \mathrm{seg}$. 


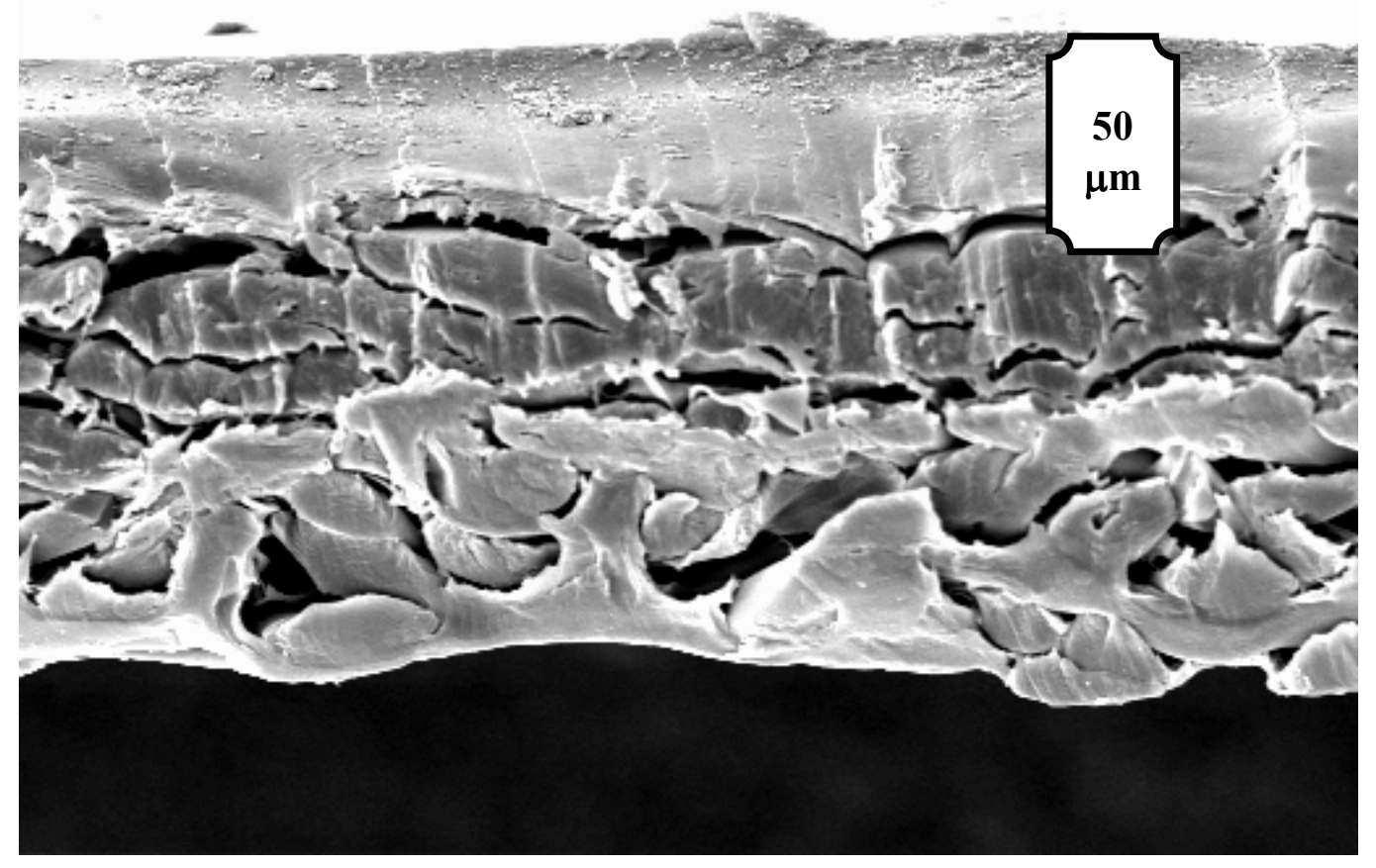

Ilustración 106. Muestra 11 - 500 X. Deposición de 50 micras sobre soporte FO-2402. Tiempo de evaporación 120 seg.

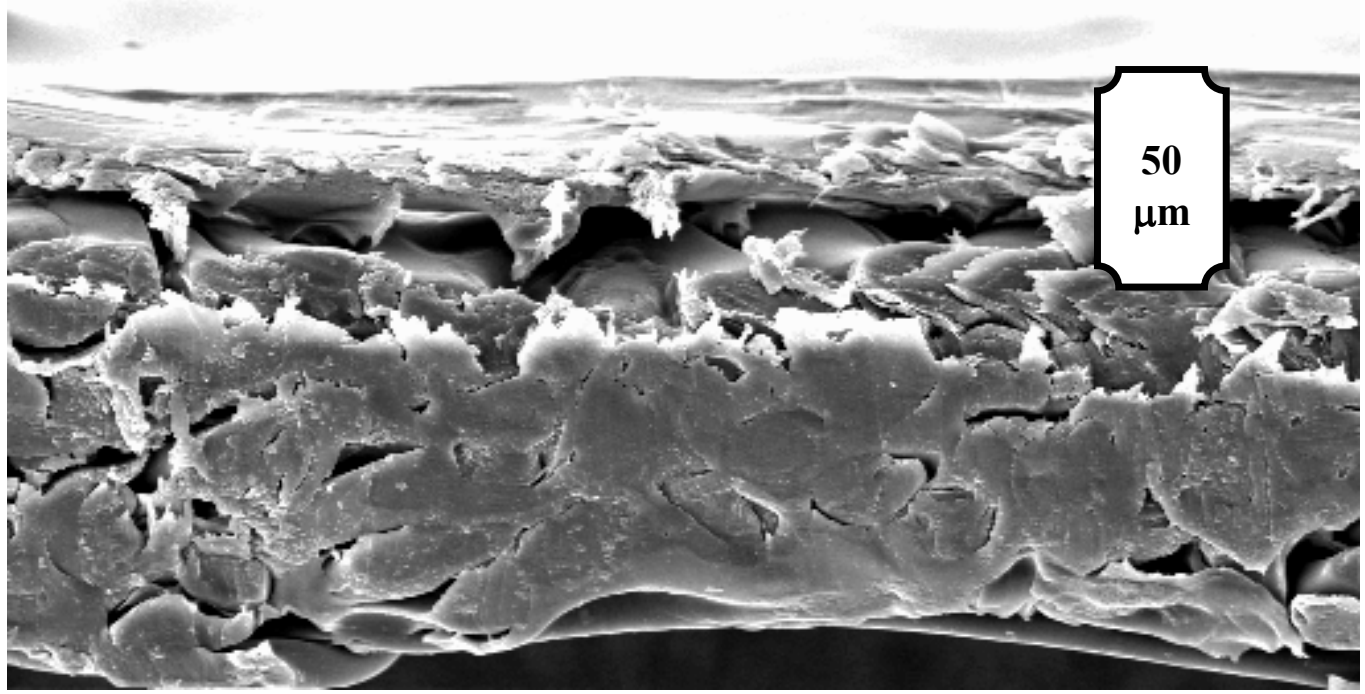

Ilustración 107. Muestra 13 - 500 X. Deposición de 36 micras sobre soporte FO-2402. Tiempo de evaporación 120 seg. 


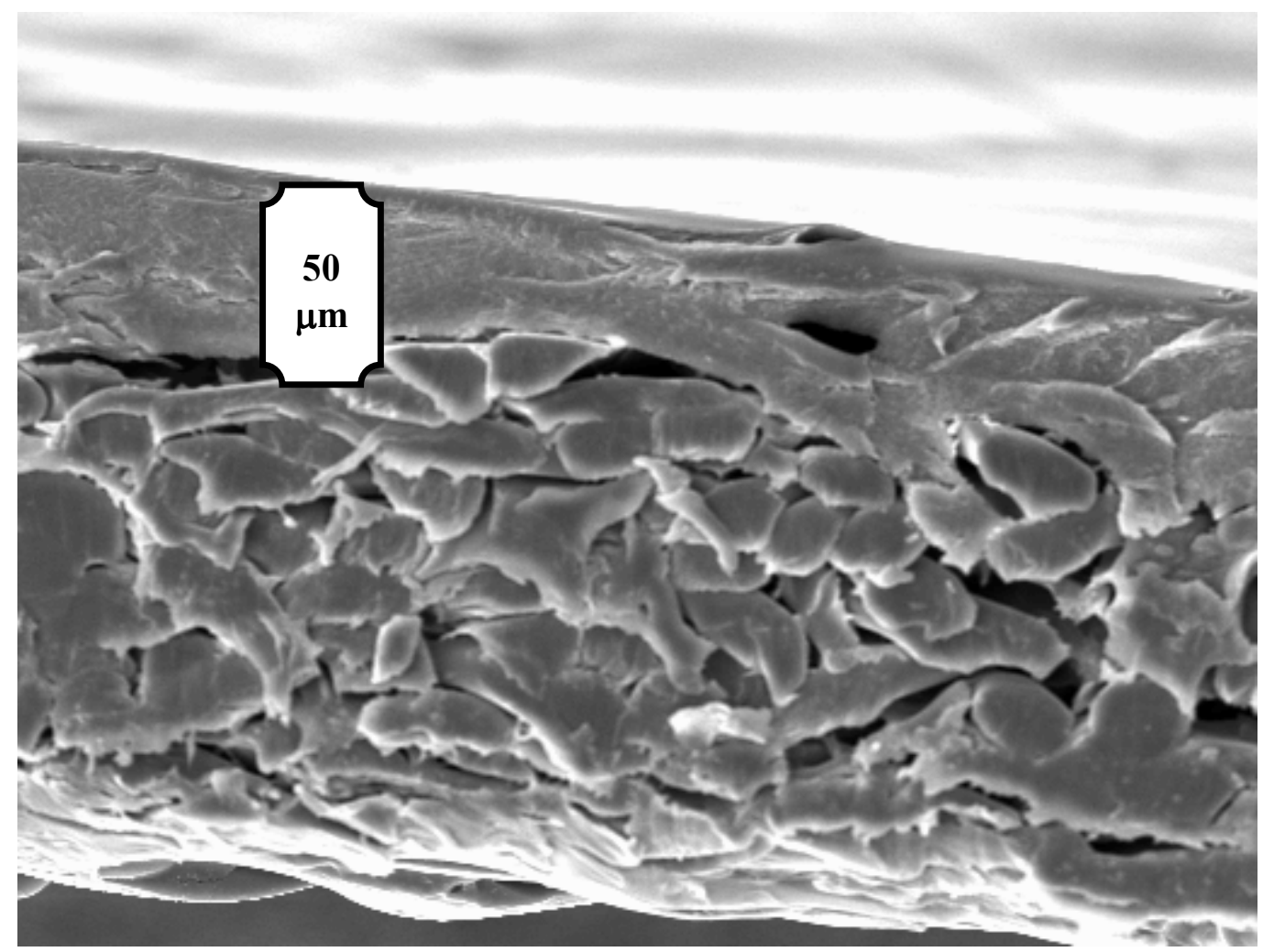

Ilustración 108. Muestra 17 - 500 X. Deposición de 50 micras sobre soporte FO-2402. Tiempo de evaporación 30 seg. 20 \% de DMA en baño.

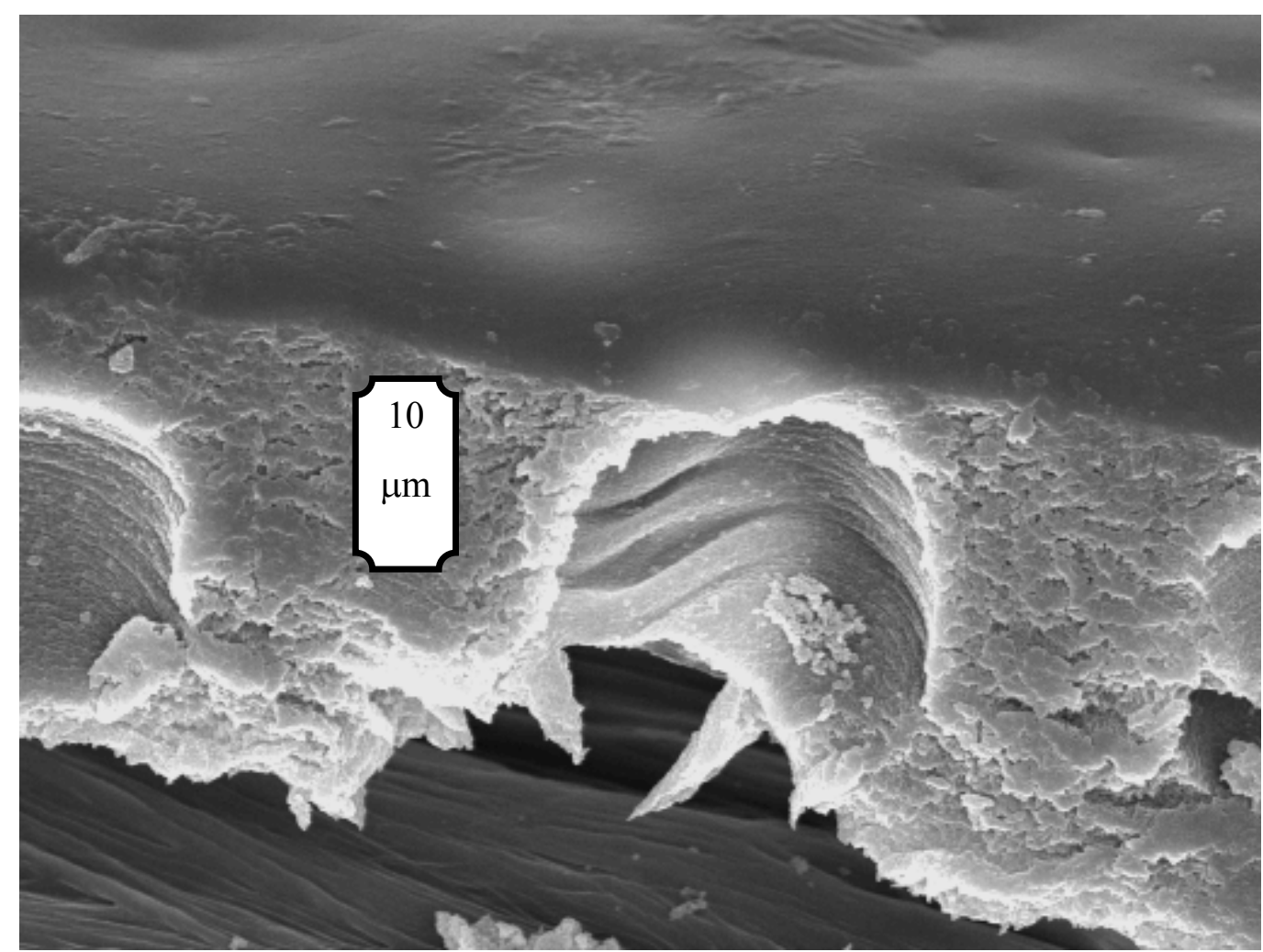

Ilustración 109. Muestra TV-2000 X. Presencia de macroporos en una membrana. Deposición de 36 micras sobre soporte Tyvek. Tiempo de evaporación $15 \mathrm{seg}$. 


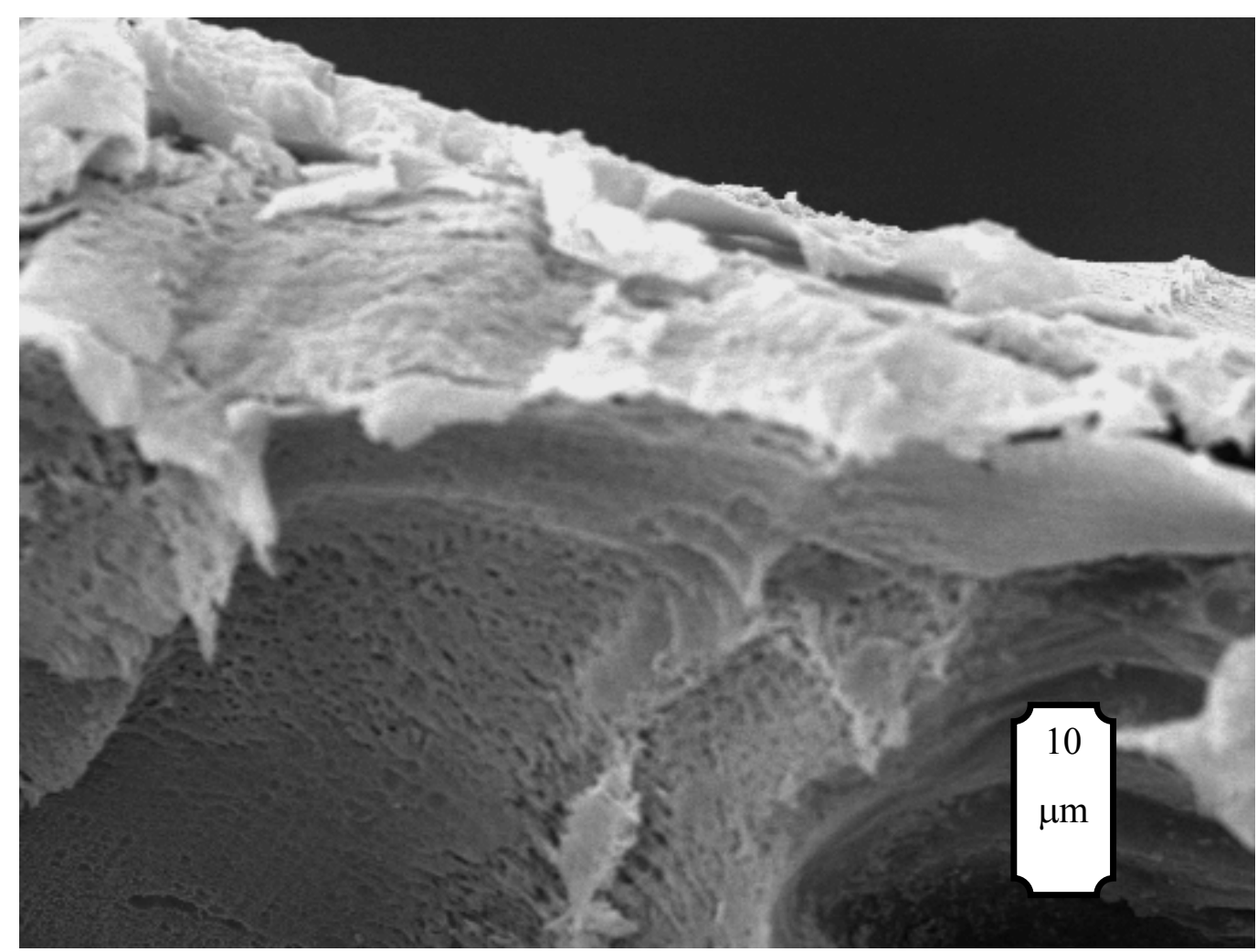

Ilustración 110. Muestra 1 - 2000 X. Estructura polimérica porosa formada para un tiempo de evaporación corto (15 seg.)

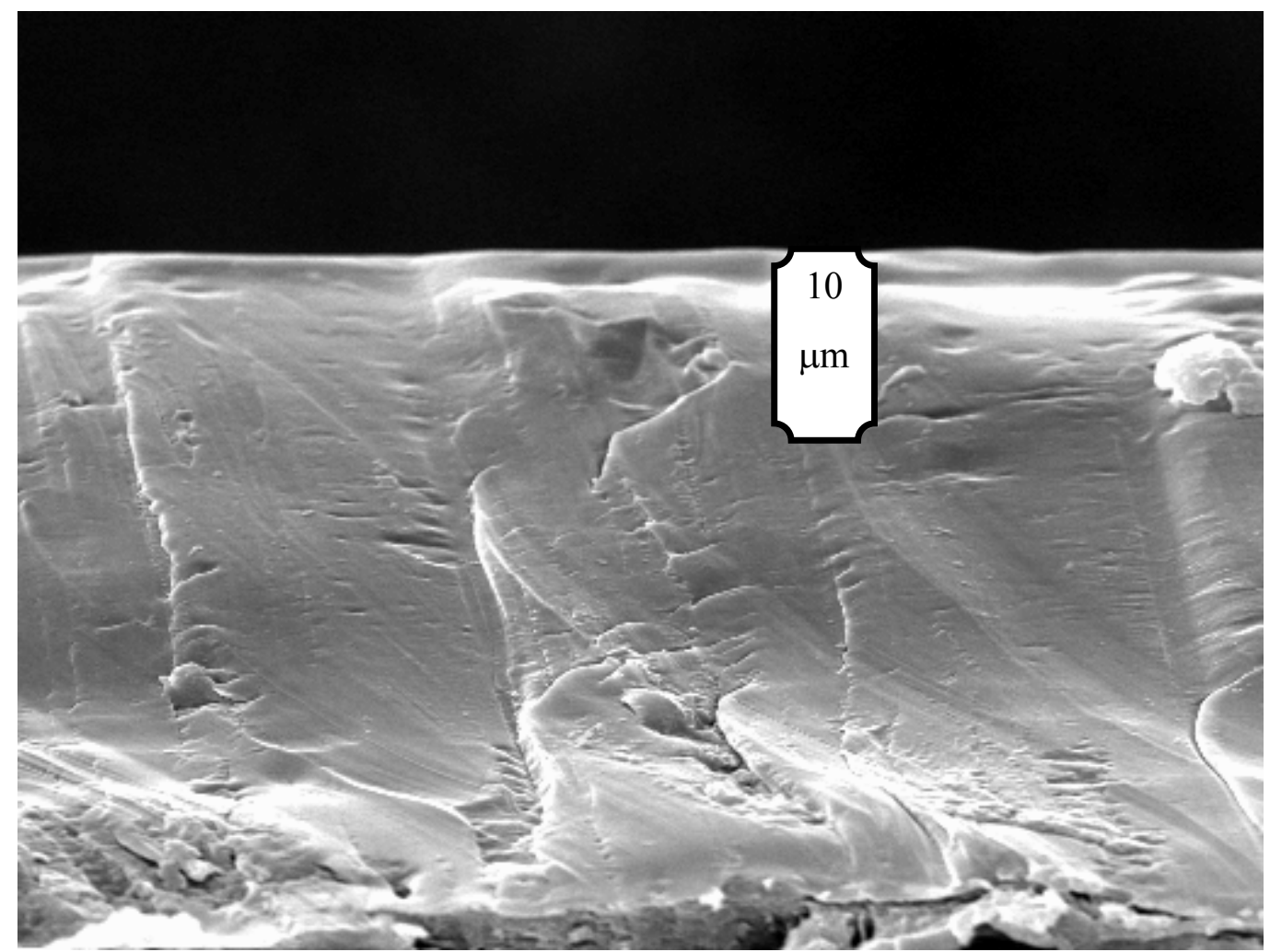

Ilustración 111. Muestra 10 - 2000 X. Estructura polimérica densa formada con un elevado tiempo de evaporación (120 seg.) 


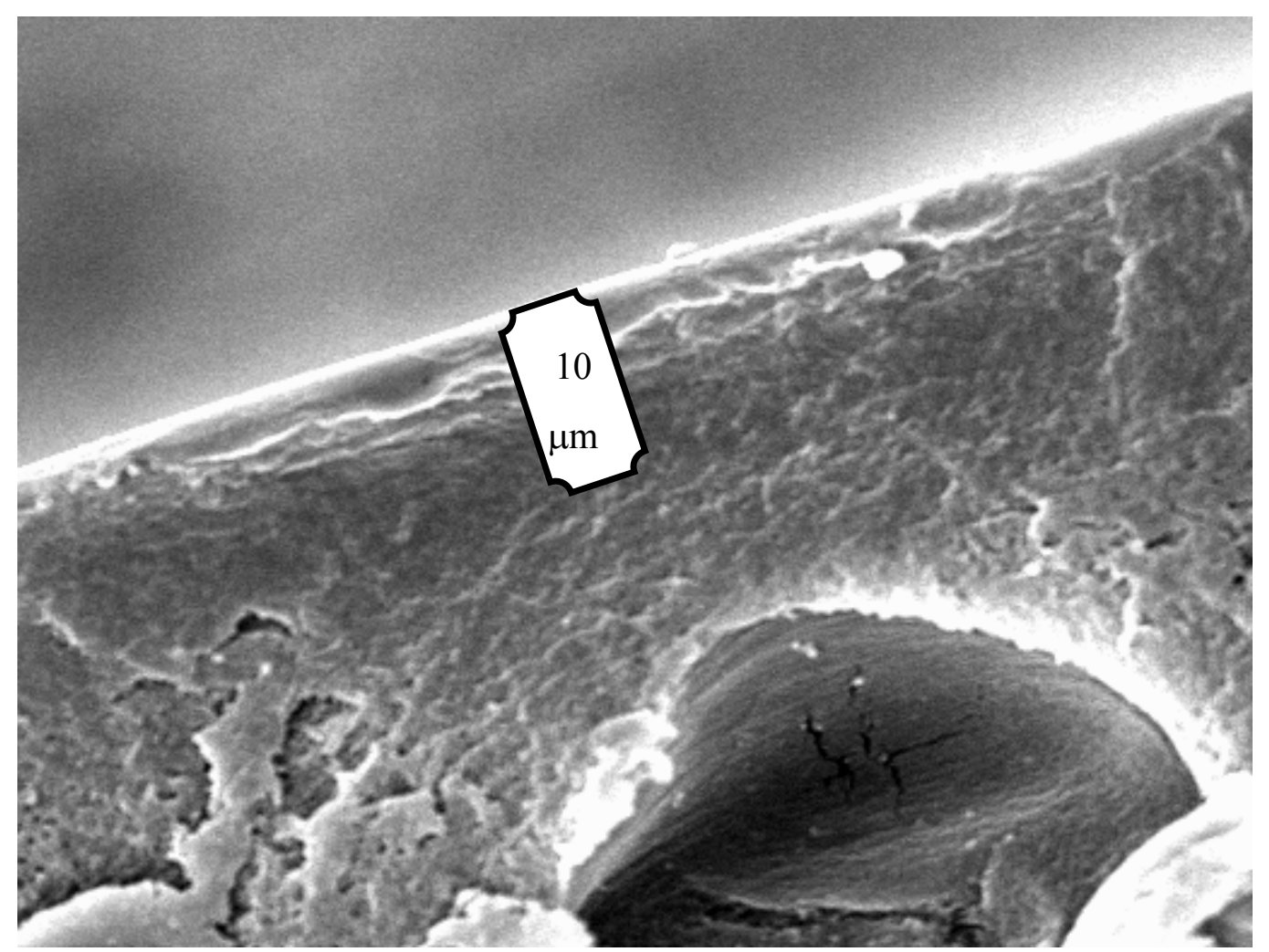

Ilustración 112. Muestra 2 - 2000 X. Estructura con poros cerrados por el tratamiento térmico.

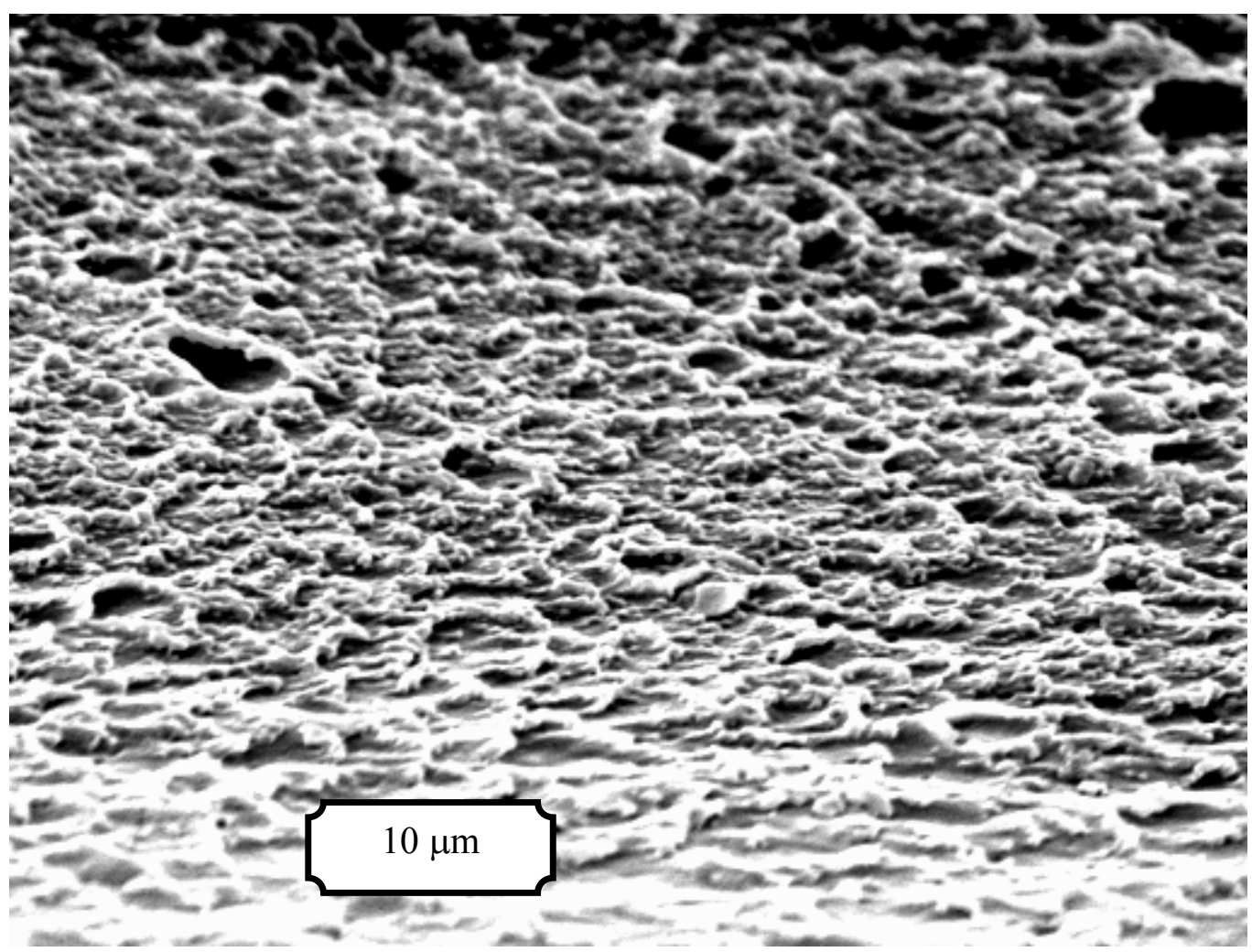

Ilustración 113. Muestra $6-2000$ X. Vista superficial de una membrana porosa. 


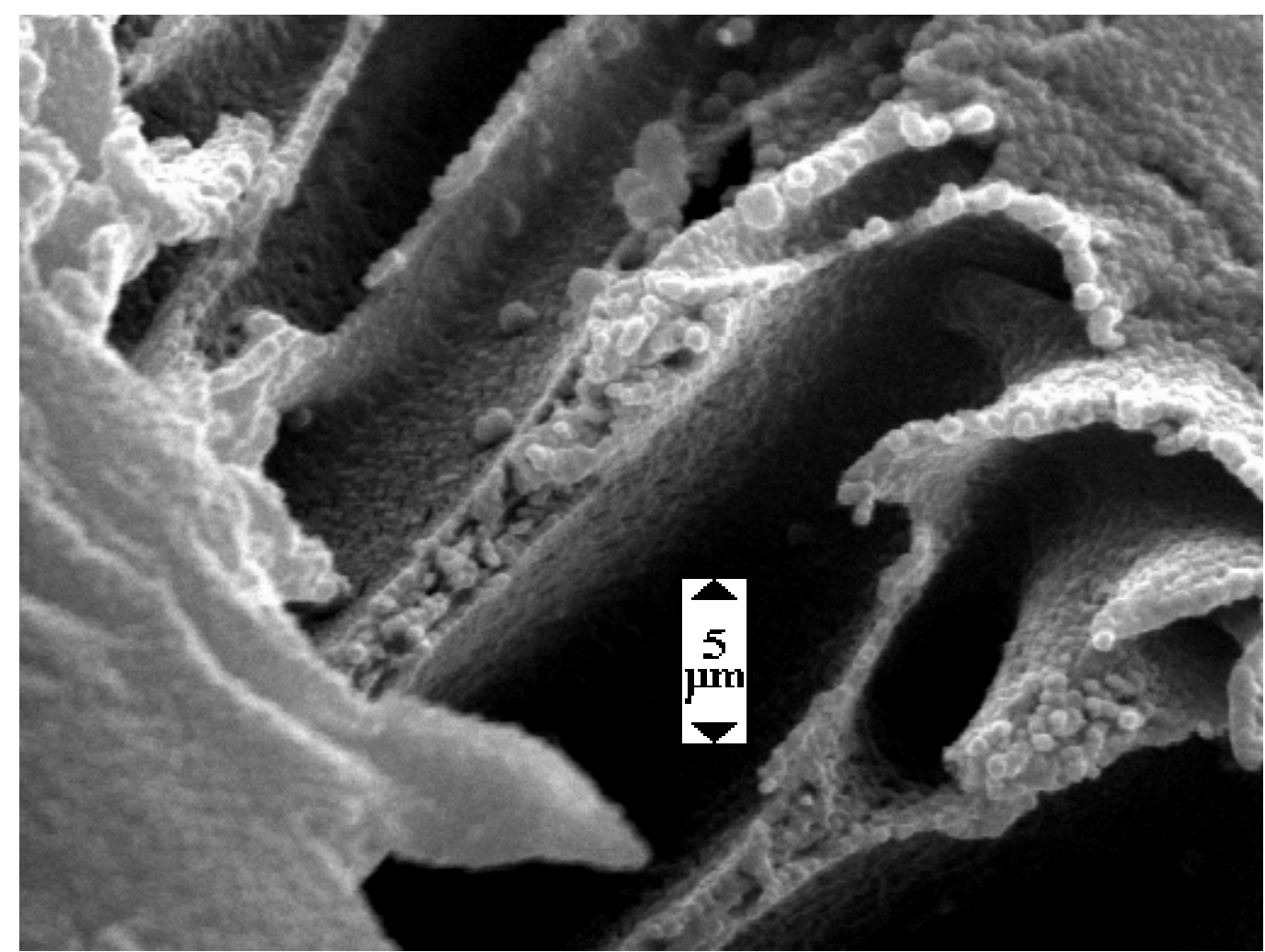

Ilustración 114. Estructura de la capa superior de una membrana de ultrafiltración $35000 X$

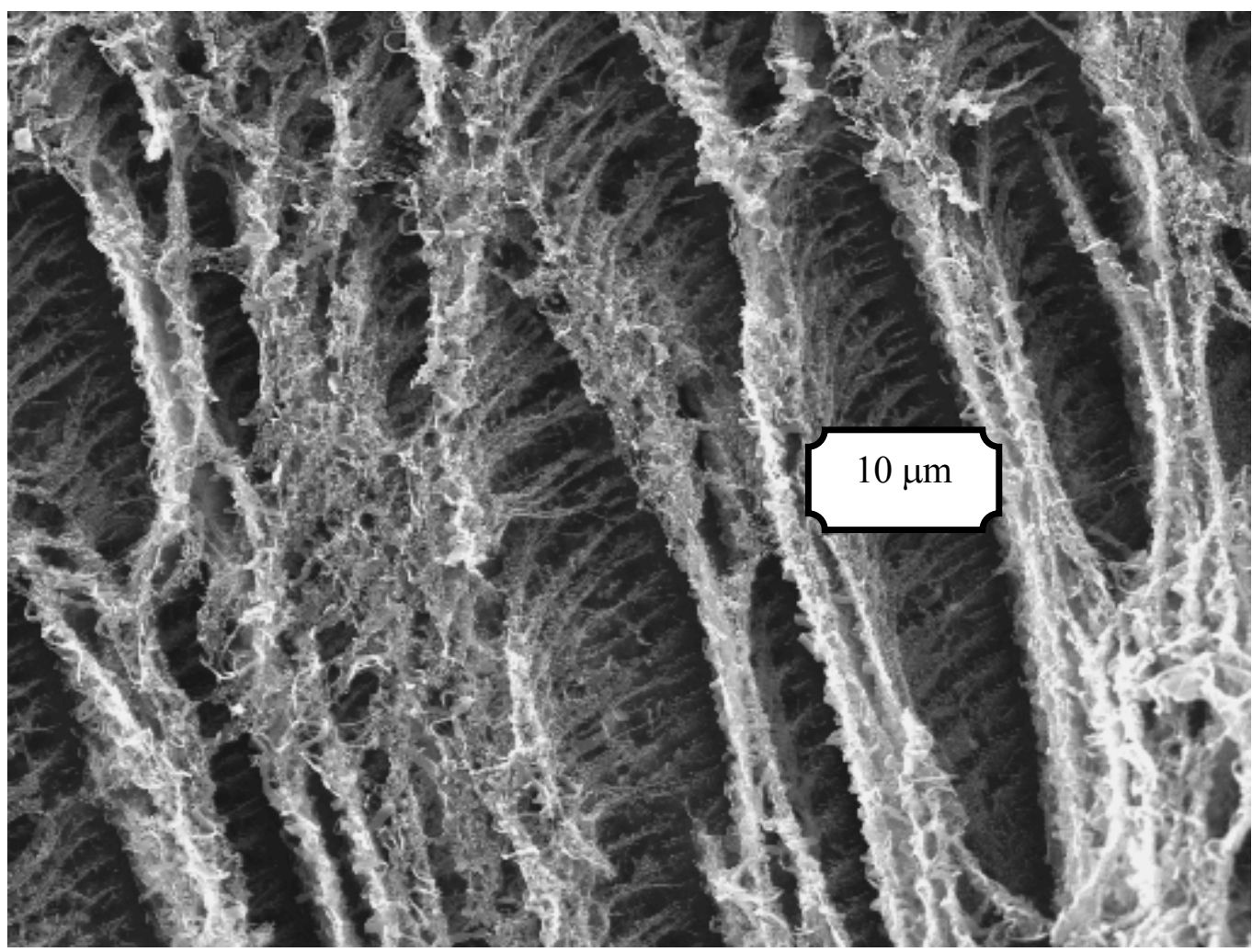

Ilustración 115. Estructura de la capa intermedia de una membrana de ultrafiltración $1000 \mathrm{X}$. 


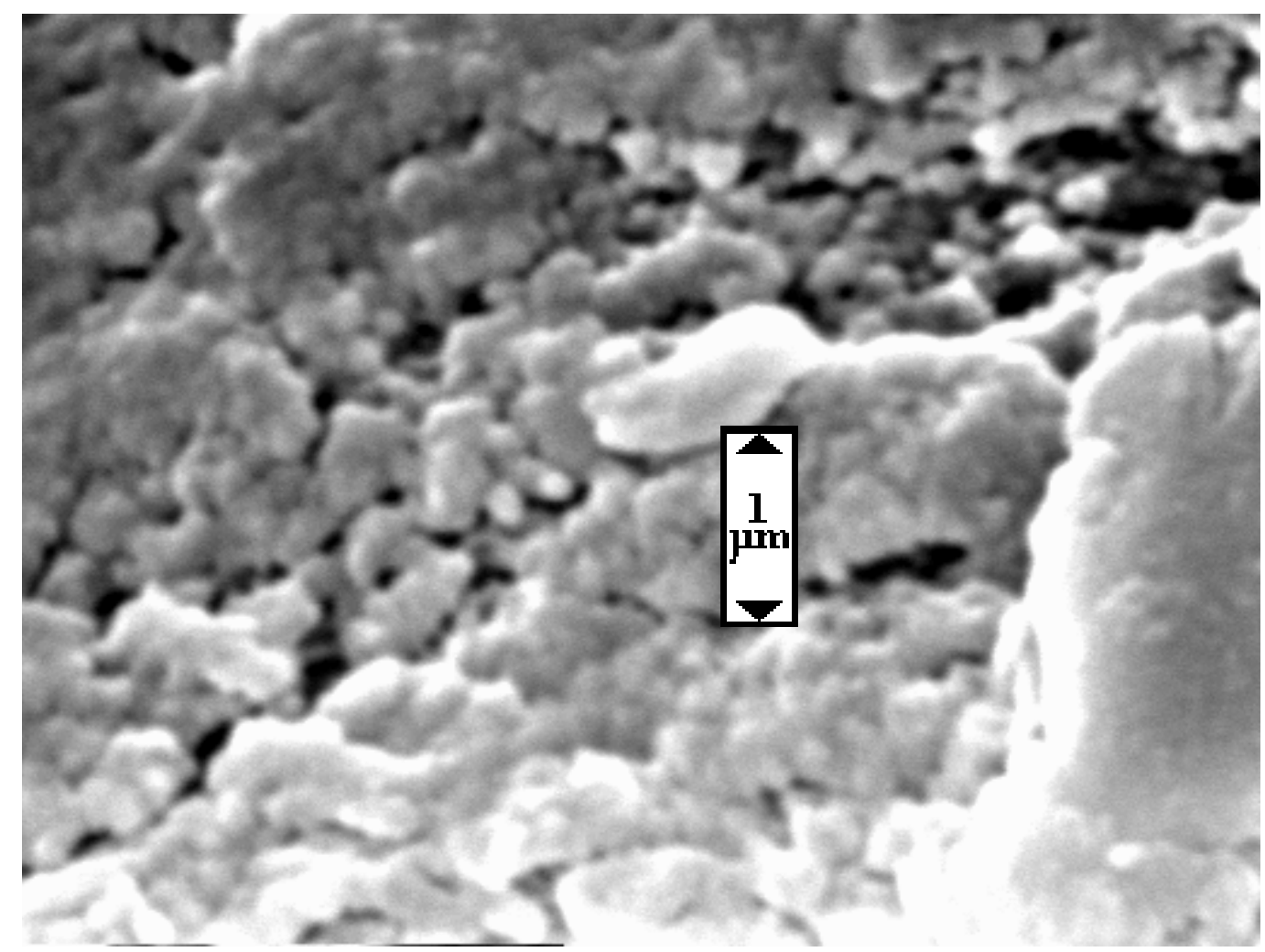

Ilustración 116. Muestra 14-20000 X. Estructura de nanofiltración

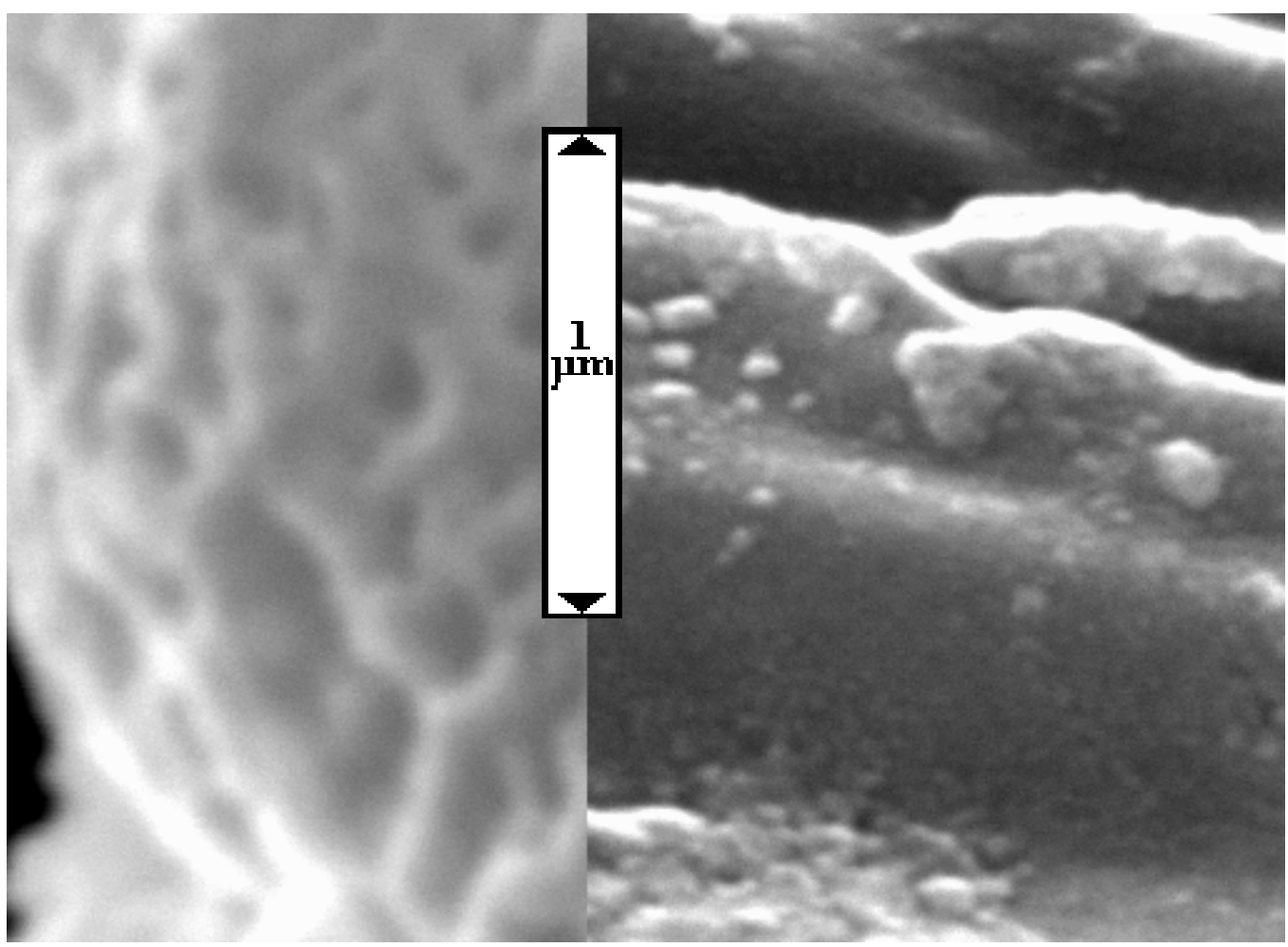

Ilustración 117. Muestra 5 y 9 -50000 X. Estructuras típicas de ósmosis inversa 


\section{ANEXO III: Determinación teórica del}

diagrama ternario 


\section{ANEXO III: Determinación teórica del diagrama ternario}

El presente anexo es la exportación a procesador de textos de un programa realizado por el autor de la Tesis en MathCad v. $6++$. La elección de este entorno para la realización de los cálculos teóricos de esta tesis ha venido determinada por la sencilla notación disponible que permite que las expresiones matemáticas aparezcan en su expresión usual, así como por los métodos de resolución de sistemas de ecuaciones y las posibilidades gráficas que incorpora.

\section{Descripción del programa}

En este programa de cálculo se ajusta el coeficiente binario disolvente polímero a partir de datos experimentales de la curva binodal y los otros dos coeficientes binarios.

Una vez ajustado el coeficiente se obtiene información sobre situación del punto crítico, rectas de reparto, curva binodal ajustada y curva espinodal. También es posible estimar los efectos que sobre el diagrama tienen la modificación de diferentes variables como el peso molecular del polímero o parámetros dependientes del disolvente.

\section{Variables matemáticas:}

Origen de los vectores utilizados:

ORIGIN $\equiv 0$

Tolerancia de error en el cálculo:

TOL $\equiv 10^{-8}$ 
Notación utilizada:

Subíndices: $\quad$ 1: Disolvente (N-N' Dimetilacetamida)

2: No-disolvente (Agua)

3: Polímero (Acetato de celulosa CA-398-3)

Superíndices: $\quad$ Comillas simple (') y doble ("): Fases A y B en equilibrio

$\phi_{\mathrm{i}} \quad$ Fracción volumétrica del componente i

$\mathrm{x}_{\mathrm{i}} \quad$ Fracción másica o molar del componente $\mathrm{i}$.

Datos y funciones auxiliares:

- Masas moleculares:

Las masas moleculares de disolvente y no-disolvente en $\mathrm{g} / \mathrm{mol}$ son:

$$
\mathrm{M}_{1}:=87.12 \quad \mathrm{M}_{2}:=18
$$

Para el polímero se considerará una longitud media de cadena y peso molecular basado en ella siguientes:

$$
\mathrm{n}:=360 \quad \mathrm{M}_{3}:=\mathrm{n} \cdot 230
$$

- Relación de volúmenes molares respecto del componente 1:

Se consideraron los siguientes datos extraídos de Henley y Seader (1988):

$$
\begin{aligned}
& \mathrm{v}_{1}:=93.0 \quad \mathrm{~V}_{2}:=18.1 \\
& \mathrm{v}_{3}:=((5 \cdot(14.8+3.7)-15)+11+14.8+2 \cdot(3.7)+7.4+3.7+2 \cdot(9.9+14.8+7.4+14.8+3 \cdot 3.7)) \cdot \mathrm{n} \\
& \mathrm{v}_{1}:=1 \quad \quad \mathrm{v}_{2}:=\frac{\mathrm{v}_{2}}{\mathrm{v}_{1}} \quad \mathrm{v}_{2}=0.195 \quad \mathrm{v}_{3}:=1.98 \mathrm{n}
\end{aligned}
$$


- Coeficientes de interacción binarios de Flory-Huggins $\left(25^{\circ} \mathrm{C}\right)$ :

El coeficiente de interacción disolvente - polímero a determinar es $\chi_{13}$.

El coeficiente de interacción no-disolvente - polímero que se obtuvo experimentalmente fue $\chi_{23}:=1.4$

El parámetro de interacción disolvente - no-disolvente depende significativamente de las concentraciones relativas entre ambos componentes por lo que viene expresado en función de la fracción volumétrica en base exenta de polímero $\mathrm{u}_{1}$

$$
\mathrm{u}_{1}=\frac{\phi_{1}}{\phi_{1}+\phi_{2}}
$$

$\mathrm{u}_{1 \exp }:=\left[\begin{array}{c}0.954 \\ 0.939 \\ 0.923 \\ 0.905 \\ 0.885 \\ 0.862 \\ 0.837 \\ 0.808 \\ 0.774\end{array}\right] \quad \mathrm{g}_{12}:=\left[\begin{array}{c}6.634 \\ 5.836 \\ 5.298 \\ 4.907 \\ 4.609 \\ 4.37 \\ 4.17 \\ 4.0 \\ 3.86\end{array}\right]$

$$
\chi_{12}\left(\mathrm{u}_{1}\right):=\operatorname{interp}\left(\operatorname{lspline}(\mathrm{X}, \mathrm{Y}), \mathrm{X}, \mathrm{Y}, \mathrm{u}_{1}\right)
$$

Abajo queda representado la evolución del parámetro en función de la composición:

$\mathrm{u}_{1}:=0.95,0.945 . .0 .78$

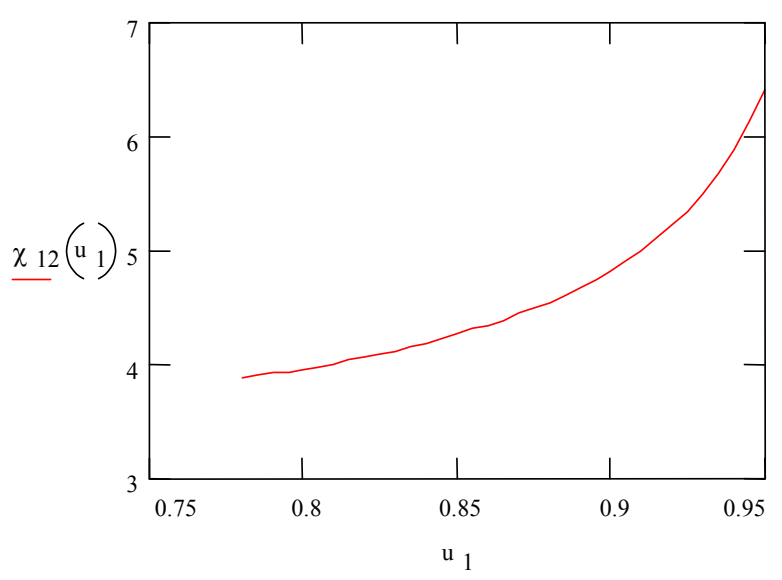


- Funciones de conversión entre fracciones volumétricas y másicas:

$$
\begin{aligned}
& \text { fmásica }\left(\phi_{1}, \phi_{2}, \phi_{3}\right):=\frac{1}{\phi_{1} \cdot \frac{\mathrm{M}_{1}}{\mathrm{v}_{1}}+\phi_{2} \cdot \frac{\mathrm{M}_{2}}{\mathrm{v}_{2}}+\phi_{3} \cdot \frac{\mathrm{M}_{3}}{\mathrm{v}_{3}}} \cdot\left[\begin{array}{c}
\phi_{1} \cdot \frac{\mathrm{M}_{1}}{\mathrm{v}_{1}} \\
\phi_{2} \cdot \frac{\mathrm{M}_{2}}{\mathrm{v}_{2}} \\
\phi_{3} \cdot \frac{\mathrm{M}_{3}}{\mathrm{v}_{3}}
\end{array}\right] \\
& \text { fvolum }\left(\mathrm{x}_{1}, \mathrm{x}_{2}, \mathrm{x}_{3}\right):=\frac{1}{\mathrm{x}_{1} \cdot \frac{\mathrm{v}_{1}}{\mathrm{M}_{1}}+\mathrm{x}_{2} \cdot \frac{\mathrm{v}_{2}}{\mathrm{M}_{2}}+\mathrm{x}_{3} \cdot \frac{\mathrm{v}_{3}}{\mathrm{M}_{3}}} \cdot\left[\begin{array}{c}
\mathrm{x}_{1} \cdot \frac{\mathrm{v}_{1}}{\mathrm{M}_{1}} \\
\mathrm{x}_{2} \cdot \frac{\mathrm{v}_{2}}{\mathrm{M}_{2}} \\
\mathrm{x}_{3} \cdot \frac{\mathrm{v}_{3}}{\mathrm{M}_{3}}
\end{array}\right]
\end{aligned}
$$

- Funciones para representación gráfica:

Para obtener las posiciones en el diagrama triangular de fracciones másicas o volumétricas se utilizará:

$$
\begin{aligned}
& \operatorname{Pos} X\left(z_{1}, z_{3}\right):=\left(1-z_{1}-z_{3}\right)+z_{3} \cdot \cos \left(\frac{\pi}{3}\right) \\
& \operatorname{Pos} Y\left(z_{1}, z_{3}\right):=z_{3} \cdot \sin \left(\frac{\pi}{3}\right)
\end{aligned}
$$

Las coordenadas de los vértices (composiciones puras) y ejes (composiciones binarias) obtenidas con las anteriores funciones son:

$$
\mathrm{k}:=0 . .2 \quad \mathrm{Xlínea}:=\left(\begin{array}{l}
\operatorname{Pos} \mathrm{X}(1,0) \\
\operatorname{Pos} \mathrm{X}(0,1) \\
\operatorname{Pos} \mathrm{X}(0,0)
\end{array}\right) \quad \text { Ylínea }:=\left(\begin{array}{l}
\operatorname{Pos} \mathrm{Y}(1,0) \\
\operatorname{Pos} \mathrm{Y}(0,1) \\
\operatorname{Pos}(0,0)
\end{array}\right)
$$




\section{Representación de puntos experimentales}

A continuación se representan los puntos de la binodal experimentales que se obtuvieron para el sistema tal y como se contempla en el apartado de Metodología.

$$
\begin{aligned}
& \text { ie }:=0 . .8 \\
& \mathrm{x}_{1 \exp _{\mathrm{e}}}:=\quad \mathrm{x}_{3 \exp _{\mathrm{e}}}:= \\
& 0.7300 \quad 0.1305 \\
& \begin{array}{|l|l|}
\hline 0.7302 & 0.1023 \\
\hline 0.7600 & 0.8502 \\
\hline
\end{array} \\
& \begin{array}{|l|l|}
\hline 0.7500 & 0.0850 \\
\hline 0.7710 & 0.067 \\
\hline
\end{array} \\
& \begin{array}{|l|l|}
\hline 0.7710 & 0.0671 \\
\hline 0.7795
\end{array} \\
& \begin{array}{l|l|}
\hline 0.7710 & 0.0498 \\
\hline 0.7845 & 0.0350 \\
\hline
\end{array} \\
& \begin{array}{|l|l|}
\hline 0.7845 & 0.0350 \\
\hline 0.7902 & 0.061 \\
\hline
\end{array} \\
& \begin{array}{|l|l|}
\hline 0.7902 & 0.0161 \\
\hline 0.7920 & 0.080 \\
\hline
\end{array} \\
& \begin{array}{|l|l|}
\hline 0.7920 & 0.0080 \\
\hline 0.7919 & 0.001
\end{array} \\
& 0.7919 \quad 0.0041 \\
& \mathrm{x}_{2 \exp _{\mathrm{ie}}}:=1-\mathrm{x}_{1 \exp _{\mathrm{ie}}}-\mathrm{x}_{3 \exp _{\mathrm{ie}}}
\end{aligned}
$$

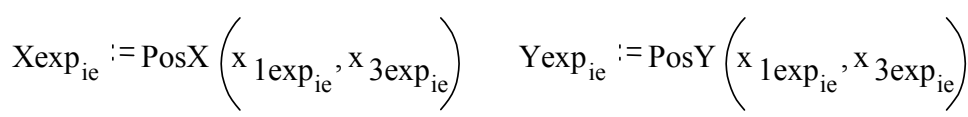

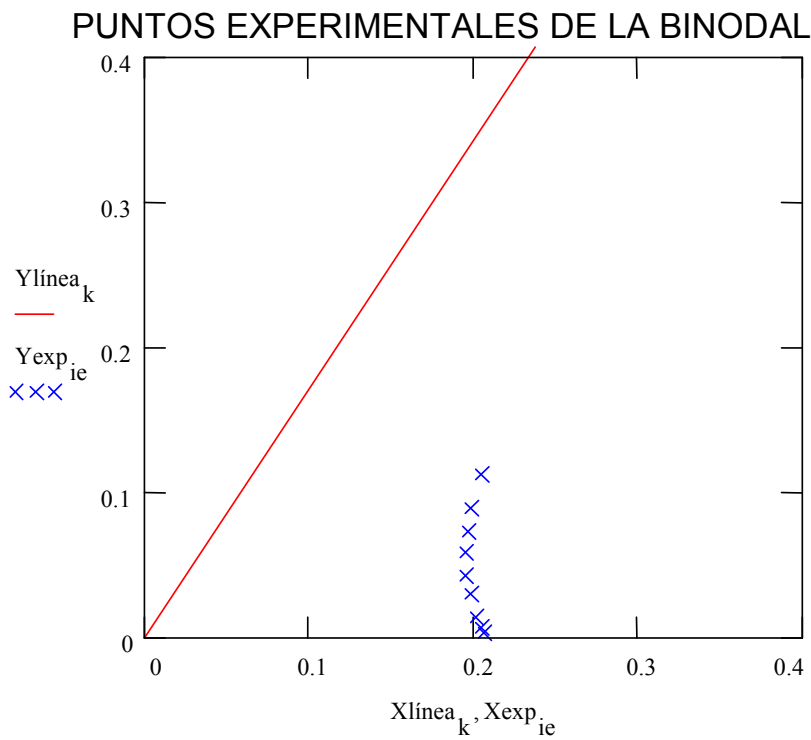

FRACCIÓN MÁSICA DE AGUA --> 


\section{Ecuaciones del modelo termodinámico para el sistema ternario}

A) Expresión para la energía libre de Gibbs específica adimensional de la mezcla

El equilibrio termodinámico en mezclas puede ser estudiado mediante el incremento de energía libre de mezcla definido como la diferencia existente entre la energía libre de la mezcla y la suma de la de los componentes por separado.

Las teorías termodinámicas de las disoluciones macromoleculares extendidas a los sistemas multicomponentes llevan a la siguiente expresión para la energía libre específica de mezcla $\Delta \mathrm{G}_{\mathrm{m}}$ en función de fracciones molares y volumétricas (Champetier y George, 1973):

$$
\begin{aligned}
\frac{\Delta \mathrm{G}_{\mathrm{m}}}{\mathrm{R} \cdot \mathrm{T}} & \mathrm{x}_{1} \cdot \ln \left(\phi_{1}\right)+\mathrm{x}_{2} \cdot \ln \left(\phi_{2}\right)+\mathrm{x}_{3} \cdot \ln \left(\phi_{3}\right) \ldots \\
& +\chi_{12} \cdot \frac{\mathrm{v}_{1}}{\mathrm{v}_{1}} \cdot \mathrm{x}_{1} \cdot \phi_{2}+\chi_{23} \cdot \frac{\mathrm{v}_{2}}{\mathrm{v}_{1}} \cdot \mathrm{x}_{2} \cdot \phi_{3}+\chi_{13} \cdot \frac{\mathrm{v}_{3}}{\mathrm{v}_{1}} \cdot \mathrm{x}_{3} \cdot \phi_{1}
\end{aligned}
$$

El tratamiento siguiente será válido para una temperatura establecida ya que no se tiene en cuenta la dependencia de los coeficientes binarios con la temperatura:

Denominando $G m=\frac{\Delta G_{m}}{R \cdot T}$ la energía libre de mezcla y relacionando fracciones volumétricas y molares queda como:

$$
\begin{aligned}
\operatorname{Gm}\left(\mathrm{x}_{1}, \mathrm{x}_{2}, \mathrm{x}_{3}\right)= & \mathrm{x}_{1} \cdot \ln \left(\phi_{1}\left(\mathrm{x}_{1}, \mathrm{x}_{2}, \mathrm{x}_{3}\right)\right)+\mathrm{x}_{2} \cdot \ln \left(\phi_{2}\left(\mathrm{x}_{1}, \mathrm{x}_{2}, \mathrm{x}_{3}\right)\right)+\mathrm{x}_{3} \cdot \ln \left(\phi_{3}\left(\mathrm{x}_{1}, \mathrm{x}_{2}, \mathrm{x}_{3}\right)\right) \ldots \\
& +\chi_{12} \cdot \frac{\mathrm{v}_{1}}{\mathrm{v}_{1}} \cdot \mathrm{x}_{1} \cdot \phi_{2}\left(\mathrm{x}_{1}, \mathrm{x}_{2}, \mathrm{x}_{3}\right)+\chi_{23} \cdot \frac{\mathrm{v}_{2}}{\mathrm{v}_{1}} \cdot \mathrm{x}_{2} \cdot \phi_{3}\left(\mathrm{x}_{1}, \mathrm{x}_{2}, \mathrm{x}_{3}\right)+\chi_{13} \cdot \frac{\mathrm{v}_{3}}{\mathrm{v}_{1}} \cdot \mathrm{x}_{3} \cdot \phi_{1}\left(\mathrm{x}_{1}, \mathrm{x}_{2}, \mathrm{x}_{3}\right)
\end{aligned}
$$




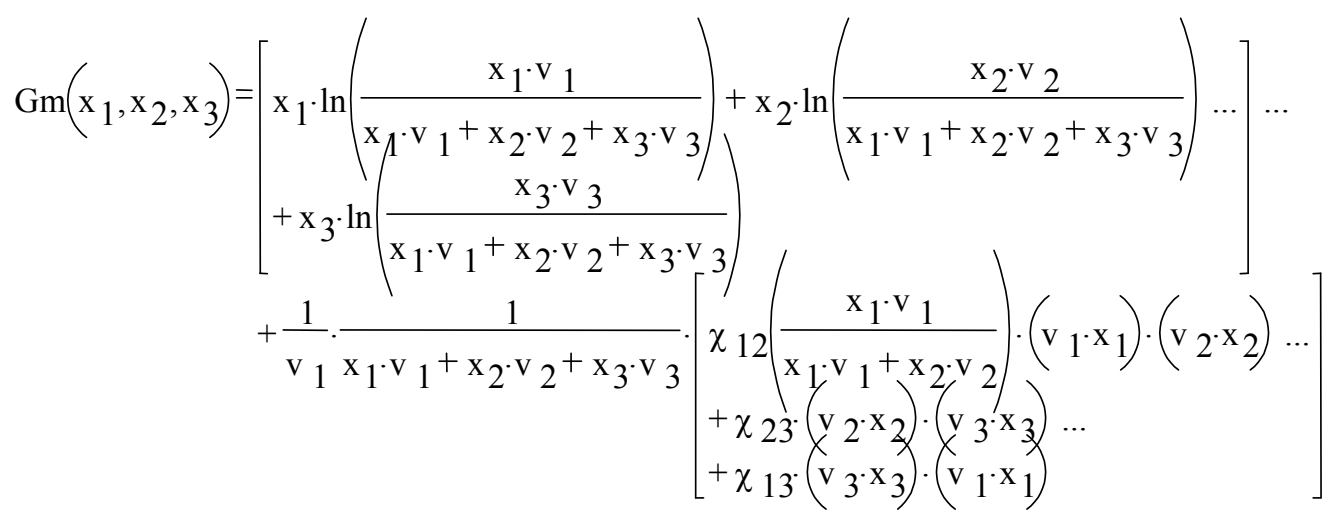

$\underline{\text { Potenciales químicos adimensionalizados del sistema ternario: }}$

A partir de la aplicación a la anterior expresión de la definición de potencial químico se pueden obtener estos para cada componente $i$ en la mezcla:

$$
\mu_{i}=\left(\frac{\delta G_{m}}{\delta x_{i}}\right)_{x_{i} \neq_{j}=\text { cte }}
$$

Para facilitar la derivación se ha desligado la influencia de la no constancia del parámetro $\chi 12$

$$
\begin{aligned}
& \mathrm{dGm}=\left(\frac{\partial \mathrm{Gm}}{\partial \mathrm{x}_{\mathrm{i}}}\right)_{\chi_{12}=\mathrm{cte}} \cdot \mathrm{dx}_{\mathrm{i}}+\left(\frac{\partial \mathrm{Gm}}{\partial \chi_{12}}\right) \cdot\left(\frac{\partial \chi_{12}}{\partial \mathrm{x}_{\mathrm{i}}}\right) \cdot \mathrm{dx}_{\mathrm{i}} \quad \mu_{\mathrm{i}}=\mu_{\mathrm{i}_{\chi_{12}=\mathrm{cte}}}+\left(\frac{\partial \mathrm{G}_{\mathrm{m}}}{\partial \chi_{12}}\right) \cdot\left(\frac{\mathrm{d}_{12}}{\mathrm{du}_{1}}\right) \cdot \frac{\mathrm{du}_{1}}{\mathrm{dx}_{\mathrm{i}}} \\
& \frac{\delta \mathrm{Gm}}{\delta \chi_{12}}=\frac{1}{\mathrm{v}_{1}} \cdot \frac{1}{\mathrm{x}_{1} \cdot \mathrm{v}_{1}+\mathrm{x}_{2} \cdot \mathrm{v}_{2}+\mathrm{x}_{3} \cdot \mathrm{v}_{3}} \cdot\left(\mathrm{v}_{1} \cdot \mathrm{x}_{1}\right) \cdot\left(\mathrm{v}_{2} \cdot \mathrm{x}_{2}\right) \\
& \mathrm{d} \chi_{12}\left(\mathrm{u}_{1}\right):=\frac{\mathrm{d}}{\mathrm{du}_{1}} \chi_{12}\left(\mathrm{u}_{1}\right) \quad \mathrm{u}_{1}=\frac{\phi_{1}}{\phi_{1}+\phi_{2}}=\frac{\mathrm{x}_{1} \cdot \mathrm{v}_{1}}{\mathrm{x}_{1} \cdot \mathrm{v}_{1}+\mathrm{x}_{2} \cdot \mathrm{v}_{2}} \\
& \frac{\mathrm{du}}{1}=\frac{\mathrm{v}_{1} \cdot \mathrm{v}_{2} \cdot \mathrm{x}_{2}}{\mathrm{dx}_{1}} \quad \frac{\mathrm{du} 1}{\left(\mathrm{x}_{1} \cdot \mathrm{v}_{1}+\mathrm{x}_{2} \cdot \mathrm{v}_{2}\right)^{2}}=\frac{-\mathrm{v}_{1} \cdot \mathrm{v}_{2} \cdot \mathrm{x}_{1}}{\mathrm{dx}_{2}} \quad \frac{\mathrm{du}}{\left(\mathrm{x}_{1} \cdot \mathrm{v}_{1}+\mathrm{x}_{2} \cdot \mathrm{v}_{2}\right)^{2}}=0
\end{aligned}
$$




$$
\begin{aligned}
& \left(\frac{\mathrm{dgm}}{\mathrm{d} \chi_{12}}\right) \cdot \frac{\mathrm{du} 1}{\mathrm{dx}}=\left[\frac{1}{\mathrm{v}_{1}} \cdot \frac{\left(\mathrm{v}_{1} \cdot \mathrm{x}_{1}\right) \cdot\left(\mathrm{v}_{2} \cdot \mathrm{x}_{2}\right)}{\mathrm{x}_{1} \cdot \mathrm{v}_{1}+\mathrm{x}_{2} \cdot \mathrm{v}_{2}+\mathrm{x}_{3} \cdot \mathrm{v}_{3}}\right] \cdot \frac{\mathrm{v}_{1} \cdot \mathrm{v}_{2} \cdot \mathrm{x}_{2}}{\left(\mathrm{x}_{1} \cdot \mathrm{v}_{1}+\mathrm{x}_{2} \cdot \mathrm{v}_{2}\right)^{2}}=\frac{\phi_{1} \cdot \phi_{2}{ }^{2}}{\left(\phi_{1}+\phi_{2}\right)^{2}} \\
& \left(\frac{\mathrm{dgm}}{\mathrm{d}_{12}}\right) \cdot \frac{\mathrm{du}}{\mathrm{dx}_{2}}=\left[\frac{1}{\mathrm{v}_{1}} \cdot \frac{\left(\mathrm{v}_{1} \cdot \mathrm{x}_{1}\right) \cdot\left(\mathrm{v}_{2} \cdot \mathrm{x}_{2}\right)}{\mathrm{x}_{1} \cdot \mathrm{v}_{1}+\mathrm{x}_{2} \cdot \mathrm{v}_{2}+\mathrm{x}_{3} \cdot \mathrm{v}_{3}}\right] \cdot \frac{-\mathrm{v}_{1} \cdot \mathrm{v}_{2} \cdot \mathrm{x}_{1}}{\left(\mathrm{x}_{1} \cdot \mathrm{v}_{1}+\mathrm{x}_{2} \cdot \mathrm{v}_{2}\right)^{2}}=\frac{-\mathrm{v}_{2}}{\mathrm{v}_{1}} \cdot \frac{\phi_{2} \cdot \phi_{1}{ }^{2}}{\left(\phi_{1}+\phi_{2}\right)^{2}}
\end{aligned}
$$

Operando con las anteriores derivadas se obtienen los siguientes términos que representan el efecto de la variación de $\chi_{12}$ con $\phi_{1}$ y $\phi_{2}$.

$$
\begin{aligned}
& \mathrm{d}_{12 \_1}\left(\phi_{1}, \phi_{2}\right):=\frac{\phi_{1} \cdot \phi_{2}{ }^{2}}{\left(\phi_{1}+\phi_{2}\right)^{2}} \cdot \mathrm{d} \chi_{12}\left(\frac{\phi_{1}}{\phi_{1}+\phi_{2}}\right) \\
& \mathrm{d} \chi_{12 \_2}\left(\phi_{1}, \phi_{2}\right):=\frac{-\mathrm{v}_{2}}{\mathrm{v}_{1}} \cdot \frac{\phi_{2} \cdot \phi_{1}{ }^{2}}{\left(\phi_{1}+\phi_{2}\right)^{2}} \cdot \mathrm{d}_{\chi_{12}}\left(\frac{\phi_{1}}{\phi_{1}+\phi_{2}}\right) \\
& \mathrm{d} \chi_{12 \_3}\left(\phi_{1}, \phi_{2}\right):=0
\end{aligned}
$$

Los potenciales químicos de cada componente son obtenidos sumando los anteriores términos a los resultados de la derivación de la energía libre de mezcla respecto de cada fracción molar para el parámetro $\chi_{12}$ mantenido constante.

Las expresiones finalmente obtenidas para los potenciales son:

$$
\begin{aligned}
\mu_{1}\left(\phi_{1}, \phi_{2}, \phi_{3}\right)= & {\left[\ln \left(\phi_{1}\right)+1-\mathrm{v}_{1} \cdot\left(\frac{\phi_{1}}{\mathrm{v}_{1}}+\frac{\phi_{2}}{\mathrm{v}_{2}}+\frac{\phi_{3}}{\mathrm{v}_{3}}\right)\right] \ldots } \\
& +\left[\chi_{12}\left(\frac{\phi_{1}}{\phi_{1}+\phi_{2}}\right) \cdot \phi_{2} \cdot\left(1-\phi_{1}\right)+\chi_{13} \cdot \phi_{3} \cdot\left(1-\phi_{1}\right)-\chi_{23} \cdot \phi_{2} \cdot \phi_{3}\right] \ldots \\
& +\mathrm{d} \chi_{12}{ }_{1}\left(\phi_{1}, \phi_{2}\right) \\
\mu_{2}\left(\phi_{1}, \phi_{2}, \phi_{3}\right)= & {\left[\ln \left(\phi_{2}\right)+1-\mathrm{v}_{2} \cdot\left(\frac{\phi_{1}}{\mathrm{v}_{1}}+\frac{\phi_{2}}{\mathrm{v}_{2}}+\frac{\phi_{3}}{\mathrm{v}_{3}}\right)\right] \ldots } \\
& +\frac{\mathrm{v}_{2}}{\mathrm{v}_{1}} \cdot\left[\chi_{12}\left(\frac{\phi_{1}}{\phi_{1}+\phi_{2}}\right) \cdot \phi_{1} \cdot\left(1-\phi_{2}\right)-\chi_{13} \cdot \phi_{1} \cdot \phi_{3}+\chi_{23} \cdot \phi_{3} \cdot\left(1-\phi_{2}\right)\right] \ldots \\
& +\mathrm{d}_{12} \chi_{12}\left(\phi_{1}, \phi_{2}\right)
\end{aligned}
$$




$$
\begin{aligned}
\mu_{3}\left(\phi_{1}, \phi_{2}, \phi_{3}\right)= & {\left[\ln \left(\phi_{3}\right)+1-\mathrm{v}_{3} \cdot\left(\frac{\phi_{1}}{\mathrm{v}_{1}}+\frac{\phi_{2}}{\mathrm{v}_{2}}+\frac{\phi_{3}}{\mathrm{v}_{3}}\right)\right] \ldots } \\
& +\frac{\mathrm{v}_{3}}{\mathrm{v}_{1}} \cdot\left[-\chi_{12}\left(\frac{\phi_{1}}{\phi_{1}+\phi_{2}}\right) \cdot \phi_{1} \cdot \phi_{2}+\chi_{13} \cdot \phi_{1} \cdot\left(1-\phi_{3}\right)+\chi_{23} \cdot \phi_{2} \cdot\left(1-\phi_{3}\right)\right] \ldots \\
& +\mathrm{d}_{12} \chi_{1}\left(\phi_{1}, \phi_{2}\right)
\end{aligned}
$$

En el equilibrio fisico-químico entre dos fases se tiene que los potenciales químicos de cada uno de los componentes en las dos fases indicadas con (') y (") son iguales.

$$
\begin{aligned}
& \mu_{1}\left(\phi^{\prime}{ }_{1}, \phi^{\prime}{ }_{2}, \phi^{\prime}{ }_{3}\right)=\mu_{1}\left(\phi^{\prime \prime}{ }_{1}, \phi^{\prime \prime}{ }_{2}, \phi^{\prime \prime}{ }_{3}\right) \\
& \mu_{2}\left(\phi^{\prime}{ }_{1}, \phi^{\prime}{ }_{2}, \phi^{\prime}{ }_{3}\right)=\mu_{2}\left(\phi^{\prime \prime}{ }_{1}, \phi^{\prime \prime}{ }_{2}, \phi^{\prime \prime}{ }_{3}\right) \\
& \mu_{3}\left(\phi^{\prime}{ }_{1}, \phi^{\prime}{ }_{2}, \phi^{\prime}{ }_{3}\right)=\mu_{3}\left(\phi^{\prime \prime}{ }_{1}, \phi^{\prime \prime}{ }_{2}, \phi^{\prime \prime}{ }_{3}\right)
\end{aligned}
$$

\section{Curva espinodal y punto crítico}

El punto crítico se encuentra a la vez en la curva binodal y espinodal. Se han probado diferentes valores de punto crítico situándolo sobre puntos experimentales de la curva binodal hasta lograr posteriormente un buen ajuste entre puntos calculados y experimentales.

Las coordenadas del punto crítico son:

$$
\begin{aligned}
& {\left[\begin{array}{l}
x_{1 c} \\
x_{2 c} \\
x_{3 c}
\end{array}\right]:=\left[\begin{array}{l}
x_{1} \exp _{c} \\
x_{2 \exp } \\
x_{3 e x p}
\end{array}\right] \quad\left[\begin{array}{l}
\phi_{1 c} \\
\phi_{2 c} \\
\phi_{3 c}
\end{array}\right]:=\operatorname{fvolum}\left(x_{1 c}, x_{2 c}, x_{3 c}\right) \quad u_{1 c}:=\frac{\phi_{1 c}}{\phi_{1 c}+\phi_{2 c}}} \\
& \mathrm{u}_{1 \mathrm{c}}=0.812 \\
& \begin{array}{r}
{\left[\begin{array}{l}
\mathrm{x}_{1 \mathrm{c}} \\
\mathrm{x}_{2 \mathrm{c}} \\
\mathrm{x}_{3 \mathrm{c}}
\end{array}\right]:=\operatorname{fmásica}\left(\phi_{1 \mathrm{c}}, \phi_{2 \mathrm{c}}, \phi_{3 c}\right) \quad\left[\begin{array}{l}
\mathrm{x}_{1 \mathrm{c}} \\
\mathrm{x}_{2 \mathrm{c}} \\
\mathrm{x}_{3 \mathrm{c}}
\end{array}\right]=\left(\begin{array}{l}
0.79 \\
0.194 \\
0.016
\end{array}\right)} \\
\text { Xcrit }:=\operatorname{PosX}\left(\mathrm{x}_{1 \mathrm{c}}, \mathrm{x}_{3 c}\right) \text { Ycrit }:=\operatorname{PosY}\left(\mathrm{x}_{1 \mathrm{c}}, \mathrm{x}_{3 c}\right)
\end{array}
\end{aligned}
$$


La ecuación de la curva espinodal viene determinada por las siguientes ecuaciones:

$$
\begin{aligned}
& \left(\frac{\partial^{2} \Delta \mathrm{G}_{\mathrm{m}}}{\partial \mathrm{x}_{\mathrm{i}}^{2}}\right)_{\mathrm{T}, \mathrm{P}}=0 \\
& \mathrm{x}_{1}+\mathrm{x}_{2}+\mathrm{x}_{3}=1
\end{aligned}
$$

A partir de la expresión de la energía libre en fracciones volumétricas se llega a la siguiente expresión para la curva espinodal:

$$
\begin{gathered}
{\left[\left(\frac{1}{\phi_{1}}+\frac{\mathrm{v}_{1}}{\mathrm{v}_{2}} \cdot \frac{1}{\phi_{2}}\right)-2 \cdot \chi_{12}\right] \cdot\left[\left(\frac{1}{\phi_{1}}+\frac{\mathrm{v}_{1}}{\mathrm{v}_{3}} \cdot \frac{1}{\phi_{3}}\right)-2 \cdot \chi_{13}\right]-\left(\frac{1}{\phi_{1}}+\chi_{23}-\chi_{12}-\chi_{13}\right)^{2}=0} \\
\phi_{1}+\phi_{2}+\phi_{3}=1
\end{gathered}
$$

La cual aplicada al punto crítico nos determina el valor del coeficiente de interacción binario:

$$
\begin{gathered}
\mathrm{a}:=\left(\frac{1}{\phi_{1 \mathrm{c}}}+\frac{\mathrm{v}_{1}}{\mathrm{v}_{2}} \cdot \frac{1}{\phi_{2 \mathrm{c}}}\right)-2 \cdot \chi_{12}\left(\mathrm{u}_{1 \mathrm{c}}\right) \quad \mathrm{b}:=\left(\frac{1}{\phi_{1 \mathrm{c}}}+\frac{\mathrm{v}_{1}}{\mathrm{v}_{3}} \cdot \frac{1}{\phi_{3 \mathrm{c}}}\right) \quad \mathrm{c}:=\frac{1}{\phi_{1 \mathrm{c}}}+\chi_{23}-\chi_{12}\left(\mathrm{u}_{1 \mathrm{c}}\right) \\
\mathrm{a} \cdot\left(\mathrm{b}-2 \cdot \chi_{13}\right)-\left(\mathrm{c}-\chi_{13}\right)^{2}=0 \\
\chi_{13}:=-\mathrm{a}+\mathrm{c}+\sqrt{\mathrm{a}^{2}-2 \cdot \mathrm{a} \cdot \mathrm{c}+\mathrm{a} \cdot \mathrm{b}} \quad \chi_{13}=0.147
\end{gathered}
$$

Considerando el valor de $\chi_{12}$ fijado en el del punto crítico se tiene

$$
\mathrm{r}_{2}:=\frac{\mathrm{v}_{1}}{\mathrm{v}_{2}} \quad \mathrm{r}_{3}:=\frac{\mathrm{v}_{1}}{\mathrm{v}_{3}} \quad \mathrm{~A}:=\chi_{23}-\chi_{12}\left(\mathrm{u}_{1 \mathrm{c}}\right)-\chi_{13}
$$

Después de un laborioso proceso se llega a los siguientes coeficientes de una ecuación cuadrática:

$$
\mathrm{a} 2\left(\phi_{3}\right):=\left(-4 \cdot \chi_{12}\left(\mathrm{u}_{1 \mathrm{c}}\right) \cdot \chi_{13}+\mathrm{A}^{2}\right) \cdot \phi_{3}+2 \cdot \chi_{12}\left(\mathrm{u}_{1 \mathrm{c}}\right) \cdot \mathrm{r}_{3}
$$




$$
\begin{aligned}
\mathrm{a} 1\left(\phi_{3}\right):= & \left(-4 \cdot \chi_{12}\left(\mathrm{u}_{1 \mathrm{c}}\right) \cdot \chi_{13}+\mathrm{A}^{2}\right) \cdot \phi_{3}{ }^{2} \cdots \\
& +\left(-2 \cdot \mathrm{r}_{2} \cdot \chi_{13}+2 \cdot \chi_{12}\left(\mathrm{u}_{1 \mathrm{c}}\right) \cdot \mathrm{r}_{3}+2 \cdot \chi_{12}\left(\mathrm{u}_{1 \mathrm{c}}\right)-\mathrm{A}^{2}+2 \cdot \mathrm{A}+4 \cdot \chi_{12}\left(\mathrm{u}_{1 \mathrm{c}}\right) \cdot \chi_{13}+2 \cdot \chi_{13}\right) \cdot \phi_{3} \cdots \\
& +\mathrm{r}_{2} \cdot \mathrm{r}_{3}-2 \cdot \chi_{12}\left(\mathrm{u}_{1 \mathrm{c}}\right) \cdot \mathrm{r}_{3}-\mathrm{r}_{3} \\
\mathrm{a} 0\left(\phi_{3}\right):= & \left(2 \cdot \mathrm{A}+2 \cdot \chi_{13}+2 \cdot \chi_{12}\left(\mathrm{u}_{1 \mathrm{c}}\right)\right) \cdot \phi_{3}{ }^{2}+\left(-\mathrm{r}_{3}-2 \cdot \mathrm{A}-2 \cdot \chi_{13}-2 \cdot \chi_{12}\left(\mathrm{u}_{1 \mathrm{c}}\right)+\mathrm{r}_{2}\right) \cdot \phi_{3}+\mathrm{r}_{3}
\end{aligned}
$$

De las dos raíces posibles sólo presenta valores con significado físico la siguiente:

$$
-\phi_{1 . \operatorname{esp}}\left(\phi_{3}\right):=\frac{-\mathrm{a} 1\left(\phi_{3}\right)+\sqrt{\mathrm{a} 1\left(\phi_{3}\right)^{2}-4 \cdot \mathrm{a} 2\left(\phi_{3}\right) \cdot \mathrm{a} 0\left(\phi_{3}\right)}}{2 \cdot \mathrm{a} 2\left(\phi_{3}\right)}
$$

Con esta expresión podemos calcular puntos de la curva espinodal:

$$
\begin{aligned}
& \text { is }:=0 . .100 \quad \phi_{3 . \text { esp }_{\text {is }}}:=\frac{\text { is }+1}{300}
\end{aligned}
$$

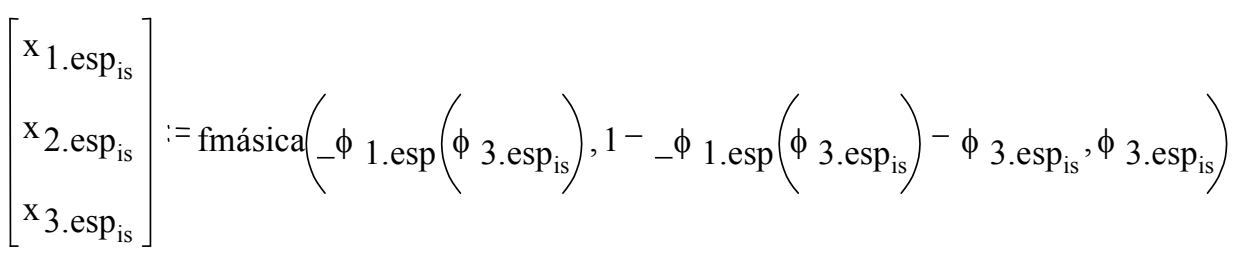

$$
\begin{aligned}
& \mathrm{Xesp}_{\text {is }}:=\operatorname{Pos} \mathrm{X}\left(\mathrm{x}_{1 . \operatorname{esp}_{\text {is }}}, \mathrm{x}_{3 . \text { esp }}\right) \quad \operatorname{Yesp}_{\text {is }}:=\operatorname{Pos} \mathrm{Y}\left(\mathrm{x}_{1 . \mathrm{esp}_{\text {is }}}, \mathrm{x}_{3 . \operatorname{esp}}\right)
\end{aligned}
$$

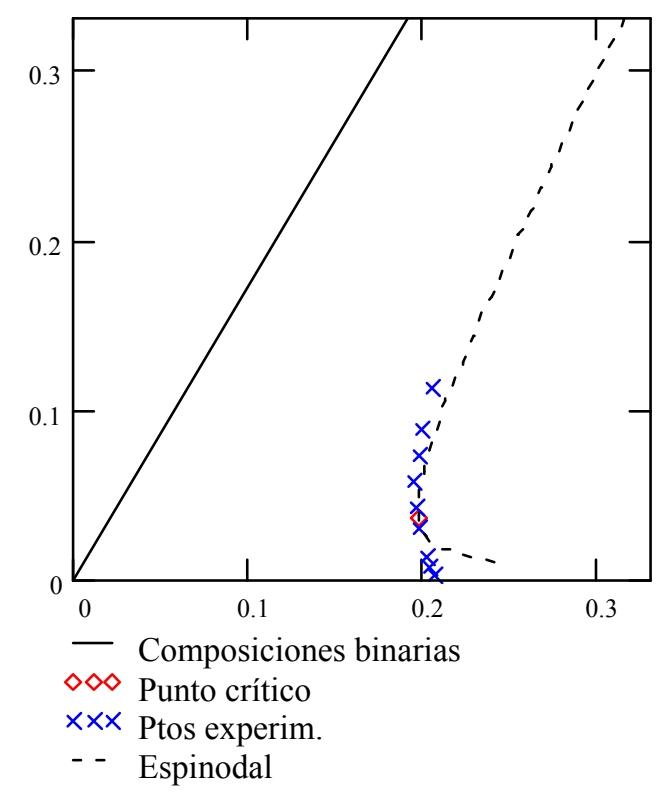




\section{Curva binodal ajustada y rectas de reparto}

Para determinar el equilibrio utilizaremos un método que busca encontrar los valores que hacen cero las diferencias entre los potenciales químicos de dos composiciones diferentes, por lo que definimos las funciones incremento de la siguiente forma:

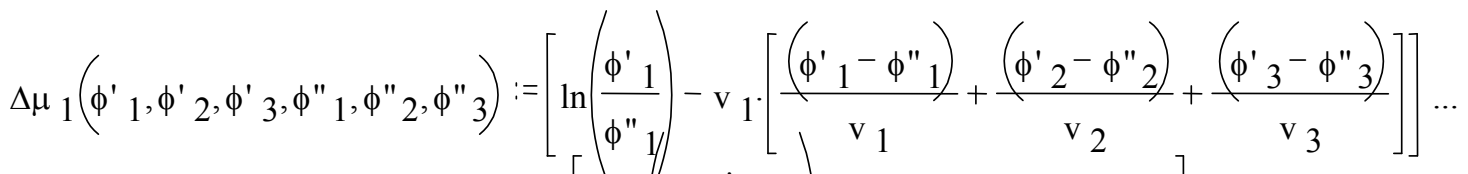

$$
\begin{aligned}
& +\left[\chi_{12}\left(\frac{\phi^{\prime} 1}{\phi^{\prime} \Lambda^{+} \phi_{2}^{\prime}}\right) \cdot \phi^{\prime} 2 \cdot\left(1-\phi^{\prime}{ }_{1}\right) \ldots\right.
\end{aligned}
$$

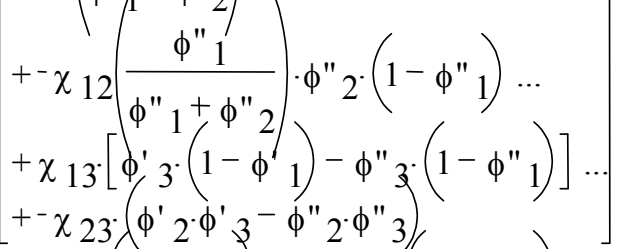

$$
\begin{aligned}
& +\mathrm{d} \chi_{12 \_1}\left(\phi^{\prime}{ }_{1}, \phi^{\prime}{ }_{2}\right)-\mathrm{d} \chi_{12}{ }_{1}\left(\phi^{\prime \prime}{ }_{1}, \phi^{\prime \prime}{ }_{2}\right) \\
& +-\chi_{12}\left(\frac{\phi^{\prime \prime}}{\phi^{\prime}{ }_{1}+\phi^{\prime}}\right) \cdot \phi^{\prime \prime}{ }_{1} \cdot\left(1-\phi^{\prime \prime}{ }_{2}\right) \ldots \\
& +\chi_{13} \cdot\left(\phi^{\prime} 1 \cdot \phi^{\prime}{ }^{3} \phi^{\prime \prime} 1_{1} \cdot \phi^{\prime \prime} 3\right) \ldots \\
& +\chi_{23} \cdot\left[\phi^{\prime} 3 ;\left(1-\phi^{\prime} 2\right)-\phi^{\prime \prime} 3 \cdot\left(1-\phi^{\prime \prime}{ }_{2}\right)\right] \\
& +\mathrm{d} \chi_{12 \_2}\left(\phi^{\prime}{ }_{1}, \phi^{\prime} 2\right)-\mathrm{d} \chi_{12 \_2}\left(\phi^{\prime \prime}{ }_{1}, \phi^{\prime \prime}{ }_{2}\right)
\end{aligned}
$$

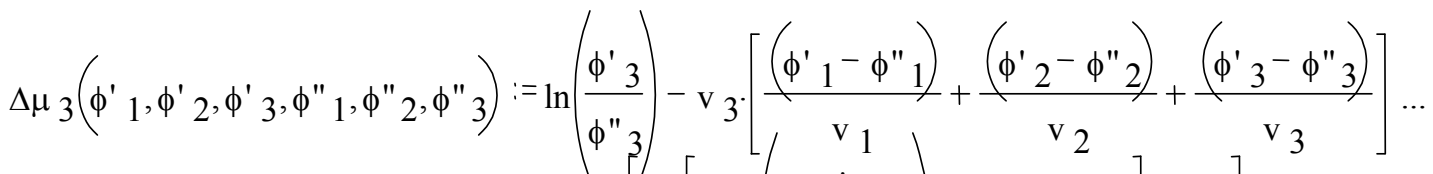

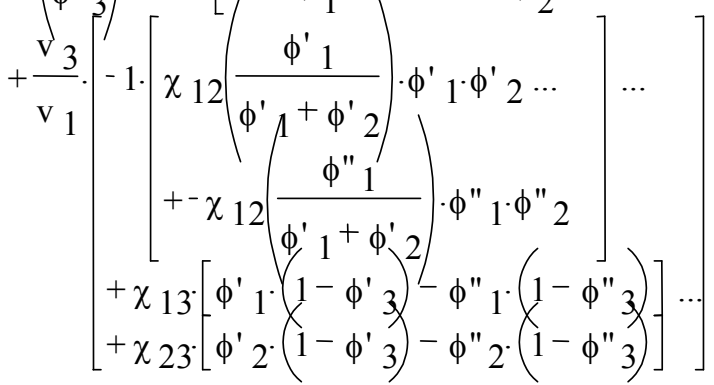

$\underline{\text { Resolución de la binodal: }}$ 
A las tres ecuaciones de igualdad de potenciales químicos debemos añadir las dos restricciones de igualdad constituidas por la condición de fracción:

$$
\begin{aligned}
& \phi^{\prime}{ }_{1}+\phi^{\prime}{ }_{2}+\phi^{\prime}{ }_{3}=1 \\
& \phi^{\prime \prime}{ }_{1}+\phi{ }_{2}+\phi^{\prime \prime}{ }_{3}=1
\end{aligned}
$$

Las seis incógnitas iniciales, correspondientes a las fracciones de los tres componentes en las dos fases en equilibrio, constituyen seis grados de libertad para la solución. Las condiciones de fracción y las igualdades de los potenciales químicos constituyen cinco ecuaciones que eliminan cinco grados de libertad. Por tanto, fijando una fracción de alguno de los componentes eliminamos el grado de libertad remanente y la solución queda determinada.

Además, para sistemas físicamente posibles se deberán cumplir restricciones de desigualdad para que las fracciones estén entre cero y uno.

El bloque de resolución de ecuaciones "Given-find" mostrado debajo proporciona una función que calcula las composiciones de equilibrio fijada la composición $\phi_{3}^{\prime}$ y unos valores de partida para la iteración. La elección de esta variable viene determinada por el hecho de que un valor fijado de ésta en un diagrama típico corta a la binodal en un solo punto, proporcionando dos puntos en equilibrio. Un valor fijado de las otras variables proporcionaría dos cortes en la binodal con lo que se obtendría cuatro puntos solución para el sistema, lo cual complicaría el proceso resolutivo.

Given

$$
\begin{aligned}
& \text { Restricciones: } \quad \phi^{\prime}{ }_{2}{ }^{+} \phi^{\prime}{ }_{3}<1 \quad \phi^{\prime \prime}{ }_{2}+\phi^{\prime \prime} 3^{<1} \\
& \phi^{\prime}{ }_{2}>0 \quad \phi "{ }_{2}>0 \quad \phi "{ }_{3}>0 \quad \phi^{\prime \prime}{ }_{3}<\phi^{\prime} 3 \\
& \text { Igualdades: } \quad \Delta \mu_{1}\left(1-\phi^{\prime}{ }_{2}-\phi^{\prime}{ }_{3}, \phi^{\prime}{ }_{2}, \phi^{\prime}{ }_{3}, 1-\phi^{\prime}{ }_{2}-\phi^{\prime}{ }_{3}, \phi^{\prime}{ }_{2}, \phi^{\prime}{ }_{3}\right)=0 \\
& \Delta \mu_{2}\left(1-\phi^{\prime}{ }_{2}-\phi^{\prime}{ }_{3}, \phi^{\prime}{ }_{2}, \phi^{\prime}{ }_{3}, 1-\phi^{\prime \prime}{ }_{2}-\phi^{\prime}{ }_{3}, \phi^{\prime \prime}{ }_{2}, \phi^{\prime \prime}{ }_{3}\right)=0 \\
& \Delta \mu_{3}\left(1-\phi^{\prime}{ }_{2}-\phi^{\prime}{ }_{3}, \phi^{\prime}{ }_{2}, \phi^{\prime}{ }_{3}, 1-\phi "_{2}-\phi{ }_{3}, \phi^{\prime}{ }_{2}, \phi^{\prime}{ }_{3}\right)=0 \\
& f\left(\phi^{\prime}{ }_{2}, \phi^{\prime}{ }_{2}, \phi^{\prime}{ }_{3}, \phi^{\prime \prime}{ }_{3}\right):=\text { find }\left(\phi^{\prime}{ }_{2}, \phi^{\prime}{ }_{2}, \phi^{\prime \prime}{ }_{3}\right)
\end{aligned}
$$

Los valores de $\phi_{3}^{\prime}$ entre los cuales resolvemos son: 
$\phi^{\prime} 3_{0}:=\phi_{3 \mathrm{c}}+0.01 \quad \mathrm{~N}:=20 \quad \phi^{\prime} 3_{\mathrm{N}}:=\phi_{3 \mathrm{c}}+0.2$

$\mathrm{i}:=1 . . \mathrm{N}$

$$
\phi_{3_{\mathrm{i}}}^{\prime}:=\phi^{\prime} 3_{0}+\frac{\phi^{\prime} 3_{\mathrm{N}}-\phi^{\prime} 3_{0}}{\mathrm{~N}} \cdot \mathrm{i}
$$

Cálculo de los valores:

$$
\begin{array}{cc}
\mathrm{A}_{0,0}:=\phi_{2 \mathrm{c}}-0.1 & \mathrm{~A}_{1,0}:=\phi_{2 \mathrm{c}}+0.001 \\
\mathrm{~A}^{<\mathrm{i}>}=\mathrm{f}\left(\phi^{\prime}{ }_{2}, \phi^{\prime \prime}{ }_{2}, \phi^{\prime}{ }_{\mathrm{i}_{\mathrm{i}}}, \phi^{\prime \prime}{ }_{3}\right) & \mathrm{A}^{<\mathrm{i}>}=\mathrm{f}\left(\mathrm{A}_{0, \mathrm{i}-1}, \mathrm{~A}_{1, \mathrm{i}-1}, \phi^{\prime}{ }_{3_{\mathrm{i}}}, \mathrm{A}_{2, \mathrm{i}-1}\right)
\end{array}
$$

$\underline{\text { Representación de la solución obtenida: }}$

Transformación a fracciones másicas:

$\mathrm{i}:=0 . . \mathrm{N}$

$$
\left[\begin{array}{c}
x^{\prime} 1_{i} \\
x^{\prime} 2_{i} \\
x^{\prime} 3_{i}
\end{array}\right]:=\text { fmásica }\left(\phi^{\prime}{ }_{1_{i}}, \phi^{\prime} 2_{i_{i}}, \phi^{\prime} 3_{i}\right) \quad\left[\begin{array}{c}
x^{\prime \prime} 1_{i} \\
x^{\prime \prime} 2_{i} \\
x^{\prime \prime} 3_{i}
\end{array}\right]:=\text { fmásica }\left(\phi^{\prime \prime} 1_{i}, \phi "{ }_{2}, \phi " 3_{i}\right)
$$

Coordenadas en diagrama ternario:

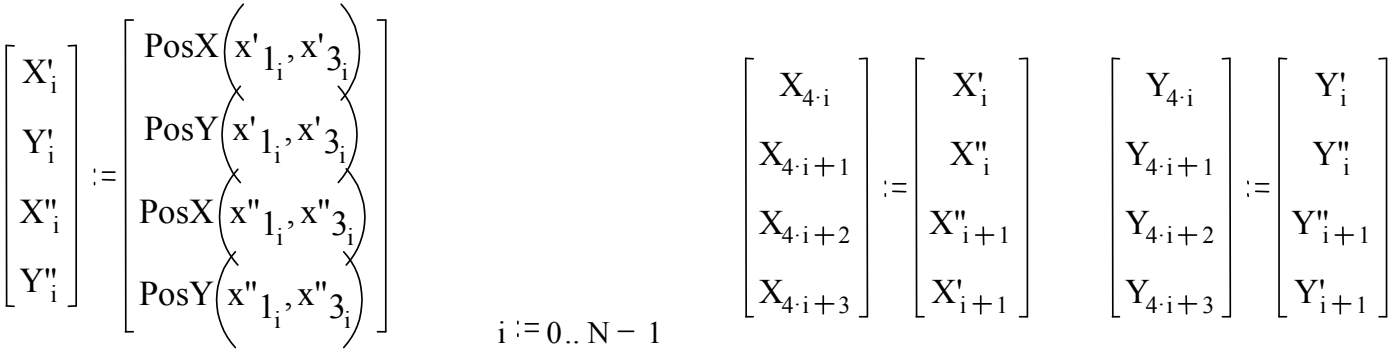

$$
\begin{aligned}
& \mathrm{i}:=0 . . \mathrm{N} \\
& {\left[\begin{array}{c}
\mathrm{Xbin}_{\mathrm{i}} \\
\mathrm{Ybin}_{\mathrm{i}} \\
\mathrm{Xbin}_{\mathrm{i}+\mathrm{N}+1} \\
\mathrm{Ybin}_{+\mathrm{N}+1}
\end{array}\right]:=\left[\begin{array}{c}
\mathrm{X}_{\mathrm{i}}^{\prime} \\
\mathrm{Y}_{\mathrm{i}}^{\prime} \\
\mathrm{X}_{\mathrm{N}-\mathrm{i}} \\
\mathrm{Y}_{\mathrm{N}-\mathrm{i}}^{\prime}
\end{array}\right]} \\
& i b:=1 . .2 \cdot \mathrm{N} \quad \mathrm{j}:=1 . .4 \cdot(\mathrm{N}-1)+3
\end{aligned}
$$




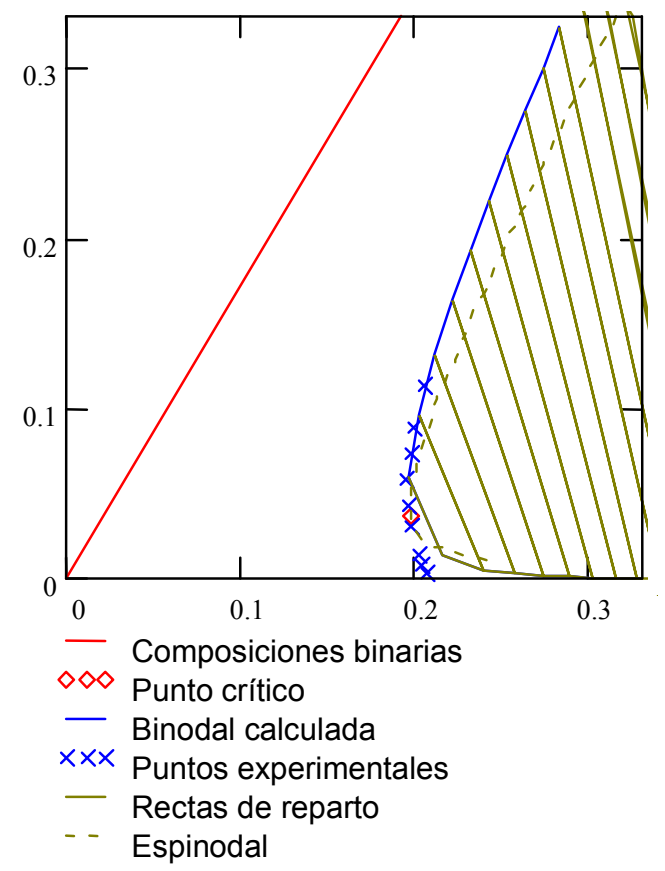

Los valores del parámetro de interacción binario $\chi_{13}$ se modifican hasta lograr que la curva binodal teórica se ajuste a la experimental. 



\section{BIBLIOGRAFÍA}

AlCAINA, I.; (1991) "Optimización del proceso de desalcoholización de vinos por pervaporación: Caracterización y selección de membranas compuestas". Tesis doctoral presentada en el Dpto. de Ingeniería Química y Nuclear de la Universidad Politécnica de Valencia.

AlvareZ, R.; (1993) "Fundamentals of Reverse Osmosis and Nanofiltration" en "Membrane processes in the food industry". Universidad de Oviedo.

ARNAL, J.M.; (1994) "Prototipo para la fabricación en continuo de membranas semipermeables utilizadas en los procesos: O.I., U.F., N.F., y P.V.”. Proyecto del Dpto. de Ingeniería Química y Nuclear de la Universidad Politécnica de Valencia presentado en la Escuela Universitaria de Ingeniería Técnica Industrial.

BernaOla, P.; (1995) "Membranas de nanofiltración para la producción de agua potable" en Ingeniería química. España.

Cabasso, I; (1987) "Membranes" en Encyclopaedia of Polymer Science and Technology”. John Wiley \& Sons, New York.

CHAMPETIER, G; MONNERIE, L.; (1973) “Introducción a la química macromolecular”. Ed. Espasa-Calpe S.A. ISBN 84-239-6320-9

Chaufer, B.; Rabiller-Baudry, M.; Guihard, L.; Daufin, G.; (1996) “Retention of ions in nanofiltration at various ionic strength" en Desalination, 104, p. 3746. Elsevier Science Publishers 
Chen, J.; Kurihara, K.; Push, L.; (1983) en Desalination, 46, p. 379. Elsevier Science Publishers

Christensen, J.J.; HANKS, R.W.; IZATT, R.M.; (1982) "Handbook of heats of mixing” Ed. Jhon Wiley \& Sons, Inc. U.S.A. ISBN 0-471-07960-X

DICKSON, J.M.; (1988) "Fundamentals aspects of reverse osmosis" en PAREKH B.S.; “Reverse Osmosis". ISBN 0-8247-7985-1

FrOMMER, M.A.; LANCET, D.; (1972) "Reverse osmosis membrane research. H.K." Londsdale and H.E. Podall. Ed. Plenum Press NY

GKSS; (1993) “Ist GKSS Workshop on membrane formation" GKSS Forschungszentrum Geesthacht GmbH.

HAN, M.J.; BHATTACHARYYA, D.; (1991) “Characterization of reverse osmosis cellulose acetate membranes by gas adsorption method: effect of casting variables and chlorine damage" en Journal of Membrane Science, 64, p. 81-92.

HAN, M-J; BHATTACHARYYA, D; (1995) “Thermal annealing effect on cellulose reverse osmosis membrane structure" en Journal of Membrane Science, 101, p. 195-200.

HENLEY E.J.; SEADER J.D.; (1988) “Operaciones de separación por etapas de equilibrio en ingeniería química”. Ed. Reverté. ISBN - 84 - 291 - 7908 - 9

Himmelblau, D.M.; Bischoff, K.B.; (1992) “Análisis y simulación de procesos”. Ed. Reverté.

IBORRA, I.; (1993) “Copolímeros de poliamidas aromáticas para síntesis de membranas sintéticas de ósmosis inversa. Aplicación a la desalación de aguas salobres”. Tesis doctoral presentada en el Dpto. de Ingeniería Química y Nuclear de la Universidad Politécnica de Valencia. 
KANG, Y.S.; KIM, H.J.; KIM U.Y.; (1991) "Asymmetric membrane formation via immersion precipitation method. I. Kinetic effect" en Journal of Membrane Science, 60, p. 219-232

Kesting, R.E.; (1984) “Phase inversion membranes" en Lloyd, D.R.; (1984) "Material science of synthetic membranes" p. 131-164.

Larbot A.; Alami-Younssi, S.; Persin M.; SARrazin J.; Cot L.; (1994) “Preparation of a $\gamma$ - alumina nanofiltration membrane" en Journal of Membrane Science, 97, p. 167-174.

LlOYD D. R.; MELUCH, T.B.; (1984) "Selection and evaluation of membrane materials for liquid separations" en LlOYD D.R.; (1984) "Material science of synthetic membranes” p. 47-79. ISBN 0-8412-0887-5

LoeB, S.; (1986) “The Loeb-Sourirajan membrane: How it came about” en Desalination \& Water reuse, Vol. 3/2. p. 20-22. Ed. Board. (U.S.A.)

LORA, J.; (1987) “Membranas compuestas de Poli (4,4'- difenilsulfona tereftalamida): Relación de las variables que definen el proceso de formación, su estructura, y propiedades en Ósmosis inversa”. Tesis doctoral presentada en el Departamento de Ingeniería Química y Nuclear de la Universidad Politécnica de Valencia.

Lora, J.; Soriano, E.; Arnal, J.M.; Alcaina, M.I.; Belanche, M.I.; (1989) "Formación de membranas compuestas por inversión de fase. I a $V$ " en Ingeniería Química, Junio, Julio, Agosto, Septiembre, Octubre.

MANUGistics, InC; (1992) “Statgraphics ${ }^{\circledR}$. Examples manual”, Font Software.

MatsuURA, T; PAgEAU, L.; SOURIRAJAn, S.; "Journal of applied polymer science" 
MAUREL, A.; (1993) "Techniques séparatives à membranes. Osmose inverse, nanofiltration, ultrafiltration, microfiltration tangentielle. Considerations théoriques"

MukherJee D.; KulKarni, A.; Gill W.N.; (1994) "Flux enhancement of reverse osmosis membranes by chemical surface modification" en Journal of Membrane Science, 97, p. 216-230.

Mulder, M. ; Kruitz, F.; Smolders, C.A.; (1975) “Journal of Applied Polymer Science”, 19, 1163

MuldeR, M.; (1984) "Pervaporation: separation of ethanol-water and of isomeric xylenes". Tesis Doctoral. TH. Twente. Holanda.

Mulder, M.; (1992) “Basic Principles of Membrane Technology”. Kluwer Academic Publishers.

Paulsen F.G.; ShojaIE, S.S.; Krantz W.B.; (1994) "Effect of evaporation step on macrovoid formation in wet-cast polymeric membranes" en Journal of Membrane Science, 91, p. 265-282.

Perry M.; Linder C.; (1989) en Desalination, 71, p.233-245. Elsevier Science Publishers.

PusCH, W.; (1986) “Measurement techniques of transport through membranes" en Desalination, 59 p.105-198. Elsevier Science Publishers.

Radovanovic, P.; Stephen, W. T.; Hwang, S-T; (1991) “Formation of asymmetric polysulfone membranes by immersion-precipitation. Part I. Modelling mass transport during gelation" en Journal of Membrane Science 65 p. 213-229.

Romero, R.; ZúNICA, L.; (1993) “Estadística”. Servicio de publicaciones de la Universidad Politécnica de Valencia. ISBN. 84-7721-223-6. 
ROMERO, R.; (1993a) "Curso de introducción a los métodos de análisis multivariante”. Servicio de publicaciones de la Universidad Politécnica de Valencia, no 505.

SAUNDERS, K.J.; (1976) “Organic polymer chemistry” ISBN-0412105802.

SCHIRG, P.; WIDMER F.; (1992) "Characterisation of nanofiltration membranes for the separation of aqueous dye-salt solutions" en Desalination, 89 p.89-107. Elsevier Science Publishers.

SIERRA, R.; (1988) “Tesis doctorales y trabajos de investigación científica”. 2a edición. Ed. Paraninfo. Madrid. ISBN: 84-283-1612-0.

Solomons, G.; (1988) “Fundamentos de Química Orgánica”. Ed. Limusa S.A. ISBN968-18-1838-5.

SORIANO, E.; (1983) “Comportamiento del polímero PTDS en los procesos de separación por membranas: Ósmosis inversa y ultrafiltración”. Tesis doctoral presentada en el Departamento de Ingeniería Química y Nuclear de la Universidad Politécnica de Valencia.

SOURIRAJAN S.; (1970) “Reverse osmosis”. Academic Press-NewYork.

STRATHMANN H.; (1984) "Production of microporous media by phase inversion processes" en LLOYD D.R.; (1984) "Material science of synthetic membranes” p. 166-195. ISBN 0-8412-0887-5

StrathmanN, H.; (1989) “Economical evaluation of membrane technology" en CeCille L.; ToussainT J.C.; Future industrial prospects of membrane processes. Elsevier Science Publishers.

Torres, M.R.; Soriano, E.; De Abajo, J; DE la CAMPA, J.G.; (1993) “Comparative study of the behaviour of experimental polyamide UF membranes" en Journal of Membrane Science 81 p. 31-42. 
WANG, D.; LI, K.; TEO, W.K.; (1994) “Relationship between mass ratio of non-solvent additive to solvent in membrane casting solution and its coagulation value" en Journal of Membrane Science 98 p. 233-240.

Wang, X.; Tsuru, T; Togoh, T. NAKAO, S.; Kimura S.; (1994) “Evaluation of pore structure and electrical properties of nanofiltration membranes" en Journal of Chemical Engineering of Japan p. 186-192.

WANG, X.; Tsuru, T; NAKAO, S.; KimURA S.; (1995) "Electrolyte transport through nanofiltration membranes by the space-charge model and the comparison with Teorell - Meyer - Sievers model" en Journal of Membrane Science p. 117-133.

Yanagishita, H.; NAKANe, T.; Yoshitime H.; (1994) "Selection criteria for solvent and gelation medium in the phase inversion process" en Journal of Membrane Science, 89, p. 215-222

ZEMAN, L.; FRASER, T.; (1993) "Formation of air-cast cellulose acetate membranes. Part I. Study of macrovoid formation" en Journal of Membrane Science, 84, p. 93-106. 


\section{NOTACIÓN}

\section{Abreviaturas y siglas}

$A C \quad$ Acetato de celulosa (sin especificar)

AC3 Acetato de celulosa Kodak ${ }^{\circledR}$ CA-398-3

AC6 $\quad$ Acetato de celulosa Kodak ${ }^{\circledR}$ CA-398-6

$A C E \quad$ Acetato de celulosa de INACSA

$A C N \quad$ Acetona

$B A C \quad$ Butirato acetato de celulosa

CRIOSEM Crio-Scanning electromicroscope

DIQN Departamento de Ingeniería Química y Nuclear de la UPV

DMA N-N'-dimetilacetamida

et al. et alia = "y otros". Término latino utilizado para indicar que el trabajo referenciado tiene otros autores además del investigador mencionado.

lph Litros por hora

PAC Propionato acetato de celulosa

p.e. $\quad$ Por ejemplo

P.E. $\quad$ Punto de ebullición

ppm Partes por millón

P.F. $\quad$ Punto de fusión

SEPS Standard on Explosion Prevention Systems

vs $\quad$ versus $=$ "frente a". Término latino utilizado para indicar que una variable o serie se representa o compara frente a otra.

UPV Universidad Politécnica de Valencia 


\section{Subíndices de las variables}

$\begin{array}{ll}A & \text { Componente disolvente, generalmente agua } \\ B & \text { Medida geométrica de la boquilla enrasadora de la máquina } \\ c o l & \text { Colodión } \\ d & \text { Componente difusiva } \\ i & \text { Componente genérico } \\ m & \text { Membrana } \\ S & \text { Componente soluto, normalmente una sal } \\ S & \text { Soporte } \\ t & \text { tubo } \\ v & \text { Componente volumétrica } \\ v_{i} & \text { Volumen molar del componente } i\end{array}$

\section{Superíndices de las variables}

$\begin{array}{ll}o & \text { Estado de referencia } \\ \text { E } & \text { Exceso }\end{array}$




\section{Variables}

\section{ALFABETO LATINO:}

$a_{i, F} \quad$ Actividad del componente $i$ en la fase $F$

$a_{B} \quad$ Abertura de la boquilla de enrase (separación entre cuchillas) del prototipo de fabricación industrial de membranas

A Coeficiente de permeabilidad del disolvente

$A^{\prime} \quad$ Coeficiente de permeabilidad del disolvente (modelo DDI)

$A_{B} \quad$ Ancho de la boquilla enrasadora $=55 \mathrm{~cm}$ (aproximadamente el de la cinta soporte)

$b \quad$ Parámetro de fricción

$B \quad$ Coeficiente de permeabilidad del soluto

$B^{\prime} \quad$ Coeficiente de permeabilidad del soluto (modelo DDI)

$C^{\prime} \quad$ Coeficiente corrector por imperfecciones (modelo DDI)

$C_{a} \quad$ Concentración de soluto en el alimento

$C_{a, m} \quad$ Concentración de soluto en la cara de la membrana en contacto con el alimento

$C_{p} \quad$ Concentración de soluto en el permeado

$C_{i, F} \quad$ Concentración molar del componente $i$ en la fase $F$

$C_{i, l m} \quad$ Concentración logarítmico media de $i$ en la membrana

D Deposición másica de polímero por unidad de área de membrana

$d_{C} \quad$ Distancia de separación de las cuchillas del prototipo de fabricación industrial de membranas

$d_{h} \quad$ Diámetro hidráulico

$d_{t} \quad$ Diámetro de los tubos de conducción de colodión al enrasador en la máquina de fabricación

$D_{i, j} \quad$ Coeficiente de difusión del componente $i$ respecto del $j$

$D_{S, p m} \quad$ Difusividad del soluto en la estructura porosa de la membrana

$D_{T i} \quad$ Coeficiente de difusión termodinámico del componente $i$

$f_{i j} \quad$ Coeficiente de fricción

$F_{i j} \quad$ Fuerza impulsora $j$

g Constante de la gravedad terrestre $=9.81 \mathrm{~m} / \mathrm{s}^{2}$ 
$\Delta G^{E} \quad$ Incremento de energía libre de Gibbs de exceso en la mezcla

$\Delta G_{m} \quad$ Incremento de energía libre de Gibbs en la mezcla

$\Delta H_{m} \quad$ Incremento de entalpía en la mezcla

$H_{T} \quad$ Altura del contrapeso de tensado del prototipo de fabricación industrial de membranas

$J_{i} \quad$ Flujo molar del componente i

$J_{v} \quad$ Flujo volumétrico

$k \quad$ Coeficiente de transferencia de masa

$K \quad$ Constante de pérdida de carga debida a elementos puntuales en la máquina de fabricación

$K_{i} \quad$ Coeficiente de partición para el componente $i$

$K_{p} \quad$ Coeficiente de partición basado en los poros

$L_{B} \quad$ Recorrido del colodión entre las cuchillas de enrase

$L_{i, j} \quad$ Parámetro fenomenológico de proporcionalidad entre el flujo de $i$ y la fuerza impulsora $j$

$L_{p} \quad$ Permeabilidad de la membrana al disolvente puro

$L_{p}^{\prime} \quad$ Permeabilidad hidráulica

$L_{\pi} \quad$ Permeabilidad osmótica de la membrana

$m_{c o l} \quad$ Flujo másico de colodión en la máquina de fabricación

$M_{i} \quad$ Masa molecular del componente i

$M_{c} \quad$ Masa molecular entre dos entrecruzamientos de una red polimérica

$\operatorname{mov}_{\mathrm{i}} \quad$ Movilidad del componente $i$

$N_{t} \quad$ Número de tubos conductores de colodión en la máquina de fabricación

$n i \quad$ Coeficiente corrector de la presión osmótica dependiente del número de iones

$p_{i} \quad$ Permeabilidad de la membrana hacia el componente $i$

$P_{F} \quad$ Presión en la fase $F$

$\Delta P \quad$ Incremento de presión entre ambas caras de la membrana

$\Delta P_{c o l} \quad$ Presión manométrica del nitrógeno en el recipiente del colodión de la máquina de fabricación

$r \quad$ Radio de poro 


$\begin{array}{ll}r_{i, j} & \text { Parámetro fenomenológico de proporcionalidad entre la fuerza impulsora } i \\ R & \text { y el flujo de } j \\ R_{a} & \text { Constante universal de los gases perfectos }\left(8.314 \mathrm{~J} \cdot \mathrm{mol}^{-1} \cdot \mathrm{K}^{-1}\right) \\ R_{m} & \text { Rechazo basado en la concentración en el seno del alimento }(\% \text { o fracción) } \\ & \text { Rechazo basado en la concentración en la cara de la membrana }(\% \text { o } \\ \Delta S_{m} & \text { fracción) } \\ t & \text { Incremento de entropía de mezcla } \\ T & \text { Tiempo } \\ u_{i} & \text { Temperatura absoluta (K) } \\ u_{S} & \text { Velocidad del componente } i \\ v_{i} & \text { Velocidad de la cinta soporte en la máquina de fabricación } \\ & \text { Volumen molar parcial del componente } i \text {. O bien, en el cálculo teórico de } \\ & \text { diagramas ternarios, relación de volumen molar respecto de otro } \\ x & \text { componente } \\ \Delta x & \text { Coordenada espacial en la dirección del flujo } \\ x_{i, F} & \text { Espesor efectivo de la membrana } \\ X & \text { Fracción molar del componente } i \text { en la fase } F \\ & \text { Fuerza impulsora }\end{array}$

\section{ALFABETO GRIEGO:}

$\alpha$

$\alpha_{E}$

$\alpha_{S}$

$\beta$

$\gamma_{i, F}$

$\Delta_{i M}$

$\Delta$

$\Delta \pi$
Parámetro ajustable de una correlación

Ángulo del dispositivo de enrase con la horizontal en el prototipo de fabricación de membranas

Ángulo del soporte en el punto de enrase con la horizontal en el prototipo de fabricación de membranas

Parámetro ajustable de una correlación

Coeficiente de actividad del componente $i$ en la fase $F$

Factor de afinidad entre el componente i y la membrana

Incremento de propiedad (consúltese la notación correspondiente a la variable)

Incremento de presión osmótica entre ambas caras de la membrana 
$\delta \quad$ Espesor de capa límite

Parámetro de solubilidad o de energía cohesiva de Hansen

$\varepsilon_{s}$

Porosidad superficial (fracción de superficie ocupada por poros)

$\varepsilon$

Porosidad volumétrica (fracción de hueco)

$\eta$

Viscosidad del fluido

$\lambda$

Longitud efectiva de poro

$\Lambda_{F}$

Conductividad de la fase $F$

$\mu_{c o l}$

Densidad del colodión

$\mu_{i, F}$

Potencial químico del componente $i$ en la fase $F$

$\mu_{i, F}^{o}$

Potencial de referencia del componente $i$ en la fase $F$

$\Delta \mu_{i}$

Incremento de potencial químico del componente $i$ entre ambas caras de

la membrana

$\pi \quad$ Constante $\mathrm{pi}=3.141592 \ldots$

$\pi_{F}$

Presión osmótica de la fase $F$

$\pi_{a, m}$

Presión osmótica en la cara de la membrana en contacto con el alimento

$\rho_{c o l}$

Densidad del colodión

$\sigma$

Coeficiente de reflexión

$\tau$

Tortuosidad de los poros

$\phi_{i}$

Fracción volumétrica del componente $i$

$\chi_{12}$

Coeficiente de interacción disolvente - no-disolvente

$\chi_{13}$

Coeficiente de interacción disolvente - polímero

$\chi_{23}$

Coeficiente de interacción no-disolvente - polímero

$\omega$

Parámetro relacionado con la permeabilidad osmótica 
La verdad es como el agua filtrada, que no llega a los labios sino a través del cieno.

Mariano Jose de Larra (1809-1837) Escritor español. 